\title{
“Utilização de Chironomus sp (Diptera, Chironomidae) para a avaliação da qualidade de sedimentos e contaminação por metais"
}

Tese apresentada à Escola de Engenharia de São Carlos, Universidade de São Paulo, como parte dos requisitos para obtenção do título de Doutor em Ciências da Engenharia Ambiental.

Orientador: Prof. Dr. Evaldo Luiz Gaeta Espíndola

São Carlos - SP

2006 
Ficha catalográfica preparada pela Seção de Tratamento da informação do Serviço de Biblioteca - EESC/USP

D713u Utilização de Chironomus sp (Diptera, Chironomidae) para avaliação da qualidade de sedimentos e contaminação por metais / Carolina Buso Dornfeld. - - São Carlos, 2006.

Tese (Doutorado) - Escola de Engenharia de São CarlosUniversidade de São Paulo, 2006.

Área: Ciências da Engenharia Ambiental.

Orientador: Evaldo Luiz Gaeta Espíndola.

1. Sedimento. 2. Metais. 3.Chironomus sp. 4. Bioensaios "in situ". 5. Testes de evitamento. I.Título 
Este trabalho é dedicado à todos que me auxiliaram e que contribuíram para minha formação. Em especial dedico aos meus pais F ritz (in memoriam) e $V$ era pelo apoio e incentivo de sempre, ao meu irmão Hugo pelo companheirismo e pela pessoa especial que é, à vovó Honorina, sempre presente em toda a minha vida. Ao M auricio, por tornar muitos dos meus sonhos possíveis de serem realizados! 


\section{Agradecimentos}

A o Prof. D r. E valdo L uiz G aeta E spíndola, coordenador do Programa de Pós-graduação em Ciências da Engenharia A mbiental, da Escola de Engenharia de São Carlos - U SP, pela atenção dispensada aos assuntos acadêmicos. E como orientador, um excelente profissional, que me auxiliou em mais uma etapa da minha formação acadêmica. U m amigo muito querido!

A o Prof. D r. F rederico F ábio $M$ auad, diretor do Centro de Recursos H ídricos e $E$ cologia A plicada (CRHEA-U SP) pela oportunidade de desenvolvimento desse trabalho nas dependências desse conceituado centro de pesquisa.

A o Prof. D r. R ui Ribeiro, do D epartamento de Z oologia da U niversidade de Coimbra, por ter me recebido muito bem para a realização do $E$ stagio de $D$ outorando no Exterior, pela dedicação e orientação nos experimentos de "A voidance". P ela amizade que se formou a partir de então...

Á CAPES pela concessão da bolsa de estudos no país e no exterior (U niversidade de Coimbra, Portugal - Processo no B E X0864-05-6).

\section{À FAPE SP PE LA CONCE SSÃO D O AU XÍLIO PE SQU ISA N 0: 2002/10494-6.}

A o Prof. D r. E duardo M ario M ediondo, responsável pela E stação M eteorológica do Centro de Recursos Hídricos e Ecologia Aplicada (CRHEA-USP), pelo fornecimento dos dados pluviométricos.

Às Profa. D ra. A na L ucia F onseca (U niversidade F ederal de I tajubá) e Profa. D ra. M aria Olímpia de Oliveira R ez ende (I nstituto de Química de São Carlos-U SP) pelas sugestões apresentadas no Exame de Qualificação.

Às M onjoletes, minhas queridas amigas e companheiras de coletas: A ndréa N ovelli, R enata F racácio, Beatriz $K$. Rodrigues, Aline $F$. Campagna e Sabrina $M$. Vianna, além das pósdoutorandas Cleoni e L iane. 
Aos amigos do Laboratório de E cotoxicologia Aquática e Limnologia: Suzilei Rodgher Alessandro $M$ inillo, J anete $B$ rigante, W ilminha e Ricardo, M árcia $E$ ler, $M$ ariana $M$ asutti, J uliana Costa, Clarice B otta-Paschoal e L uci Z anata pelas conversas e ensinamentos fundamentais para a minha formação acadêmica!

A os funcionários da Secretaria do PPG -SE A e da A dministração do CR HE A, Claudete A p. Poinas da Silva, pela amizade è̀ Sonia B ueno, N elson, W ellington, Paulo de L ucca e M ara Cotrim Gomes pelo auxílio em questões administrativas e bibliotecárias.

À equipe técnica do L aboratório de L imnologia do CRHE A : M arcelo N . M enezes, A mândio N. M enezes e à L uci A. Queiroz pelos auxílios nos trabalhos de campo e laboratório e pela amizade adquirida durante esse período.

A os amigos da escola da vida: J ulieta, A ndréa Cassiano e V ictor, V itinho, P azu, A na Célia, M elges e M atheus, Paulo L odi, R osane, I sabela e L ucas, E dna e J efferson, A lessandro e Carmem; à amiga que apesar de distante está sempre muito próxima de mim, Adriana N óbrega; às queridas amigas e excelentes profissionais de Coimbra, Rita Rosa, M atilde M oreira Santos, I sabel L opes...saudades...; às amigas de graduação Tati , D ani e N ilce.... sempre presentes!

À F amília Leite: Sr Omar, D. Sylza, M aria Eugênia (minha Florzinha!), A guinaldo (o Sapinho!), M urillo e Ligia, pelo carinho, incentivo, apoio sempre presentes ... M uito Obrigada!

À minha família, SU PE R M ÃE E SU PER IRM Ã O, meus primos e tios, pessoas especiais com quem sempre posso contar! Aprendi isso em momentos muito difíceis do ano de 2004. B usolândia! Obrigada pelos grandes momentos!

Ao M auricio Augusto L eite ... sem palavras para descrever o que significa para mim! F undamental para o equilíbrio e harmonia dos meus dias! A uxiliando e incentivando-me a ser sempre melhor! Querido!! Que este seja o nosso destino...A mar, viver e começar cada dia juntos."

À DE U S, por permitir que concluísse mais uma fase de minha vida. M uito obrigada! 
"... há situações que constituem a nossa prova aflitiva e áspera, mas redentora e santificante. Perdoemos as pedras da vida pelo ouro de experiência e de luz que nos of erecem". (B ez erra de M enezes)

"Para além da curva da estrada Talvez haja um poço, e talvez um castelo, E talvez apenas a continuação da estrada. $\mathrm{N}$ ão sei nem pergunto. Enquanto vou na estrada antes da curva Só olho para a estrada antes da curva, Porque não posso ver senão a estrada antes da curva. D e nada me serviria estar ol hando para outro lado E para aquilo que não vejo. I mportemo-nos apenas com o lugar onde estamos. Há belez a bastante em estar aqui e não noutra parte qualquer. Se há al guém para além da curva da estrada, E sses que se preocupem com o que há para além da curva da estrada. E ssa é que é a estrada para eles. Se nós tivermos que chegar lá, quando lá chegarmos saberemos. Por ora só sabemos que lá não estamos. A qui há só a estrada antes da curva, e antes da curva Há a estrada sem curva nenhuma." (F ernando Pessoa) 


\section{Resumo - Domfeld, C.B. (2006). Utilização de Chironomus sp (Diptera,} Chironomidae) para a avaliação da qualidade de sedimentos e contaminação por metais. Pós-graduação em Ciências da Engenharia Ambiental, EESCUSP.

O objetivo do presente estudo foi avaliar a viabilidade do uso das espécies Chironomus x anthus e Chironomus riparius na avaliação da qualidade de sedimentos e da contaminação por metais por meio de diferentes ensaios ecotoxicológicos. As amostras de sedimento foram coletados no rio Monjolinho e tributários (14 estações de amostragem). Foi realizada a análise da qualidade da água e do sedimento do sistema utilizando diversas variáveis, tais como nutrientes e metais, sendo possível observar um gradiente crescente de contaminação da Nascente em direção à Foz do rio Monjolinho. As concentrações dos agrotóxicos organoclorados foram superiores àquelas estabelecidas pela resolução CONAMA 357/05 em apenas algumas estações. Os resultados dos bioensaios laboratoriais com sedimentos indicaram toxicidade aguda em duas estações (Federal e Usina) e nos ensaios "in situ" observaram-se maiores porcentagens de mortalidade em relação aos ensaios laboratoriais. Os metais $\mathrm{Cd}$ e $\mathrm{Cu}$ estiveram acima do limite estabelecido pela resolução CONAMA 357/ 05 em algumas estações de amostragem e, portanto, foram utilizados nos testes de toxicidade aguda e crônica com $C$. xanthus. Observou-se para o IV instar a CL5096h de 0,30 mg.L-1 de Cu e de 0,70 mg.L-1 de $\mathrm{Cd}$. Os testes crônicos com o I instar foram realizados utilizando as concentrações

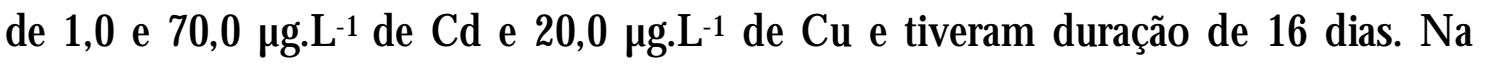
concentração de 1,0 $\mu \mathrm{g} \cdot \mathrm{L}^{-1}$ de $\mathrm{Cd}$ os resultados foram similares aos apresentados para 0 controle, exceto para a deformidade do mento. Na concentração de 70,0 $\mu \mathrm{g} \cdot \mathrm{L}^{-1}$ de $\mathrm{Cd}$ os efeitos foram a redução na sobrevivência, no tamanho do corpo, cápsula cefálica e atraso no tempo de emergência (3 dias). $\mathrm{Na}$ exposição ao $\mathrm{Cu}$, não foi observada diferença significativa em nenhum parâmetro analisado quando comparado ao controle. Nos testes de evitamento com C. riparius, verificou-se que as larvas de I instar não evitaram o sedimento contaminado com 2,0 mg. $\mathrm{L}^{-1} \mathrm{de} \mathrm{Cu}$ e as larvas de II ínstar não evitaram compartimentos com as maiores concentrações de $\mathrm{Cu}\left(3,4 \mathrm{mg} \cdot \mathrm{L}^{-1}\right)$ promovido no experimento de fluxo contínuo. As fêmeas 
adultas depositaram seus ovos tanto no meio contaminado $\left(1,3 \mathrm{mg} \cdot \mathrm{L}^{-1} \mathrm{de} \mathrm{Cu}\right)$ quanto no meio não contaminado, indicando a não preferência. Porém, observaram-se efeitos adversos nas taxas de eclosão e viabilidade dos ovos e das larvas. Com esses resultados conclui-se que as espécies C. xanthus e C. riparius podem ser utilizadas em estudos de toxicidade de sedimentos e de avaliação de risco ecológico, como na contaminação por metais, porém, diferentes parâmetros de avaliação do teste devem ser estudados e cuidadosamente utilizados dependendo da finalidade do estudo.

Palavras-chaves: sedimento, metais, Chironomus sp, bioensaios "in situ" e testes de evitamento 


\section{Abstract - Dornfeld, C.B. (2006). Use of Chironomus sp (Diptera, Chironomidae) to assess the quality of sediment and metal contamination. Pós-graduação em Ciências da Engenharia Ambiental, EESC-USP.}

The purpose of this study was to evaluate the use of Chironomus xanthus and Chironomus riparius to assess sediment quality and metal contamination using different ecotoxicological bioassays. Sediment was collected from Monjolinho River and tributaries (14 sampling stations). Water and sediment analyses were performed by different variables including nutrients and metals. There was an increase of the contamination levels from the fountainhead to the mouth of the river. Organochloride pesticide showed high concentrations (above CONAMA 357/ 05) in a few number of sampling stations. Laboratory bioassays with sediment demonstrated acute toxicity in two sampling stations (Federal and Usina), and "in situ" bioassays showed higher percentages of mortality than laboratory bioassay. Acute and chronic toxicity tests were performed with $\mathrm{C}$. x anthus exposed to $\mathrm{Cd}$ and $\mathrm{Cu}$. These metals were selected because they presented concentration values above limit established by the CONAMA resolution $357 / 05$. The $\mathrm{LC}_{50} 96 \mathrm{~h}$ for 4 th instar larvae was $0.30 \mathrm{mg} \cdot \mathrm{L}^{-1}$ of $\mathrm{Cu}$ and $0.70 \mathrm{mg} \cdot \mathrm{L}^{-1}$ of $\mathrm{Cd}$. Chronic tests were carried out in 16 days using 1st instar larvae; the test concentrations were 1.0 and $70.0 \mu \mathrm{gg} \cdot \mathrm{L}^{-1}$ of $\mathrm{Cd}$ and $20.0 \mu \mathrm{g} . \mathrm{L}^{-1}$ of $\mathrm{Cu}$. No differences were observed between control and 1.0 $\mu g . L^{-1}$ of $\mathrm{Cd}$, except to mentum deformities. Adverse effects were observed at 70.0 $\mu \mathrm{g} . \mathrm{L}^{-1}$ for $\mathrm{Cd}$. These effects were reduction in survival, body length and cephalic capsule width, as well as, emergence time delay (3 days). No differences were observed between control and treatment in relation to $\mathrm{Cu}$. Avoidance tests using $\mathrm{C}$. riparius showed that 1st instar larvae did not avoid sediment contaminated with 2.0 mg.L. $\mathrm{L}^{-1}$ of $\mathrm{Cu}$. Similarly, 2nd instar larvae of $\mathrm{C}$. riparius submitted to the flowthrough system did not avoid the compartments with the higher concentration of copper (3.4 mg.L-1). Egg-laying females deposited egg-masses in both contaminated (1.3 mg. $\mathrm{L}^{-1}$ of $\mathrm{Cu}$ ) and uncontaminated media. Therefore, there was no preference in relation to oviposition. On the other hand, adverse effects were observed for eclosion and eggs hatchability. The conclusion is that $\mathrm{C}$. $\mathrm{x}$ anthus and $\mathrm{C}$. riparius can be used in toxicity bioassays to asses sediment quality and ecological risk, like metal 
contamination, but different end points have to be selected and applied carefully used depending on the study purpose.

Key-words: sediment, metals, C hironomus sp, "in situ" bioassays and avoidance test. 


\section{Lista de Figuras}

\section{Lista de Figuras - Capítulo 1}

Figura 1 - Mapa do Estado de São Paulo, com a subdivisão em 22 UGRHIs. A Bacia do Tietê/ Jacaré está indicada pelo número 13 (FONTE - CETESB, 2001)............. 4

Figura 2 - Bacia Hidrográfica do Tietê/Jacaré e localização da sub-bacia do rio Monjolinho, São Carlos, SP - Brasil (modificado de Turene, 2006)...................... 5

Figura 3 - Área de estudo demonstrando as principais sub-bacias do município de São Carlos, localizando a sub-bacia do rio Monjolinho (Fonte: Conferência da Cidade -Prefeitura Municipal de São Carlos, Secretaria de Habitação e D esenvolvimento Urbano, 2002)..

Figura 4 - Área de estudo (rio Monjolinho e tributários) com a localização das estações de coleta, São Carlos, SP. Fonte: Espíndola et al. (2000). A bacia hidrográfica do rio Monjolinho, RiMa editora..

Figura 5 - Imagens das estações de coleta no rio Monjolinho e tributários.. 12

Figura 6 - Imagens das estações de coleta - Nascente e Federal 170

Figura 7 - Imagens das estações de coleta - USP e Usina.

Figura 8 - Imagens das estações de coleta - Ponte caída e Foz (Fotos: Sabrina M. Viana, 2004).

Figura 9 - Imagens das estações de coleta - Madalena e Tijuco.

Figura 10 - Imagens das estações de coleta - Mineirinho, Água Quente e G regório.. 174

Figura 11 - Imagens das estações de coleta - Água Fria e Cancan. 175

\section{Lista de Figuras - Capítulo 2}

Figura 1 - Variação da pluviosidade (mm) em São Carlos, durante o período de estudo. Os dados pluviométricos foram fornecidos pela Estação Meteorológica do Centro de Recursos Hídricos e Ecologia Aplicada, EESC/ USP.

Figura 2 - Vazão $\left(\mathrm{m}^{3} . \mathrm{s}^{-1}\right)$ no rio Monjolinho e tributários durante o período de estudo.......

Figura 3 - Material em suspensão orgânico e inorgânico (mg.L-1 ${ }^{-1}$ no rio Monjolinho e tributários, durante período de estudo (Notar a diferença de escala em janeiro/ 04).

Figura 4 - Formas fosfatadas (fosfato total dissolvido - PTD, fosfato inorgânico - PI e fósforo total - PT, em $\mu g . L^{-1}$ ) no rio Monjolinho e tributários em março/ 03....

Figura 5 - Formas fosfatadas (fosfato total dissolvido - PTD, fosfato inorgânico - PI e fósforo total - PT, em $\mu g . L^{-1}$ ) no rio Monjolinho e tributários em julho/ 03...... 
Figura 6 - Formas fosfatadas (fosfato total dissolvido - PTD, fosfato inorgânico - PI e fósforo total - PT, em $\mu g . L^{-1}$ ) no rio Monjolinho e tributários em outubro/ 03.31

Figura 7 - Formas fosfatadas (fosfato total dissolvido - PTD, fosfato inorgânico - PI e fósforo total - PT, em $\mu g . L^{-1}$ ) no rio Monjolinho e tributários em janeiro/ 04... 32

Figura 8 - Formas fosfatadas (fosfato total dissolvido - PTD, fosfato inorgânico - PI e fósforo total - PT, em $\mu \mathrm{g} . \mathrm{L}^{-1}$ ) no rio Monjolinho e tributários em abril/ 04.........

Figura 9 - Formas nitrogenadas (nitrato $-\mathrm{NO}_{3}$, íon amônio - $\mathrm{NH}_{4}$ e nitrito - $\mathrm{NO}_{2}$, em $\left.\mu \mathrm{g} . \mathrm{L}^{-1}\right)$ no rio Monjolinho e tributários em março/ $03 .$.

Figura 10 - Formas nitrogenadas (nitrato - $\mathrm{NO}_{3}$, íon amônio - $\mathrm{NH}_{4}$ e nitrito - $\mathrm{NO}_{2}$, em $\mu \mathrm{g} \cdot \mathrm{L}^{-1)}$ no rio Monjolinho e tributários em julho/ 03.

Figura 11 - Formas nitrogenadas (nitrato - $\mathrm{NO}_{3}$, íon amônio - $\mathrm{NH}_{4}$ e nitrito - $\mathrm{NO}_{2}$, em $\left.\mu \mathrm{g} . \mathrm{L}^{-1}\right)$ no rio Monjolinho e tributários em outubro/ 03.

Figura 12 - Formas nitrogenadas (nitrato - $\mathrm{NO}_{3}$, íon amônio - $\mathrm{NH}_{4}$ e nitrito - $\mathrm{NO}_{2}$, em $\left.\mu \mathrm{g} . \mathrm{L}^{-1}\right)$ no rio Monjolinho e tributários em janeiro/ 04.

Figura 13 - Formas nitrogenadas (nitrato - $\mathrm{NO}_{3}$, íon amônio - $\mathrm{NH}_{4}$ e nitrito - $\mathrm{NO}_{2}$, em $\left.\mu \mathrm{g} . \mathrm{L}^{-1}\right)$ no rio Monjolinho e tributários em abril/ 04 .

Figura 14 - Nitrogênio orgânico total (NOT) na água do rio Monjolinho e tributários durante o período de estudo...

Figura 15 - Concentrações (mg.L-1) de cloretos obtidos no rio Monjolinho e tributários durante o período de estudo...

Figura 16 - Concentrações (mg. $\left.\mathrm{L}^{-1}\right)$ de sulfatos obtidos no rio Monjolinho e tributários durante o período de estudo.....

Figura 17 - Concentrações (mg.L-1) de sulfetos obtidos no rio Monjolinho e tributários durante o período de estudo...

Figura 18 - Demanda Química de Oxigênio (mg. $\left.\mathrm{L}^{-1}\right)$ no rio Monjolinho e Tributários durante o período de estudo...

Figura 19 - D emanda Bioquímica de Oxigênio $\left(\mathrm{mg}^{\mathrm{L}} \mathrm{L}^{-1}\right)$, no rio Monjolinho e tributários durante o período de estudo

Figura 20 - Concentrações de cromo, cádmio e cobre ( $\mu$ g. $\left.L^{-1}\right)$ obtidas nas águas das estações de coleta do rio Monjolinho durante o período de estudo.

Figura 21 - Concentrações de zinco e manganês ( $\left.\mu g . L^{-1}\right)$ e ferro (mg. $\left.L^{-1}\right)$ obtidas nas águas das estações de coleta do rio Monjolinho durante o período de estudo.

Figura 22 - Concentrações de cromo, cobre e cádmio ( $\mu g . L^{-1}$ ) obtidas nas águas dos tributários do rio Monjolinho durante o período de estudo.

Figura 23 - Concentrações de zinco e manganês ( $\left.\mu g . L^{-1}\right)$ e ferro (mg.L-1) nas águas dos tributários do rio Monjolinho durante o período estudado.

Figura 24 - Concentrações de Clorofila-ạ ( $\left.\mu . L^{-1}\right)$ no rio Monjolinho e tributários durante 
o período de estudo.

Figura 25 - Variação dos valores de pH no rio Monjolinho e tributários durante o período de estudo

Figura 26 - Variação dos valores de condutividade elétrica $\left(\mu \mathrm{S} . \mathrm{cm}^{-1}\right)$ no rio Monjolinho e tributários durante o período de estudo.

Figura 27 - Variação dos valores de temperatura da água $\left({ }^{\circ} \mathrm{C}\right)$ no rio Monjolinho e tributários durante o período de estudo.

Figura 28 - Variação da concentração de oxigênio dissolvido (mg. $\left.\mathrm{L}^{-1}\right)$ no rio Monjolinho e tributários durante o período de estudo.

Figura 29 - Porcentagem de matéria orgânica no sedimento do rio Monjolinho e tributários durante o período de estudo.

Figura 30 - Concentração de fósforo total $\left(\mu \mathrm{g} \cdot \mathrm{g}^{-1}\right)$ no sedimento do rio Monjolinho e tributários durante o período de estudo.

Figura 31 - Porcentagem de nitrogênio orgânico total no sedimento do rio Monjolinho e tributários durante o período de estudo.

Figura 32 - Potencial redox $(\mathrm{mV})$ e temperatura $\left({ }^{\circ} \mathrm{C}\right)$ do sedimento do rio Monjolinho e tributários durante o período de estudo.

Figura 33 - Granulometria do sedimento do rio Monjolinho e tributários durante 0 período de estudo.

\section{Lista de Figuras - Capítulo 3}

Figura 1 - Bandeja de cultivo de Chironomus xanthus (A), estágios do ciclo de vida (B) e esquema genérico do ciclo de vida de Chironomus sp (exemplo de $C$. tentans) (C)

Figura 2 - Esquema das câmaras utilizadas nos bioensaios "in situ" com Chironomus x anthus.

Figura 3 - Seqüência da montagem do experimento "in situ": (A) Câmaras de PVC (B) Colocação do sedimento da estação e (C) Colocação do experimento na estação selecionada.

Figura 4 - Resultados dos testes de sensibilidade ao $\mathrm{KCl}$ realizados com C. xanthus, mostrando a faixa de sensibilidade sugerida por FO NSECA (1997).

Figura 5 - Bioensaios de toxicidade aguda do sedimento do rio Monjolinho e tributários utilizando Chironomus xanthus como organismo-teste durante o período estudado

Figura 6 - Comparação da mortalidade de Chironomus xanthus nos bioensaios "in situ" e laboratoriais. 
Figura 7 - Porcentagem de matéria orgânica, de silte + argila e de mortalidade nas estações de coleta do rio Monjolinho (São Carlos, SP).

Figura 8 - Concentração de metais potencialmente biodisponíveis no sedimento (Cr e $\mathrm{Cu}$ ) e porcentagem de mortalidade nas estações de coleta do rio Monjolinho (São Carlos, SP)

\section{Lista de Figuras - Capítulo 4}

Figura 1 - Desenho experimental para a realização do teste crônico com metais utilizando Chironomus $\mathrm{x}$ anthus.

Figura 2 - Representação gráfica dos resultados dos testes de toxicidade com Cádmio realizados com $\mathrm{C}$. x anthus.

Figura 3 - Representação gráfica dos resultados dos testes de toxicidade com Cobre realizados com $C$. x anthus.

Figura 4 - $\quad$ Análise da sobrevivência (\%) e peso seco (mg) dos organismos expostos aos tratamentos. CdCo (Cádmio - CONAMA), CdCe (Cádmio -CENO) e $\mathrm{CuCo} / \mathrm{Ce}$ (Cobre - CONAMA/ CENO).

Figura 5 - Total de emergência de Chironomus x anthus no Controle e tratamentos com $\mathrm{Cd}$ e $\mathrm{Cu}$, durante 15 dias de exposição. CdCo (Cádmio - CONAMA), CdCe (Cádmio -CENO) e CuCo/ Ce (Cobre - CONAMA/ CENO).

Figura 6 - Emergência cumulativa (somatória dos Testes Crônicos 1 e 3). CdCo (Cádmio - CONAMA), CdCe (Cádmio -CENO) e CuCo/Ce (Cobre CONAMA/ CENO).

Figura 7 - Emergência de machos e fêmeas durante 16 dias de exposição de Chironomus xanthus ao Controle e aos Tratamentos de Cd e Cu. CdCo (Cádmio CONAMA), CdCe (Cádmio -CENO) e CuCo/Ce (Cobre CONAMA/ CENO)

Figura 8 - Comprimento e largura das cápsulas cefálicas de Chironomus x anthus expostos ao teste crônico - (A) Controle; (B) Cd CONAMA, (C) Cd CENO e (D) $\mathrm{Cu}$ CONAMA/ CENO

Figura 9 - Distribuição do tamanho do corpo em Chironomus xanthus submetidos ao Teste Crônico: A) Controle; (B) Cd CONAMA, (C) Cd CENO e (D) $\mathrm{Cu}$ CONAMA/ CENO

Figura 10 - Total de organismos, número de deformidades e porcentagem de deformidades nos organismos expostos ao teste crônico.

Figura 11 - Cápsula cefálica de Chironomus x anthus (aumento de 10x), com detalhe de parte 
do tubo digestivo 204

Figura 12 - D etalhe do aparato bucal de Chironomus x anthus (aumento de 40x)..

Figura 13 - Exemplos de mento normal e com deformidades obtidas nos Testes Crônicos com metais..

Figura 14 - Exemplos de mentos de Chironomus xanthus sem deformidades.

Figura 15 - Exemplos de mentos de Chironomus xanthus com deformidades presentes no Controle do Teste Crônico 1.

Figura 16 - Exemplos de mentos de Chironomus xanthus com deformidades presentes nos organismos expostos ao Cd CONAMA (CdCo) do Teste Crônico 1.

Figura 17 - Exemplos de mentos de Chironomus xanthus com deformidades presentes nos organismos expostos ao $\mathrm{Cu}$ CONAMA/ CENO (CuCo/ Ce) do Teste Crônico 1 ...

Figura 18 - Exemplos de mentos de Chironomus xanthus com deformidades presentes nos organismos expostos ao Cd CONAMA (CdC) do Teste Crônico 3.

Figura 19 - Exemplos de mentos de $C$ hironomus xanthus com deformidades presentes nos organismos expostos ao Cu CONAMA/ CENO do Teste Crônico 3.

Figura 20 - Concentrações de $\mathrm{Cd}\left(\mu g \cdot \mathrm{L}^{-1}\right)$ na água após 10 dias de exposição (final do teste).

Figura 21 - Concentração de Cd ( $\mu$ g.g-1 $\left.{ }^{-1}\right)$ potencialmente biodisponível no sedimento após 10 dias de exposição..

Figura 22 - Concentração de Cd ( $\left.\mu g \cdot g^{-1}\right)$ em C hironomus x anthus após 10 dias de exposição..

Figura 23 - Concentrações de $\mathrm{Cu}\left(\mu \mathrm{g} \cdot \mathrm{L}^{-1}\right)$ na água após 10 dias de exposição.

Figura 24 - Concentração de $\mathrm{Cu}\left(\mu \mathrm{g} \cdot \mathrm{g}^{-1}\right)$ potencialmente biodisponível no sedimento após 10 dias de exposição

Figura 25 - C Concentração de $\mathrm{Cu}\left(\mu g . g^{-1}\right)$ em Chironomus xanthus após 10 dias de exposição..

\section{Lista de Figuras - Capítulo 5}

Figura 1 - Cultivo de Chironomus riparius. Vista geral da caixa de acrílico (A) e detalhe dos cristalizadores com mangueiras de aeração e cristalizador sem sedimento para a postura de ovos (B).

Figura 2 - D Desenho esquemático do Experimento de Evitamento - seleção de substrato por larvas de I instar de C hironomus riparius..

Figura 3 - Experimento de Evitamento - Seleção de substrato. D etalhe do becker com a distribuição dos frascos(A); Distribuição das réplicas(B e C); Frascos individuais para crescimento das larvas de $C$. riparius (D e E).

Figura 4 - Esquema do Teste de Evitamento - Gradiente de contaminação, mostrando 
as partes integrantes do Sistema de Fluxo Contínuo

Figura 5- Experimento de Evitamento - Gradiente de Contaminação. $\mathrm{C}=$ compartimentos; $\mathrm{R}$ = réplicas; os reservatórios de ASTM e de descarte dos resíduos não aparecem nessa imagem (Modificado de D onato et al., 2004).........

Figura 6 - Cobertura utilizada durante os Testes de Evitamento - Gradiente de Contaminação. Sobre essa armação de tela plástica e papel branco, coloca-se uma cobertura de tecido preto. Em preto, são janelas para observação dos compartimentos (D onato et al., 2004).

Figura 7 - D esenho esquemático do Experimento de Evitamento - Oviposição. 


\section{Lista de tabelas}

\section{Lista de Tabelas - Capítulo 1}

Tabela 1 - Principais características das estações de coleta no rio Monjolinho.

\section{Lista de Tabelas - Capítulo 2}

Tabela 1 - Variáveis, metodologias e referências utilizadas para a caracterização da qualidade da água do rio Monjolinho e seus tributários (São Carlos, SP).

Tabela 2 - Variáveis, metodologias e referências utilizadas para a caracterização do sedimento do rio Monjolinho e seus tributários (São Carlos, SP).............................. 26

Tabela 3 - Pluviosidade diária durante o período de estudo. Em destaque estão os dias em que foram realizadas as coletas de campo.

Tabela 4 - Valores de vazão $\left(\mathrm{m}^{3} . \mathrm{s}^{-1}\right)$ durante o período de estudo.

Tabela 5 - Material em suspensão (total, inorgânico e orgânico) em mg.L-1 durante 0 período de estudo...

Tabela 6 - Concentrações de nutrientes na água obtidos em março/ 03.

Tabela 7 - Concentrações de nutrientes na água obtidos em julho/ 03.

Tabela 8 - Concentrações de nutrientes na água obtidos em outubro/ 03

Tabela 9 - Concentrações de nutrientes na água obtidos em janeiro/ 04.

Tabela 10 - Concentrações de nutrientes na água obtidos em abril/ $04 .$.

Tabela 11 - Concentrações (mg.L-1) de Cloretos na água durante o período de estudo..

Tabela 12 - Concentrações (mg.L-1) de Sulfatos na água durante o período de estudo.

Tabela 13 - Concentrações (mg. $\mathrm{L}^{-1}$ ) de Sulfetos na água durante o período de estudo.

Tabela 14 - Demanda Q uímica de Oxigênio (mg.L-1) durante o período de estudo.

Tabela 15 - D emanda Bioquímica de Oxigênio (mg.L-1) durante o peńodo de estudo.

Tabela 16 - Concentrações de metais na água do rio Monjolinho e tributários em março/ $03 .$.

Tabela 17 - Concentrações de metais na água do rio Monjolinho e tributários em julho/ 03.... 181

Tabela 18 - Concentrações de metais na água do rio Monjolinho em outubro/ 03..................... 181

Tabela 19 - Concentrações de metais na água do rio Monjolinho e tributários em janeiro/ 04. 181

Tabela 20 - Concentrações de metais na água do rio Monjolinho em abril/ 04............................. 182

Tabela 21 - Resumo das concentrações de metais totais na água rio Monjolinho e seus tributários durante o período estudado.

Tabela 22 - Concentrações de agrotóxicos organoclorados ( $\mu$ g. $L^{-1}$ ) obtidos nas amostras de água do rio Monjolinho e tributários localizados na imediações da Usina da Serra.

Tabela 23 - Concentrações de clorofila a ( $\left.\mu g . L^{-1}\right)$ na água durante o período de estudo. 
Tabela 24 - Coliformes fecais e totais no rio Monjolinho e tributários durante o período de estudo.

Tabela 25 - V Variação do pH no rio Monjolinho e tributários durante o período de estudo.......

Tabela 26 - Variação da condutividade $\left(\mu \mathrm{S} . \mathrm{cm}^{-1}\right)$ no rio Monjolinho e tributários durante 0 período de estudo

Tabela 27 - Variação da temperatura da água $\left({ }^{\circ} \mathrm{C}\right)$ no rio Monjolinho e tributários durante 0 período de estudo

Tabela 28 - Variação da concentração de oxigênio dissolvido na água (mg. $\left.\mathrm{L}^{-1}\right)$ do rio Monjolinho e tributários durante o período de estudo.

Tabela 29 - Porcentagem de matéria orgânica no sedimento durante o período de estudo........

Tabela 30 - Concentração de fósforo total $\left(\mu g \cdot g^{-1}\right)$ no sedimento durante 0 período de estudo.

Tabela 31 - Porcentagem de nitrogênio orgânico total no sedimento durante o período de estudo

Tabela 32 - Valores do potencial redox $(\mathrm{mV})$ do sedimento durante o período de estudo....... 184

Tabela 33 - Porcentagens das frações granulométricas em março/ 03. 185

Tabela 34 - Porcentagens das frações granulométricas em julho/ 03. 185

Tabela 35 - Porcentagens das frações granulométricas em outubro/ 03. 185

Tabela 36 - Porcentagens das frações granulométricas em janeiro/ 04. 185

Tabela 37 - Porcentagens das frações granulométricas em abril/ 04 185

Tabela 38 - Frações granulométricas predominantes no sedimento do rio Monjolinho e tributários durante o período de estudo.

Tabela 39 - Concentração de metais potencialmente biodisponíveis no sedimento do rio Monjolinho durante o período de estudo. Em cinza escuro, valores mínimos e em cinza claro, valores máximo.

Tabela 40 - Concentrações de metais potencialmente biodisponíveis no sedimento dos tributários do rio Monjolinho durante o período de estudo. Em cinza escuro, valores mínimos e em cinza claro, valores máximo.

Tabela 41 - Resumo da distribuição de metais potencialmente biodisponíveis no sedimento do rio Monjolinho e seus tributários durante o período de estudo.

Tabela 42 - Agrotóxicos organoclorados ( $\mu g . \mathrm{Kg}^{-1}$ ) nas amostras de sedimento do rio Monjolinho e tributários localizados na imediações da Usina da Serra.

Tabela 43 - Classificação atual do rio Monjolinho e tributários, segundo Resolução CONAMA 357/ 05, em julho/ 03 (período seco). Classe 1 - branco, Classe 2 cinza claro, Classe 3 - cinza escuro e Classe 4 - preto.

Tabela 44 - Classificação atual do rio Monjolinho e tributários, segundo Resolução CONAMA 357/ 05, em janeiro/ 04 (período chuvoso). Classe 1 - branco, Classe 
2 - cinza claro, Classe 3 - cinza escuro e Classe 4 - preto.

Tabela 45 - Análise comparativa das concentrações de metais ( $\left.\mu g . L^{-1}\right)$ de diferentes sistemas lóticos. Em negrito, concentrações acima do estabelecido pela resolução CO NAMA 357/ 05 para águas Classe 2.

Tabela 46 - Análise comparativa do rio Monjolinho (presente estudo) com os dados da Cetesb (2005) referentes aos principais rios pertencentes à UGRHI 13. Resultados expressos em mg.L-1

Tabela 47 - Potencial redox, metais potencialmente biodisponíveis e matéria orgânica durante o período de estudo no rio Monjolinho e tributários.

Tabela 48 - Dados da Cetesb (2005) em relação aos metais no sedimento dos rios do Estado de São Paulo. Entre parêntesis está apresentado o número da UGRHI a que pertence o rio

Tabela 49 - V Valores guias estabelecidos por Smith et al. (1996) e MacD onald (2000) e análise comparativa das concentrações de metais nos sedimentos de diferentes sistemas lóticos. Em negrito, valores mais restritivos e nas células cinzas estão as concentrações acima do proposto pelos autores.

\section{Lista de Tabelas - Capítulo 3}

Tabela 1 - Teste de Sensibilidade de Chironomus xanthus ao Cloreto de Potássio em 11/ 04/ 03..

Tabela 2 - Teste de Sensibilidade de Chironomus xanthus ao Cloreto de Potássio em 06/06/03.

Tabela 3 - Teste de Sensibilidade de Chironomus xanthus ao Cloreto de Potássio em $21 / 08 / 03$.

Tabela 4 - Teste de Sensibilidade de Chironomus xanthus ao Cloreto de Potássio em 12/10/ 03 .

Tabela 5 - Teste de Sensibilidade de Chironomus xanthus ao Cloreto de Potássio em 23/ 01/ 04 .

Tabela 6 - Teste de Sensibilidade de Chironomus xanthus ao Cloreto de Potássio em $14 / 05 / 04$

Tabela 7 - Teste de Sensibilidade de Chironomus xanthus ao Cloreto de Potássio em 25/11/04.

Tabela 8 - Resultados dos testes de sensibilidade ao Cloreto de Potássio $(\mathrm{KCl})$ realizados com C. xanthus, expresso em g.L-1 de $\mathrm{KCl}$.

Tabela 9 - Análise estatística dos resultados referentes aos testes de sensibilidade ao $\mathrm{KCl}$, utilizando C. xanthus..

Tabela 10 - Porcentagem de mortalidade de C. x anthus durante o período estudado. 
Tabela 11 - Análise estatística de Fisher (TOXSTAT 3.4) do bioensaio de toxicidade aguda do sedimento do rio Monjolinho e tributários em março/ 03.

Tabela 12 - Análise estatística de Fisher (TOXSTAT 3.4) do bioensaio de toxicidade aguda do sedimento do rio Monjolinho e tributários em julho/ 03.

Tabela 13 - Análise estatística de Fisher (TOXSTAT 3.4) do bioensaio de toxicidade aguda do sedimento do rio Monjolinho e tributários em outubro/ 03.

Tabela 14 - Análise estatística de Fisher (TOXSTAT 3.4) do bioensaio de toxicidade aguda do sedimento do rio Monjolinho e tributários em janeiro/ 04.

Tabela 15 - Análise estatística de Fisher (TOXSTAT 3.4) do bioensaio de toxicidade aguda do sedimento do rio Monjolinho e tributários em abril/ 04.

Tabela 16 - Correlação de Pearson em março de 2003.

Tabela 17 - Correlação de Pearson em julho de 2003.

Tabela 18 - Correlação de Pearson em outubro de 2003.

Tabela 19 - Correlação de Pearson em janeiro de 2004.

Tabela 20 - Correlação de Pearson em abril de 2004.

Tabela 21 - Variáveis iniciais e finais dos Bioensaios "in situ" realizados em outubro/ 03 e janeiro/ 04 no rio Monjolinho (São Carlos, SP)..

Tabela 22 - Resumo dos bioensaios de toxicidade realizados com amostras de água do rio Monjolinho (Fonte: NOVELLI, 2005; CAMPAGNA, 2005).

Tabela 23 - Resumo dos bioensaios de toxicidade realizados com amostras de sedimento do rio Monjolinho (Fonte: NOVELLI, 2005; CAMPAGNA, 2005)..

Tabela 24 - Comparação da toxicidade entre os diferentes organismos testes expostos a amostras de sedimentos dos diferentes pontos de coleta do sistema Monjolinho, em julho/ 03 (Fonte: Espíndola, 2005: Relatório Final FAPESP processo 2002/ 10494-6).

Tabela 25 - Comparação da toxicidade entre os diferentes organismos testes expostos a amostras de sedimento dos diferentes pontos de coleta do sistema Monjolinho, em janeiro/ 04 (Fonte: Espíndola 2005, Relatório Final FAPESP processo 2002/ 10494-6)

Tabela 26 - Categorias de poluição de sedimento estabelecidas por THOMAS (1987), Critério Canadense (2002) e MacD O NALD et al. (2000), sendo a concentração de metal expressa mg.Kg ${ }^{-1}$

\section{Lista de Tabelas - Capítulo 4}

Tabela 1 - Teste de Sensibilidade de C hironomus x anthus ao Cádmio em 17/ 05/ 04. 193

Tabela 2 - Teste de Sensibilidade de Chironomus x anthus ao Cádmio em 24/ 05/ 04 193

Tabela 3 - Teste de Sensibilidade de C hironomus x anthus ao Cádmio em 05/ 06/ 04. 193 
Tabela 4 - Teste de Sensibilidade de Chironomus x anthus ao Cádmio em 14/ 06/ 04................... 193

Tabela 5 - $\quad$ Teste de Sensibilidade de Chironomus xanthus ao Cádmio em 15/ 06/ 04................... 194

Tabela 6 - $\quad$ Teste de Sensibilidade de Chironomus xanthus ao Cádmio em 15/ 07/ 04................... 194

Tabela 7 - Teste de Sensibilidade de C hironomus x anthus ao Cádmio em 28/ 06/ 04.................... 194

Tabela 8 - $\quad$ Teste de Sensibilidade de Chironomus x anthus ao Cádmio em 26/ 07/ 04................... 194

Tabela 9 - Teste de Sensibilidade de Chironomus x anthus ao Cádmio em 18/ 07/ 04................... 195

Tabela 10 - Teste de Sensibilidade de Chironomus x anthus ao Cádmio em 13/ 08/ 04................... 195

Tabela 11 - Resultados dos testes de toxicidade com Cádmio, realizados com C. xanthus, expresso em mg. $\mathrm{L}^{-1}$ de Cd........................................................................................... 109

Tabela 12 - Análise estatística dos resultados dos testes de toxicidade com Cádmio, utilizando C. xanthus.................................................................................................. 109

Tabela 13 - Teste de Sensibilidade de Chironomus x anthus ao Cobre em 17/ 05/ 04...................... 195

Tabela 14 - Teste de Sensibilidade de Chironomus xanthus ao Cobre em 18/ 05/ 04...................... 195

Tabela 15 - Teste de Sensibilidade de Chironomus x anthus ao Cobre em 24/ 05/ 04...................... 196

Tabela 16 - Teste de Sensibilidade de Chironomus x anthus ao Cobre em 14/ 06/ 04....................... 196

Tabela 17 - Teste de Sensibilidade de Chironomus x anthus ao Cobre em 14/ 06/ 04...................... 196

Tabela 18 - Teste de Sensibilidade de Chironomus x anthus ao Cobre em 28/ 06/ 04...................... 196

Tabela 19 - Teste de Sensibilidade de Chironomus x anthus ao Cobre em 15/ 07/ 04...................... 197

Tabela 20 - Teste de Sensibilidade de Chironomus x anthus ao Cobre em 26/ 07/ 04...................... 197

Tabela 21 - Teste de Sensibilidade de Chironomus xanthus ao Cobre em 28/ 07/ 04..................... 197

Tabela 22 - Teste de Sensibilidade de Chironomus x anthus ao Cobre em 13/ 08/ 04...................... 197

Tabela 23 - Resultados dos testes toxicidade com Cobre, realizados com C. xanthus, expresso em mg.L.1 de Cu.................................................................................................... 110

Tabela 24 - Análise estatística dos resultados dos testes de toxicidade com Cobre, utilizando C. xanthus.

Tabela 25 - Resultados dos Testes Crônicos 1, 2 e 3 demonstrando a \% de sobrevivência e 0 peso seco individual (mg) de Chironomus x anthus após 10 dias de exposição.

Tabela 26 - Resultados dos Testes Crônicos 1, 2 e 3 demonstrando a emergência de Chironomus $x$ anthus.

Tabela 27 - Resultados dos Testes Crônicos 1, 2 e 3 demonstrando a emergência de fêmeas e machos de Chironomus xanthus..

Tabela 28 - Medidas do comprimento $(\mu \mathrm{m})$ e largura $(\mu \mathrm{m})$ da cápsula cefálica de C hironomus xanthus expostos aos tratamentos do Teste Crônico 1

Tabela 29 - Medidas do comprimento $(\mu \mathrm{m})$ e largura $(\mu \mathrm{m})$ da cápsula cefálica de Chironomus xanthus expostos aos tratamentos do Teste Crônico 3.

Tabela 30 - Comprimento do corpo (cm) de Chironomus xanthus referentes aos Testes Crônicos 1 e 3. 
Tabela 31 - Valores das medidas das cápsulas cefálicas (comprimento e largura) e do comprimento do corpo total dos indivíduos de C. xanthus analisados após 10 dias de exposição - Teste 1

Tabela 32 - Valores das medidas das cápsulas cefálicas (comprimento e largura) e do comprimento do corpo total dos indivíduos de C. xanthus analisados após 10 dias de exposição - Teste 3

Tabela 33 - Concentrações de Cd na água pós-teste, biodisponível no sedimento e organismos.

Tabela 34 - Valores médios do Fator de Bioacumulação (FB) de Cd relacionando as concentrações médias na água ( $\left.\mu g . L^{-1}\right)$ e nos organismos ( $\mu g . g^{-1}$ )

Tabela 35 - Fator de Bioacumulação (FB) de Cd relacionando as concentrações na água $\left(\mu g . L^{-1}\right)$ e as concentrações nos organismos $\left(\mu g \cdot g^{-1}\right)$

Tabela 36 - Concentrações de $\mathrm{Cu}$ na água pós-teste, biodisponível no sedimento e organismos.

Tabela 37 - Valores médios do Fator de Bioacumulação (FB) de $\mathrm{Cu}$ relacionando as concentrações médias na água ( $\left.\mu g . L^{-1}\right)$ e nos organismos ( $\left.\mu g . g^{-1}\right)$

Tabela 38 - Fator de Bioacumulação (FB) de $\mathrm{Cu}$ relacionando as concentrações na água ( $\left.\mu \mathrm{g} . \mathrm{L}^{-1}\right)$ e as concentrações nos organismos ( $\mu \mathrm{g} . \mathrm{g}^{-1}$ )

Tabela 39 - Critérios de seleção de organismos para testes de bioacumulação (Modificado de INGERSO LL et al., 1998; EPA, 2000)

\section{Lista de Tabelas - Capítulo 5}

Tabela 1 - Resultados da réplica 4, destinada à distribuição uniforme para validação do experimento

Tabela 2 - Número de organismos encontrados em cada frasco de $50 \mathrm{ml}$, contendo sedimento artificial.

Tabela 3 - Resultados dos testes de distribuição uniforme 24h utilizando C. riparius.

Tabela 4 - Resultados do teste de evitamento ao gradiente de contaminação utilizando 3,8 mg. $\mathrm{L}^{-1}$ de $\mathrm{Cu}(100 \%)$, durante $24 \mathrm{~h}$

Tabela 5 - Total de massas de ovos obtidas em cada cristalizador durante o período de teste.

Tabela 6 - Análise das desovas após postura (72h)...

Tabela 7 - Análise da eclosão e viabilidade dos ovos e larvas após 72h da postura..... 


\section{Apresentação da Tese}

Esta Tese é parte integrante de um projeto financiado pela FAPESP (Processo ํㅡ 2002/ 10494-6), intitulado “Estudos limnológicos e ecotoxicológicos (laboratoriais e "in situ") no rio Monjolinho (São Carlos, SP), com ênfase na avaliação da toxicidade de metais e pesticidas organoclorados no zooplâncton (D aphnia similis e C eriodaphnia dubia), bentos (C hironomus x anthus) e peixes ( $D$ anio rerio e Poecilia reticulta)", que esteve sob coordenação do Prof. Dr. Evaldo Luiz Gaeta Espíndola. À partir desse financiamento foi possível realizar uma monografia de conclusão de curso (Rodrigues, 2005), quatro dissertações de mestrado (Campagna, 2005; Novelli, 2005, Vianna, 2005 e Turene, 2006) e duas teses de doutorado (Fracácio, 2006 e o presente estudo). Além dos trabalhos científicos apresentados aos programas de Pós-G raduação (FZEA/ USP; PPG -SEA/ EESC/ USP; PPG ERN/UFSCar), os membros participantes do Projeto realizaram projeto de extensão à comunidade de São Carlos, sob a forma de Palestras e Feira de Ciências em escolas do município.

Esta Tese apresenta-se dividida em 6 capítulos, sendo abordados aspectos limnológicos e ecotoxicológicos como ferramenta de avaliação da qualidade ambiental e também da avaliação de risco ecológico.

No Capítulo 1, está apresentada uma introdução à problemática da poluição de ecossistemas aquáticos e a caracterização da área de estudo.

No Capítulo 2, são apresentados os dados limnológicos referentes aos compartimentos água e sedimento do rio Monjolinho (São Carlos, SP) e realizado um estudo comparativo entre trabalhos realizados anteriormente nesse mesmo sistema e também com estudos realizados em outras localidades.

No Capítulo 3, são apresentados os bioensaios de toxicidade com Chironomus $\mathrm{xanthus} \mathrm{com} \mathrm{as} \mathrm{amostras} \mathrm{ambientais,} \mathrm{tanto} \mathrm{laboratoriais} \mathrm{quanto} \mathrm{"in} \mathrm{situ",}$ procurando correlacionar os resultados dos bioensaios com aqueles obtidos no Capítulo 2. 
No Capítulo 4, são apresentados os testes de toxicidade com substâncias de referência, sendo selecionados os metais $\mathrm{Cd}$ e $\mathrm{Cu}$. Foram realizados testes agudos e crônicos com variação nos parâmetros finais de avaliação.

No Capítulo 5, são apresentados os testes de evitamento ao cobre, uma nova proposta para testes laboratoriais com espécies aquáticas, no caso Chironomus riparius. Esses experimentos foram realizados na Universidade de Coimbra (Portugal), no D epartamento de Zoologia sob a orientação do Prof. Dr. Rui Ribeiro durante 0 estágio de doutorado no exterior.

No Capítulo 6 estão apresentadas as considerações finais e recomendações da tese, utilizando a integração dos capítulos anteriores com a finalidade de avaliação integral do rio Monjolinho, bem como do emprego de Chironomus (C. xanthus e C. riparius) em ensaios de toxicidades e sua importância para 0 monitoramento e avaliação de risco ecológico de sistemas aquáticos. 


\section{Sumário Geral}

Capítulo 1 - Apresentação da problemática da poluição de ecossistemas aquáticos e caracterização da área de estudo.

1. INTRODUÇÃO .................................................................... 1

2. OBJETIVOS 3

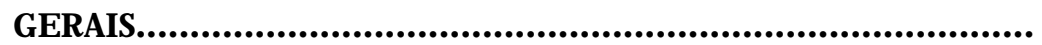

3. CARACTERIZAÇão DA ÁREA DE 3

ESTUDO

3.1. BACIA HIDROGRÁFICA DO

TIETÊ/ JACARÉ

3.2. SUB-BACIA HIDROGRÁFICA DO RIO

MONJOLINHO.

4. Períodos de amostragem e estaÇões de

COLETA

5. Bibliografia.

Capítulo 2 - Análise limnológica (água e sedimento) do rio Monjolinho e tributários, São Carlos (São Paulo, Brasil)........................................ 17

1. Introdução................................................................................. 17

1.1. Poluição de ecossistemas aquáticos............................................ 18

1.1.1. Agrotóxicos........................................................................ 18

1.1.2. Metais.............................................................................. 21

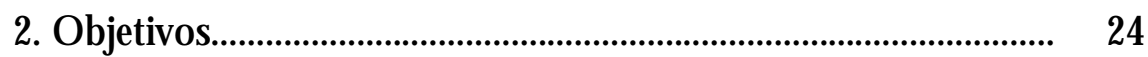

3. Materiais e Métodos................................................................... 24

3.1. Análise química, física e biológica da água................................. 24

3.2. Análise química e física do sedimento....................................... 26

4. Resultados.............................................................................. 27

4.1. Precipitação pluviométrica.......................................................... 27

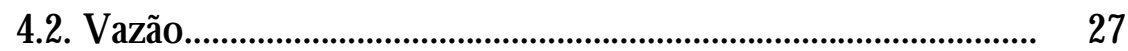

4.3. Material em suspensão na água................................................. 28

4.4. Nutrientes fosfatados e nitrogenados na água.......................... 29

4.4.1. Formas fosfatadas.............................................................. 29

4.4.2. Formas nitrogenadas............................................................ 32 
4.5. Íons (Cloretos, Sulfatos e Sulfetos) na água............................ 36

4.6. D emanda química de oxigênio (D Q O )................................... 39

4.7. D emanda bioquímica de oxigênio (DBO )............................... 39

4.8. Metais na água.............................................................................. 40

4.8.1. Rio Monjolinho...................................................................... 40

4.8.2. Tributários do rio Monjolinho............................................... 43

4.9. Agrotóxicos organoclorados na água......................................... 46

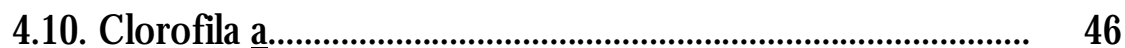

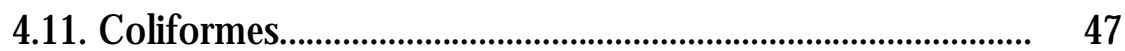

4.12. Potencial Hidrogênionico - pH............................................. 48

4.13. Condutividade elétrica.............................................................. 49

4.14. Temperatura da água.............................................................. 49

4.15. Oxigênio dissolvido ................................................................ 50

4.16. Matéria orgânica, fósforo total e nitrogênio orgânico total no sedimento ................................................................................... 51

4.17. Potencial redox do sedimento................................................ 53

4.18. G ranulometria......................................................................... 54

4.19. Metais potencialmente biodisponíveis no sedimento........... 56

4.19.1. Rio Monjolinho................................................................... 56

4.19.2. Tributários do rio Monjolinho.............................................. 57

4.20. Agrotóxicos organoclorados no sedimento.......................... 59

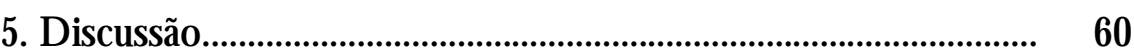

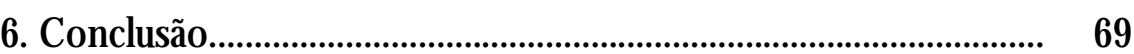

7. Bibliografia.................................................................................... 70

Capítulo 3 - Avaliação ecotoxicológica do sedimento do rio Monjolinho e tributários por meio de bioensaios laboratoriais e "in situ" utilizando Chironomus x anthus (Chironomidae - D iptera).

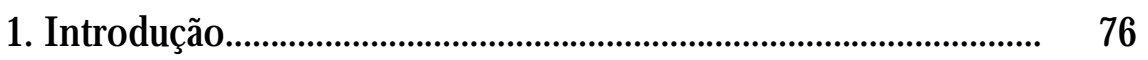

2. Objetivos................................................................................ $\quad 79$

3. Materiais e métodos.......................................................................... 79

3.1. Manutenção dos organismos-teste - Chironomus x anthus....... 79

3.2. Avaliação das culturas dos organismos-teste.......................... 81

3.3. Procedimentos para realização dos bioensaios......................... 81 
3.3.1. Coleta de sedimento para os bioensaios de toxicidade aguda.

3.3.2. Bioensaios de toxicidade aguda com amostras de sedimento utilizando Chironomus x anthus.

3.3.3. Bioensaios "in situ" utilizando Chironomus x anthus.............. 82

4. Resultados.

4.1. Teste de sensibilidade de Chironomus x anthus ao Cloreto de Potássio.

4.2. Bioensaios laboratoriais com amostras de sedimento. 85

4.3. Bioensaios "in situ". 86

5. Discussão. 88

6. Conclusão 96

7. Bibliografia. 97

Capítulo 4 - Avaliação da toxicidade de metais ( $\mathrm{Cd}$ e $\mathrm{Cu}$ ) em ensaios agudos e crônicos utilizando Chironomus x anthus (Chironomidae Díptera).

1. Introdução. 102

2. Objetivos. 105

3. Materiais e métodos 105

3.1. Testes de toxicidade com metais $(\mathrm{Cd} \mathrm{e} \mathrm{Cu})$.............................. 105

3.1.1. D eterminação da $\mathrm{CL}_{50}$ e da CENO 105

3.1.2. Testes crônicos com metais (sobrevivência, crescimento, deformidade do mento e bioacumulação)

4. Resultados.

4.1. Testes de toxicidade com metais $(\mathrm{Cd} \mathrm{e} \mathrm{Cu})$.............................. 109

4.1.1. Cádmio .................................................................................. 109

4.1.2. Cobre............................................................................... 110

4.2. Testes de toxicidade crônica com metais $(\mathrm{Cd} \mathrm{e} \mathrm{Cu})$............... 111

4.2.1. Sobrevivência, peso seco e emergência................................ 111

4.2.2. Medidas da cápsula cefálica e do comprimento do corpo. 114

4.2.3. D eformidade do mento ........................................................ 117

4.2.4. Frações dos metais cádmio e cobre nos diferentes compartimentos dos testes de toxicidade crônica.

4.2.4.1. Frações de cádmio nos compartimentos água, sedimento e organismos. 
xxviii

4.2.4.2. Frações de cobre nos compartimentos água, sedimento e organismos

5. Discussão

6. Conclusão 134

7. Bibliografia.

Capítulo 5 - Experimentos de evitamento ao cobre utilizando a espécie Chironomus riparius (Chironomidae, D iptera) 140

1. Introdução 140

2. Objetivos. 141

3. Materiais e métodos 142

3.1. Manutenção das culturas. 142

3.2. Teste de evitamento de contaminantes (cobre). 143

3.2.1. Evitamento - recrutamento (seleção de substrato). 143

3.2.2. Evitamento - gradiente de contaminação 145

3.2.3. Evitamento - oviposição 148

4. Resultados 149

4.1. Evitamento - recrutamento (seleção de substrato). 149

4.2. Evitamento - gradiente de contaminação. 150

4.3. Evitamento - oviposição 152

5. Discussão. 154

6. Conclusão 158

7. Bibliografia. 158

Capítulo 6 - Utilização de Chironomus sp para avaliação da qualidade de sedimentos e contaminação por metais - Considerações finais e recomendações.

1. Considerações finais e recomendações........................................... 163

2. Bibliografia........................................................................................ 167

Apêndices

Apêndice 1.................................................................................. 170

Apêndice 2..................................................................................... 176

Apêndice 3......................................................................................... 186

Apêndice 4................................................................................. 193 


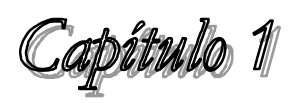

Apresentação da problemática da poluição de ecossistemas aquáticos e caracterização da área de estudo

\section{INTRODUÇÃO}

A água representa, além do insumo básico essencial à vida em todas as suas formas, um bem de consumo para quase todas as atividades humanas e, em vista de sua importância em relação a seus usos diversos e à manutenção de sua qualidade e quantidade, os recursos hídricos são considerados um bem comum que deve ser gerenciado de forma integrada, garantindo, assim, um aproveitamento otimizado com um mínimo de conflitos (CHAUD HRY, 2000).

Porém, devido ao desenvolvimento tecnológico, a contaminação química dos recursos hídricos tem merecido grande atenção da sociedade, uma vez que o uso de substâncias sintéticas tem aumentado de maneira quase exponencial. Atualmente, cerca de seis milhões de substâncias químicas são conhecidas, das quais 63 mil são de uso cotidiano e, por conseqüência, freqüentemente encontradas no ambiente (ZAGATTO, 1999).

D entre os ecossistemas, os aquáticos têm merecido maiores estudos, pois além de serem os mais suscetíveis, recebem diretamente esses agentes químicos provenientes de despejos industriais e domésticos, ou indiretamente, por águas de chuva e carreamento superficial dos solos urbanos e agrícolas.

Buscando solucionar os problemas relacionados à poluição de recursos hídricos o Governo Federal tem lançado Leis de Proteção e Conservação dos Recursos Hídricos e incentivado os municípios a construírem as plantas de tratamento de esgotos domésticos. Por exemplo, a Lei no 9.433/97, que cria 0 Sistema Nacional de G erenciamento de Recursos Hídricos, apresenta que os planos são de longo prazo, elaborados por bacia hidrográfica, por estado e para o país, e que devem incluir, entre outros, metas de racionalização de uso, aumento da quantidade e melhoria da qualidade dos recursos hídricos disponíveis. Além disso, em relação às industrias existem normas de lançamento de efluentes (D ecreto 
Estadual 8468/ 76 - São Paulo, 1976 e Resolução CO NAMA 357/ 05) e, fiscalização por parte de CETESB (Companhia de Tecnologia e Saneamento Ambiental) no Estado de São Paulo, o que tem diminuído os lançamentos de substâncias tóxicas acima do limite que o corpo hídrico possa se re-estabelecer. A criação dos Comitês de Bacia também colaborou para uma maior conscientização da população e na estruturação das tomadas de decisão mais relevantes para cada bacia hidrográfica em questão.

Porém, em relação aos problemas ambientais decorrentes de atividades agrícolas, sabe-se que são considerados de difícil prevenção devido ao custo das metodologias de análise, da avaliação e valoração dos riscos e dos impactos relacionados a essas atividades. A principal dificuldade está associada aos procedimentos de mensuração e controle das fontes difusas de poluição (PIRES et al., 2000). Os riscos das atividades agrícolas têm sido associados à degradação dos componentes ambientais (desestruturação e contaminação), que em geral são trabalhados de forma quantitativa e adimensional em termos da probabilidade de ocorrência e da magnitude do impacto (PIRES et al., op. cit)

Os problemas de poluição hídrica citados acima são cada vez mais comuns em nossos corpos d água, principalmente naqueles que estão localizados próximos à grandes centros urbanos ou aqueles que fazem parte da paisagem urbana, como é 0 caso do rio Monjolinho, objeto do presente estudo.

Existem diferentes formas de avaliação e monitoramento dos recursos hídricos, sendo que atualmente, as análises químicas são utilizadas em conjunto com as análises das comunidades biológicas e dos ensaios ecotoxicológicos tanto para a água quanto para o sedimento. Essas análises são convergentes e complementares, 0 que proporciona um melhor diagnóstico da qualidade ambiental do ecossistema em estudo.

Nesse sentido, estudos têm sido conduzidos para que haja o reconhecimento dos elementos impactantes e quantificação de seus efeitos, utilizando-se de medidas e avaliações de diversas variáveis ambientais, as quais são quantificadas em escala temporal e espacial. Estes estudos caracterizam-se por uma fase de observação de campo, com coletas de dados, análises de laboratório e avaliação dos resultados obtidos, mas apesar de serem amplos são restritivos pela sua característica descritiva, 
no qual diversos processos não são estimados por deficiências metodológicas, escala de amostragem, entre outros. Porém, é a partir desses resultados que alguns elementos impactantes são diagnosticados e estes poderão ser avaliados de forma isolada ou conjunta em sistemas experimentais, como nos testes de toxicidade laboratoriais e "in situ", experimentos em mesocosmos e outros sistemas que têm sido utilizados para avaliação da qualidade ambiental.

O uso dos testes de toxicidade como ferramenta para avaliação dos sistemas ecológicos tem sido de grande importância, pois segundo FERNICOLA et al. (2003), a Ecotoxicologia tem capacidade de gerar conhecimento para subsidiar a formulação segura de dispositivos legais, normas, programas e diretrizes gerenciais para enfrentar questões de riscos ecotoxicológicos, determinados pelo uso e lançamento de agentes químicos no ambiente, contribuindo assim para a sua recuperação, monitoramento ou manutenção de suas características.

\section{OBJETIVOS GERAIS}

O presente estudo teve como objetivos gerais, avaliar as características físicas, químicas, biológicas e ecotoxicológicas dos compartimentos água e sedimento do rio Monjolinho e tributários, enfatizando as concentrações de agrotóxicos organoclorados e metais e de seus potenciais efeitos, os quais serão avaliados a partir de bioensaios de toxicidade aguda (laboratoriais e "in situ") e crônica com Chironomus xanthus e Chironomus riparius e avaliar a potencialidade do uso dessas espécies para avaliação da qualidade de sedimentos e contaminação por metais.

\section{CARACTERIZAÇÃO DA ÁREA DE ESTUDO}

\subsection{Bacia hidrográfica do Tietê/ Jacaré}

A Lei Estadual n. ${ }^{0}$ 7.663, de dezembro de 1991, que instituiu a Política Estadual de Recursos Hídricos e o Sistema Integrado de Gerenciamento de Recursos Hídricos, dividiu o Estado de São Paulo em 22 Unidades de Gerenciamento de Recursos Hídricos - UG RHIs (Figura 1). Segundo SETTI (2001), 
essa divisão hidrográfica considera aspectos físicos (divisores hidrográficos, hidrogeologia, clima, solo e aspectos ambientais) e aspectos sócio-políticos (desenvolvimento econômico e social e coesão política).
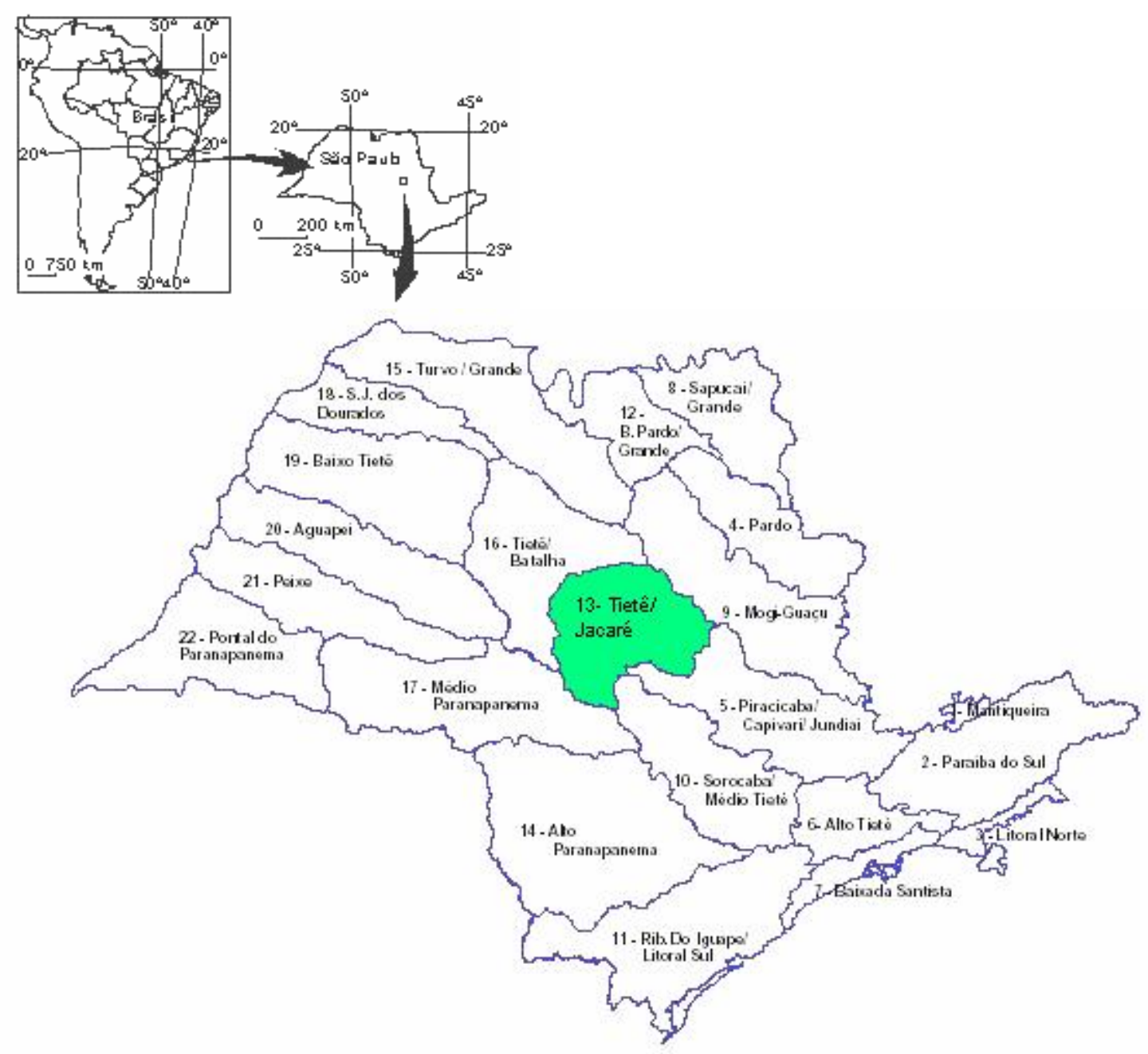

Figura 1. Mapa do Estado de São Paulo, com a subdivisão em 22 UGRHIs. A Bacia do Tietê/ Jacaré está indicada pelo número 13 (modificado de CETESB, 2005).

A bacia do Tietê/Jacaré (Figura 2), uma das unidades de gerenciamento de recursos hídricos (UGRHI), é composta por 34 municípios e possui área de drenagem de $11.537 \mathrm{~km}^{2}$. Nessa bacia está inserido o rio Monjolinho, importante tributário do rio Jacaré-Guaçu, sendo este um dos afluentes da margem direita do rio Tietê, contribuindo para a formação do reservatório de Ibitinga, um dos sistemas 
pertencentes ao complexo de reservatórios construídos em cascata no rio Tietê (ESPÍND OLA, 2000).

Os principais usos do solo da bacia são divididos em áreas destinadas às atividades urbanas, industriais e agropecuária, grandes áreas de pastagens e de culturas, destacando-se café, cana-de-açúcar, milho e citrus.

Segundo a CETESB (2005) a utilização da água nessa bacia é para fins de abastecimento público e industrial, afastamento de efluentes domésticos e industriais e irrigação de plantações.

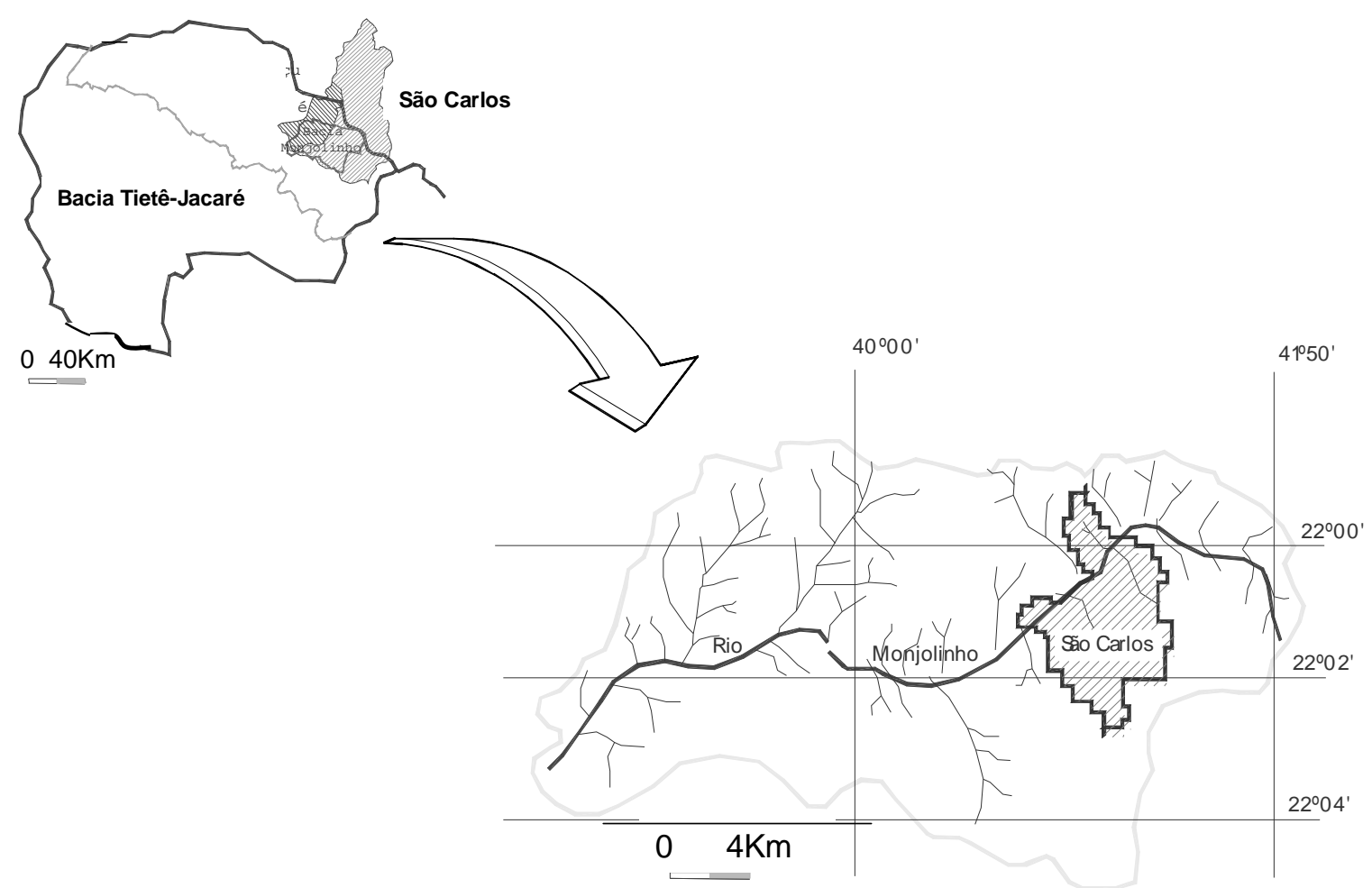

Figura 2. Bacia Hidrográfica do Tietê/Jacaré e localização da sub-bacia do rio Monjolinho, São Carlos, SP - Brasil (modificado de Turene, 2006).

A CETESB realiza monitoramento em quatro pontos nessa bacia e, em todos, o IQA médio tem mostrado que a qualidade da água é boa. Esses pontos estão localizados no rio Tietê (2 pontos), rio Jacaré-Pepira (1 ponto) e rio JacaréGuaçu (1 ponto).

Pela análise do Relatório de Águas Interiores da CETESB (2005), verifica-se que das 34 cidades que compõe essa unidade de gerenciamento, somente São Carlos 
despeja seus resíduos diretamente no rio Monjolinho, o qual é objeto de estudo da presente pesquisa.

De acordo com o Censo 2000 (CETESB, 2005), o município de São Carlos possui uma população urbana de 192.923 habitantes, sendo que 183.369 habitam a área urbana (95\%). A coleta de esgoto ocorre em 96\% do município, mas apenas $3 \%$ recebe algum tipo de tratamento, acarretando uma carga poluidora potencial de $9.902 \mathrm{Kg}$ D BO / dia e remanescente de $9.674 \mathrm{Kg}$ D BO / dia.

\subsection{Sub-bacia hidrográfica do rio Monjolinho}

A sub-bacia hidrográfica do rio Monjolinho (Figura 3) abrange uma área de aproximadamente $275 \mathrm{Km}^{2}$, com a maior parte contida no município de São Carlos (Estado de São Paulo) (ESPÍND OLA, 2000), fazendo divisa com Ibaté e Ribeirão Bonito, dois municípios de pequeno porte, com população de 26.453 e 11.228 habitantes, respectivamente (CETESB, 2005).

0 rio Monjolinho possui $43,25 \mathrm{Km}$ de extensão e está localizado entre os

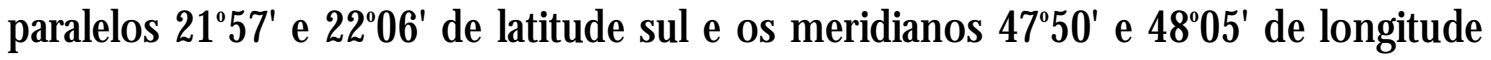
oeste. Suas nascentes estão localizadas no planalto de São Carlos (MENDES, 1998), sendo duas na Fazenda Santa Terezinha. Antes de percorrer a área urbana, este rio recebe os tributários, córrego da Matinha, córrego Ponte de Tábua e córrego São Rafael, entre outros de menor porte, sendo que estes córregos percorrem áreas de bairros periféricos do município de São Carlos. $\mathrm{Na}$ área urbana este rio foi parcialmente canalizado, recebendo contribuições de diversos tributários, como os córregos Maria Madalena, Tijuco Preto, Mineirinho e Gregório. Recebe também águas residuárias da região norte de São Carlos e despejos provenientes de aproximadamente 400 indústrias (curtumes, papel, tintas, alimentos, etc.) (G ONÇALVES, 1986). Na área rural (pós-área urbana) recebe contribuições dos córregos Água Q uente e Água Fria, além dos córregos da Serra, Cancan e Palmital, localizados na área da Usina da Serra (usina de cana-de-açúcar), percorrendo, portanto, solos destinados às atividades agro-pastoris, para, finalmente, desembocar no rio Jacaré-Guaçu, sendo seu principal afluente na parte alta (PELÁEZROD RIG UES, 2001). 
A travessando a cidade de São Carlos (SP) no sentido noroeste-sudeste, o rio Monjolinho apresenta os impactos decorrentes das atividades urbanas, como 0 lançamento in natura de esgotos domésticos, industriais e agropastoris. Em relação aos efluentes gerados, há um sistema coletor de 96\% do esgoto doméstico, o qual é lançado in natura no rio Monjolinho, pois a cidade possui sistemas de tratamento para apenas 3\% do esgoto total gerado (CETESB, 2005). Em relação aos efluentes industriais, $45 \%$ correspondem aos resíduos inorgânicos e 17\% aos resíduos orgânicos, contribuindo para a poluição deste rio.

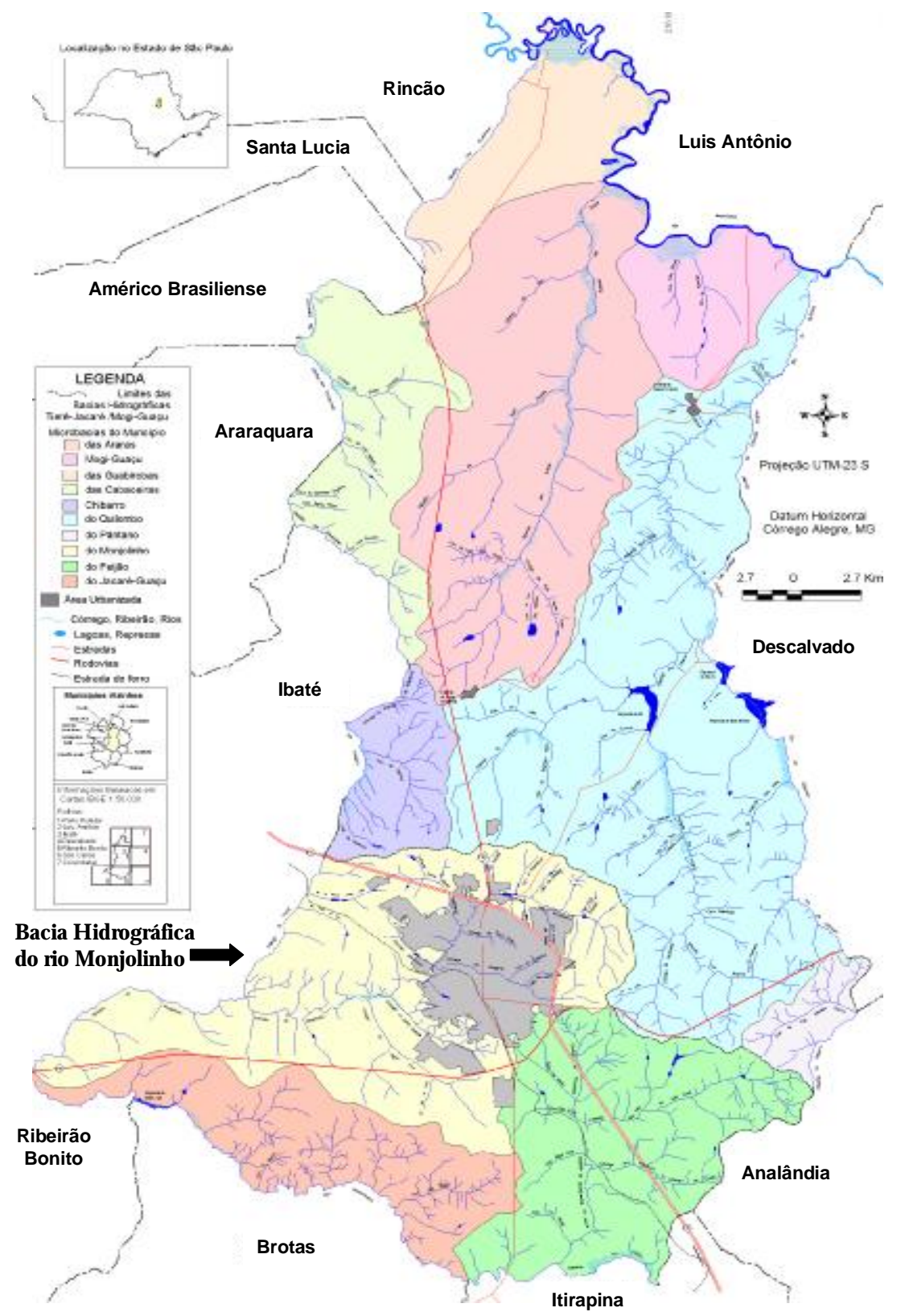

Figura 3: Área de estudo, demonstrando as principais sub-bacias do município de São Carlos, localizando a sub-bacia do rio Monjolinho (Fonte: Conferência da Cidade -Prefeitura Municipal de São Carlos, Secretaria de Habitação e D esenvolvimento Urbano, 2002). 
Diversos estudos foram realizados no rio Monjolinho, os quais contribuíram para um diagnóstico do sistema em relação às características físicas e químicas da água e do sedimento (RIOS, 1993; BARRETO, 1999; PELÁEZ-RODRIGUES, et al., 2000; MARINELLI, et at., 2000), estrutura das comunidades aquáticas (GUERESCHI \& MELÃO, 1998; CHINAGLIA, 1996; REGALADO et al., 2000), toxicidade (MENDES, 1998; FRACÁCIO, et al., 2000), além do aspecto educacional (SÉ, 1992; ALMEID A, 2000). Outros buscaram uma análise do rio em função das atividades antropogênicas desenvolvidas na bacia hidrográfica, enfocando os aspectos históricos da expansão urbana e deterioração dos recursos naturais (ESPÍND O LA, 2000).

Segundo SÉ (1992), as águas do rio Monjolinho vêm sendo aproveitadas principalmente para a geração de energia (no curso baixo - Fazenda São José) e como receptoras e escoadoras de materiais e resíduos oriundos da lixiviação superficial, de efluentes industriais, agroindustriais e de esgotos doméstico.

De acordo com estudo realizado por CRISCUOLO et al. (2000), no qual os autores comparam períodos distintos do desenvolvimento do município (1965 e 1998), observou-se que o cultivo de cana-de-açúcar totaliza 35,7\% de toda área (crescimento de 10,8\%) e, em relação à área urbana, São Carlos ocupava 6,4\% em 1965, atingindo 15,0\% em 1998.

MARINELLI et al. (2000), avaliando a qualidade da água, concluíram que vários parâmetros, inclusive os nutrientes, demonstraram o efeito da ação antrópica, comprovada por um gradiente decrescente da qualidade da água desde a nascente em direção a foz. Estes autores consideraram que as principais funções de força que determinam a qualidade da água deste rio são os lançamentos de esgoto doméstico e industrial, além da expansão das atividades agrícolas (principalmente a cana-deaçúcar).

BARRETO (1999), observou um decréscimo da qualidade da água do rio Monjolinho, da nascente em direção a foz, e concluiu que em relação às concentrações de metais obtidas na água, apenas a nascente se enquadra como rio de classe 1 (segundo CONAMA 357/05), sendo as demais estações classificadas como 3 e 4, ou seja, usos menos exigentes. Além da água, a autora encontrou concentrações elevadas de metais biodisponíveis nos sedimentos. 
CAMPAG NA (2005), NOVELLI (2005) e VIANNA (2005), verificaram que a análise de metais e pesticidas na água do rio Monjolinho e tributários demonstrou o elevado impacto antrópico no sistema, sendo que os metais cobre, cádmio, ferro e manganês e os agrotóxicos organoclorados aldrin, heptachlor e endosulfan sulfato foram detectados em concentrações acima dos limites estabelecidos pela resolução CONAMA 357/ 05. Segundo CAMPAGNA (op cit.), não foram encontradas altas concentrações de metais biodisponíveis nos sedimentos do rio Monjolinho e tributários, estando os valores detectados abaixo do Critério Canadense de Qualidade de Sedimento, porém foi verificada alta toxicidade nos ensaios ecotoxicológicos com peixes em todas as estações amostradas.

De acordo com os trabalhos citados, o rio Monjolinho apresenta características de ambiente poluído ou altamente poluído, observando-se efeitos adversos em algumas espécies expostas à água ou ao sedimento do sistema.

Em geral, os estudos foram realizados com espécies planctônicas (microcrustáceos) ou nectônicas (peixes), sendo poucos os estudos com espécie bentônica. Nesse sentido, a utilização do gênero Chironomus sp (C. xanthus e C. riparius) como organismos-teste, tem por finalidade complementar os resultados gerados nos estudos anteriores (estudos com amostras ambientais), bem como aprimorar a utilização destes organismos em ensaios ecotoxicológicos.

\section{PERÍOdOS DE AMOSTRAGEM E ESTAÇÕES DE COLETA}

As coletas foram realizadas em cinco meses (março, julho e outubro de 2003 e janeiro e abril de 2004), em seis estações de coleta em março/ 03, outubro/ 03 e abril/ 04 (períodos intermediários) e em quatorze estações em julho/ 03 e janeiro/ 04 (períodos seco e chuvoso, respectivamente), apresentadas nas Figuras 4 e 5 e que foram consideradas representativas no rio Monjolinho (Tabela 1). As estações de coleta foram escolhidas baseando-se em trabalhos anteriormente realizados no rio Monjolinho quanto aos aspectos de qualidade de água e sedimento (SÉ, 1992; GUERESCHI \& MELÃO, 1998; MENDES, 1998; BARRETO, 1999; PELÁEZRODRIGUES, 2000; ESPÍND O LA et al, 2000). No Apêndice 1 estão apresentadas imagens das estações de coleta (Figuras 6-11). 
Tabela 1. Principais características das estações de coleta no rio Monjolinho.

\begin{tabular}{|c|c|}
\hline Estações & Características principais \\
\hline \multicolumn{2}{|l|}{ Rio Monjolinho } \\
\hline Nascente (1) & $\begin{array}{l}\text { Trecho de cabeceira do rio Monjolinho, em uma área de mananciais a } \\
\text { aprox imadamente } 3 \mathrm{Km} \text { da nascente principal; Fazenda Santa T erezinha. } \\
\text { L ocaliza-se na entrada da área urbana do munićpio de São Carlos, próx imo à } \\
\text { rodovia W ashington L uiz. }\end{array}$ \\
\hline USP (3) & L ocaliza-se a alguns metros a jusante da confluência com o órrego do Tijuc Preto. \\
\hline Usina (4) & $\begin{array}{l}\text { Situa-se no trecho médio do rio M onjolinho, logo após passar a área urbana, na } \\
\text { U sina H idrelétrica do M onjolinho. }\end{array}$ \\
\hline Ponte caída (5) & Situa-se em área rural, sofrendo influência do cultivo de cana-deaçúcar. \\
\hline Foz (6) & Á rea rural, alguns metros antes do enœontro œm o rio JacaréG uaqu. \\
\hline \multicolumn{2}{|l|}{ Tributánios } \\
\hline Cór. Maria Madalena (7) & Á rea urbana, próx imo ao Bairro Santa Paula. \\
\hline Cór. Tijuco Preto (8) & Á rea urbana, em frente à U SP, na A venida Trabalhador São C arlense. \\
\hline Cór. do Mineirinho (9) & Á rea urbana, próx imo ao Shopping Iguatemi São Carlos. \\
\hline Cór. Gregório (10) & Á rea urbana, próx imo ao Sesc São Carlos. \\
\hline Cór. Água Quente (11) & $\begin{array}{l}\text { Á rea rural, antes do Canil e do Matadouro } \mathrm{M} \text { unicipal, sofrendo influência do } \\
\text { Bairro Cidade A racy e A ntenor } \mathrm{G} \text { arcia. }\end{array}$ \\
\hline Cór. Água Fria (12) & Á rea rural, logo após o Canil e o M atadouro M unicipal \\
\hline Cór. Cancan (13) & Á rea rural, sofrendo influência do aultivo de cana-deaaúcar (U sina da Serra). \\
\hline Cór. Serra (14) & Á rea rural, sofrendo influência do cultivo de cana-deacúcar (U sina da Serra). \\
\hline
\end{tabular}




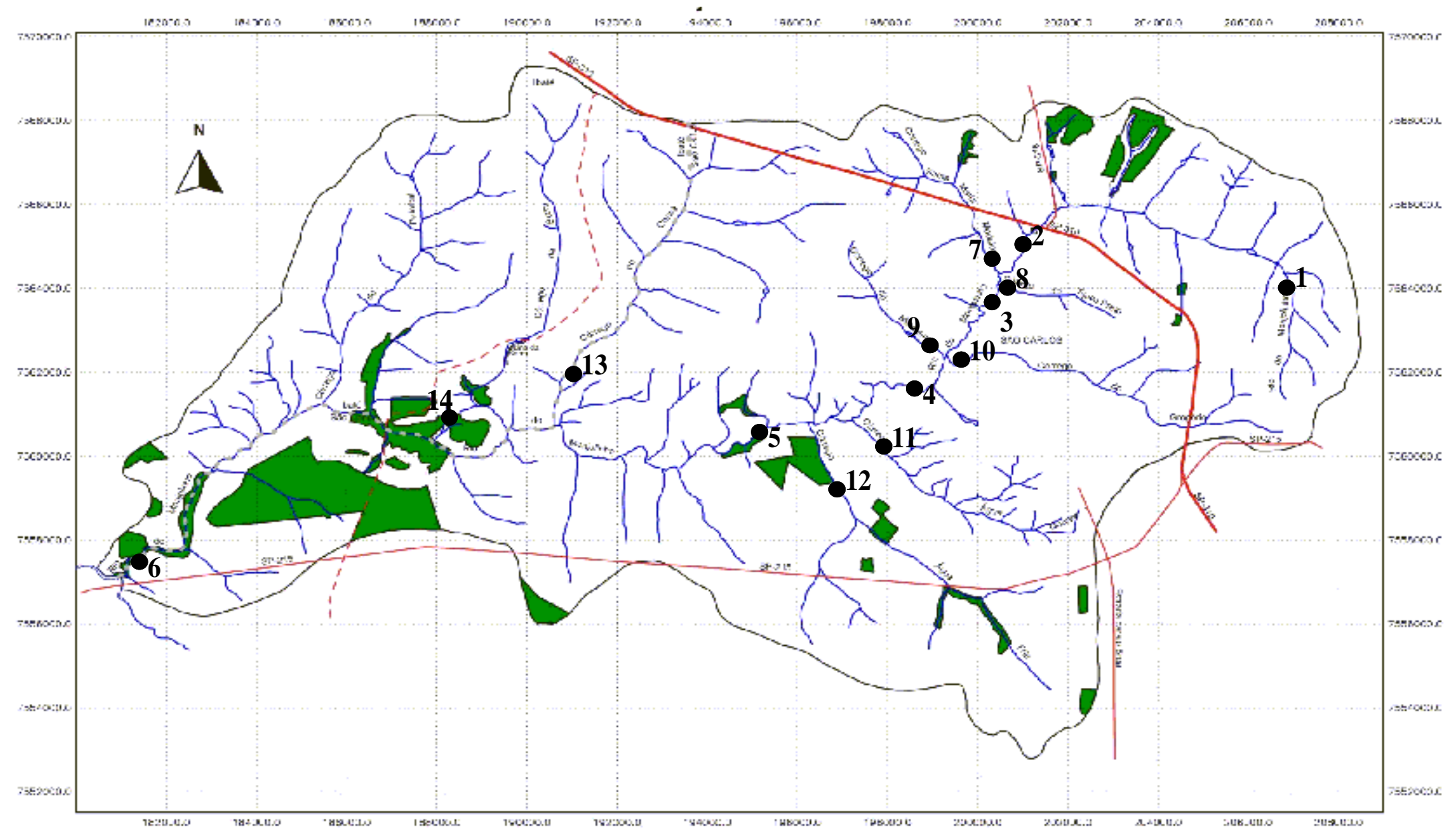

Figura 4. Área de estudo (rio Monjolinho e tributánios) com localização das estações de coleta, São Carlos, SP. Fonte: Espíndola et al. (2000). A Bacia do rio Monjolinho, RiMa E ditora 


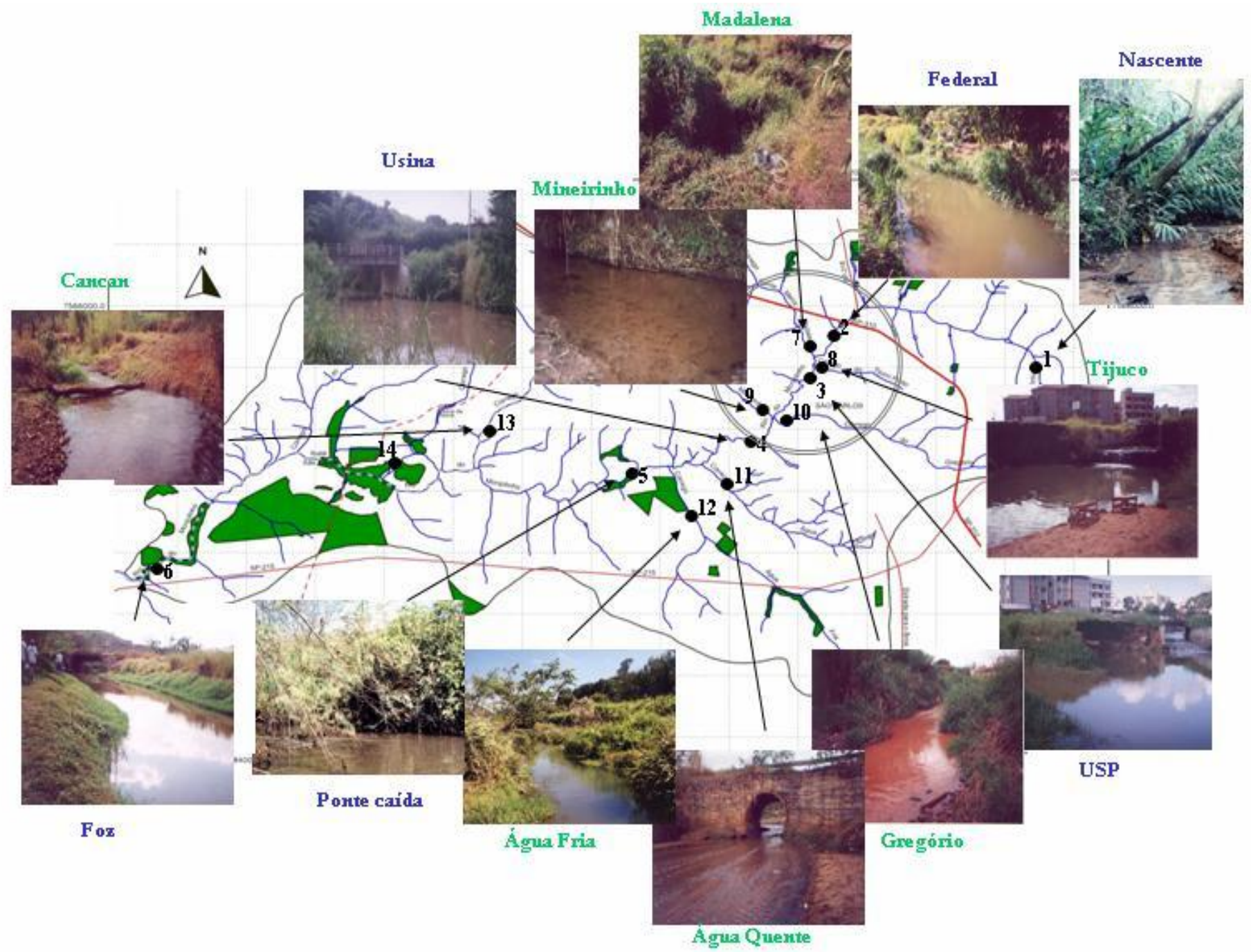

Figura 5. Imagens das estações de coleta do rio Monjolinho e tributários (em azul: rio Monjolinho e em verde: tributários). 


\section{BIBLIOGRAFIA}

ALMEIDA, R.C.; KUNIEDA, E.; PRATES, K.V.M.C.; SÉ, J.A.S.; GONZAGA, J.L. Experiências em educação ambiental. In: ESPÍND OLA, E.L.G; SILVA, J.S.V; MARINELLI, C.E \& ABDON, M.M. A Bacia Hidrográfica do rio Monjolinho, RiMa Editora, São Carlos, SP, 2000. p. 163-174.

BARRETO, A.S. Estudo da distribuição de metais em ambiente lótico, com ênfase na assimilação das comunidades biológicas e a sua quantificação no sedimento e água, 1999. 274p. Tese (Doutorado), Escola de Engenharia de São Carlos, Universidade de São Paulo, 1999.

CAMPAGNA, A.F. Toxicidade dos sedimentos da Bacia Hidrográfica do rio Monjolinho (São Carlos - SP): ênfase nas substâncias cobre, aldrin e heptacloro, 2005. 281p. Dissertação (Mestrado). Faculdade de Zootecnia e Engenharia de Alimentos, Universidade de São Paulo, 2005.

CHAUDHRY, F.H. Aproveitamento de recursos hídricos. In: CASTELLANO, E.G. \& CHAUD HRY, F.H. (eds.). D esenvolvimento sustentado: problemas e estratégias. Publicação EESC/ USP, p. 27-38, 2000.

CHINAGLIA, F.A. Caracterização e verificação da aplicabilidade do uso das populações de protozoários para avaliação da qualidade da água dos rios Monjolinho e Jacaré-Guaçu, São Carlos - SP, 1996, 101p. Dissertação de mestrado, São Carlos, Universidade Federal de São Carlos, 1996.

COMPANHIA DE TECNOLOgIA E SANEAMENTO AMBIENTAL CETESB (2005). Relatório de água interiores do Estado de São Paulo - 2004, Série Relatórios/ CETESB, 307p.

CONSELHO NACIONAL DO MEIO AMBIENTE - CONAMA 357/05 Resolução CONAMA 357 de 17 de março de 2005. Ministério do Meio Ambiente - www.mma.gov.br, 2005.

CRISCUOLO, C; VASCONCELOS, C.H \& SILVA, J.S.V. (). Uso e O cupação da terra em 1965 e 1968. In: ESPÍND OLA, E.L.G; SILVA, J.S.V; MARINELLI, C.E \& ABD ON, M.M. A Bacia Hidrográfica do rio Monjolinho, RiMa Editora, São Carlos, SP, 2000. p.104-113. 
ESPÍND OLA, E.L.G. O Rio Monjolinho: um estudo de caso. In: ESPÍND OLA, E.L.G; SILVA, J.S.V; MARINELLI, C.E \& ABDON, M.M. A Bacia Hidrográfica do rio Monjolinho, RiMa Editora, São Carlos, SP, 2000. p. 36-40. FERNICOLA， N.A.G.G.; BOHRER-MOREL, M.B.B.; BAINY, A.C.D. Ecotoxicologia. In: AZEVEDO, F.A. \& CHASIN, A.A.M., As bases ecotoxicológicas da ecotoxicologia, RiMa editora, InterTox, 2003. p.221-243.

FRACÁCIO, R.; ROD GHER, S.; ESPÍND O LA,E.L.G .; PASCHOAL, C.M.R.B.; LIMA, D; NASCIMENTO, A.P. \& RODRIGUES, M.H. Abordagem ecotoxicológica. In: ESPÍND O LA, E.L.G; SILVA, J.S.V; MARINELLI, C.E \& ABD ON, M.M. A Bacia Hidrográfica do rio Monjolinho. RiMa Editora, São Carlos, SP, 2000. p 150-162.

GUERESCHI, R.M.; MELÃO, M.G.G. (1998) Monitoramento biológico da bacia hidrográfica do Monjolinho pelo uso de macroinvertebrados bentônicos. Anais do VIII Seminário Regional de Ecologia, Volume VIII, p. 1199-1216, Pósgraduação em Ecologia e Recursos Naturais, Universidade Federal de São Carlos, São Carlos, SP.

GONÇALVES, A.R.L. G eologia Ambiental da área de São Carlos, 1986. 138p + anexos. Tese (D outorado), Escola de Engenharia de São Carlos, Universidade de São Paulo, 1986.

MARINELLI, C.E; MORETTO,E.M; BRUCHA, G \& LUCCA, J.V. Limnologia. In: ESPÍND O LA, E.L.G; SILVA, J.S.V; MARINELLI, C.E \& ABD O N, M.M. A Bacia Hidrográfica do rio Monjolinho, RiMa Editora, São Carlos, SP, 2000. p.133-149.

MENDES, A.J.S. Avaliação dos impactos sobre a comunidade macrozoobentônica no córrego do Monjolinho, 1998. 106p. Dissertação (Mestrado), Escola de Engenharia de São Carlos, Universidade de São Paulo, 1998.

NOVELLI, A. Estudo limnológico e ecotoxicológico da água e sedimento do rio Monjolinho - São Carlos (SP), com ênfase nas substâncias de referência cádmio e cobre, 2005. 288p. Dissertação (Mestrado). Escola de Engenharia de São Carlos, Universidade de São Paulo, 2005. 
PELÁEZ-RODRIGUES, M.. Avaliação da qualidade da água da Bacia do Alto Jacaré-G uaçú/ SP (Ribeirão do Feijão e Rio do Monjolinho) através de variáveis físicas, químicas e biológicas, 2001. 145p. + anexos. Tese (D outorado), Escola de Engenharia de São Carlos, Universidade de São Paulo, 2001.

PELÁEZ-RODRIGUES, M.; PERET, A. M.; MATSUMURA-TUNDISI, T.; ROCHA, O . Análise da qualidade da água e aplicação do Índice de proteção da Vida aquática (IVA) em duas sub-bacias da bacia hidrográfica do rio JacaréGuaçu, In: E.L.G. ESPÍND OLA; C.M.R. BOTTA-PASCHOAL; O. ROCHA; M.B.C. BOHRER; A.L.OLIVEIRA-NETO, Ecotoxicologia - perspectivas para o século XXI, São Carlos, RiMa Editora, São Carlos, SP, 2000. p. 95-114.

PIRES, J.S.R.; SANTOS, J.E.; PIRES, A.M.Z.C.R.. Análise de riscos ambientais no entorno de uma Unidade de Conservação (Estação Ecológica de Jataí, Luiz Antônio, SP), In: SANTOS, J.E.; PIRES, J.S.R. (eds.) Estação Ecológica de Jataí, Volume 2. RiMa E ditora, São Carlos, 2000. p. 73-93.

PREFEITURA MUNICIPAL DE SÃO CARLOS. Conferência da Cidade, Cd rom elaborado pela Secretaria de Habitação e D esenvolvimento Urbano, São Carlos, SP, 2002.

REGALAD O, L.B.; GOBBO, P.R.S.; MARINELLI, C.E.; SMITH, W.H. Fauna de Vertebrados, In: ESPÍND OLA, E.L.G; SILVA, J.S.V; MARINELLI, C.E \& ABD ON, M.M. A Bacia Hidrográfica do rio Monjolinho, RiMa Editora, São Carlos, SP, 2000. p.88-103.

RIOS, L. Estudo limnológico dos córregos da Água Fria e da Água Quente, 1993. 146p. Dissertação (Mestrado), Escola de Engenharia de São Carlos, Universidade de São Paulo, 1993.

SÃO PAULO. Decreto 8468 de 8 de setembro de 1976. Aprova o regulamento da Lei ํo 997 de 31 de maio de 1976 que dispõe sobre a Prevenção e o Controle da Poluição do Meio Ambiente. 1976, 58p.

SÉ, J.A.S. O rio Monjolinho e sua bacia hidrográfica como integradores de sistema ecológicos: um conjunto de informações para 0 início de um processo de pesquisas ecológicas, de educação, planejamento e gerenciamento ambientais a 
longo prazo, 1992. 381p. D issertação (Mestrado) - Escola de Engenharia de São Carlos, Universidade de São Paulo, 1992.

SETTI, A.A., LIMA, J.F.W.; CHAVES, A.G.M.; PEREIRA, I.C. Introdução ao gerenciamento de recursos hídricos. Brasília. Agência Nacional de Energia Elétrica, Agência Nacional de Águas, 2001. 328 p.

TURENE, C.D. Percepção ambiental: uma análise na bacia hidrográfica do rio Monjolinho, São Carlos, SP, 2006. 86p. Dissertação (Mestrado), Escola de Engenharia de São Carlos, Universidade de São Paulo, 2006.

VIANA, S.M.. Riqueza e distribuição de macrófitas aquáticas no rio Monjolinho e tributários (São Carlos, SP) e análise de sua relação com variáveis físicas e químicas no ambiente estudado, 2005. 122p. Dissertação (Mestrado), Escola de Engenharia de São Carlos, Universidade de São Paulo, 2005.

ZAGATTO, P.A. Apostila - Mini-curso Ecotoxicologia Aquática. VII Congresso Brasileiro de Limnologia - Universidade Federal de Santa Catarina, Florianópolis, SC, 1999. 18p. 
Capictulo?

Análise limnológica (água e sedimento) do rio Monjolinho e tributários,

São Carlos - São Paulo.

\section{INTRODUÇÃO}

Os rios são sempre os receptores de descartes de substâncias em seu curso diário normal e algumas dessas substâncias químicas de uso doméstico, como surfactantes e outros produtos de limpeza, são introduzidas nos sistemas aquáticos pelos sistemas públicos de coleta ou tratamento de esgotos (GILLESPIE et al., 1998), além dos lançamentos de esgotos industriais que podem possuir grandes quantidades de metais pesados (poluição pontual) e a poluição difusa, ocasionada pelo carreamento de solos contendo fertilizantes e agrotóxicos que ocorre em regiões de intensa atividade agrícola.

A pesquisa em sistema - rio é um trabalho difícil, porém bastante interessante, devido ao alto grau de variabilidade espacial e temporal de muitas de suas características. Assim, a caracterização ecológica de um rio deve considerar 0 encadeamento espaço-temporal de suas comunidades bióticas, direcionado principalmente pelo trabalho desenvolvido pelo fluxo d'água e pelos processos climáticos, geológicos, geomorfológicos, hidrológicos, hidráulicos, físicos, químicos e biológicos em geral, que ocorrem em escalas de tempo e espaço bastante diferenciadas e que podem variar muito de bacia para bacia, de região para região e conforme o grau de interferência antrópica na bacia em questão (SÉ, 1992).

Alguns estudos têm sido conduzidos para que haja o reconhecimento dos elementos impactantes e quantificação de seus efeitos, utilizando-se de medidas e avaliações de diversas variáveis ambientais, as quais são quantificadas em escala temporal e espacial. Estes estudos caracterizam-se por uma fase de observação de campo, com coletas de dados, análises de laboratório e avaliação dos resultados obtidos, mas apesar de serem amplos são restritivos pela sua característica descritiva, na qual diversos processos não são estimados por deficiências metodológicas, escala de amostragem, entre outros. Porém, é a partir desses resultados que alguns 
elementos impactantes são diagnosticados e estes poderão ser avaliados de forma isolada ou conjunta em sistemas experimentais.

Portanto, a avaliação dos impactos em recursos hídricos pode ser realizada de formas diferentes, mas complementares, como é o caso de análises químicas e físicas da água e sedimento, da utilização de testes de toxicidade laboratoriais e "in situ", e análise de características individuais de alguns tipos de organismos que pode indicar a exposição à agentes estressantes.

D entre os agentes estressantes encontrados nos sistemas aquáticos, pode-se citar os metais e agrotóxicos que possuem diversas formas de entrada no ambiente e diferentes formas de ação e que quando presentes em determinadas concentrações degradam a qualidade ambiental modificando a biota.

\subsection{Poluição de ecossistemas aquáticos}

\subsubsection{Agrotóxicos}

O crescimento da população mundial vem causando o aumento na demanda de alimentos, levando à necessidade de produção em larga escala e à modernização da agricultura. No entanto, o plantio de grandes áreas com uma única cultura conduz, freqüentemente, ao aparecimento de diversas pragas que necessitam ser combatidas e isto ocorre devido à perda de complexidade, estabilidade e biodiversidade dos ecossistemas naturais causada pela implantação de monoculturas.

Segundo SCHULZ \& LIESS (1999), a entrada de materiais derivados de áreas agrícolas produzem mudanças marcantes nas condições abióticas dos rios, podendo-se citar, além do estresse hidráulico, o aumento nas concentrações de materiais em suspensão, nutrientes e agrotóxicos.

A "Lei dos Agrotóxicos" (Lei Federal no 7802, de 11 de julho de 1989; Decreto no 4.074, de 4 de janeiro de 2002 - ANVISA, 2004), define agrotóxicos como "0 s produtos e os componentes de processos físicos, químicos ou biológicos destinados ao uso nos setores de produção, armazenamento e beneficiamento de produtos agríolas, nas pastagens, na 
protecão de florestas nativas ou implantadas e de outros ecossistemas e também ambientes urbanos, hídricos e industriais, auja finalidade seja alterar a composição da flora e da fauna, a fim de preservá-la da ação danosa de seres vivos considerados nocivos, bem como substâncias e produtos empregados como desfolhantes, estimuladores e inibidores do crescimento."

Portanto, os múltiplos usos a que se destinam os agrotóxicos, faz com que apareçam a cada dia novas formulações e novos produtos no mercado.

Os agrotóxicos representam um grupo químico único por serem ministrados intencionalmente no ambiente para destruir ou controlar alguma forma de vida indesejada (D ORES \& FREIRE, 1999). Embora tenham sido desenvolvidos com 0 objetivo de eliminar pragas e aumentar a produtividade agrícola, além de eliminar vetores transmissores de doenças, apresentam dois graves problemas: afetar não só os organismos alvos e persistirem no ambiente por longos períodos de tempo, uma vez que são substâncias químicas sintéticas.

Os agrotóxicos podem ser classificados de várias maneiras, baseados no seu estado físico, espécies alvo, propósito da aplicação ou natureza química. Quando classificados de acordo com as espécies alvo, a maioria dos agrotóxicos pode ser definido como fungicida, inseticida, herbicida, acaricida ou formicida (LAWS, 1999).

Outras formas de classificação são o modo de ação (de ingestão, de contato, microbiano e fumigante), origem (orgânicos e inorgânicos), propriedades químicas (organoclorados, organofosforados, piretróides, clorofenoxiacéticos, glicinas e triazinas) e toxicidade (ALMEID A, 2002), como pode-se observar a seguir:

ÿ Classe toxicológica I (rótulo vermelho): compostos considerados altamente tóxicos para a saúde humana, $\mathrm{DL}_{50} \mathrm{de} 5 \mathrm{mg} / \mathrm{kg}$ ou menos (uma pitada ou algumas gotas pode causar a morte em humano);

ÿ Classe toxicológica II (rótulo amarelo): compostos considerados moderadamente tóxicos à saúde humana, $\mathrm{DL}_{50}$ de $5-50 \mathrm{mg} / \mathrm{kg}$ (algumas gotas ou uma colher de chá pode causar a morte em humano);

ÿ Classe toxicológica III (rótulo azul): compostos considerados pouco tóxicos aos humanos, DL 50 de 50-500 mg/ kg (uma colher de chá a duas colheres de sopa pode causar a morte em humano); 
$\ddot{y}$ Classe toxicológica IV (rótulo verde): produto pouco tóxico, $\mathrm{DL}_{50}$ de 500-5000 mg/ kg (uma colher de sopa a um copo pode causar a morte em humano);

$\ddot{y}$ Classe toxicológica $\mathrm{V}$ (rótulo verde): produto muito pouco tóxico, $\mathrm{DL}_{50}$ de $5000 \mathrm{mg} / \mathrm{kg}$ ou mais (um copo a um litro pode causar a morte em humano)

Segundo LAWS (1999), o efeito adverso dos agrotóxicos em espécies nãoalvo tem sido a maior causa da preocupação devido ao uso de agrotóxicos em grande escala, sendo que esses efeitos e suas conseqüências incluem envenenamentos humanos e de animais (agropecuária), a redução de inimigos naturais das pragas, redução na polinização devido ao envenenamento de abelhas, perda de safras e árvores e perda de espécies de peixes e outros tipos de animais aquáticos e terrestres.

Dentre os inseticidas orgânicos sintéticos, os organoclorados são os que permanecem por mais tempo no ambiente, chegando a atingir 40 anos após aplicação (BRIGANTE et al., 2003) no solo e em seres vivos, contaminando 0 homem diretamente ou através da cadeia alimentar (ALMEIDA, 2002). Esses agrotóxicos foram muito utilizados na agricultura, porém seu emprego tem sido progressivamente reduzido ou mesmo proibido, devido à lenta degradação e à capacidade de acumulação no ambiente.

Segundo ALMEIDA (op cit.), entre os principais produtos lançados no mercado estão o Aldrin, Endrin, BHC (Hexaclorobenzeno), DDT (Dicloro Difenil Tricloroetano), Endosulfan, Heptacloro, Lindane, Mirex e Toxafeno. D estes, grande parte foi retirada do mercado ou teve seu uso restrito e, no Brasil, somente 0 Endosulfan e o Mirex, encontram-se disponíveis legalmente. A utilização de Aldrin (controle de formigas) e de DDT e BHC (campanhas de saúde pública) possuem uso restrito e limitado pela Portaria no 329 de 02 de setembro de 1985 (site ANVISA, 2004).

Esses agrotóxicos podem ser absorvidos por via oral, respiratória e dérmica, atingindo o sistema nervoso central e periférico (ZAMBRONE, 1986). Para a saúde humana, segundo a O rganização Mundial da Saúde (BRIGANTE et al., 2003), esses compostos causam lesões hepáticas, lesões renais, neurite periférica, ação neurotóxica retardada e mutagênese. Essas substâncias podem também causar, 
segundo OKI \& PEREIRA (1999), hipersensibilidade, hiperatividade, convulsão, prostração e morte.

A necessidade da avaliação do risco de contaminação dos recursos hídricos deve-se ao fato de que a agricultura e a pecuária exigem um considerável suprimento de água, o que conduz ao desenvolvimento destas atividades próximo a rios e lagos. Nesse contexto, segundo FELLENBERG (2003), tem-se que os agrotóxicos atingem o sistema aquático de diversas formas, sendo que as diferentes possibilidades de contaminação da água por essas substâncias são: (1) propagação pelo vento de substâncias empregadas na forma de aerossóis, (2) lixiviação do solo pela ação da água da chuva, (3) despejo de restos de soluções de agrotóxicos e (4) limpeza de recipientes e utensílios utilizados durante a aplicação. Segundo D ORES \& FREIRE (1999), quando nos ambientes aquáticos, os agrotóxicos podem sofrer adsorção ou dessorção das partículas de sedimentos, podem ser degradados por vias químicas, biológicas ou fotólise, bem como, ser volatilizado.

Diante do exposto, torna-se de fundamental importância o estudo do impacto dos agrotóxicos nos sistemas aquáticos, preocupando-se com a saúde ambiental (estabilidade dos ecossistemas) e com a expectativa da vida humana.

\subsection{Metais}

Dos elementos químicos, os metais são o maior grupo, entretanto suas características diferem grandemente na biosfera. Segundo FORSTNER \& WITTMAN (1983), o termo metal designa um elemento que é um bom condutor de eletricidade e que a resistência elétrica é diretamente proporcional à temperatura absoluta. Algumas características dos metais são: alta condutividade, alta densidade e maleabilidade. Além disso, a abundância dos elementos na litosfera geralmente diminui com 0 aumento da massa atômica.

Segundo os mesmos autores, para propósitos práticos, outros termos, tais como metais traço, metais pesados, microelementos e micronutrientes podem ser tratados como sinônimos do termo elementos traço. 
As fontes de poluição por metais em ecossistemas aquáticos podem ser divididas da seguinte forma: desgaste ou erosão geológica, efluentes de mineração, efluentes industriais, efluentes domésticos e escoamento superficial urbano, escoamento de áreas rurais e fontes atmosféricas (FORSTNER \& WITTMAN, 1983)

A toxicidade de uma dada concentração de um metal presente em um curso d'água natural depende do $\mathrm{pH}$ e da quantidade de carbono dissolvido e em suspensão, já que as interações como complexação e adsorção podem remover de forma satisfatória alguns íons metálicos e eliminar sua atividade biológica potencial (BAIRD , 2002).

BAIRD (op cit.) comenta que a toxicidade dos metais pesados depende em grande parte da forma química do elemento, isto é, da sua especiação, sendo que as formas quase que totalmente insolúveis passam pelo organismo sem causar grandes danos. Algumas formas possuem ação imediata causando a morte, e podem passar por membranas, tais como a do cérebro e da placenta, causando sérios problemas. Segundo FORSTNER \& WITTMAN (op cit.) o termo especiação refere-se à forma física e química nas quais o elemento ocorre, sendo que até recentemente a maioria das pesquisas ambientais sobre metais traço foi baseada na avaliação da concentração total do metal. Mas torna-se evidente que o impacto ambiental de uma espécie particular de metal pode ser mais importante que a concentração total do mesmo, mesmo sabendo-se que a especiação química é realmente um problema complexo quando aplicado aos sistemas reais devido às interações entre as várias espécies iônicas.

No contexto de poluição ambiental, os metais podem ser classificados de acordo com 3 critérios (WOOD , 1974): 1. não críticos (Na, K, Mg, Ca, Fe, Li, Rb, $\mathrm{Sr}, \mathrm{Al}$ ); 2. tóxicos, mas muito insolúveis ou raros (Ti, Hf, Zr, W, Nb, Ta, Re, La, Os, $\mathrm{Rh}, \mathrm{Ir}, \mathrm{Ru}$ e $\mathrm{Ba}$ ) e 3. muito tóxicos e relativamente acessíveis ( $\mathrm{Be}, \mathrm{Co}, \mathrm{Ni}, \mathrm{Cu}, \mathrm{Zn}$, $\mathrm{Sn}, \mathrm{As}, \mathrm{Pd}, \mathrm{Ag}, \mathrm{Cd}, \mathrm{Pt}, \mathrm{Au}, \mathrm{Hg}, \mathrm{Tl}, \mathrm{Sb}$ e Bi).

Os metais mais tóxicos e relativamente acessiveis também parecem ser fracos aceptores de elétrons, isto é, esses metais formam, particularmente, ligações estáveis com doadores fracos de elétrons, tais como os grupamentos - $\mathrm{SH}$. 
Um número de treze metais e metalóides têm sido reconhecidos como potencialmente perigosos à saúde humana e à biota aquática, sendo incluídos na "Priority Pollutants List (Black L ist)" por agências de controle ambiental em todo o mundo, incluindo o antimônio, arsênio, berílio, cádmio, cromo, cobre, chumbo, mercúrio, níquel, selênio, prata, tálio e zinco. Entre as mais freqüentes descargas de metais (fontes pontuais de poluição) estão o cobre, zinco, cromo, chumbo e níquel, devendo-se considerar ainda as quantidades expressivas de metais que estão presentes no escoamento de áreas urbanas (NOVOTNY, $1995^{1}$ apud LEITE, 2002).

Concentrações elevadas de metais ocorrem em muitos ecossistemas aquáticos devido às atividades antropogênicas, e sabe-se que o sedimento constitui 0 mais importante reservatório de metais e outros poluentes (BERVOETS et al., 1997). 0 mesmo autor considera que os componentes de maior importância para a disponibilidade de metais são os níveis de matéria orgânica e argila, a concentração de óxidos de ferro e manganês e as características da água intersticial.

Segundo SALOMONS \& FORSTNER (1984), os sedimentos são importantes carreadores de metais no ciclo hidrológico, podendo refletir a atual qualidade do sistema, bem como o desenvolvimento histórico de certos parâmetros hidrológicos e químicos.

Dentre as justificativas de se estudar a contaminação dos sedimentos por metais/metalóides, as duas mais importantes são: (1) a presença desses contaminantes nos sedimentos de rios, lagos, represas, áreas alagáveis, estuários e águas marinhas costeiras representa um potencial latente da degradação continuada desses ambientes mesmo que a coluna d'água e sua biota não apresentem concentrações desses elementos acima daquelas previstas na legislação vigente da qualidade da água, e (2) os sedimentos são uma fonte significativa de poluição que pode (dada a eventual baixa taxa de liberação desses contaminantes à coluna d'água e à biota) deteriorar, persistentemente, a qualidade da água desses mananciais mesmo após a redução ou interrupção completa das emissões (MOZETO 2001).

\footnotetext{
${ }^{1}$ Novotny, V. Diffuse sources of pollution by toxic metals and impacts on receiving waters. In: Heavy metals: problems and solutions. Eds. Salomons, W.; Forstner, U.; Mader, P. Springer. (1995). p. 33-52.
} 
Algumas definições relacionadas aos estudos dos metais em ambientes aquáticos devem ser conhecidas, tais como bioacumulação, bioconcentração e biomagnificação. Segundo EGELER et al. (1999) e ASTM (2000), a biocumulação é definida como um aumento de uma substância química em um organismo relativo à concentração no meio ambiente ou alimento, consistindo de vários processos e origens. Estes processos são, por um lado, a bioconcentração, que resulta exclusivamente da entrada do meio ambiente via superfície corpórea e por outro lado a biomagnificação, que é definida como um aumento na concentração corpórea resultante da contaminação do alimento, usualmente ao longo da série predadorpresa. A perda de uma substância do organismo por processos passivos ou ativos é denominada de eliminação.

Verifica-se, assim, que esses poluentes estão distribuídos em diversos compartimentos dos ecossistemas aquáticos (água, sedimento e organismos), com efeitos significativos à biota, podendo atingir o ser humano através do processo de bioacumulação ou pela ingestão direta da água contaminada (D O RNFELD , 2002).

Considerando-se os riscos à saúde do ecossistema e a necessidade de se monitorar os sistemas aquáticos com a finalidade de atender os usos múltiplos ao qual ele se destina, é de fundamental importância a determinação dos contaminantes que estão envolvidos na dinâmica desse sistema.

\section{OBJETIVOS}

O objetivo do presente estudo foi caracterizar física, química e biologicamente (clorofila a e coliformes) a água e o sedimento do rio Monjolinho com ênfase para a determinação das concentrações dos agrotóxicos organoclorados (Aldrin, Heptachlor e Endosulfan sulfato) e metais ( $\mathrm{Cd}, \mathrm{Cr}, \mathrm{Cu}, \mathrm{Fe}, \mathrm{Mn}$ e Zn).

\section{MATERIAIS E MÉTODOS}

\subsection{Análise química, física e biológica da água}

Para a caracterização do ambiente de estudo foram efetuadas algumas análises da água, as quais encontram-se listadas na Tabela 1. 
A metodologia utilizada para a análise da vazão de cada trecho de rio amostrado foi a do medidor de corrente, do tipo molinete ou correntômetro, segundo MARTINELLI \& KRUSCHE (2004).

As medidas de precipitação pluviométrica foram obtidas na Estação Meteorológica do Centro de Recursos Hídricos e Ecologia Aplicada, da Escola de Engenharia de São Carlos - USP, localizada em Itirapina, São Paulo.

Tabela 1. Variáveis, metodologias e referências utilizadas para a caracterização da qualidade da água do rio Monjolinho e seus tributários (São Carlos, SP).

\begin{tabular}{|c|c|}
\hline Variável & Metodologia/ Referência \\
\hline 1. Temperatura $\left({ }^{\circ} \mathrm{C}\right)$ & Multi-sensor HORIBA U-10 \\
\hline 2. $\mathrm{pH}$ & Multi-sensor HORIBA U-10 \\
\hline 3. Condutividade $\left(\mu \mathrm{S}_{\mathrm{cm}}{ }^{-1}\right)$ & Multi-sensor HORIBA U-10 \\
\hline 4. Oxigênio dissolvido (mg. $\left.\mathrm{L}^{-1}\right)$ & Multi-sensor HORIBA U-10 \\
\hline 5. Material em suspensão (mg.L-1 $)$ & $\begin{array}{c}\text { Gravimetria (Filtro GF/ C - 0,45 } \mu \mathrm{m} \text { )/ } \\
\text { TEIXEIRA et al. (1965) }\end{array}$ \\
\hline 6. Nitrito e nitrato ( $\left.\mu g . L^{-1}\right)$ & Espectrofotometria/ MACHERETH et al.(1978) \\
\hline 7. Íon amônio $\mu \mathrm{g} \cdot \mathrm{L}^{-1}$ & Espectrofotometria/ KOROLEFF (1976) \\
\hline 8. Nitrogênio orgânico total (mg.L-1) & Espectrofotometria/ APHA (1995) \\
\hline $\begin{array}{l}\text { 9. Fosfato total dissolvido e fosfato } \\
\text { inorgânico }\left(\mu \mathrm{g} \cdot \mathrm{L}^{-1}\right)\end{array}$ & Espectrofotometria/ GOLTERMAN (1978) \\
\hline 10. Fósforo Total $\left(\mu \mathrm{g} \cdot \mathrm{L}^{-1}\right)$ & Espectrofotometria/ APHA (1995) \\
\hline 11. Clorofila a ( $\left.\mu g . L^{-1}\right)$ & Espectrofotometria/ NUSH (1980) \\
\hline 12. Coliformes (NMP) & Colorimétrico (Collilert)/ APHA (1995) \\
\hline 13.Sulfeto, sulfato e cloreto (mg. $\mathrm{L}^{-1}$ ) & $\mathrm{HACH}(\mathrm{DR} / 2000)$ \\
\hline $\begin{array}{l}\text { 14. D emanda Bioquímica de O xigênio } \\
\mathrm{DBO}_{5}-\left(\mathrm{mg} \cdot \mathrm{L}^{-1}\right)\end{array}$ & $\begin{array}{l}\text { Titlulação com Tiossulfato de sódio e incubação } \\
\text { por } 5 \text { dias a 20C/ APHA (1995) }\end{array}$ \\
\hline $\begin{array}{l}\text { 15. D emanda Química de O xigênio - } \\
\text { DQO - (mg.L-1) }\end{array}$ & $\mathrm{HACH}(\mathrm{DR} / 2000)$ \\
\hline 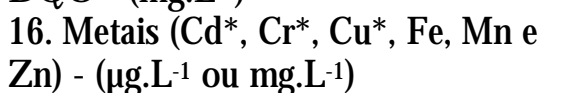 & $\begin{array}{l}\text { Espectrofotometria (Absorção Atômica - Chama } \\
\text { e Forno de Grafite*)/ APHA (1995) }\end{array}$ \\
\hline $\begin{array}{l}\text { 17. Agrotóxicos Organoclorados } \\
\left(\mu \mathrm{g} . \mathrm{L}^{-1}\right)\end{array}$ & $\begin{array}{l}\text { Cromatografia gasosa (extração em fase sólida)/ } \\
\text { LANÇAS (1997) }\end{array}$ \\
\hline
\end{tabular}

As amostras de água foram coletadas com garrafa de Van D orn ou tomada direta da água de superfície, dependendo da estação coletada, sendo acondicionadas e preservadas até o momento da análise, seguindo as metodologias específicas para cada análise:

ÿ nutrientes: congeladas até 0 momento da análise;

ÿ clorofila ạ: amostras de água filtradas em filtros $\mathrm{GF} / \mathrm{C}$ não calcinados, sendo que após secagem os filtros foram mantidos em freezer, em frascos escuros contendo sílica gel, até o momento da análise; 
ÿ material em suspensão: amostras de água filtradas em filtros GF/C calcinados, sendo que após a secagem os filtros foram mantidos em dessecador até o momento da análise;

$\ddot{y} \quad$ metais: fixadas com ácido nítrico (até $\mathrm{pH}=2$, em geral $1 \mathrm{ml}$ de $\mathrm{HNO}_{3}$ para cada litro de amostra);

ÿ agrotóxicos organoclorados: fixadas com ácido sulfúrico (até $\mathrm{pH}=2$, em geral $1 \mathrm{ml} \mathrm{de} \mathrm{H}_{2} \mathrm{SO}_{4}$ para cada litro de amostra);

ÿ íons (sulfato, sulfeto e cloreto), DBO e DQO: as análises foram realizadas no mesmo dia da coleta, não sendo necessário procedimento de preservação da amostra.

\subsubsection{Análise física e química do sedimento}

As amostras de sedimento foram coletadas com uma draga do tipo EckmanBirge ou coletor de tubo de PVC, dependendo da profundidade do local de amostragem, com três réplicas por estação, sendo imediatamente homogeneizadas e acondicionadas em potes plásticos. Uma parte permaneceu em temperatura ambiente (para secagem) para posterior análise de matéria orgânica, granulometria, fósforo total, nitrogênio orgânico total, metais potencialmente biodisponíveis e agrotóxicos organoclorados (Tabela 2). A análise do potencial redox foi realizada com o sedimento recém coletado (fresco e em temperatura ambiente).

Tabela 2. Variáveis, metodologias e referências utilizadas para a caracterização do sedimento do rio Monjolinho e seus tributários (São Carlos, SP).

\begin{tabular}{|c|c|}
\hline Variável & Metodologia/ Referência \\
\hline 1. Matéria orgânica (\%) & Incineração em mufla/ TRIND ADE (1980) \\
\hline 2. Granulometria (\%) & Peneiramento e densímetro/ ABNT (1968) \\
\hline 3. Fósforo total $\left(\mu \mathrm{g} \cdot \mathrm{g}^{-1}\right)$ & Espectrofotometria/ ANDERSEN (1976) \\
\hline 4. Nitrogênio orgânico total (\%) & KJELD HAL/ APHA (1995) \\
\hline 5. Potencial redox (mV) & Potenciômetro/ APHA (1995) \\
\hline 6. Metais potencialmente biodisp & m $\mathrm{HCl} 0,1 \mathrm{M}$ e leitura em \\
\hline$\left(\mathrm{Cd}^{*}, \mathrm{Cr}^{*}, \mathrm{Cu}^{*}, \mathrm{Fe}, \mathrm{Mn}\right.$ e Zn) (mg.L-1) & $\begin{array}{l}\text { Espectrofotometria (Absorção Atômica por Chama } \\
\text { e Forno de grafite*)/ SILVÉRIO (1999) }\end{array}$ \\
\hline 7. Agrotóxicos organoclora & $\begin{array}{l}\text { Cromatografia gasosa } \\
\text { (extração em fase sólida)/ LANÇAS (1997) }\end{array}$ \\
\hline
\end{tabular}




\section{RESULTADOS}

\subsection{Precipitação pluviométrica}

Os dados de pluviosidade (Figura 1) indicam que as estações seca e chuvosa estiveram bem definidas durante o período de coleta. Considerando os meses em que foram realizadas coletas, a menor precipitação mensal $(4,5 \mathrm{~mm})$ foi observada em julho/ 03 e a maior (302,0 mm) em janeiro/ 04.

Na Tabela 3 (Apêndice 2), observa-se que a coleta de março/ 03 foi realizada em dias chuvosos (12,0 e 4,2 mm), sendo esta a única coleta com chuva. Porém, observa-se em janeiro/ 04, que no dia da retirada dos ensaios "in situ" (Capítulo 3), ocorreu o maior índice pluviométrico do mês, sendo de $84,0 \mathrm{~mm}$.

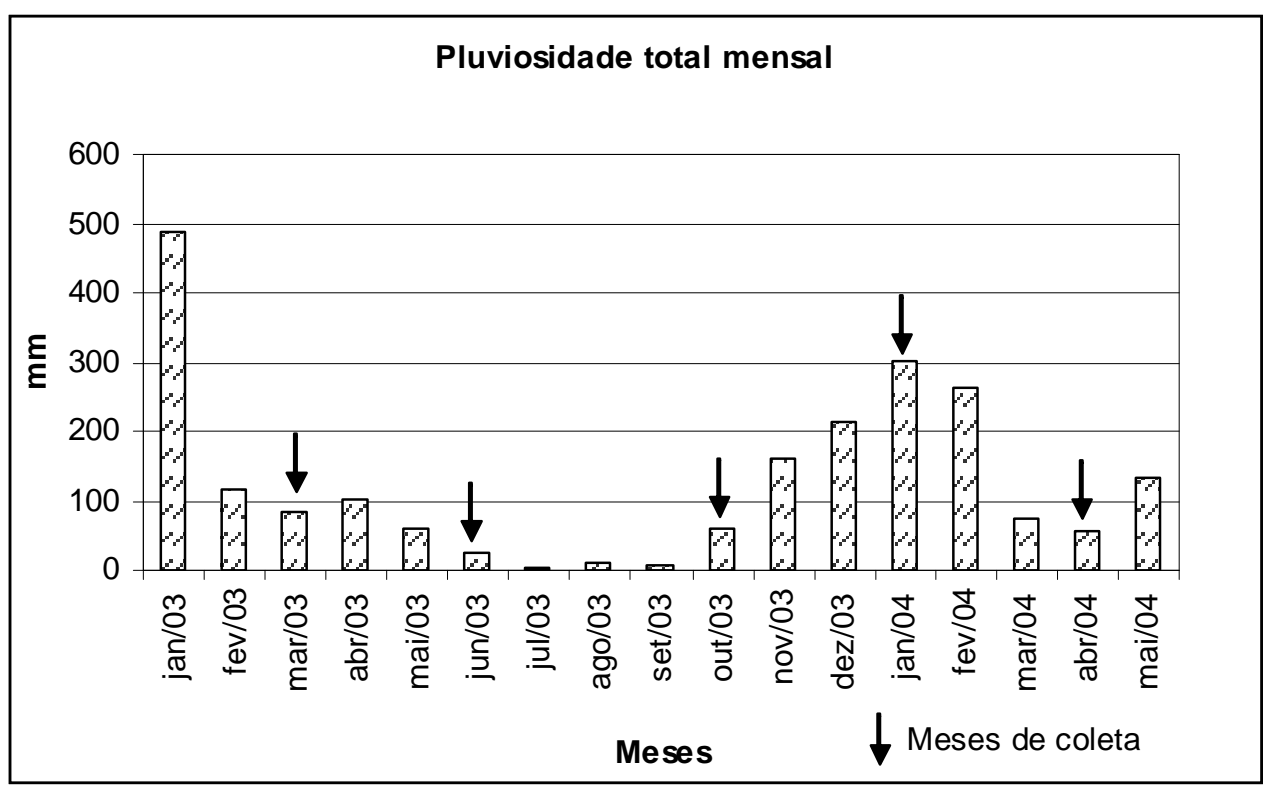

Figura 1. Variação da pluviosidade (mm), durante o período de estudo. Os dados pluviométricos foram fornecidos pela Estação Meteorológica do Centro de Recursos Hídricos e Ecologia Aplicada, EESC/ USP.

\subsection{Vazão}

Os resultados de vazão estão apresentados na Figura 2 e na Tabela 4 (Apêndice 2), sendo obtida a maior vazão na Foz (3,36 $\mathrm{m}^{3} \cdot \mathrm{s}^{-1}$, julho/ 03) e menor na Federal $\left(0 \mathrm{~m}^{3} \cdot \mathrm{s}^{-1}\right.$, abril/ 04). Não foi possível observar uma relação direta entre aumento da pluviosidade e aumento da vazão, sendo que em geral as medidas das vazões foram realizadas em dias que antecederam as chuvas. 

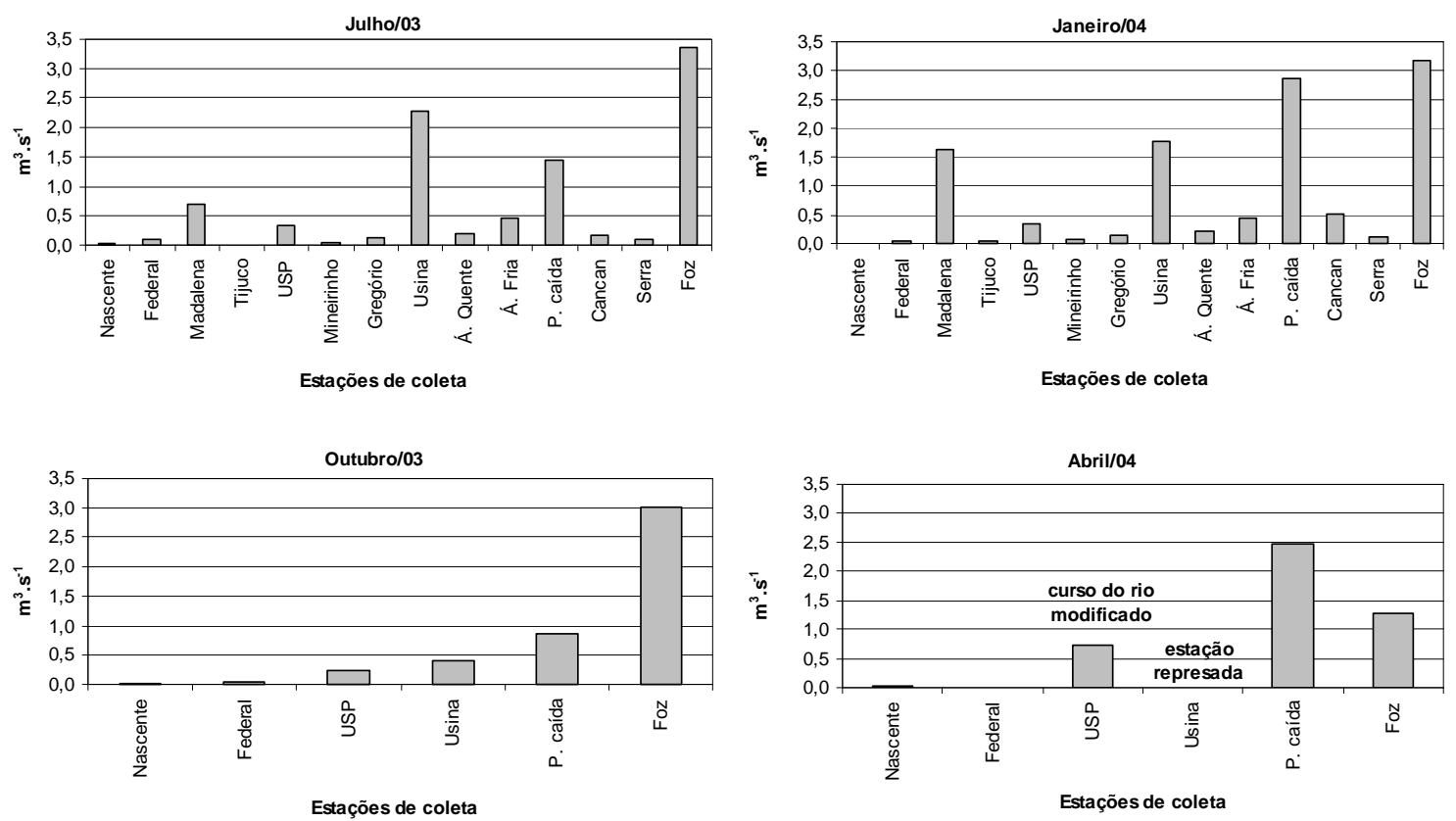

Figura 2. Vazão $\left(\mathrm{m}^{3} \cdot \mathrm{s}^{-1}\right)$ no rio Monjolinho e tributários durante o período de estudo.

\subsection{Material em suspensão na água}

A análise de material em suspensão não foi realizada em março/ 03 e nem em todas as estações de amostragem em julho/ 03, como pode ser observado na Figura 3 e na Tabela 5 (Apêndice 2).

As menores concentrações de material em suspensão total, orgânico e inorgânico foram verificadas na Nascente em todo o período de estudo. As concentrações mais baixas foram obtidas em abril/ 04 (Nascente - 2,36; 1,48 e 0,53 mg.L-1 , respectivamente), e as mais altas em janeiro/ 04 (Água Quente - 130,0; 25,06 e 105,0 mg.L-1 ${ }^{-1}$, respectivamente).

Verifica-se um aumento gradual na concentração do material em suspensão no eixo longitudinal do rio Monjolinho (sentido Nascente - Foz) apenas em outubro/ 03, com as menores concentrações na Nascente (2,46; 1,65 e 0,81 mg.L-1, respectivamente) e as maiores na Foz (39,8; 13,5 e 26,2 mg.L-1, respectivamente). Nos demais meses as maiores concentrações ocorreram na Ponte caída (julho/ 03 23,7; 6,7 e 16,9 mg.L-1 ${ }^{-1}$ respectivamente) e Usina (abril/ 04 - 29,4; 8,2 e 21,1 mg.L-1, respectivamente). 


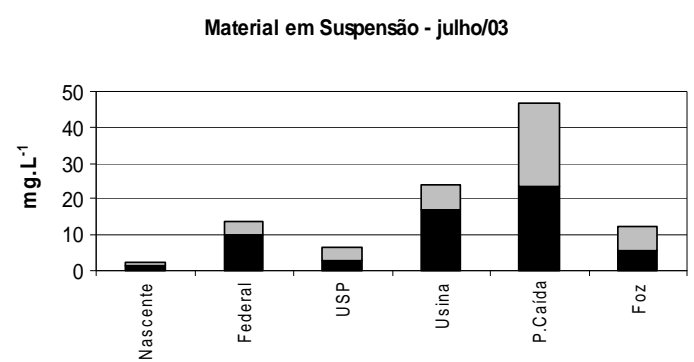

Estações de coleta

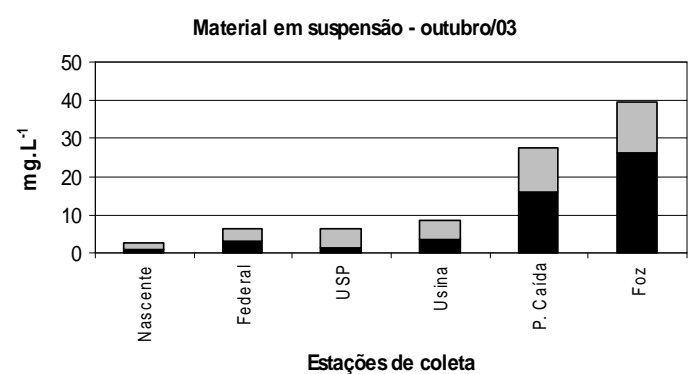

Material em suspensão - janeiro/04

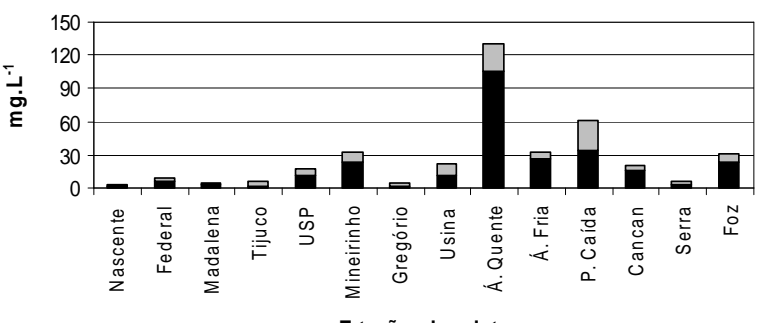

Estações de coleta

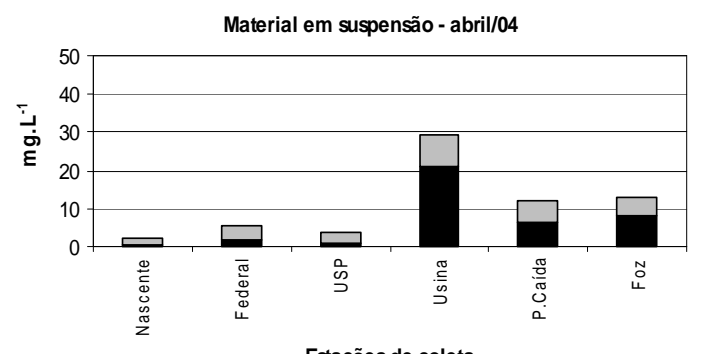

Estações de coleta

— inorgânico $\square$ orgânico

Figura 3. Material em suspensão orgânico e inorgânico (mg.L-1) no rio Monjolinho e tributários, durante período de estudo (Notar a diferença de escala em janeiro/ 04).

\subsection{Nutrientes fosfatados e nitrogenados na água}

Os resultados referentes às concentrações de nutrientes na água do rio Monjolinho e seus tributários estão apresentados nas Figuras 4 a 14 (e nas Tabelas de 6 a 10, Apêndice 2), sendo separadas em formas fosfatadas (fosfato total dissolvido, fosfato inorgânico e fósforo total) e formas nitrogenadas (nitrato, nitrito, íon amônio e nitrogênio orgânico total), em cada período de coleta, para uma melhor avaliação dos resultados.

\subsubsection{Formas fosfatadas}

Em março/ 03 (Figura 4), observa-se um aumento gradual nas concentrações de PTD, PI e PT da Nascente (10,91; 9,66 e 30,26 $\mu \mathrm{g} \cdot \mathrm{L}^{-1}$, respectivamente) em direção à Ponte caída (107,28; 94,21 e 329,23 $\mu \mathrm{g} . \mathrm{L}^{-1}$, respectivamente), sendo que as concentrações diminuem quando se considera a Foz (64,94; 45,99 e 123,19 $\mu \mathrm{g} . \mathrm{L}^{-1}$, respectivamente), o que pode ser devido à diluição proporcionada pelos tributários, Cancan e Serra. Dentre os tributários, Tijuco (289,06; 282,79 e 476,67 $\mu \mathrm{g} \cdot \mathrm{L}^{-1}$, 
respectivamente) e Gregório (130,49; 103,41 e 173,43 $\mu g . \mathrm{L}^{-1}$, respectivamente) apresentaram as maiores concentrações e Madalena (13,26; 9,24; 81,47 $\mu \mathrm{g} \cdot \mathrm{L}^{-1}$, respectivamente) e Cancan (16,17; 11,32 e 32,12 $\mu g . L^{-1}$, respectivamente) apresentaram as menores concentrações das formas fosfatadas.

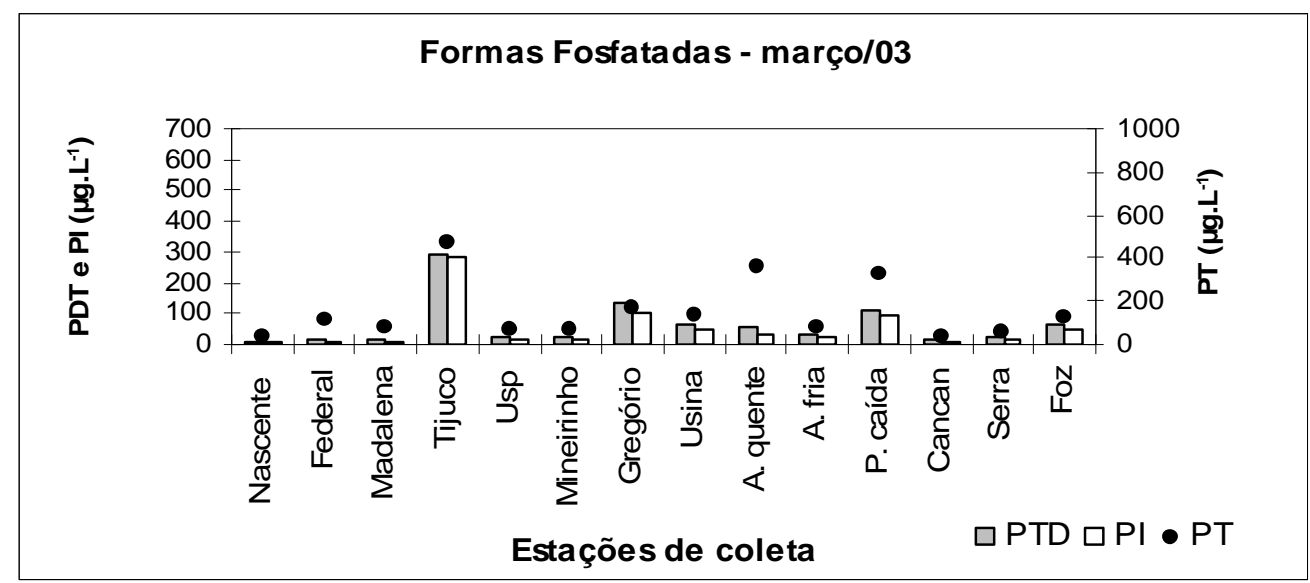

Figura 4. Formas fosfatadas (fosfato total dissolvido - PTD, fosfato inorgânico - PI e fósforo total - PT, em $\mu g . \mathrm{L}^{-1}$ ) no rio Monjolinho e tributários em março/ 03.

Em julho/ 03 ocorreu um aumento nas concentrações das formas fosfatadas da nascente em direção à foz, mas os valores não aumentam gradualmente e 0 rio Monjolinho se mostra claramente influenciado pelos tributários. Observa-se na Figura 5 as concentrações de PTD, PI e PT, com as mínimas verificadas na Nascente (6,12; 5,22 e 18,00 $\mu \mathrm{g} . \mathrm{L}^{-1}$, respectivamente), Cancan (9,90; 8,71 e 53,26 $\mu \mathrm{g} . \mathrm{L}^{-1}$, respectivamente) e Serra (9,63; 8,42 e 54,08 $\mu \mathrm{g} \cdot \mathrm{L}^{-1}$, respectivamente). As concentrações máximas foram observadas na Ponte caída (241,25; 233,99 e 682,56 $\mu \mathrm{g} . \mathrm{L}^{-1}$, respectivamente), na Foz (357,96; 355,10 e 615,27 $\mu \mathrm{gg} . \mathrm{L}^{-1}$, respectivamente) e no Tijuco (218,11; 202,95 e 444,34 $\mu \mathrm{g} \cdot \mathrm{L}^{-1}$, respectivamente).

Em outubro/ 03 não foram coletadas amostras dos tributários, podendo-se observar na Figura 60 aumento gradual das concentrações de nutrientes fosfatados

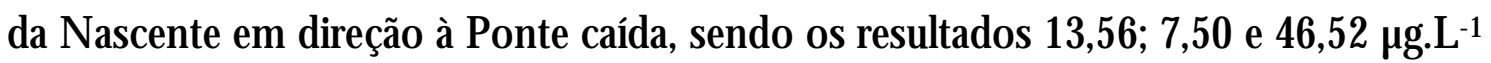
e 387,58; 341,77 e 787,37 $\mu . L^{-1}$, respectivamente para PTD , PI e PT. 


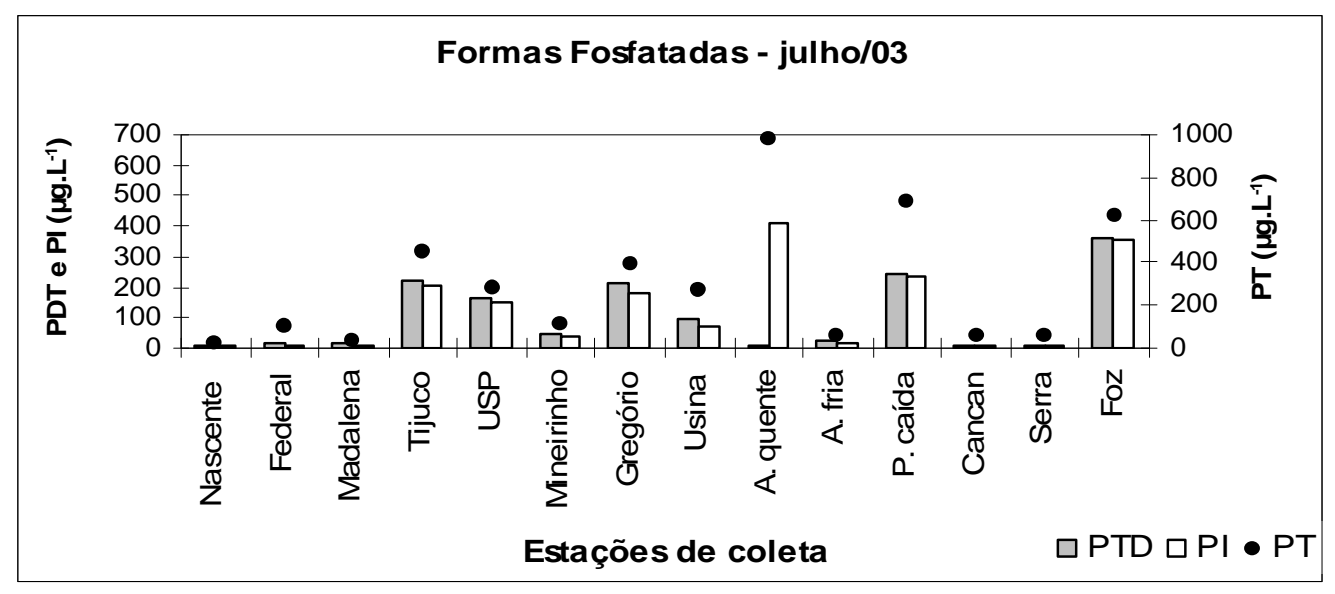

Figura 5. Formas fosfatadas (fosfato total dissolvido - PTD, fosfato inorgânico - PI e fósforo total - PT, em $\left.\mu g . L^{-1}\right)$ no rio Monjolinho e tributários em julho/ 03.

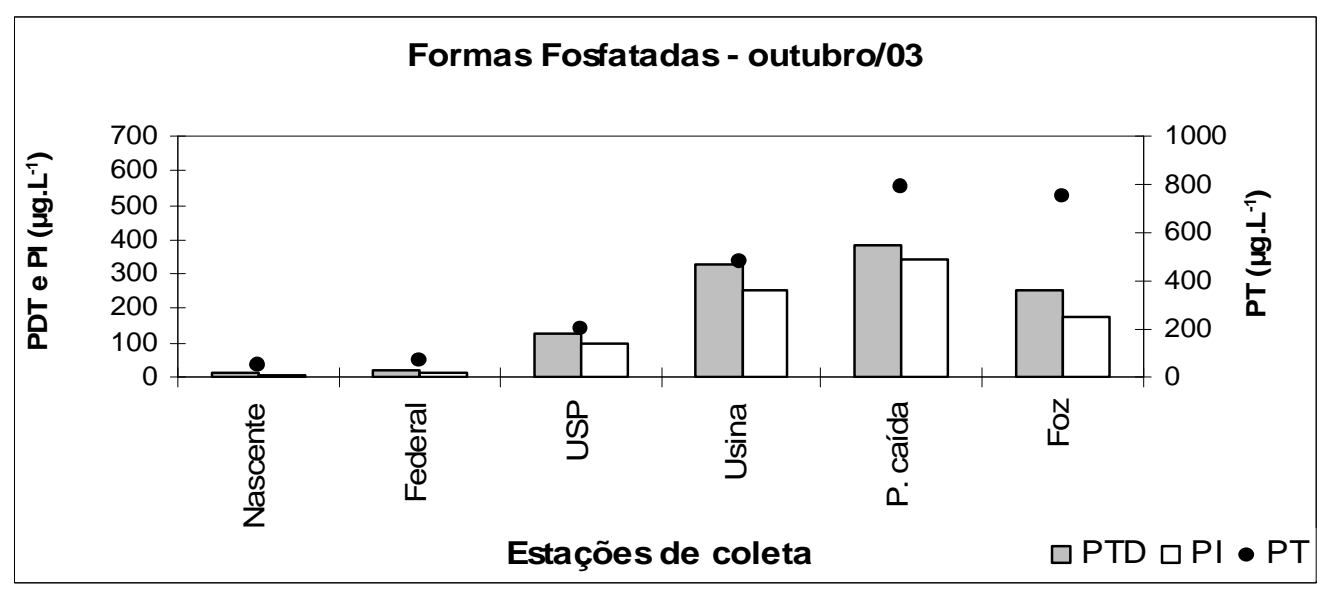

Figura 6. Formas fosfatadas (fosfato total dissolvido - PTD, fosfato inorgânico - PI e fósforo total - PT, em $\left.\mu g . L^{-1}\right)$ no rio Monjolinho e tributários em outubro/ 03.

Os resultados de PDT, PI e PT de janeiro/ 04 (Figura 7) apresentaram-se inferiores aos dos demais meses amostrados da Nascente até o córrego do Mineirinho, sendo que deste ponto em diante, frente à contribuição apresentada

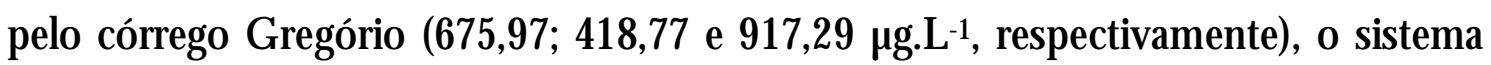
passa a ter maiores concentrações das formas fosfatadas. As concentrações mínimas foram detectadas na Nascente (15,80; 12,00 e 61,38 $\mu \mathrm{g} . \mathrm{L}^{-1}$, respectivamente) e no córrego Madalena (24,60; 15,17 e 42,10 $\mu g . \mathrm{L}^{-1}$, respectivamente). 


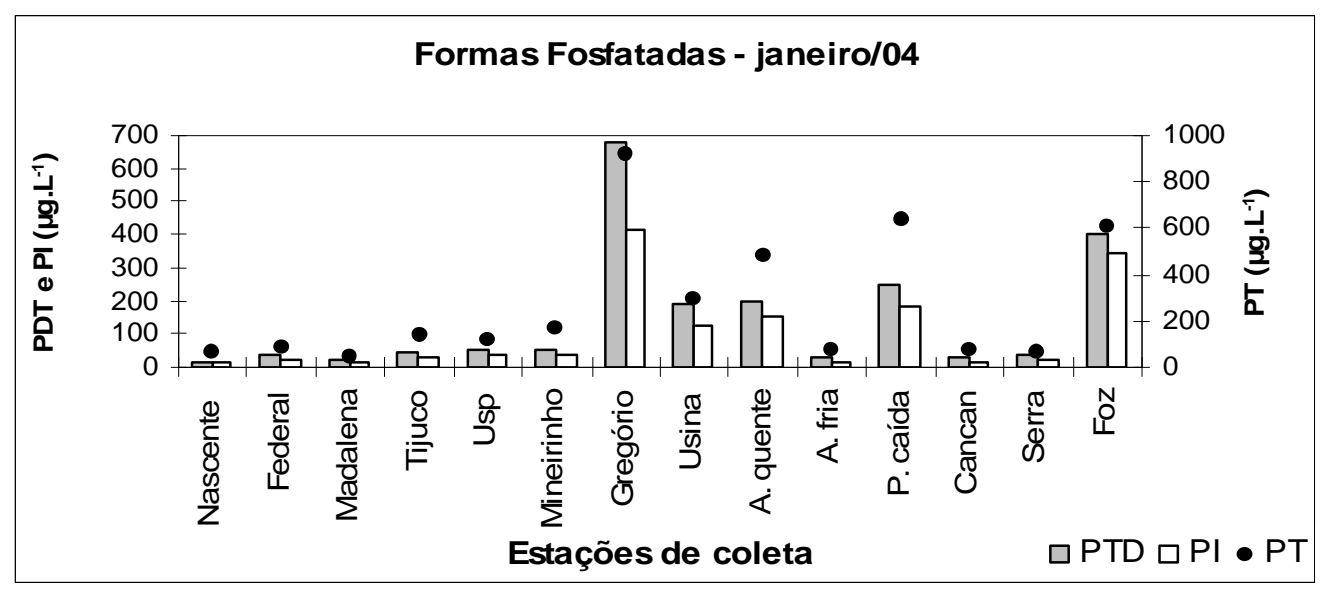

Figura 7. Formas fosfatadas (fosfato total dissolvido - PTD, fosfato inorgânico - PI e fósforo total - PT, em $\left.\mu g \cdot L^{-1}\right)$ no rio Monjolinho e tributários em janeiro/ 04.

Em abril/ 04 (Figura 8), assim como em outubro/ 03, não foram coletadas amostras dos tributários. Os valores máximos e mínimos de PTD, PI e PT foram verificados nas mesmas estações de coleta, isto é, Nascente (19,02; 16,26 e 58,40 $\mu g . L^{-1}$, respectivamente) e Ponte caída $\left(405,41 ; 353,40\right.$ e 644,10 $\mu g . L^{-1}$, respectivamente).

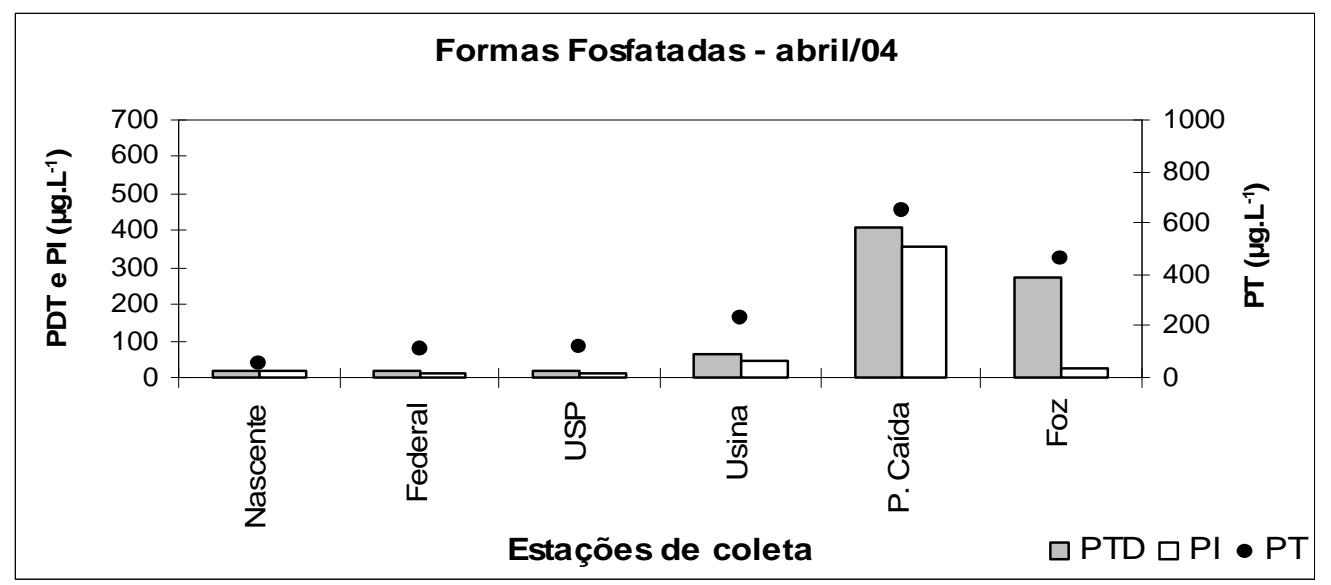

Figura 8. Formas fosfatadas (fosfato total dissolvido - PTD, fosfato inorgânico - PI e fósforo total - PT, em $\mu g . L^{-1}$ ) no rio Monjolinho e tributários em abril/ 04.

\subsubsection{Formas nitrogenadas}

Em relação às formas nitrogenadas $\left(\mathrm{NO}_{3}, \mathrm{NH}_{4}\right.$ e $\left.\mathrm{NO}_{2}\right)$, em março/ 03 (Figura 9) foram observados os maiores valores nos tributários Tijuco (2701,40; 
2682,25 e 261,51 $\mu \mathrm{g} \cdot \mathrm{L}^{-1}$, respectivamente), Gregório (2351,90; 1280,00 e 141,78 $\mu g . L^{-1}$, respectivamente) e Água Quente $\left(419,20 ; 2700,30\right.$ e 83,74 $\mu g . L^{-1}$, respectivamente) e no rio Monjolinho nas estações Ponte caída (260,30; 2016,50 e

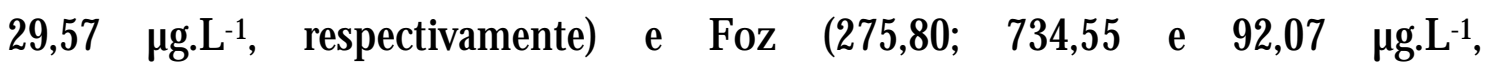
respectivamente). As menores concentrações foram observadas nas estações Cancan (74,98; 39,43 e 1,92 $\mu \mathrm{g} \cdot \mathrm{L}^{-1}$, respectivamente) e Madalena (75,93; 55,50 e 3,74 $\mu \mathrm{g} \cdot \mathrm{L}^{-1}$, respectivamente).

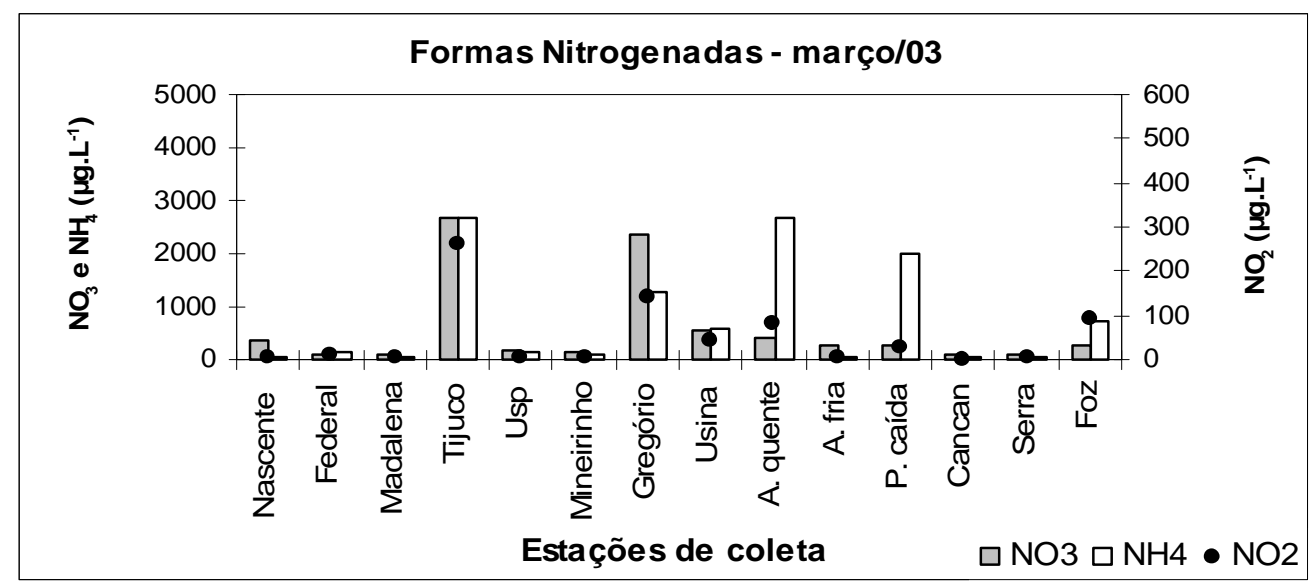

Figura 9. Formas nitrogenadas (nitrato - $\mathrm{NO}_{3}$, íon amônio - $\mathrm{NH}_{4}$ e nitrito - $\mathrm{NO}_{2}$, em $\mu g \cdot \mathrm{L}^{-1}$ ) no rio Monjolinho e tributários em março/ 03.

Em julho/03 (Figura 10), observa-se altas concentrações nas mesmas estações que em março/03, Tijuco (3979,10; 1006,70 e 528,22 ug.L-1, respectivamente), Gregório (3755,80; 1923,50 e 519,80 $\mu \mathrm{g} . \mathrm{L}^{-1}$, respectivamente), enquanto no Água Q uente e Ponte caída as maiores concentrações foram para o íon amônio (2220,30 e 2218,60 $\mu \mathrm{g} \cdot \mathrm{L}^{-1}$, respectivamente). As menores concentrações foram observadas para a Nascente (31,89 e 2,19 $\mu \mathrm{g} \cdot \mathrm{L}^{-1}$ para $\mathrm{NH}_{4}$ e $\mathrm{NO}_{2}$, respectivamente), Federal (2,18 $\left.\mu \mathrm{g} \cdot \mathrm{L}^{-1} \mathrm{NO}_{2}\right)$, Madalena (3,14 $\left.\mu \mathrm{g} \cdot \mathrm{L}^{-1} \mathrm{NO}_{2}\right)$, Cancan

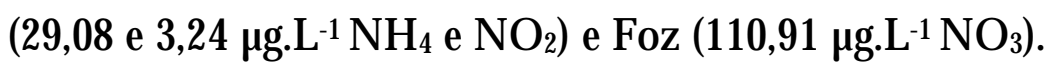

Em outubro/ 03 (Figura 11), observa-se um aumento das concentrações de $\mathrm{NO}_{2}$ e $\mathrm{NO}_{3}$ da Nascente até a Usina e depois uma redução nesses valores. Em relação ao $\mathrm{NH}_{4}$ observa-se um aumento gradual da Nascente em direção à Foz. Os menores valores, portanto, foram verificados na Nascente (131,34; 278,52 e 2,29 $\mu g . L^{-1}$, respectivamente) e as maiores concentrações de $\mathrm{NO}_{3}$ e $\mathrm{NO}_{2}$ foram obtidas 
na Usina (229,10 e 174,5 $\mu g \cdot \mathrm{L}^{-1}$, respectivamente) e de $\mathrm{NH}_{4}$ foi observada na Foz $\left(2668,00 \mu g . L^{-1}\right)$.

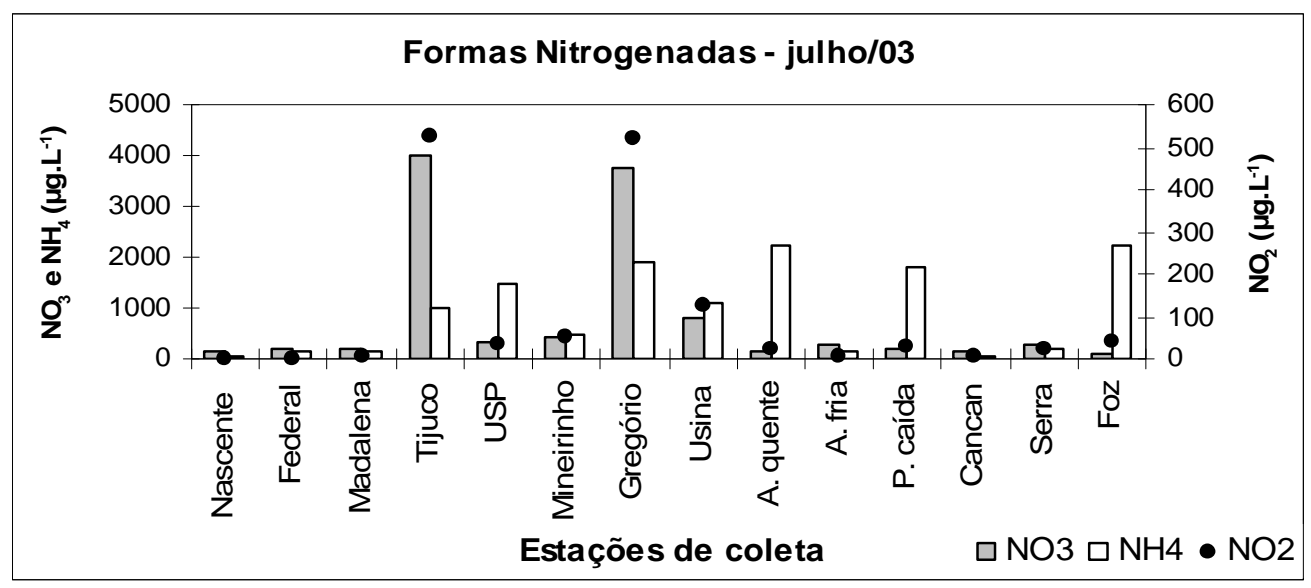

Figura 10. Formas nitrogenadas (nitrato - $\mathrm{NO}_{3}$, íon amônio - $\mathrm{NH}_{4}$ e nitrito - $\mathrm{NO}_{2}$, em $\mu g . \mathrm{L}^{-1}$ ) no rio Monjolinho e tributários em julho/ 03.

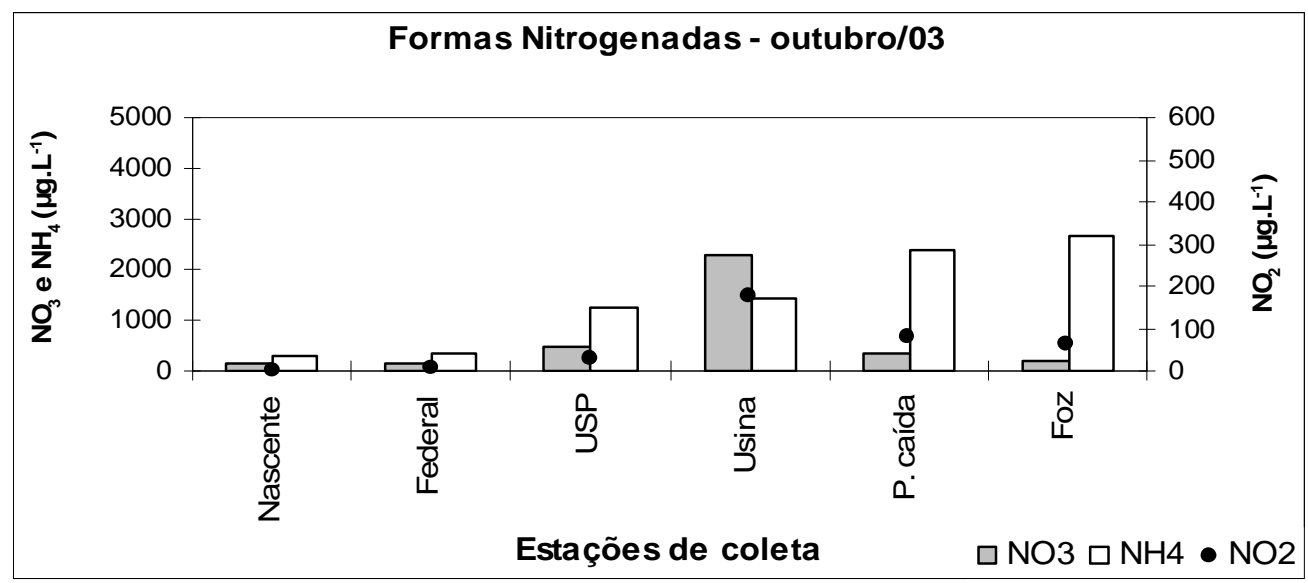

Figura 11. Formas nitrogenadas (nitrato - $\mathrm{NO}_{3}$, íon amônio - $\mathrm{NH}_{4}$ e nitrito - $\mathrm{NO}_{2}$, em $\mu g . L^{-1}$ ) no rio Monjolinho e tributários em outubro/ 03.

Em janeiro/ 04 (Figura 12), as maiores concentrações ocorreram no Tijuco

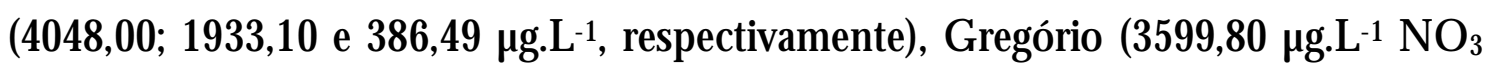

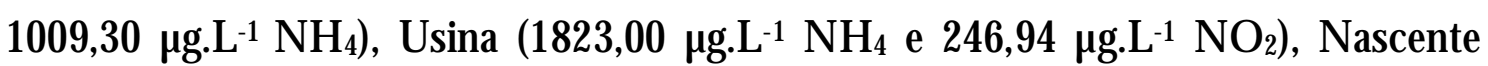
(1815,40 $\left.\mu g . L^{-1} \mathrm{NH}_{4}\right)$ e USP $\left(1970,00 \mu g . \mathrm{L}^{-1} \mathrm{NH}_{4}\right)$. As menores concentrações foram observadas na Ponte caída (64,01 $\mu \mathrm{g} \cdot \mathrm{L}^{-1} \mathrm{NO}_{3}$ e 29,80 $\left.\mu \mathrm{g} \cdot \mathrm{L}^{-1} \mathrm{NH}_{4}\right)$, Cancan (64,27; 48,50 e 1,57 $\mu \mathrm{g} \cdot \mathrm{L}^{-1}$, respectivamente) e Madalena (45,56 $\mu \mathrm{g} \cdot \mathrm{L}^{-1} \mathrm{NO}_{3} \mathrm{e}$ 1,82ug.L-1 $\mathrm{NO}_{2}$ ). Em abril/ 04 (Figura 13), observou-se um aumento gradual de 
$\mathrm{NO}_{2}$ da nascente em direção à foz. Verificou-se nas estações Ponte caída e Foz as maiores concentrações de $\mathrm{NH}_{4}$, sendo de 1598,00 e de 2454,00 $\mu \mathrm{g} . \mathrm{L}^{-1}$, respectivamente. Neste mês, foram detectados os menores valores de $\mathrm{NO}_{3}$ e $\mathrm{NH}_{4}$ para a Nascente em todo o período estudado, sendo de 87 e $24 \mu \mathrm{g} \cdot \mathrm{L}^{-1}$, respectivamente.

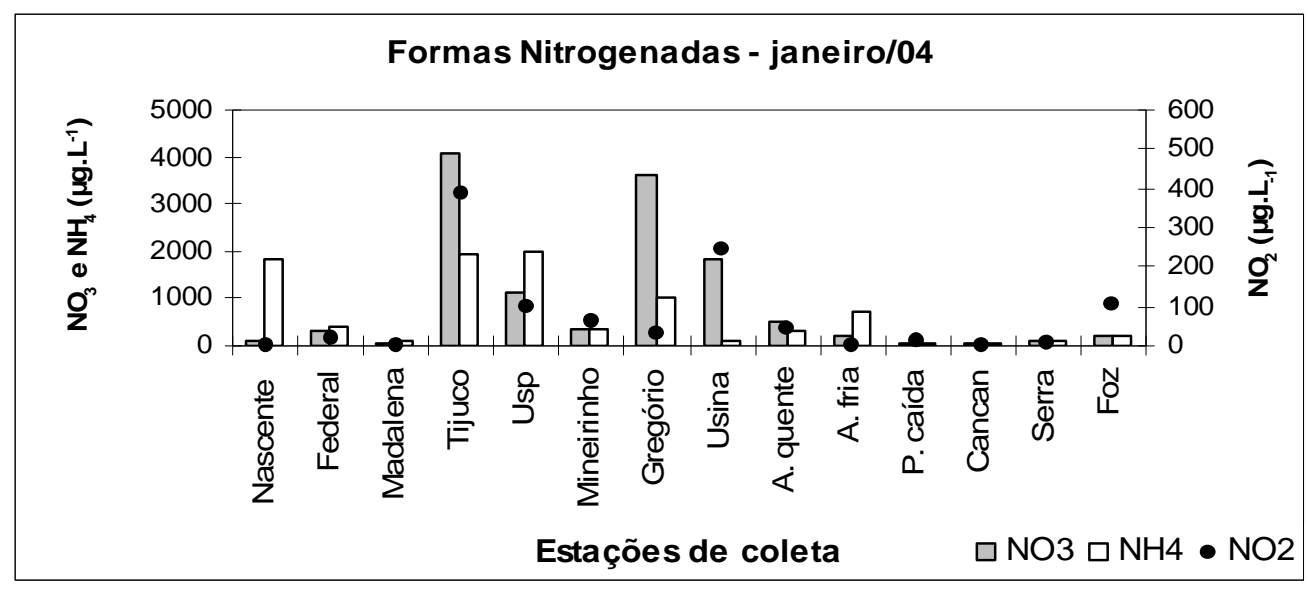

Figura 12. Formas nitrogenadas (nitrato - $\mathrm{NO}_{3}$, íon amônio $-\mathrm{NH}_{4}$ e nitrito - $\mathrm{NO}_{2}$, em $\mu \mathrm{g} \cdot \mathrm{L}^{-1}$ ) no rio Monjolinho e tributários em janeiro/ 04.

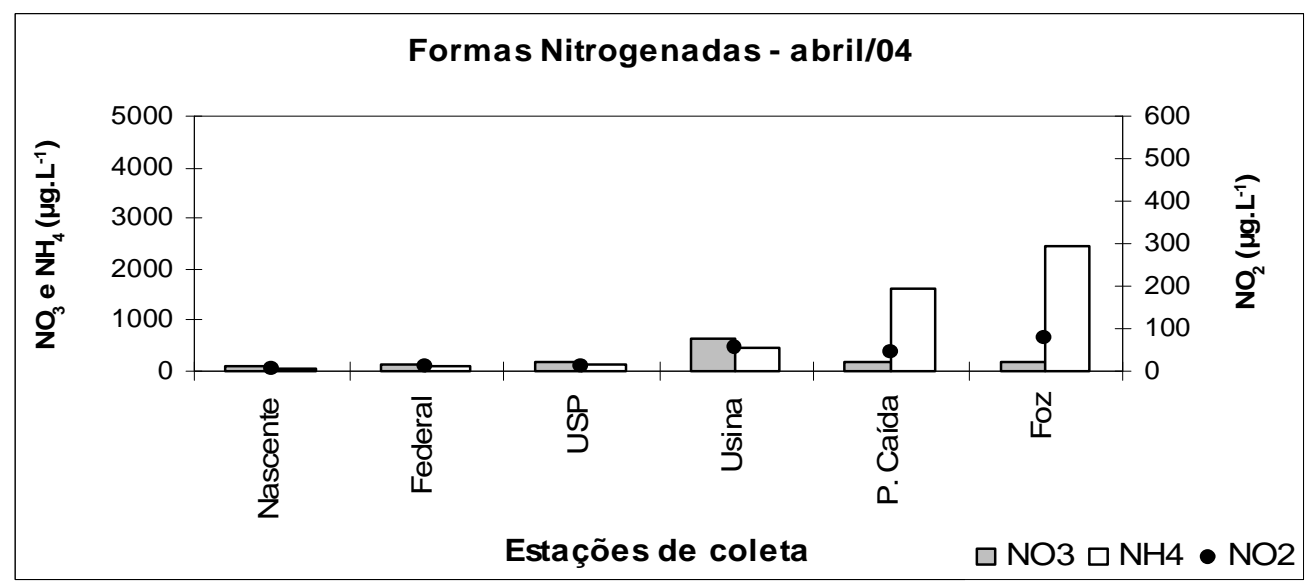

Figura 13. Formas nitrogenadas (nitrato - $\mathrm{NO}_{3}$, íon amônio - $\mathrm{NH}_{4}$ e nitrito - $\mathrm{NO}_{2}$, em $\mu g \cdot \mathrm{L}^{-1}$ ) no rio Monjolinho e tributários em abril/ 04.

Em relação ao nitrogênio orgânico total (NOT), a Figura 14 mostra de forma comparativa as concentrações obtidas em todo período estudado. Em março/ 03 e janeiro/ 04 foram obtidos os maiores valores, sendo nas estações USP (15 mg.L-1), Gregório (15 mg. $\left.\mathrm{L}^{-1}\right)$ e Usina (11 mg. $\left.\mathrm{L}^{-1}\right)$ em março/ 03 e no Tijuco (15 mg. $\left.\mathrm{L}^{-1}\right)$, 
G regório (15 mg.L-1) e Usina (11 mg.L-1) em janeiro/ 04. As menores concentrações foram observadas na Nascente (0,02 mg.L-1, em março/ 03, janeiro/ 04 e abril/ 04), na Serra (0,19 mg.L-1 , em julho/ 04) e na Federal (0,37 mg.L-1 , em outubro/ 03).
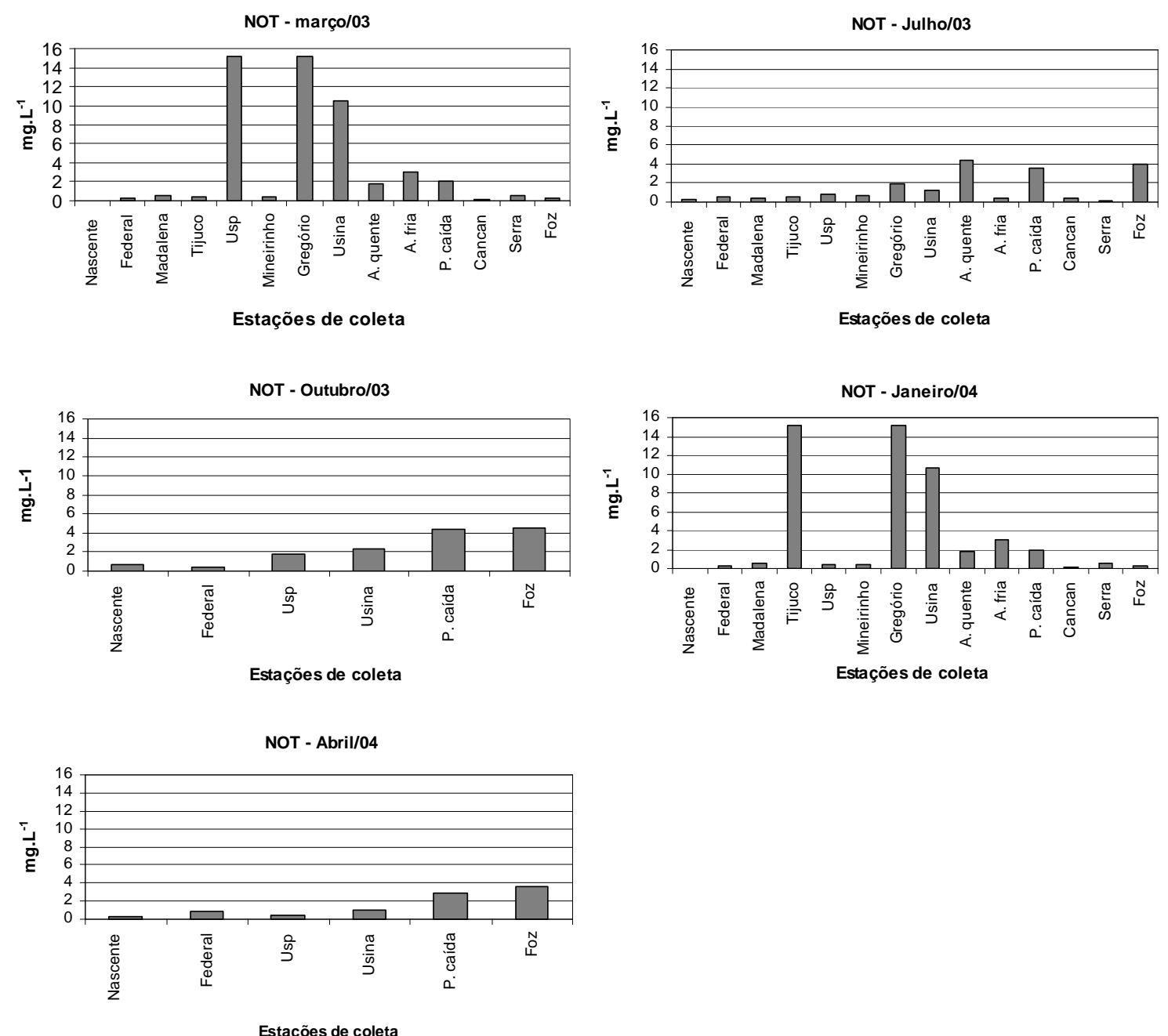

Figura 14. Nitrogênio orgânico total (NOT) na água do rio Monjolinho e tributários durante 0 período de estudo.

\section{5. Íons (Cloretos, Sulfatos e Sulfetos) na água}

Os resultados dos íons cloretos estão apresentados na Figura 15 e na Tabela 11 (Apêndice 2), nas quais pode-se observar que a concentração máxima, encontrada em todo período estudado, foi de $24,50 \mathrm{mg} \cdot \mathrm{L}^{-1}$ no córrego Água Quente em março/ 03 e a concentração mínima foi de 0,04 mg.L-1 na Nascente em julho/ 03. 
Observa-se que as maiores concentrações foram obtidas nas estações Tijuco, Gregório, Água Q uente, Ponte caída e Foz, enquanto as menores concentrações foram observadas na Nascente, Madalena, Água Fria e Serra.

Em nenhuma estação foi ultrapassada a concentração limite estabelecida pela CONAMA 357/ 05, que é de 250,00 mg.L-1 para rios Classe 2 ou 3.

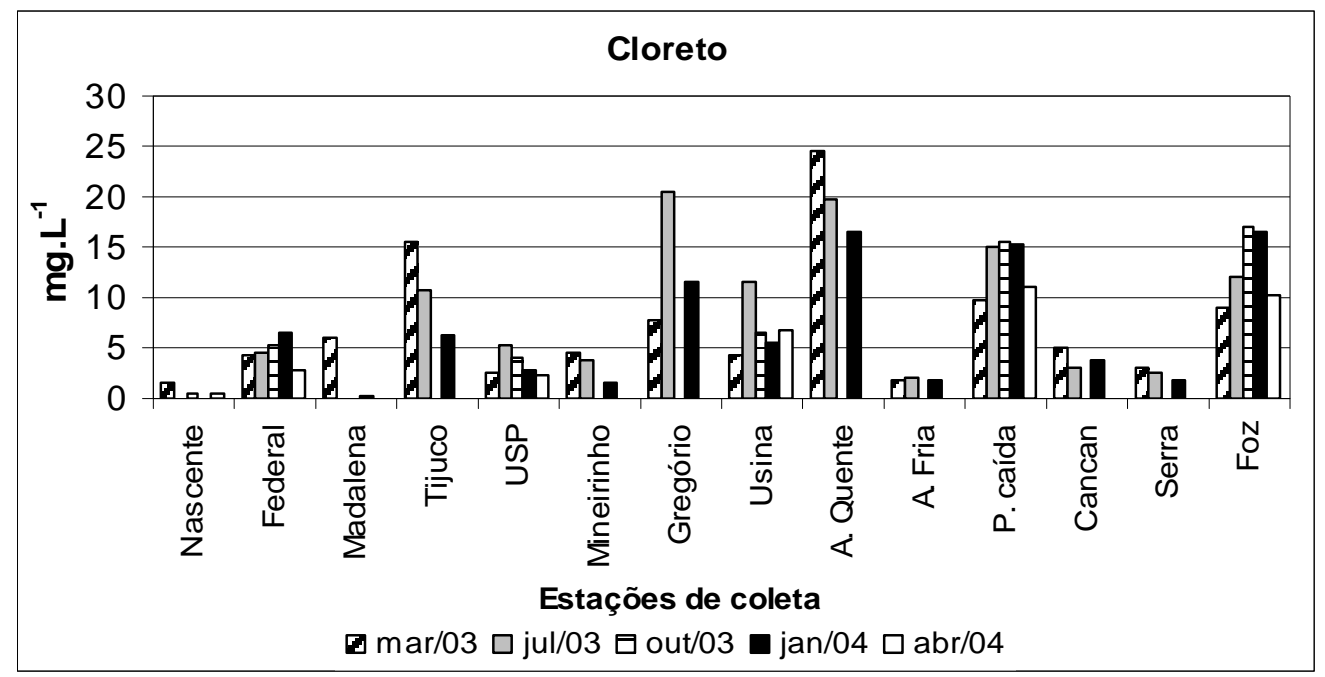

Figura 15. Concentrações (mg. $\left.\mathrm{L}^{-1}\right)$ de cloretos obtidos no rio Monjolinho e tributários durante 0 período de estudo.

Em relação ao íon sulfato (Figura 16 e Tabela 12 - Apêndice 2), as concentrações máxima e mínima obtidas durante o período de estudo foram de 59,00 mg.L-1 (G regório, julho/ 03) e 0,00 mg.L-1 (Mineirinho, julho/ 03 e janeiro/ 04), respectivamente. As maiores concentrações foram observadas nas estações Gregório, Água Quente e Ponte caída, enquanto as menores concentrações foram observadas na Nascente, Madalena, Cancan e Serra. Segundo a CONAMA 357/ 05, a concentração máxima permitida para rios Classe 2 ou 3 é de 250,00 mg. $L^{-1}$, observando, portanto, que em nenhuma estação esse valor foi ultrapassado.

A maior concentração de sulfeto (Figura 17 e na Tabela 13 - Apêndice 2) foi obtida no Gregório (julho/03), sendo de 0,151 mg. $\mathrm{L}^{-1}$, enquanto a menor concentração foi obtida no Serra, sendo de 0,001 mg.L-1 (janeiro/ 04). Observa-se que as maiores concentrações foram obtidas na Federal, Gregório e Água Q uente e as menores concentrações foram obtidas na Nascente, Tijuco, USP e Água Fria. Em relação à resolução CONAMA 357/ 05, verificou-se que todas as estações, exceto 
Serra $\left(0,001 \mathrm{mg} \cdot \mathrm{L}^{-1}\right.$ - janeiro/ 04), ultrapassaram 0 limite estabelecido para rios Classe 2, que é de $0,002 \mathrm{mg} \cdot \mathrm{L}^{-1}$. Porém quando utilizada a concentração estabelecida para rios Classe $3\left(0,3 \mathrm{mg} \cdot \mathrm{L}^{-1}\right)$, observa-se que esse limite não foi ultrapassado em nenhuma estação amostrada durante todo o estudo.

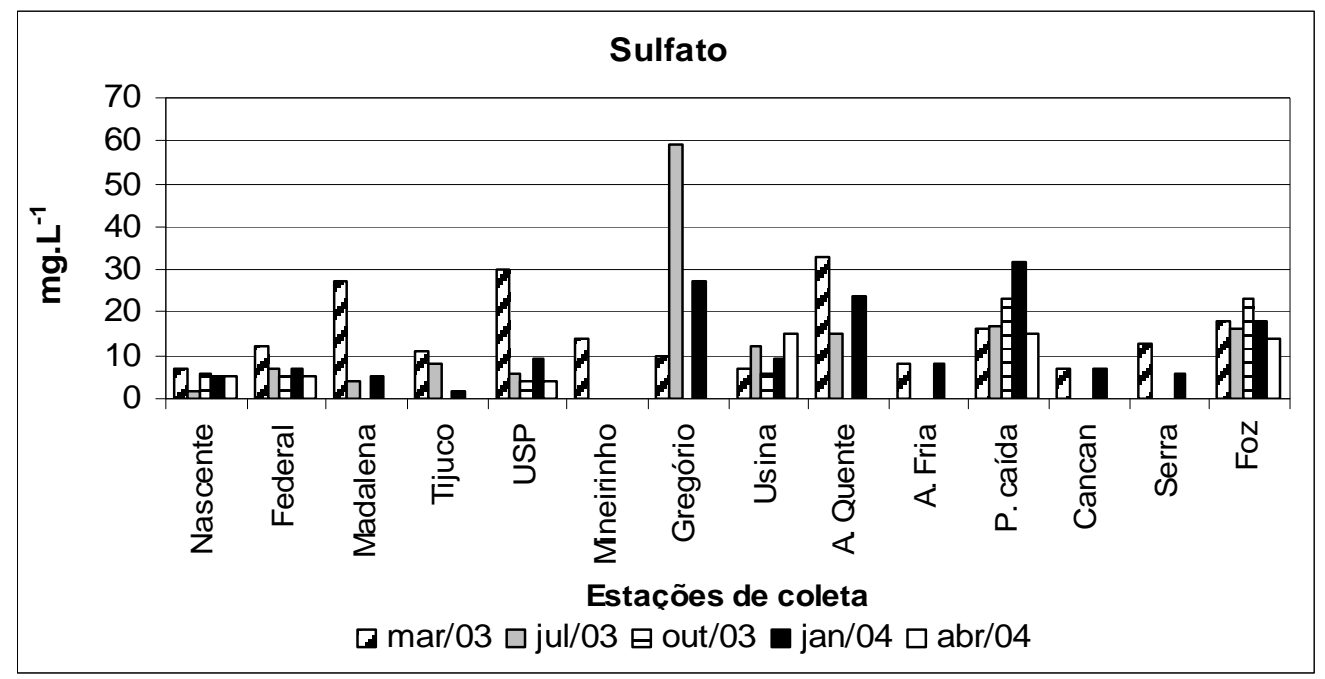

Figura 16. Concentrações (mg. $\left.\mathrm{L}^{-1}\right)$ de sulfatos obtidos no rio Monjolinho e tributários durante 0 período de estudo.

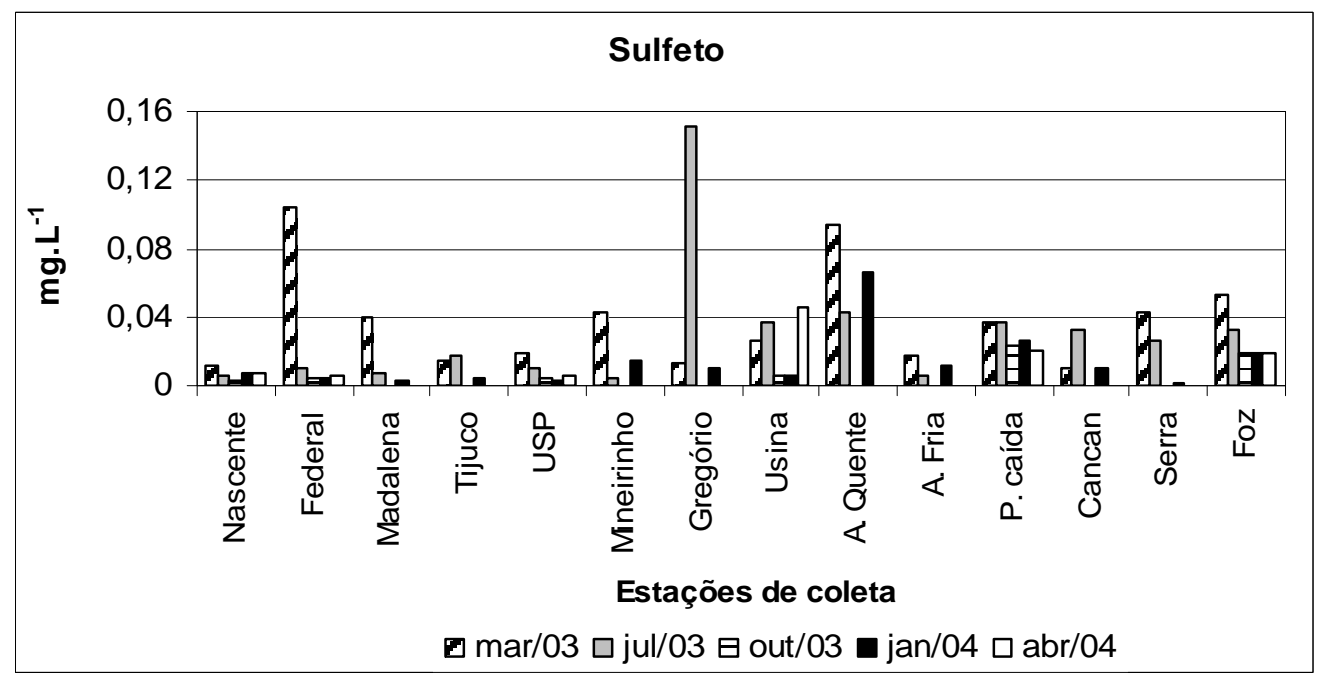

Figura 17. Concentrações (mg. $\mathrm{L}^{-1}$ ) de sulfetos obtidos no rio Monjolinho e tributários durante 0 período de estudo.

\subsection{Demanda Química de Oxigênio (DQO)}

Os resultados da Demanda Química de Oxigênio estão apresentados na Figura 18 (Tabela 14, Apêndice 2), verificando-se que a Nascente apresentou os 
menores valores (entre 0,0 e 1,0 mg. $\mathrm{L}^{-1}$ ) em todo período amostrado, exceto em outubro/ 03, onde foi registrado 9,0 mg.L-1. Em julho/ 03, foi registrado 0,0 mg.L-1 de D Q O , para a Nascente, Federal e Água Fria.

Os maiores valores foram obtidos na Federal (março/ 03 - 40,0 mg.L-1 e janeiro/ 04 - 55,0 mg..-12), Água Quente (julho/ 03 - 53,0 mg.L-12), Ponte caída (outubro/ 03 - 33,0 mg.L.-1) e Foz (abril/ 04 - 28,0 mg.L-1).

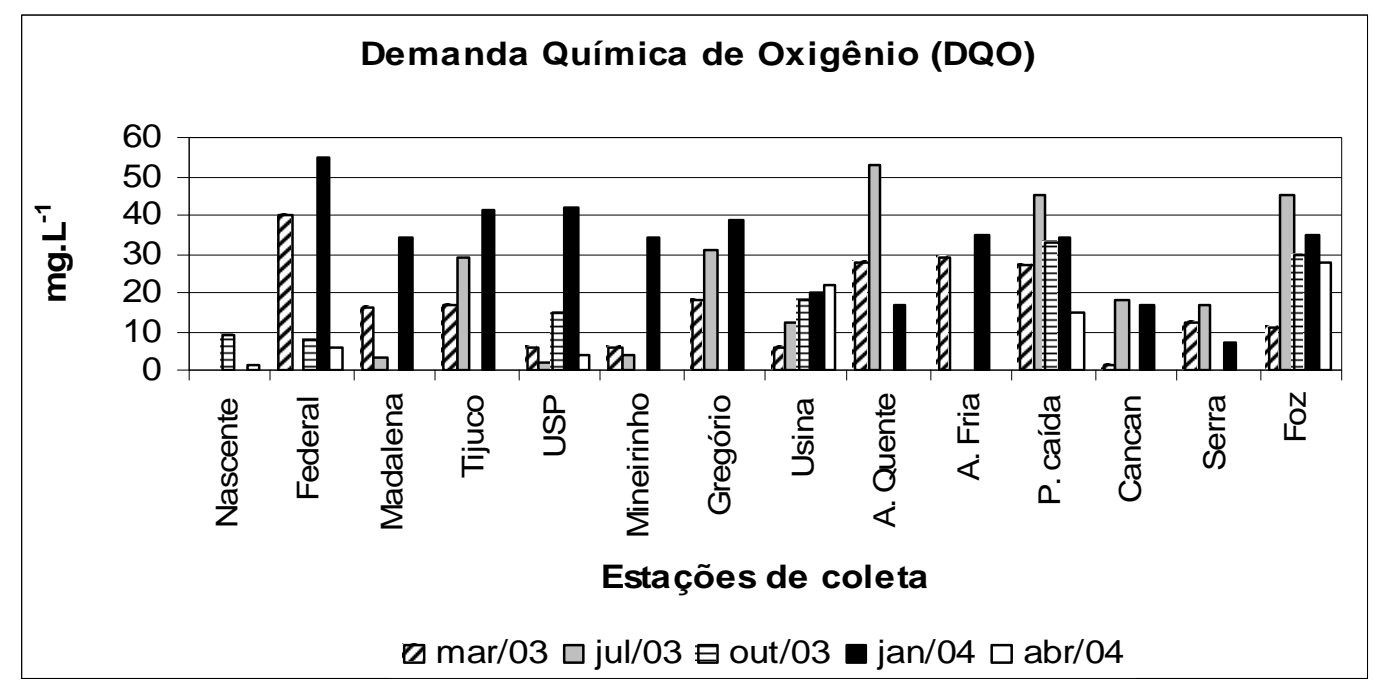

Figura 18. D emanda Química de Oxigênio (mg. $\left.\mathrm{L}^{-1}\right)$ no rio Monjolinho e Tributários durante 0 período de estudo.

\subsection{Demanda Bioquímica de Oxigênio $\left(\mathrm{DBO}_{5}\right)$}

Os resultados da D BO no rio Monjolinho e tributários estão apresentados na Figura 19 e na Tabela 15 (Apêndice 2), observando-se os maiores valores em julho/ 03 e outubro/ 03 e menores em janeiro/ 04 e abril/ 04.

Os maiores valores da DBO foram obtidos na Ponte caída em julho/ 03, outubro/ 03 e abril/ 04, sendo os valores de 28,19; 24,54 e 12,99 mg.L-1, respectivamente. A estação Água Quente apresentou o maior valor da $\mathrm{DBO}_{5} \mathrm{em}$ janeiro/ 04 (16,35 mg.L-1). Os menores valores foram obtidos nas estações Água Fria (12,51 mg.L-1 , julho/ 03), Nascente (14,32 mg.L-1 , outubro/ 03), Serra (0,21 mg.L.-1, janeiro/ 04) e USP (1,98 mg.L.-1, abril/ 04).

Os valores da $\mathrm{DBO}_{5}$ do mês de março/ 03 foram perdidos devido à falta de diluição das amostras, o que ocasionou depleção total do oxigênio após os 5 dias de incubação, impossibilitando a realização do cálculo. 


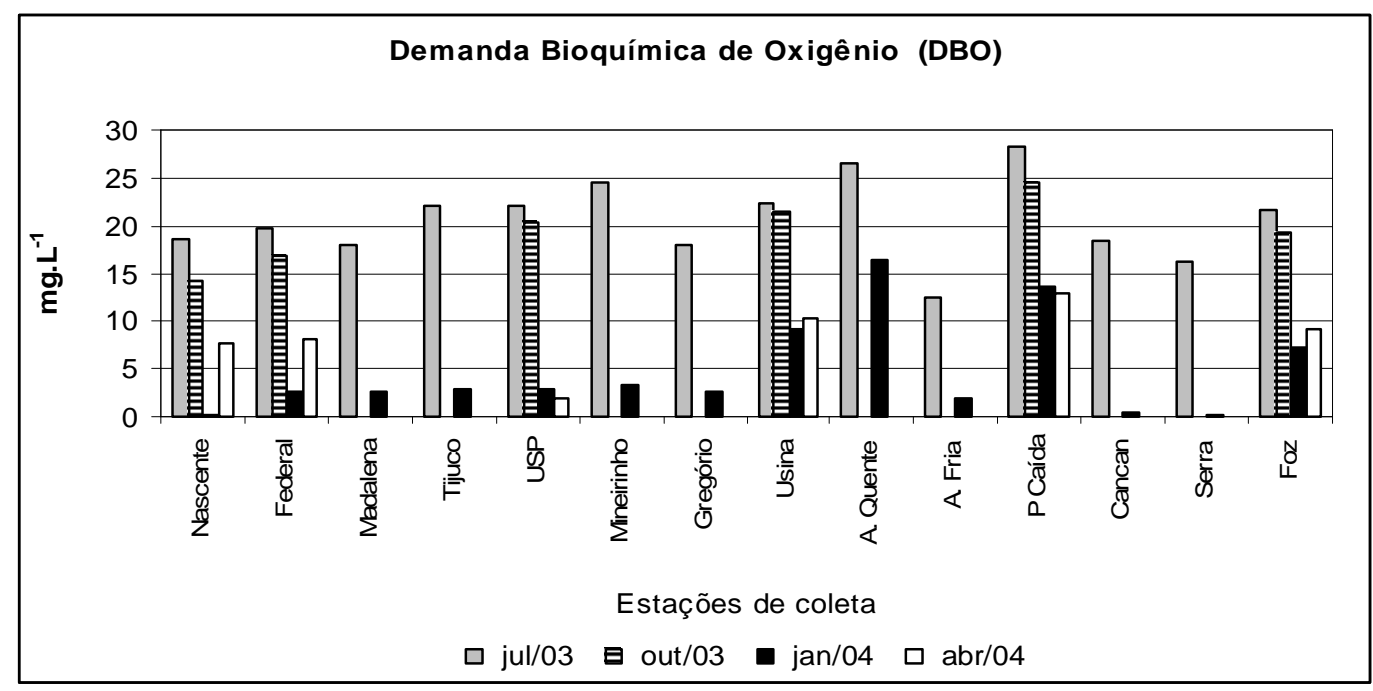

Figura 19. Demanda Bioquímica de Oxigênio $\left(m g \cdot \mathrm{L}^{-1}\right)$, no rio Monjolinho e tributários durante 0 período de estudo.

\subsection{Metais na água}

\subsubsection{Rio Monjolinho}

Foi realizada uma análise, separadamente, dos metais presentes na água das estações do rio Monjolinho e dos tributários com a finalidade de possibilitar uma visão espacial no eixo longitudinal do rio. As concentrações de metais encontradas nos tributários serão apresentadas posteriormente tentando-se associar os efeitos de diluição ou concentração ao longo do sistema.

Observando a Figura 20 e as Tabelas de 16 a 20 (Apêndice 2) , verifica-se as maiores concentrações de $\mathrm{Cr}$, $\mathrm{Cd}$ e $\mathrm{Cu}$ em março e julho de 2003, quando comparado aos demais meses amostrados.

O bserva-se, também, que nenhuma estação apresentou valores de $\mathrm{Cr}$ acima da concentração limite estabelecida pela CONAMA 357/ 05, que é de $50 \mu \mathrm{g} \cdot \mathrm{L}^{-1}$, sendo a concentração máxima observada de 22,40 $\mu \mathrm{g} . \mathrm{L}^{-1}$ (Nascente, março/ 03). A análise de $\mathrm{Cd}$ não foi realizada em março/ 03, porém foi realizada nos demais meses amostrados. Observou-se concentração máxima de 4,00 $\mu \mathrm{g} \cdot \mathrm{L}^{-1}$ (Foz, julho/03) e algumas estações de amostragem (25\%) apresentaram valores acima do limite estabelecido pela CONAMA 357/ 05 que é de 1,00 $\mu$ g.L.- ${ }^{-1}$ (Federal, USP, Usina e 
Foz - julho/ 03 e Ponte caída e Foz - janeiro/ 04). Em relação ao Cu, observa-se que a concentração máxima foi de 29,60 $\mu \mathrm{g} \cdot \mathrm{L}^{-1}$ (Foz - julho/ 03) e que quatro estações de amostragem (14\%) apresentaram concentrações superiores ao estabelecido pela CONAMA 20/ 86, que é $20 \mu$ g.L.-1 (Federal - março/ 03 e Usina, Ponte caída e Foz julho/ 03). A Resolução CONAMA 357/ 05 estabelece somente a concentração de Cu dissolvido $\left(9,0 \mu g \cdot L^{-1}\right)$.
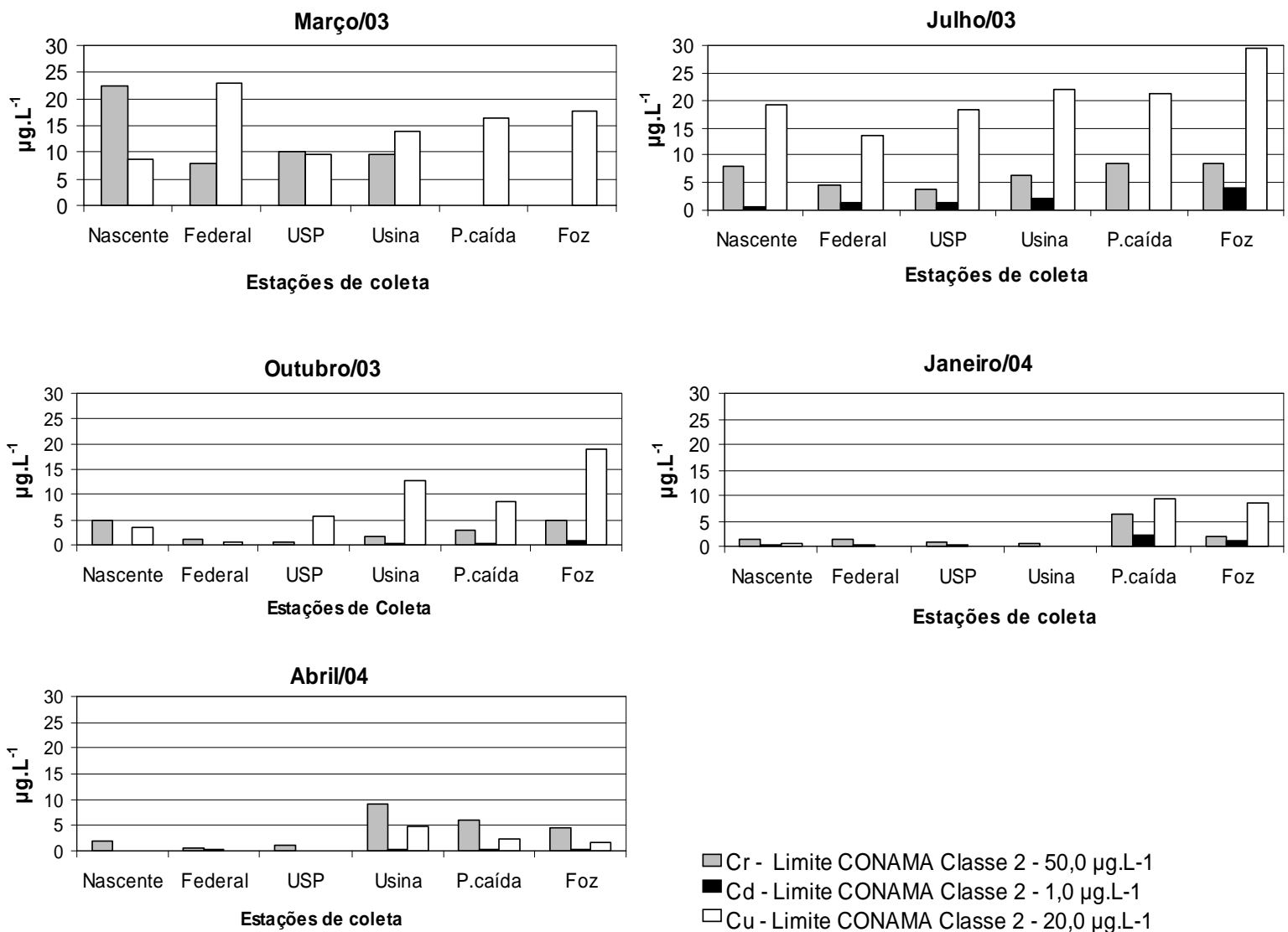

$\square \mathrm{Cr}$ - Limite CONAMA Classe 2 - 50,0 $\mu \mathrm{g} . \mathrm{L}-1$
$\mathbf{C d}^{\mathrm{C}}$ - Limite CONAMA Classe 2 - 1,0 $\mu \mathrm{g} . \mathrm{L}-1$
$\square \mathrm{Cu}$ - Limite CONAMA Classe 2 - 20,0 $\mu \mathrm{g} . \mathrm{L}-1$

Figura 20. Concentrações de cromo, cádmio e cobre ( $\left.\mu g . L^{-1}\right)$ obtidas nas águas das estações de coleta do rio Monjolinho durante o período de estudo.

As concentrações de $\mathrm{Zn}\left(\mu \mathrm{g} \cdot \mathrm{L}^{-1}\right)$, Mn ( $\left.\mu \mathrm{g} \cdot \mathrm{L}^{-1}\right)$ e Fe $\left(\mathrm{mg} \cdot \mathrm{L}^{-1}\right)$ podem ser observadas na Figura 21, notando-se que, em geral, existe um acréscimo nas concentrações desses metais no eixo longitudinal do rio, isto é, da nascente em direção à foz. 

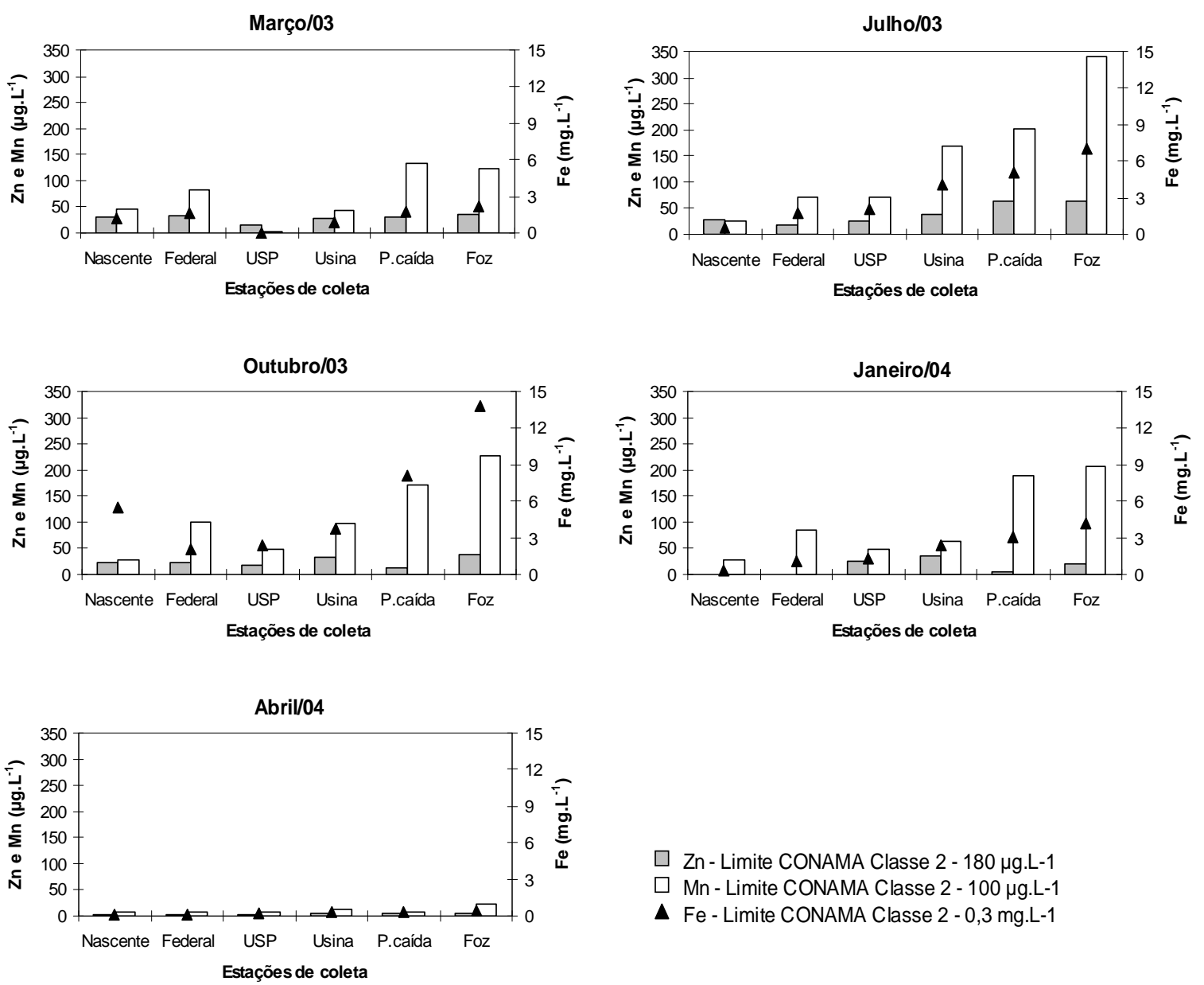

$\square$ Zn - Limite CONAMA Classe 2 - $180 \mu \mathrm{g} . \mathrm{L}-1$

$\square \mathrm{Mn}$ - Limite CONAMA Classe 2 - $100 \mu \mathrm{g}$.L-1

$\Delta$ Fe - Limite CONAMA Classe 2 - 0,3 mg.L-1

Figura 21. Concentrações de zinco e manganês ( $\left.\mu g . L^{-1}\right)$ e ferro $\left(m g \cdot L^{-1}\right)$ obtidas nas águas das estações de coleta do rio Monjolinho durante o período de estudo.

Pode-se perceber que as concentrações de Fe foram maiores, especialmente em julho/ 03 e outubro/ 03, sendo a maior concentração observada na estação Foz, em outubro/ 03 (13,81 mg.L-1). Em 86\% das estações, as concentrações de Fe foram superiores ao limite estabelecido pela CONAMA 357/ 05 para águas Classe 2, que é de 0,30 mg. $\mathrm{L}^{-1}$, excetuando-se as estações USP (março/ 03) e Nascente, Federal e USP (abril/ 04). Em relação ao Zn, verificou-se que nenhuma estação de amostragem ultrapassou o limite estabelecido pela resolução CONAMA 20/ 86 para rios Classe 2, que é de $180 \mu \mathrm{g} \cdot \mathrm{L}^{-1}$, sendo que a maior concentração observada foi de 64,00 $\mu g . L^{-1}$ na Ponte caída em julho/03. Para 0 Mn, a concentração máxima observada foi de $340 \mu \mathrm{g} \cdot \mathrm{L}^{-1}$ (Foz - julho/03) e cerca de 30\% das estações apresentaram concentrações superiores ao limite estabelecido pelo CONAMA 
357/ 05, que é de $100 \mu$ g.L-1 (Ponte caída e Foz - março/ 03; Usina, Ponte caída e Foz - julho/ 03; Ponte caída e Foz - outubro/ 03 e janeiro/ 04).

\subsubsection{Tributários do rio Monjolinho}

Na Figura 22, bem como nas Tabelas de 16 a 20 (Apêndice 2), podem ser observadas as concentrações de $\mathrm{Cr}$, Cd e Cu em março e julho de 2003 e em janeiro de 2004. A análise de Cd não foi realizada em março/ 03 e, para os demais meses, as menores concentrações foram observadas para esse metal, quando comparado com $\mathrm{Cr}$ e $\mathrm{Cu}$ (concentração máxima de 4,24 $\mu \mathrm{g} \cdot \mathrm{L}^{-1}$ e mínima de $0,00 \mu \mathrm{g} \cdot \mathrm{L}^{-1}$ ). Verificou-se que $44 \%$ das estações apresentaram valores superiores ao estabelecido pela CONAMA 357/ 05 (1,00 $\left.\mu g . L^{-1}\right)$, como os córregos Madalena, Gregório, Cancan e Serra em julho/ 03 e Água Q uente, Água Fria e Cancan, em janeiro/ 04.

Em relação ao $\mathrm{Cr}$, observa-se que apenas uma estação de coleta (Madalena março/ 03, 58,00 $\mu \mathrm{g} \cdot \mathrm{L}^{-1}$ ) apresentou valor superior ao limite estabelecido pela CONAMA 357/05. As concentrações variaram de 0 a 58,00 $\mu \mathrm{g} \cdot \mathrm{L}^{-1}$, com concentração média de 5,64 $\mu \mathrm{g} \cdot \mathrm{L}^{-1}$.

As concentrações de $\mathrm{Cu}$ variaram de 0 a 32,00 $\mu \mathrm{g} \cdot \mathrm{L}^{-1}$, com 0 valor máximo observado no córrego do Gregório (julho/ 03). Verificou-se que 17\% das estações amostradas apresentaram valores superiores ao limite estabelecido pela CONAMA 20/ 86, como os córregos Madalena (março/ 03) e Gregório, Água Quente e Serra (julho/ 03). 

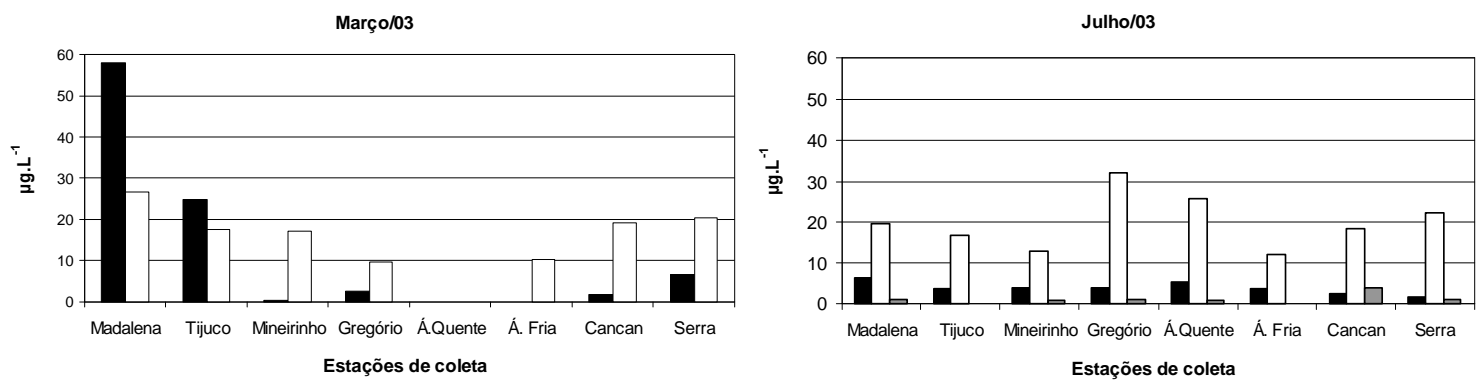

Estações de coleta

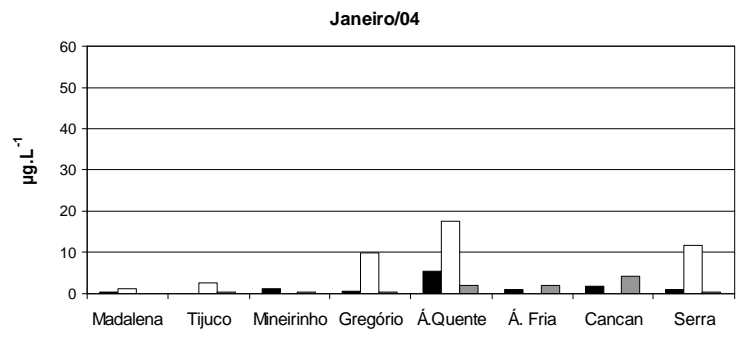

Estações de coleta

- Cr - Limite CONAMA Classe 2 - 50,0 $\mu$ g.L-1

C Cu - Limite CONAMA Classe 2 - 20,0 $\mu \mathrm{g} \cdot \mathrm{L}-1$

Cd - Limite CONAMA Classe 2 - 1,0 $\mu \mathrm{g} . \mathrm{L}-1$

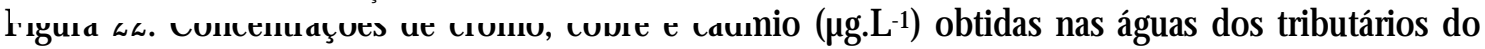
rio Monjolinho durante o período de estudo.

Na Figura 23 (e também nas Tabelas de 16 a 20, Apêndice 2) pode-se observar as concentrações de Zn ( $\left.\mu \mathrm{g} \cdot \mathrm{L}^{-1}\right)$, Mn ( $\left.\mu \mathrm{g} \cdot \mathrm{L}^{-1}\right)$ e Fe (mg.L-1). Verifica-se que 90\% das estações amostradas apresentaram concentrações de Fe acima do permitido pela CONAMA 357/ 05 (0,3 mg.L-1), sendo que a concentração máxima obtida foi de 8,5 mg.L-1 (Água Quente, julho/ 03) e a mínima de 0,001 mg.L-1 (Água Fria, março/ 03). As concentrações médias para os meses de março/ 03, julho/03 e janeiro/ 04 foram de 1,64; 2,97 e 1,78 mg.L-1-1 respectivamente.

As concentrações obtidas para Zn estiveram sempre abaixo do limite determinado pela CONAMA 357/ 05, que é de 180,0 $\mu \mathrm{g} \cdot \mathrm{L}^{-1}$. A concentração mínima foi de $0 \mathrm{mg} \cdot \mathrm{L}^{-1}$ (Madalena e Tijuco, janeiro/ 04) e a máxima foi de 97,8 $\mu \mathrm{g} \cdot \mathrm{L}^{-1}$ (Gregório, janeiro/ 04). Observaram-se concentrações médias de 23,9; 34,9 e 19,1 $\mu \mathrm{g} . \mathrm{L}^{-1}$, para os meses de março/ 03, julho/ 03 e janeiro/ 04, respectivamente.

Em relação ao Mn, observou-se que 30\% das estações amostradas apresentaram concentrações acima do estabelecido pela resolução CONAMA 357/ 05, que é de $100 \mu \mathrm{g} \cdot \mathrm{L}^{-1}$, sendo a concentração máxima de 400,0 $\mu \mathrm{g} \cdot \mathrm{L}^{-1}$ (Água Quente, julho/ 03) e mínima de 5,2 $\mu \mathrm{g} \cdot \mathrm{L}^{-1}$ (Água Fria, março/ 03). As concentrações médias foram 49,9; 139,1 e 92,2 $\mu g . \mathrm{L}^{-1}$ para os meses de março/ 03, julho/ 03 e janeiro/ 04, respectivamente. 


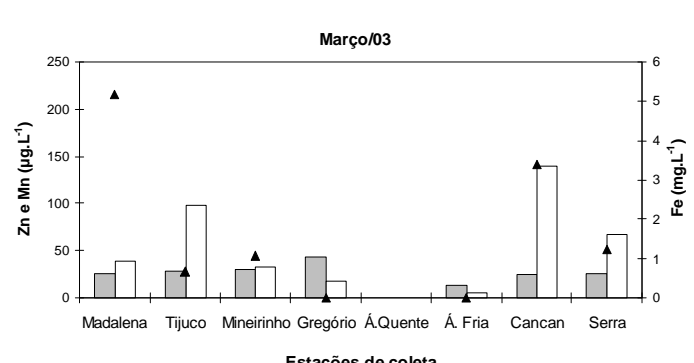

Estaçōes de coleta

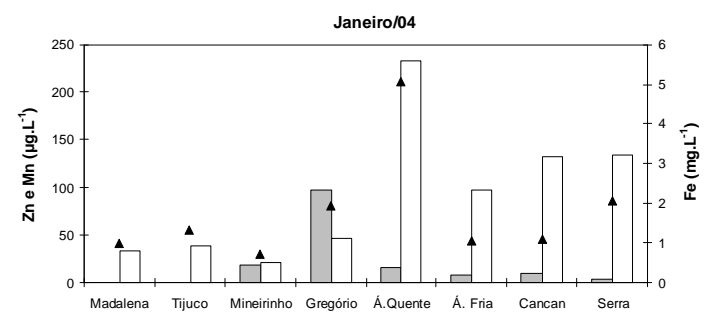

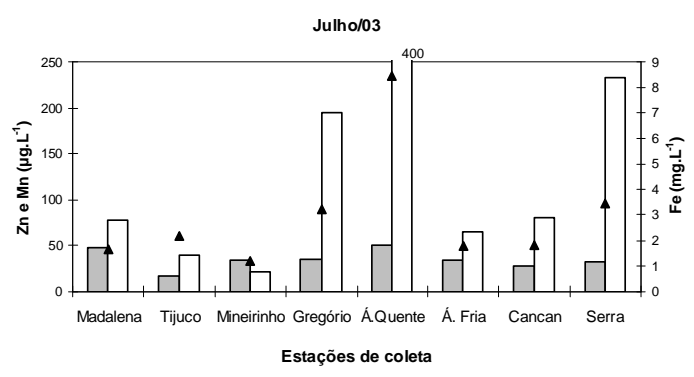

Zn - Limite CONAMA Classe 2 - $180 \mu \mathrm{gg} . \mathrm{L}-1$ Mn-Limite CONAMA Classe 2 - $100 \mu \mathrm{\mu g} . \mathrm{L}-1$

Figura 23. Concentrações de zinco e manganês $\left(\mu \mathrm{g} \cdot \mathrm{L}^{-1}\right)$ e ferro (mg.L $\left.\mathrm{L}^{-1}\right)$ nas águas dos tributários do rio Monjolinho durante o período estudado.

$\mathrm{Na}$ Tabela 21 apresenta-se um resumo das concentrações de metais. Observa-se que a Nascente e o Mineirinho são as estações com as menores concentrações, enquanto que as maiores foram obtidas na Foz e na estação do córrego Água Quente.

Tabela 21. Resumo das concentrações de metais totais na água do rio Monjolinho e seus tributários durante o período estudado.

\begin{tabular}{|c|c|c|c|}
\hline \multicolumn{2}{|c|}{ Peńodo e corpo hídrico } & Menores concentrações & Maiores concentrações \\
\hline Março/ 03 & $\begin{array}{c}\text { nio } \\
\text { tributánio }\end{array}$ & $\begin{array}{c}\text { USP } \\
\text { Água Fria }\end{array}$ & $\begin{array}{c}\text { Foz } \\
\text { Madalena }\end{array}$ \\
\hline Julho/ 03 & $\begin{array}{c}\text { nio } \\
\text { tributánio }\end{array}$ & $\begin{array}{c}\text { Nascente } \\
\text { Mineirinho }\end{array}$ & $\begin{array}{c}\text { Foz } \\
\text { Água Quente }\end{array}$ \\
\hline Outubro/ 03 & $\begin{array}{c}\text { nio } \\
\text { tributánio }\end{array}$ & $\begin{array}{c}\text { Foz } \\
\text { não coletado }\end{array}$ & $\begin{array}{c}\text { Federal } \\
\text { não coletado }\end{array}$ \\
\hline Janeiro/ 04 & $\begin{array}{c}\text { nio } \\
\text { tributánio }\end{array}$ & $\begin{array}{l}\text { Nascente/ Usina } \\
\text { Mineirinho }\end{array}$ & $\begin{array}{c}\text { Ponte caída } \\
\text { Água Quente }\end{array}$ \\
\hline Abril/ 04 & $\begin{array}{c}\text { nio } \\
\text { tributánio }\end{array}$ & $\begin{array}{c}\text { USP } \\
\text { não coletado }\end{array}$ & $\begin{array}{c}\text { Usina } \\
\text { não coletado }\end{array}$ \\
\hline
\end{tabular}

\subsection{Agrotóxicos organoclorados na água}

Os resultados dos agrotóxicos organoclorados estão apresentados na Tabela 22. Pode-se observar que Aldrin esteve fora dos valores estabelecidos pela resolução CONAMA 357/ 05, bem como pela Portaria 518/ 04 (Brasil, 2004), em quase todas as estações nas quais foi possível detectá-lo, sendo a mesma situação observada para 
o Heptachlor. No caso do Endosulfan, as concentrações foram inferiores ao estabelecidos na legislação citada, exceto na estação USP em janeiro/04, que apresentou valor acima do estabelecido na CONAMA 357/ $05\left(0,113 \mu \mathrm{g} \cdot \mathrm{L}^{-1}\right)$.

Tabela 22. Concentrações de agrotóxicos organoclorados (ug.L-1) obtidos nas amostras de água do rio Monjolinho e tributários localizados na imediações da Usina da Serra.

\begin{tabular}{|c|c|c|c|c|c|c|}
\hline \multirow{4}{*}{$\begin{array}{l}\text { Pontos de } \\
\text { coleta }\end{array}$} & \multicolumn{2}{|c|}{ Aldrin (jg.L. $\left.{ }^{-1}\right)$} & \multicolumn{2}{|c|}{ Endosulfan sulfato ( $\left.\mu \mathrm{g} \cdot \mathrm{L}^{-1}\right)$} & \multicolumn{2}{|c|}{ Heptachlor ( $\left.\mu g . L^{-1}\right)$} \\
\hline & \multirow{2}{*}{\multicolumn{2}{|c|}{$\begin{array}{c}\text { CONAMA 357/ } 05-0,01 \\
\text { Portaria 518/ } 04-0,03\end{array}$}} & \multirow{2}{*}{\multicolumn{2}{|c|}{$\begin{array}{c}\text { CONAMA 357/ } 05 \text { - 0,056 } \\
\text { Portania 518/ } 04 \text { - 20,0 }\end{array}$}} & \multirow{2}{*}{\multicolumn{2}{|c|}{$\begin{array}{c}\text { CONAMA 357/ } 05 \text { - 0,01 } \\
\text { Portania 518/ } 04 \text { - 0,03 }\end{array}$}} \\
\hline & & & & & & \\
\hline & jul/ 03 & jan/ 04 & jul/ 03 & jan/ 04 & jul/ 03 & jan/ 04 \\
\hline Nascente & nd & 0,147 & $<\mathrm{LD}$ & nd & $<\mathrm{LD}$ & 0,148 \\
\hline \multirow{3}{*}{ USP } & 0,087 & nd & nd & 0,012 & 0,098 & nd \\
\hline & frasco & & frasco & & frasco & \\
\hline & quebrou & 0,621 & quebrou & 0,113 & quebrou & nd \\
\hline Usina & 0,113 & 0,154 & nd & 0,014 & 0,381 & nd \\
\hline Ponte caída & nd & 0,003 & nd & nd & nd & nd \\
\hline Cancan* & 0,078 & nd & 0,015 & nd & nd & nd \\
\hline Senra* & $<\mathrm{ld}$ & nd & nd & 0,022 & nd & nd \\
\hline & nd & nd & nd & F. & 0,062 & 0,027 \\
\hline
\end{tabular}

nd - não detectado; <ld - abaixo do limite detectado pelo método utilizado; * Tributários localizados em área de influência da monocultura de cana de açúcar.

\subsection{Clonofila a}

Os resultados referentes às concentrações de Clorofila-a no rio Monjolinho e tributários estão apresentados na Figura 24 e Tabela 23 (Apêndice 2), na qual podese observar que a Nascente apresentou, em geral, as menores concentrações durante o período de estudo, com valores de $0,0 \mu \mathrm{g} \cdot \mathrm{L}^{-1}$ (julho/ 03), 2,79 $\mu \mathrm{g} \cdot \mathrm{L}^{-1}$ (outubro/ 03) e 0,93 $\mu \mathrm{g} \cdot \mathrm{L}^{-1}$ (abril/ 04). Em março/ 03 a menor concentração foi registrada no Cancan (1,74 $\left.\mu g . L^{-1}\right)$ e em janeiro/ 04 na USP $\left(0,0 \mu g . L^{-1}\right)$. As maiores concentrações foram registradas na Federal, em julho/ 03 (85,0 $\left.\mu \mathrm{g} . \mathrm{L}^{-1}\right)$ e no Tijuco e Gregório, em janeiro/ 04 (65,5 e 42,3 $\mu g . L^{-1}$, respectivamente). 


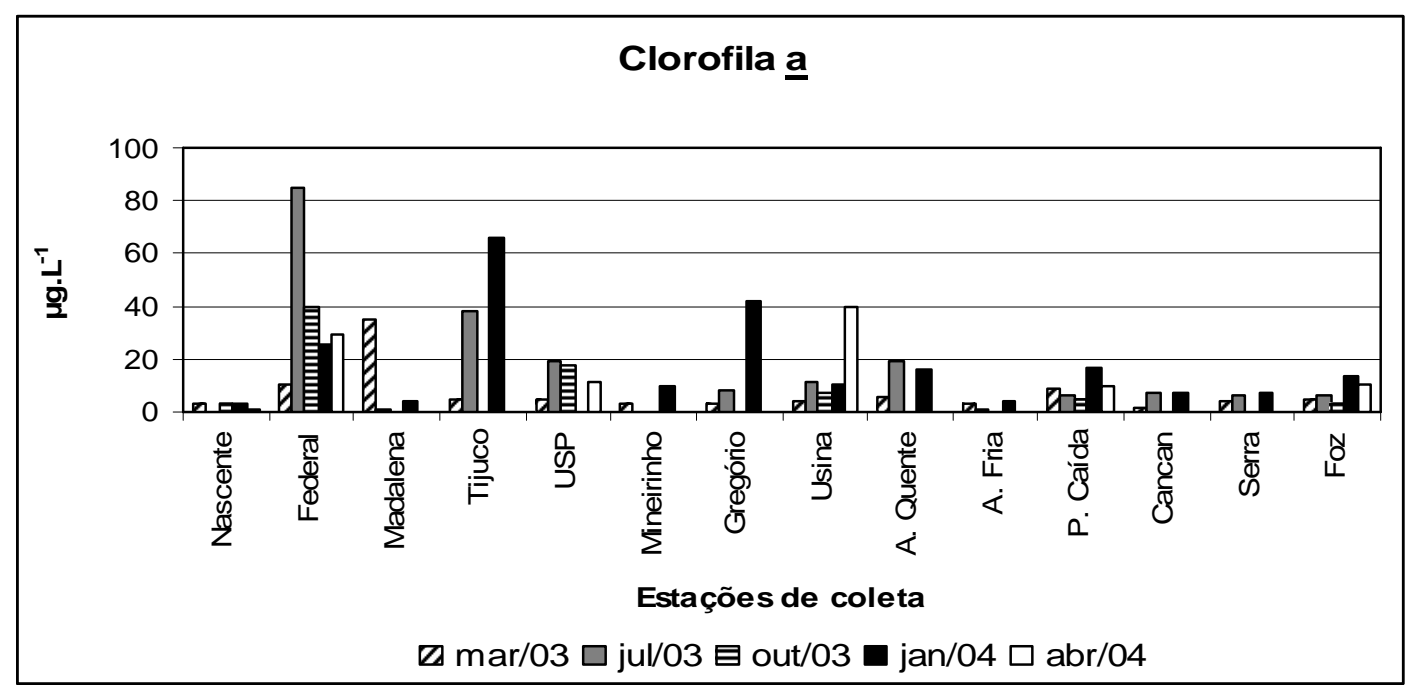

Figura 24. Concentrações de Clorofila-ạ ( $\left.\mu g . L^{-1}\right)$ no rio Monjolinho e tributários durante o período de estudo.

\subsection{Coliformes}

Os resultados das análises de coliformes totais e fecais nas estações de coleta estão apresentadas na Tabela 24, podendo-se observar os maiores valores de coliformes totais no Tijuco (março/ 03 e julho/ 03), Água Quente (março/ 03), Ponte caída (março/ 03, outubro/ 03), G regório (janeiro/ 04) e Usina (abril/ 04). Os maiores valores de coliformes fecais foram registrados na Água Q uente (março/ 03), Tijuco (julho/ 03), Usina (outubro/ 03) e Ponte caída (janeiro/ 04 e abril/ 04).

No córrego Tijuco, foram registrados os maiores valores de coliformes totais e fecais, sendo de 86.640.000 NMP e 3.790.000 NMP, respectivamente, ambos em julho/ 03.

Os valores mínimos de coliformes totais foram registrados no Cancan (março/ 03), Nascente (julho/ 03, janeiro/ 04 e abril/ 04) e USP (outubro/ 03). Em relação aos coliformes fecais, observou-se valores mínimos na estação Serra (março/ 03 e julho/ 03), Nascente (outubro/ 03 e abril/ 04) e Água Fria (janeiro/ 03).

Os menores valores de coliformes totais e fecais foram de 2.224 NMP (Cancan) e de 30,5 NMP (Serra), respectivamente, ambos em março/ 03. 
Tabela 24. Coliformes fecais e totais no rio Monjolinho e tributários durante o período de estudo.

\begin{tabular}{|l|c|c|c|c|c|c|c|c|c|c|}
\hline $\begin{array}{l}\text { Pontos } \\
\text { coleta }\end{array}$ & \multicolumn{2}{|c|}{$\mathbf{m a r} \mathbf{0 3}$} & \multicolumn{2}{c|}{ jul/ 03 } & \multicolumn{2}{c|}{ jut/ 03 jan/ 04 } & \multicolumn{3}{c|}{ abr/ 04 } \\
\hline & Totais & Fecais & Totais & Fecais & Totais & Fecais & Totais & Fecais & Totais & Fecais \\
\hline Nascente & 141.136 & $1.906,28$ & $\mathbf{1 3 . 7 4 0}$ & 648,8 & $>2.419,2$ & $\mathbf{7 3 , 3}$ & $\mathbf{1 3 . 1 3 0}$ & 143,9 & $\mathbf{1 1 . 0 0 0}$ & $\mathbf{4 9 , 4}$ \\
\hline Federal & 141.136 & 8.010 & 198.628 & 2.560 & 129.965 & 2.090 & 173.287 & 1.630 & 83.600 & 71.200 \\
\hline Madalena & $>241.920$ & 41.600 & 1.299 .650 & 12.230 & - & - & 29.240 & 1.580 & & \\
\hline Tijuc0 & $>2.419 .200$ & 1.413 .600 & 86.640 .000 & 3.790 .000 & - & - & 689.300 & 32.400 & & \\
\hline USP & 85.200 & $>2.419,2$ & 1.046 .240 & 32.700 & $\mathbf{3 4 . 3 6 0}$ & 4.220 & 198.628 & 17.790 & 163.100 & 145.000 \\
\hline Mineirinho & 81.640 & 4.140 & 1.119 .850 & 33.100 & - & - & 104.624 & 18.600 & & \\
\hline Gregório & 517.200 & 86.200 & 1.986 .280 & 260.200 & - & - & 1.986 .250 & 39.300 & & \\
\hline Usina & 2.419 .170 & 260.200 & 2.400 .000 & 74.000 & 231.000 & $>100.000$ & 184.700 & 4.100 & 1.413 .600 & 163.100 \\
\hline A. Quente & $>2.419 .200$ & $>2.419 .200$ & 5.475 .000 & 285.000 & - & - & 1.732 .870 & 163.800 & & \\
\hline A. Fria & 25.950 & 196,8 & 13.710 & 137 & - & - & 15.760 & $\mathbf{1 0 7 , 1}$ & & \\
\hline P. Caída & $>2.419 .200$ & 1.732 .870 & 19.862 .800 & 100.000 & 3.076 .000 & 121.000 & 223.000 & 488.400 & 387.300 & 318.000 \\
\hline Cancan & $\mathbf{2 . 2 2 4}$ & 91,1 & 104.624 & 100 & - & - & 38.730 & $1.046,24$ & & \\
\hline Serra & 18.720 & $\mathbf{3 6 , 8}$ & 111.985 & $\mathbf{3 0 , 5}$ & - & - & 22.540 & 2.280 & & \\
\hline Foz & 2.419 .170 & 74.800 & 4.160 .000 & 20.000 & 1.281 .000 & $>10.000$ & 686.700 & 50.400 & 441.000 & 59.100 \\
\hline
\end{tabular}

- células em cinza = valores máximos; em negrito = valores mínimos; - não coletado

\subsection{Potencial Hidrogeniônico - pH}

Os valores do $\mathrm{pH}$ obtidos no rio Monjolinho e em seus tributários estão apresentados na Figura 25 (Tabela 25, Apêndice 2), onde pode-se verificar o valor máximo de 7,70 (Tijuco, janeiro/ 04) e o mínimo de 4,17 (Madalena, março/ 03). Verifica-se, também, que entre as estações, foi na Nascente (julho/ 03, outubro/ 03, janeiro/ 04 e abril/ 04) e no Madalena (março/ 03) que se encontraram os menores valores, sendo que os valores máximos variaram entre os meses amostrados, principalmente nas estações Água Fria (março/ 03 e julho/ 03), Usina (outubro/ 03), Tijuco (janeiro/ 04) e Ponte caída (abril/ 04).

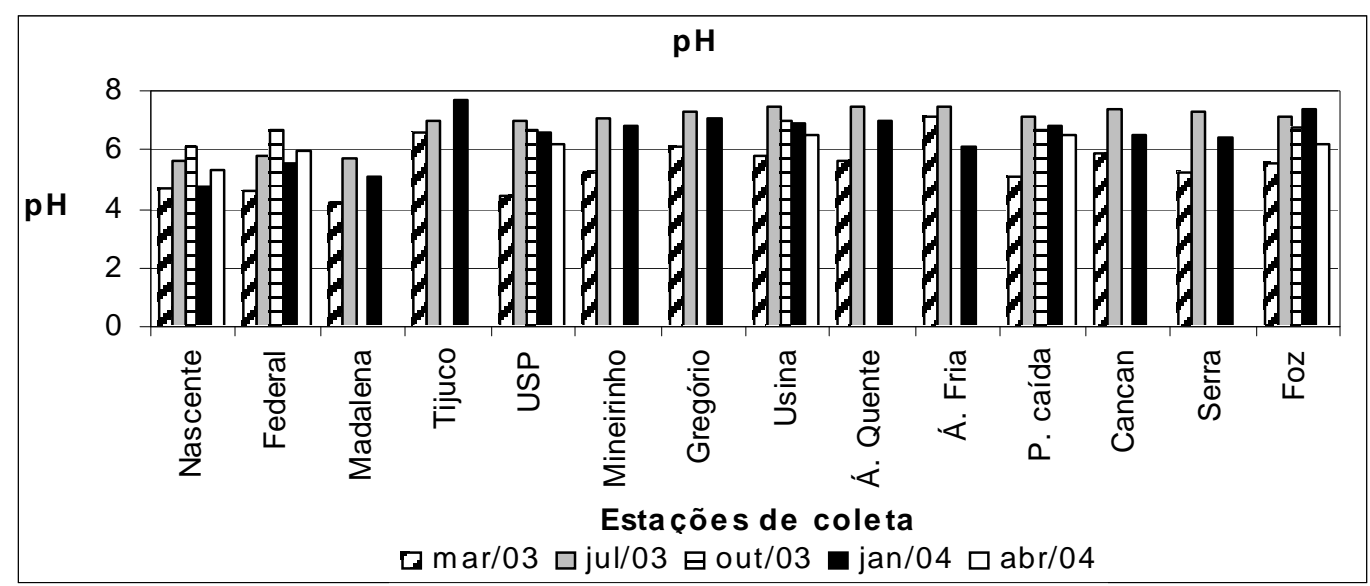

Figura 25. Variação dos valores de pH no rio Monjolinho e tributários durante o período de estudo. 


\subsection{Condutividade elétrica}

O s valores da condutividade elétrica da água estão apresentados na Figura 26 e na Tabela 26 (Apêndice 2), observando-se os menores valores para a Nascente em todo período amostrado, exceto em março/ 03 (Madalena, $18 \mu \mathrm{S} . \mathrm{cm}^{-1}$ ). Os valores máximos encontrados variaram entre as estações durante o período amostrado, com maiores valores na Ponte caída (março/ 03, $392 \mu \mathrm{S} . \mathrm{cm}^{-1}$ ), G regório (julho/ 03 e janeiro/ 04, 290 e $229 \mu \mathrm{S} . \mathrm{cm}^{-1}$, respectivamente) e Foz (outubro/ 03 e abril/ 04, 168 e $116 \mu \mathrm{S} . \mathrm{cm}^{-1}$, respectivamente).

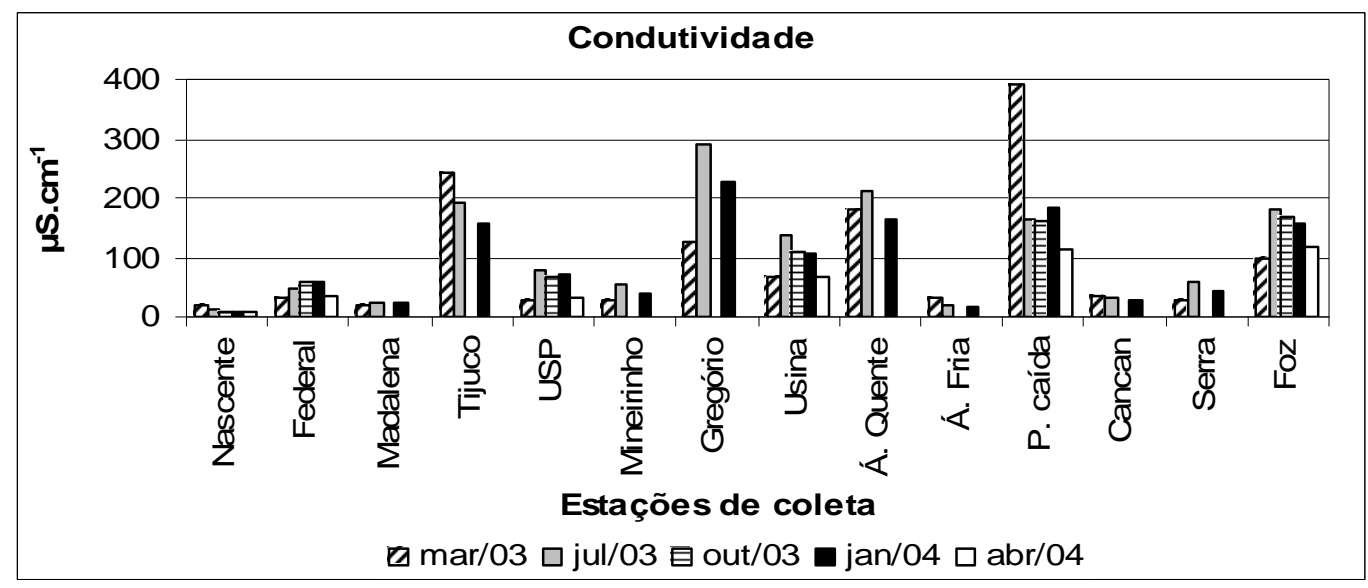

Figura 26. Variação dos valores de condutividade elétrica $\left(\mu \mathrm{S} . \mathrm{cm}^{-1}\right)$ no rio Monjolinho e tributários durante o período de estudo.

\subsection{Temperatura da água}

Pelos valores da temperatura da água (Figura 27 e Tabela 27, Apêndice 2) verifica-se uma variação temporal bem definida, com valor mínimo de $17,5{ }^{\circ} \mathrm{C}$ (julho/ 03, Madalena) e máximo de $25,2{ }^{\circ} \mathrm{C}$ (janeiro/ 04, Federal). D eve-se salientar que as diferentes temperaturas encontradas nas estações de coleta em um mesmo mês de amostragem podem ser atribuídas ao horário de coleta, bem como da região de entorno da estação, como no caso da Nascente, que possui um trecho de mata ciliar na região selecionada. 


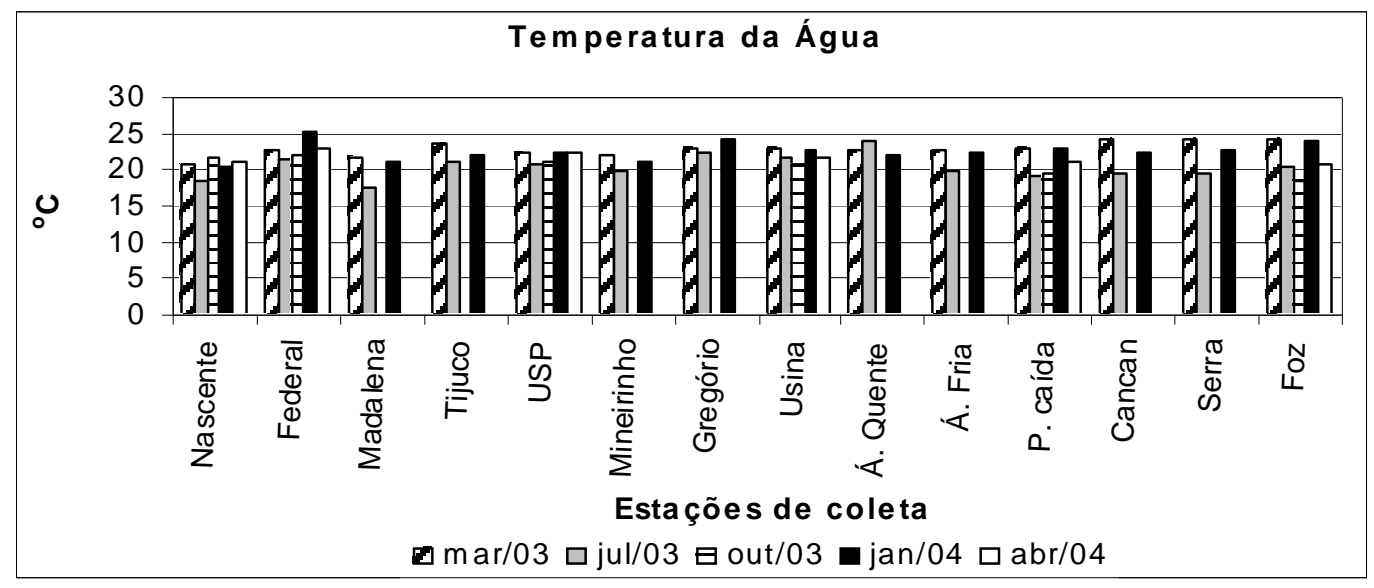

Figura 27. Variação dos valores de temperatura da água $\left({ }^{\circ} \mathrm{C}\right)$ no rio Monjolinho e tributários durante o período de estudo.

\subsection{Oxigênio dissolvido}

As concentrações de oxigênio dissolvido (OD) variaram de 1,56 mg. $\mathrm{L}^{-1}$ (Ponte caída, janeiro/ 04) a 17,18 mg.L-1 (Serra, julho/ 03). Na Figura 28 (Tabela 28, Apêndice 2), observa-se que na estação Ponte caída foram obtidos os menores valores de oxigênio dissolvido, enquanto os maiores ocorreram nos tributários Cancan e Serra.

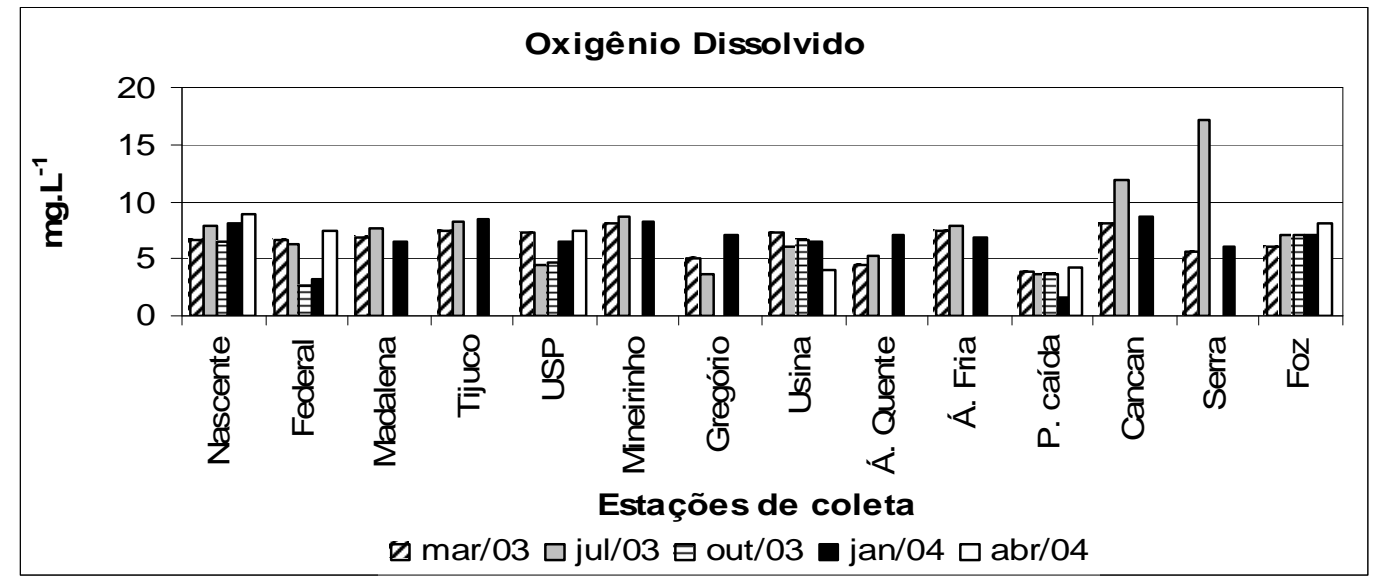

Figura 28. Variação da concentração de oxigênio dissolvido (mg.L-1) no rio Monjolinho e tributários durante o período de estudo. 


\subsection{Matéria ongânica, fósforo total e nitrogênio orgânico total no sedimento}

Os resultados de matéria orgânica (MO), fósforo total (PT) e nitrogênio orgânico total (NOT) estão apresentados nas Figuras 29, 30 e 31 e nas Tabelas 29, 30 e 31 (Apêndice 2).

Em março/ 03 a coleta referente à estação Nascente foi realizada na área alagada e não na fase rio, como foi decidido posteriormente, por ser mais representativo do sistema. Portanto, quando se compara os valores de MO, PT e NOT, verifica-se que houve grande diferença nas concentrações devido à essa diferença espacial, com os valores superiores ocorrendo em março/03 quando comparados com os demais meses amostrados.

Em geral, o sedimento do sistema estudado é caracterizado como inorgânico, segundo ESTEVES (1988), exceto para a estação Ponte Caída, em março/ 03, com valor superior a 10\% de matéria orgânica (10,75\%).

Os resultados da porcentagem de MO no sedimento variaram de 0,06\% (USP, outubro/ 03) a 10,75\% (Ponte caída, março/ 03).

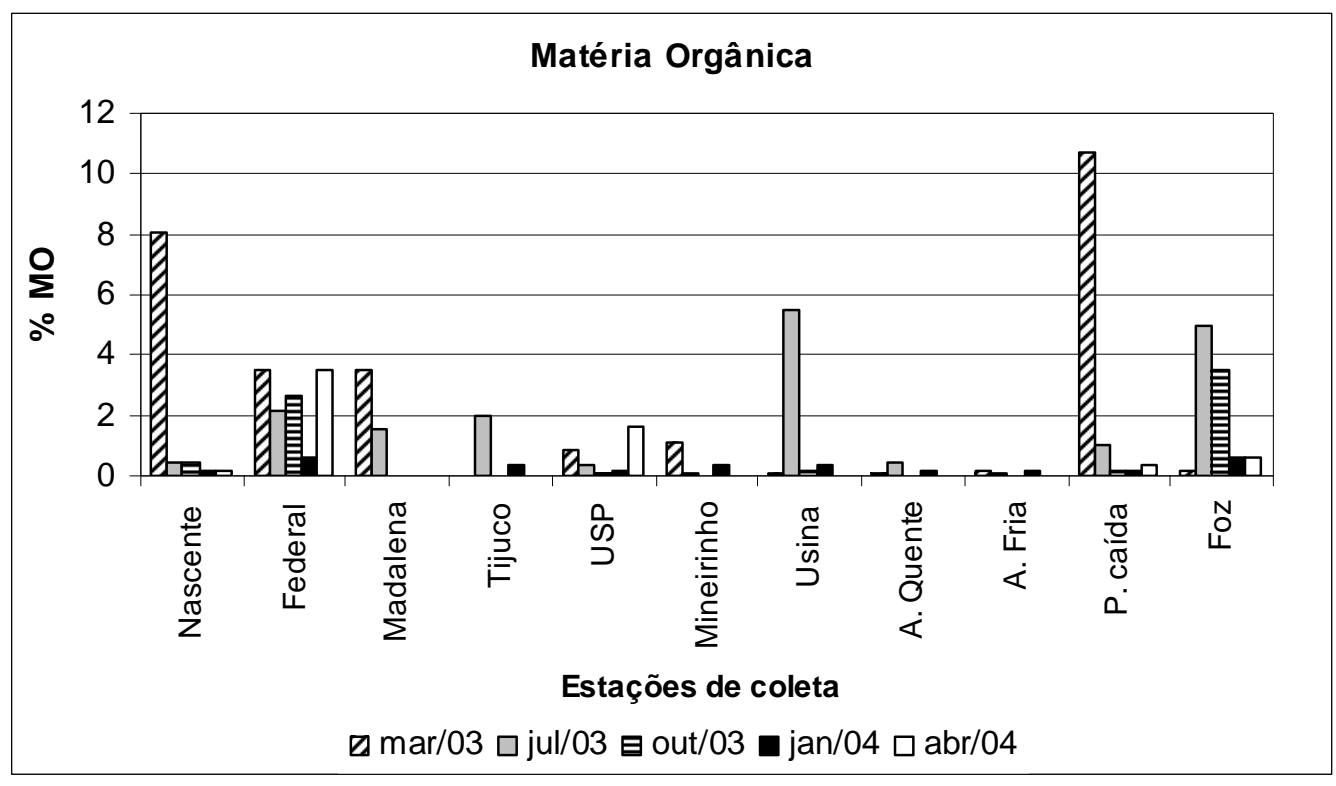

Figura 29. Porcentagem de matéria orgânica no sedimento do rio Monjolinho e tributários durante o período de estudo. 
A concentração de PT apresentou um padrão semelhante ao observado para MO. Porém, pode-se observar que na estação Foz, em quase todo período de estudo, ocorreram concentrações superiores às demais estações. As concentrações de PT variaram de 16,84 $\mu \mathrm{g} \cdot \mathrm{g}^{-1}$ (nascente, abril/04) a 794,60 $\mu \mathrm{g}^{-g^{-1}}$ (Foz, outubro/ 03), sendo os menores valores observados no Água Fria (março/03 e julho/ 03) e Nascente (outubro/03, janeiro/04 e abril/04). As maiores concentrações foram observadas na Federal (março/03 e abril/04) e na Foz (julho/ 03, outubro/ 03 e janeiro/ 04).

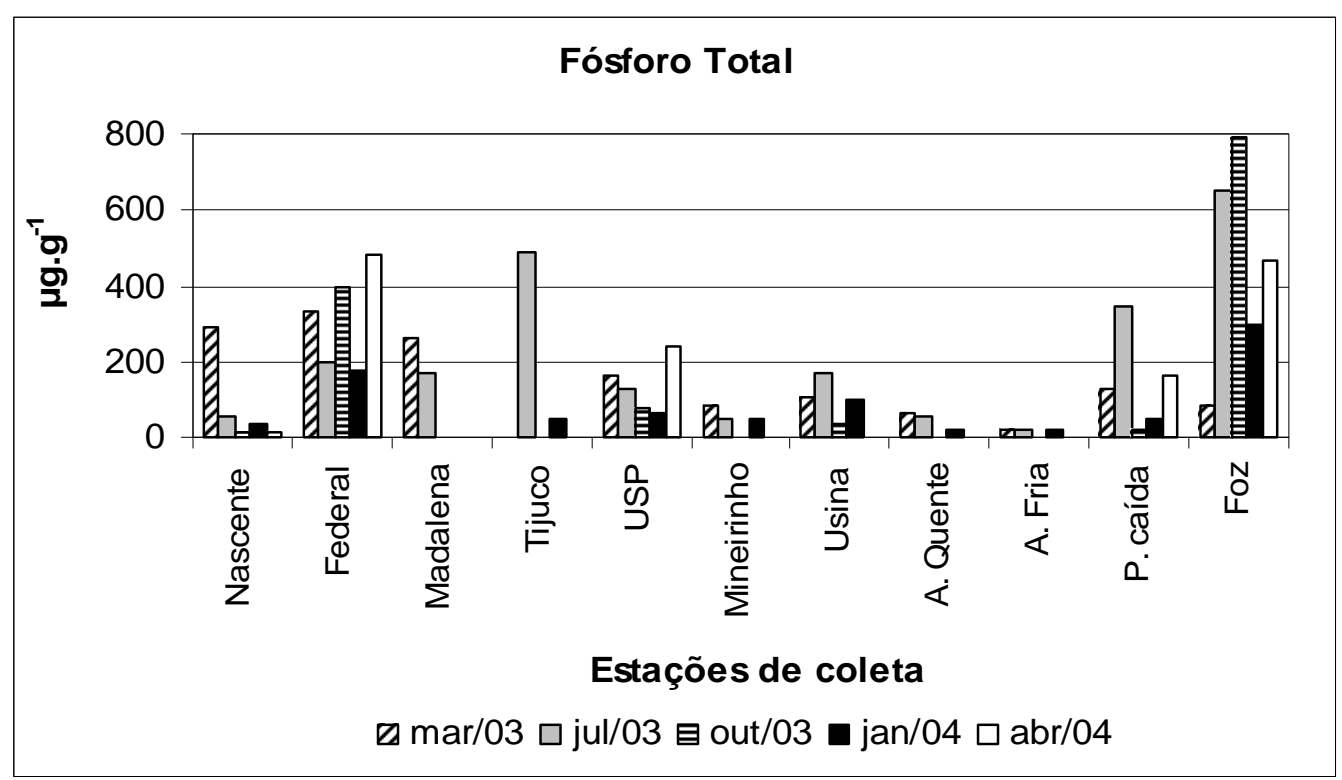

Figura 30. Concentração de fósforo total ( $\left.\mu \mathrm{g} \cdot \mathrm{g}^{-1}\right)$ no sedimento do rio Monjolinho e tributários durante o período de estudo.

Em relação à porcentagem de NOT, verifica-se 0 mesmo padrão que para MO e PT, com os maiores valores observados nas estações Federal e Foz, sendo as maiores porcentagens de 0,16\% (abril/ 04) e 0,25\% (outubro/ 03), respectivamente.

A porcentagem de NOT variou de 0,0056\% (Água Quente, março/03) à 0,25\% (Foz, outubro/ 03). 


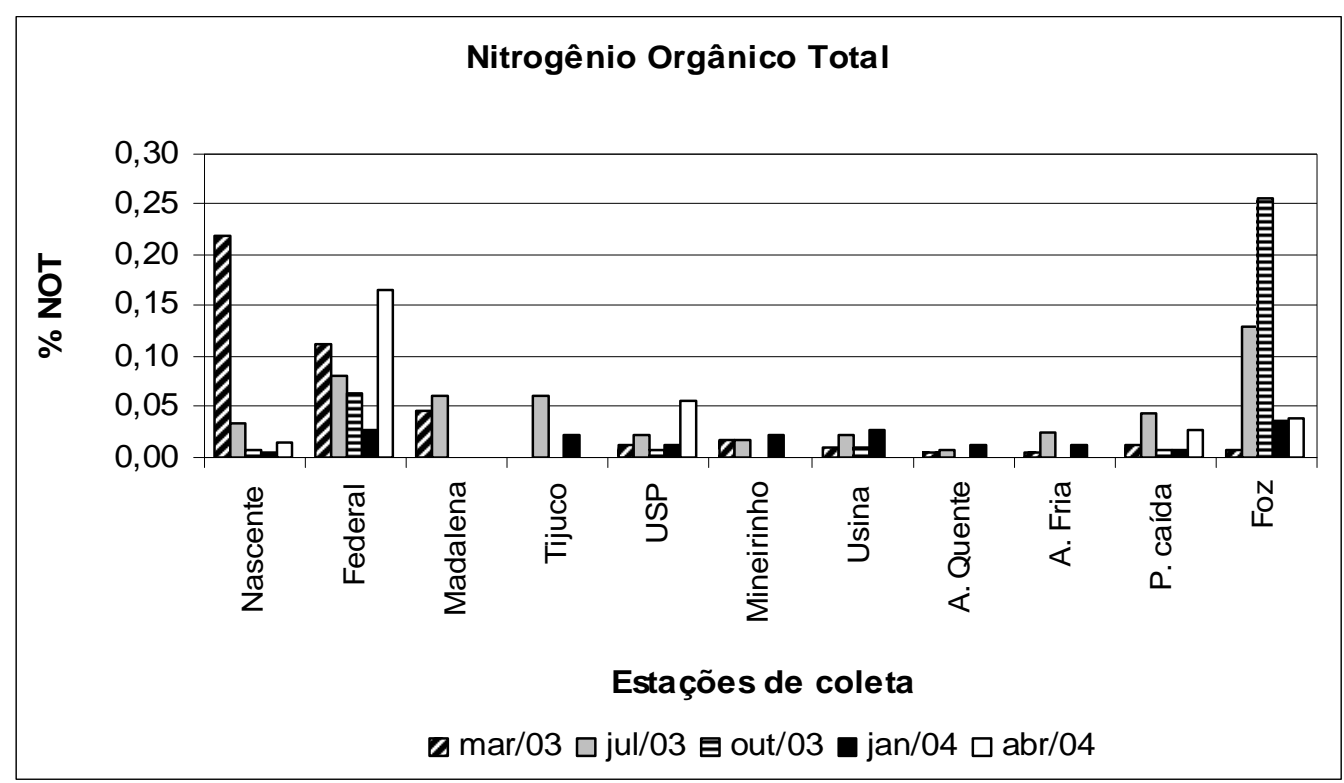

Figura 31. Porcentagem de nitrogênio orgânico total no sedimento do rio Monjolinho e tributários durante o período de estudo.

\subsection{Potencial redox do sedimento}

O potencial redox do sedimento do rio Monjolinho e de seus tributários foi mensurado nos meses de julho/ 03, outubro/ 03, janeiro/ 04 e abril/ 04, sendo que em março/ 03 o aparelho não estava disponível para a coleta. Os resultados estão apresentados na Figura 32 e na Tabela 32 (Apêndice 2).

Em geral, valores negativos foram obtidos para 0 potencial redox, exceto para o sedimento da Nascente, com valores positivos em todas as coletas.

Os valores variaram de $-210 \mathrm{mV}$ (Tijuco, julho/ 03) a $270 \mathrm{mV}$ (Nascente, abril/04), com a menor amplitude de valores, entre as estações amostradas, ocorrendo em janeiro/ 04.

A temperatura das amostras variou de $14^{\circ} \mathrm{C}$ (USP, janeiro/ 04) a $25^{\circ} \mathrm{C}(\mathrm{Foz}$, julho/ 03 e Federal, USP, Ponte caída e Foz em abril/ 04). 

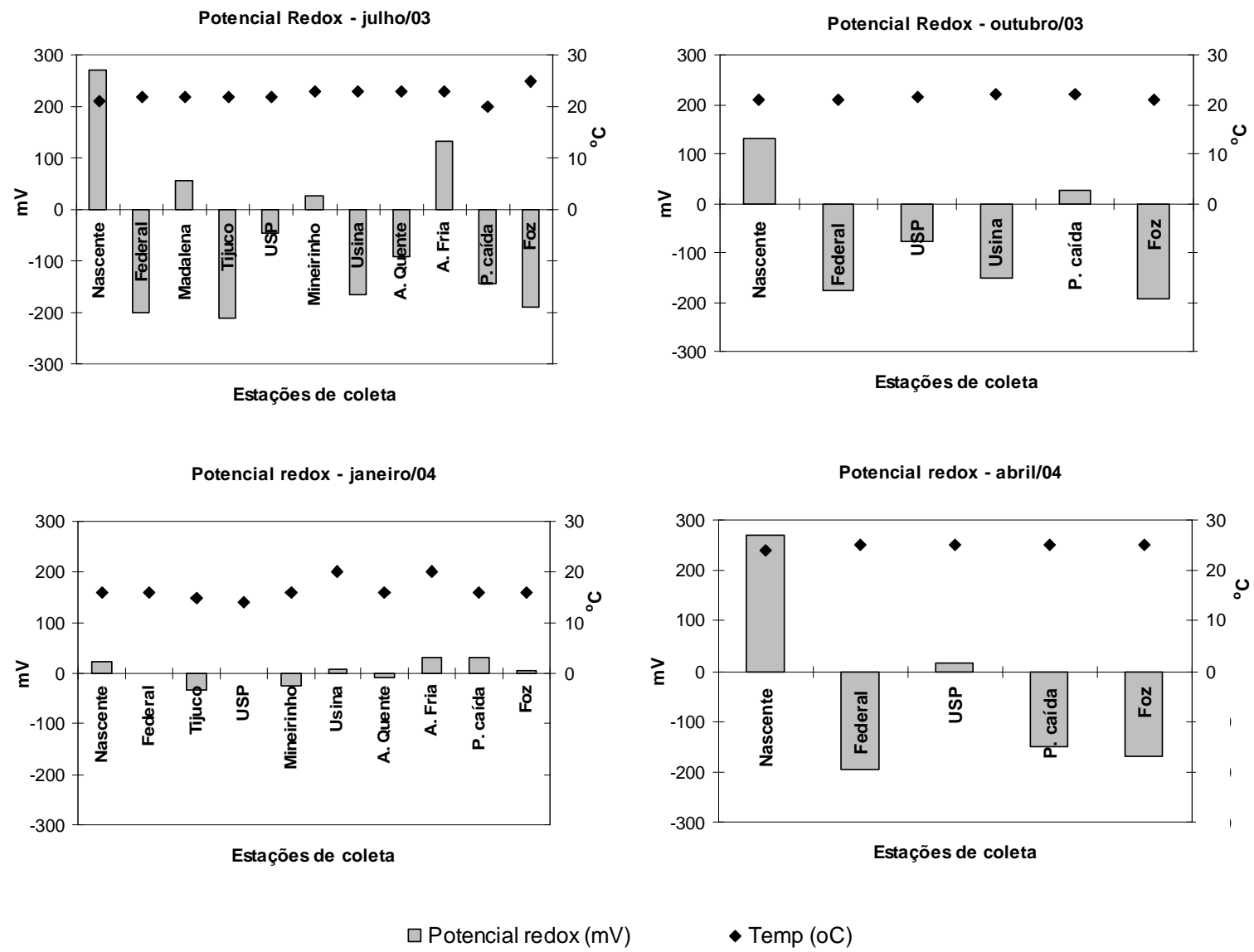

Figura 32. Potencial redox $(\mathrm{mV})$ e temperatura $\left({ }^{\circ} \mathrm{C}\right)$ do sedimento do rio Monjolinho e tributários durante 0 período de estudo.

\subsection{Granulometria}

Os resultados da análise granulométrica estão apresentados na Figura 33, nas Tabelas de 33 a 37 (no Apêndice 2) e na Tabela 38.

Em geral, como pode ser observado na Tabela 38, o sedimento do rio Monjolinho e tributários é do tipo arenoso, sendo que 38,09\% das amostras são compostas, predominantemente, pela fração areia média e 35,70\% pela fração areia fina. As frações pedregulho, areia grossa e silte + argila foram predominantes em $2,40 \%, 2,40 \%$ e $21,40 \%$ das amostras analisadas, respectivamente. 
Tabela 38. Frações granulométricas predominantes no sedimento do rio Monjolinho e tributários durante o período de estudo.

\begin{tabular}{|c|c|c|c|c|c|}
\hline $\begin{array}{c}\text { Estaçóes/ } \\
\text { período }\end{array}$ & Mar/ 03 & Jul/ 03 & Out/ 03 & Jan/ 04 & Abr/ 04 \\
\hline Nascente & silte argiloso & areia média & areia fina & areia média & areia média \\
\hline Federal & areia média & areia média & areia fina & areia média & areia média \\
\hline Madalena & areia grossa & areia grossa & . & - & - \\
\hline Tijuco & - & $\begin{array}{l}\text { pedregulho } \\
\text { muito fino }\end{array}$ & - & areia média & - \\
\hline USP & areia fina & areia média & areia grossa & areia média & areia grossa \\
\hline Mineininho & areia grossa & areia grossa & * & areia média & \\
\hline Usina & areia grossa & areia grossa & areia média & areia média & - \\
\hline A. Quente & areia grossa & areia fina & . & areia média & - \\
\hline A. Fria & areia fina & areia fina & - & areia fina & \\
\hline P. caída & areia fina & areia média & areia fina & areia fina & areia fina \\
\hline Foz & areia fina & areia fina & areia fina & areia fina & areia média \\
\hline
\end{tabular}

- sedimento não coletado
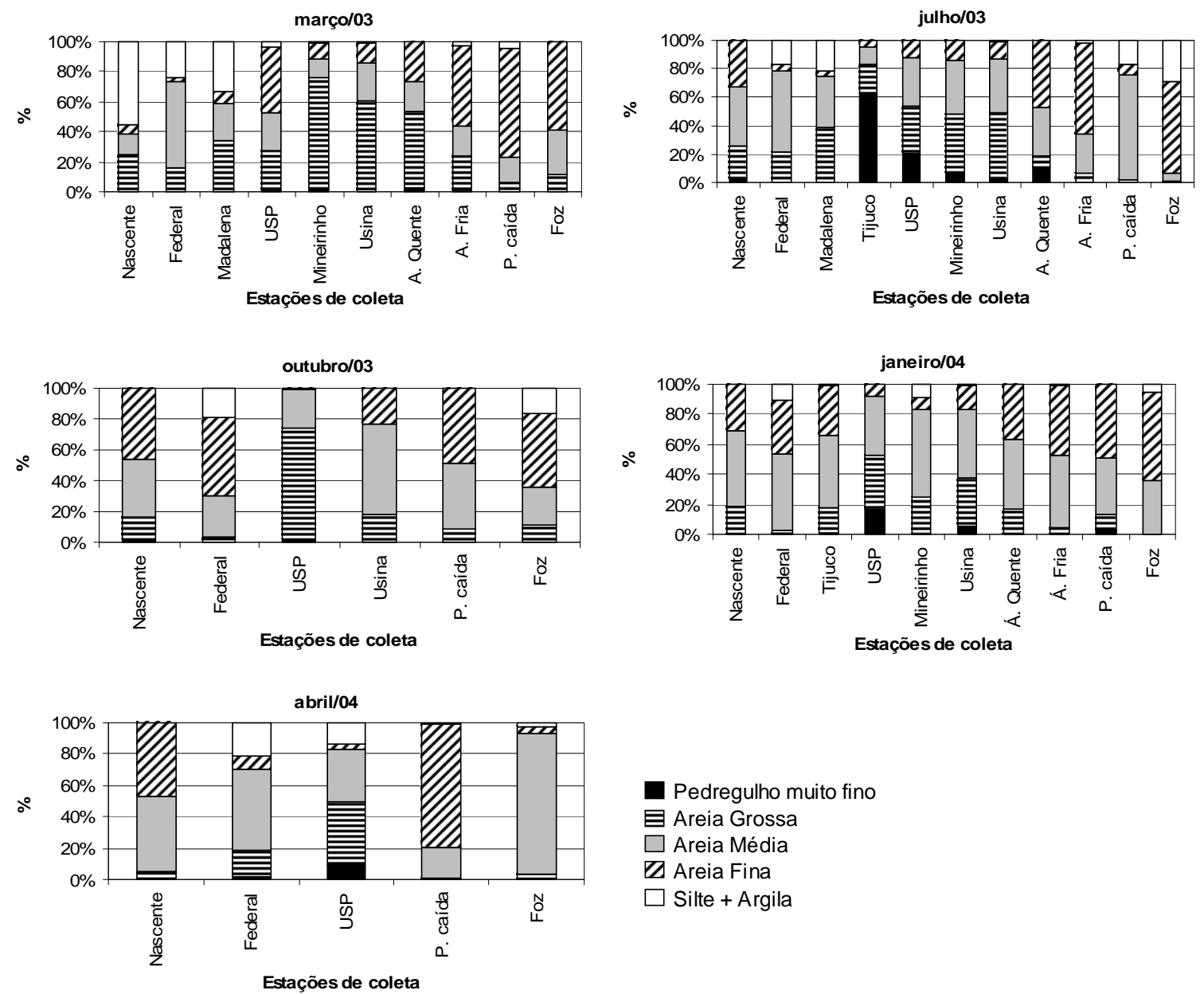

Pedregulho muito fino

目 Areia Grossa

$\square$ Areia Média

$\square$ Areia Fina

$\square$ Silte + Argila

Figura 33. Granulometria do sedimento do rio Monjolinho e tributários durante o período de estudo. 


\subsection{Metais potencialmente biodisponíveis no sedimento}

\subsubsection{Rio Monjolinho}

Os resultados das concentrações de metais potencialmente biodisponíveis no sedimento estão apresentados nas Tabela 39 e 40.

Os resultados apontam para a Nascente como sendo a estação do rio Monjolinho com menor concentração de metais, exceto para março/ 03, onde foram observadas as maiores concentrações de Cd (0,09 mg. $\left.\mathrm{kg}^{-1}\right)$ e Fe (11172,10 mg.kg-1). Como explicado anteriormente, nesse mês a coleta do sedimento foi realizada na área alagada, cuja composição é muito diferente dos demais meses amostrados.

Em março/ 03, a Federal apresentou os maiores valores para $\mathrm{Cr}, \mathrm{Cu}, \mathrm{Zn}$ e Mn, (2,35; 12,61; 334,00 e 360,00 mg.kg-1, respectivamente) As menores concentrações foram obtidas na Usina (Cd, Mn e Fe) e Foz (Cr, Cu e Zn), como pode ser observado na Tabela 39.

O sedimento da estação de coleta Federal apresentou os maiores valores de $\mathrm{Cr}, \mathrm{Zn}, \mathrm{Mn}$ e Fe, em julho/ 03 (4,00; 136,00; 368,00 e 3595,00 mg.kg-1, respectivamente). As maiores concentrações de $\mathrm{Cd}$ e $\mathrm{Cu}$ foram registradas na $\mathrm{Foz}$ (0,05 e 13,55 mg.kg-1), enquanto que as menores concentrações neste mês foram obtidas na Nascente (Cd, Cu, Zn, Mn e Fe) e na USP (Cr).

O sedimento da Nascente também apresentou as menores concentrações dos metais nos meses de outubro/ 03 ( $\mathrm{Cr}, \mathrm{Cd}, \mathrm{Cu}, \mathrm{Zn}, \mathrm{Mn}$ e Fe), janeiro/ 04 (Cr, Cu, Zn, $\mathrm{Mn}$ e Fe) e abril/ 04 (Cu, Zn, Mn e Fe).

Em outubro/03, o sedimento da estação Foz apresentou as maiores concentrações de $\mathrm{Cd}\left(0,09 \mathrm{mg} \cdot \mathrm{kg}^{-1}\right), \mathrm{Cu}\left(27,71 \mathrm{mg} \cdot \mathrm{kg}^{-1}\right), \mathrm{Zn}$ (1328,00 mg.kg-1), Mn (2470,00 mg.kg-1) e Fe (191960,00 mg.kg-1 ${ }^{-1}$. A maior concentração de Cr foi obtida na Federal $\left(4,50 \mu \mathrm{g} \cdot \mathrm{g}^{-1}\right)$.

Em janeiro/04 as maiores concentrações de metais potencialmente biodisponíveis no sedimento foram observadas na Federal para $\mathrm{Cr}$ (2,32 mg.kg-1), $\mathrm{Cu}$ (10,40 mg.kg-1), Zn (195,00 mg.kg-1)e Fe (8560,00 mg.kg-1). A maior concentração de Cd ocorreu na Nascente $\left(0,03 \mathrm{mg} \cdot \mathrm{kg}^{-1}\right)$ e a maior concentração de Mn ocorreu na Foz (610,00 mg.kg-1). 
O sedimento da Federal apresentou as maiores concentrações de metais em abril/ 04, como observado também para os demais meses estudados. Os valores de $\mathrm{Cd}$ e $\mathrm{Cu}$ foram de 0,06 e 5,48 mg.kg-1, respectivamente, e de Zn, Mn e Fe foram de 6,82, 19,85 e 286,87 mg.kg-1, respectivamente.

Tabela 39. Concentração de metais potencialmente biodisponíveis no sedimento do rio Monjolinho durante 0 período de estudo. ${ }^{1}=$ valores máximos e ${ }^{2}=$ valores mínimos .

\begin{tabular}{|c|c|c|c|c|c|c|}
\hline mg.kg-1 & $\mathrm{Cr}$ & Cd & $\mathrm{Cu}$ & $\mathrm{Zn}$ & Mn & Fe \\
\hline \multicolumn{7}{|c|}{ Março/ 03} \\
\hline Nascente & 1,15 & $0,09^{1}$ & 6,32 & 54,00 & 310,00 & $11172,10^{1}$ \\
\hline Federal & 2,351 & 0,07 & $12,62^{1}$ & $334,00^{1}$ & $360,00^{1}$ & 9879,20 \\
\hline USP & 1,04 & 0,02 & 6,09 & 92,00 & 278,00 & 3082,00 \\
\hline P. caída & 0,27 & 0,02 & 3,42 & 56,00 & 192,00 & 2400,00 \\
\hline Usina & 0,28 & $0,01^{2}$ & 2,39 & 46,00 & $108,00^{2}$ & $1062,00^{2}$ \\
\hline Foz & 0,192 & 0,02 & $1,66^{2}$ & $34,00^{2}$ & 186,00 & 2557,00 \\
\hline \multicolumn{7}{|c|}{ Julho/ 03} \\
\hline Nascente & 0,08 & 0,007 & $0,40^{2}$ & $\mathrm{nd}^{2}$ & $n d^{2}$ & $n \mathrm{n}^{2}$ \\
\hline Federal & $4,00^{1}$ & 0,04 & 9,51 & 136,001 & $368,00^{1}$ & $3595,00^{1}$ \\
\hline USP & $0,05^{2}$ & $n d^{2}$ & 0,50 & 35,00 & 75,00 & 786,00 \\
\hline Usina & 0,43 & 0,04 & 10,64 & 69,00 & 240,00 & 1979,00 \\
\hline P. caída & 0,55 & 0,03 & 7,04 & 98,00 & 206,00 & 778,00 \\
\hline Foz & 1,71 & $0,05^{1}$ & $13,55^{1}$ & 1,00 & 4,00 & $n d^{2}$ \\
\hline \multicolumn{7}{|c|}{ Outubro/ 03} \\
\hline Nascente & $n d^{2}$ & $n d^{2}$ & $0,33^{2}$ & $n d^{2}$ & $10,00^{2}$ & $n d^{2}$ \\
\hline Federal & $4,50^{1}$ & 0,03 & 13,88 & 486,00 & 573,00 & 109360,00 \\
\hline USP & 0,19 & $n d^{2}$ & 2,81 & 42,00 & 127,00 & 3593,00 \\
\hline Usina & 0,13 & 0,002 & 3,49 & 85,00 & 162,00 & 2046,00 \\
\hline P. caída & 0,13 & $n d^{2}$ & 1,73 & 64,00 & 65,00 & 2022,00 \\
\hline Foz & 2,80 & $0,09^{1}$ & $27,72^{1}$ & $1328,00^{1}$ & $2470,00^{1}$ & $191960,00^{1}$ \\
\hline \multicolumn{7}{|c|}{ Janeiro/ 04} \\
\hline Nascente & 0,07 & $0,03^{1}$ & $0,39^{2}$ & $n \mathrm{n}^{2}$ & $n d^{2}$ & $n d^{2}$ \\
\hline Federal & $2,32^{1}$ & $n d^{2}$ & $10,40^{1}$ & $195,00^{1}$ & 86,00 & $8560,00^{1}$ \\
\hline USP & 0,35 & $n d^{2}$ & 1,60 & 62,00 & 80,00 & 7593,00 \\
\hline Usina & 0,14 & $n d^{2}$ & 6,75 & 116,00 & 229,00 & 6299,00 \\
\hline P. caída & $0,05^{2}$ & $n d^{2}$ & 1,3 & 37,00 & 67,00 & 2612,00 \\
\hline Foz & 0,86 & $n d^{2}$ & 8,46 & 185,00 & $610,00^{1}$ & $n d^{2}$ \\
\hline \multicolumn{7}{|c|}{ Abril/ 04} \\
\hline Nascente & $0,06^{2}$ & $n \mathrm{~d}^{2}$ & $0,26^{2}$ & $0,12^{2}$ & $0,25^{2}$ & $2,05^{2}$ \\
\hline Federal & 1,27 & $0,06^{1}$ & $5,48^{1}$ & $6,82^{1}$ & $19,85^{1}$ & 286,871 \\
\hline USP & 2,531 & $n d^{2}$ & 1,69 & 0,82 & 1,82 & 20,60 \\
\hline P. caída & 0,16 & $n d^{2}$ & 0,66 & 0,82 & 0,92 & 33,82 \\
\hline Foz & 0,68 & 0,01 & 3,43 & 1,87 & 4,75 & 116,02 \\
\hline
\end{tabular}

\subsubsection{Tributários do rio Monjolinho}

$\mathrm{Na}$ Tabela 40 verifica-se que as maiores concentrações de metais, em março/ 03, foram obtidas no sedimento do córrego da Serra, para todos os metais analisados exceto o Cr. As menores concentrações obtidas foram no córrego Água Fria, com valores inferiores às demais estações, para $\mathrm{Cd}, \mathrm{Cu}, \mathrm{Zn}, \mathrm{Mn}$ e Fe. 
Em julho/03, observa-se que as maiores concentrações de metais foram obtidas no sedimento do córrego Tijuco e as menores no córrego Mineirinho. Em janeiro/ 04, a estação com maiores concentrações foi, novamente, o córrego Tijuco, e a estação com as menores concentrações foi o córrego Água Fria.

Tabela 40. Concentrações de metais potencialmente biodisponíveis no sedimento dos tributários do rio Monjolinho durante 0 período de estudo. ${ }^{1}=$ valores máximos e ${ }^{2}=$ valores mínimos.

\begin{tabular}{|c|c|c|c|c|c|c|}
\hline mg.kg-1 & $\mathrm{Cr}$ & Cd & $\mathrm{Cu}$ & Zn & Mn & Fe \\
\hline \multicolumn{7}{|c|}{ Março/ 03} \\
\hline A. Fria & 0,04 & $n d^{2}$ & 0,492 & $6,00^{2}$ & $51,00^{2}$ & $592,00^{2}$ \\
\hline Á. Quente & 0,09 & 0,02 & 1,47 & 17,00 & 124,00 & 884,00 \\
\hline Mineininho & 0,271 & 0,02 & 2,66 & 18,00 & 65,00 & 1238,00 \\
\hline Serma & $n d^{2}$ & $0,20^{1}$ & $4,45^{1}$ & $81,00^{1}$ & $1846,00^{1}$ & $8750,90^{1}$ \\
\hline Madalena & $n d^{2}$ & $0,20^{1}$ & 3,12 & 49,00 & 648,00 & 8533,00 \\
\hline \multicolumn{7}{|c|}{ Julho/ 03} \\
\hline Madalena & 0,05 & $\mathrm{nd}^{2}$ & 1,80 & 103,00 & 176,00 & 1835,00 \\
\hline Tijuco & $0,86^{1}$ & $0,05^{1}$ & $9,72^{1}$ & $253,00^{1}$ & 394,00 & $2464,00^{1}$ \\
\hline Mineirinho & $n d^{2}$ & $\mathrm{nd}^{2}$ & 0,27 & $8,00^{2}$ & $22,00^{2}$ & 255,00 \\
\hline Á. Fria & 0,05 & 0,01 & 0,56 & 40,00 & 1403,00 & 927,00 \\
\hline Á. Quente & 0,05 & $n d^{2}$ & 0,52 & 29,00 & 60,00 & $56,00^{2}$ \\
\hline Cancan & 0,02 & $\mathrm{nd}^{2}$ & $0,15^{2}$ & 71,00 & 311,00 & 99,00 \\
\hline Serma & 0,07 & $\mathrm{nd}^{2}$ & 3,50 & 61,00 & $1775,00^{1}$ & 2153,00 \\
\hline \multicolumn{7}{|c|}{ Janeiro/ 04} \\
\hline Tijuco & $0,55^{1}$ & $n d^{2}$ & $6,25^{1}$ & $129,00^{1}$ & $232,00^{1}$ & $7863,00^{1}$ \\
\hline Mineininho & 0,13 & $\mathrm{nd}^{2}$ & 1,83 & 21,00 & 123,00 & 2259,00 \\
\hline Á. Fria & $0,03^{2}$ & $n d^{2}$ & 1,12 & $n d^{2}$ & $29,00^{2}$ & $1045,00^{2}$ \\
\hline Á. Quente & 0,05 & $\mathrm{nd}^{2}$ & $0,74^{2}$ & 24,00 & 73,00 & 1172,00 \\
\hline
\end{tabular}

nd - não detectado pelo método utilizado; cinza-escuro - concentração mínima; cinza-claro - concentração máxima

Na Tabela 41 pode-se observar que a Federal é a estação do rio Monjolinho com maiores concentrações de metais em quase todo o período amostrado, exceto em outubro/ 03, onde o sedimento da Foz apresentou valores de $\mathrm{Cd}, \mathrm{Cu}, \mathrm{Zn}, \mathrm{Mn}$ e Fe acima das concentrações obtidas nas demais estações.

As estações de coleta que apresentaram as menores concentrações de metais potencialmente biodisponíveis no sedimento foram: Usina, Água Fria, Mineirinho e Nascente; enquanto que as estações que apresentaram as maiores concentrações foram: Federal, Serra, Tijuco e Foz. 
Tabela 41. Resumo da distribuição de metais potencialmente biodisponíveis no sedimento do rio Monjolinho e seus tributários durante o período de estudo.

\begin{tabular}{lccc}
\hline \multicolumn{2}{c}{ Peń́odo e compo hídrico } & Menores concentrações & Maiores concentrações \\
\hline \multirow{2}{*}{ Março/ 03 } & no & Usina & Federal \\
& tributário & Água Fnia & Serra \\
\hline \multirow{2}{*}{ Julho/ 03 } & no & Nascente & Federal \\
& tributário & Mineirinho & Tijuco \\
\hline \multirow{2}{*}{ Outubro/ 03 } & nio & Nascente & FoZ \\
& tributário & não coletado & não coletado \\
\hline \multirow{2}{*}{ Janeiro/ 04 } & no & Nascente & Federal \\
& tributário & Água Fria & Tijuco \\
\hline \multirow{2}{*}{ Abril/ 04 } & nio & Nascente & Federal \\
& tributário & não coletado & não coletado \\
\hline
\end{tabular}

\subsection{Agrotóxicos organoclorados no sedimento}

Os resultados referentes às concentrações dos agrotóxicos organoclorados no sedimento estão apresentados na Tabela 42, na qual pode-se verificar que na maioria das estações amostradas o agrotóxico não foi detectado. Observa-se a maior concentração de Aldrin em julho/03, na Foz $\left(0,07 \mu \mathrm{gg}^{\mathrm{kg}}{ }^{-1}\right)$, sendo que em

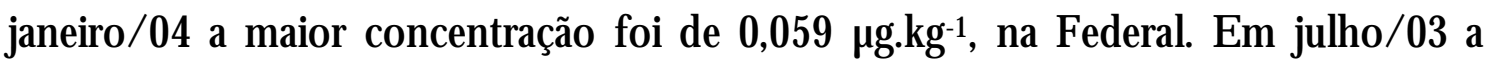
maior concentração de Endosulfan sulfato foi de 9,11 $\mu \mathrm{ggg}^{-1}$ (Usina) e em janeiro/04 não foi detectado em nenhuma estação analisada. Em relação ao Heptachlor, observa-se baixas concentrações nos locais onde o agrotóxico foi detectado, exceto na Foz, em julho/ 03, na qual foi verificada uma concentração de $10,64 \mu \mathrm{g} \cdot \mathrm{Kg}^{-1}$.

Tabela 42. Agrotóxicos organoclorados ( $\mu \mathrm{g} \cdot \mathrm{Kg}^{-1}$ ) nas amostras de sedimento do rio Monjolinho e tributários localizados na imediações da Usina da Serra.

\begin{tabular}{|c|c|c|c|c|c|c|}
\hline \multirow{2}{*}{$\begin{array}{c}\text { Pontos de } \\
\text { coleta }\end{array}$} & \multicolumn{2}{|c|}{ Aldrin $\left(\mu \mathrm{g} . \mathrm{Kg}^{-1}\right)$} & \multicolumn{2}{|c|}{ Endosulfan sulfato $\left(\mathrm{\mu g} \mathrm{Kg}^{-1}\right)$} & \multicolumn{2}{|c|}{ Heptacloro $\left(\mu \mathrm{g} . \mathrm{Kg}^{-1}\right)$} \\
\hline & jul/ 03 & jan/ 04 & jul/ 03 & $\mathrm{jan} / 04$ & jul/ 03 & jan $/ 04$ \\
\hline Nascente & nd & nd & nd & nd & nd & nd \\
\hline Federal & nd & 0,059 & nd & nd & nd & nd \\
\hline USP & $<\mathrm{ld}$ & 0,003 & 5,88 & nd & nd & nd \\
\hline Usina & nd & 0,041 & 9,11 & nd & nd & nd \\
\hline Ponte caída & 0,034 & nd & 0,029 & nd & nd & nd \\
\hline Cancan & 0,054 & nc & 0,52 & nc & 0,892 & nc \\
\hline Serra & 0,062 & nc & nd & nc & nd & $\mathrm{nc}$ \\
\hline Foz & 0,07 & 0,044 & nd & $<\mathrm{ld}$ & 10,64 & 0,219 \\
\hline
\end{tabular}

nd - não detectado; nc - não coletado; <ld - abaixo do limite de detecção do método utilizado. 


\section{DISCUSSÃO}

Um breve histórico sobre os resultados dos trabalhos realizados recentemente no rio Monjolinho será apresentado, bem como, uma discussão sucinta dos resultados mais relevantes em relação à limnologia e aos parâmetros relacionados à toxicidade do sistema. Deve-se mencionar que, no Capítulo 1, apresentou-se um resumo sobre as áreas do conhecimento avaliadas nesse sistema e, para um melhor detalhamento, pode-se consultar a dissertação de VIANA (2005), que realizou um projeto de mestrado vinculado ao presente estudo e fez uma excelente revisão bibliográfica referente às pesquisas desenvolvidas no rio Monjolinho entre os anos de 1971 e 2003.

Porém, apesar de terem sido gerados muitos dados a respeito da qualidade das águas desse sistema, para se realizar um estudo ecotoxicológico, uma série de parâmetros precisam ser avaliados para que seja possível um melhor embasamento e discussão dos resultados obtidos nos testes de toxicidade realizados com a espécie bentônica Chironomus x anthus, tanto em condições laboratoriais quanto "in situ".

Em relação aos trabalhos mais recentes desenvolvidos nesse sistema, com enfoque limnológico e toxicológico, pode-se citar BARRETO (1999), BARBOSA (2000), MARINELLI et al. (2000) e PELAEZ-ROD RÍG UES (2001), além daqueles gerados em conjunto com o presente estudo, que são o de CAMPAGNA (2005), NOVELLI (2005) e VIANA (2005). Para os tributários, tem-se os trabalhos realizados por SANTOS (1993 - Córregos Água Fria e Água Q uente), OLIVEIRA (2003 - Córrego do Cancan) e BENINI (2005 - Córrego do Mineirinho).

Em geral, os resultados apontam que o rio Monjolinho apresenta um gradiente longitudinal de poluição, da nascente em direção à foz, com concentrações de nutrientes nitrogenados, fosfatados, metais e organoclorados elevadas, o que 0 caracteriza como um sistema impactado, seja pelo despejo de efluentes domésticos ou industriais ou pelo carreamento de material proveniente de solos agrícolas contaminados. MARINELLI et al. (2000) também observou esse gradiente decrescente da qualidade da água (nascente - foz), refletida pelo aumento no grau de trofia, sendo que a Nascente foi considerada como um ambiente com características oligotróficas, o ponto 2 (USP) mesotrófico e os pontos 3 (Usina) e 4 (Ponte Caída) eutróficos. 
Os tributários do rio Monjolinho, principalmente o Tijuco, Gregório e Água Quente, contribuíram com a entrada de fósforo total, nitrogênio orgânico total e cloretos para o leito principal do rio, aumentando as concentrações e alterando as suas características limnológicas.

Outro fator preocupante são as altas concentrações de organoclorados nas estações amostradas, que deixam uma dúvida no que se refere à origem desses produtos, já que, excetuando o Endosulfan, os demais estão proibidos de serem utilizados pela legislação vigente (Portaria 329/ 85, ANVISA, 2004). Esses produtos podem estar sendo aplicados atualmente nas lavouras, principalmente as de cana-deaçúcar, mesmo de maneira ilegal, ou então podem ser um resíduo de usos em período anterior.

Um dos aspectos mais abordados pelas discussões que envolvem as variáveis limnológicas estudadas é o enquadramento dos corpos hídricos em Classes, sendo que o limite máximo de cada parâmetro permitido para cada Classe foi estabelecido pela resolução CONAMA 357/ 05, antiga CONAMA 20/86. Considerando alguns parâmetros sugeridos para o enquadramento, apresenta-se nas Tabelas 43 e 44 uma síntese da classificação atual dos corpos de água estudados, em julho/03 e janeiro/ 04, representando as estações seca e chuvosa, respectivamente As tabelas foram construídas considerando que a partir do momento em que havia um parâmetro em desconformidade com a resolução para o enquadramento em Classe 2 (uso mais restritivo), o trecho foi gradualmente alocado em Classes 3 ou 4, com característica de usos menos restritivos. Sabe-se, entretanto, que o enquadramento dos corpos de água não se baseia no seu estado atual, mas nos níveis de qualidade que deveria possuir para atender às necessidades definidas pela sociedade (LEEUWESTEIN et al, 2000), mas segundo a CETESB (2001), somente estão enquadrados o Córrego do Gregório e o rio Monjolinho após a confluência com 0 Córrego do Gregório, sendo ambos pertencentes a Classe 4.

No presente trabalho, todo o sistema foi classificado como pertencente às Classes 3 ou 4, corroborando os dados obtidos por BARRETO (1999 - exceto a Nascente que foi considerada como Classe 1 pela autora). Segundo a autora, a concentração de metais, sulfeto e D BO foram determinantes para o enquadramento das estações de coleta do rio Monjolinho em Classes com usos menos exigentes, 
mas, no presente estudo, as variáveis mais importantes para essa classificação foram o fósforo total, sulfetos, cádmio e os agrotóxicos organoclorados.

Tabela 43. Classificação atual do rio Monjolinho e tributários, segundo Resolução CONAMA 357/ 05, em julho/ 03 (período seco). Classe 1 - branco, Classe 2 - cinza claro, Classe 3 - cinza escuro e Classe 4 - preto.

\begin{tabular}{|c|c|c|c|c|c|c|c|c|c|c|c|c|c|c|c|c|}
\hline Julho/ 03 & \multicolumn{15}{|c|}{ PARÂMETROSANALISADOS } & \multirow{3}{*}{$\begin{array}{c}\text { CONAMA } \\
\text { 357/ 05 } \\
\text { (Classes) }\end{array}$} \\
\hline \multirow{2}{*}{ Estação } & & & & & & & & íon & & & neta & & & ano & & \\
\hline & 1 & 2 & 3 & 4 & 5 & 6 & 7 & 8 & 9 & 10 & 11 & 12 & 13 & 14 & 15 & \\
\hline Nascente & & & & & & & & & & & & & & & & Classe 3 \\
\hline Federal & & & & & & & & & & & & & & & 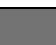 & Classe 4 \\
\hline Madalena & & & & & & & & & & & & & & - & & Classe 3 \\
\hline Tijuco & & & & & & & & & & & & & - & - & - & Classe 4 \\
\hline USP & & & & & & & & & & & & & - & - & - & Classe 4 \\
\hline Mineininho & & & & & & & & & & & & & - & - & - & Classe 3 \\
\hline Gregónio & & & & & & & & & & & & & - & - & - & Classe 4 \\
\hline Usina & & & & & & & & & & & & & & & & Classe 4 \\
\hline A. quente & & & & & & & & & & & & & & - & & Classe 4 \\
\hline A. fria & & & & & & & & & & & & & - & - & - & Classe 3 \\
\hline P. caída & & & & & & & & & & & & & & & & Classe 4 \\
\hline Cancan & & & & & & & & & & & & & & & & Classe 4 \\
\hline Sema & & & & & & & & & & & & & & & & Classe 3 \\
\hline Foz & & & & & & & & & & & & & & & & Classe 4 \\
\hline
\end{tabular}

1-pH; 2-oxigênio dissolvido; 3-fósforo total; 4-nitrito; 5-nitrato; 6-íon amônio; 7-cloreto; 8-sulfato; 9-sulfeto; 10-Cd; 11-Cr; 12-Cu; 13-Aldrin; 14-E ndosulfan sulfato; 15-Heptachlor; - análise não realizada.

Tabela 44. Classificação atual do rio Monjolinho e tributários, segundo Resolução CONAMA 357/ 05, em janeiro/ 04 (período chuvoso). Classe 1 - branco, Classe 2 - cinza claro, Classe 3 cinza escuro e Classe 4 - preto.

\begin{tabular}{|c|c|c|c|c|c|c|c|c|c|c|c|c|c|c|c|c|}
\hline Janeiro/ 04 & \multicolumn{15}{|c|}{ PARÂMETROS ANALISADOS } & \multirow{3}{*}{$\begin{array}{c}\text { CONAMA } \\
\text { 357/ 05 } \\
\text { (Classes) }\end{array}$} \\
\hline \multirow{2}{*}{ Estação } & & & & & & & & íons & & & letai & & & anoc & & \\
\hline & 1 & 2 & 3 & 4 & 5 & 6 & 7 & 8 & 9 & 10 & 11 & 12 & 13 & 14 & 15 & \\
\hline Nascente & & & & & & & & & & & & & & & & Classe 4 \\
\hline Federal & & & & & & & & & & & & & & & & Classe 4 \\
\hline Madalena & & & & & & & & & & & & & - & - & - & Classe 3 \\
\hline Tijuco & & & & & & & & & & & & & - & - & - & Classe 3 \\
\hline USP & & & & & & & & & & & & & & . & & Classe 4 \\
\hline Mineininho & & & & & & & & & & & & & - & - & - & Classe 4 \\
\hline Gregónio & & & & & & & & & & & & & - & - & - & Classe 4 \\
\hline Usina & & & & & & & & & & & & & & & & Classe 4 \\
\hline A. quente & & & & & & & & & & & & & & - & - & Classe 4 \\
\hline A. fria & & & & & & & & & & & & & - & - & - & Classe 3 \\
\hline P. caída & & & & & & & & & & & & & & & & Classe 4 \\
\hline Cancan & & & & & & & & & & & & & & & & Classe 3 \\
\hline Sema & & & & & & & & & & & & & & & & Classe 3 \\
\hline Foz & & & & & & & & & & & & & & & & Classe 4 \\
\hline
\end{tabular}

1-pH; 2-0 xigênio dissolvido; 3-fósforo total; 4-nitrito; 5-nitrato; 6-íon amônio; 7-cloreto; 8-sulfato; 9-sulfeto; 10-Cd; 11-Cr; 12-Cu; 13-Aldrin; 14-E ndosulfan sulfato; 15-Heptachlor; - análise não realizada.

Para PELAEZ-ROD RÍG UES (2001), apesar dos metais chumbo, cobre, ferro, manganês e zinco estarem em algum momento (estação ou período) em 
desconformidade com o que estabelece a resolução CONAMA 20/ 86 para águas Classe 2, 0 maior problema foi detectado em relação aos agrotóxicos organoclorados. D entre os organoclorados analisados foram encontrados Aldrin, Endrin, Endrin-aldeído, $\alpha$-Endosulfan, $\beta$-Endosulfan, Endosulfan sulfato, Heptacloro e Epóxido de Heptacloro, em altas concentrações, inclusive na Nascente, sendo que no sistema todo, o Endosulfan sulfato variou de 0,014 a 0,028 $\mu g . L^{-1}$, o Aldrin de 0,011 a $0,028 \mu g . L^{-1}$ e o Heptacloro de 0,049 a 1,036 $\mu g . L^{-1}$. D entre os 3 organoclorados analisados no presente estudo, apenas o Aldrin foi encontrado em maiores concentrações quando comparados com os resultados de PELAEZ-RODRÍGUES (op. cit), além da presença de agrotóxicos na região da Nascente.

Além dos metais estudados no presente trabalho, BARBOSA (2000) analisou as concentrações de alumínio na água e constatou que os valores (de 10 a 15 mg.L-1) estavam cerca de 50 vezes acima do estabelecido pela resolução CONAMA (na época 20/86), que é de 0,1 mg.L-1. A autora menciona que para uma análise ambiental deve-se considerar os aspectos geológicos das bacias hidrográficas onde os corpos receptores estão inseridos, mas que para o caso em estudo, a maioria dos metais apresentou suas concentrações bem acima daquelas de ocorrência natural, indicando degradações provenientes de influências antrópicas.

Em relação aos tributários, SANTOS (1993), estudando os córregos Água Quente e Água Fria, concluiu que, embora os dois sistemas possuam localização geográfica próxima, os mesmos apresentam características limnológicas distintas, sendo que o córrego Água Fria foi considerado como de melhor qualidade do ponto de vista ecológico. Em relação ao córrego Água Quente, TONISSI (2005), utilizando a Educação Ambiental em conjunto com análises limnológicas, verificou 0 adiantado estágio de degradação ambiental, decorrente da interferência antrópica mal planejada. Os dois estudos citados corroboram os dados obtidos no presente estudo. OLIVEIRA (2003) classificou o Córrego do Cancan como sendo de Classe 2, em relação aos parâmetros $\mathrm{pH}$, oxigênio dissolvido, material em suspensão, fosfato total, nitrito e nitrato. Porém, no presente estudo, devido às altas concentrações de sulfetos, cádmio e aldrin, esse córrego foi classificado como sendo de Classe 3 e 4, nos períodos chuvoso e seco, respectivamente. 
Ainda sobre os tributários, BENINI (2005), estudando o Córrego do Mineirinho, obteve valores de $\mathrm{pH}(6,87)$ e fósforo total $\left(260,0 \mu \mathrm{g} \cdot \mathrm{L}^{-1}\right)$, próximo ao verificado nesse estudo, porém os valores de DQO $\left(41,74 \mathrm{mg} \cdot \mathrm{L}^{-1}\right)$ e nitrogênio orgânico total (5,11 mg. $\left.\mathrm{L}^{-1}\right)$ foram superiores. No presente estudo os valores obtidos foram de 6,35, 110,0 $\mu \mathrm{g} \cdot \mathrm{L}^{-1}, 14,66 \mathrm{mg} \cdot \mathrm{L}^{-1}$ e $0,53 \mathrm{mg} \cdot \mathrm{L}^{-1}$, respectivamente. BENINI (op cit) menciona que todos os parâmetros analisados estão em desacordo com a resolução CONAMA 357/ 05 para rios de Classe 2.

Os resultados obtidos pelos autores nos tributários do rio Monjolinho são de fundamental importância para a avaliação do sistema como um todo, já que foram amostradas estações ao longo do corpo hídrico, diferente desse estudo, que amostrou apenas uma estação (próxima à foz) de cada tributário. Porém, deve-se ter cuidado quando da comparação dos resultados, e mesmo, quando da inserção do corpo de água nas Classes estabelecidas pelo CONAMA, já que os parâmetros analisados em cada estudo podem ser diferentes, conferindo qualidade de água e classificação, também diferentes.

$\mathrm{Na}$ Tabela 45 pode-se analisar comparativamente 0 presente estudo com trabalhos realizados anteriormente e também com diferentes sistemas. Q uando se faz uma média das concentrações de metais obtidas em todas as estações de coleta, verifica-se que, em relação ao estudo de BARRETO (1999), houve uma melhora na qualidade do sistema em questão. Porém, deve-se ter em mente que, quando as estações são analisadas separadamente, muitas delas estão em desacordo com a resolução CONAMA 357/ 05, como apresentado anteriormente nas tabelas 43 e 44 , sendo estas estações classificadas como Classe 3.

D entre os rios utilizados para essa análise comparativa, destacam-se os rios Sarandi e Ressaca (ambos tributários formadores do reservatório da Pampulha MG) pelas altas concentrações de todos os metais analisados, sendo derivadas principalmente de efluentes industriais (RIETZLER et al, 2001). No caso do rio Sarandi, grande parte dos efluentes do Complexo Industrial de Contagem são lançados no rio, sendo que a sua composição varia devido à diversidade de atividades desenvolvidas nesse complexo (industrias de ferro e aço, de construção civil, solventes e tintas). Em relação ao rio Ressaca, o maior contribuidor para as altas concentrações de metais é o efluente líquido do depósito de lixo da cidade. 
Tabela 45. Análise comparativa das concentrações de metais ( $\mu$ g.L-1 $\left.{ }^{-1}\right)$ de diferentes sistemas lóticos. Em negrito, concentrações acima do estabelecido pela resolução CONAMA 357/ 05 para águas Classe 2.

\begin{tabular}{lccccc}
\hline Rios/ Metais & Cd & $\mathbf{C u}$ & $\mathbf{C r}$ & $\mathbf{Z n}$ & $\mathbf{M n}$ \\
\hline Resolução Conama 357/ 05 - Classe 2 & $\mathbf{1 , 0 0}$ & $\mathbf{9 , 0 0 1}(\mathbf{2 0 , 0})$ & $\mathbf{5 0 , 0 0}$ & $\mathbf{1 8 0 , 0 0}$ & $\mathbf{1 0 0 , 0 0}$ \\
\hline Rio Monjolinho - presente estudo & 0,66 & 9,69 & 4,70 & 22,20 & 88,72 \\
Rio Monjolinho - Barreto (1999)* & $\mathbf{7 , 7 7}$ & 8,88 & 22,22 & $\mathbf{3 7 7 , 7 0}$ & $\mathbf{1 0 5 , 5 5}$ \\
Rio Atibaia - Domfeld (2002) & $\mathbf{4 , 0 0}$ & $\mathbf{3 2 , 0 0}$ & 43,00 & 51,00 & $\mathbf{2 3 0 , 0 0}$ \\
Rio Peliteira - Faria (2005) & $\mathbf{3 0 , 0 0}$ & nd & nd & $\mathbf{2 3 3 0 , 0 0}$ & $\mathbf{2 2 4 0 , 0 0}$ \\
Rio Piracicaba - Rodgher (2003) & $\mathbf{6 , 9 0}$ & 2,70 & 28,00 & $\mathbf{6 1 1 , 0 0}$ & na \\
Rio Sarandi - Rietzler et al (2001) & nd & $\mathbf{5 5 , 0 0}$ & $\mathbf{4 5 0 , 0 0}$ & $\mathbf{3 0 0 , 0 0}$ & $\mathbf{1 5 0 0 , 0 0}$ \\
Rio Ressaca - Rietzler et al (2001) & $\mathbf{9 5 , 0 0}$ & $\mathbf{1 2 0 , 0 0}$ & $\mathbf{1 2 5 , 0 0}$ & $\mathbf{1 3 0 0 , 0 0}$ & $\mathbf{1 0 5 0 0 , 0 0}$ \\
\hline * média da coleta 1 (dezembro de 1996); nd - não & detectado; na - nẫo analisado; ${ }^{1-}$ - Cu dissolvido \\
(CONAMA 357/ 05); ${ }^{2}$ - Cu total (CO NAMA 20/ 86). & & & &
\end{tabular}

Considerando-se os dados da CETESB (2005) (Tabela 46) referentes aos principais rios que compõem a UGRHI 13 (Tietê-Jacaré), a qual pertence 0 rio Monjolinho, observaram-se problemas em relação ao Fe e fósforo total (PT), bem como para $\mathrm{Pb}, \mathrm{Hg}$ e $\mathrm{Al}$, estes últimos não analisados no presente estudo. Segundo a CETESB (op cit) o rio Jacaré-G uaçu apresentou um IAP (Índice de Qualidade das Águas para Fins de Abastecimento) médio anual Regular, enquanto que as classificações médias dos rios Tietê e Jacaré-Pepira enquadraram-se na categoria Boa. As recomendações da CETESB foram a minimização das fontes adicionais de nutrientes neste trecho do rio Tietê, priorizando o tratamento dos esgotos domésticos gerados nas sub-bacias dos rios Jacaré-G uaçu, Jacaré-Pepira e Lençóis, e também a implementação de programas de conservação do solo e reconstituição de mata ciliar.

Tabela 46. Análise comparativa da água do rio Monjolinho com os dados da Cetesb (2005) referentes aos principais rios pertencentes à UGRHI 13. Resultados expressos em mg.L-1.

\begin{tabular}{|c|c|c|c|c|c|c|c|}
\hline Rios/ Variáveis & $\mathrm{Cl}^{-2}$ & $\mathrm{Cu}$ & Fe & Mn & Zn & OD & PT \\
\hline C0NAMA 357/ 05 & 250,0 & $0,009^{*} / 0,02^{* *}$ & 0,30 & 0,10 & 0,18 & $>5,0$ & 0,10 \\
\hline $\begin{array}{l}\text { rio Monjolinho } \\
\text { (presente estudo) }\end{array}$ & 5,44 & 0,009 & 2,58 & 0,088 & 0,02 & 6,50 & 0,27 \\
\hline $\begin{array}{l}\text { no Jacaré-Guaçu } \\
\text { no Jacaré-Pepira } \\
\text { no Tietê } \\
\text { no Lençóis }\end{array}$ & $\begin{array}{c}3,93 \\
1,46 \\
24,30 \\
-\end{array}$ & $\begin{array}{l}<0,01 \\
<0,01 \\
<0,01 \\
<0,01\end{array}$ & $\begin{array}{l}3,53 \\
4,14 \\
0,32 \\
5,09\end{array}$ & $\begin{array}{l}0,090 \\
0,090 \\
0,046 \\
0,085\end{array}$ & $\begin{array}{l}<0,02 \\
<0,02 \\
<0,02 \\
0,03\end{array}$ & $\begin{array}{l}5,40 \\
6,63 \\
5,95 \\
5,80\end{array}$ & $\begin{array}{l}0,10 \\
0,05 \\
0,09 \\
0,15\end{array}$ \\
\hline
\end{tabular}


Em relação aos sedimentos do sistema, verificou-se que, em geral, são do tipo arenoso, e, portanto, possuem baixas concentrações de fósforo total e nitrogênio orgânico total, os quais poderiam estar ligados diretamente com a fração argila e com a matéria orgânica associada. As estações com maiores concentrações dessas variáveis foram a Federal e a Foz por possuírem maiores porcentagens de matéria orgânica e, em sua constituição granulométrica, as maiores porcentagens de areia fina e silte + argila, em relação às demais estações.

Dentre os parâmetros utilizados no estudo da qualidade de sedimentos, percebeu-se que o potencial redox apresentou-se como uma variável importante, sendo que no sistema em estudo, o potencial redox representou bem as características das estações mais problemáticas em relação às concentrações de metais potencialmente biodisponíveis. Por exemplo, em julho/03, as estações Federal, Tijuco e Foz apresentaram os valores de potencial redox mais negativos (Tabela 47) e as concentrações mais elevadas dos metais, bem como de matéria orgânica.

Tabela 47. Potencial redox, metais potencialmente biodisponíveis e matéria orgânica durante 0 período de estudo no rio Monjolinho e tributários.

\begin{tabular}{lccc}
$\begin{array}{c}\text { Meses e estações de } \\
\text { amostragem }\end{array}$ & Potencial redox & $\begin{array}{c}\text { Metais com concentrações } \\
\text { mais elevadas }\end{array}$ & $\begin{array}{c}\text { Maiores \% de } \\
\text { Matéria orgânica }\end{array}$ \\
\hline Federal - jul/ 03 & -201 & $\mathrm{Cr} / \mathrm{Zn} / \mathrm{Mn} / \mathrm{Fe}$ & $*$ \\
Tijuco- jul/ 03 & -210 & $\mathrm{Cr} / \mathrm{Cd} / \mathrm{Cu} / \mathrm{Zn}$ & $*$ \\
Foz- jul/ 03 & -189 & $\mathrm{Cd} / \mathrm{Cu}$ & $*$ \\
Federal - out/ 03 & -177 & $\mathrm{Cr}$ & $*$ \\
Foz- out/ 03 & -192 & $\mathrm{Cd} / \mathrm{Cu} / \mathrm{Zn} / \mathrm{Mn} / \mathrm{Fe}$ & \\
Tijuco - jan/ 04 & -34 & $\mathrm{Cr} / \mathrm{Cu} / \mathrm{Zn} / \mathrm{Mn} / \mathrm{Fe}$ & $*$ \\
Federal - abr/ 04 & -194 & $\mathrm{Cd} / \mathrm{Cu} / \mathrm{Zn} / \mathrm{Mn} / \mathrm{Fe}$ & $*$ \\
\hline
\end{tabular}

A CETESB inseriu na sua rede de monitoramento de águas interiores a análise de sedimentos, que apesar de ainda possuir poucos pontos de coleta em relação à de água, tem mostrado a importância do estudo desse compartimento para o monitoramento dos recursos hídricos do Estado de São Paulo. A Tabela 48 é uma compilação dos dados obtidos pela CETEB (2005) e mostra o estágio avançado de contaminação do sedimento de vários ambientes lóticos. 
Tabela 48. Dados da Cetesb (2005) em relação aos metais no sedimento dos rios do Estado de São Paulo. Entre parêntesis está apresentado o número da UGRHI a que pertence o rio.

\begin{tabular}{lcccccc}
\multicolumn{1}{c}{ Estação de coleta } & $\mathbf{P b}$ & $\mathbf{C r}$ & $\mathbf{N i}$ & $\mathbf{Z n}$ & $\mathbf{C u}$ & $\mathbf{H g}$ \\
\hline Rio Paraíba do Sul (2) & $*$ & $*$ & $*$ & $*$ & nd & nd \\
Rio Atibaia (5) & $*$ & $*$ & $* *$ & $* *$ & $*$ & nd \\
Rio Piracicaba (5) & $*$ & $*$ & $*$ & $*$ & $*$ & nd \\
Rio Tatu (5) & $*$ & $*$ & $* *$ & $*$ & $* *$ & nd \\
Ribeirão do Q uilombo (5) & $*$ & $*$ & $* *$ & $*$ & $*$ & nd \\
Rio Tietê (6 - Alto Tietê) & $*$ & nd & nd & nd & nd & nd \\
Rio Cubatão (7) & $*$ & $*$ & $*$ & $*$ & $*$ & $*$ \\
Rio Mogi-Guaçú (9) & $*$ & nd & nd & nd & nd & nd \\
Rio Sorocaba (10) & nd & nd & nd & nd & nd & nd \\
Ribeira de Iguape (11) & $* *$ & $*$ & $*$ & $*$ & $*$ & nd \\
Rio do Peixe (21) & nd & nd & nd & nd & $*$ & nd \\
\hline *- concentrações acima do TEL (threshold effect level), valor guia estabelecido pelo “Canadian Council of \\
Ministers of the Environment"; ** - concentrações severas; nd - não detectado.
\end{tabular}

SMITH et al (1996) e MacD ONALD et al. (2000) sugeriram critérios para avaliação da qualidade de sedimento e, dentre os parâmetros utilizados, aqueles referentes aos metais no sedimento estão apresentados na Tabela 49. De uma forma comparativa, analisou-se as concentrações de metais presentes no sedimento de outros sistemas em relação aos critérios sugeridos pelos autores. As concentrações sugeridas por SMITH et al. (op cit.) em relação ao PEL ("problable effect level") são aquelas utilizadas pelas Normas Canadenses de Qualidade Ambiental (2002). Para a elaboração das Normas Canadenses de Qualidade de Sedimento para proteção da vida aquática alguns critérios foram avaliados, podendo-se citar os testes de toxicidade com sedimento e água intersticial, estrutura da comunidade bentônica, tríade de qualidade de sedimentos, resíduos em tecidos e as normas de qualidade de água (CCME, 1995). Dessa forma, o documento baseia-se em critérios químicos, toxicológicos e biológicos para uma avaliação integrada do sedimento.

Observa-se que o rio Monjolinho apresentou as menores concentrações de metais potencialmente biodisponíveis no sedimento quando comparado com outros sistemas. Isso pode ocorrer devido à sua granulometria, composta por grande porcentagem de areia em todo o seu curso, o que dificulta a sorção de metais, deixando-os provavelmente disponíveis na água ou para os organismos. D entre as citações estudadas, destaca-se os rios Tietê, Spokane, Puttershoek e Dommel Neerpelt pelas altas concentrações de metais no sedimento. A pesar da granulometria desses rios citados também variarem da areia fina à grossa, os autores sugerem que 0 
uso e ocupação do solo de entorno, bem como o lançamento de efluentes industriais, tem contribuído para o grande acúmulo de metais nos sedimentos. 0 rio Peliteira possui também altas concentrações de metais e é contaminado porque sua bacia de drenagem inclui uma mina de ouro abandonada desde 1992, sendo 14,4 ha de depósito a céu aberto de resíduos da mina contendo altas concentrações de Ar, $\mathrm{Cd}$, Cu e Zn (FARIA, 2005).

Tabela 49. Valores guias estabelecidos por Smith et al. (1996) e MacD onald (2000) e análise comparativa das concentrações de metais nos sedimentos de diferentes sistemas lóticos. Em negrito, valores mais restritivos $\mathrm{e}^{*}=$ concentrações acima do proposto pelos autores.

\begin{tabular}{|c|c|c|c|c|}
\hline Metais no sedimento (mg.kg-1) & Cd & $\mathrm{Cu}$ & $\mathrm{Cr}$ & Zn \\
\hline SMITH et al. & $\mathbf{0 , 6 0}$ & 35,70 & 37,30 & 123,00 \\
\hline (1996) & 3,50 & 197,00 & 90,00 & 315,00 \\
\hline MACDONALD et al. (2000) & 0,99 & 32,00 & 43,00 & 121,00 \\
\hline rio Monjolinho - presente estudo & 0,03 & 4,37 & 0,70 & 118,94 \\
\hline rio Monjolinho - Barreto (1999) & 0,00 & 5,89 & 2,00 & 15,10 \\
\hline rio Monjolinho - Pelaez-Rodrigues (2001) & 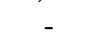 & $<10,00$ & $<0,35$ & $<25,00$ \\
\hline rio Atibaia- D ornfeld (2002) & 0,35 & 14,20 & $44,30 *$ & 46,70 \\
\hline rio Tietê - Rodgher (2005) & $1,23 *$ & $39,16 *$ & 8,93 & $147,03^{*}$ \\
\hline rio Piracicaba - Rodgher (2005) & $1,83^{*}$ & $33,90 *$ & 8,86 & 101,15 \\
\hline rio Spokane - Johnson \& Norton (2001) & $12,70^{*}$ & 21,60 & 21,00 & $1520,50 *$ \\
\hline rio Detroit - Giesy (1990) & $24,7 *$ & $111,3 *$ & $89,30 *$ & $562,70^{*}$ \\
\hline rio Puttershoek - Lahr et al (2003) & $5,53 *$ & $94,40^{*}$ & $137,00 *$ & $600,00^{*}$ \\
\hline rio D ommel Neerpelt - Lah et al (2003) & $37,30 *$ & 16,00 & 10,70 & $542,00^{*}$ \\
\hline rio Peliteira - Faria et al. (2005) & 0,07 & 0,20 & 0,35 & 3,64 \\
\hline rio Mondego - Vale et al (2002) & 0,25 & 29,50 & $55,50 *$ & 89,00 \\
\hline
\end{tabular}

${ }^{1}$ TEL - threshold effect level (concentrações abaixo deste valor são raramente associadas à efeitos biológicos adversos); ${ }^{2}$ PEL - problable effect level (concentrações acima deste valor são freqüentemente associadas à efeitos biológicos adversos). O s valores apresentados são a média encontrada para o sistema em estudo.

Com os resultados apresentados do presente estudo, pode-se sugerir medidas de mitigação desses impactos na qualidade dos corpos hídricos. Embora tenha sido apresentado exemplos de sistemas que possuem problemas de contaminação, tanto da água quanto do sedimento, piores do que aqueles apresentados pelo rio Monjolinho, deve-se considerar a urgência da tomada de decisão no que se refere à contaminação desse sistema, considerando que este apresenta ainda usos múltiplos em alguns trechos, tais como a dessedentação de animais, pesca e irrigação de áreas agrícolas.

Uma das medidas mais emergenciais seria a construção da Estação de Tratamento de Esgoto no município de São Carlos (SP), que está com a licença de instalação aprovada pelo órgão ambiental competente. Além disso, dever-se-ia fazer 
cumprir a legislação ambiental vigente, promovendo uma diminuição nas concentrações dos compostos lançados nos efluentes industriais. Em relação ao uso dos agrotóxicos organoclorados no Brasil, sabe-se que existe uma legislação bastante restritiva e somente uma maior fiscalização junto aos proprietários rurais seria eficiente para que houvesse um maior controle dos tipos de agrotóxicos que têm sido utilizados atualmente nos cultivos. Portanto, somente um trabalho em conjunto com os Órgãos Públicos, nas esferas Municipal, Estadual e Federal, bem como a participação da sociedade civil organizada, conseguirá reverter esse quadro de contaminação do rio Monjolinho e seus tributários.

\section{CONCLUSÃO}

A partir dos resultados obtidos, foi possível concluir que o rio Monjolinho apresenta um gradiente longitudinal de contaminação crescente da Nascente em direção à Foz, mas mostrando um pequeno processo de autodepuração entre as estações Ponte Caída e Foz, devido à contribuição de tributários com melhor qualidade de água, como os córregos do Cancan e da Serra.

D evido às altas concentrações dos compostos nitrogenados, fosfatados, de metais e organoclorados, fica evidente a contaminação do rio Monjolinho e de seus tributários, principalmente o córrego do Tijuco, Gregório e Água Quente. Essa contaminação é causada pelo lançamento de efluentes não tratados, tanto industriais quanto domésticos, bem como pelo uso de agrotóxicos nas culturas no entorno do rio, principalmente a monocultura de cana-de-açúcar.

\section{BIBLIOGRAFIA}

ASSOCIAÇÃO BRASILEIRA DE NORMAS TÉCNICAS - ABNT. Análise granulométrica de solos, 1968. 32p.

ALMEIDA, P.J. Intoxicação por agrotóxicos: informações selecionadas para abordagem clínica e tratamento, Ed. Andrei, $1^{0}$ edição, São Paulo, 2002. 165p.

ANDERSEN, J.M. An ignition method for determination of total phosphorus in lake sediments. Water Research; 10: 329-331, 1976. 
AGÊNCIA NACIONAL DE VIGILÂNCIA SANITÁRIA - ANVISA. www.anvisa.gov.br, 2004.

AMERICAN PUBLIC HEALTH ASSOCIATION - APHA - American Water Work Association; Water Control Federation. Standard methods for the examination of water and wastewater. 19 Ed. New York, 1995. 1268p.

AMERICAN SOCIETY FOR TESTING AND MATERIALS - ASTM. Standard guide for determination of the bioaccumulation of sediment-associated contaminants by benthic invertebrates - E1688-00, 2000. 54p.

BAIRD , C. Q uímica Ambiental, Artmed ${ }^{\circledR}$ Editora, Porto Alegre, RS, 2002. 622p.

BARBOSA, R.. Avaliação do impacto de efluentes (lodos) de Estações de Tratamento de Água à biota aquática através de testes de toxicidade, 2000. Tese (D outorado), Escola de Engenharia de São Carlos, Universidade de São Paulo, 2000. 199p.

BARRETO , A.S., Estudo da distribuição de metais em ambiente lótico , com ênfase na assimilação das comunidades biológicas e a sua quantificação no sedimento e água, 1999. Tese (Doutorado), Escola de Engenharia de São Carlos, Universidade de São Paulo, 1999. 274p.

BENINI, R.M.. Cenários de ocupação urbana e seus impactos no ciclo hidrológico na bacia do córrego do Mineirinho, 2005. Dissertação (Mestrado), Escola de Engenharia de São Carlos, Universidade de São Paulo, 2005. 122p.

BERVOETS, L.; BLUST, R.; WIT, M; VERHEYEN, R.. Relationships between river sediment characteristics and trace metal concentrations in tubificid worms and chironomid larvae, Environmental .Pollution, 95:354-356, 1997.

BRASIL - MINISTÉRIO DA SAÚDE. Portaria no 518 de 25 de março de 2004. Estabelece os procedimentos e responsabilidades relativos ao controle e vigilância da qualidade da água para consumo humano e seu padrão de potabilidade, e dá outras providências, 2004, 15p.

BRIG ANTE, J.; ESPÍND O LA, E.L.G. Limnologia fluvial: um estudo no rio MogiGuaçu, São Carlos, Rima Editora, 2003. 278p.

CAMPAGNA, A.F. Toxicidade dos sedimentos da Bacia Hidrográfica do rio Monjolinho (São Carlos - SP): ênfase nas substâncias cobre, aldrin e heptacloro, 
2005. Dissertação (Mestrado). Faculdade de Zootecnia e Engenharia de Alimentos, Universidade de São Paulo, 2005. 281p.

CANADIAN COUNCIL OF MINISTERS OF THE ENVIRONMENT - CCME EPC-98E. Protocol for the derivation of Canadian Sediment Q uality Guidelines for the Proteccion of Aquatic Life, 1995, 35p.

Canadian Sediment Quality Guidelines for the Proteccion of Aquatic Life - Summary tables, 2002, 7p.

CETESB - Companhia de Tecnologia e Saneamento Ambiental. Relatório de qualidade das águas interiores do Estado de São Paulo 2000. Secretaria do Meio Ambiente, 2001. 213p.

Relatório de qualidade das águas interiores do Estado de São Paulo 2004. Secretaria do Meio Ambiente, 2005. 307p.

CONSELHO NACIONAL DO MEIO AMBIENTE - CONAMA - Resolução CONAMA 20 de 12 junho de 1986. In: Coletânea de Legislação Ambiental Federal - Estadual, 1991. Imprensa O ficial do Estado do Paraná.

Resolução CONAMA 357 de 17 de março de 2005. Ministério do Meio Ambiente - www.mma.gov.br, 2005.

D ORES, E.F.G de; FREIRE, E.M. de L. Contaminação de ambientes aquáticos por agrotóxicos: via de contaminação e dinâmica, dos agrotóxicos no ambiente aquático. Revista Toxicologia e Meio Ambiente, Curitiba, 9:1-18, 1999.

D ORNFELD , C.B. Utilização de análises limnológicas e bioensaios toxicológicos em macroinvertebrados bentônicos para 0 diagnóstico ambiental do reservatório de Salto Grande (Americana -SP), 2002. Dissertação (mestrado). São Carlos, 2002. 196p.

EGELER, P.; RÖMBKE, J.; MELLER, M.; KNACKER, T; NAGEL, R. Bioaccumulation test with Tubificid Sludgeworms in artificial media development of a standardisable method, Hidrobiologia 406: 271-280, 1999.

ESTEVES, F.A. Fundamentos de Limnologia. Rio de Janeiro. Interciência, FINEP, 1988, 575p.

FARIA, M; RÉ, A.; MALCATO, J.; SILVA, P.C.L.D .; AGRA, A.R.; PESTANA, J.; NOGUEIRA, A.J.A.; SOARES, A.M.V.M.. Chapter 1. Biological and functional responses of in situ bioassays with Chironomus riparius larvae to assess 
river water quality and contamination. In: Ecological assessment of water quality using in situ bioassay with C. riparius. Tese (D outorado), Universidade de Aveiro, Portugal, 2005. 143p.

FELLENBERG, G. Introdução aos problemas da poluição ambiental. $4^{\circ}$ reimpressão, Editora Pedagógica e Universitária (EPU) LTD A., 2003. 196p.

FORSTNER, U.; WITTMAN, G.T.W.. Metal pollution in the aquatic environment, Springer-Verlag, $2^{\circ}$ edição revisada, Berlin, Alemanha, 1983. 475p.

GIESY, J.P.; ROSIU, C.J.; GRANEY, R.L.. Benthic invertebrate bioassays with toxic sediment and pore water. Environmental Toxicolology and Chemistry. 9:233-248, 1990.

GILLESPIE, W.B; RODGERS, J.H; DORN, P.B. Responses of aquatic invertebrates to a linear alcohol ethoxylate surfactant in stream mesocosms. Ecotoxoxicology Environment and Safety, 41: 215-221, 1998.

GOLTERMAN, H.L.; CLYMO, R.S.; OHNSTAD, M.A.M. Methods for physical and chemical analysis of fresh water. 2 ed. Oxford, Blackweel Scintific Publications (IBP, 8), 1978. 213p.

JOHNSON, A.; NORTON, D . Chemical Analysis and Toxicity Testing of Spokane River Sediments Collected in October 2000, Environmental Assessment Program Olympia, Washington, 188p, 2001.

KOROLEFF, F. Determination of nutrients. In: GRASSOHOF, K. Methods of seawater analysis. Verlag. Chemie. Weinhein., 1976.p. 117-181.

LAHR, J., MAAS-DIEPEVEEN, J.L., STUIJFZAND, S.C., LEONARD S, P.E.G., D RUKE, J.M., L.UCKER, S., ESPELD O ORN, A., KERKUM, L.C.M., VAN STEE, L.L.P, HEND RIKS, A.J. Responses in sediment bioassays used in the Netherlands: can observed toxicity be explained by routinely monitored priority pollutants? Water Research 37:1691-1710, 2003.

LANÇAS, F.M. Extração em fase sólida. Apostila- Instituto de QuímicaUniversidade de São Paulo, 1997. 53p.

LAWS, E.A. Aquatic pollution: an introductory text. 2. ed. Interscience publication, John Wiley \& Sons, INC. New York, 1999, 611p. 
LEEUWESTEIN, J.M.; MONTEIRO, R.A.; ARAÚJO FILHO, A.. Procedimentos técnicos para o enquadramento de corpos de água - Documento Orientativo. Ministério do Meio Ambiente, Secretaria de Recursos Hídricos, 2000. 47p.

LEITE, M.A. Análise do aporte, da taxa de sedimentação e da concentração de metais na água, plâncton e sedimento do reservatório de Salto Grande, Americana - SP, 2002. Tese (doutorado),. Escola de Engenharia de São Carlos, Universidade de São Paulo, 2002. 197p

MACD ONALD, D.D.; INGERSOLL, C.G.; BERGER, T.A. Development and Evaluation of Consensus-Based Sediment Quality Guidelines for Freshwater Ecosystems. Achieves Environment Contamination Toxicology. 39:20-31, 2000. MACKERETH, S.J.H., HERON, J., TALLING, J.S. Water analysis some revised methods for limnology. Kendal, freshwater Biol. Assoc. Sci. Publ. 36., Wilson and Sons, 1978. 117p.

MARINELLI, C.E; MORETTO,E.M; BRUCHA, G \& LUCCA, J.V. Limnologia. In: ESPÍND OLA, E.L.G; SILVA, J.S.V; MARINELLI, C.E \& ABD O N, M.M. A Bacia Hidrográfica do rio Monjolinho, RiMa Editora, São Carlos, SP, 2000. p.133-149.

MARTINELLI, L.A. \& KRUSCHE, A.V. Amostragem em rios, In: BICUDO, C.E.M. \& BICUD O, D.C. (orgs.) Amostragem em Limnologia, RiMa Editora, São Carlos, SP, 2004. p. 263-280.

MOZETO, A.A. Critérios de qualidade de sedimentos (CQS) para metais pesados: fundamentos teóricos e técnicos para implementação. Anexo do relatório de Pós-doutorado FAPESP, 2001. 86p.

NOVELLI, A. Estudo limnológico e ecotoxicológico da água e sedimento do rio Monjolinho - São Carlos (SP), com ênfase nas substâncias de referência cádmio e cobre, 2005. Dissertação (Mestrado). Escola de Engenharia de São Carlos, Universidade de São Paulo, 2005. 288p.

NUSH, E.A. Comparasion of different methods for chlorophyl and phaeopigments determination. Arch. Fur. Hydrobiol., 14:14-36, 1980.

OKI, J; PEREIRA, E.M. Poluição ambiental causada por descarte de organoclorados: o impacto do uso de organoclorados como agrotóxicos. http:/ /junoki.vila.bol.com.br/ organoclorados/ organoclorados.html, 1999. 
OLIVEIRA, S.R. Avaliação da qualidade da água e do balanço de nutrientes do córrego do Cancã, município de São Carlos - SP, 2003. Dissertação (Mestrado). Escola de Engenharia de São Carlos, Universidade de São Paulo, 2003. 140p.

PELAEZ-RODRIGUES, M. Avaliação da qualidade da água da Bacia do Alto Jacaré-G uaçú/ SP (Ribeirão do Feijão e Rio do Monjolinho) através de variáveis físicas, químicas e biológicas, 2001. Tese (D outorado), Escola de Engenharia de São Carlos, Universidade de São Paulo, 2001. 45p. + anexos.

RIETZLER, A.C.; FONSECA, A.L.; LOPES, G.P.. Heavy metals in tributaries of Pampulha reservoir, Minas Gerais. Brazilian Journal Biology, 61(3):363-370, 2001.

ROD GHER, S.; ESPÍND O LA, E.L.G .; ROCHA, O ; FRACACIO, R.; PEREIRA, R.H.G.; RODRIGUES, M.H.S. Ecotoxicological analysis of the water and sediment from middle and low Tietê river cascade reservoirs (State of São Paulo, Brazil). Acta Limnologica Brasiliensia, 15 (3):81-93, 2003.

ROD GHER, S.; ESPÍND O LA, E.L.G .; ROCHA, O ;FRACACIO, R.; PEREIRA, R.H.G .; ROD RIG UES, M.H.S. Limnological and ecotoxicological studies in the cascade of reservoirs in the Tietê river (São Paulo, Brazil). Brazilian Journal Biology, 65(4):697-710, 2005.

SALOMONS, W.; FÖ RSTNER, U. Metals in the hydrocycle. Springer-Verlag, 1984. $349 \mathrm{p}$.

SANTOS, M.J. Estudo limnológico dos córregos Água Fria e Água Quente, 1993. Tese (Doutorado), Escola de Engenharia de São Carlos, Universidade de São Paulo, 1993. 294p.

SCHULZ, R; LIESS, M. A field study of the effects of a agriculturally derived insecticide input on stream macroinvertebrate dynamics. Aquatic Toxicology 46: 155-176, 1999.

SÉ, J.A.S. O rio Monjolinho e sua bacia hidrográfica como integradores de sistema ecológicos: um conjunto de informações para o início de um processo de pesquisas ecológicas, de educação, planejamento e gerenciamento ambientais a longo prazo, 1992. Dissertação (mestrado) - Escola de Engenharia de São Carlos, Universidade de São Paulo, 1992. 381p. 
SILVÉRIO, P.F. Partição, biodisponibilidade e toxicidade de metais pesados a organismos bentônicos em sedimentos. São Carlos, 1999. Dissertação (Mestrado). D epartamento de Química - Universidade Federal de São Carlos, 1999. 77p.

SMITH, S.L.; MacD ONALD , D.D .; KENNLEYSIDE, K.A.; INGERSO LL, C.G .; FIELD, L.J. A preliminary evaluation of sediment quality assessment values for freshwater ecosystems. Journal G reat Lakes and Research, 22:624-638, 1996.

TEIXEIRA, C., TUNDISI, J.G., KUTNER, M.B. Plankton studies in mangrove environmental. II. The standing stock and some ecological factors. Boletim do Instituto O ceanográfico, 24:23-41, 1965.

TONISSI, R.M.T. Percepção e caracterização ambientais da área verde da microbacia do córrego da Água Quente (São Carlos, SP) como etapas de um processo de educação ambiental, 2005. Tese (Doutorado), Escola de Engenharia de São Carlos, Universidade de São Paulo, 2005. 281p.

TRINDADE, M.. Nutrientes em sedimento da represa do Lobo (Brotas/ Itirapina, SP). São Carlos, 1980. Dissertação (Mestrado) - Universidade Federal de São Carlos, 1980. 219p.

VALE, C.; FERREIRA, A.; CAETANO, M; BRITO, P. Elemental composition and contaminants in surface sediments of the Mondego river estuary, In: PARDAL, M.A.; MARQUES, J.C.; GRAÇA, M.A. Aquatic/ ecology of the Mondego river basin - Global Importance of Local Experience, 2002. p.541550.

VIANA, S.M.. Riqueza e distribuição de macrófitas aquáticas no rio Monjolinho e tributários (São Carlos, SP) e análise de sua relação com variáveis físicas e químicas no ambiente estudado, 2005. Dissertação (Mestrado), Escola de Engenharia de São Carlos, Universidade de São Paulo, 2005. 122p.

WO OD , J.M. Biological cycles for toxic elements in the environment. Science. 183: 1049-1052, 1974.

ZAMBRONE, F.A.D. Perigosa família. Revista Ciência Hoje - Revista SBPC. Janeiro/ Fevereiro, p.44-47, 1986. 
Cappitunlo 3)

\author{
Avaliação ecotoxicológica do sedimento do rio Monjolinho e \\ tributánios por meio de bioensaios laboratoriais e "in situ" utilizando \\ Chironomus xanthus (Diptera, Chironomidae).
}

\title{
1. INTRODUÇÃO
}

A toxicologia ambiental e a ecotoxicologia são termos empregados para descrever o estudo científico dos efeitos adversos causados sobre os organismos vivos pelas substâncias químicas liberadas no ambiente (FERNICO LA et al., 2003), sendo que o primeiro termo é mais utilizado quando se abordam os efeitos causados sobre os seres humanos (RAND , 1995) e o segundo quando se abordam os efeitos sobre os ecossistemas e seus componentes não-humanos.

A ecotoxicologia alerta para as substâncias químicas que representam risco e, assim, sugere a aplicação de medidas preventivas antes que ocorram graves danos aos ecossistemas naturais (PAASIVIRTA, $1991^{2}$ apud FERNICO LA et al., 2003), preocupando-se "em estudar como os ecossistemas metabolizam, transformam, degradam, eliminam e sofrem a ação da toxicidade dos produtos químicos que nele penetram" (MELLO, $1981^{3}$ apud FERNICO LA et al., op. cit.).

O s efeitos adversos nos organismos incluem tanto os efeitos letais, expressos em mortalidade ou sobrevivência (em bioensaios agudos - curta duração - e crônicos - longa duração), quanto os efeitos sub-letais, que são mudanças no desenvolvimento, crescimento, comportamento, reprodução, atividades de entrada e detoxicação e estrutura dos tecidos (RAND , 1995). Segundo o mesmo autor, efeitos adversos em cada indivíduo incluem indução ou inibição de enzimas, ou de sistemas enzimáticos, e suas funções associadas. Além disso, devido ao fato de a exposição a agentes tóxicos ocorrer pela água, sedimento e alimento, as quantidades,

2 Paasivirta, J. Chemical Ecotoxicology. Chelsea: Lewis Publishers, Inc., 1991. 210p.

${ }^{3}$ Mello, D. de. Ecotoxicologia: introdução, conceito, principais ramos. In: Jornada Brasileira de Ecologia, 2., 1981, Campinas. p.127-131. 
concentrações e a biodisponibilidade desses agentes nesses compartimentos são de fundamental interesse.

O sedimento representa um compartimento no sistema aquático responsável pelo acúmulo de substâncias, tornando-se, portanto, um sumidouro desses elementos. Mas, dependendo das condições ambientais, tais como mudança no pH e condições de anoxia, o sedimento pode se tornar uma fonte de substâncias tóxicas para a coluna d'água, causando uma alteração geral nas condições do sistema em estudo. Por isso, os bioensaios ecotoxicológicos com sedimento são ferramentas importantes que fornecem informações sobre o nível de contaminação e também sobre os locais que proporcionam maior risco à biota aquática.

Organismos bentônicos para avaliação de qualidade e toxicidade de sedimentos têm sido utilizados em vários estudos no Brasil (FONSECA, 1997; PAMPLIN, 1999 e D ORNFELD , 2002) e no exterior (BURTO N, 1992; JANSSEN DE BISTHOVEN et al., 1998; MEREGALLI \& OLLEVIER, 2001). No Brasil, a espécie de quironomídeo mais utilizada em bioensaios de toxicidade é Chironomus xanthus, enquanto que no exterior as espécies padronizadas são $C$. riparius e $C$. tentans.

A Agência de Proteção Ambiental dos Estados Unidos (U.S. EPA) em 2000 normatizaram os bioensaios para avaliação da qualidade de sedimentos com os seguintes organismos bentônicos: H yalella azteca (Amphipoda), Chironomus riparius (Diptera) e L umbriculus variegatus (Oligochaeta). Outros protocolos internacionais, como por exemplo, da ASTM-E1706 (2000), protocolou os bioensaios de toxicidade de sedimentos utilizando $\mathrm{H}$ yalella azteca (Amphipoda), Chironomus tentans (D iptera), Chironomus riparius (D iptera), D aphnia magna (Cladocera), C eriodaphnia dubia (Cladocera), $\mathrm{H}$ ex agenia spp (Ephemeroptera), Tubifex tubifex (Oligochaeta) e D iporeia spp (Amphipoda). Também existe um protocolo para trabalhos com bioacumulação de contaminantes associados ao sedimento por invertebrados bentônicos (ASTME1688-00, 2000).

Dentre os tipos de bioensaios, os agudos têm sido preferidos por apresentarem uma resposta em curto período de tempo, o que é vantajoso em casos de monitoramento e tomadas de decisão. Porém, os bioensaios crônicos têm mostrado ser uma eficiente ferramenta de avaliação da contaminação por utilizar 
diferentes "endpoints" ou parâmetros finais, além da sobrevivência/ mortalidade utilizada em bioensaios agudos.

Historicamente, pesquisas sobre o desenvolvimento e padronização de métodos para avaliação da toxicidade em sedimentos contaminados tem principalmente enfatizado bioensaios laboratoriais, sendo que muitos desses bioensaios têm sido incorporados nas estruturas de regulamentações sobre avaliação e monitoramento de sedimentos contaminados e no desenvolvimento de critérios de qualidade de sedimento. Recentemente, uma maior ênfase tem sido dada no desenvolvimento e uso de técnicas para avaliação da contaminação de sedimentos em bioensaios "in situ" (SIBLEY et al., 1999).

D eve-se considerar que os bioensaios "in situ" são relativamente recentes na ecotoxicologia aquática baseados em estudos de campo, e muitas técnicas têm sido adaptadas para estudar especificamente a toxicidade "in situ" pela exposição de organismos-bioensaio diretamente nas condições do ambiente investigado. D essa forma, alterações nas condições de exposição, devido à transferências das amostras para o laboratório, podem ser evitadas ou minimizadas. Considerando que uma das desvantagens dos bioensaios laboratoriais com sedimentos é o fato de haver grande manipulação do mesmo, seja durante a coleta ou no preparo do ensaio, os bioensaios "in situ" vêm fornecer uma avaliação ecologicamente mais realista de poluentes no ambiente com o mínimo de manipulação do sedimento (CASTRO et al., 2003), embora apresentem alguns aspectos negativos, tais como a transferência dos organismos do laboratório para o campo e 0 estresse da maior manipulação.

Segundo MEREGALLI et al. (2000), vários bioensaios "in situ" tem sido desenvolvidos para monitorar os sistemas aquáticos, utilizando diferentes tipos de organismos, como peixes, dafinídeos, anfípodas, quironomídeos entre outros. SIBLEY et al. (op cit.), por exemplo, utilizaram Chironomus tentans e L umbriculus variegatus para avaliação da qualidade do sedimento em rios em Minnesota (USA), sendo os parâmetros finais de avaliação a sobrevivência e desenvolvimento (biomassa).

MELETTI (1997) e TONISSI (2000), empenharam-se no desenvolvimento de metodologias para utilização de peixes em bioensaios "in situ". É necessário, porém, um esforço para o desenvolvimento desses bioensaios com diferentes tipos 
de organismos e também para as condições encontradas em países tropicais, como é o caso do Brasil, já que as adaptações de bioensaios de regiões temperadas podem não ser totalmente satisfatórias.

\section{OBJETIVOS}

O objetivo do presente estudo foi avaliar a toxicidade aguda do sedimento do rio Monjolinho e tributários, por meio de ensaios laboratoriais e "in situ", utilizando como organismo-teste a espécie $\mathrm{C}$ hironomus $\mathrm{x}$ anthus.

\section{MATERIAIS E MÉTODOS}

\subsection{Manutenção dos organismos-teste - Chironomus xanthus}

O organismo-teste selecionado foi a espécie bentônica Chironomus xanthus (Chironomidae, Diptera), cujos exemplares foram obtidos em culturas mantidas no Laboratório de Ecotoxicologia e Ecofisiologia de Organismos Aquáticos (CRHEA Centro de Recursos Hídricos e Ecologia Aplicada) da Universidade de São Paulo, campus São Carlos. A escolha desta espécie deve-se, principalmente, a facilidade na obtenção e manutenção em grande quantidade, além de já ter sido alvo de estudos ecotoxicológicos anteriores (FONSECA, 1997; PAMPLIN, 1999; DORNFELD, 2002).

O cultivo da espécie de Chironomidae foi realizado em bandejas plásticas brancas cobertas por gaiolas de nylon para a retenção dos organismos adultos (Figura 1). Para iniciar a cultura são adicionadas aproximadamente 200 larvas do I instar. Nas bandejas foram colocados o sedimento-controle (esterilizado em mufla a $550^{\circ} \mathrm{C}$ por 1 hora) e 4 litros de água de manutenção (pH 6,5 - 7,5 e dureza de 12 - 16 $\mathrm{mgCaCO}_{3} \cdot \mathrm{L}^{-1}$ ), sendo que o cultivo dos organismos foi mantido sob constante aeração, em sala com temperatura controlada (entre 23 e 25ํㅡ) e fotoperíodo de 12 horas. Para a alimentação das larvas utilizou-se uma concentração de $10^{5}$ células/ mL de algas (clorofícea Selenastrum capricornutum), apenas no primeiro dia, e ração para 
peixes TetraMin ${ }^{\circledR}$ na proporção de $0,04 \mathrm{mg} / \mathrm{ml}$ de água nos demais dias (FONSECA, 1997; PAMPLIN, 1999; U.S. EPA, 2000 e D O RNFELD , 2002).
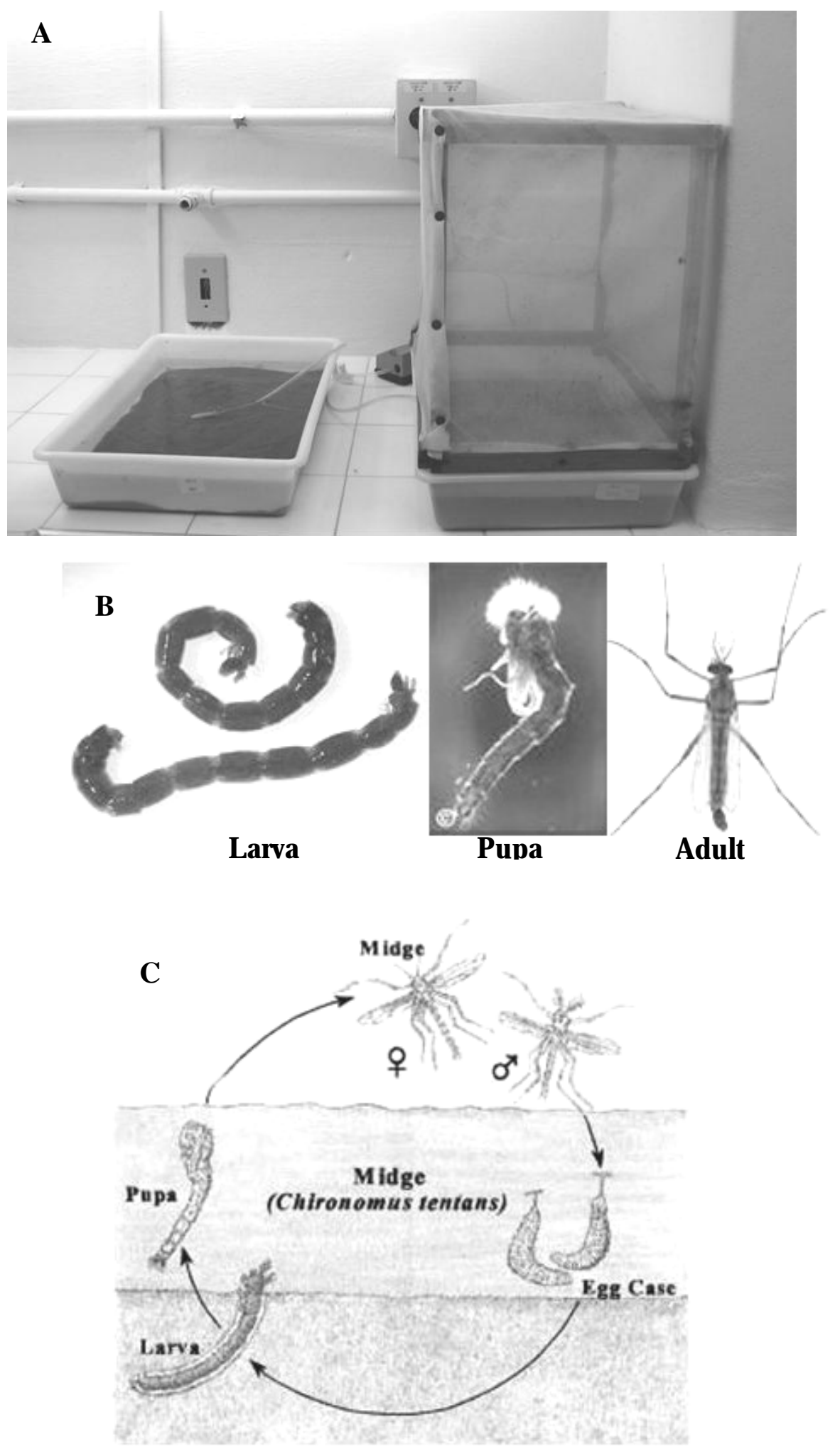

Wwwspringbornsmithers.com (acesso em 26 de julho de 2006)

Figura 1. Bandeja de cultivo de Chironomus xanthus (A), estágios do ciclo de vida (B) e esquema genérico do ciclo de vida de C hironomus sp (exemplo de Chironomus tentans) (C). 


\subsection{Avaliação das culturas dos organismos-teste}

Foram realizados testes de sensibilidade para avaliação da qualidade das culturas de $\mathrm{C}$ hironomus xanthus, os quais consistiram em expor os organismos-teste à diferentes concentrações de uma substância de referência.

A substância de referência utilizada para $C$. xanthus foi 0 cloreto de potássio $(\mathrm{KCl})$, nas concentrações de 1,5; 2,25; 3,5; 5,0 e 7,5 g.L-1. Para a realização desses testes utilizou-se $200 \mathrm{~mL}$ da solução de $\mathrm{KCl}$ e 6 organismos em cada réplica, totalizando 3 réplicas de cada concentração, com duração de 96h (FONSECA, 1997). O s resultados foram analisados utilizando programa Spearman-Karber, com a finalidade de se obter a CL50 para o Cloreto de Potássio.

\subsection{Procedimentos para realização dos bioensaios}

\subsubsection{Coleta de sedimento para os bioensaios de toxicidade aguda}

As amostras do sedimento foram coletadas no ambiente utilizando draga do Tipo Ekman-Birge, com área de $225 \mathrm{~cm}^{2}$, coletor de tudo PVC ou diretamente no pote plástico dependendo da profundidade da coluna d'água. Após a coleta as amostras foram mantidas sob baixa temperatura $\left(4^{\circ} \mathrm{C}\right)$, e, como proposto por BURTON (1992), a realização dos bioensaios de toxicidade não ultrapassou 0 tempo máximo de seis semanas após a coleta do material.

As coletas das amostras de sedimento para os bioensaios de toxicidade aguda foram realizadas em março, julho e outubro de 2003 e janeiro e abril de 2004. Foram coletadas amostras em 11 estações em março/03, julho/03 e janeiro/04 (Nascente, Federal, Madalena, USP, Mineirinho, Usina, Água Quente, Água Fria, Ponte caída, Serra e Foz) e 6 estações em outubro/ 03 e janeiro/ 04 (Nascente, Federal, USP, Usina, Ponte caída e Foz).

\subsubsection{Bioensaios de toxicidade aguda com amostra de sedimento utilizando-se Chironomus xanthus}

Os bioensaios de toxicidade aguda com sedimento foram realizados empregando-se a metodologia descrita em FONSECA (1997), que consiste em expor 6 organismos do IV ínstar em $60 \mathrm{~g}$ de sedimento fresco e $240 \mathrm{ml}$ de água de 
cultivo, mantendo a proporção proposta por BURTON (1992) de 1:4 sedimento:água. As condições de temperatura e fotoperíodo foram as mesmas utilizadas na manutenção das culturas. Visou-se caracterizar as estações de coleta em: tóxicas (mortalidade $>50 \%)$, indícios de toxicidade $(10<$ mortalidade $<50 \%)$ e não tóxicas (mortalidade < 10), como proposto por BARBOSA (2000).

Realizou-se a análise estatística de Fischer (TOXSTAT 3.4, WEST Inc., 1994) para comparação das estações de amostragem em relação ao controle laboratorial. Também foi realizada a análise de Correlação de Pearson para verificar quais variáveis ambientais da água (cloreto, sulfeto, fósforo total e amônio) e do sedimento (metais potencialmente disponíveis, matéria orgânica, nitrogênio orgânico total e fósforo total) podem explicar a toxicidade observada nos bioensaios.

\subsubsection{Bioensaios " in situ" utilizando Chironomus xanthus}

A metodologia seguiu as recomendações de BURTON (1992), BURTON et al. (1996), TONISSI (2000) e MELETTI \& ROCHA (2002), adaptadas para bioensaios com quironomídeos. Utilizou-se tubos de PVC com comprimento de 30 $\mathrm{cm}$ e diâmetro de $7 \mathrm{~cm}$ (Figura 2), com telas com abertura de malha de $300 \mu \mathrm{m}$ nas laterais e nas extremidades da câmara, de forma a permitir o fluxo de água e 0 contato com o sedimento. Colocou-se sedimento de cada estação no interior das câmaras, tomando-se o cuidado de triar os sedimentos para evitar a presença de organismos indesejáveis. As câmaras foram fixadas com arame em uma estaca de madeira, em triplicata, sendo posteriormente colocadas na água e fixadas no sedimento (Figura 3).

As estações selecionadas para a realização dos bioensaios "in situ" foram Nascente, Federal e Ponte caída, em outubro/ 03. Em janeiro/ 04, não foi possível instalar as câmaras na estação Ponte caída, substituída, então, pela estação Foz.

As câmaras foram expostas ao ambiente 24 horas antes do início do bioensaio. No primeiro dia, colocou-se 10 organismos do III - IV ínstar em cada réplica e a duração foi de 96 horas, sendo contabilizada a sobrevivência ao final do período de exposição e realizada as medidas de $\mathrm{pH}$, condutividade, oxigênio dissolvido e temperatura ao final do ensaio. 


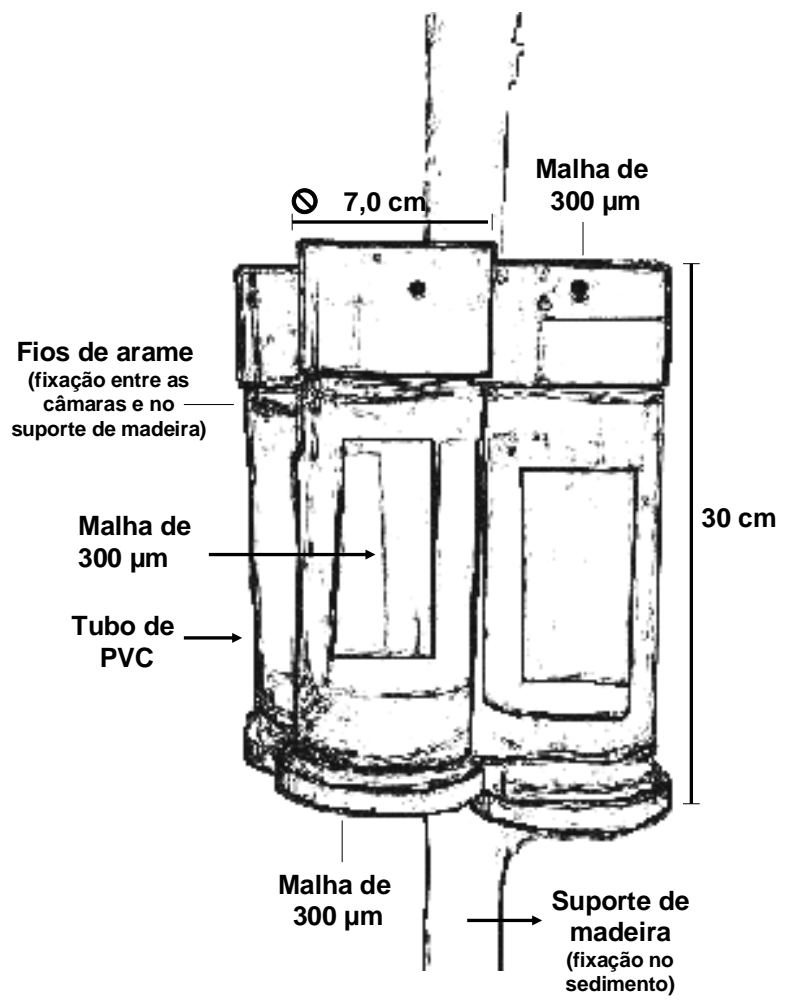

Figura 2. Esquema das câmaras utilizadas nos bioensaios "in situ" com Chironomus x anthus.
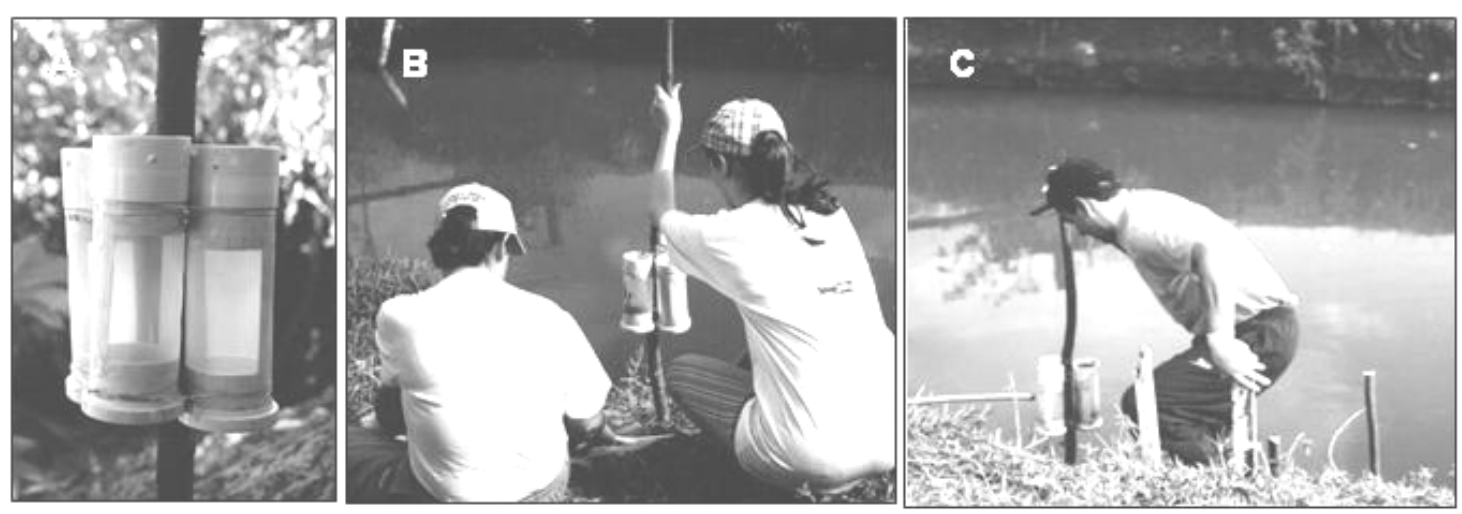

Figura 3. Seqüência da montagem do experimento "in situ": (A) Câmaras de PVC (B) Colocação do sedimento da estação e (C) Colocação do experimento na estação selecionada.

Realizou-se a análise estatística Teste-t para investigar se havia diferença significativa entre os resultados dos bioensaios laboratoriais e "in situ". 


\section{RESULTADOS}

\subsection{Teste de sensibilidade de Chironomus xanthus ao Cloreto de}

\section{Potássio}

Foram realizados 6 testes de sensibilidade ao $\mathrm{KCl}$, em datas próximas às coletas de campo, com a finalidade de garantir a boa qualidade das culturas utilizadas nos bioensaios.

Os resultados referentes aos testes de sensibilidade estão apresentados nas Tabelas de 1 a 8 no Apêndice 3, bem como na Figura 4, podendo-se verificar que a $\mathrm{CL}_{50}$ variou de 3,55 a 5,36 g.L-1 , com coeficiente de variação (CV) de 16\%. Em nenhum teste realizado os valores foram superiores à faixa de sensibilidade sugerida por FONSECA (1997), que varia de 2,6 a 6,4 g.L-1 . Na Tabela 9 pode-se observar as variáveis da estatística descritiva para a $\mathrm{CL}_{50}$ e os limites inferiores e superiores dos bioensaios de sensibilidade.

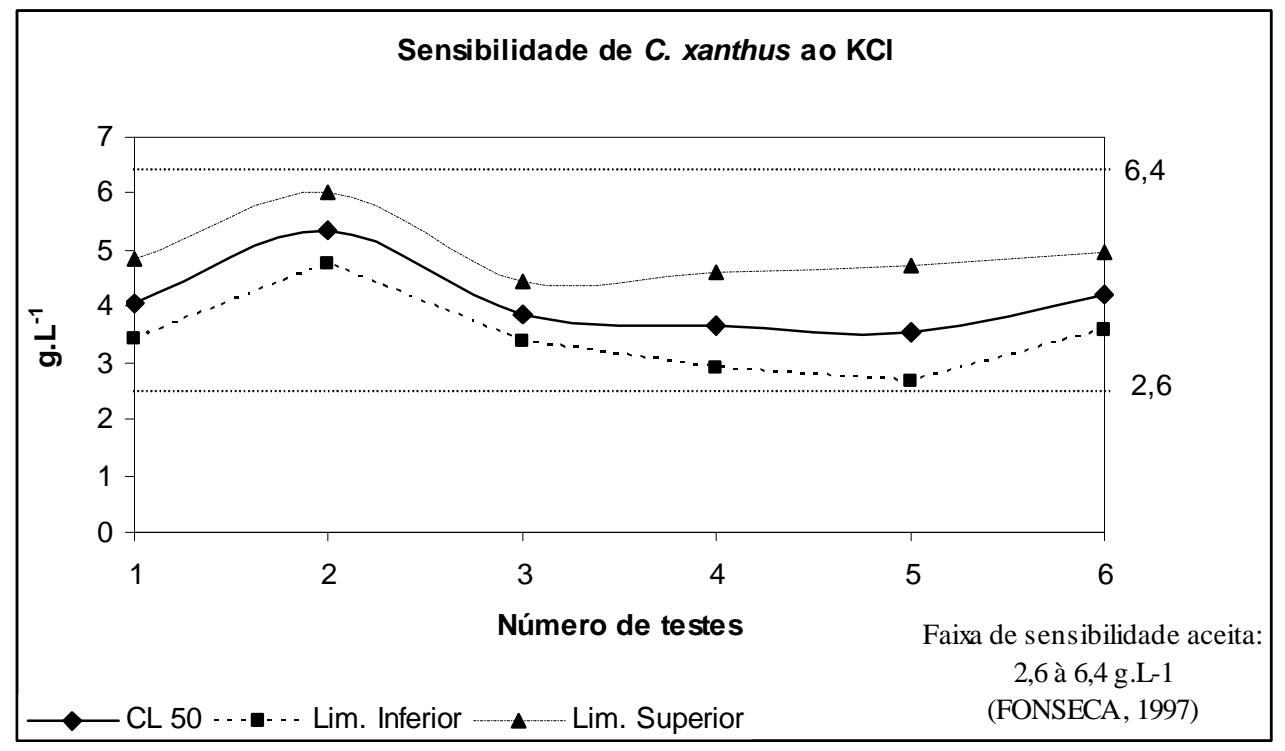

Figura 4. Resultados dos testes de sensibilidade ao $\mathrm{KCl}$ realizados com $\mathrm{C}$. xanthus, mostrando a faixa de sensibilidade sugerida por FO NSECA (1997). 
Tabela 9. Análise estatística dos resultados referentes aos testes de sensibilidade ao $\mathrm{KCl}$, utilizando C. xanthus.

\begin{tabular}{l|ccc}
\hline Variáveis - & CL 50 & Lim. Inferior & Lim. Superior \\
Estatística Descritiva & KCl & KCl & KCl \\
\hline Desvio padrão & 0,65 & 0,72 & 0,56 \\
Erro padrão & 0,26 & 0,29 & 0,23 \\
Máximo & 5,36 & 4,76 & 6,03 \\
Média & 4,11 & 3,45 & 4,93 \\
Mínimo & 3,55 & 2,69 & 4,45 \\
Variância da amostra & 0,43 & 0,52 & 0,32 \\
Contagem & 6 & 6 & 6 \\
\hline
\end{tabular}

\subsection{Bioensaios laboratoriais com amostras de sedimento}

Os resultados dos bioensaios laboratoriais com amostras do sedimento do rio Monjolinho e tributários estão apresentados na Figura 5 e Tabela 10 (Apêndice 3), sendo a análise estatística de Fisher apresentada no Apêndice 3, nas Tabelas de 11 a 15. Os resultados apontam que o sedimento apresenta-se tóxico à espécie $C$. xanthus em apenas duas estações amostradas, Usina (julho/03) e Federal (outubro/03), segundo classificação proposta por BARBO SA (2000), e com indícios de toxicidade nas estações Nascente, Federal, Serra (março/ 03), USP (julho/ 03, outubro/ 03 e janeiro/ 04), Ponte caída (outubro/ 03), Tijuco, Água Fria e Foz (janeiro/ 04).

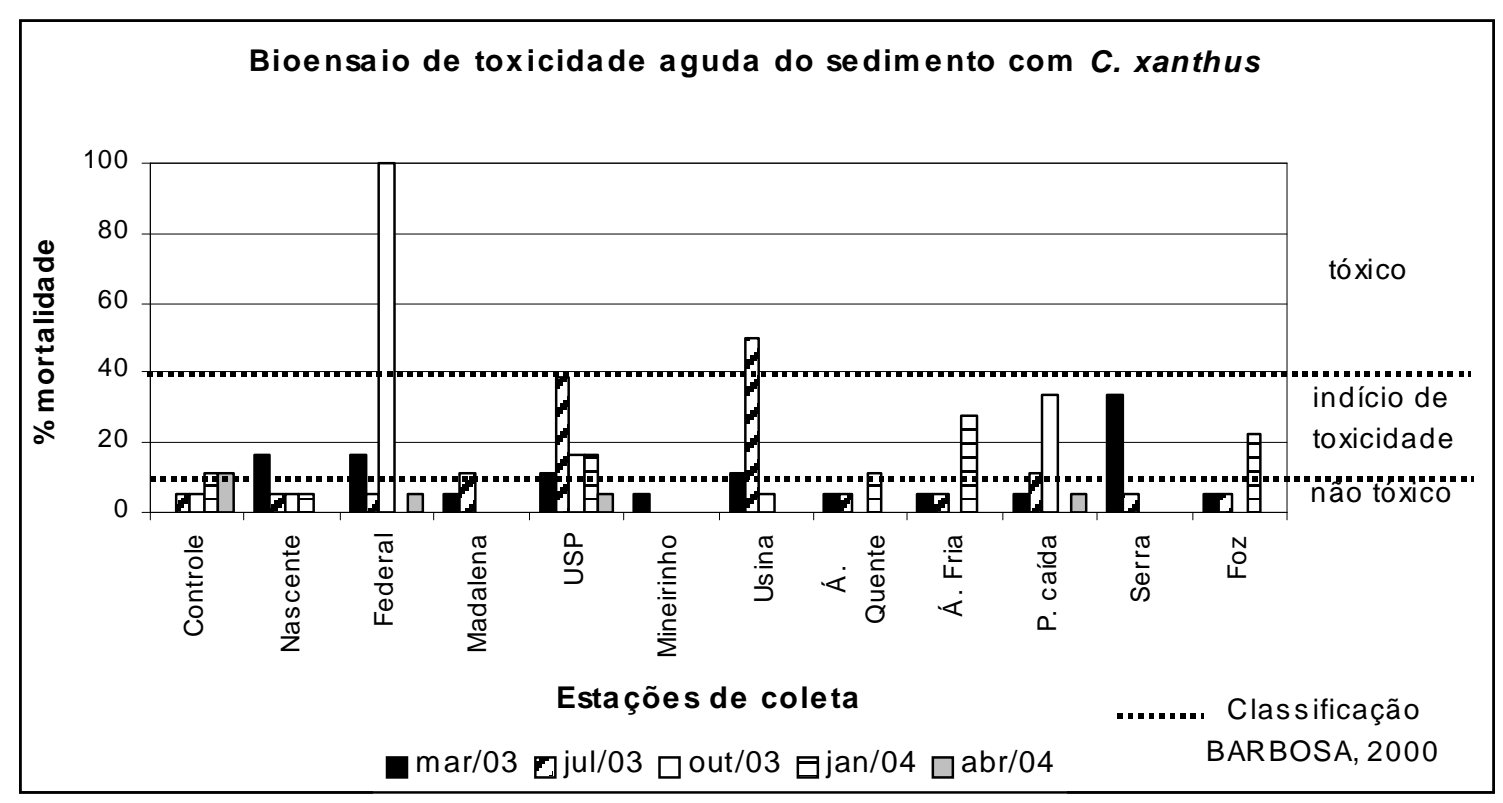

Figura 5. Bioensaios de toxicidade aguda do sedimento do rio Monjolinho e tributários utilizando Chironomus x anthus como organismo-teste durante o período estudado. 
Pela análise estatística de Fisher (Tabelas 11 a 15, Apêndice 3) observou-se que as estações Serra (março/ 03), USP e Usina (julho/ 03), Federal e Ponte caída (outubro/ 03) apresentaram toxicidade aguda ao Chironomus xanthus.

Quando se comparam os resultados obtidos no Teste de Fischer, com aqueles definidos pela classificação de BARBO SA (2000), observa-se que a partir de $30 \%$ de mortalidade o teste estatístico considera que a amostra possui diferença significativa quando comparada ao controle, e, portanto, apresenta toxicidade aguda.

0 Teste de Correlação de Pearson indicou correlação de diferentes parâmetros em relação à toxicidade dos ensaios laboratoriais nos diferentes períodos estudados (Tabelas 16 a 20, Apêndice 3). Em março/ 03, a correlação positiva foi para Cd, Mn e Fe biodisponíveis no sedimento e fósforo total (PT) na água. Em julho/ 03 não houve correlação da mortalidade com nenhum parâmetro analisado, sendo que em outubro/03 a correlação foi em relação à todos os metais potencialmente biodisponíveis no sedimento, bem como PT, nitrogênio orgânico total (NOT) e matéria orgânica (MO) no sedimento. Em janeiro/04 não foi observada nenhuma correlação e em abril/ 04 observou-se correlação positiva entre a mortalidade e MO e NOT.

\subsection{Bioensaios "in situ"}

Os resultados dos bioensaios "in situ" apontam para uma baixa sobrevivência dos organismos (entre 3 e 16\% em outubro/ 03 e entre 30 e 40\% em janeiro/ 04), como mostra a Figura 6. Observou-se, porém, que esses resultados não indicam, necessariamente, as estações com maior ou menor grau de toxicidade, já que houve alta mortalidade na nascente $(90$ e $60 \%$, em outubro/03 e janeiro/04, respectivamente). Quando se comparam os ensaios laboratoriais e "in situ", observa-se que nos bioensaios laboratoriais, a porcentagem de mortalidade foi sempre inferior àquela apresentada pelo bioensaio "in situ", sendo abaixo de 33,3\%, exceto na estação Federal em outubro/ 03. 


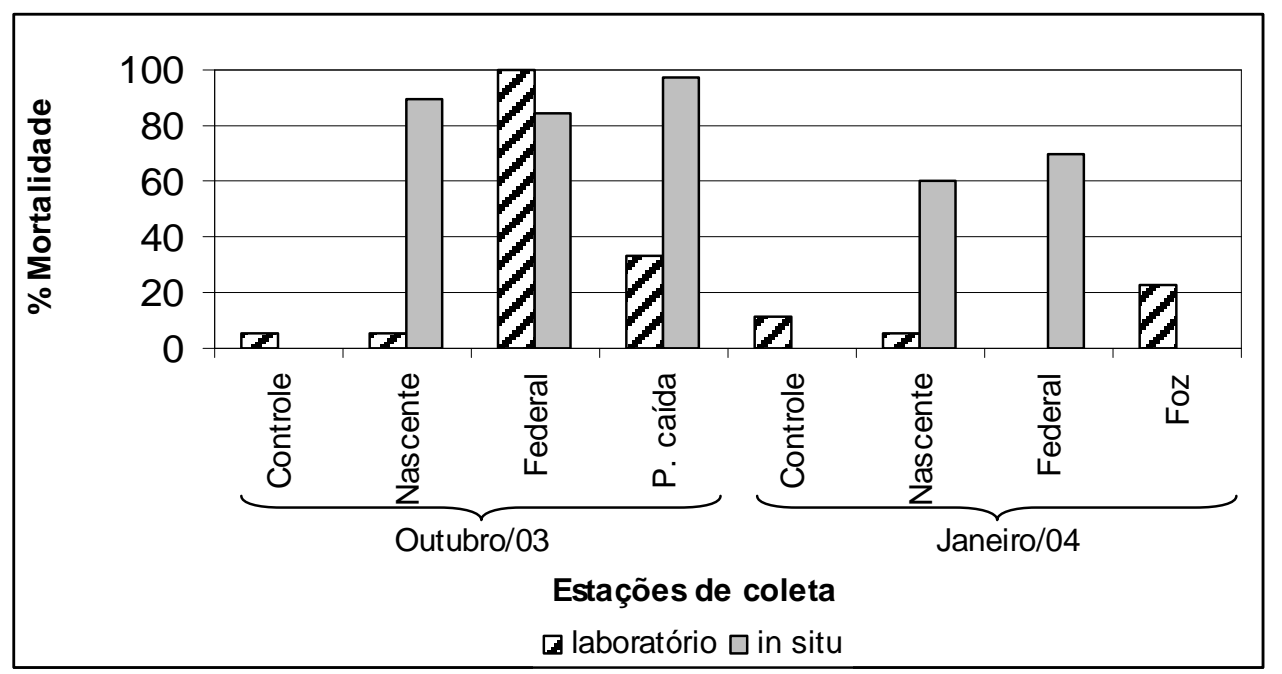

Figura 6. Comparação da mortalidade de C hironomus $\mathrm{x}$ anthus nos bioensaios "in situ" e laboratoriais.

Na Tabela 21, pode-se observar as variáveis iniciais e finais (após 96h), mensuradas com 0 multisensor Horiba U-10. Verifica-se que não há muita variação em outubro/ 03 em relação ao pH e à temperatura da água nas estações amostradas; porém existe uma diferença acentuada quando se compara as estações, como por exemplo, na condutividade (valor mínimo de $8 \mu \mathrm{S} . \mathrm{cm}^{-1}$ e valor máximo de 159 $\mu \mathrm{S} . \mathrm{cm}^{-1}$ ) e no oxigênio dissolvido (concentração máxima de 6,5 mg.L-1 e mínima de 0,33 mg. $\mathrm{L}^{-1}$ ), sendo as melhores condições ambientais observadas na Nascente.

Em relação à janeiro/ 04, pode-se observar que 0 pH não se alterou entre as estações, mas apresentou valores inferiores (valor mínimo de 4,77 e máximo de 5,62 ) aos observados em outubro/ 03. A condutividade manteve valores semelhantes aos apresentados em outubro/03 e a concentração de oxigênio dissolvido apresentou valores superiores ao observado em outubro/ 03 (concentração máxima de 8,07 mg.L-1). A temperatura da água mostrou variação devido ao horário de instalação das câmaras de incubação, bem como da maior exposição ao sol das estações de coleta (Nascente mais protegida pela vegetação ciliar), sendo observado o valor mínimo de $20,4{ }^{\circ} \mathrm{C}$ e máximo de $25,2{ }^{\circ} \mathrm{C}$. 
Tabela 21. Variáveis iniciais e finais dos Bioensaios "in situ" realizados em outubro/ 03 e janeiro/ 04 no rio Monjolinho (São Carlos, SP).

\begin{tabular}{|c|c|c|c|c|c|c|c|c|}
\hline \multirow[t]{2}{*}{ Parâmetros } & \multicolumn{4}{|c|}{ Outubro de 2003} & \multicolumn{4}{|c|}{ Janeiro de 2004} \\
\hline & pH & $\begin{array}{l}\text { Condut. } \\
\mu . \text { S.cm-1 }^{-1}\end{array}$ & $\begin{array}{l}\text { OD } \\
\text { mg.L-1 }\end{array}$ & $\underset{\text { oC }}{\text { Temp. }}$ & pH & $\begin{array}{l}\text { Condut. } \\
\mu . \text { S.cm-1 }^{-1}\end{array}$ & $\begin{array}{l}\text { OD } \\
\text { mg.L-1 }\end{array}$ & $\begin{array}{l}\text { Temp. } \\
\text { oC }\end{array}$ \\
\hline & \multicolumn{4}{|c|}{ Nascente - 10\% de sobrevivência } & \multicolumn{4}{|c|}{ Nascente $-40 \%$ de sobrevivência } \\
\hline iniciais & 6,13 & 8 & 6,48 & 21,7 & 4,77 & 8 & 8,07 & 20,4 \\
\hline finais & 6,09 & 8 & 6,5 & 20,1 & 5,62 & 10 & 7,76 & 20,7 \\
\hline & \multicolumn{4}{|c|}{ Federal - 16\% de sobrevivência } & \multicolumn{4}{|c|}{ Federal - 30\% de sobrevivência } \\
\hline iniciais & 6,63 & 58 & 2,7 & 22 & 5,54 & 57 & 3,29 & 25,2 \\
\hline \multirow[t]{2}{*}{ finais } & 6,7 & 85 & 0,33 & 23,8 & 5,61 & 27 & 5,86 & 21,6 \\
\hline & \multicolumn{4}{|c|}{ Ponte caída - 3\% de sobrevivência } & \multicolumn{4}{|c|}{ Foz } \\
\hline iniciais & 6,65 & 159 & 3,66 & 19,5 & \multirow{2}{*}{\multicolumn{4}{|c|}{$\begin{array}{l}\text { D evido à forte chuva após a montagem do } \\
\text { bioensaio, as câmaras foram perdidas. }\end{array}$}} \\
\hline finais & 7.01 & 159 & 1.05 & 20,5 & & & & \\
\hline
\end{tabular}

Os resultados do Teste-t indicam que não há diferença entre os resultados do bioensaio "in situ" e laboratoriais realizados em outubro/03 ( $\mathrm{p}=0,18)$, mas há diferença para os bioensaios realizados em janeiro/ $04(p=0,005)$. Juntando-se os dois meses analisados, obtém-se $\mathrm{p}=0,03$, mostrando que há diferença significativa entre os resultados dos dois tipos de ensaios realizados.

\section{DISCUSSÃO}

Os testes de toxicidade são uma ferramenta importante na avaliação da qualidade do sedimento. Atualmente, são utilizadas as análises químicas e físicas do sedimento em conjunto com as análises dos testes de toxicidade para uma melhor tomada de decisão em pesquisas de avaliação de risco ambiental.

Este estudo, como mencionado anteriormente, foi desenvolvido em parceria com outros projetos e cada autor realizou bioensaios com diferentes espécies, tais como, os microcrustáceos D aphnia similis e C eriodaphnia dubia (NOVELLI, 2005), os peixes D anio rerio e Poecilia reticulata (CAMPAGNA, 2005), e o díptero Chironomus $x$ anthus (presente estudo), sendo avaliado a mortalidade de D. similis, D. rerio, P. reticulata e $C$. x anthus e a fecundidade de $C$. dubia. As autoras realizaram bioensaios de toxicidade com amostras de água e sedimento, e os resultados estão sumarizados nas Tabelas 22 e 23, respectivamente. 
D ornfeld, C.B. (2006). U tilização de Chironomus sp (D iptera, Chironomidae)...

Tabela 22. Resumo dos bioensaios de toxicidade realizados com amostras de água do rio Monjolinho (Fonte: NOVELLI, 2005; CAMPAGNA, 2005).

\begin{tabular}{|c|c|c|c|c|c|c|c|c|c|c|c|c|c|c|c|c|c|c|}
\hline \multirow[t]{2}{*}{$\begin{array}{l}\text { Amostras } \\
\text { de Água }\end{array}$} & \multicolumn{5}{|c|}{$\begin{array}{l}\text { D. similis } \\
\text { Agudo 48h }\end{array}$} & \multicolumn{4}{|c|}{$\begin{array}{l}\text { C. dubia } \\
\text { Crônico 7d }\end{array}$} & \multicolumn{4}{|c|}{$\begin{array}{c}\text { D. renio juvenil } \\
\text { Crônico parcial 96h }\end{array}$} & \multicolumn{5}{|c|}{$\begin{array}{c}\text { P. reticulata juvenil } \\
\text { Crônico parcial } \\
96 \mathrm{~h}\end{array}$} \\
\hline & $\overline{11}$ & $\overline{2}$ & $\overline{3}$ & $\bar{~} \overline{4}$ & \begin{tabular}{l|l}
5 & 6
\end{tabular} & \begin{tabular}{|l|l|}
1 & 2 \\
\end{tabular} & $\overline{3}$ & $\overline{44}$ & \begin{tabular}{l|l}
5 & 6
\end{tabular} & \begin{tabular}{l|l}
1 & 2 \\
\end{tabular} & \begin{tabular}{l|l}
2 & 3
\end{tabular} & $\overline{\overline{4}}$ & \begin{tabular}{l|l}
5 & 6
\end{tabular} & \begin{tabular}{l|l}
1 & 2 \\
\end{tabular} & $\overline{3}$ & $\overline{44}$ & $\overline{55}$ & $\overline{\overline{6}}$ \\
\hline julho/ $\mathbf{0 3}$ & & & & & & testes I & não re & ealizą & zados & & & & & & & & & \\
\hline outubro/ 03 & & & & & & & & & & testes & ș não & reali & izados & testes & não 1 & reali; & $\mathrm{zad}$ & \\
\hline janeiro/ 04 & & & & & & & & & & & & & & & & & & \\
\hline abril/ 04 & & & & & & & & & & testes & es não & reali & izados & testes & não 1 & reali; & $\mathrm{zad}$ & \\
\hline
\end{tabular}

Tabela 23. Resumo dos bioensaios de toxicidade realizados com amostras de sedimento do rio Monjolinho (Fonte: NOVELLI, 2005; CAMPAGNA, 2005).

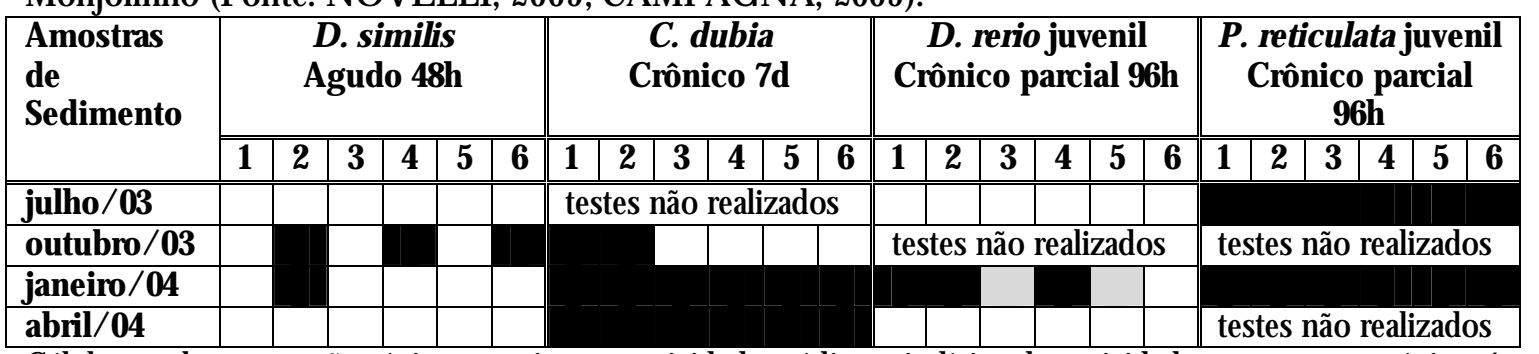

Células em branco - não tóxico; em cinza - toxicidade média ou indícios de toxicidade e em preto - tóxico; 1 - Nascente; 2 - Federal; 3 - USP; 4 - Usina; 5 - Ponte Caída; 6 - Foz

Segundo NOVELLI (2005), para os testes com água utilizando como organismos-teste D . similis e C. dubia, observou-se mortalidade na Nascente, o que pode ser devido à composição da água da nascente que é mais pobre em relação aos íons e matéria orgânica, e não necessariamente à contaminantes presentes, embora em janeiro/04 tenha sido observado a presença de organoclorados. Também verificou-se um aumento na fecundidade de $\mathrm{C}$. dubia no eixo longitudinal do rio devido, provavelmente, ao enriquecimento orgânico proveniente dos tributários, bem como dos lançamentos de esgoto in natura. Em relação aos peixes, CAMPAGNA (2005) encontrou uma diferença significativa em relação ao controle quando se mensurou o peso e comprimento dos exemplares de P. reticulata em janeiro/ 04. Algumas alterações branquiais também foram verificadas, tais como, proliferação de células entre as lamelas secundárias, dilatação de capilares e fusão de lamelas.

Para as amostras de sedimento, NOVELLI (2005) verificou maior toxicidade à $\mathrm{C}$. dubia quando comparados com os testes com amostras de água e com os testes com D . similis. CAMPAGNA (2005) também observou toxicidade à P. reticulata. 
Houve uma diferença significativa, quando comparado ao controle, no peso e comprimento de $\mathrm{P}$. reticulata apenas nos organismos expostos ao sedimento de julho/ 03. Em janeiro/ 04, devido à alta mortalidade, não foi possível mensurar essas variáveis. Além disso, as autoras observaram alterações nas brânquias com redução da área de trocas gasosas, tais como, proliferações celulares e fusão entre lamelas, dilatação dos vasos sanguíneos e diminuição do espaço interlamelar.

Q uando esses resultados são comparados com àqueles obtidos nos testes com sedimento utilizando C. x anthus (Tabelas 24 e 25), observa-se a importância da realização de ensaios com representantes de diferentes níveis tróficos para uma mesma amostra ambiental. Existe diferença nos resultados apresentados para os diferentes organismos testados, mas nos casos em que a toxicidade da estação amostrada foi muito acentuada, verificaram-se efeitos adversos em dois ou mais organismos testados, como por exemplo, as estações Madalena, USP, Usina e Foz em julho/ 03 e as estações Nascente, Federal, USP, Usina e Foz em janeiro/ 04.

Tabela 24. Comparação da toxicidade entre os diferentes organismos testes expostos a amostras de sedimentos dos diferentes pontos de coleta do sistema Monjolinho, em julho/ 03 (Fonte: Espíndola, 2005: Relatório Final FAPESP processo 2002/ 10494-6).

\begin{tabular}{|c|c|c|c|c|c|}
\hline Tipos de testes & \multicolumn{5}{|c|}{ Testes de toxicidade com amostras de sedimentos - julho/ 03} \\
\hline & \multicolumn{2}{|c|}{ AGUD0S } & \multicolumn{3}{|c|}{ CRÓNICOS } \\
\hline $\begin{array}{l}\text { Organismo teste } \\
\text { Pontos de coleta }\end{array}$ & D. similis & C. $x$ anthus & C. dubia & D. rerio & P. reticulata \\
\hline Controle & $\mathrm{Ac}$ & $\mathrm{Ac}$ & $\mathrm{Ac}$ & $\mathrm{Ac}$ & $\mathrm{Ac}$ \\
\hline Nascente & NT & NT & NT & NT & $\mathbf{T}$ \\
\hline Federal & NT & NT & NT & NT & $\mathbf{T}$ \\
\hline Madalena & - & $\mathbf{T}$ & - & NT & $\mathbf{T}$ \\
\hline USP & NT & $\mathbf{T}$ & $\mathbf{T}$ & NT & $\mathbf{T}$ \\
\hline Tijuco & - & NT & - & NT & $\mathbf{T}$ \\
\hline Mineininho & - & NT & - & NT & $\mathbf{T}$ \\
\hline Usina & NT & $T$ & NT & NT & $\mathbf{T}$ \\
\hline Água. Quente & - & NT & - & NT & $\mathbf{T}$ \\
\hline Água Fria & - & NT & - & NT & $\mathrm{T}$ \\
\hline Ponte Caída & NT & NT & NT & NT & $\mathbf{T}$ \\
\hline Cancan & - & NT & - & NT & $\mathbf{T}$ \\
\hline Serma & - & NT & 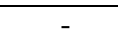 & NT & $\mathbf{T}$ \\
\hline Foz & NT & NT & $\mathbf{T}$ & NT & $\mathbf{T}$ \\
\hline
\end{tabular}

T : tóxico; NT : não tóxico; Ac : aceito, - : não realizado 
Tabela 25. Comparação da toxicidade entre os diferentes organismos testes expostos a amostras de sedimento dos diferentes pontos de coleta do sistema Monjolinho, em janeiro/ 04 (Fonte: Espíndola 2005, Relatório Final FAPESP processo 2002/ 10494-6).

\begin{tabular}{|l|c|c|c|c|c|}
\hline \multicolumn{5}{|c|}{ Tipos de testes } & \multicolumn{2}{|c|}{ AGUD deS } & \multicolumn{3}{c|}{ CRONIC0 } \\
\hline $\begin{array}{l}\text { Organismo teste } \\
\text { Pontos de coleta }\end{array}$ & D. similis & C. x anthus & C. dubia & D . rerio & P. reticulata \\
\hline Controle & & & & & \\
\hline Nascente & AC & AC & AC & AC & Ac \\
\hline Federal & NT & NT & T & T & T \\
\hline Madalena & - & NT & T & NT & T \\
\hline USP & NT & T & - & NT & NT \\
\hline Tijuco & - & NT & - & NT & T \\
\hline Mineininho & - & NT & - & NT & NT \\
\hline Usina & NT & NT & T & T & NT \\
\hline Aggua. Quente & - & T & - & NT & NT \\
\hline Agua Fria & - & T & - & NT & NT \\
\hline Ponte Caída & NT & NT & T & NT & NT \\
\hline Cancan & - & NT & - & NT & NT \\
\hline Serra & - & NT & - & NT & NT \\
\hline Foz & NT & T & T & NT & NT \\
\hline
\end{tabular}

T : tóxico; NT : não tóxico; Ac : aceito, - : não realizado

Em relação aos trabalhos realizados anteriormente no mesmo sistema, FRACACIO et al. (2000) observaram ausência ou baixa toxicidade (mortalidade $<20 \%$ ) do sedimento do rio Monjolinho para Danio rerio, Ceriodaphinia dubia e D aphnia similis; entretanto, foi verificada toxicidade aguda da água intersticial à Selenastrum capricornutum, com inibição do crescimento algal de 93,2\% em média.

BARBOSA (2000) observou baixa toxicidade (entre 10 e $15 \%$ de mortalidade) para D . similis e C. xanthus, também estudando o rio Monjolinho.

BIANCHI (2005) realizou um estudo de genotoxicidade e mutagenicidade utilizando amostras de água do rio Monjolinho e expondo o organismo-teste A llium cepa (cebola) e observou pequenas alterações no meristema de raiz e sugere que as águas do rio Monjolinho devem conter substâncias potencialmente mais citotóxicas do que mutagênicas, considerando que não ocorreram induções de células com quebras cromossômicas ou portadoras de micronúcleo.

Em relação aos testes de toxicidade com sedimento de outros sistemas, pode-se citar inúmeros trabalhos, tais como os desenvolvidos por GIESY et al. (1990) com o sedimento do rio Detroit (Canadá); COSTA \& ESPÍNDOLA (2000) em tributários do reservatório de Barra Bonita; DORNFELD et al. (2002) em tributários da represa do Lobo; RODGHER et al. (2003) nos reservatórios em 
cascata do rio Tietê; ESPÍND OLA et al. (2003) no rio Mogi-Guaçu; LAHR et al. (2003) em rios e lagos da Holanda; BRAMO RSK I et al. (2004) nos compartimentos iniciais do reservatório de Barra Bonita; MAESTRE et al. (2005) nas bacias hidrográficas do Norte e do Ebro, na Espanha.

D entre eles, destaca-se os trabalhos desenvolvidos por G IESY et al. (1990) e LAHR et al. (2003). GIESY et al. (op cit) estudou a toxicidade do sedimento do rio D etroit (Canadá), utilizando bioensaios com D . magna (água intersticial) e C. tentans (sedimento total). No sedimento da estação que causou toxicidade, não havia presença de nenhum macroinvertebrado bentônico no momento da coleta. No sedimento da estação de referência foram observadas populações de Chironomus e $\mathrm{H}$ ex agenia limbata. A amostra do sedimento tóxico causou redução no ganho de peso de $C$. tentans em $81,6 \%$. Os autores verificaram que o crescimento de $C$. tentans foi mais sensível à toxicidade do sedimento do que a mortalidade de D. magna e $\mathrm{H}$. limbata.

LAHR et al. (2003), em estudo realizado em rios e lagos da Holanda questiona se as respostas dos bioensaios com sedimentos podem ser explicadas pela análise química de poluentes do monitoramento realizado rotineiramente. Os rios Helmond e D ommel apresentam características diferentes quanto à granulometria, concentração de metais no sedimento e toxicidade à C. riparius. Ambos possuem concentrações de metais superiores aos encontrados no rio Monjolinho, porém as porcentagens de mortalidade dos organismos testados são baixas, sendo 2 e 7\%, respectivamente. $\mathrm{O}$ rio Dommel possui concentrações de metais acima do PEL, proposto por SMITH et al. (1996) e comentado no Capítulo 2. O parâmetro crescimento foi avaliado e os autores obtiveram uma ausência de crescimento para os organismos expostos ao sedimento do rio Helmond e uma redução de 18\% no crescimento dos organismos expostos ao sedimento do rio Dommel, quando comparados com a condição controle. Segundo os autores, os resultados demonstram que a toxicidade de sedimentos extremamente poluídos pode parcialmente, mas não totalmente, ser explicados pelas análises químicas dos poluentes mais comuns para a avaliação da toxicidade. Mencionam também que os metais contribuíram mais com a toxicidade dos sedimentos, e em alguns casos 0 PAHs, e consideram os pesticidas organoclorados, clorobenzenos e PCBs como de 
menor importância para a toxicidade. Ambos os autores dos trabalhos citados, consideram que a toxicidade observada pode não estar bem relacionada com as concentrações de substâncias tóxicas presentes no sedimento.

JANSSEN DE BISTHOVEN et al. (2004) estudaram o comportamento de Chironomus expostos à amostras de AMD - São Domingos/ Portugal (Acid Mine D rainage). A análise dos movimentos foi realizada por meio do sistema MFB (Multispecies Freshwater Biomonitor) que utiliza freqüências diferentes para movimentos lentos (como a locomoção) e rápidos (como a ventilação) e observou que os organismos expostos à essas amostras, que possuem altas concentrações de metais, apresentaram movimentos de locomoção inferior à situação controle, demonstrando um efeito subletal da contaminação de metais e da acidificação nesses organismos.

O utro aspecto analisado nesse capítulo são os testes "in situ" com C. x anthus. Na Figura 7, observa-se uma tendência ao aumento da mortalidade conforme aumenta a porcentagem de silte + argila e de matéria orgânica, com os maiores valores obtidos na estação Federal. Segundo SALOMONS \& FORSTNER (1984), quanto maior a porcentagem de partícula finas no sedimento (silte + argila), maior a adsorção de metais, podendo apresentar características de maior toxicidade à biota se este metal tornar-se disponível aos organismos por alguma alteração nas condições ambientais. Esta tendência pode ser visualizada na Figura 8, quando se observa a estação Federal em outubro/ 03 (ambos os testes) e verifica-se a alta mortalidade em decorrência, provavelmente, das maiores concentrações de $\mathrm{Cr}$ e $\mathrm{Cu}$ (4,5 e 13,8 $\mu \mathrm{g} \cdot \mathrm{g}^{-1}$, respectivamente), aliada à baixa concentração de oxigênio dissolvido. Em janeiro/ 04, as concentrações de $\mathrm{Cr}$ e $\mathrm{Cu}$ na estação Federal foram inferiores e a concentração de oxigênio dissolvido foi superior, em comparação com outubro/ 03, podendo justificar as diferenças na mortalidade entre os dois períodos analisados. 


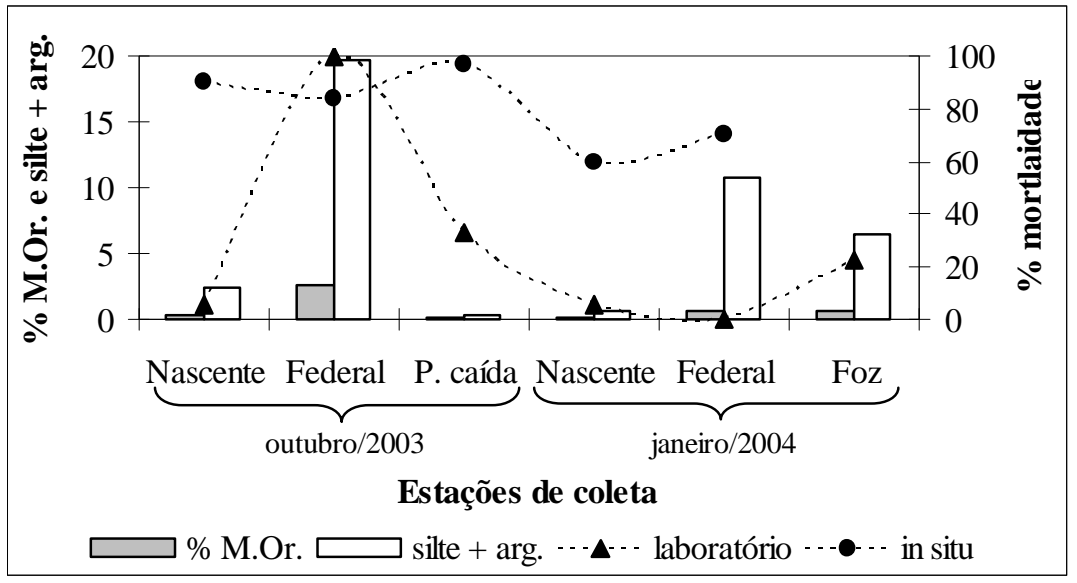

Figura 7. Porcentagem de matéria orgânica, de silte + argila e de mortalidade nas estações de coleta do rio Monjolinho (São Carlos, SP).

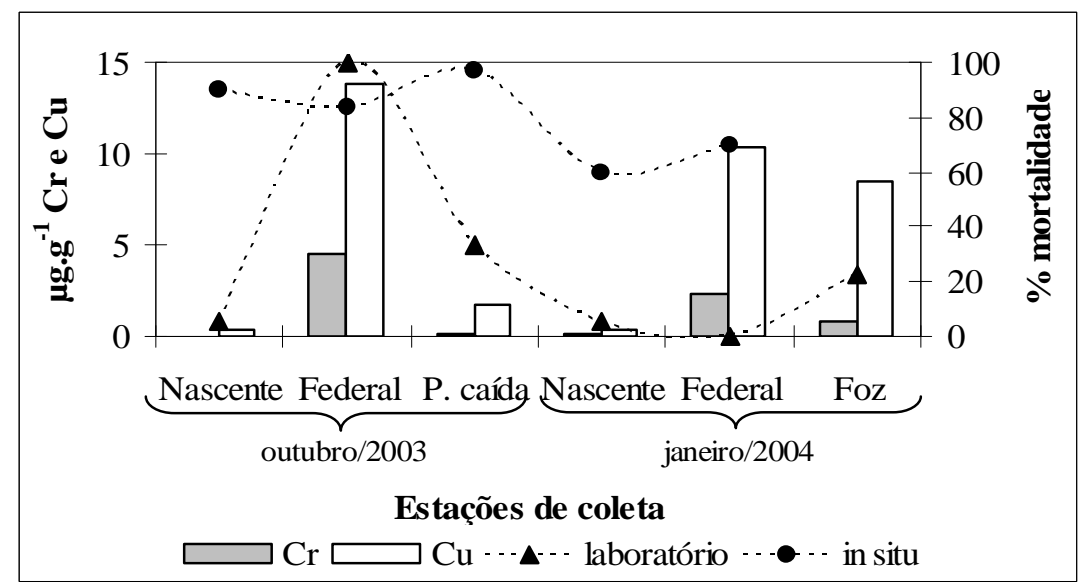

Figura 8. Concentração de metais potencialmente biodisponíveis no sedimento ( $\mathrm{Cr}$ e $\mathrm{Cu}$ ) e porcentagem de mortalidade nas estações de coleta do rio Monjolinho (São Carlos, SP).

A mortalidade observada na Nascente, no bioensaio "in situ", pode ser atribuída a diferentes fatores que confundem a avaliação final dos experimentos, como também observado por CASTRO et al. (2003), tais como saturação da malha com material em suspensão (alterando o fluxo de água e diminuindo a aeração das câmaras), diferentes texturas do sedimento e qualidade da água que flui pelas câmaras. O baixo pH da água da Nascente em janeiro/ 04 (entre 4,77 e 5,62), também pode diminuir a sobrevivência dos organismos expostos. Para as demais estações amostradas, observa-se que, além das baixas concentrações de oxigênio dissolvido, a presença de organismos invasores nas câmaras pode influenciar os resultados, considerando que foram encontrados oligoquetas, hirudíneos e outras 
espécies de quironomídeos, podendo haver competição e predação no interior das mesmas durante o período de exposição.

SIBLEY et al. (1999), também menciona o problema com organismos invasores nas câmaras, principalmente em relação à presença de organismos predadores que podem reduzir a sobrevivência, e o resultado pode ser interpretado erroneamente como uma resposta de contaminantes associados aos sedimentos.

Além dos problemas relacionados ao organismo-teste, como a não adaptação às variáveis ambientais (tipo de sedimento da Nascente, por exemplo), deve-se considerar as características do próprio ambiente, o qual é impactado por atividades da pecuária, plantios de hortaliças, café e laranja. A pesar do sedimento ser arenoso, não favorecendo a adsorção de contaminantes (baixos valores de $\mathrm{Cr}$ e $\mathrm{Cu}$, por exemplo), e classificado como não poluído segundo os critérios propostos por THOMAS (1987), deve-se reconhecer que os organismos nos testes "in situ" também estão em contato com a água que passa pelas câmaras, que apresenta concentrações de metais (principalmente $\mathrm{Cd}$ e $\mathrm{Cu}$ ) e organoclorados (Aldrin, Endosulfan sulfato e Heptachlor) acima do recomendado pela legislação brasileira vigente, como comentado no Capítulo 2. A reduzida concentração de oxigênio dissolvido em algumas estações de coleta também pode ter colaborado com a maior mortalidade dos organismos expostos. Por outro lado, os resultados dos bioensaios laboratoriais, em geral, apontam para um sedimento não tóxico para a espécie testada, corroborando com as baixas concentrações de metais, considerando as concentrações e faixas de concentrações propostas por THOMAS (1987), MacD onald et al. (2000) e pelo Critério Canadense (2002).

Tabela 26. Categorias de poluição de sedimento estabelecidas por THOMAS (1987), Critério Canadense (2002) e MacD O NALD et al. (2000), sendo a concentração de metal expressa mg.Kg-1.

\begin{tabular}{|c|c|c|c|c|c|}
\hline \multirow{2}{*}{$\begin{array}{l}\text { Metal } \\
\left(\mathrm{mg}^{-K^{-1}}\right)^{-}\end{array}$} & \multicolumn{3}{|c|}{ Thomas (1987) } & \multirow{2}{*}{$\begin{array}{l}\text { MacDonald et } \\
\text { al. (2000) }\end{array}$} & \multirow{2}{*}{$\begin{array}{c}\text { Critério } \\
\text { Canadense } \\
\text { (2002) }\end{array}$} \\
\hline & Não poluído & $\begin{array}{l}\text { Moderadamente } \\
\text { poluído }\end{array}$ & $\begin{array}{l}\text { Altamente } \\
\text { poluído }\end{array}$ & & \\
\hline Cd & - & - & $>6$ & 0,99 & 3,50 \\
\hline $\mathrm{Cr}$ & $<25$ & $25-70$ & $>70$ & 43,00 & 90,00 \\
\hline $\mathrm{Cu}$ & $<25$ & $25-50$ & $>50$ & 32,00 & 197,00 \\
\hline Fe & $<17000$ & $17000-25000$ & $>25000$ & - & - \\
\hline Mn & $<300$ & $300-500$ & $>500$ & - & - \\
\hline Zn & $<90$ & $90-200$ & $>200$ & 121,00 & 123,00 \\
\hline
\end{tabular}

$\mathrm{PEL}=$ "problable effect level" 
FARIA (2005), utilizando ensaios "in situ" com C. riparius, verificou que 0 resultado do crescimento dos organismos foi mais sensível do que a utilização de Índices Bióticos para a caracterização do ambiente estudado, no caso, rios contaminados por metais. Porém, o ensaio não se mostrou adequado para detectar contaminação por organoclorados, sugerindo que um ensaio com uma espécie mais sensível seria mais adequado.

Portanto, os resultados deste estudo apresentam uma diferença entre os bioensaios "in situ" e os laboratoriais. Em relação à qualidade do sedimento, os testes laboratoriais (condições ambientais mais controladas e uso de água do meio cultivo) indicam ausência de toxicidade, porém, os bioensaios "in situ" demonstram toxicidade elevada (acima de 60\%), caracterizando um efeito sinérgico dos compartimentos água e sedimento, mas não revelando o potencial de contaminação isolado do sedimento.

Embora ainda existam alguns problemas metodológicos na realização dos ensaios "in situ", como citados pelos autores e apresentados no presente estudo, 0 investimento no aprimoramento destes ensaios é de fundamental importância para a ecotoxicologia aquática. Estes ensaios complementam os resultados obtidos em ensaios laboratoriais e fazem uma aproximação entre o que ocorre no ambiente natural e no laboratório, assim como os experimentos em meso e macrocosmos que quando comparados com testes com uma única espécie, permite a previsão do destino de poluentes sob condições semelhantes às naturais (JACK, et al., 1996), incluindo a presença de sedimentos, animais e plantas de ocorrência natural, isto é, simulam condições ambientais, nas quais complexas interações podem ser observadas e, portanto, aproximam os testes ecotoxicológicos da realidade do ambiente.

\section{CONCLUSÃO}

A análise dos dados permite concluir que testes "in situ" foram ferramentas importantes para avaliar o potencial de toxicidade do ambiente de forma mais ampla (água + sedimento), uma vez que estão sujeitos às interferências locais, mas não 
revelaram, de forma isolada, os efeitos de toxicidade do compartimento sedimento. Reconhece-se, desta forma, que os bioensaios laboratoriais e "in situ" são ferramentas importantes, sendo os resultados complementares na avaliação ambiental.

Os testes de toxicidade laboratoriais apresentaram porcentagem de mortalidade inferior aos testes "in situ".

Recomenda-se, também, o uso de outros parâmetros de avaliação final do teste, tal como o crescimento (ganho de peso), que segundo vários autores, parece ser mais sensível do que a mortalidade.

\section{BIBLIOGRAFIA}

AMERICAN SOCIETY FOR TESTING AND MATERIALS - ASTM. E1688-00

- Standard guide for determination of the bioaccumulation of sedimentassociated contaminants by benthic invertebrates, 2000. 54p.

AMERICAN SOCIETY FOR TESTING AND MATERIALS - ASTM E1706-00 - Test method for measuring the toxicity of sediment-associated contaminants with freshwater invertebrates, 2000. 117p.

BARBOSA, R.. Avaliação do impacto de efluentes (lodos) de Estações de Tratamento de Água à biota aquática através de testes de toxicidade, 2000. Tese (D outorado), Escola de Engenharia de São Carlos, Universidade de São Paulo, 2000. 199p.

BIANCHI, J. 0 uso de técnicas de citogenética em sistema-teste de A llium œpa, como instrumento de avaliação do potencial mutagênico de águas de rios utilização do rio Monjolinho (São Carlos, SP) como modelo, 2005. Trabalho de Conclusão de Curso, Instituto de Biociências, Universidade Estadual Paulista "Júlio de Mesquita Filho", Rio Claro, SP, 2005. 81p.

BRAMORSKI, J.; VILLELA, S.M.; DORNFELD, C.B.; MIRANDA, V.F.. Avaliação ecotoxicológica de sedimentos recentes dos principias compartimentos iniciais do reservatório de Barra Bonita. In: Espíndola, E.L.G.; Wendland, E., eds. Bacia Hidrográfica: diversas abordagens em pesquisa, São Carlos: RiMa Editora, 2004. p. 205-215. 
BURTON JR, G.A. (ed.). Sediment toxicity assessment. Boca Raton, Fla. : Lewis Publishers, 1992. 457p.

BURTON, G.A.; NORBERG-KING, T.J.; INGERSOLL, C.G.; BENOIT, D.A.; ANKLEY, G.T.; WINGER, P.V .; KUBITZ, J.; LAZORCHAK, J.M.; SMITH, M.E.; GREER, E.; DWYER, F.J.; CALL, D.J.; DAY, K.E. Interlaboratory study of precision: Hyalella azteca and Chironomus tentans freshwater sediment toxicity assays. Environmental Toxicololgy and Chemistry 15:1335-1343, 1996.

CANADIAN COUNCIL OF MINISTERS OF THE ENVIRONMENT - CCME Canadian Sediment Quality Guidelines for the Proteccion of Aquatic Life Summary tables, 2002, 7p. www.ccme.ca.

CAMPAGNA, A.F. Toxicidade dos sedimentos da Bacia Hidrográfica do rio Monjolinho (São Carlos - SP): ênfase nas substâncias cobre, aldrin e heptacloro, 2005. Dissertação (Mestrado). Faculdade de Zootecnia e Engenharia de Alimentos, Universidade de São Paulo, 2005. 281p.

CASTRO, B.B.; GUILHERMINO, L.; RIBEIRO, R. In situ bioassay chambers and procedures for assessment of sediment toxicity with Chironomus riparius. Environmental Pollution, 125: 325-335, 2003.

COSTA, J.B. da; ESPÍND OLA, E.L.G.. Avaliação ecotoxicológica da água e sedimentos em tributários do reservatório de Barra Bonita (Médio Tietê Superior, SP). In: ESPÍND OLA, E.L.G.; PASCHOAL, C.M.R.B.; ROCHA, O ; BOHRER, M.B.C.; OLIVEIRA-NETO, A.L. (orgs.). Ecotoxicologia: perspectivas para o Século XXI, 2000. p. 75-94.

DORNFELD, C.B.; MASUTTI, M.B.; SILVÉRIO, P.F.; ANDRADE, C.A.; ALMEID A, C.A.. Caracterização ecotoxicológica do sedimento da represa do Lobo (Itirapina-Brotas, SP) e seus tributários. IN: ESPÍND OLA, E.L.G.; MAUAD , F.F.; SCHALCH, V.; ROCHA, O ; FELICIDADE, N.; RIETZLER, A.C. (orgs.). Recursos hidroenergéticos: usos, impactos e planejamento integrado, 2002. p.75-89.

D ORNFELD , C.B. Utilização de análises limnológicas e bioensaios toxicológicos em macroinvertebrados bentônicos para 0 diagnóstico ambiental do reservatório de Salto Grande (Americana -SP), 2002. Dissertação (mestrado). São Carlos, 2002. 196p. 
ESPÍND OLA， E.L.G.; BRIGANTE， J.; DORNFELD， C.B. Estudos ecotoxicológicos no rio Mogi-Guaçu. In: BRIGANTE, J. \& ESPÍND OLA, E.L.G. Limnologia fluvial: um estudo no rio Mogi-G uaçu, 2003. p.129-148.

ESPÍND OLA, E.L.G. Estudos limnológicos e ecotoxicológicos (laboratoriais e in situ) no rio Monjolinho (São Carlos, SP), com ênfase na avaliação da toxicidade de metais e pesticidas organoclorados no zooplâncton, peixes e bentos. RELATÓRIO FINAL - FAPESP - Proc. n² 2002/ 10494-6, 2005, 202p + anexos.

FARIA, A.M.S. Ecological assessment of water quality using in situ bioassays with C. riparius, 2005. Tese (D outorado), Universidade de Aveiro, Portugal, 2005. 143p.

FERNICOLA， N.A.G.G.; BOHRER-MOREL， M.B.B.; BAINY， A.C.D .. Ecotoxicologia. In: AZEVEDO, F.A. \& CHASIN, A.A.M., As bases ecotoxicológicas da Ecotoxicologia, Rima editora, InterTox, 2003. p. 221-243.

FONSECA, A.L. Avaliação da qualidade da água do rio Piracicaba/SP através de testes de toxicidade com invertebrados, 1997. Tese (doutorado). São Carlos. Escola de Engenharia de São Carlos, Universidade de São Paulo, 1997. 211p.

FRACÁCIO, R.; RODGHER, S.; ESPÍND O LA,E.L.G.; PASCHOAL, C.M.R.B.; LIMA, D; NASCIMENTO, A.P. \& RODRIGUESS, M.H.. Abordagem ecotoxicológica. IN: ESPÍND O LA, E.L.G; SILVA, J.S.V; MARINELLI, C.E \& ABD ON, M.M. A Bacia Hidrográfica do rio Monjolinho. São Carlos, RiMa Editora, 2000. p. 150-162.

GIESY, J.P.; ROSIU, C.J.; GRANEY, R.L. Benthic invertebrate bioassays with toxic sediment and pore water. Environmental Toxicology and Chemistry, 9:233-248, 1990.

JACK, R.G.; MAAS, J.L.; SCHOLTEN, M.C.T. Evaluation of laboratory derived toxic effect concentration on a mixture of metals by testing fresh water plankton communities in enclosures. Water Research, 30(5): 1215-1227, 1996.

JANSSENS DE BISTHOVEN, L.; NUYTS, P.; GODDEERIS, B.; OLLIVIER, F. Sublethal parameters in morphologically deformed Chironomus larvae: clues to understanding their bioindicator value. Freshwater Biology, 39:179-191, 1998. 
JANSSENS DE BISTHOVEN, L.; GERHARDT, A.; SOARES, A.M.V.M. Effects of Acid Mine D rainage on Larval C hironomus (D iptera, Chironomidae) measured with the Multispecies Freshwater Biomonitort. Environmental Toxicology and Chemistry, 23(5):1123-1128, 2004.

LAHR, J.; MAAS-DIEPEVEEN, J.L.; STUIJFZAND, S.C.; LEONARD S, P.E.G .; DRUKE, J.M.; LUCKER, S.; ESPELD OORN, A.; KERKUM, L.C.M.; VAN STEE, L.L.P.; HEND RIKS, A.J. Responses in sediment bioassays used in the Netherlands: can observed toxicity be explained by routinely monitored priority pollutants? Water Research, 37:1691-1710, 2003.

MACDONALD, D.D.; INGERSOLL, C.G.; BERGER, T.A. Development and Evaluation of Consensus-Based Sediment Q uality Guidelines for Freshwater Ecosystems. Achieves Environment Contamination Toxicology. 39:20-31, 2000. MAESTRE, Z.; MARTINEZ-MADRID, M.; RODRÍGUES, P. Evaluación de la ecotoxicidad de sedimentos fluviales mediante el bioensayo crônico de Tubifex tubifex. Resúmenes do $6^{0}$ Congreso Ibérico y $3^{0}$ Iberoamericano de Contaminación y Toxicología A mbiental, 2005. p.225.

MELETTI, P.C.. Avaliação da qualidade da água na bacia do rio Piracicaba através de testes de toxicidade aguda com peixes, 1997. São Carlos. Dissertação (Mestrado) - Escola de Engenharia de São Carlos, Universidade de São Paulo, 1997. 148p

MELETTI, P.C. \& ROCHA O. D evelopment of a chamber for in situ toxicity tests with small fishes. Brazilian Journal Biology, 62: 187-190, 2002.

MEREGALLI, G.; OLLEVIER, F. Exposure of Chironomus riparius larvae to 17ethynylestradiol: effects on survival and mouthpart deformities. The Science of the Total Environment, 269: 157-161, 2001.

MEREGALLI, G.; VERMEULEN, A.C.; OLLEVIER, F. The use of chironomidae deformation in an in situ test for sediment toxicity, Ecotoxicology and Environmental Safety, 47: 231-238, 2000.

NOVELLI, A.. Estudo limnológico e ecotoxicológico da água e sedimento do rio Monjolinho - São Carlos (SP), com ênfase nas substâncias de referência cádmio e cobre 2005. Dissertação (Mestrado). Escola de Engenharia de São Carlos, Universidade de São Paulo, 2005. 288p. 
PAMPLIM, P.A.Z. Avaliação da qualidade ambiental da represa de Americana (SP Brasil) com ênfase no estudo da comunidade de macroinvertebrados bentônicos e parâmetros ecotoxicológicos, 1999. Dissertação (Mestrado). Escola de Engenharia de São Carlos, Universidade de São Paulo, 1999. 88p.

RAND, G.M. Fundamentals of aquatic toxicology, effects, environmental fate and risk assessment, $2^{\circ}$ ed., Taylor \& Francis Publishers, London, 1995. 1125p.

ROD G HER, S. ESPÍND O LA, E.L.G.; ROCHA, O .; FRACACIO, R.; PEREIRA, R.H.G.; RODRIGUES, M.H.S.. Ecotoxicological analysis of the water and sediment from middle and low Tietê river cascade reservoirs (State of SãoPaulo, Brazil). Acta Limnologica Brasiliensia, 15(3):81-93, 2003.

SALOMONS, W.; FÖRSTNER, U. Metals in the hydrocycle. Springer-Verlag, 1984. 349p.

SIBLEY, P.K.; BENOIT, D.A.; BALCER, M.D.; PHIPSS, G.L.; WEST, C.W.; HOKE, R.A.; ANKLEY, G. In situ bioassay chamber for assessment of sediment toxicity and bioaccumulation using benthic invertebrates. Environmental Toxicology and Chemistry, 18(10): 2325-2336, 1999.

SMITH， S.L.; MACDONALD, D.D.; KEENLEYSIDE, K.A.; INGERSOLL, C.G.; FIELD, L.J. A preliminary evaluation of sediment quality assessment values for freshwater ecosystems. Journal Great Lakes Research, 22:624-638, 1996.

THOMAS, R.L. A protocol for the selection of process-oriented remedial options to control in situ sediment contaminants. Hydrobiologia, 149:247-258, 1987.

TONISSI, F.B.; ESPÍNDOLA, E.L.G. Utilização de bioensaios agudo, crônicoparcial e in situ com D anio rerio para avaliação ecotoxicológica do reservatório de Salto Grande (Americana, SP), IN: E.L.G. ESPÍND OLA; C.M.R. BOTTAPASCHOAL; O. ROCHA; M.B.C. BOHRER; A.L.OLIVEIRA-NETO, Ecotoxicologia - perspectivas para o século XXI, São Carlos, 2000, p.483-500.

UNITED STATES ENVIRONMENTAL PROTECTION AGENCY. U.S. EPA/ 600/ R- 99/ 064. Methods for measuring the toxicity and bioaccumulation of sediment associated contaminant with freshwater invertebrates. 2 ed. Washington. D.C., 2000.192p. 


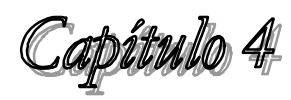

Avaliação da toxicidade de metais (Cádmio e Cobre) em ensaios agudos e crônicos utilizando Chironomus xanthus (Chironomidae - Díptera)

\section{INTRODUÇÃO}

O impacto dos contaminantes industriais é uma das maiores ameaças para a saúde dos ecossistemas aquáticos e atenção crescente tem sido dada para as respostas de organismos ou comunidades afetadas como um indicador da degradação ambiental (DIG G INS \& STEWART, 1993).

Segundo WILLIAMS et al. (2001) tem sido estabelecido que os Chironomidae respondem de maneira previsível para certos poluentes ambientais, sendo que algumas dessas respostas ocorrem em nível de população (por exemplo, a eliminação de um típico taxa que ocupa ambientes oligotróficos quando o sistema se torna eutrófico), e outras respostas ocorrem com a indução de deformidades físicas, em indivíduos expostos a um poluente. Portanto, as repostas toxicológicas em quironomídeos pode ocorrer em nível de população, indivíduo ou mesmo subindivíduo (como alterações moleculares e bioquímicas).

D evido a essas alterações que ocorrem individualmente, muitos autores têm afirmado que as larvas de Chironomidae demonstram ser um excelente organismoteste por estarem intimamente em contato com o sedimento e alimentarem-se de detritos e algas associados à ele, e por essa razão, elas tem sido freqüentemente utilizadas em estudos de avaliação da toxicidade de sedimentos (D ICKMAN et al., 1992).

Segundo SERVIA et al. (2000), os organismos indicadores são comumente usados para avaliar a toxicidade potencial e a biodisponibilidade de contaminantes químicos em sedimentos. Entre os Chironomidae, principalmente Chironomus riparius Meigen, 1804 e Chironomus tentans Fabricius, 1805, têm sido utilizados como organismos-teste extensivamente.

Segundo U.S. EPA (2000), alguns métodos têm sido descritos para culturas e testes de organismos nativos que podem ter sensibilidade maior ou igual à das 
espécies recomendadas pela Agência. Porém, a U.S. EPA (op cit.) atualmente permite 0 uso dessas espécies nativas somente onde regulamentações dos Estados requerem seu uso ou proíbem a importação das espécies recomendadas. Nos locais que estão desenvolvendo suas próprias culturas e métodos para espécies além daquelas recomendadas, resultados da sensibilidade da espécie substituta devem ser obtidos com sedimentos ou substâncias de referência para assegurar que a espécie selecionada seja tão sensível e apropriada quanto as espécies recomendadas.

No Brasil ainda não existem protocolos ou normas específicas para organismos bentônicos, e este trabalho é mais uma colaboração para a geração de um banco de dados confiável para a elaboração de uma norma com Chironomus x anthus, espécie utilizada atualmente, e que tem se mostrado tão sensível quanto as outras espécies de Chironomidae empregadas.

Nos trabalhos com substâncias de referência, como no caso dos metais, uma ampla gama de resultados pode ser obtida, tanto em testes agudos quanto em crônicos. Nos testes agudos pode-se obter a porcentagem de mortalidade, obtendose a CL50, isto é, concentração letal que causa a morte a $50 \%$ da população exposta. No caso dos testes crônicos, parâmetros como crescimento, emergência, deformidades e bioacumulação podem ser obtidos.

A análise de incidência de deformidades em mento do gênero Chironomus é empregada com a finalidade de se verificar a ocorrência de efeito crônico sobre a biota devido à presença de contaminantes nos sedimentos e discutir sua aplicação em programas de monitoramento (KUHLMANN et al., 2000). A mesma autora menciona que a maioria dos estudos de deformidade em quironomídeos relata a freqüência e o local (principalmente mento e antena) dessas anomalias morfológicas com efeitos crônicos "in situ" promovidos por contaminantes inorgânicos (metais) e orgânicos (PCBs, PAHs e pesticidas). Segundo alguns autores (DIGGINS \& STEWART, 1993; JANSSENS DE BISTHOVEN, 1998a), a deformidade em larvas de Chironomidae é um reflexo da poluição de sedimentos por metais pesados e compostos orgânicos tóxicos e não da poluição por esgotos domésticos.

Apesar dessa prática estar em uso, há ainda muitas questões para serem respondidas sobre deformidades. Por exemplo, estudos da relação dose-resposta entre deformidades e contaminantes ainda são escassos (SERVIA et al., 2000), 
Deve-se considerar também, que devido ao fato de as deformidades de Chironomidae serem utilizadas como "end-points" de muitos bioensaios, seja em aplicações de campo ou laboratório, é necessário que haja uma clara demonstração de quais poluentes específicos podem induzir deformidades nesses organismos (MARTINEZ et al., 2001). Além disso, a incidência "natural" de deformidades precisa ser melhor entendida para que não ocorra erros nas avaliações (BIRD et al., 19954 apud SERVIA et al.,2000).

O utro aspecto a ser observado é a bioacumulação e a transferência na cadeia alimentar de substâncias tóxicas. Segundo a U.S. EPA (2000), várias espécies de organismos têm sido sugeridas para o estudo de bioacumulação química de ambientes aquáticos e vários critérios devem ser considerados antes da adoção de uma espécie para uso em rotina para esse fim. Esses critérios incluem a disponibilidade do organismo no ano todo, conhecimento histórico da exposição química, massa de tecido adequada para análises químicas, fácil manuseio, tolerância à grande número de características físicas e químicas do sedimento, baixa sensibilidade às substâncias associadas ao sedimento e capacidade de permanecer por longo tempo em exposição sem adição de alimento. Ainda segundo U.S. EPA (op cit.), tem-se as definições de bioacumulação e fator de bioacumulação. A bioacumulação é definida como sendo o acúmulo de substâncias por um organismo como resultado da entrada por diferentes fontes, e o fator de bioacumulação como sendo a razão entre a concentração encontrada no tecido do organismo e a concentração encontrada na fonte contaminante.

De acordo com SERVIA et al. (2000), as variáveis indicadoras da qualidade de sedimentos também devem incluir a sobrevivência, taxa de crescimento e emergência de adultos. Essas variáveis ainda podem ser utilizadas quando 0 interesse é sobre 0 efeito de substâncias tóxicas, como é o caso de metais e segundo PASCOE et al. (1989), é reconhecido que investigações examinando o ciclo de vida inteiro da espécie em questão e outros efeitos além da mortalidade são necessários para a estimativa da concentração máxima aceitável do tóxico (MATC - maximum

${ }^{4}$ Bird, G.A.; Rosentreter, M.J.; Schawartz, W.J. Deformities in the menta of chironomid larvae from the Experimental Lakes Area, Ontario. Can. J. Fish. Aquat. Sci., 52:2290-2295, 1995. 
acceptable toxicant concentration), para uso em formulações de padrões de qualidade de água e para predizer efeitos da poluição aquática.

Considerando as possibilidades acima mencionadas, procurou-se neste trabalho realizar ensaios agudos e crônicos com metais $(\mathrm{Cd} \mathrm{e} \mathrm{Cu}$ ), utilizando alguns "end points" propostos e os possíveis efeitos adversos em todo o ciclo de vida de Chironomus $x$ anthus.

\section{OBJETIVOS}

Os objetivos do presente trabalho foram determinar, para Chironomus x anthus, a concentração letal ( $\left.\mathrm{CL}_{50}\right)$ de cádmio e cobre, metais que foram encontrados no rio Monjolinho acima do limite estabelecido pela resolução CONAMA 20/86 (atual 357/ 05) para rios Classe 2 e avaliar a toxicidade crônica desses metais utilizando os parâmetros sobrevivência, peso seco, emergência, bioacumulação e deformidade do mento de Chironomus $x$ anthus.

\section{MATERIAIS E MÉTODOS}

A manutenção dos organismos-teste e a avaliação das culturas foram realizadas da mesma forma que no Capítulo 3.

\subsection{Testes de toxicidade com metais (Cádmio e Cobre)}

\subsubsection{Determinação da $\mathrm{CL}_{50}$ e da CENO}

Foram realizados bioensaios de toxicidade aguda com C. xanthus (IV ínstar), com a finalidade de calcular a concentração letal média $\left(\mathrm{CL}_{50}\right)$, isto é, a concentração do contaminante que causa mortalidade a $50 \%$ dos organismos-teste, e também a concentração de efeito não observado (CENO) destes elementos tóxicos. Segundo a CETESB (1992), a CENO é calculada dividindo-se o valor encontrado da $\mathrm{CL}_{50}$ por 10, considerando a CENO como uma estimativa da toxicidade crônica. 
Para o desenvolvimento dos testes foram utilizados frascos de vidro com capacidade de $250 \mathrm{~mL}$, nos quais foram adicionados $240 \mathrm{~mL}$ da solução-teste. Os reagentes utilizados foram Cloreto de Cádmio - 100\%, 6858 da marca Mallinckodt e Sulfato de Cobre - 100\%, 4844 da marca Mallinckodt.

Para Cd utilizou-se as concentrações de 0,10; 0,25; 0,50; 0,75 e 3,00 mg.L.-1 e para $\mathrm{Cu}$ utilizou-se as concentrações de 0,10; 0,20; 0,40; 0,80 e 1,60 mg.L-1. Foram realizados 10 testes definitivos para o cálculo da CL $_{50} 96 \mathrm{~h}$ e coeficiente de variação (CV).

Os testes foram desenvolvidos utilizando 3 réplicas, sendo adicionados 6 organismos em cada uma e com duração de 96h nas condições de temperatura e fotoperíodo iguais aos de cultivo.

Utilizou-se 0 programa computacional Spearmen-Karber para efetuar 0 cálculo da CL5096h.

\subsubsection{Testes crônicos com metais (sobrevivência, crescimento,} deformidade do mento e bioacumulação)

Os testes crônicos foram realizados com $\mathrm{Cd}$ e $\mathrm{Cu}$, metais que estiveram em desacordo com a Resolução CONAMA 20/ 86 para rios Classe 2, atual Resolução CONAMA 357/ 05. Os valores são 1,0 e 20,0 $\mu g . \mathrm{L}^{-1}$ de $\mathrm{Cd}$ e $\mathrm{Cu}$, respectivamente.

Os reagentes utilizados foram os mesmos utilizados nos testes agudos.

Os testes foram realizados expondo-se organismos do I instar aos contaminantes, sendo o tempo de exposição de 10 dias para observação dos seguintes parâmetros: sobrevivência, crescimento, deformidade do mento e bioacumulação de metais. Para a análise da emergência o teste foi prolongado por no máximo 6 dias. A concentração do contaminante a ser utilizada para a realização desses bioensaios foi a CENO e aquela estabelecida pela resolução citada anteriormente.

As características do desenho experimental seguiram 0 proposto por VERMEULEN et al. (2000), sendo que o experimento foi desenvolvido em recipientes de 1 litro, contendo $800 \mathrm{~mL}$ da solução-teste (feita com água de cultivo) e $120 \mathrm{~g}$ de substrato (areia) e ração Tetramin como alimento. A areia pôde ser 
utilizada porque o quartzo possui baixa capacidade de adsorver metais. 0 experimento foi realizado em duplicata e os recipientes foram aerados por 24 horas, antes da colocação dos organismos. Em cada recipiente foram colocadas cerca de 80 larvas do I ínstar. As condições do teste foram iguais às de cultivo, com fotoperíodo de 12 horas e temperatura de 23 a 25ํC. Para cada concentração utilizada foi retirada uma alíquota de água e de sedimento suficientes para determinação de metais totais e metais potencialmente biodisponíveis, respectivamente, seguindo as metodologias descritas em APHA (1995) e SILVÉRIO (1999).

Os "endpoints" ou os parâmetros de avaliação final dos ensaios, após exposição de 10 dias, foram determinados da seguinte forma:

- sobrevivência: simples contagem dos organismos vivos;

- crescimento: alguns organismos foram separados e secos em estufa à 60C para obtenção do peso-seco; outros organismos foram fixados em álcool para posterior análise do comprimento do corpo (utilizando um paquímetro) e comprimento e largura da cápsula cefálica (montagem de lâminas semi-permanentes e medidas em microscópio);

- deformidade do mento: montagem de lâminas semi-permanentes, com a cápsula cefálica dos organismos sobreviventes, para avaliação do mento de cada indivíduo, utilizando meio de Hoyer para a confecção das lâminas. Foi considerada deformidade do mento a ausência ou adição de dentes e "gap" (fendas) (KULMANN et al., 2000) (Figura 11, Apêndice 4).

- bioacumulação: os organismos sobreviventes foram secos em estufa $\left(60^{\circ} \mathrm{C}\right)$ e sofreram digestão por ácido nítrico e peróxido de hidrogênio, como proposto em TIMMERMANS et al. (1992) e SILVÉRIO (1999).

- emergência: este teste teve duração superior aos demais, coletando-se a cada dia os organismos que emergirem em formas adultas aladas, os quais foram preservados em álcool (70\%) para posterior análise da proporção de machos e fêmeas em estereomicroscópio e do tempo de emergência, de acordo com PASCOE et al. (1989) e SILD ANCHAND RA \& CRANE (2000). 

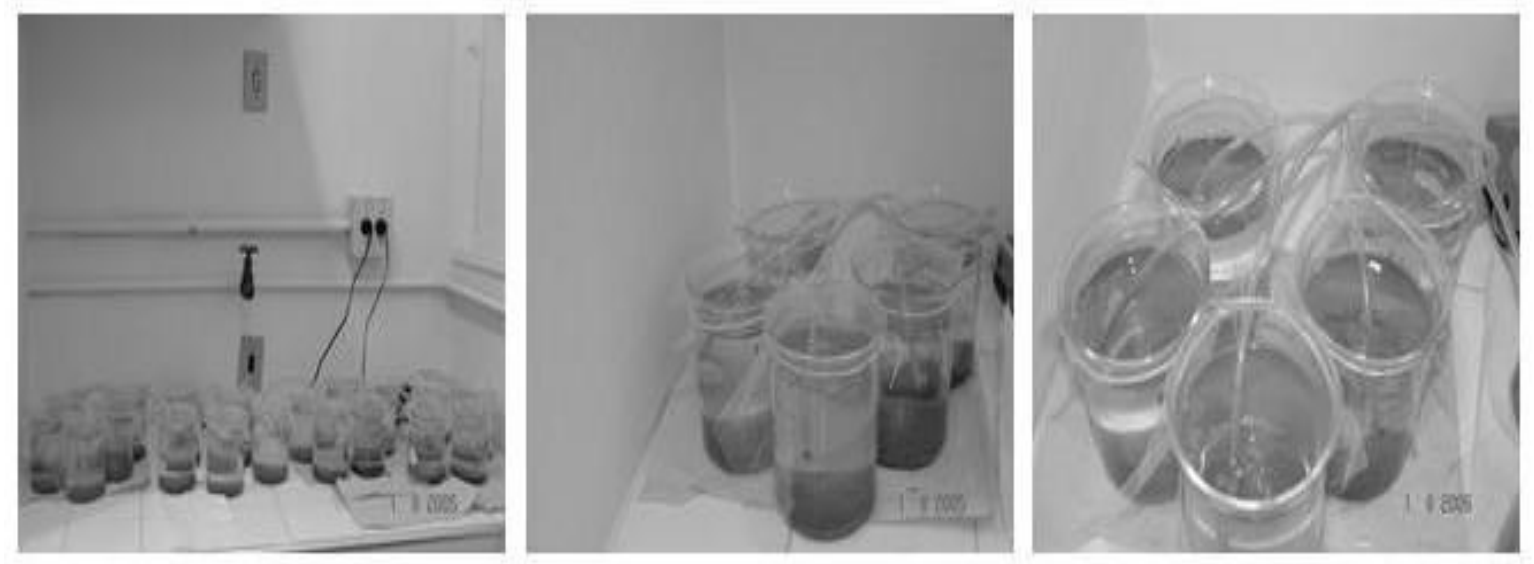

Figura 1. Desenho experimental para a realização do teste crônico com metais utilizando Chironomus x anthus.

De acordo com os resultados obtidos na determinação da $C_{50}$ para cada metal, optou-se por utilizar o valor da CENO (CL5o/ 10, segundo Cetesb 1992) e 0 proposto pela resolução CONAMA 20/ 86 para rios de classe 2 para a realização dos Testes Crônicos. Portanto utilizou-se as concentrações de 1,0 $\mu$ g.L-1-1 (CONAMA

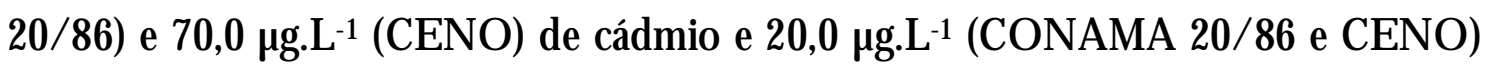
de cobre.

Foram realizados 3 testes, sendo que em todos os testes foram acompanhados os parâmetros de sobrevivência, peso seco e bioacumulação de metais nas larvas e emergência dos adultos. Nos testes 1 e 3 foram feitas lâminas semi-permanentes e analisadas as deformidades do mento da cápsula cefálica de cada organismo, bem como, comprimento total do corpo $(\mathrm{cm})$ e comprimento $(\mu \mathrm{m})$ e largura $(\mu m)$ da cápsula cefálica.

\section{RESULTADOS}

Os resultados dos testes de sensibilidade ao Cloreto de Potássio $(\mathrm{KCl})$ estão apresentados no Capítulo 3. Pelos resultados obtidos pôde-se perceber que a sensibilidade dos organismos testados esteve dentro do limite estabelecido (2,6 a 6,4 g. $\mathrm{L}^{-1}$ de $\mathrm{KCl}$ ) que caracteriza a boa qualidade das culturas, proposto por FO NSECA (1997). 


\subsection{Testes de toxicidade aguda com metais ( $\mathrm{Cd}$ e $\mathrm{Cu})$}

\subsubsection{Cádmio}

Os resultados, expressos em mg.L-1 ${ }^{-1}$ estão apresentados na Tabela 11, podendo-se observar que a $\mathrm{CL}_{50}$ média foi de $0,702 \mathrm{mg} . \mathrm{L}^{-1}$ de Cd. A partir desses resultados foi possível calcular o coeficiente de variação (CV), que foi de 42,55\%, considerado alto quando comparado com o CV de $\mathrm{KCl}(16 \%)$. Na Figura 2, verifica-se que o limite inferior variou de 0,170 a 0,920 mg. $\mathrm{L}^{-1}$ e 0 limite superior variou de 0,530 a 1,630 mg.L-1 . Na Tabela 12, observa-se que a média para o limite inferior foi de $0,517 \mathrm{mg} \cdot \mathrm{L}^{-1}$ e para 0 limite superior foi de $0,965 \mathrm{mg} \cdot \mathrm{L}^{-1}$. Os resultados da análise estatística estão apresentados nas Tabelas de 1 a 10, no Apêndice 4.

Tabela 11. Resultados dos testes de toxicidade com Cádmio, realizados com C . xanthus, expresso em mg.L-1 de Cd.

\begin{tabular}{c|cccc}
\hline No do Teste & Data & CL $_{\mathbf{5 0}}$ & Lim. Inferior & Lim. Superior \\
\hline 1 & $17 / 05 / 04$ & 0,741 & 0,55 & 0,99 \\
2 & $24 / 05 / 04$ & 1,228 & 0,92 & 1,63 \\
3 & $05 / 06 / 04$ & 1,050 & 0,89 & 1,24 \\
4 & $14 / 06 / 04$ & 0,762 & 0,58 & 1,00 \\
5 & $15 / 06 / 04$ & 0,536 & 0,40 & 0,72 \\
6 & $28 / 06 / 04$ & 0,300 & 0,17 & 0,53 \\
7 & $15 / 07 / 04$ & 0,329 & 0,18 & 0,60 \\
8 & $26 / 07 / 04$ & 0,879 & 0,69 & 1,12 \\
9 & $28 / 07 / 04$ & 0,702 & 0,44 & 1,12 \\
10 & $13 / 08 / 04$ & 0,498 & 0,35 & 0,70 \\
\hline \multicolumn{7}{r}{} & Média & $\mathbf{0 , 7 0 2}$ & $\mathbf{0 , 5 1 7}$ & $\mathbf{0 , 9 6 5}$ \\
\hline
\end{tabular}

Tabela 12. Análise estatística dos resultados dos testes de toxicidade com Cádmio, utilizando C. xanthus.

\begin{tabular}{l|ccc}
\hline $\begin{array}{l}\text { Variáveis } \\
\text { Estatística Descritiva }\end{array}$ & $\begin{array}{c}\text { CL 50 } \\
\text { Cádmio }\end{array}$ & $\begin{array}{c}\text { Lim. Inferior } \\
\text { Cádmio }\end{array}$ & $\begin{array}{c}\text { Lim. Superior } \\
\text { Cádmio }\end{array}$ \\
\hline Desvio padrão & 0,299 & 0,262 & 0,337 \\
Emo padrão & 0,095 & 0,083 & 0,106 \\
Máximo & 1,228 & 0,920 & 1,630 \\
Média & 0,703 & 0,517 & 0,965 \\
Mínimo & 0,300 & 0,170 & 0,530 \\
Variância da amostra & 0,089 & 0,069 & 0,113 \\
Contagem & 10 & 10 & 10 \\
\hline
\end{tabular}




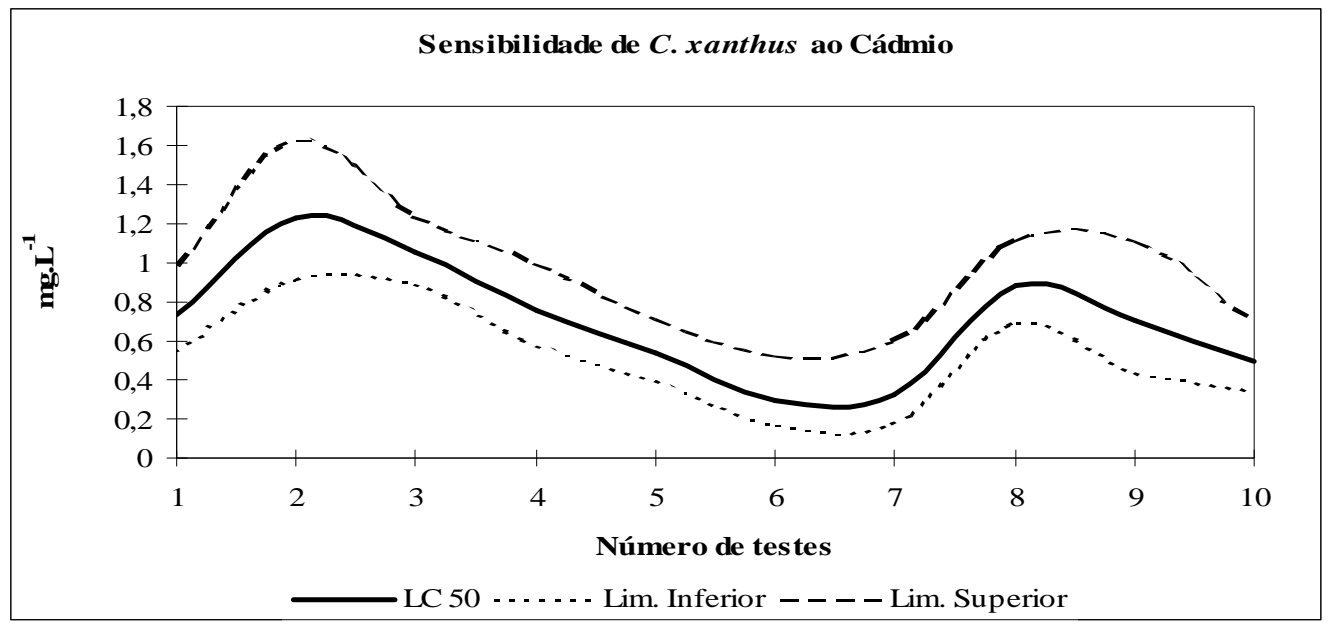

Figura 2. Representação gráfica dos resultados dos testes de toxicidade com Cádmio realizados com C. xanthus.

\subsubsection{Cobre}

Os resultados foram expressos em mg.L-1 e estão apresentados na Tabela 23, podendo-se observar que a CL50 média foi de $0,301 \mathrm{mg} \cdot \mathrm{L}^{-1} \mathrm{de} \mathrm{Cu}$. $\mathrm{O}$ coeficiente de variação (CV) foi de 26,16\%, valor comparável ao encontrado para $\mathrm{KCl}(16 \%)$ e inferior ao obtido para $\mathrm{Cd}(42,55 \%)$. Na Figura 3, verifica-se que o limite inferior variou de 0,09 a 0,360 mg.L-1 e o limite superior de 0,280 a 0,510 mg.L-1. Na Tabela 24, observa-se que a média para o limite superior foi de $0,401 \mathrm{mg} \cdot \mathrm{L}^{-1} \mathrm{e}$ para 0 limite inferior foi de 0,232 mg.L-1. Os resultados da análise estatística estão apresentados nas Tabelas de 13 a 22, no Apêndice 4.

Tabela 23. Resultados dos testes toxicidade com Cobre, realizados com C. xanthus, expresso em mg. $\mathrm{L}^{-1}$ de Cu.

\begin{tabular}{c|cccc}
\hline No do Teste $^{\circ}$ & Data & CL 50 & Lim. Inferior & Lim. Superior \\
\hline 1 & $14 / 05 / 04$ & 0,427 & 0,36 & 0,51 \\
2 & $17 / 05 / 04$ & 0,360 & 0,30 & 0,43 \\
3 & $18 / 05 / 04$ & 0,289 & 0,23 & 0,36 \\
4 & $14 / 06 / 04$ & 0,395 & 0,32 & 0,49 \\
5 & $14 / 06 / 04$ & 0,292 & 0,17 & 0,49 \\
6 & $28 / 06 / 04$ & 0,270 & 0,17 & 0,44 \\
7 & $15 / 07 / 04$ & 0,155 & 0,09 & 0,28 \\
8 & $26 / 07 / 04$ & 0,290 & 0,24 & 0,36 \\
9 & $13 / 08 / 04$ & 0,304 & 0,26 & 0,36 \\
10 & $01 / 10 / 04$ & 0,230 & 0,18 & 0,29 \\
\hline & Média & $\mathbf{0 , 3 0 1}$ & $\mathbf{0 , 2 3 2}$ & $\mathbf{0 , 4 0 1}$ \\
\hline
\end{tabular}


Tabela 24. Análise estatística dos resultados dos testes de toxicidade com Cobre, utilizando C. xanthus.

\begin{tabular}{l|ccc}
\hline $\begin{array}{l}\text { Variáveis } \\
\text { Estatística Descritiva }\end{array}$ & $\begin{array}{c}\text { CL } 50 \\
\text { Cobre }\end{array}$ & $\begin{array}{c}\text { Lim. Inferior } \\
\text { Cobre }\end{array}$ & $\begin{array}{c}\text { Lim. Superior } \\
\text { Cobre }\end{array}$ \\
\hline Desvio padrão & 0,079 & 0,082 & 0,083 \\
Emo padrão & 0,025 & 0,026 & 0,026 \\
Máximo & 0,427 & 0,360 & 0,510 \\
Média & 0,301 & 0,232 & 0,401 \\
Mínimo & 0,155 & 0,090 & 0,280 \\
Variância da amostra & 0,006 & 0,007 & 0,007 \\
Contagem & 10 & 10 & 10 \\
\hline
\end{tabular}

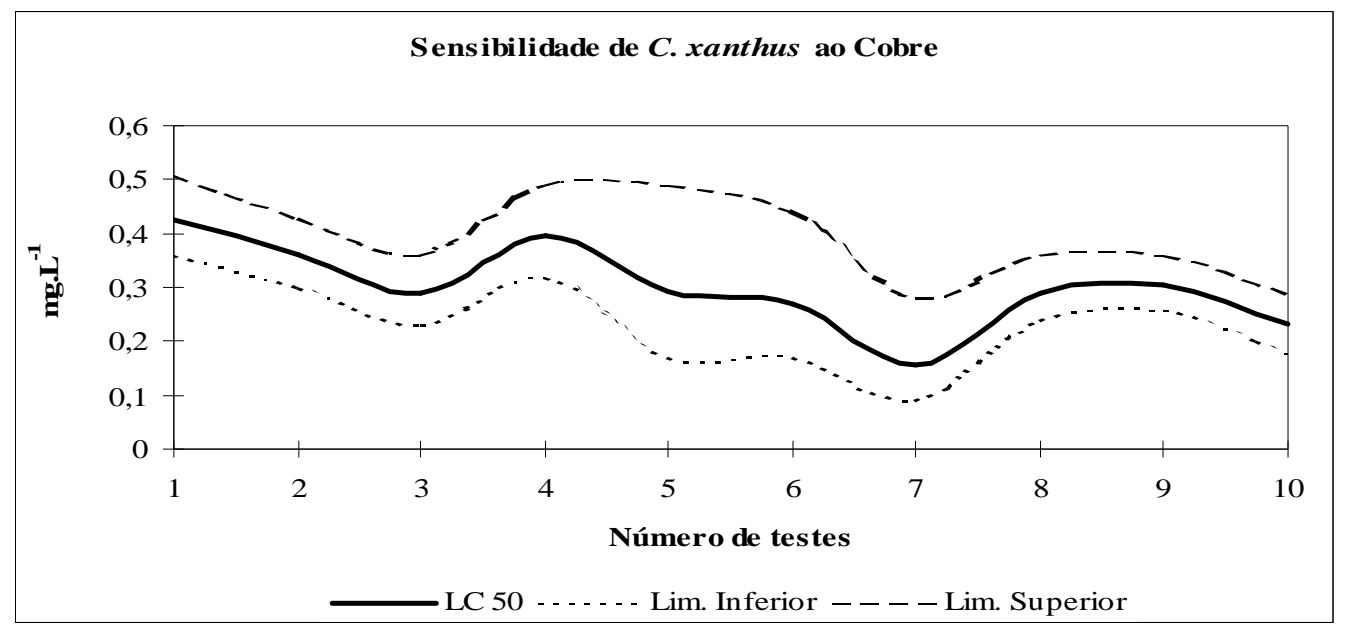

Figura 3. Representação gráfica dos resultados dos testes de toxicidade com Cobre realizados com C. xanthus.

\subsection{Testes de toxicidade crônica com metais ( $\mathrm{Cd}$ e $\mathrm{Cu}$ )}

Os resultados apresentados são a média dos valores obtidos nos 3 testes, sendo que os resultados brutos podem ser encontrados no Apêndice 4, nas Tabelas de 25 a 30. As seguintes abreviações foram utilizadas para representar os diferentes tratamentos: CdCo (Cádmio - concentração CONAMA), CdCe (Cádmio concentração CENO) e CuCo/Ce (Cobre - concentração CONAMA/CENO), referentes às concentrações dos metais utilizados.

\subsubsection{Sobrevivência, peso seco e emergência}

Pode-se observar na Figura 4 os resultados referentes à sobrevivência e peso seco individual para os tratamentos estudados. Observa-se uma maior sobrevivência em $\mathrm{CdCo}(81 \%)$ e um maior peso seco dos organismos expostos ao $\mathrm{CuCo} / \mathrm{Ce}(0,35$ 
mg). $O$ menor peso foi observado em CdCe, com 0,12 mg. A análise estatística (Teste-t) demonstrou que não houve diferença significativa entre os tratamentos para os dois parâmetros analisados, sendo que para a sobrevivência $0,13<p<0,40$ e para o peso seco $0,09<\mathrm{p}<0,69$.

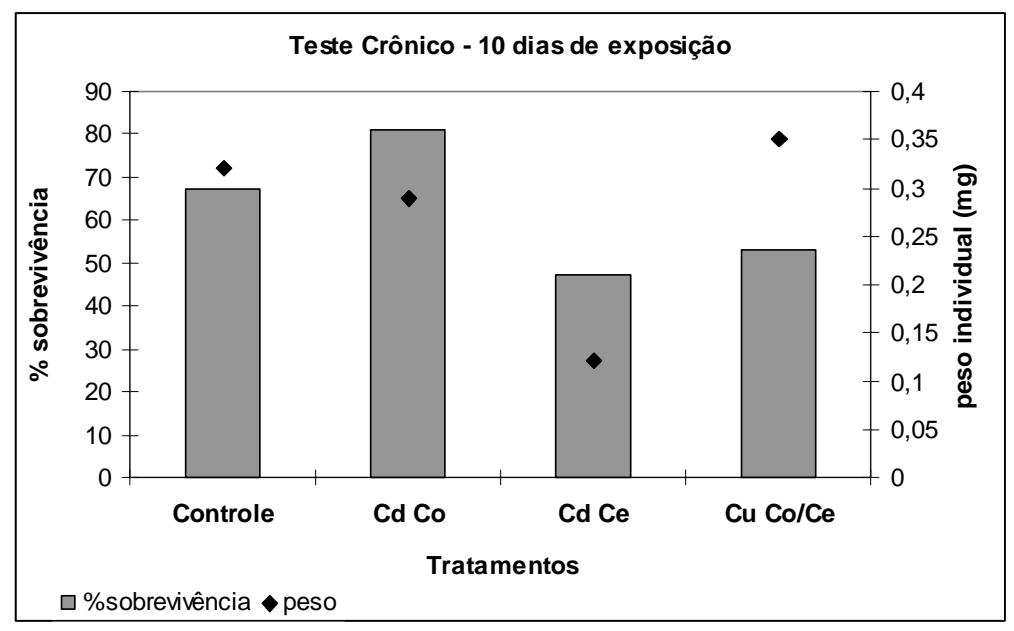

Figura 4. Análise da sobrevivência (\%) e peso seco $(\mathrm{mg})$ dos organismos expostos aos tratamentos. CdCo (Cádmio - CONAMA), CdCe (Cádmio - CENO) e CuCo/ Ce (Cobre - CONAMA/ CENO)

Na Figura 5 observa-se 0 número médio de adultos que emergiram nos testes durante 6 dias, totalizando 16 dias de exposição. O tratamento com menor emergência foi $\mathrm{CdCe}$, no qual os organismos emergiram com atraso de 3 dias. A maior emergência foi verificada no $6^{0}$ dia, sendo que no controle emergiram 13 organismos. Há diferença significativa (Teste-t) na emergência apenas quando 0 controle é comparado com o tratamento $\mathrm{CdCe}(\mathrm{p}=0,03)$.

Na Figura 6 estão apresentados os dados referentes à emergência cumulativa dos diferentes tratamentos estudados. Pode-se observar que os maiores valores foram observados no tratamento $\mathrm{CdCo}$ e no Controle, obtendo-se 100 e 73 organismos adultos, respectivamente.

Pela análise estatística (Teste-t) observou-se diferença significativa apenas quando o Controle foi comparado ao tratamento $\mathrm{CdCe}(\mathrm{p}=0,003)$ e quando da comparação entre os dois tratamentos com $\mathrm{Cd}$ (CdCo e CdCe), obtendo-se $\mathrm{p}=0,003$. 


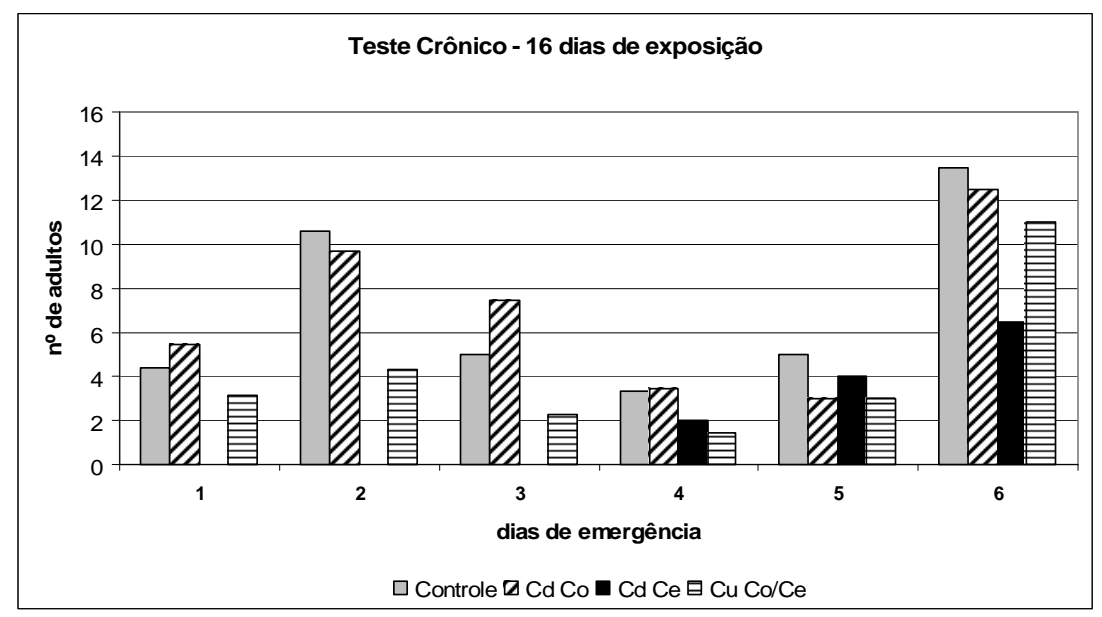

Figura 5. Total de emergência de Chironomus xanthus no Controle e tratamentos com $\mathrm{Cd}$ e $\mathrm{Cu}$, durante 15 dias de exposição. CdCo (Cádmio - CONAMA), CdCe (Cádmio -CENO) e CuCo/ Ce (Cobre - CONAMA/CENO)

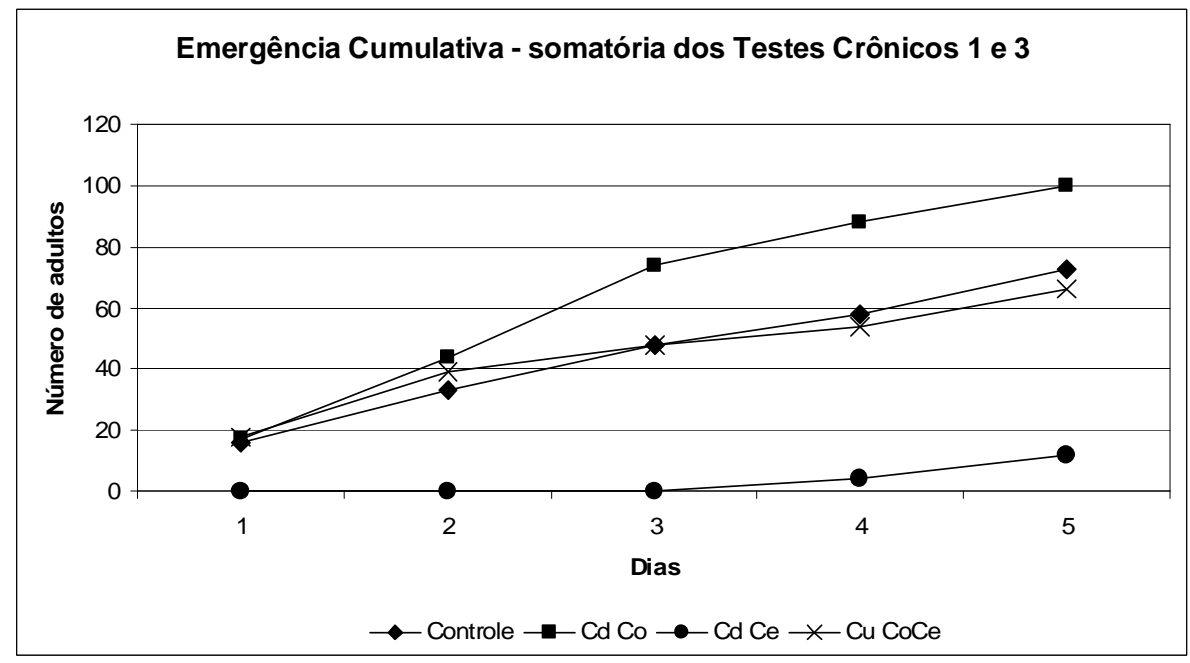

Figura 6. Emergência cumulativa (somatória dos Testes Crônicos 1 e 3). CdCo (Cádmio CONAMA), CdCe (Cádmio - CENO) e CuCo/ Ce (Cobre - CONAMA/ CENO).

Na Figura 7 pode-se observar a emergência de machos e fêmeas em cada dia e em cada tratamento. Comparando o número de emergências de machos e fêmeas em um mesmo tratamento, não foi verificada diferença significativa (Teste-t - 0,12 < $p<0,87)$. Em relação à emergência de machos também não foi verificada diferença significativa entre os tratamentos quando comparados com 0 controle $(0,11<\mathrm{p}<$ $0,68)$. Porém, em relação às fêmeas, observou-se diferença significativa quando 0 tratamento CdCe foi comparado com o controle, obtendo-se $\mathrm{p}=0,01$ devido ao reduzido número de fêmeas que emergiram nesse tratamento em relação ao 
controle. Os demais tratamentos não apresentaram diferença significativa em relação ao controle.
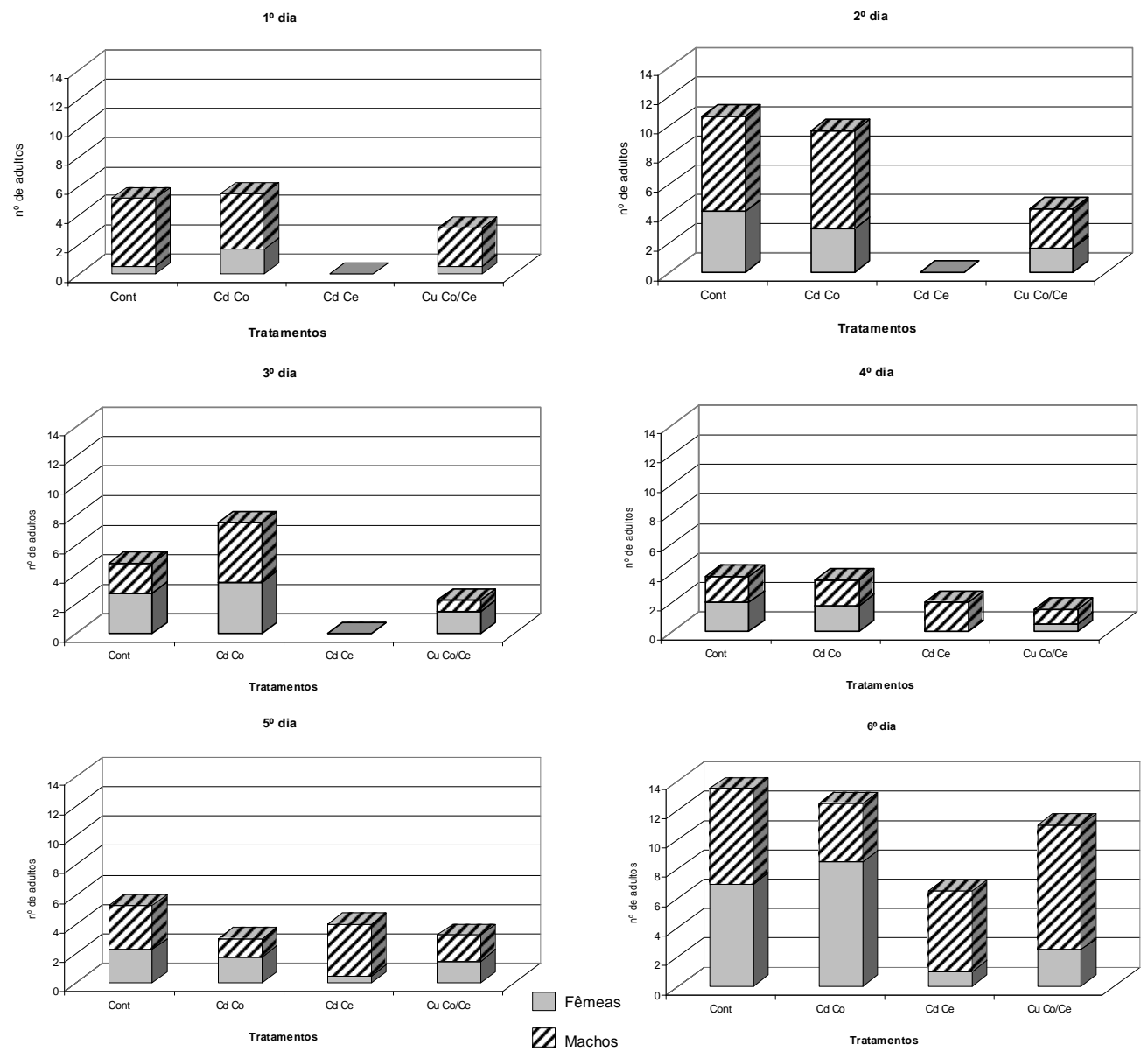

Figura 7. Emergência de machos e fêmeas durante 16 dias de exposição de Chironomus xanthus ao Controle e aos Tratamentos de Cd e Cu. CdCo (Cádmio - CONAMA), CdCe (Cádmio -CENO) e $\mathrm{CuCo} / \mathrm{Ce}$ (Cobre - CONAMA/ CENO)

\subsubsection{Medidas da cápsula cefálica e do comprimento do como}

Os resultados referentes ao comprimento e largura das cápsulas cefálicas dos organismos analisados estão na Figura 8. Observa-se diferença no padrão de distribuição apenas para os organismos expostos à concentração de $70,0 \mu \mathrm{gg} \cdot \mathrm{L}^{-1} \mathrm{de}$ $\mathrm{Cd}$. A análise do Teste t demonstrou diferença significativa no tratamento CdCe para os 3 parâmetros analisados (comprimento da cápsula cefálica $\mathrm{p}<10^{-6}$; largura da cápsula cefálica $\mathrm{p}<10^{-4}$; comprimento do corpo $\mathrm{p}<10^{-9}$ ). 
Nas tabelas 31 e 32 (Apêndice 4) estão apresentados os valores máximos, mínimos e as médias das larguras e comprimentos observados em organismos expostos aos tratamentos controle, $\mathrm{Cd}$ e $\mathrm{Cu}$ em dois Testes Crônicos distintos.
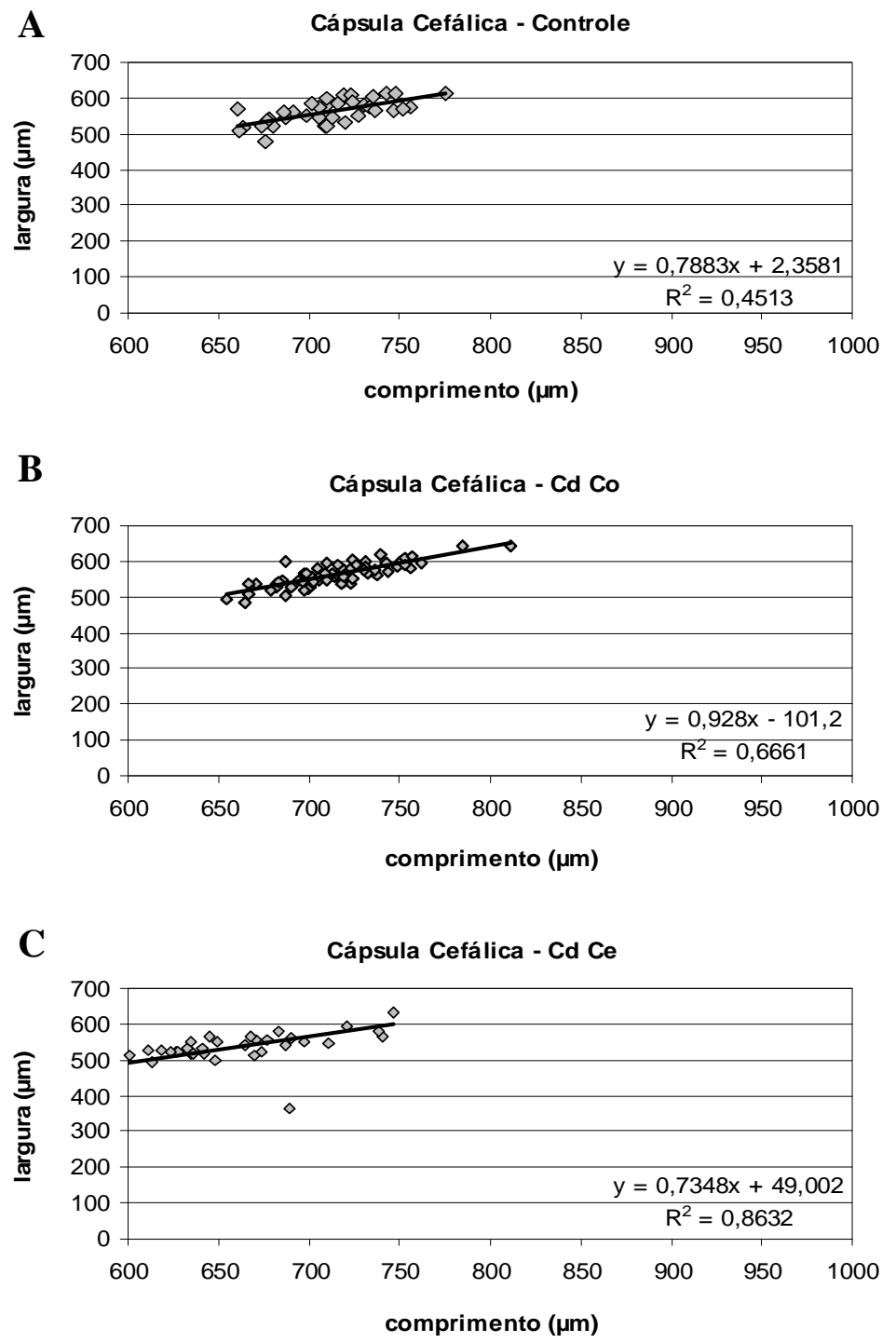

D

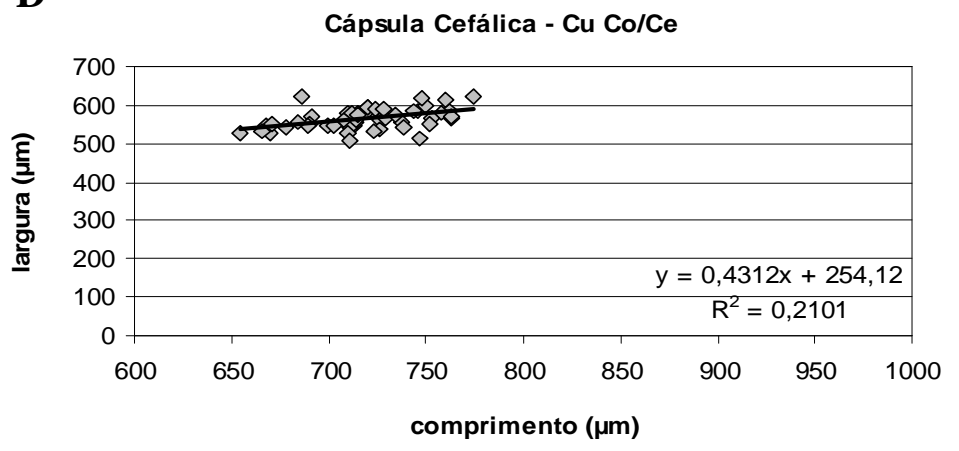

Figura 8. Comprimento e largura das cápsulas cefálicas de Chironomus xanthus expostos ao teste crônico - (A) Controle; (B) Cd CONAMA, (C) Cd CENO e (D) Cu CONAMA/ CENO. 
A Distribuição dos tamanhos de $C$. xanthus Controle

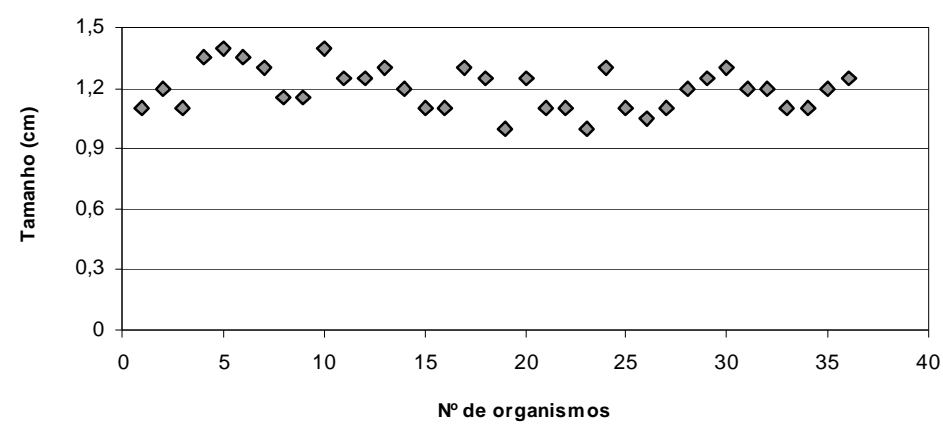

B

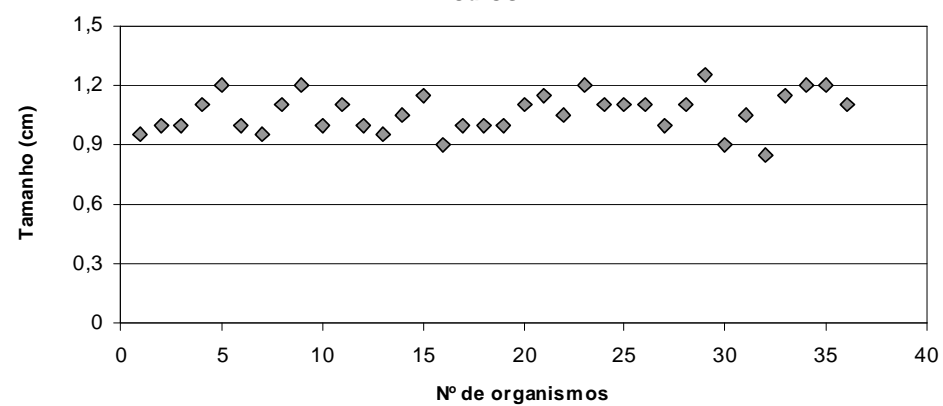

C

Cd CENO

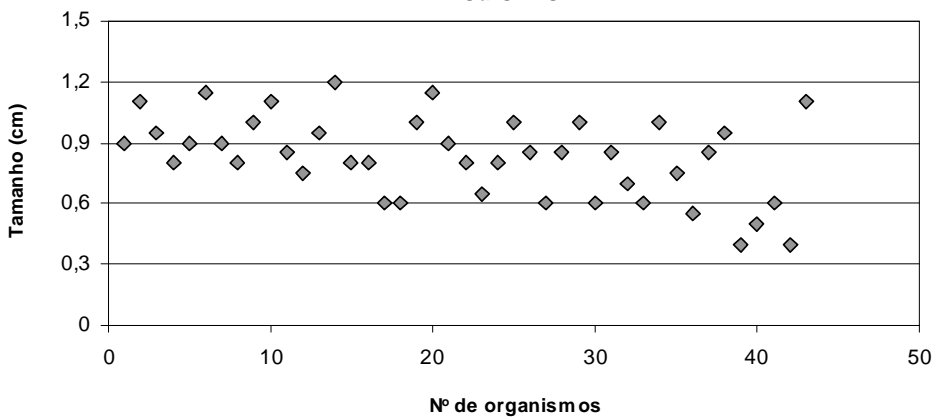

D

Cu CONAMA/CENO

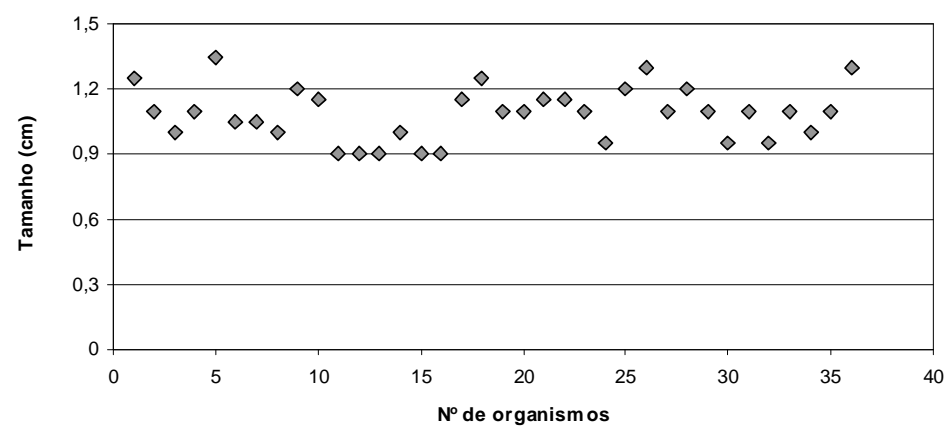

Figura 9. Distribuição do tamanho do corpo em Chironomus xanthus submetidos ao Teste Crônico: A) Controle; (B) Cd CONAMA, (C) Cd CENO e (D) Cu CONAMA/ CENO. 


\subsubsection{D eformidade do mento}

Os resultados da deformidade do mento dos espécimes de Chironomus x anthus estão apresentados na Figura 10, observando-se as maiores porcentagens de deformidade em CdCo (7,6\%) e CuCo/ Ce (6,5\%). Pela análise estatística (Teste t), não há diferença significativa entre as porcentagens de deformidades dos tratamentos em relação ao controle, sendo $\mathrm{p}=0,40$ para 0 tratamento com $\mathrm{Cd}$ e $\mathrm{p}=0,45$ para o tratamento com $\mathrm{Cu}$. As deformidades foram 100\% do tipo gap (com maior ou menor intensidade), considerando que no local onde havia a falta de um dente, formava-se uma fenda, diferente da deformidade do tipo ausência de dentes, no qual não há formação de fenda, mas sim um novo ajuste dos dentes no mento. Nas Figuras 11 e 12 (Apêndice 4), pode-se observar a estrutura da cápsula cefálica, bem como alguns detalhes do aparato bucal de $C$. $x$ anthus, além de algumas imagens selecionadas das lâminas semi-permanentes (Figuras de 14 a 19).

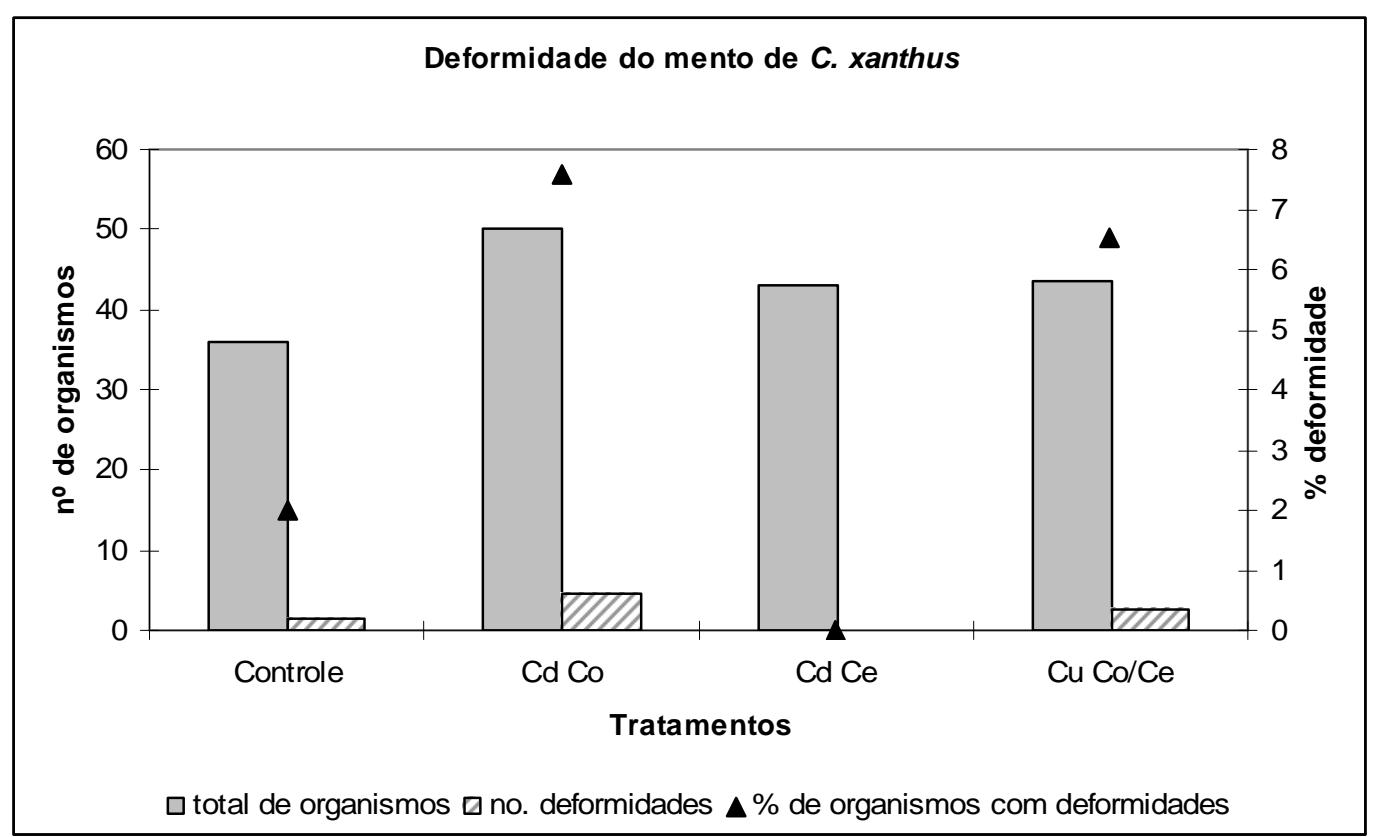

Figura 10. Total de organismos, número de deformidades e porcentagem de deformidades nos organismos expostos ao teste crônico. CdCo (Cádmio - CONAMA), CdCe (Cádmio -CENO) e $\mathrm{CuCo} / \mathrm{Ce}$ (Cobre - CONAMA/ CENO).

Na Figura 13 apresenta-se um exemplo de mento sem deformidade e um com deformidade, sendo que outros exemplos, relativos aos Testes Crônicos 1 e 3, 
podem ser observados nas Figuras de 14 a 19, no Apêndice 4, nas quais se verifica os diferentes tipos de deformidades de mento observadas no presente estudo.

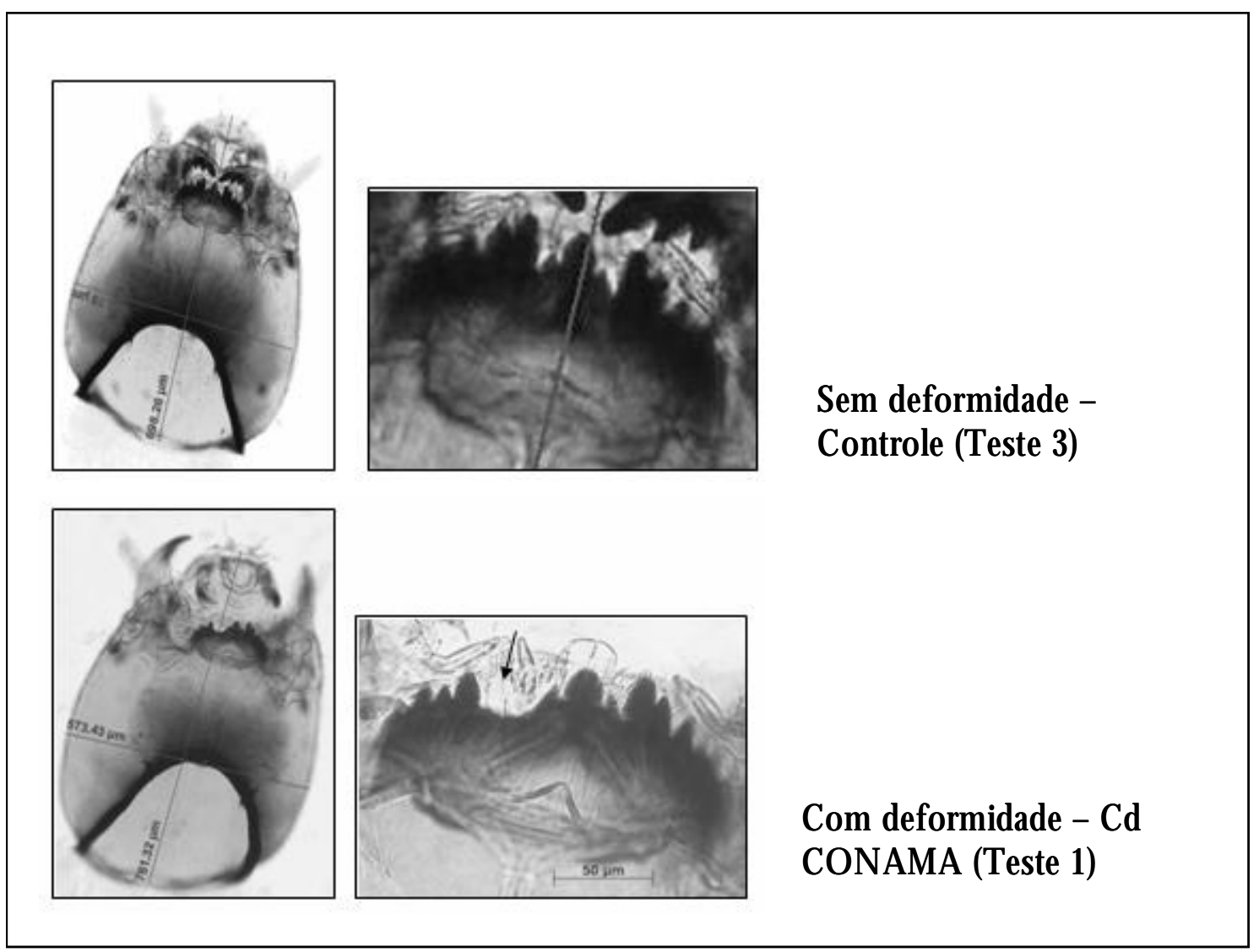

Figura 13. Exemplos de mento normal e com deformidades obtidas nos Testes Crônicos com metais.

4.2.4. Frações dos metais cádmio e cobre nos diferentes compartimentos dos testes de toxicidade crônica

4.2.4.1. Frações de cádmio nos compartimentos água, sedimento e organismos

Os resultados da concentração de $\mathrm{Cd}$ nas frações água, sedimento e organismos estão apresentados na Tabela 33 (Apêndice 4) e nas Figuras 20, 21 e 22, respectivamente.

Na Figura 20 pode-se observar as concentrações obtidas na água pós-teste. As concentrações estiveram abaixo do valor nominal inicial (1,0 e 70,0 $\left.\mu \mathrm{g} \cdot \mathrm{L}^{-1} \mathrm{de} C \mathrm{~d}\right)$, 
principalmente para CdCe que apresentou concentração máxima de 8,10 $\mu g \cdot \mathrm{L}^{-1}$ de Cd.

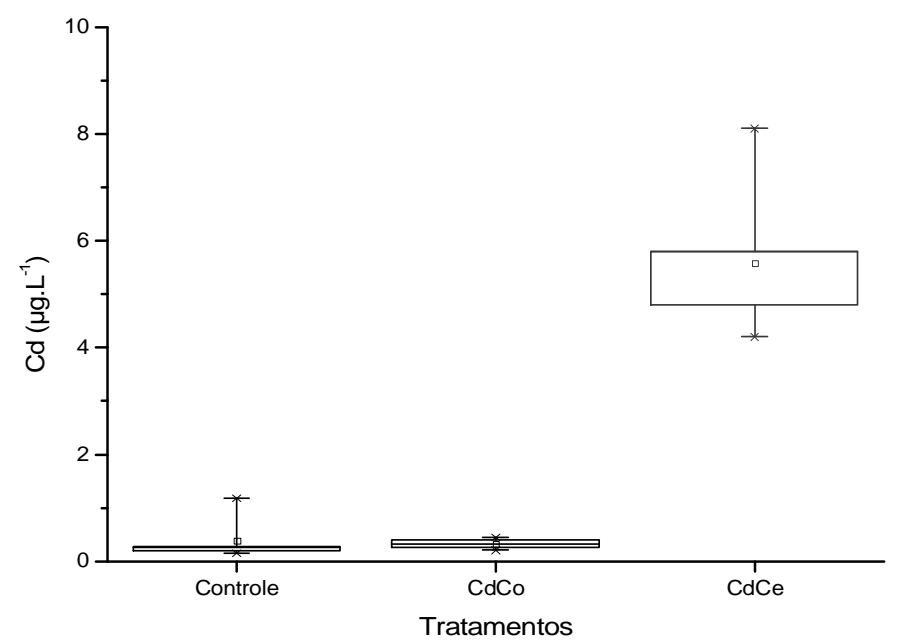

Figura 20. Concentrações de $\mathrm{Cd}\left(\mu \mathrm{g} \cdot \mathrm{L}^{-1}\right)$ na água após 10 dias de exposição. CdCo (Cádmio CONAMA), CdCe (Cádmio -CENO)

As concentrações de Cd potencialmente biodisponíveis no sedimento (Figura 21) foram extremamente baixas, indicando que não ocorreu adsorção de $\mathrm{Cd}$ nas partículas de sedimento, o que era o esperado por se tratar de areia, com granulometria que não facilita a adsorção de metais.

No Controle a concentração variou de 0,0021 a $0,0233 \mu \mathrm{g} \cdot \mathrm{g}^{-1}$, no tratamento CdCo de 0,0036 a 0,0134 $\mu \mathrm{g} \cdot \mathrm{g}^{-1}$ e no tratamento CdCe de 0,0516 a 0,1068 $\mu \mathrm{g} \cdot \mathrm{g}^{-1}$.

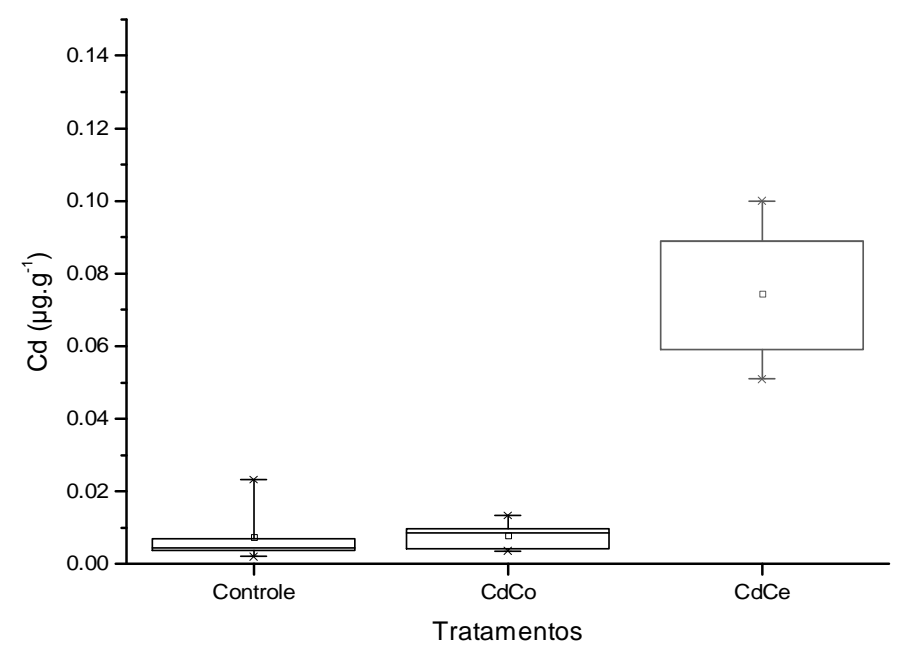

Figura 21. Concentração de Cd $\left(\mu \mathrm{g} \cdot \mathrm{g}^{-1}\right)$ potencialmente biodisponível no sedimento após 10 dias de exposição. CdCo (Cádmio - CONAMA), CdCe (Cádmio -CENO) 
As concentrações de $\mathrm{Cd}$ nos organismos foram superiores àquelas encontradas no sedimento, indicando bioacumulação (Figura 22), calculada através do Fator de Bioacumulação (Tabela 34) de Cd nos C hironomus x anthus expostos aos tratamentos. As concentrações nos organismos estiveram entre 5,47 e 21,11 $\mu \mathrm{g} . \mathrm{g}^{-1}$ no Controle, entre 5,25 e 21,11 $\mu \mathrm{g} \cdot \mathrm{g}^{-1}$ no tratamento de CdCo e entre 125,41 e $324,67 \mu \mathrm{g} \cdot \mathrm{g}^{-1}$ no tratamento de CdCe.

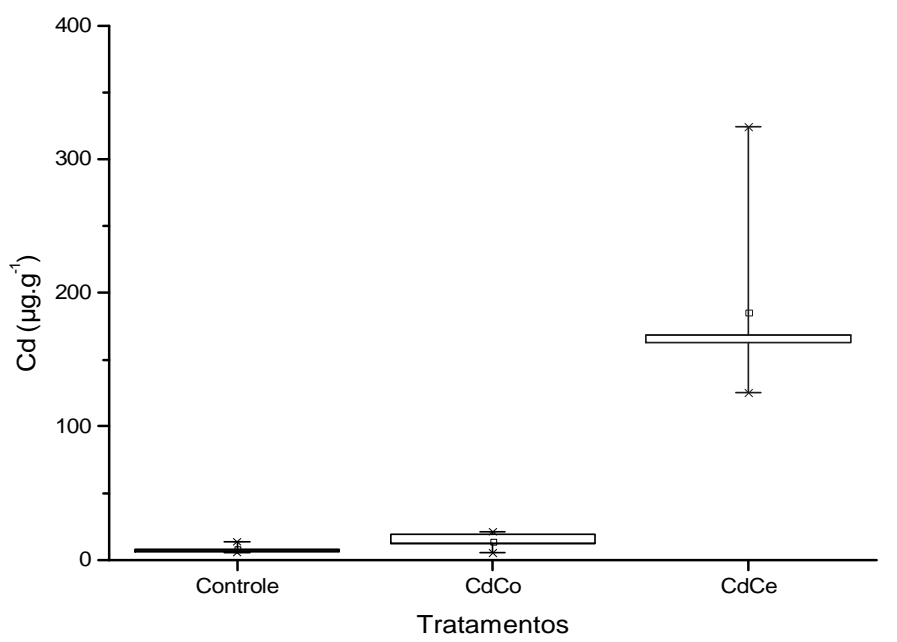

Figura 22. Concentração de $\mathrm{Cd}\left(\mu \mathrm{g} \cdot \mathrm{g}^{-1}\right)$ em Chironomus xanthus após 10 dias de exposição CdCo (Cádmio - CONAMA), CdCe (Cádmio - CENO)

Na Tabela 34 pode-se verificar que nos dois tratamentos analisados houve bioacumulação de $\mathrm{Cd}$ nos organismos, sendo que esta variou de 3,38 a 34,43 no controle, de 6,13 a 73,07 no tratamento CdCo e de 3,81 a 40,08 no tratamento CdCe. Os dados brutos estão apresentados na Tabela 35, no Apêndice 4.

Tabela 34. Valores médios do Fator de Bioacumulação (FB) de Cd relacionando as concentrações médias na água $\left(\mu g . L^{-1}\right)$ e nos organismos $\left(\mu g . g^{-1}\right)$.

\begin{tabular}{cccc}
\hline Testes Crônicos - Cd & Organismos $\mathbf{( \mu g \cdot \mathbf { g } ^ { - 1 } )}$ & Água $\left(\mathbf{\mu g} \cdot \mathbf{L}^{-\mathbf{1}}\right)$ & FB \\
\hline Controle & 6,43 & 0,43 & 21,08 \\
Cd Co & 11,58 & 0,41 & 37,02 \\
Cd Ce & 144,22 & 6,24 & 23,94 \\
\hline
\end{tabular}




\subsubsection{Frações de cobre nos compartimentos água, sedimento e organismos}

Os resultados da concentração de $\mathrm{Cu}$ nas frações água, sedimento e organismos estão apresentados nas Figuras 23, 24 e 25, respectivamente, e também na Tabela 36 (Apêndice 4).

Na Figura 23 pode-se observar as altas concentrações de $\mathrm{Cu}$ obtidas no controle, que foram em média de 17,17 $\mu g . L^{-1}$, variando de 5,58 a 26,17 $\mu \mathrm{g} \cdot \mathrm{L}^{-1}$.

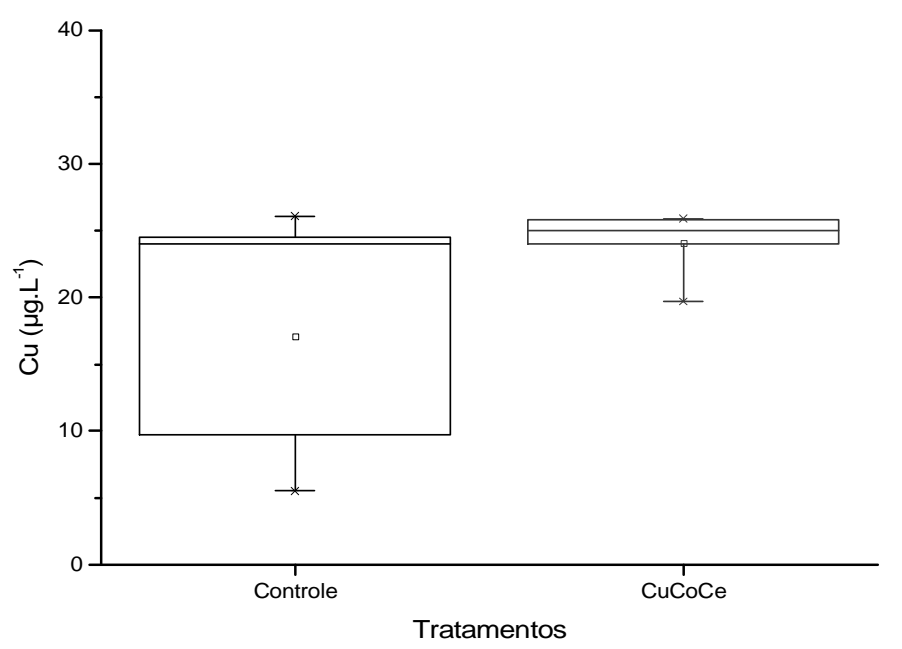

Figura 23. Concentrações de $\mathrm{Cu}\left(\mu \mathrm{g} \cdot \mathrm{L}^{-1}\right)$ na água após 10 dias de exposição. CuCo/ Ce (Cobre CONAMA/ CENO)

As concentrações de $\mathrm{Cu}$ potencialmente biodisponíveis no sedimento (Figura 24) foram extremamente baixas, indicando que não ocorreu adsorção de $\mathrm{Cu}$ nas partículas de sedimento, como nos testes com $\mathrm{Cd}$.

No Controle a concentração variou de 0,00 a 2,05 $\mu \mathrm{g} \cdot \mathrm{g}^{-1}$, e no tratamento de $\mathrm{CuCo} / \mathrm{Ce}$ variou de 0,29 a 1,69 $\mu \mathrm{g} \cdot \mathrm{g}^{-1}$. 


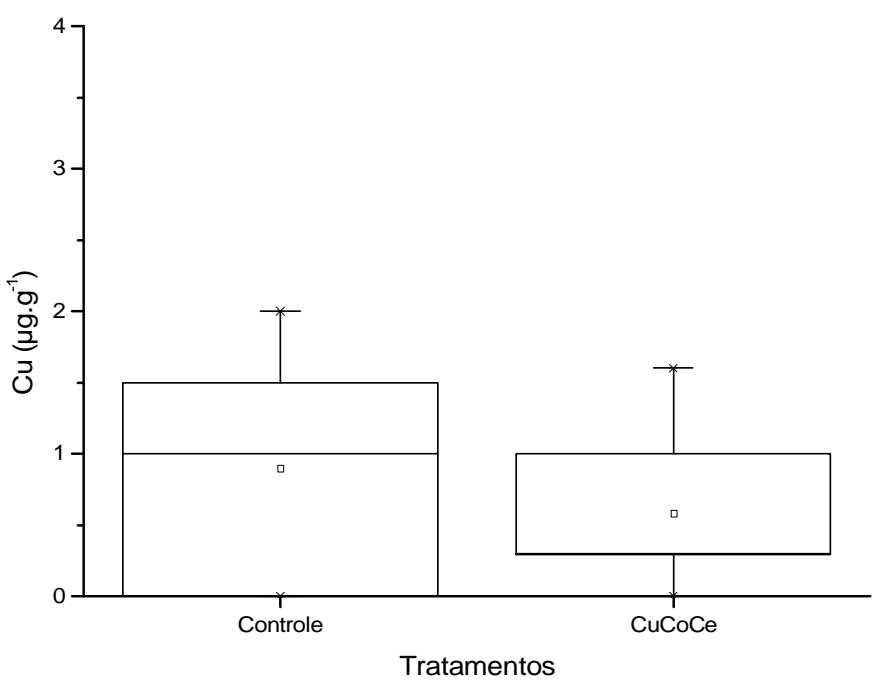

Figura 24. Concentração de $\mathrm{Cu}\left(\mu \mathrm{g} \cdot \mathrm{g}^{-1}\right)$ potencialmente biodisponível no sedimento após 10 dias de exposição. $\mathrm{CuCo} / \mathrm{Ce}$ (Cobre - CONAMA/ CENO)

Pelos resultados apresentados na Figura 25 e nas Tabelas 37 e 38 (esta última no Apêndice 4), pode-se observar que houve bioacumulação de $\mathrm{Cu}$ nos organismos, sendo que o Fator de Bioacumulação variou de 2,51 (Controle - Teste 2) a 35,83 (Cobre, Teste 3).

As concentrações de cobre nos organismos estiveram entre 60,53 e 218,15 $\mu \mathrm{g} \cdot \mathrm{g}^{-1}$ no Controle e entre 66,64 e 920,88 $\mu \mathrm{g} \cdot \mathrm{g}^{-1}$ no tratamento de $\mathrm{CuCo} / \mathrm{Ce}$.

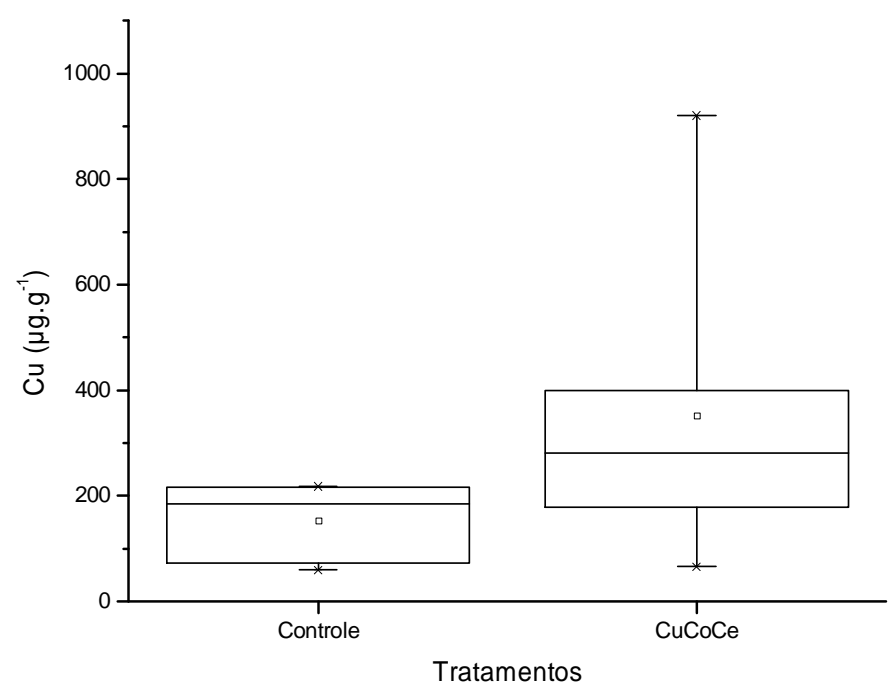

Figura 25. Concentração de $\mathrm{Cu}\left(\mu \mathrm{g} \cdot \mathrm{g}^{-1}\right)$ em Chironomus x anthus após 10 dias de exposição. $\mathrm{CuCo} / \mathrm{Ce}$ (Cobre - CONAMA/CENO) 
Tabela 37. Valores médios do Fator de Bioacumulação (FB) de $\mathrm{Cu}$ relacionando as concentrações médias na água ( $\left.\mu \mathrm{g} \cdot \mathrm{L}^{-1}\right)$ e nos organismos $\left(\mu \mathrm{g} \cdot \mathrm{g}^{-1}\right)$.

\begin{tabular}{cccc}
\hline Testes Crônicos - Cd & Organismos $\left(\mathbf{p g} \cdot \mathbf{g}^{-1}\right)$ & Água $\left(\mathbf{\mu g} \cdot \mathbf{L}^{-\mathbf{1}}\right)$ & FB \\
\hline Controle & 154,31 & 17,19 & 12,53 \\
$\mathbf{C u ~ C o} / \mathbf{C e}$ & 214,51 & 24,42 & 14,15 \\
\hline
\end{tabular}

\section{DISCUSSÃO}

O emprego de testes de toxicidade crônica, isto é, com maior tempo de exposição dos organismos-teste ao agente tóxico, é de fundamental importância, pois tendem a mostrar os efeitos subletais dos contaminantes aos organismos, sendo importantes na avaliação da dinâmica populacional e também nas extrapolações para os prováveis efeitos à saúde ambiental e humana.

Para a realização dos testes crônicos deste estudo, inicialmente realizou-se testes agudos para se obter a CL50 $96 \mathrm{~h}$ dos metais selecionados, e a partir dos valores encontrados foram calculadas as concentrações para aplicação em testes com maior tempo de duração para os dois metais (cádmio e cobre).

Os metais, provavelmente devido à sua presença natural e também devido à sua ocorrência em efluentes (industriais e domésticos), estão entre as primeiras substâncias tóxicas a serem testadas em ensaios ecotoxicológicos (MOUNT et al., 1995). Sabe-se que, embora muitos metais sejam requeridos como micronutrientes pelos sistemas biológicos, eles tornam-se tóxicos para a maioria dos organismos aquáticos quando em concentrações um pouco acima da quantidade requerida para o funcionamento normal do organismo (FARGASOVÁ 1997).

Os resultados obtidos da $\mathrm{CL}_{50} 96 \mathrm{~h}$ para Chironomus x anthus, tanto em relação ao $\mathrm{Cd}$ quanto ao $\mathrm{Cu}$, não podem ser comparados de uma forma direta com trabalhos realizados no exterior, já que a dureza da água utilizada nos ensaios é diferente. A dureza utilizada para os testes com C. xanthus (12-16 $\left.\mathrm{mgCaCO}_{3} \cdot \mathrm{L}^{-1}\right)$ é cerca de 10 vezes inferior àquela utilizada em países europeus, por exemplo, que fazem o meio ASTM duro (hard medium). Nesse caso, quanto maior a dureza, menor a disponibilidade do metal, isto é, o metal torna-se menos disponível aos organismos, tendo como resultado o aumento da resistência ao tóxico. 
Apesar disso, pode-se citar alguns trabalhos que realizaram testes agudos, tais como o de FARGOSOVÁ (1997), SUEDEL et al. (1997) e o de MASTIN \& ROD GERS (2000).

FARG OSOVÁ (op cit.) utilizou a espécie Chironomus plumosus em testes de 96h de exposição e observou que, dentre os metais estudados, os íons mais tóxicos foram $0 \mathrm{Cu}^{2+}$ e $0 \mathrm{Cu}^{+}$, apresentando toxicidade 10 vezes superior à dos demais metais testados (Mn, MO, V e Ni). Estes últimos foram considerados não tóxicos por apresentarem valores da $\mathrm{CL}_{50}$ muito acima das concentrações encontradas naturalmente nos ambientes. 0 experimento também contou com a mistura de metais e dentre as combinações testadas houve um maior número de interações de antagonismo, isto é, o metal puro apresentou maior toxicidade do que quando combinado, observando-se sinergismo apenas na relação $\mathrm{Ni}-\mathrm{Cu}$. Neste estudo, a $\mathrm{CL}_{50}$ 96h para $\mathrm{Cu}\left(0,09 \mu \mathrm{g} \cdot \mathrm{L}^{-1}\right.$ de $\left.\mathrm{Cu}^{2+}\right)$, determinada para C. plumosus, foi extremamente baixa quando comparada ao presente estudo. Para C. xanthus a CL50 96h foi de 0,30 mg.L.-1 de Cu, ou seja, $300 \mu \mathrm{g} \cdot \mathrm{L}^{-1}$ de $\mathrm{Cu}$, o que corresponde a 3000 vezes a concentração encontrada pelo autor.

MASTIN \& ROD GERS (op cit.) realizaram estudo utilizando três herbicidas a base de cobre para conhecer a toxicidade desses três produtos em espécies nãoalvos, incluindo $C$. tentans. Os autores mencionam que a entrada de cobre ocorre principalmente pela alimentação, isto é, material orgânico ligado com o cobre. No caso de C. tentans a $\mathrm{CL}_{50} 48 \mathrm{~h}$ para Clearigate, Cutrine-Plus e Sulfato de Cobre, foram de 373,5; 460,9 e 1136,5 $\mu \mathrm{g} \cdot \mathrm{L}^{-1}$ de $\mathrm{Cu}$, respectivamente, devendo-se ressaltar que a dureza da água dos testes variou de 48 a $100 \mathrm{mg} \cdot \mathrm{L}^{-1}$ de $\mathrm{CaCO} 3$, valor superior ao utilizado nos testes com C . x anthus. Similarmente, GAUSS et al. (1985) 5 e SUEDEL et al. (1996) 6 (ambos citados por MASTIN \& RODGERS, op cit.), expondo C. tentans ao $\mathrm{CuSO}_{4}$, obtiveram $\mathrm{CL}_{50} 96 \mathrm{~h}$ e $\mathrm{CL}_{50} 48 \mathrm{~h}$ de 999,5 e 529,0 $\mu \mathrm{g} \cdot \mathrm{L}^{-1}$ de $\mathrm{Cu}$, respectivamente.

PASCHOE et al. (1989), verificaram que quironomídeos são relativamente tolerantes aos metais pesados, tais como o cádmio. Entretanto, muitas das

\footnotetext{
${ }^{5}$ G auss JD, Woods PE, Winner RW, Skillings JH. Acute toxicity of copper to three life stages of C hironomus tentans as affected by water hardness-alkalinity. Environ Pollut Series A 37:149-157, 1985

${ }_{6}$ Suedel BC, D eaver E, Rodgers JH Jr. Experimental factors that may affect toxicity of aqueous and sediment-bound copper to

freshwater organisms. Arch Environ Contam Toxicol 30:40-46, 1996.
} 
evidências para esta conclusão são baseadas em testes agudos com um estágio do ciclo de vida, freqüentemente os maiores ínstares. Testes crônicos realizados com baixas concentrações e por um período de tempo mais longo do ciclo de vida do organismo demonstram que efeitos deletérios ocorrem em concentrações de $\mathrm{Cd}$ substancialmente mais baixas que aquelas que causam respostas agudas para $C$. riparius. Os resultados do presente trabalho com C. xanthus ilustra a importância de testes de toxicidade aguda e crônica com macroinvertebrados de água doce com 0 propósito de identificar a sensibilidade dos diferentes estágios do ciclo de vida e das atividades dos organismos.

Em estudos realizados por SUEDEL et al. (1997), comparando a sensibilidade de diferentes espécies ao Cloreto de Cádmio, foi observado que a espécie menos sensível foi $\mathrm{C}$. tentans. Para a realização dos testes os autores utilizaram uma dureza de 6-28 mg...-1 de $^{-} \mathrm{CaCO}_{3}$, comparável à utilizada no presente estudo, e registraram as seguintes $\mathrm{CL}_{50}: 48 \mathrm{~h}, 96 \mathrm{~h}, 7 \mathrm{~d}$, 10d e 14d de 29,5; 8,0; 1,7; 0,9 e 0,6 mg. $\mathrm{L}^{-1}$ de $\mathrm{Cd}$, respectivamente. Os autores sugerem que além do tempo de duração, outro fator muito importante é o "end point" selecionado, já que para $C$. tentans o crescimento foi consideravelmente mais sensível que a sobrevivência. No caso desse organismo-teste, os autores concluíram que avaliações conduzidas em laboratório com C. tentans com um tempo de duração insuficiente (menor que 14 dias) e "end point" menos sensível (como a sobrevivência) podem levar a conclusões errôneas de que amostras contendo $\mathrm{Cd}$ não são tóxicas, o que também pode ser considerado no presente trabalho. A CL5096h obtida por SUEDEL et al. (op. cit.) para C. tentans é 10 vezes superior à $\mathrm{CL}_{50} 96 \mathrm{~h}$ obtida para $\mathrm{C}$. xanthus no presente trabalho $\left(0,70 \mathrm{mg} \cdot \mathrm{L}^{-1} \mathrm{de} \mathrm{Cd}\right)$.

Segundo JANSSENS DE BISTHOVEN et al. (1998b), os "end points" como desenvolvimento, sobrevivência e crescimento são freqüentemente utilizados para avaliação da toxicidade em invertebrados bentônicos. Portanto, vários são os trabalhos realizados com quironomídeos que apontam os testes de longa duração e "end points" mais sensíveis que a sobrevivência como ferramentas importantes para avaliação da toxicidade ambiental.

Os resultados referentes aos testes crônicos, tal como o crescimento (comprimento do corpo, cápsula cefálica e peso seco), indicaram que não houve 
diferença significativa entre o Controle e os Tratamentos com Cd $\left(1,0 \mu g . L^{-1}\right)$ e $\mathrm{Cu}$

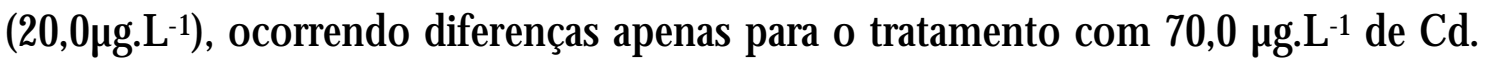
Alguns autores, que serão citados no decorrer desta discussão, também observaram uma diminuição no crescimento e alteração na emergência dos adultos, fato ocorrido no presente estudo.

WENTSEL et al. (19787 apud JANSSENS DE BISTHOVEN et al., 1998b), por exemplo, demonstraram uma redução e retardo na emergência de adultos de Chironomus quando as larvas foram expostas a sedimentos contendo altas concentrações de Cd, Zn e Cr.

SILD ANCHAND RA et al. (2000), observaram um declínio no peso da larva de C. riparius em relação ao aumento das concentrações de Cd. Na emergência cumulativa não foi verificada diferença significativa entre machos e fêmeas, exceto quando expostos à $3200 \mathrm{mg} \cdot \mathrm{L}^{-1}$ (concentração no sedimento de $317 \mathrm{mg} \cdot \mathrm{Kg}^{-1}$ ) em que a emergência das fêmeas foi atrasada em relação à dos machos. 0 estudo confirmou que a contaminação do sedimento com $\mathrm{Cd}$ pode reduzir a sobrevivência, crescimento, desenvolvimento e emergência de $\mathrm{C}$. riparius quando expostos a altas concentrações.

KRANTZBERG (19928 apud JANSSENS DE BISTHOVEN et al., 1998b), menciona que a diminuição no crescimento e reprodução são conseqüências de uma ruptura bioquímica depois da exposição a contaminantes presentes no sedimento. Efeitos no organismo ou população incluem atraso no desenvolvimento, baixa capacidade reprodutiva e deformidades. Esses efeitos são sempre inter-relacionados e, por isso, cada um pode trazer entendimento sobre o outro em um nível maior de organização e vice-versa. Os resultados do presente estudo vão de encontro com a proposta mencionada acima, já que houve um menor desenvolvimento e atraso na emergência nos organismos expostos à maior concentração de $\mathrm{Cd}$. Porém, um resultado inesperado ocorreu em relação ao parâmetro deformidade do mento, pois os organismos expostos à maior concentração $\left(70,0 \mu g . L^{-1} \mathrm{de} C \mathrm{~d}\right)$ não apresentaram

\footnotetext{
7 Wentsel, R.; McIntosh, A.; MacCafferty, W.P. Emergence of the midge Chironomus tentans when exposed to heavy metal contaminated sediment. Hydrobiologia, 57:195-196, 1978.

${ }^{8}$ Krantberg, G. \& Sotkes, P.M. Metal regulation, tolerance and body burdens in the larval of the genus Chironomus. Can. J. Fish. Aquat. Sci., 46:389-398, 1989.
} 
deformidades, enquanto que aqueles expostos à menor concentração $\left(1,0 \mu g \cdot \mathrm{L}^{-1}\right.$ de Cd) apresentaram porcentagem de deformidade de 7,6\%.

Em estudo realizado por POSTMA et al. (1994), não foram observados nenhum efeito significativo no crescimento, reprodução ou mortalidade das larvas de $C$. riparius expostas à $2,0 \mu g . L^{-1}$ de $C d$, sendo que os efeitos negativos começaram a ser observados na concentração de 16,2 $\mu g . L^{-1}$ de Cd. POSTMA (1995) sugere que a adaptação das populações à exposição ao cádmio possui base genética. Segundo 0 autor, a aquisição de tolerância em ambientes poluídos por metais tem sido estabelecida para muitas espécies animais, incluindo alguns dípteras, porém os mecanismos fisiológicos que causam esse aumento na tolerância ainda são pouco entendido, estando possivelmente relacionado com a indução de proteínas que se ligam aos metais e a formação de grânulos que contém esse metal.

PÉRY et al. (2002) mencionam que o entendimento do uso da energia por Chironomidae para o crescimento e reprodução, e do efeito das substâncias tóxicas, podem ajudar a entender 0 efeito dessas substâncias na população, citando 0 exemplo de que se houver um aumento na diferença do tempo de emergência entre machos e fêmeas, pode haver uma diminuição na probabilidade de encontros e, conseqüentemente, diminuir a oviposição.

O utro trabalho, com ênfase no uso de energia, é o de D UCROT et al (2004). Segundo os autores, a alocação de energia para a reprodução é um processo contínuo que ocorre durante todo o desenvolvimento larval, sendo a energia acumulada, provavelmente, na forma de reserva de lipídeos, convertida posteriormente em massas de ovos. Estes autores dividiram o desenvolvimento larval em dois períodos: crescimento somático (divididos entre os quatro estágios larvais) e desenvolvimento gamético (desde a estabilização do tamanho corpóreo do IV instar até pupa). No experimento, os pesquisadores verificaram que a energia para a reprodução é acumulada em maior quantidade no período do desenvolvimento gamético e que a fecundidade está relacionada com a quantidade de alimento ingerido pela fêmea durante esta fase. Quando as larvas foram expostas a diferentes concentrações de cobre (de 6,5 a 50,0 mg. $\mathrm{kg}^{-1} \mathrm{de} \mathrm{Cu}$ ), independente do período de desenvolvimento, foram observados distúrbios na reprodução, principalmente na redução do número de ovos por fêmea. A conclusão do trabalho 
foi de que a exposição ao cobre, independentemente do período de desenvolvimento, leva a efeitos similares na reprodução, o que sugere que no caso de estresse induzido por poluentes, uma vez que os mecanismos de resistência tenham sido induzidos (tal como indução da produção de metalotioninas), a sua atividade persiste até o desenvolvimento completo da larva, mesmo se a exposição ao tóxico for cessada.

De acordo com os trabalhos desenvolvidos por SERVIA et al. (2006), o $\mathrm{Cu}$ reduz 0 crescimento das larvas de $C$. riparius e a produção de ovos pelas fêmeas adultas. No estudo realizado pelos autores, que tinha por finalidade avaliar o custo energético da exposição de larvas de C. riparius ao cobre, verificou-se que os níveis de açúcares não tiveram grandes variações, enquanto as concentrações de lipídeos foram reduzidas quando as larvas foram expostas na concentração mais elevada (50 $m g . \mathrm{Kg}^{-1}$ de $\mathrm{Cu}$ ), sendo que a alteração nos níveis de lipídeos esteve intimamente relacionada com a fecundidade das fêmeas, medida em número de ovos por desova. D e acordo com os autores, os níveis de formas estocadas e circulantes de açúcares e lipídeos, os dois principais recursos energéticos do metabolismo dos insetos, podem variar conforme a intensidade do estresse. Portanto, os níveis de reservas desses dois componentes durante o estágio larval, podem ocasionar conseqüências em outros estágios do ciclo de vida de C. riparius, tal como na formação da pupa e em outros estágios da metamorfose.

Alguns trabalhos sobre deformidades em Chironomidae foram realizados e cada autor avalia uma estrutura corpórea preferencial para mensurar essas anomalias. WARWICK (1990) menciona que as deformidades que ocorrem em Chironominae (tribos Chironomini e Tanytarsini) e Orthocladiinae são mais abundantes no mento, em relação a outras partes do organismo (antena, mandíbula, placa ventro-mental).

Há grande evidência de que anomalias morfológicas desenvolvem-se em organismos bentônicos em resposta à contaminação, sendo que a maioria dos estudos com macroinvertebrados bentônicos tem examinado a ocorrência de deformidades em Chironomidae (WARWICK et al., 1987). De acordo com DIGGINS \& STEWART (1993) as espécies com deformidades ocorrem em áreas com entrada de efluentes industriais e agrícolas, mas não em áreas que recebem 
somente efluentes domésticos. Também, segundo SERVIA et al. (2000), as deformidades são freqüentemente observadas em larvas coletadas em locais poluídos e têm sido reportadas em diversos gêneros de Chironomidae, tais como, Chironomus, Procladius, Cryptochironomus, Micropsectra e Prodiamesa.

D ICKMAN et al. (1992) estudaram a relação entre a concentração de PAH e deformidade em Chironomus anthracinus e concluíram que organismos com deformidades absorveram maior quantidade de PAH do que organismos normais. $\mathrm{O}$ autor também observou que a geração F1 desses organismos, quando cultivadas em sedimentos não contaminados, apresentaram menor porcentagem de deformidades, concluindo que os PAHs analisados funcionam como agentes teratogênicos e não como mutagênicos.

Os estudos de JANSSENS DE BISTHOVEN et al. (1998 a, b) demonstraram que cuidados devem ser tomados na interpretação das deformidades em larvas de quironomídeos utilizados como indicadores de toxicidade do sedimento, pois as porcentagens de deformidades podem depender de pressões ambientais, bem como, da história da população com a possibilidade de adaptação aos metais pesados.

SERVIA et al. (2000), estudando deformidades em larvas recentemente eclodidas (I ínstar), elaborou quatro hipóteses, que não são mutuamente exclusivas, para a ocorrência de deformidades nessas larvas: 1) efeitos teratogênicos de contaminantes na água; 2) efeitos teratogênicos de contaminantes acumulados no corpo da mãe; 3) hereditariedade genética da indução de mutações pelos contaminantes e 4) desenvolvimento espontâneo, isto é, independente da genética ou do efeito teratogênico.

Assim como no presente estudo, para os testes utilizando Cd, MARTINEZ et al. (2003) não observaram uma relação linear entre a concentração do metal e a taxa de deformidades, observando as maiores porcentagens de deformidades na menor concentração testada $\left(9,0 \mu \mathrm{g} . \mathrm{g}^{-1}\right)$. 0 mesmo autor realizou testes com Zn e $\mathrm{Pb}$ e encontrou resultados similares (MARTINEZ et al., 2003). Segundo MARTINEZ (2003), uma das conclusões do trabalho é de que altas concentrações de metais podem reduzir a taxa de alimentação, reduzindo desta forma, a entrada de metais nos organismos e, portanto, diminuindo a taxa de deformidades. No presente 
estudo, a taxa de alimentação foi reduzida, sendo comprovada pelos menores valores de peso seco dos organismos expostos à 70,0 $\mu \mathrm{gg} \cdot \mathrm{L}^{-1}$ de $\mathrm{Cd}$ em comparação com aqueles expostos à 1,0 $\mu g . L^{-1}$ de Cd. MARTINEZ et al. (2003), também encontrou deformidades nos organismos expostos ao $\mathrm{Cu}$.

A CETESB (2005), dentro de sua rede de monitoramento da qualidade de sedimentos realiza a análise da deformidade de mento em Chironomus coletados no ambiente. Esta análise baseia-se na freqüência de deformidade em mento de larvas de IV instar de C hironomus, e utiliza para a incidência natural da população valores de até 3\%, como citado em literatura (BURT et al., $2003^{9}$ apud CETESB, op cit.). Assim, considera-se ótima a condição de freqüências de deformidade inferiores ou iguais a 3\%, regulares entre 3 e $6 \%$ e péssima aquelas superiores a 6\%. Como exemplo, tem-se os resultados relacionados à Bacia do Rio Piracicaba, os quais demonstraram valores elevados para o rio Piracicaba $(37 \%, \mathrm{~N}=255)$ e 0 ribeirão Quilombo (38\%, $\mathrm{N}=108)$, mas baixo para o ribeirão Tatu $(4 \%, \mathrm{~N}=102)$, indicando que o efluente com potencial para causar esse tipo de dano deve estar localizado na sub-bacia do Ribeirão Quilombo.

No presente estudo, observou-se somente $2,0 \pm 2,8 \%$ de deformidade no mento das larvas do controle. Este é um fato importante, considerando que no trabalho de VERMEULEN et al. (2000), um dos maiores questionamentos foram os motivos que o levaram a ter entre 34 e 56\% de deformidade em suas culturas e no controle de seus testes. Segundo o mesmo autor (VERMEULEN, $1995^{10}$ apud VERMEULEN, 2000), 0,8\% seria o nível supostamente natural de ocorrência de deformidade. VERMEULEN et al. (2000) compararam vários trabalhos e concluíram que o cruzamento entre parentes nas culturas é tido como o maior fator responsável pelos altos níveis de deformidades em controles. Além disso, para realizar ensaios com várias substâncias (como exemplo, agrotóxicos e $\beta$-sitosterol), os controles devem conter uma concentração de acetona e esta também pode induzir deformidades no mento.

\footnotetext{
9 Burt, J.; Ciborowski, J.J.H.; Reynoldson, T.B. Baseline incidence of mouthpart deformities in Chironomidae (Diptera) from the Laurentian Great Lakes, Canada. J. Great Lakes Res., 29(1):172-180, 2003.

${ }^{10}$ Vermeulen, A.C. Elaborating chironomid deformities as bioindicators of toxic sediment stress: the potential application of mixture toxicity concepts. Annales Zoologici Fennici, 32: 265-285, 1995.
} 
Considerando a bioacumulação de metais, INGERSOLL et al. (1998), mencionam que a escolha do organismo-teste tem a maior influência na relevância, sucesso e interpretação do teste, e vários organismos têm sido sugeridos para uso em estudos de bioacumulação química de sedimentos de sistemas continentais. O bserva-se na Tabela 39 alguns parâmetros utilizados para a seleção de organismos para testes de bioacumulação e pode-se verificar que os quironomídeos não seriam os organismos mais indicado para esse tipo de análise, quando comparados aos oligoquetos e moluscos. Porém, utilizando-se o IV instar de C. xanthus, foi possível obter uma quantidade suficiente de massa de tecido corpóreo, e os organismos apresentaram baixa sensibilidade aos contaminantes testados, quando comparados aos trabalhos que utilizam C. tentans e C. riparius, isto é, espécies já padronizadas.

Os resultados do presente estudo revelaram que houve bioacumulação de metais em todas as concentrações estudadas, mesmo na mais baixa, considerando 1,0 $\mu \mathrm{g} . \mathrm{L}^{-1}$ de $\mathrm{Cd}$, mostrando a importância dessa variável em testes de toxicidade com metais pesados.

Segundo EGELER et al. (1999), a bioacumulação, que é definida como 0 aumento de substâncias químicas nos organismos relativa com as concentrações no meio ambiente ou alimento, consiste de vários processos e aumentos da soma de todas as possíveis rotas de exposição. As medidas da bioacumulação em organismos bentônicos podem indicar uma avaliação de risco ecotoxicológico dos químicos associados ao sedimento em ecossistemas aquáticos. D eve-se também considerar que mudanças nas condições ambientais, tais como potencial redox, $\mathrm{pH}$, temperatura, salinidade, atividade biológica e tipos e concentração de ligantes, podem afetar a especiação de metais, sua complexação e, conseqüentemente, a mobilidade, biodisponibilidade e toxicidade (LION et al. $1982^{11}$ apud FARG OSOVÁ, 1997).

Segundo BERVOETS et al. (1997) a relação entre as concentrações de metal total no sedimento e nos organismos é muito fraca, sendo uma melhor correlação encontrada com as concentrações de metais na água intersticial, sugerindo que a principal rota de exposição é a ingestão de matéria particulada. A ausência de uma

11 Lion, L.W., Altmann, R.S., Leckie, J.O. Trace metal adsorption characteristics of estuarine particulate matter: Evaluation of contributions of $\mathrm{Fe} / \mathrm{Mn}$ oxide and organic surface coatings. Environ Sci Technol 16:660-666, 1982. 
clara relação é principalmente devido às mudanças na biodisponibilidade dos metais e às mudanças nas características geoquímicas dos sedimentos. Os autores sugeriram ainda, que a fraca correlação das concentrações de metais em Chironomidae e Tubificidae pode indicar que o conhecimento da química do ambiente não é suficiente para predizer a concentração em organismos.

Tabela 39. Critérios de seleção de organismos para testes de bioacumulação (Modificado de INGERSO LL et al., 1998; EPA, 2000).

\begin{tabular}{|l|c|c|c|c|c|c|}
\hline Variáveis & 0ligoqueta & Moluscos & Quironomideos & Anfípodas & Cladoceros & Peixes \\
\hline $\begin{array}{l}\text { Cultura de } \\
\text { laboratónio }\end{array}$ & + & - & + & + & + & + \\
\hline $\begin{array}{l}\text { Exposição } \\
\text { química } \\
\text { conhecida }\end{array}$ & + & - & + & + & + & + \\
\hline $\begin{array}{l}\text { Massa de } \\
\text { tecido } \\
\text { adequada }\end{array}$ & $+/-$ & + & - & - & - & + \\
\hline $\begin{array}{l}\text { Baixa } \\
\text { sensibilidade à } \\
\text { contaminantes }\end{array}$ & + & + & - & - & - & $+/-$ \\
\hline $\begin{array}{l}\text { Alimentação } \\
\text { não requerida } \\
\text { durante o teste }\end{array}$ & + & + & - & - & - & + \\
\hline $\begin{array}{l}\text { Exposição } \\
\text { realista }\end{array}$ & + & $+/-$ & + & + & - & - \\
\hline $\begin{array}{l}\text { Tolerância à } \\
\text { físico-química } \\
\text { do sedimento }\end{array}$ & + & $?$ & $+/-$ & + & NA & NA \\
\hline $\begin{array}{l}\text { "End points" } \\
\text { monitorados }\end{array}$ & B; S; R & B & S; C; E; R & S; C; M; R & S; C; R & ?? \\
\hline
\end{tabular}

Legenda: + ou - indicam atributos positivos ou negativos, respectivamente; NA - não aplicável; ? sem conhecimento; S - sobrevivência; C - Crescimento; B - Bioacumulação; R - Reprodução; M - Maturação; E Emergência.

Em estudo realizado por HWANG et al. (2001), foi observado que um aumento na concentração de HCBP (hexachlorobiphenyl) no corpo de C. riparius (bioacumulação) acontecia em cada aumento sucessivo do desenvolvimento larval, provavelmente devido ao maior período de exposição, bem como, ao maior conteúdo de lipídeos no corpo. Os mesmos autores observaram uma diminuição no número de ovos por fêmea nas maiores concentrações de exposição. Para o IV ínstar, observou-se uma diminuição no peso daqueles organismos com as maiores concentrações de HCBP bioacumulado. Nesse estudo, os autores mencionam que pode-se utilizar o ganho de peso, como parâmetro de avaliação, durante os quatro ínstares da larva, mas não quando o organismo começa a tornar-se pupa, 
considerando-se que a pupa jovem é mais pesada que a pupa em estágio mais avançado de desenvolvimento. Isso acontece porque as pupas param de se alimentar e passam por processos de reconstrução, onde estruturas da larva são destruídas e estruturas do adulto são elaboradas, consumindo somente a energia armazenada durante 0 estágio larval. Segundo este trabalho, os problemas com as múltiplas rotas de exposição podem ser resolvidos utilizando os resíduos corporais (concentração da substância no organismo).

Alguns estudos têm realizado inovações em técnicas e utilizado diferentes "end points" para avaliação dos testes de toxicidade, sejam com amostras ambientais ou com substâncias de referências. Neste sentido, MEREGALLI et al. (2002), estudaram a relação entre a indução da deformidade do mento e o aumento da atividade dos nucléolos dos cromossomos politênicos de C. riparius, verificando que a síntese de proteínas adicionais pode aumentar a tolerância das larvas com deformidade aos agentes tóxicos. Com esses resultados, os autores sugerem que além da deformidade do mento, que já é utilizada em programas de biomonitoramento, a atividade dos nucléolos também pode ser um parâmetro a ser analisado como bioindicador de poluição.

PRINTES (2005), estudou o efeito de metais sobre as enzimas colinesterases (AchE) e glutationa-s transferase (GST) em C. xanthus expostos aos metais $\mathrm{Cu}$ e Cd. Em concentrações que variaram de 0,10 a 0,40 mg. $\mathrm{L}^{-1}$ de $\mathrm{Cu}$, apesar de ter havido uma tendência à diminuição da atividade de AchE nos organismos expostos as concentrações mais altas, não houve diferença significativa entre os tratamentos. Já para 0 cádmio, em concentrações de 0,25 a 0,50 mg.L-1 de Cd, o teste realizado mostrou uma diminuição significativa da atividade de AchE. Em relação a GST, os resultados obtidos até o momento não permitiram concluir sobre a viabilidade da utilização da atividade de GST em C. xanthus como uma ferramenta da avaliação ambiental.

Dessa forma, pôde-se observar com o esforço deste trabalho e pautado na extensa bibliografia com as diferentes espécies de Chironomidae, que 0 uso da espécie Chironomus x anthus é adequado para fins de ensaios ecotoxicológicos, sendo que os ensaios e os "end points" analisados exibem uma ampla gama de variedades, 
tornando-a uma espécie de fácil manipulação na busca de diferentes formas de expressar resultados dos testes de toxicidade.

\section{CONCLUSÃO}

A análise dos resultados demonstrou a importância da utilização de diferentes parâmetros de avaliação final dos testes de toxicidade com Chironomus xanthus, mostrando que dados sobre 0 crescimento e emergência são importantes em nível individual e de população.

Sobre as deformidades, maiores estudos devem ser realizados para uma melhor conclusão acerca dos resultados apresentados nas larvas expostas a $70 \mu \mathrm{gg} \cdot \mathrm{L}^{-1}$ de $\mathrm{Cd}$. $\mathrm{O}$ fato de não ter ocorrido deformidades nessas larvas, levam a inferir que mecanismos bioquímicos possam ter sido iniciados, impedindo a ocorrência da má formação, isto é, o metal pode ter sido quelado por uma enzima e se tornado indisponível para o organismo. A pesar deste fato e baseado na literatura consultada, este é um dos poucos estudos no qual a deformidade de Chironomus foi induzida em estudos laboratoriais, utilizando concentrações similares àquelas encontradas no ambiente.

A bioacumulação dos metais nas larvas também foi comprovada como sendo de grande importância. Porém, os trabalhos publicados com Chironomidae expostos à metais ainda são escassos, o que pode ter prejudicado a discussão sobre este tópico.

Como o objetivo do presente estudo foi testar as concentrações estabelecidas pela Resolução CONAMA 20/ 86 (atual 357/ 05) e pela CENO, ficou uma lacuna a ser preenchida com trabalhos posteriores, com o intuito de identificar a faixa de concentração de $\mathrm{Cd}$ e $\mathrm{Cu}$ nas quais começam a ocorrer os efeitos crônicos em $\mathrm{C}$. $\mathrm{x}$ anthus, especialmente no caso das deformidades de mento.

Conclui-se, ainda, que a espécie Chironomus xanthus pode ser utilizada em estudos de toxicidade de sedimentos e de avaliação de risco ecológico, desde que sejam utilizados diferentes parâmetros de avaliação dos testes, além da sobrevivência. 


\section{BIBLIOGRAFIA}

AMERICAN PUBLIC HEALTH ASSOCIATION (APHA); American Water Work Association; Water Control Federation. Standard Methods for the Examination of Water and Wastewater. 19 Ed. New York, 1995. 1268p.

BERVOETS, L.; BLUST, R.; DE WIT, M.; VERHEYEN, R. Relationships between river sediment characteristics and trace metal concentrations in tubificid worms and chironomid larvae. Environmental Pollution, 95(3):345-356, 1997.

COMPANHIA DE TECNOLOGIA E SANEAMENTO AMBIENTAL -

CETESB - Implementação de testes de toxicidade no controle de efluentes líquidos, São Paulo, 1992, 17p.

COMPANHIA DE TECNOLOGIA E SANEAMENTO AMBIENTAL CETESB. Relatório de qualidade das águas interiores do Estado de São Paulo 2004. Secretaria do Meio Ambiente, 2005. 307p.

CONSELHO NACIONAL DO MEIO AMBIENTE - CONAMA - Resolução CONAMA 20 de 12 junho de 1986. In: Coletânea de Legislação Ambiental Federal - Estadual, 1991. Imprensa O ficial do Estado do Paraná.

Resolução CONAMA 357 de 17 de março de 2005. Ministério do Meio Ambiente - www.mma.gov.br, 2005.

DICKMAN, M.; BRINDLE, I.; BENSON, M. Evidence of teratogens in sediments of the Niagara river watershed as reflected by chironomid (Diptera: Chironomidae) deformities, Journal G reat Lakes Reservoir, 18(3):467-480, 1992.

DIGGINS, T. P.; STEWART, K.M. Deformities of aquatic larval midges (Chironomidae: Diptera) in the sediments of the Buffalo river, New York, Journal of G reat Lakes Research, 19(4):648-659, 1993.

DUCROT, V.; PÉRY, A.R.R.; MONS, R.; GARRIC, J. Energy-based modeling as a basis for the analysis of reproductive data with the midge (Chironomus riparius). Environmental Toxicology and Chemistry, 23(1): 225-231, 2004.

EGELER, P.; ROMBKEL, J.; MELLER, M. KNACKER, T.; NAGEL, R.. Bioaccumulation test with Tubificid Sludgeworms in artificial media development of a standardisable method. Hydrobiologia 406: 271-280, 1999. 
FARGASOVA, A. Sensitivity of Chironomus plumosus larvae to $\mathrm{V}^{5+}, \mathrm{Mo}^{6+}, \mathrm{Mn}^{2+}$, $\mathrm{Ni}^{2+}, \mathrm{Cu}^{2+}$ and $\mathrm{Cu}^{+}$metal ions and their combinations. Bull. Environmental Contamination Toxicology, 59: 956-962, 1997.

FONSECA, A.L. Avaliação da qualidade da água do rio Piracicaba/ SP através de testes de toxicidade com invertebrados, 1997. Tese (doutorado). São Carlos. Escola de Engenharia de São Carlos, Universidade de São Paulo, 1997. 211p.

HWANG, H.; FISHER, S.W.; LANDRUM, P.F. Identifying body residues of HCBP associated with 10-d mortality and partial life cycle effects in the midge, Chironomus riparius. Aquatic Toxicology, 52: 251-26, 2001.

INGERSOLL, C.G.; BRUNSON, E.L.; DWYER, F.J. Methods for assessing bioaccumulation of sediment-associated contaminants with freshwater invertebrates. In: U.S. EPA (1998). National Sediment Bioaccumulation Conference (Proceedings). EPA 823-R-98-002, 1998, p. 25-29.

JANSSENS DE BISTHOVEN, L.; NUYTS, P.; GODDEERIS, B.; OLLIVIER, F.. Sublethal parameters in morphologically deformed Chironomus larvae: clues to understanding their bioindicator value. Freshwater Biology, 39:179-191, 1998a.

JANSSENS DE BISTHOVEN, L.; VERMEULEN, A.; OLLEVIER, F. Experimental induction of morphological deformities in Chironomus riparius larvae by chronic exposure to copper and lead. Archives Environmental Contamination Toxicology, 35: 349-356, 1998b.

KUHLMANN, M.L.; HAYASHIDA, C.Y. \& ARAUJO, R.P.A. Using Chironomus (Chironomidae: Diptera) mentum deformities in environmental assessment, Acta Limnologica Brasiliensia, 12:55-61, 2000.

MARTINEZ, E.A.; MOORE, B.C.; SCHAUMLOFFEL, J.; DASGUPTA, N.. Induction of morphological deformities in Chironomus tentans exposed to zinc and lead spiked sediments, Environmental Toxicology and Chemistry, 30(11):24752481, 2001.

MARTINEZ, E.A.; MOORE, B.C.; SCHAUMLOFFEL, J.; DASGUPTA, N.. Morphological abnormalities in Chironomus tentans exposed to cadmium-and copper-spiked sediment. Ecotoxicology Environmental and Safety, 55:204-212, 2003. 
MASTIN, B.J;; RODGERS JR, J.H. Toxicity and bioavailability of copper herbicides (Clearigate, Cutrine-Plus, and Copper Sulfate) to freshwater animals. Archives Environmental Contamination Toxicology, 39:445-451, 2000.

MEREGALLI, G.; BETTINETTI, R.; PLUYMERS, L.; VERMEULEN, A.C.; ROSSARO, B.; OLLEVIER, F. Mouthparts deformities and nucleolus activity in field collected Chironomus riparius larvae. Archives Environmental Contamination Toxicology, 42:405-409, 2002.

MOUNT, D.I.. D evelopment and current use of single species aquatic toxicity tests, In:Cairs Jr, J.; Niederlehner, B.R., Ecological toxicity testing: scale, complexity and relevance, Lewis Publishers, Boca Raton, 1995. p. 97-104.

PASCOE, D.; WILLIAMS, K.A.; GREEN, W.J. Chronic toxicity of cadmium to Chironomus riparius Meigen - effects upon larval development and adult emergence. Hydrobiologia, 175:109-115, 1989.

PÉRY, A.R.R.; MONS, R.L.; FLAMMARION, P.; LAGADIC, L.; GARRIC, J.. A modeling approach to link food availability, growth, emergence, and reproduction for the midge Chironomus riparius. Environmental Toxicology and Chemistry, 21(11):2507-2513, 2002.

POSTMA, J.F.; BUCKERT-DE JONG, M.C.; STAATS, N.; DAVID S, C. Chronic toxicity of cadmium to Chironomus riparius (Diptera) at different food levels. Archives Environmental Contamination Toxicology, 26:143-148, 1994.

POSTMA, J.F.. Adaptation to metals in the midge Chironomus riparius. Universiteit van Amsterdam, Amsterdam, The Netherlands, 1995. 156p.

PRINTES, L.B. Implementação de biomarcadores bioquímicos em Chironomus x anthus (Díptera) para avaliação do impacto ecotoxicológico de poluentes na bacia hidrográfica do rio do Monjolinho (São Carlos, SP) Relatório de Atividades - Pós-doutorado encaminhado à FAPESP. Escola de Engenharia de São Carlos/ USP, 2005. 44p.

SERVIA, M.J.; COBO , F.; GONZÁLEZ, M.A. Incidence and causes of deformities in recently hatched larvae of Chironomus riparius Meigen, 1804 (Diptera, Chironomidae), Archiv für Hydrobiologie, 149(3):387-401, 2000. 
SERVIA, M.J.; PÉRY, A.R.R.; HEYDORFF, M.; GARRIC, J.; LAGADIC, L. Effects of copper on energy metabolism and larval development in the midge Chironomus riparius. Ecotoxicology, 15:229-240, 2006.

SILDANCHANDRA, W.; CRANE, M. Influence of sexual dimorphism in Chironomus riparius Meigen on toxic effects of cadmium. Environmental Toxicology and Chemistry, 19(9):2309-2313, 2000.

SILVÉRIO, P.F. Partição, biodisponibilidade e toxicidade de metais pesados a organismos bentônicos em sedimentos, 1999. Dissertação (Mestrado). Departamento de Química - Universidade Federal de São Carlos, São Carlos, 1999. $77 \mathrm{p}$.

SUEDEL, B.C.; ROD GERS JR, J.H.; DEAVER, E. Experimental factors that may affect toxicity of Cadmium to freshwater organisms. Archives Environmental Contamination Toxicology, 33:188-193, 1997.

TIMMERMANS, K.R.; PEETERS, W.; TONKES, M. Cadmium, zinc, lead and copper in Chironomus riparius (Meigen) larvae (Diptera, Chironomidae): uptake and effects. Hydrobiologia, 241:119-134, 1992.

UNITED STATES ENVIRONMENTAL PROTECTION AGENCY. U.S. EPA/600/R- 99/ 064. Methods for measuring the toxicity and bioaccumulation of sediment associated contaminant with freshwater invertebrates. 2 ed. Washington. D.C., 2000. 192p.

VERMEULEN, A.C., LIBERLOO G., DUMONT, P, OLLEVIER F., GODDEERIS, B. Exposure of Chironomus riparius larvae (Diptera) to lead, mercury and b-sitosterol: effects on mouthpart deformation and moulting. Chemosphere 41:1581-1591, 2000.

WARWICK, W.F. Morphological deformities in Chironomidae (Diptera) larvae from the Lac St. Louis and Laprairie basins of the St. Lawrence river. Journal of G reat Lakes Research, 16(2):185-208, 1990.

WARWICK, W.F.; FITCHKO, J.; MCKEE, P.M.; HART, D .R.; BURT, A.J., The incidence of deformities in Chironomus spp. from Port Hope Harbour, Lake Ontario. Journal of G reat Lakes Research, 13(1):88-92, 1987. 
WILLIAMS, D .D .; NESTEROVITCH, A.I.; TAVARES, A.F.; MUZZATTI, E.G .. Morphological deformities occurring in Belarusian chironomids (Diptera: Chironomidae) subsequent to the Chernobyl nuclear disaster. Freshwater Biology, 46:503-512, 2001. 
(appitullo 5)

\section{Experimentos de evitamento ao cobre utilizando Chironomus riparius}

(Chironomidae, Diptera)

\section{INTRODUÇÃO}

Se as populações naturais têm habilidade de evitar contaminantes ambientais antes de sofrerem efeitos letais e sub-letais, então os ensaios laboratoriais com espécies padronizadas envolvendo a exposição forçada dos organismos podem estar subestimando a toxicidade. De fato, testes de evitamento têm sido mencionados como um indicador muito sensível de efeitos ambientais e deveriam ser utilizados como uma ferramenta complementar em estudos de avaliação de risco (LOPES et al., 2004). De acordo com YEARDLEY et al. (1996) e HELLOU et al. (2005), os organismos podem exibir uma resposta comportamental a um nível de estresse químico inferior àquele que causa efeito agudo, e mesmos aqueles em que testes de toxicidade crônica são capazes de detectar, sugerindo que os testes de evitamento são mais sensíveis do que outros parâmetros sub-letais.

Várias espécies de invertebrados têm demonstrado comportamento de evitamento em ambientes enriquecidos com matéria orgânica, metais ou hidrocarbonetos policíclicos aromáticos. Ensaios de evitamento foram desenvolvidos utilizando oligoquetos (E usenia fetida, YARDLEY et al., 1996; A porrectodea tuberculata, L umbricus rubellus, and D endrobaena octaedra, LUKKARI et al. 2005), colembola (Folsomia candida, D A LUZ, 2004), anfípodos (E ohaustorius estuaries, KRAVITZ et al., 1999; Corophium volutator, HELLOU et al., 2005), cladóceros (D aphnia logispina, LO PES et al., 2004) e moluscos (A nodonta cygnea, KAD AR et al., 2001; Physella columbiana, LEFCORT et al., 2004). Além disso, muitos estudos foram desenvolvidos com organismos vertebrados, como pequenos peixes (D anio rerio, MOREIRA-SANTOS et al., 2005), grandes peixes (Salmo trutta, BEAUMONT et al., 1995; O norhynchus mykiss, SVECEVICIUS, 2001) e anfíbios (Rana luteiventris, LEFCORT, 1999). Em todos os casos citados acima, os autores encontraram um comportamento de evitamento nos organismos testados, sugerindo que para níveis 
de contaminantes que não são intensivamente agudos os organismos conseguiram evitar um contaminante em menor tempo do que aquele que seria necessário para se obter um efeito sub-letal, como os efeitos no crescimento ou na reprodução.

Existem poucos estudos com ênfase no comportamento de evitamento utilizando espécies bentônicas de água doce. Estes comportamentos podem ser as estratégias de reprodução (seleção de habitat para postura de ovos) e mecanismos de dispersão de quironomídeos que poderiam ser utilizados para avaliação da qualidade ambiental. O comportamento de evitamento foi pouco estudado e o primeiro estudo registrado foi desenvolvido por WENTSEL et al. (1977) utilizando Chironomus tentans e um gradiente de sedimento contaminado com $\mathrm{Cd}$, $\mathrm{Zn}$ e $\mathrm{Cr}$, no qual o autor observou um comportamento de evitamento para o $\mathrm{Cd}$ e Zn.

Nesse sentido, o presente estudo visa colaborar com os estudos envolvendo espécies bentônicas de água doce. Assim como Chironomus xanthus, Chironomus riparius (Chironomidae, Diptera) pode ser encontrado em ambientes lênticos e lóticos, tipicamente enriquecidos com material orgânica, e que tem sido largamente utilizada como bioindicador (POST MA, 1995).

Ensaios de evitamento para avaliação da qualidade de solos foram padronizados pela ISO/TC 190/SC 4 (2003), utilizando a espécie de oligoqueto terrestre E isenia fetida. Existem alguns protocolos internacionais (ASTM, 2000; U.S. EPA, 2000 e O ECD , 2004) sugerindo C. riparius para estudos ecotoxicológicos para avaliação da toxicidade do sedimento, porém, este novo conceito de testes de evitamento ainda não foi incluído nesses protocolos e precisa ser melhor estudado para que haja a validação do mesmo.

\section{OBJETIVOS}

O objetivo geral deste estudo foi avaliar o possível comportamento de evitamento nos estágios larval e adulto de C hironomus riparius utilizando cobre como contaminante.

Os objetivos específicos foram:

1. Verificar se larvas do I ínstar de C. riparius possuem capacidade de evitar 0 sedimento artificial contaminado com cobre; 
2. Verificar se larvas do II ínstar de C. riparius percebem um gradiente de contaminação e evitam locais com maiores concentrações de cobre;

3. Verificar se fêmeas adultas de C. riparius são capazes de selecionar o habitat para oviposição, em relação à contaminação por cobre, e, em caso negativo, qual a viabilidade das desovas e das larvas recém-eclodidas.

\section{MATERIAIS E MÉTODOS}

\subsection{Manutenção das culturas}

O organismo-teste selecionado foi a espécie bentônica Chironomus riparius (Chironomidae, Diptera), cujos exemplares foram obtidos em culturas mantidas no Laboratório do Instituto do Ambiente e Vida, Departamento de Zoologia, da Universidade de Coimbra, Portugal.

A unidade de cultivo de C. riparius foi uma caixa de acrílico transparente contendo todo o aparato necessário para o desenvolvimento de todo o ciclo de vida dos quironomídeos, e suficientemente grande para permitir a emergência e a cópula dos adultos (OECD , 2004). O cultivo foi realizado em cristalizadores de vidro, contendo 160g de areia (MERCK) e $350 \mathrm{ml}$ de meio ASTM (hard medium) (Figura 1).
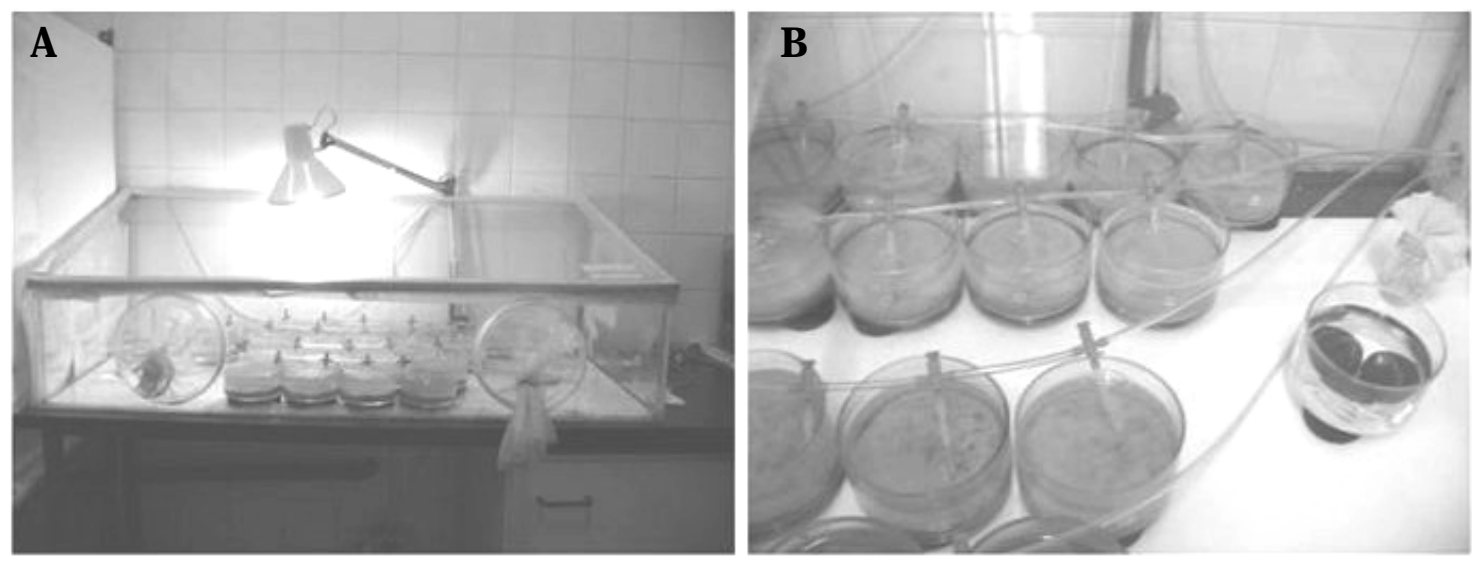

Figura 1. Cultivo de Chironomus riparius. Vista geral da caixa de acrílico (A) e detalhe dos cristalizadores com mangueiras de aeração e cristalizador sem sedimento para a postura de ovos (B). 
O cultivo dos organismos foi mantido sob constante aeração, em sala com temperatura controlada ( $\left.20^{\circ} \mathrm{C}\right)$ e fotoperíodo de 14h:10h (claro:escuro). Para a alimentação das larvas utilizou-se ração para peixes TetraMin ${ }^{\circledR}$ na proporção de 0,1g/ cristalizador. Como alimento dos adultos, utilizou-se uma solução saturada de açúcar (8g de açúcar em $50 \mathrm{~mL}$ de meio ASTM).

\subsection{Teste de evitamento de contaminantes (cobre)}

\subsubsection{Evitamento - Recrutamento (seleção de substrato)}

0 desenho do experimento está apresentado na Figura 2, sendo que foram montadas 3 réplicas. D uas réplicas continham frascos com sedimento e meio ASTM e sedimento com $\mathrm{Cu}$, distribuídos uniformemente dentro do becker. A terceira réplica foi montada somente com sedimento e meio ASTM e serviu como um controle da distribuição uniforme das larvas.

O sedimento artificial foi feito de acordo com o proposto por RIBEIRO et al. (1999) e LOPES \& RIBEIRO (2005), utilizando a proporção de 70\% de areia (MERCK), 20\% kaolin (SIG MA) e 10\% alpha-cellulose (SIGMA). Separou-se 0 sedimento em duas metades, sendo que uma foi misturada somente com meio ASTM e a outra com solução de 2,0 mg. $\mathrm{L}^{-1}$ de $\mathrm{Cu}$. Durante duas horas esse sedimento foi misturado mecanicamente antes de ser colocado nos frascos utilizados no experimento. A concentração de $2,0 \mathrm{mg} \cdot \mathrm{L}^{-1}$ de $\mathrm{Cu}$ foi escolhida por causar mortalidade à 50\% das larvas de I ínstar em 48h de exposição (D O RNFELD, 2006).

A unidade experimental foi composta por 3 frascos plásticos (50 ml) contendo $75 \mathrm{~g}$ (peso seco) de sedimento artificial com solução de ASTM e 3 frascos contendo sedimento artificial misturado com solução de cobre. Estes frascos foram colocados ao redor de um frasco de $100 \mathrm{ml}$ e de um de $50 \mathrm{ml}$ (ambos contendo areia e tampa), como pode ser observado na Figura 3 (A-C). Essa unidade foi colocada dentro de um becker de $2000 \mathrm{~mL}$ e os espaços entre os frascos foram preenchidos com areia (Merck). 


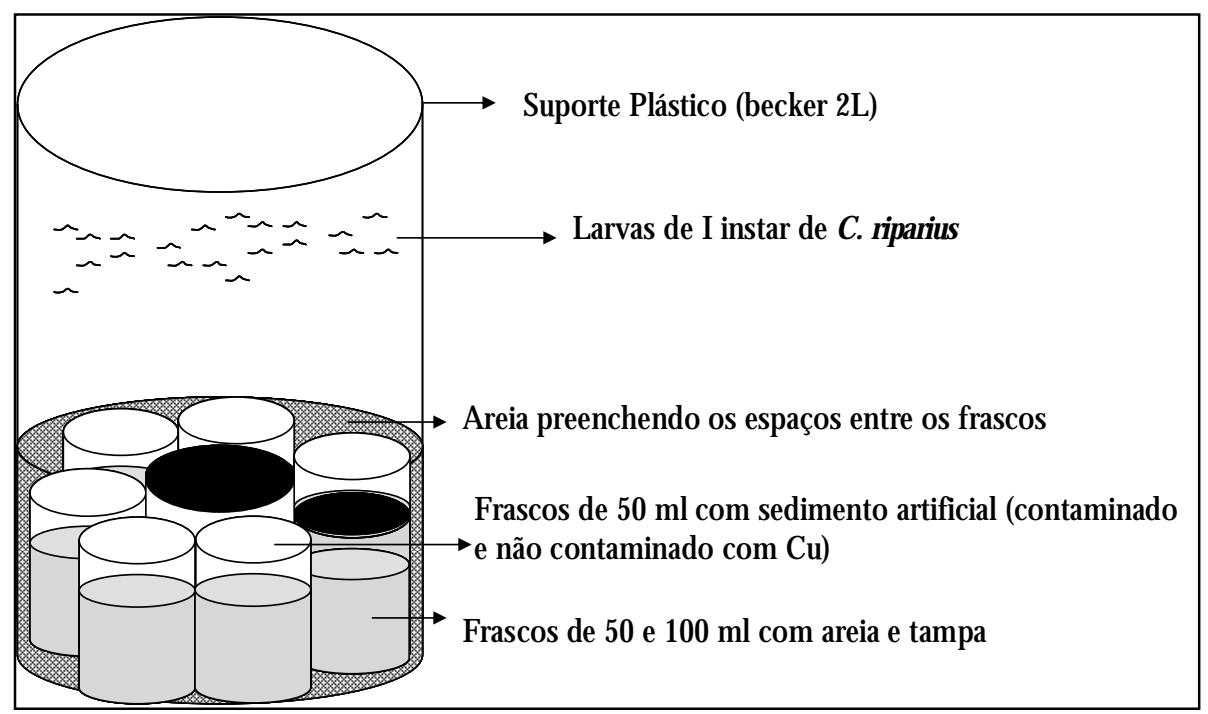

Figura 2. D esenho esquemático do Experimento de Evitamento - seleção de substrato por larvas de I instar de Chironomus riparius.

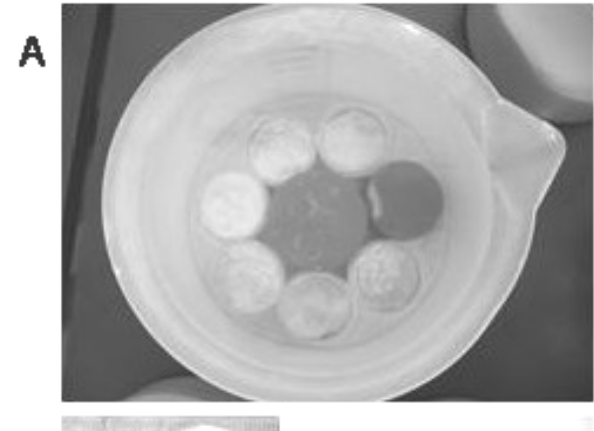

B
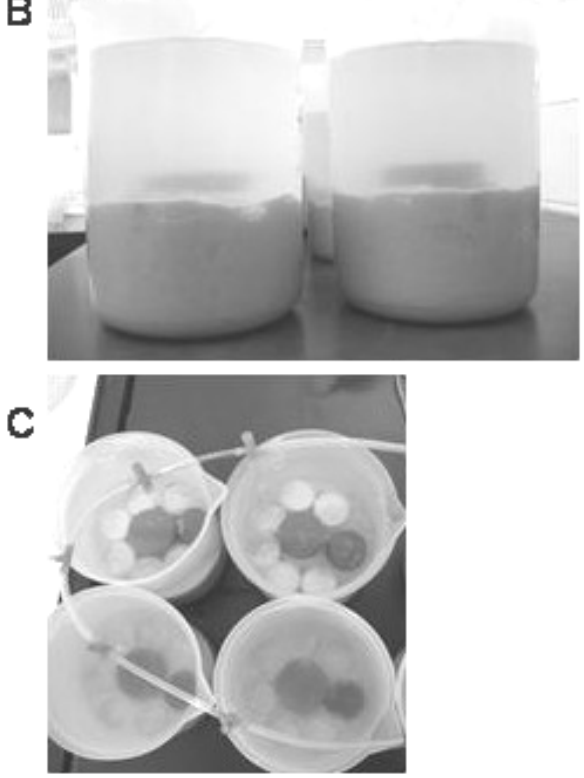

D

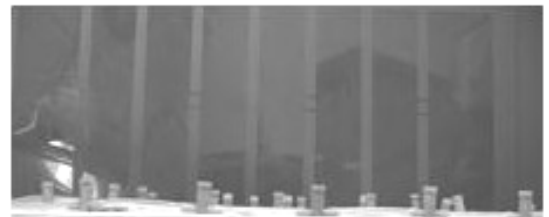

$E$

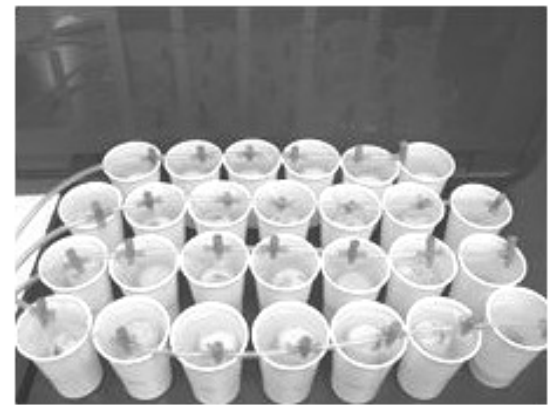

Figura 3. Experimento de Evitamento - Seleção de substrato. Detalhe do becker com a distribuição dos frascos(A); Distribuição das réplicas(B e C); Frascos individuais para crescimento das larvas de C. riparius (D e E). 
0 becker de $2000 \mathrm{~mL}$ foi preenchido com $1500 \mathrm{~mL}$ de água de cultivo, cuidadosamente para evitar a suspensão do sedimento. 0 experimento foi deixado estabilizar durante a noite, e no dia seguinte 30 larvas foram introduzidas nas 3 réplicas. 0 teste teve duração de 9 dias com aeração, adição de alimento (OECD, 2004) e fotoperíodo de 14h:10h (claro:escuro). Porém, devido à dificuldade em se localizar as larvas de I ínstar no sedimento, após 2 dias, os frascos foram colocados individualmente em copos plástico, preenchido com $150 \mathrm{~mL}$ de meio ASTM e mantidos sob aeração e com adição de alimento durante mais 7 dias, período suficiente para que as larvas desenvolvessem até o II ínstar e fossem localizadas mais facilmente (Figura 3, D-E).

\subsubsection{Evitamento - gradiente de contaminação}

O sistema de fluxo contínuo foi uma adaptação e otimização do sistema previamente desenvolvido para ensaios de evitamento com Daphnia longispina, por LOPES et al (2004). Essencialmente, o sistema é composto por 3 reservatórios de soluções (somente ASTM, 50 e 100\% da concentração selecionada do tóxico), duas bombas peristálticas (uma para entrada e outra para saída das soluções), três réplicas das câmaras de ensaio (cada uma com cinco compartimentos conectados formando um gradiente de 90, 70, 50, 30 e 10\% da maior concentração, aproximadamente) e um reservatório para descarte da solução (Figura 4). 0 sistema é formado por quatro tubos de entrada e cinco de saída ligados em cada conjunto de câmaras; os tubos de entrada estão conectados no meio de cada junção e os tubos de saída no meio e no lado de cada compartimento (Figura 5).

Brevemente, a entrada das soluções dos reservatórios se faz por tubos de silicone para a primeira bomba peristáltica, e através de tubos de silicone para as câmaras, e então, a saída da solução se faz por tubos plásticos partindo das câmaras para a segunda bomba peristáltica, e em direção ao reservatório de descarte. Em ensaios anteriores usando somente ASTM, observou-se que C. riparius evitou locais com maior incidência de luz, e, portanto, uma cobertura feita de tecido e plástico preto foi usada para evitar a entrada de luz e promover a manutenção do ambiente sem nenhuma luz (Figura 6). 


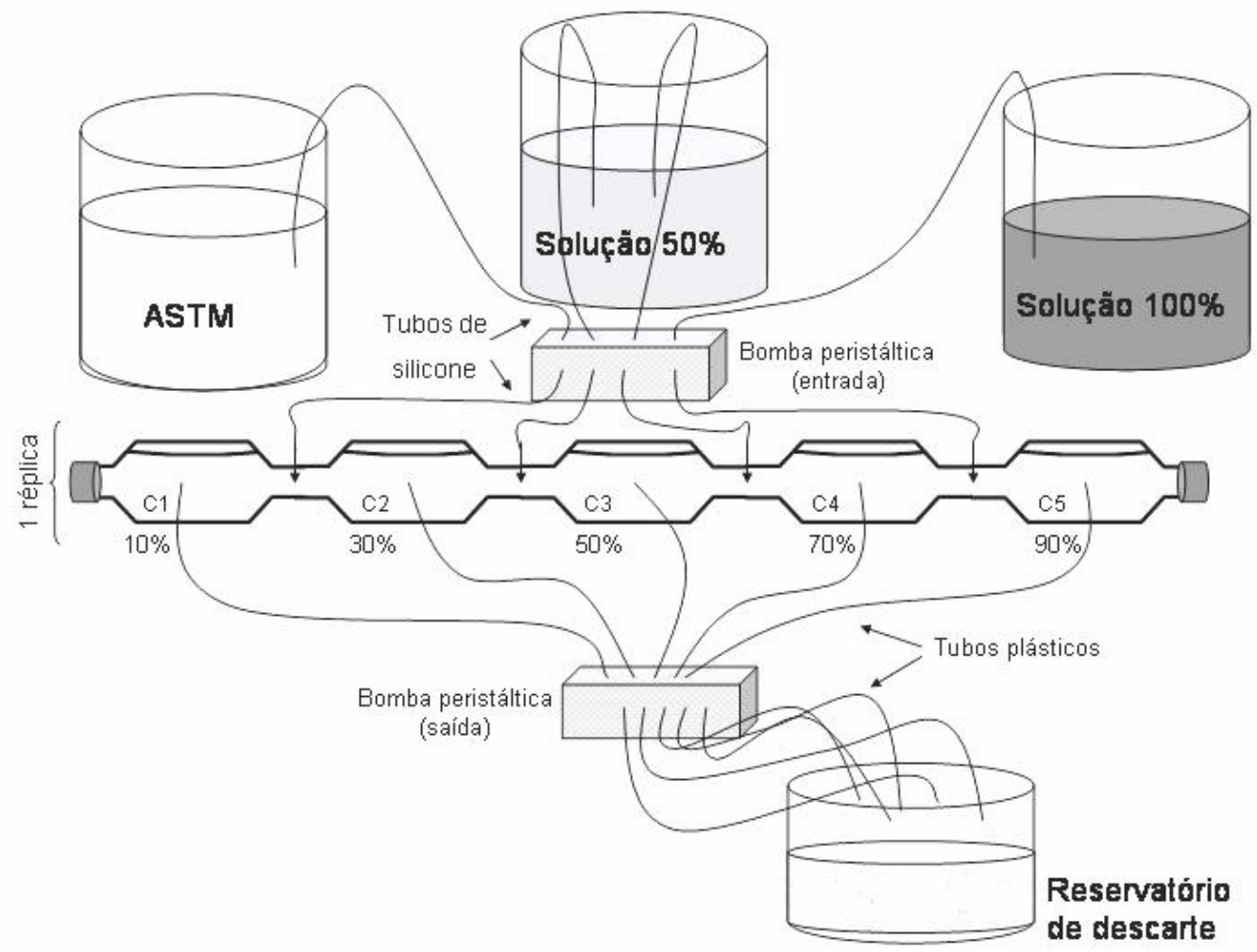

Figura 4. Esquema do Teste de Evitamento - Gradiente de contaminação, mostrando as partes integrantes do Sistema de Fluxo Contínuo.

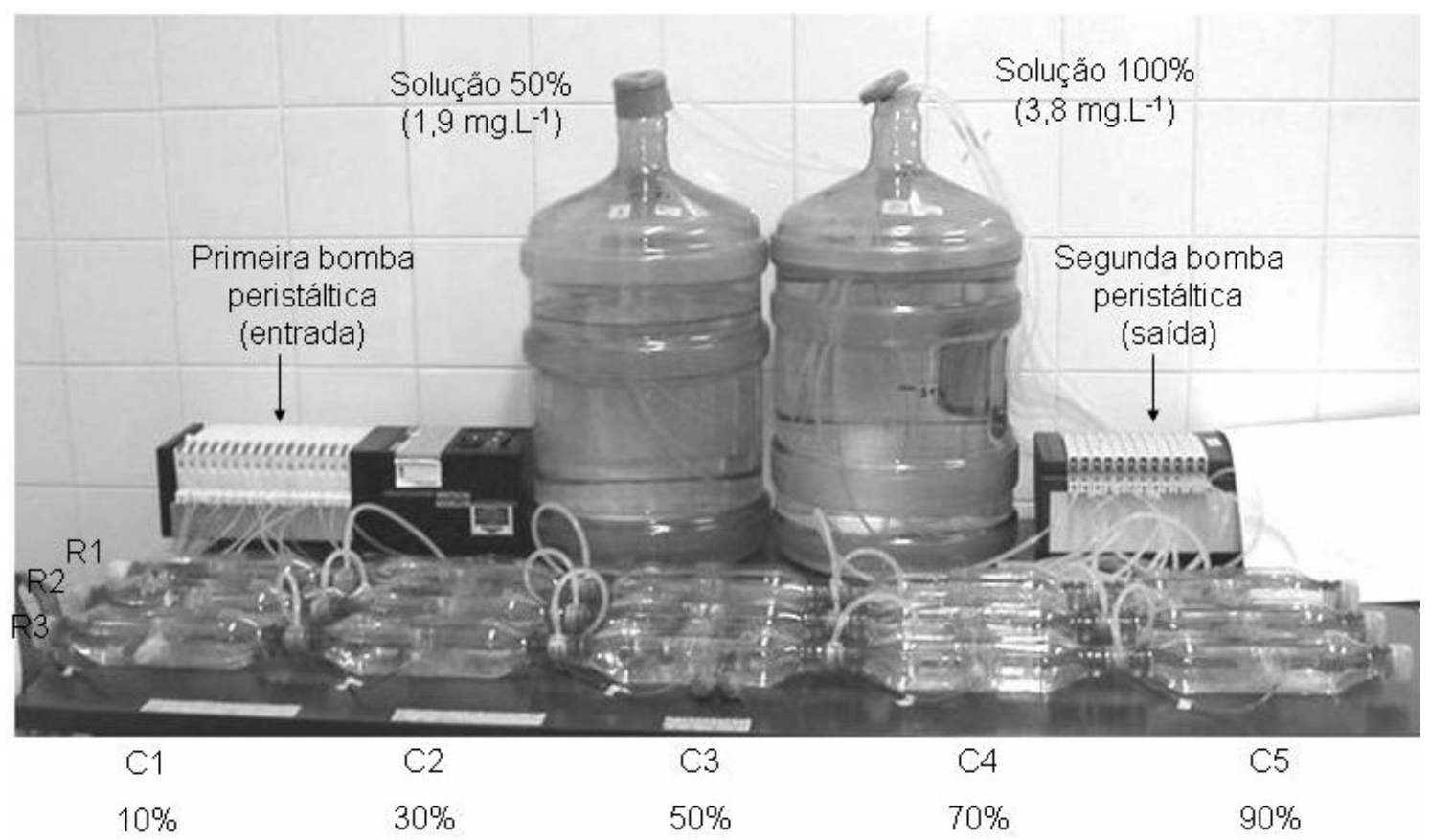

Figura 5. Experimento de Evitamento - Gradiente de Contaminação. $\mathrm{C}=$ compartimentos; $\mathrm{R}=$ réplicas; os reservatórios de ASTM e de descarte dos resíduos não aparecem nessa imagem (Modificado de D onato et al., 2004). 


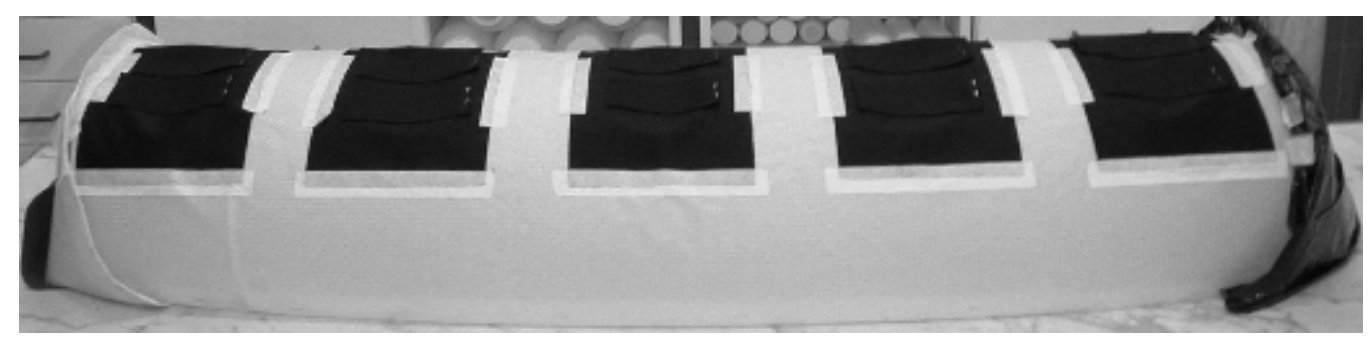

Figura 6. Cobertura utilizada durante os Testes de Evitamento - Gradiente de Contaminação. Sobre essa armação de tela plástica e papel branco, coloca-se uma cobertura de tecido preto. Em preto, são janelas para observação dos compartimentos (D onato et al., 2004).

Para testar a hipótese de que C. riparius teria uma distribuição uniforme nos compartimentos das câmaras, um experimento foi realizado somente utilizando ASTM. Cinco larvas do II ínstar foram colocadas no centro de cada compartimento, totalizando 25 larvas por réplica (5 compartimentos). A duração do teste foi de $24 \mathrm{~h}$, sem luz e sem adição de alimento e com temperatura de $20 \pm 1^{\circ} \mathrm{C}$.

Considerando os experimentos previamente realizados no laboratório, com larvas de IV ínstar, optou-se por trabalhar com a mesma concentração, isto é 3,8 mg.L.-1 de $\mathrm{Cu}$.

Para calcular o número de organismos que evitaram o compartimento com maior concentração da solução-teste (compartimento 5), utiliza-se a equação 1 e para calcular a porcentagem de evitamento de cada compartimento (2 a 5), utiliza-se a equação 2 (RIBEIRO et al., 2004):

$$
\mathrm{A}_{5}=\mathrm{N}-\mathrm{O}_{5} \quad \text { (equação 1) }
$$

Onde:

$\mathrm{A}_{5}=$ número de organismos que evitaram o compartimento 5 ;

$\mathrm{N}=$ número de organismos colocados no compartimento 5 no início do teste (5 quironomídeos);

$\mathrm{O}_{5}=$ número de indivíduos observados no compartimento 5. 


$$
A_{i}(\%)=\frac{A_{i}}{A_{i}+O_{i}} \times 100 \quad \text { (equação 2) }
$$

Onde:

$\mathrm{A}_{\mathrm{i}}=$ número de indivíduos que evitaram o compartimento $\mathrm{i}$;

$\mathrm{i}$ = número do compartimento, variando de 2 a 4 (concentrações em ordem crescente)

$\mathrm{O}_{\mathrm{i}}=$ número de indivíduos observados no compartimento $\mathrm{i}$

\subsubsection{Evitamento - oviposição}

Foram montados 12 cristalizadores para o experimento de oviposição, utilizando 180 adultos, que começaram a emergir entre 15 e 17 dias.

No ambiente de cultivo, foram colocados aleatoriamente cristalizadores com meio ASTM e com meio contendo solução de $1,3 \mathrm{mg} \cdot \mathrm{L}^{-1}$ de $\mathrm{Cu}$. 0 desenho experimental está apresentado na Figura 7.

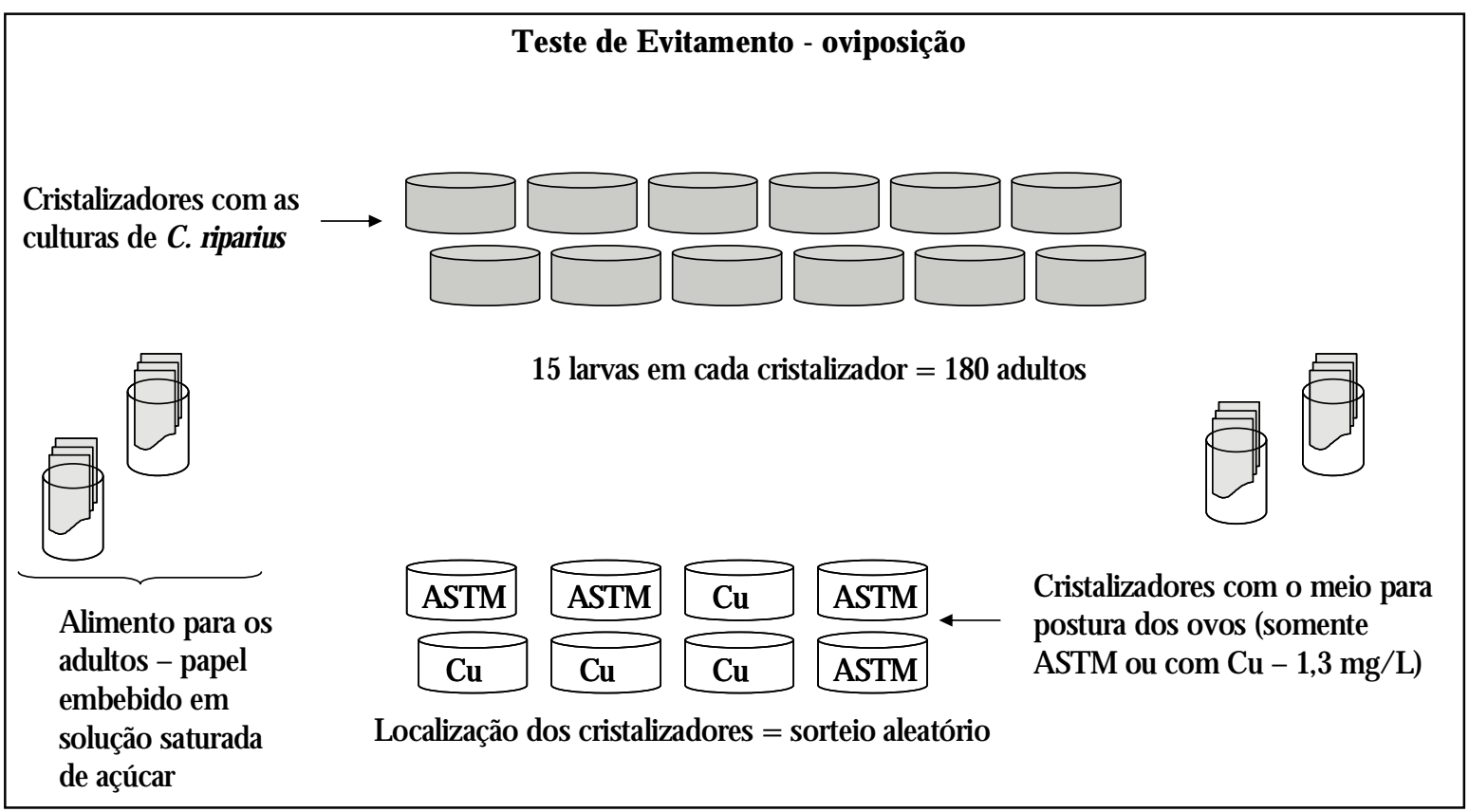

Figura 7. D esenho esquemático do Experimento de Evitamento - O viposição. 
As desovas foram coletadas diariamente durante 5 dias, sendo que 3 desovas de cada tratamento foram avaliadas quando à taxa de eclosão, viabilidade dos ovos e viabilidade das larvas (análise em estereomicroscópio) após 72h da coleta. Foi verificado o número de ovos, o número de larvas do I instar vivas e o número de larvas do I instar mortas.

Para 0 cálculo do porcentual de eclosão utilizou-se a equação 3, para a viabilidade dos ovos a equação 4 e para a viabilidade das larvas a equação 5, como demonstrado a seguir:

$$
\text { Eclosão }(\%)=\frac{\text { Larvas vivas }+ \text { larvas mortas }}{\text { Total de ovos }} \times 100 \quad \text { (equação 3) }
$$

Viabilidade dos ovos $(\%)=\frac{\text { Larvas vivas }}{\text { Total de ovos }} \times 100 \quad$ (equação 4)

Viabilidade das larvas $(\%)=\frac{\text { Larvas vivas }}{\text { Larvas vivas + larvas mortas }} \times 100 \quad$ (equação 5)

\section{RESULTADOS}

\subsection{Evitamento - Recrutamento (seleção de substrato)}

Os resultados referentes à réplica 3 , composta somente por sedimento com ASTM e cuja finalidade era observar se a distribuição dos organismos no teste foi uniforme, está apresentado na Tabela 1. Por meio do Teste-t, observou-se que não há diferença significativa entre a distribuição esperada e observada $(p=0,69)$.

Na Tabela 2 estão apresentados os resultados das 2 réplicas compostas por sedimento + meio ASTM e sedimento + solução de $\mathrm{Cu}$. A análise dos resultados foi 
composta pela soma dos organismos encontrados nos frascos com ASTM e nos frascos com $\mathrm{Cu}$. Considerando a distribuição dos organismos em relação ao sedimento contaminado e sedimento controle, por meio do Teste $t$ não foi verificada diferença significativa entre os dois tratamentos $(p=0,89)$ indicando que o I ínstar de C. riparius não evitou a concentração de cobre de 2,0 mg.L-1.

Tabela 1. Resultados da réplica 3, destinada à distribuição uniforme para validação do experimento.

\begin{tabular}{|c|c|c|c|c|c|c|c|}
\hline Frasco & $\mathbf{1}$ & $\mathbf{2}$ & $\mathbf{3}$ & $\mathbf{4}$ & $\mathbf{5}$ & $\mathbf{6}$ & Total \\
\hline $\begin{array}{c}\mathbf{n}^{\mathbf{0}} \text { organismos } \\
\text { esperado }\end{array}$ & 5 & 5 & 5 & 5 & 5 & 5 & 30 \\
\hline $\begin{array}{c}\mathbf{n}^{\mathbf{0}} \text { organismos } \\
\text { observado }\end{array}$ & 4 & 3 & 6 & 8 & 3 & 4 & 28 \\
\hline
\end{tabular}

- D ois organismos no final do teste estavam localizados na areia.

Tabela 2. Número de organismos encontrados em cada frasco de $50 \mathrm{ml}$, contendo sedimento artificial.

\begin{tabular}{|c|c|c|}
\hline Réplicas/ Tratamento & Réplica 1 & Réplica 2 \\
\hline ASTM1 & 3 & 4 \\
\hline ASTM2 & 1 & 4 \\
\hline ASTM3 & 3 & 5 \\
\hline Cu1 & 5 & 2 \\
\hline Cu2 & 3 & 1 \\
\hline Cu3 & 2 & 8 \\
\hline Areia & 10 & 6 \\
\hline TOTAL & 27 & 30 \\
\hline
\end{tabular}

$0 \mathrm{pH}$ inicial foi de 7,59 e a condutividade de $565 \mu \mathrm{S} . \mathrm{cm}^{-1}$, sendo que após 48h houve pequena variação nesses valores, passando para 7,72 e $568 \mu \mathrm{S} . \mathrm{cm}^{-1}$, respectivamente.

\subsection{Evitamento - gradiente de contaminação}

Foram realizados dois testes com o sistema de fluxo contínuo utilizando somente o meio ASTM para verificar a distribuição uniforme das larvas de II ínstar de C. riparius (Tabela 3). O bservou-se que na ausência de contaminante, as larvas se distribuíam uniformemente nas câmaras e por meio da análise estatística (Teste-t), nenhuma diferença significativa foi observada entre as 3 réplicas, atestando a repetibilidade do ensaio. 
Tabela 3. Resultados dos testes de distribuiç̧ão uniforme 24h utilizando C . riparius.

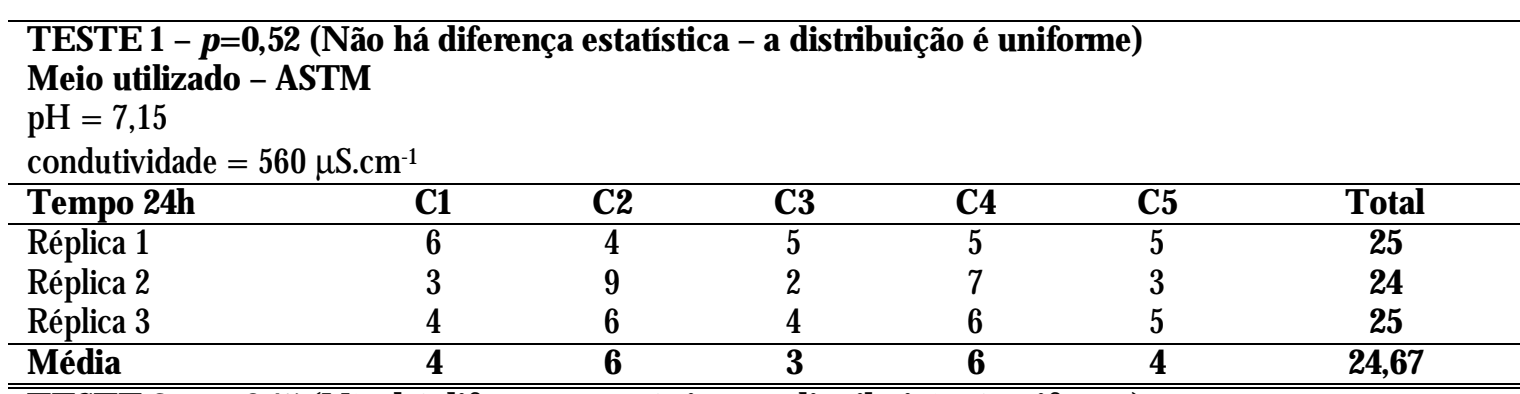

TESTE 2 - p=0,15 (Não há diferença estatística - a distribuição é uniforme)

Meio utilizado - ASTM

$\mathrm{pH}=7,64$

condutividade $=566 \mu \mathrm{S} . \mathrm{cm}^{-1}$

\begin{tabular}{lcccccc}
\hline Tempo 24h & C1 & C2 & C3 & C4 & C5 & Total \\
\hline Réplica 1 & 6 & 5 & 4 & 6 & 4 & $\mathbf{2 5}$ \\
Réplica 2 & 5 & 6 & 3 & 5 & 6 & $\mathbf{2 5}$ \\
Réplica 3 & 3 & 6 & 3 & 7 & 6 & $\mathbf{2 5}$ \\
\hline Média & $\mathbf{4}$ & $\mathbf{5}$ & $\mathbf{3}$ & $\mathbf{6}$ & $\mathbf{5}$ & $\mathbf{2 5}$ \\
\hline
\end{tabular}

- C = compartimento da câmara.

Os resultados do teste de evitamento do gradiente de contaminação estão apresentados na Tabela 4. Pode-se observar que não houve evitamento das larvas de II ínstar, nem mesmo nas maiores concentrações testadas. Ao invés de haver migração para os compartimentos com menores concentrações de cobre, houve mortalidade das larvas nesses mesmos compartimentos.

Tabela 4. Resultados do teste de evitamento ao gradiente de contaminação utilizando 3,8 mg. $\mathrm{L}^{-1}$ de $\mathrm{Cu}(100 \%)$, durante $24 \mathrm{~h}$.

Meio utilizado - ASTM

$\mathrm{pH}=7,59$ - condutividade $=557 \mu \mathrm{S} . \mathrm{cm}^{-1}$

\begin{tabular}{|c|c|c|c|c|c|c|}
\hline \multirow[t]{2}{*}{ Tempo - 24h } & C1 & C2 & C3 & $\mathrm{C} 4$ & C5 & \multirow[t]{3}{*}{ Total } \\
\hline & $10 \%$ & $30 \%$ & $50 \%$ & $70 \%$ & $90 \%$ & \\
\hline $\begin{array}{l}\text { Concentração } \\
\text { aproximada } \mathrm{Cu}\left(\mathrm{mg} \cdot \mathrm{L}^{-1}\right)\end{array}$ & 0,38 & 1,14 & 1,90 & 2,67 & 3,43 & \\
\hline \multirow[t]{2}{*}{ Réplica 1} & $5 \mathrm{v}$ & $4 \mathrm{v}$ & $3 \mathrm{v}$ & $5 \mathrm{v}$ & $1 \mathrm{v}$ & $18 v$ \\
\hline & $0 \mathrm{~m}$ & $0 \mathrm{~m}$ & $1 \mathrm{~m}$ & $3 \mathrm{~m}$ & $3 \mathrm{~m}$ & $7 \mathrm{~m}$ \\
\hline \multirow[t]{2}{*}{ Réplica 2} & $5 \mathrm{v}$ & $4 \mathrm{v}$ & $2 \mathrm{v}$ & $3 \mathrm{v}$ & $6 \mathrm{v}$ & $20 \mathrm{v}$ \\
\hline & $0 \mathrm{~m}$ & $0 \mathrm{~m}$ & $0 \mathrm{~m}$ & $0 \mathrm{~m}$ & $5 \mathrm{~m}$ & $5 \mathrm{~m}$ \\
\hline \multirow[t]{2}{*}{ Réplica 3} & $9 \mathrm{v}$ & $4 \mathrm{v}$ & $3 \mathrm{v}$ & $5 \mathrm{v}$ & $2 \mathrm{v}$ & $23 v$ \\
\hline & $0 \mathrm{~m}$ & $0 \mathrm{~m}$ & $0 \mathrm{~m}$ & $1 \mathrm{~m}$ & $1 \mathrm{~m}$ & $2 \mathrm{~m}$ \\
\hline \multirow[t]{3}{*}{ total } & $19 \mathrm{t}$ & 12t & $9 t$ & $17 t$ & $18 \mathrm{t}$ & $75 \mathrm{t}$ \\
\hline & $19 v$ & $12 \mathrm{v}$ & $8 v$ & $13 \mathbf{v}$ & $9 v$ & $61 \mathrm{v}$ \\
\hline & $0 \mathrm{~m}$ & $0 \mathrm{~m}$ & $1 \mathrm{~m}$ & $4 m$ & $9 m$ & $14 \mathrm{~m}$ \\
\hline média & 6 & 4 & 3 & 5 & 6 & 25 \\
\hline$\%$ mort. & $\mathbf{0}$ & $\mathbf{0}$ & 11 & 23 & 50 & \\
\hline pHi & 7,62 & 7,67 & 7,65 & 7,61 & 7,57 & \\
\hline pHf & 7,99 & 8,07 & 8,09 & 8,10 & 8,00 & \\
\hline Condutividadei ( $\left(\mu \mathrm{S} . \mathrm{cm}^{-1}\right)$ & 559 & 555 & 554 & 552 & 550 & \\
\hline Condutividadef $\left(\mu \mathrm{S} . \mathrm{cm}^{-1}\right)$ & 562 & 562 & 560 & 556 & 556 & \\
\hline
\end{tabular}


A mortalidade das larvas foi de 50, 23 e 11\% em 3,43 mg.L-1 (90\%), 2,67 mg.L.-1 (70\%) e 1,90 mg.L-1 (50\%) da maior concentração de cobre utilizada no teste (100\% - 3,8 mg.L-1 de Cu). D esde que larvas vivas e mortas foram consideradas em cada compartimento das câmaras para o cálculo final, observou-se uma distribuição uniforme $(p=0,74)$, e este fato baseia a informação de que estas larvas, realmente, não evitam as concentrações de cobre testadas.

As médias de condutividade e $\mathrm{pH}$ no final do ensaio foram $559 \mu \mathrm{S} . \mathrm{cm}^{-1} \mathrm{e}$ 8,05, respectivamente. A maior variação observada para cada parâmetro entre os compartimentos foi de $9 \mu \mathrm{S} . \mathrm{cm}^{-1}$ e 0,11, para a condutividade e $\mathrm{pH}$, respectivamente.

Utilizando a equação 1, verificou-se um resultado negativo (-3) indicando que não houve evitamento dos organismos neste compartimento. Utilizando a equação 2, as percentagens de evitamento foram de -20\% para C5, -13\% para C4, $40 \%$ para C3 e 20\% para C2.. As porcentagens negativas indicam que não houve evitamento, ao contrário, houve uma migração das larvas para esses compartimentos, mesmo sendo os de maiores concentrações de cobre. A alta porcentagem de evitamento de C3 não indica que os organismos migraram somente para o compartimento de concentração inferior, observando na Tabela 40 número maior de organismos tanto em $\mathrm{C} 2$ quanto em $\mathrm{C} 4$.

\subsection{Evitamento - oviposição}

Na Tabela 5 está apresentada a somatória das desovas obtidas em cada cristalizador. Os resultados apontam para a ausência de evitamento das fêmeas para a postura das desovas em cristalizadores contendo a solução de cobre na concentração de 1,3 mg. $\mathrm{L}^{-1}$ de $\mathrm{Cu}$, confirmado pelo Teste $\mathrm{t}(\mathrm{p}=0,11)$.

As massas de ovos coletadas foram acondicionadas em meio ASTM ou solução de cobre, conforme a sua origem, e analisadas após 72h. Na Tabela 6 estão apresentados os resultados da análise das desovas e na Tabela 7 os dados de eclosão e viabilidade. 
Tabela 5. Total de massas de ovos obtidas em cada cristalizador durante o período de teste.

\begin{tabular}{lcc}
\hline \multicolumn{2}{c}{ Cristalizador } & Desovas \\
\hline $\mathbf{n}^{\mathbf{0}}$ & Meio & \\
\hline $\mathbf{1}$ & ASTM & 2 \\
$\mathbf{2}$ & ASTM & 1 \\
$\mathbf{3}$ & Cobre & 1 \\
$\mathbf{4}$ & ASTM & 6 \\
$\mathbf{5}$ & Cobre & 6 \\
$\mathbf{6}$ & Cobre & 3 \\
$\mathbf{7}$ & Cobre & 4 \\
$\mathbf{8}$ & ASTM & 6 \\
\hline Total & & \\
\hline ASTM & & $\mathbf{1 5}$ \\
COBRE & & $\mathbf{1 4}$ \\
\hline
\end{tabular}

Tabela 6. Análise das desovas após postura (72h).

\begin{tabular}{lcccccccc}
\hline Desovas & $\mathbf{1}$ & Réplicas ASTM & Total & Réplicas Cu & Total \\
& 161 & 307 & $\mathbf{3}$ & ASTM & $\mathbf{1}$ & $\mathbf{2}$ & $\mathbf{3}$ & $\mathbf{C u}$ \\
\hline Vivos & 6 & 3 & 0 & 754 & 260 & 94 & 155 & 509 \\
Mortos & 6 & 44 & 21 & 6 & 9 & 18 & 9 & 36 \\
Ovos & 0 & $\mathbf{3 5}$ & 47 & 464 & 423 & 934 \\
\hline Total & $\mathbf{1 6 7}$ & $\mathbf{3 5 4}$ & $\mathbf{3 0 7}$ & $\mathbf{8 2 8}$ & $\mathbf{3 1 6}$ & $\mathbf{5 7 6}$ & $\mathbf{5 8 7}$ & $\mathbf{1 4 7 9}$ \\
\hline
\end{tabular}

Vivos - organismos do I ínstar vivos após eclosão; Mortos - organismos do I ínstar mortos logo após eclosão; Ovos - ovos sem desenvolvimento embrionário, separados da massa de ovos.

Tabela 7. Análise da taxa de eclosão e viabilidade dos ovos e larvas após 72h da postura.

\begin{tabular}{|c|c|c|c|c|c|c|}
\hline & \multicolumn{3}{|c|}{ Réplicas ASTM } & \multicolumn{3}{|c|}{ Réplicas Cu } \\
\hline & 1 & 2 & 3 & 1 & 2 & 3 \\
\hline $\mathrm{n}^{0}$ desovas & 1 & 1 & 1 & 1 & 1 & 1 \\
\hline $\begin{array}{l}\mathbf{n}^{0} \text { ovos } \\
\text { postos }\end{array}$ & 167 & 354 & 307 & 316 & 576 & 587 \\
\hline Média & & 276 & & & 493 & \\
\hline $\begin{array}{l}\text { Eclosão } \\
\text { Média }\end{array}$ & $100 \%$ & $\begin{array}{l}87,57 \% \\
93,57 \%\end{array}$ & $93,16 \%$ & $85,13 \%$ & $\begin{array}{l}19,44 \% \\
44,17 \%\end{array}$ & $27,94 \%$ \\
\hline $\begin{array}{l}\text { Viabilidade } \\
\text { (ovos) } \\
\text { Média }\end{array}$ & $96,41 \%$ & $\begin{array}{l}86,72 \% \\
92,09 \%\end{array}$ & $93,16 \%$ & $82,28 \%$ & $\begin{array}{c}16,32 \% \\
41,67\end{array}$ & $26,41 \%$ \\
\hline $\begin{array}{l}\text { Viabilidade } \\
\text { (larvas) } \\
\text { Média }\end{array}$ & $96 \%$ & $\begin{array}{c}99 \% \\
98,33 \%\end{array}$ & $100 \%$ & $96 \%$ & $\begin{array}{c}83 \% \\
91,00 \%\end{array}$ & $94 \%$ \\
\hline
\end{tabular}

A análise estatística (Mann-Whitney) demonstrou diferença significativa na taxa de eclosão $(p=0,04)$, sendo observado eclosão de 93,5\% e 44,1\% no ASTM e na solução de cobre, respectivamente. Utilizando a mesma análise estatística, observou-se que há diferença significativa $(p=0,04)$ na viabilidade dos ovos quando 
os dois tratamentos são comparados, verificando-se uma redução de $50 \%$ na viabilidade.

Em relação à viabilidade das larvas, não houve diferença significativa entre as larvas expostas ao ASTM ou a 1,3 mg. $\mathrm{L}^{-1}$ de Cu. Porém, este resultado deve ser analisado com cautela, considerando que $92 \%$ dos ovos são viáveis no tratamento com ASTM e que apenas $41 \%$ são viáveis quando expostos ao $\mathrm{Cu}$, desses $41 \%$ é que se considera $91 \%$ de viabilidade das larvas, revelando assim, um efeito ecológico adverso na população quando exposta ao $\mathrm{Cu}$.

\section{DISCUSSÃO}

O rganismos de locais poluídos são geralmente considerados como passivos à entrada de substâncias tóxicas e esta informação é verdadeira quando se considera os organismos autótrofos (LEFCORT et al., 2004). Entretanto, para outros organismos que são capazes de se mover na coluna de água ou nos sedimentos essa informação parece ser falsa. D evido a esse fato, e para entender o comportamento das populações que vivem em locais poluídos, testes de evitamento têm sido desenvolvidos com vários tipos de organismos.

Considerando os três tipos de testes de evitamento desenvolvidos nesse estudo, foi possível avaliar o comportamento de evitamento ao cobre para vários estágios do ciclo de vida de C. riparius.

O comportamento de dispersão e escolha de substrato por quironomídeos ainda apresenta poucos estudos, sendo que um dos estudos mais completos é o de DAVIES (1976). Segundo este autor, é função do I ínstar larval, já que este apresenta comportamento zooplanctônico, dispersar através do sistema e selecionar um substrato adequado para viver. Esse fato justifica a utilização do I ínstar de C. riparius para o teste de evitamento-recrutamento. Pela análise dos resultados, pode-se observar que o I ínstar não foi capaz de evitar o substrato contaminado, pelo menos em relação à concentração utilizada (2,0 mg.L-1 de $\mathrm{Cu})$.

Porém, não é apenas o I ínstar que pode se locomover na coluna d'água e promover a dispersão da espécie na natureza. Segundo DAVIES (1976) existem evidências de que larvas em estágios mais avançados do desenvolvimento não são 
permanentemente estáticas, e podem, temporariamente, entrar na coluna d'água, 0 que permite que a larva viva em uma área ou encontre, por escolha, um local com melhores condições. Esse fenômeno é denominado de "drift" e é responsável por essa dispersão, sendo que organismos de diversos estágios podem se locomover no sistema lótico levados pela correnteza. De acordo com WATERS (1972) e ALLAN (1996) as razões da ocorrência do "drift" podem ser acidentais (muita correnteza), a alta densidade de organismos, competição, predação e forrageamento oportunista. Porém, em uma visão ecotoxicológica, segundo DAVIES (op cit.) e PETTS \& CALOW (1996) o "drift" pode ocorrer em cursos d'água que apresentam depleção de oxigênio e/ ou são altamente poluídos, sendo considerado um escape da introdução de substâncias tóxicas. Sabendo dessa mobilidade de diferentes estágios larvais utilizou-se o II ínstar de C. riparius no teste de evitamento do gradiente de contaminação.

Porém, pelos resultados apresentados, observou-se que os organismos do II ínstar de C. riparius não evitaram as concentrações de cobre utilizadas no teste de gradiente de contaminação, nem mesmo sendo esta concentração acima daquelas observadas em ambientes contaminados, ao contrário, houve uma migração das larvas para os compartimentos mais concentrados. Em estudo realizado por MOREIRA-SANTOS (informação verbal), foi testado o mesmo sistema, mas utilizando solução de cobre + substrato (areia) e solução de cobre somente. Observou-se que os organismos do IV ínstar não evitaram a contaminação por cobre em nenhum dos casos. Observou-se, porém, que a porcentagem de mortalidade no experimento realizado com adição de substrato foi inferior à do sem substrato, ocorrendo mortalidade de $21 \%$ e $45 \%$, respectivamente, na maior concentração do gradiente $\left(3,44 \mathrm{mg} \cdot \mathrm{L}^{-1} \mathrm{de} \mathrm{Cu}\right), 0$ que demonstra a importância do substrato como uma barreira de proteção contra contaminantes presentes na coluna d'água.

Estes ensaios, utilizando o sistema de fluxo contínuo, demonstraram um resultado inesperado, porque esse sistema havia sido utilizado previamente em ensaios com diferentes linhagens de D aphnia logispina (LOPES at al., 2004) e D anio rerio (MOREIRA-SANTOS et al., 2005). Ambos os organismos demonstraram comportamento de evitamento e o desenho experimental do sistema foi 
considerado bom para esse tipo de estudo. LOPES et al. (op cit.), por exemplo, observou que todas as linhagens de D. logispina testadas evitaram o cobre quando expostas a um gradiente de concentração entre 3 e $87 \mu g \cdot L^{-1}$ de $\mathrm{Cu}$, e as linhagens mais sensíveis evitaram essas concentrações de cobre em menor tempo do que as linhagens mais resistentes. No estudo de MOREIRA-SANTOS et al. (op cit), D. rerio evitou o cobre, se deslocando no sistema para os compartimentos com menores concentrações. Além disso, como o evitamento ocorreu em níveis de contaminação inferiores aos que causariam efeitos em outros parâmetros sub-letais, e dada a sua implicação para o funcionamento dos ecossistemas, a autora sugere que o ensaio de evitamento com essa espécie deveria ser implementado em avaliação de risco ambiental.

Os resultados da presente pesquisa mostraram 0 não evitamento de $C$. riparius às concentrações de cobre testadas, mas, por outro lado, esses valores podem ser tóxicos para 0 I ínstar da larva. 0 teste de evitamento - oviposição (postura) mostrou que as fêmeas de C. riparius também não evitaram concentrações de 1,3 mg.L-1 de Cu para a postura, mas a taxa de eclosão dos ovos foi afetada.

Alguns testes de oviposição foram realizados utilizando mosquitos da família Culicidae (BENTLEY \& DAY, 1989 e BLAUSTEIN et al., 2004) e os autores verificaram uma seleção de habitat para oviposição em resposta aos riscos de predação ou substâncias de origem biológica, como bioextratos, hormônios e feromônios. No caso de quironomídeos, estudos foram realizados utilizando as espécies Polypedilum nubifer (HATAKEYAMA, 1988), C hironomus tepperi (STEVENS et al., 2003) e Chironomus riparius (WILLIAMS et al., 1987; EITAM et al., 2002; BLAUSTEIN et al., 2004). Estudos envolvendo substâncias que causam contaminação ambiental, como metais pesados e pesticidas, são muito escassos.

HATAKEYAMA (1988) encontrou taxa de eclosão superior a 95\% na maior concentração de cobre testada (30 $\mu \mathrm{g} \cdot \mathrm{L}^{-1}$, de $\mathrm{Cu}$, em meio de água com baixa dureza), entretanto, os resultados mostraram que para os quironomídeos que tinham sido alimentados com $1170 \mu \mathrm{g} \cdot \mathrm{g}^{-1}$ de $\mathrm{Cu}$, o sucesso da oviposição não foi prejudicado se comparado com o controle.

Em experimento usando cádmio como substância teste, WILLIAMS et al. (1987), observaram que significativamente muitas desovas foram colocadas no 
controle e em baixas concentrações (0,3 e $\left.30 \mathrm{mgCd} \cdot \mathrm{L}^{-1}\right)$ em comparação com

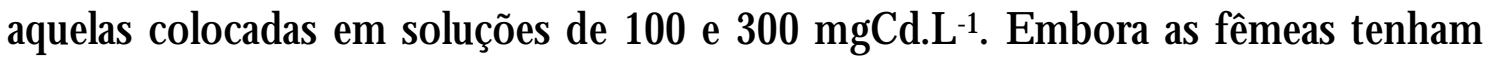
sido capazes de discriminar entre soluções contendo diferentes soluções de cádmio, essa capacidade de detecção foi relativamente limitada, pois não conseguem detectar e evitar soluções contendo níveis de cádmio que causam toxicidade aguda para o I ínstar da larva. No caso das desovas colocadas diretamente nas soluções de cádmio, as porcentagens de viabilidade foram muito menores. De acordo com STEVENS et al. (2003), C. tepperi desenvolveu um método sensível de seleção de locais para oviposição na detecção de compostos produzidos por larvas de espécies coespecíficas, outras larvas de quironomídeos, e possivelmente, outros dípteros aquáticos. Os resultados apresentados pelas pesquisas citadas estão intimamente relacionados e de acordo com os resultados do presente trabalho.

Neste contexto, outros tipos de sistemas e "end points" dos testes foram testados para provar o comportamento de evitamento de organismos bentônicos. Por exemplo, KÁDÁR et al. (2001), utilizando o bivalve de água doce A nodonta cygnea, observaram que esses organismos foram capazes de detectar e responder a um aumento das concentrações de alumínio em água natural de um lago pelo fechamento de suas conchas e pela redução na entrada do referido metal no organismo. KRAVITZ et al. (1999), demonstraram em um "dual-test" com 0 anfípodo E ohaustorius estuaries, que os organismos evitam contaminação do sedimento com PAH por moverem-se em direção ao sedimento controle. Também estudando o evitamento de anfípodos, HELLOU et al (2005) concluíram que Corophium volutator parece ser sensível à presença de PAHs.

Considerando o presente estudo e os demais citados nessa discussão, acredita-se que os resultados dos testes de evitamento merecem atenção futura para delinear em maiores detalhes as variáveis biológicas, químicas e físicas que afetam a resposta de evitamento ou preferência dos organismos à alguma substância contaminante ou amostra ambiental. 


\section{CONCLUSÃO}

Os resultados dos experimentos mostraram que Chironomus riparius não apresentou um comportamento de evitamento nas concentrações de cobre estudadas. As larvas de I instar não foram seletivas na escolha do substrato para se enterrarem e as larvas de II instar não migraram para os compartimentos com menores concentrações de cobre. As fêmeas adultas também não demonstraram comportamento de evitamento ao cobre para a postura dos ovos, porém observouse um efeito adverso na viabilidade e na taxa de eclosão desses, o que pode comprometer toda a dinâmica populacional, apresentando, portanto, um efeito ecológico adverso da exposição ao contaminante.

À partir do desenho dos experimentos de evitamento e dos resultados apresentados, deve-se considerar que, para um melhor entendimento dos efeitos de contaminantes no comportamento de C. riparius, diferentes concentrações deverão ser testadas, bem como deve ser realizado um aperfeiçoamento desse aparato experimental.

\section{REFERÊNCIAS BIBLIOGRÁFICAS}

ALLAN, J.D . Stream ecology - structure and function of running waters. Chapman \& Hall, New York, 1996. 388p.

AMERICAN SOCIETY FOR TESTING AND MATERIALS - ASTM. E1706-00

- Test method for measuring the toxicity of sediment-associated contaminants with freshwater invertebrates, 2000.117p.

BEAUMONT, M. W., BUTLER, P. J. AND TAYLOR, E. W.. Exposure of brown trout, Salmo trutta, to sub-lethal copper concentrations in soft acidic water and its effects upon sustained swimming performance. Aquatic Toxicology 33: 45-63, 1995.

BENTLEY, M.D.; DAY, J.F. Chemical ecology and behavioural aspects of mosquito oviposition. Annual Review of Entomology, 34:401-421, 1989. 
BLAUSTEIN, L.; KIFLAWI, M.; EITAM, A.; MANGEL, M.; COHEN, J.E.. Oviposition habitat selection in response to risk of predation in temporary pools: mode of detection and consistency across experimental venue. O ecologia, 138: 300-305, 2004.

DA LUZ, T.; RIBEIRO, R.; SOUSA, J.P. Avoidance tests with collembola and and earthworms as early screening tools for site-specific assessment of polluted soils. Environmental Toxicology and Chemistry, 23:2188-2193, 2004.

DAVIES, B.R. The dispersal of Chironomidae larvae: a review. Journal of the Entomological Society Southern Africa, 39(1): 39-62, 1976.

DONATO, C.; MOREIRA-SANTOS, M.; RIBEIRO, R. Construction of a flowthrough system to perform laboratory avaidance assays with small freshwater fish. Satandard Operating Procedure, Instituto Ambiente e Vida, Universidade de Coimbra, Coimbra, Portugal, 2004.6p.

DORNFELD, C.B. Teste comportamental (evitamento de contaminantes) com Chironomus riparius como ferramenta de avaliação da qualidade de sedimento. Relatório Final (Processo BEX 0864-05-6) apresentado como um dos requisitos necessários para encerramento do processo do Programa de Estágio de D outorando no Exterior - CAPES, 2006. 32p.

EITAM, A.; BLAUSTEIN, L.; MANGEL, M. Effects of A nisops sardea (Hemiptera: Notonectidae) on oviposition habitat selection by mosquitoes and other dipterans and on community structure in artificial pools. Hydrobiologia 485: 183-189, 2002.

HATAKEYAMA, S. Chronic effects of $\mathrm{Cu}$ on reproduction of Polypedilum nubifer (Chironomidae) through water and food. Ecotoxicology Environmental Safety, 16:1-10, 1988.

HELLOU, J.; CHEESEMAN, K.; JOUVENELLE, M.L.; ROBERTSON, S. Behavioral response of $\mathrm{C}$ orophium volutator relative to experimental conditions, physical and chemical disturbances. Environmental Toxicology and Chemistry, 24(12):3061-3068, 2005. 
ISO/ TC 190/ SC 4N 0238. Soil quality - Avoidance test for testing the quality of soils and the toxicity of chemicals - tests with earthworms (E isenia fetida). D raft, 2003. 23p.

KÁDÁR， E.; SALÁNKI， J.; JUGDAOHSINGH， R.; POWELL， J.J.; MCCROHANA, C.R.; WHITE, K.N.. Avoidance responses to aluminium in the freshwater bivalve A nodonta cygnea. Aquatic Toxicology, 55:137-148, 2001.

KRAVITZ, M.J.; LAMBERSO N, J.O .; FERRARO, S.P.; SWARTZ, R.C.; BOESE, B.L.; SPECHT, D.T. Avoidance response of the estuarine amphipod Eohaustorius estuarius to polycyclic aromatic hydrocarbon-contaminated, fieldcollected sediments. Environmental Toxicology and Chemistry, 18(6):12321235, 1999.

LEFCORT, H.; THOMSON, S.M.; COWLES, E.E.; HAROWICZ, H.L.; LIVAUDAIS, B.M.; ROBERTS, W.E.; ETTINGER, W.F. Ramifications of predator avoidance: predator and heavy metal-mediated competition between tadpoles and snails. Ecological Applications, 9(4):1477-1489, 1999.

LEFCORT, H.; ABBOTT, D .P.; CLEARY, D .A.; HOWELL, E.; KELLER, N.C.; SMITH, M.M.. Aquatic snails from mining sites have evolved to detect and avoid heavy metals. Archives of Environmental Contamination and Toxicology, 46:478-484, 2004.

LOPES, I.; BAIRD, D.J.; RIBEIRO, R. Avoidance of copper contamination by field populations of Daphnia longispina. Environmental Toxicology and Chemistry, 23(7):1702-1708, 2004.

LOPES, I.; RIBEIRO, R.. Optimization of a Pressurization Methodology for Extracting Pore-Water. Chemosphere, 61(10):1505-1511, 2005.

LUKKARI, T.; AATSINKI, M.; VAISANEN, A.; HAIMI, J. Toxicity of copper and zinc assessed with three different earthworm tests. Applied Soil Ecology 30: 133-146, 2005.

MOREIRA-SANTOS, M.; DONATO, C.; RIBEIRO, R.. A short-term sub-lethal assay with small fish based on avoidance. Proceedings - 6o Congreso Ibérico e 3o Iberoamericano de Contaminación y Toxicología Ambiental, Cadiz, 2005. p.179. 
PETTS, G.; CALOW, P. (eds). River Biota: diversity and dynamics. Blackwell Science USA, 1996. 257p.

POSTMA, J.F.. Adaptation to metals in the midge Chironomus riparius. Universiteit van Amsterdam, Amsterdam , The Netherlands, 1995, 153p.

ORGANIZATION FOR ECONOMIC COOPERATION AND DEVELOPMENT - OECD. Guidelines for the testing of chemicals. Sedimentwater Chironomid Toxicity Test using spiked sediment, 2004. 21p.

RIBEIRO, R.; KELLY, L.A.; GONÇALVES, F.; BURTON JR, G.A.; SOARES, A.M.V.M. New artificial sediment for Chironomus riparius toxicity testing. Bull. Environmental Contamination and Toxicology, 63:691-697, 1999.

RIBEIRO, R.; DONATO, C., MOREIRA-SANTOS, M.. Calculation of the avoidance percentage in the laboratory avoidance assays with daphnids and small freshwater fish. Satandard Operating Procedure, Instituto Ambiente e Vida, Universidade de Coimbra, Coimbra, Portugal, 2004. 2p.

STEVENS, M.M.; WARREN, G.N.; BRAYSHER, B.D .. Oviposition response of Chironomus tepperi to nitrogenous compounds and bioextracts in two-choice laboratory tests. Journal of Chemical Ecology, 29(4):911-920, 2003.

SVECEVICIUS, G.. Avoidance response of rainbow trout 0 noorhynchus mykiss to heavy metal model mixtures: a comparison with acute toxicity tests. Bull. Environmental Contamination and Toxicology, 67(5):680-687, 2001.

UNITED STATES ENVIRONMENTAL PROTECTION AGENCY - U.S. EPA/ 600/ R- 99/ 064. Methods for measuring the toxicity and bioaccumulation of sediment associated contaminant with freshwater invertebrates. 2 ed. Washington. D.C., 2000, 192p.

WATERS, T.F.. The drift of stream insects. Annual Review of Entomology, 17: 253-272, 1972.

WENTSEL, R.; MCINTOSH, A.; MCCAFFERTY, W.; ATCHISON, G.; ANDERSON, V. Avoidance response of midge larvae (Chironomus tentans) to sediments containing heavy metals. Hydrobiologia, 55(2):171-175, 1977. 
WILLIAMS, K.A.; GREEN, D.W.J.; PASCOE, D.; GOWER, D.E. Effect of Cadmium on Oviposition and egg viability in Chironomus riparius (Diptera: Chironomidae). Bull. Environmental Contamination and Toxicology, 38:86-90, 1987.

YEARDLEY JR, R.B.; LAZORCHAK, J.M.; GAST, L.C. The potential of an earthworm avoidance test for evaluation of hazardous waste sites. Environmental Toxicology and Chemistry, 15(9):1532-1537, 1996. 
Capieinule 6

Utilização de Chironomus sp para avaliação da qualidade de sedimentos e contaminação por metais - Considerações finais e

recomendações

\section{CONSIDERAÇÕES FINAIS E RECOMEN DAÇÕES}

Os quironomídeos compreendem, em geral, a maior porcentagem da biomassa de invertebrados bentônicos associados com sedimentos de água doce e são uma significante porção da dieta de invertebrados predadores e peixes. Como resultado, os quironomídeos são importantes na transferência de contaminantes do sedimento para níveis tróficos superiores.

Segundo D ICKMAN et al. (1992), as larvas de quironomídeos têm mostrado ser excelentes organismos para bioensaios porque possuem seu ciclo de vida intimamente em contato com sedimentos contaminados e alimentam-se de detritos e algas associados à eles. Por essas razões, esses organismos têm sido freqüentemente utilizados em estudos padronizados sobre a toxicidade do sedimento, como mencionado durante o desenvolvimento desse trabalho.

Porém, somente os dados sobre a toxicidade não são suficientes para a realização de uma avaliação de risco ecológico e da qualidade ambiental do sistema. A análise de diferentes parâmetros, cujos resultados se convergem e complementam-se, é de fundamental importância para uma avaliação integrada.

Nesse sentido, pode-se observar que as análises químicas e físicas da água e do sedimento contribuíram para uma melhor avaliação dos testes laboratoriais e "in situ" com amostras de sedimento. Em alguns momentos não foi possível afirmar quais substâncias ou compostos foram responsáveis pela toxicidade, considerando que uma quantidade muito maior de substâncias encontradas nos ambientes aquáticos e potencialmente tóxicas não foram analisadas, tais como outros tipos de agrotóxicos (organofosforados), hidrocarbonetos aromáticos policíclicos, bifenilas policloradas entre outros. 
Porém, os resultados das análises de que dispomos, são suficientes para caracterizar a Bacia do rio Monjolinho como impactada pelas ações antrópicas desenvolvidas na área de entorno, pois as concentrações de alguns metais na água, especialmente $\mathrm{Cd}$ e $\mathrm{Cu}$ estiveram acima do estabelecido pela resolução CONAMA 357/ 05 em algumas estações de amostragem. Os agrotóxicos organoclorados estudados (Aldrin, Endosulfan e Heptachlor) também apresentaram em algumas estações valores superiores aos estabelecidos pela legislação vigente de potabilidade de água (Portaria 518/04) e da proteção da vida aquática (resolução CONAMA 357/ 05). Esses valores podem indicar que houve aplicação desses produtos em épocas passadas e que atualmente estão sendo lixiviados pela ação da chuva e chegando ao corpo hídrico, ou mesmo que está havendo recentemente o uso clandestino desses produtos por produtores agrícolas da região.

Os sedimentos foram avaliados por meio de parâmetros químicos, físicos e toxicológicos e, embora não possua quantidades de metais suficientemente altas para causar efeitos adversos à biota (de acordo com alguns autores e normas consultadas, tais como THOMAS (1987), SMITH et al. (1996), MACD ONALD et al. (2000) e Critério Canadense (2002)), causaram mortalidade nos ensaios laboratoriais de toxicidade aguda em algumas estações de amostragem.

Além da análise da qualidade do sedimento, utilizando a espécie $C$. xanthus em bioensaios laboratoriais de toxicidade aguda, outros ensaios toxicológicos foram realizados com a finalidade de se ampliar os conhecimentos e resultados do uso de espécies bentônicas.

Entre eles, foram realizados ensaios "in situ" que apresentaram grande importância e relevância, pois foi possível constatar as diferenças existentes entre os ensaios laboratoriais e aqueles realizados em campo. Segundo CHAPMAN et al. (1998), as extrapolações dos resultados laboratoriais para as circunstâncias de campo devem ser realizadas com muita cautela. Para os autores, o problema associado à essas extrapolações reside no fato de que é muito difícil simular completamente todas as variáveis ambientais que podem influenciar a resposta de um receptor para a substância-teste. Este fato foi comprovado no presente estudo, pois se somente os resultados dos testes laboratoriais fossem considerados, haveria um equívoco, considerando que as estações submetidas aos bioensaios "in situ" apresentaram 
maiores porcentagens de mortalidade. Apesar de apresentarem resultados diferentes, esses testes foram complementares e a utilização de um ou de outro depende dos objetivos de estudo, da disponibilidade de material e pessoal para saídas de campo e de locais apropriados para a instalação das câmaras dos bioensaios "in situ".

Em relação à biodisponibilidade e bioacumulação de metais, HUND-RINKE \& KORD EL (2003), sugerem que os métodos padronizados dos experimentos para investigação da biodisponibilidade existem apenas para a determinação dos efeitos tóxicos nos organismos. As normas são restritas à testes que utilizam somente uma espécie e cobrem um espectro de organismos-teste considerando os diferentes níveis tróficos, habitats e rotas de exposição. As concentrações ambientais nem sempre estão relacionadas com os resíduos no corpo dos organismos devido à diversidade de interações entre organismos e 0 meio ambiente, a biologia dos organismos e fatores físico-químicos. Além disso, os autores sugerem a utilização de micro e mesocosmos que incluem uma biocenose e aumentam a relevância ambiental do ensaio.

Os testes com substâncias de referência $(\mathrm{Cd}$ e $\mathrm{Cu}$ ) revelaram que as espécies C. $x$ anthus e C. riparius são adequadas para uso em ensaios de toxicidades, desde que utilizados diferentes "end points". Nos trabalhos analisados, observou-se uma grande preocupação com a tolerância de $\mathrm{C}$ hironomus aos contaminantes. Porém, os resultados do presente estudo mostraram que quando o teste é desenvolvido com maior tempo de duração e parâmetros diferentes são analisados (tamanho do corpo, tamanho da cápsula cefálica, peso, emergência e deformidades), além da mortalidade, os testes apresentam uma boa resposta, que pode ser utilizada em situações de avaliação de risco ecológico.

Além do "end point", o estágio de desenvolvimento do organismo influencia a toxicidade aos contaminantes. Segundo RISTOLA (2000) a sensibilidade de C. riparius diminui com a idade e, portanto, para a avaliação do risco ecológico potencial de uma substância, recomenda-se o uso do estágio mais sensível do ciclo de vida. Segundo RISTO LA (op cit.), apesar de o I instar ser o mais sensível, o II e III instars têm sido mais utilizados nos ensaios de toxicidade, devido à alta taxa de mortalidade natural observada para 0 I estágio larval. Em relação aos ensaios desenvolvidos tanto para C. xanthus quanto para C . riparius, constatou-se essa relação 
de diminuição da sensibilidade com o aumento da idade. Nos testes com $\mathrm{Cd}$ e Cu, não foi observada alta taxa de mortalidade nos ensaios crônicos que foram iniciados com o I instar, isto é, a mortalidade foi inferior a 30\%, como recomendado pela OECD (2000) para ensaios crônicos. Recomenda-se uma complementação dos testes crônicos utilizando diversas concentrações de $\mathrm{Cd}$ e $\mathrm{Cu}$, com a finalidade de se detectar, principalmente em relação às deformidades do mento, quais as concentrações que estimulam ou inibem a sua formação.

Em alguns testes de toxicidade crônico ou sub-crônico seria adequado que os organismos não fosses alimentados durante o período do teste para que a entrada da substância tóxica não ocorra via alimentação. Porém, no caso de Chironomus, essa condição não pode ser atendida, pois segundo PERY et al. (2002), a falta de alimento pode causar a morte dos organismos-teste, gerando falsos positivos, isto é, reduzir a sobrevivência, desenvolvimento e reprodução por outras razões que não seja a toxicidade. Os autores desenvolveram um modelo que indica qual o nível mínimo de alimento que deve ser adicionado nos testes com larvas de diferentes instars

Q uanto ao tempo de duração dos testes crônicos, observou-se que ao utilizar C. x anthus a duração do teste foi inferior ao recomendado pelas Normas (U.S. EPA, 2000; OECD , 2000; 2004). 0 desenvolvimento de C. xanthus é mais rápido que de C. tentans e C. riparius, sendo que em apenas 11 dias, é possível observar a emergência de adultos. Enquanto nos experimentos com C. xanthus os organismos estavam no IV instar larval após uma semana de cultivo, C. riparius, com uma semana de cultivo estava apenas no II instar. Essas diferenças são intrínsecas de cada espécie e, portanto, as Normas reconhecidas internacionalmente para testes com quironomídeos sofrem algumas modificações quando do uso de C. xanthus como organismo-teste.

Em relação aos testes de evitamento, utilizando C. riparius, recomenda-se 0 emprego de diferentes concentrações, bem como diferentes períodos de duração do teste. Apesar de não ter sido obtida a resposta comportamental esperada dos organismos submetidos aos testes de seleção de substrato e do gradiente de contaminação (fluxo contínuo), o teste de postura de ovos indicou que efeitos adversos podem ocorrer quando a população é exposta ao cobre. Recomenda-se, 
portanto, a repetição desses ensaios alterando-se o tempo de duração, bem como as concentrações e as substâncias testadas.

Finalmente, recomenda-se o uso de C. xanthus e C. riparius para avaliação da qualidade de sedimentos, bem como do risco ecológico de substâncias contaminantes, desde que observadas as variáveis que compõem o teste, tais como tempo de duração e "end points" mais adequados para cada situação. A complementação dos resultados dos testes com parâmetros bioquímicos, tal como conteúdo de lipídeos e biomarcadores, além de características do gasto energético também é aconselhável para que ocorra uma aproximação mais real dos resultados obtidos nos testes de toxicidade com o que ocorre no ambiente natural.

\section{BIBLIOGRAFIA}

CANADIAN COUNCIL OF MINISTERS OF THE ENVIRONMENT - CCME

- Canadian Sediment Quality Guidelines for the Proteccion of Aquatic Life Summary tables, 2002, 7p.

CAMPAGNA, A.F. Toxicidade dos sedimentos da Bacia Hidrográfica do rio Monjolinho (São Carlos - SP): ênfase nas substâncias cobre, aldrin e heptacloro, 2005. Dissertação (Mestrado). Faculdade de Zootecnia e Engenharia de Alimentos, Universidade de São Paulo, 2005. 281p.

CHAPMAN, P.M.; FAIRBROTHER, A.; BROWN, D. A critical evaluation of safety (uncertainty) factor for ecological risk assessment. Environmental Toxicology and Chemistry, 17(1):99-108, 1998.

DICKMAN, M.; BRINDLE, I.; BENSON, M. Evidence of teratogens in sediments of the Niagara River watershed as reflected by chironomid (Diptera: Chironomidae) deformities. Journal of Great Lakes and Research, 18(3):467480, 1992.

HUND-RINKE, K.; KORDEL, W. Underlying issues in bioaccessibility and bioavailability: experimental methods. Ecotoxicology Environmetal and Safety, 56:52-62, 2003. 
MACD ONALD, D.D.; INGERSOLL, C.G.; BERGER, T.A. Development and Evaluation of Consensus-Based Sediment Quality Guidelines for Freshwater Ecosystems. Achieves Environment Contamination Toxicology. 39:20-31, 2000. NOVELLI, A. Estudo limnológico e ecotoxicológico da água e sedimento do rio Monjolinho - São Carlos (SP), com ênfase nas substâncias de referência cádmio e cobre, 2005. D issertação (Mestrado). Escola de Engenharia de São Carlos, Universidade de São Paulo, 2005. 288p.

ORGANIZATION FOR ECONOMIC COOPERATION AND DEVELOPMENT - OECD . Guidelines for the testing of chemicals. Sedimentwater Chironomid Toxicity Test using spiked sediment - Draft document., 2000. 23p.

ORGANIZATION FOR ECONOMIC COOPERATION AND DEVELOPMENT - OECD. Guidelines for the testing of chemicals. Sedimentwater Chironomid Toxicity Test using spiked sediment, 2004. 21p.

PÉRY, A.R.R.; MONS, R.L.; FLAMMARION, P.; LAGADIC, L.; GARRIC, J. A modeling approach to link food availability, growth, emergence, and reproduction for the midge Chironomus riparius. Environmental Toxicology and Chemistry, 21(11):2507-2513, 2002.

RISTOLA, T. Assessment of sediment toxicity using the midge Chironomus riparius (Diptera: Chironomidae). University of Joensuu, PhD Dissertations of Biology $\mathrm{n}-5,2000.29 \mathrm{p}$.

SMITH, S.L.; MacD ONALD, D.D .; KENNLEYSIDE, K.A.; INGERSOLL, C.G .; FIELD , L.J. A preliminary evaluation of sediment quality assessment values for freshwater ecosystems. Journal G reat Lakes and Research, 22:624-638, 1996.

THOMAS, R.L. A protocol for the selection of process-oriented remedial options to control in situ sediment contaminants. Hydrobiologia, 149:247-258, 1987.

UNITED STATES ENVIRONMENTAL PROTECTION AGENCY. U.S. EPA/ 600/R- 99/ 064. Methods for measuring the toxicity and bioaccumulation of sediment associated contaminant with freshwater invertebrates. 2ed., Washington. D.C., 2000. 192p. 


\section{APÊNDICES}


Apêndice 1

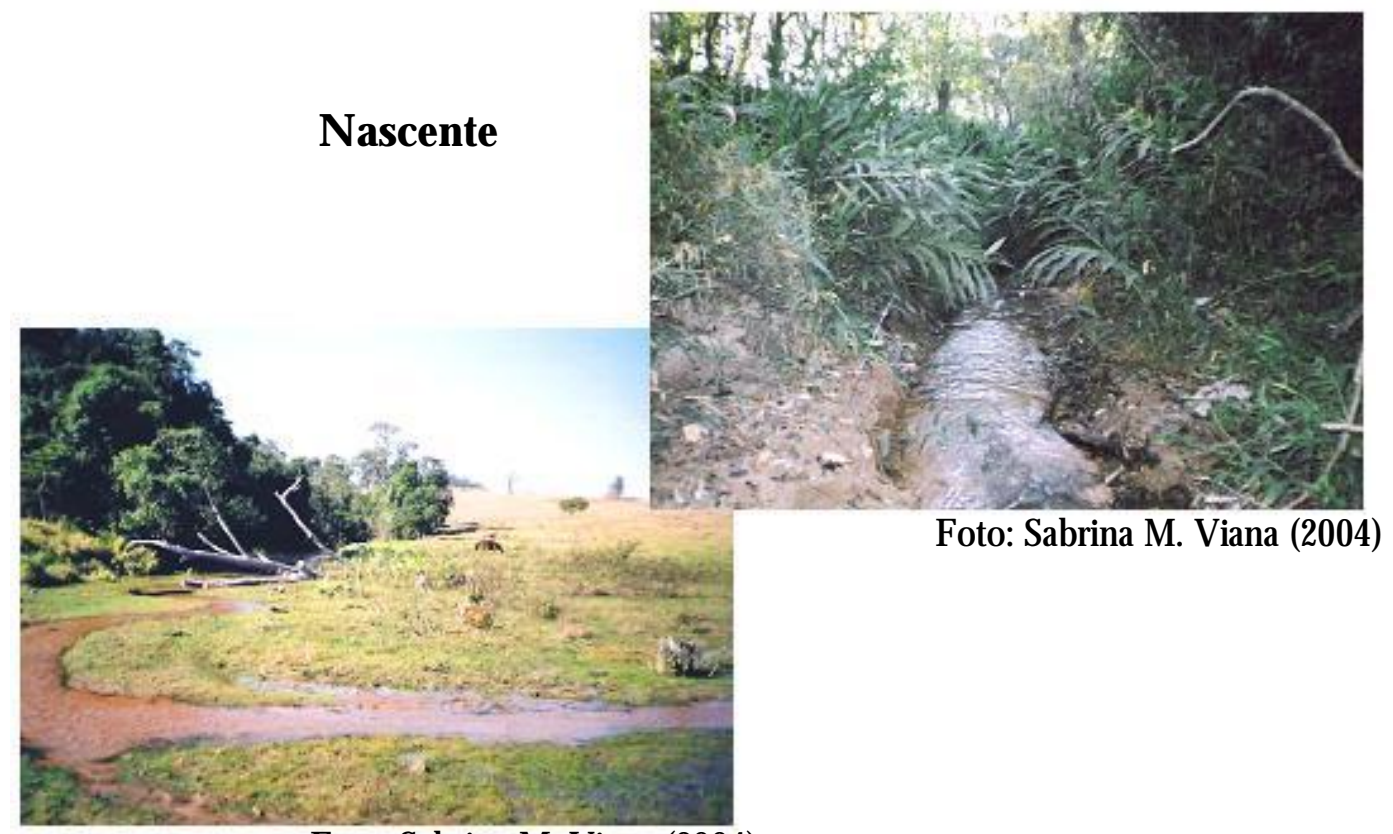

Foto: Sabrina M. Viana (2004)

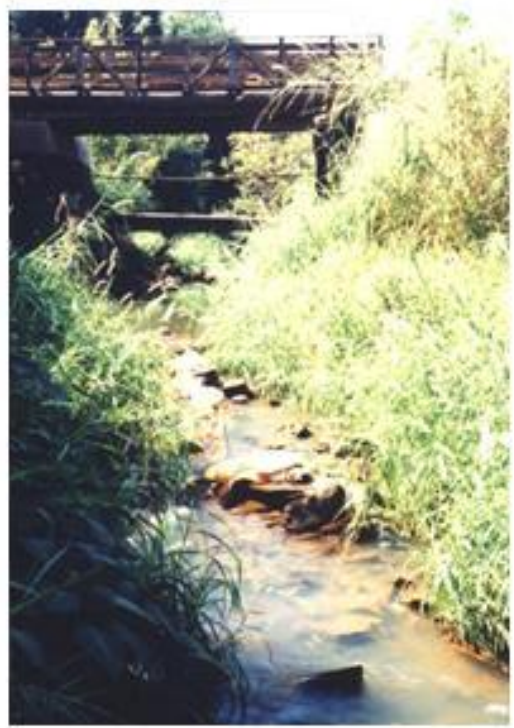

\section{Federal}

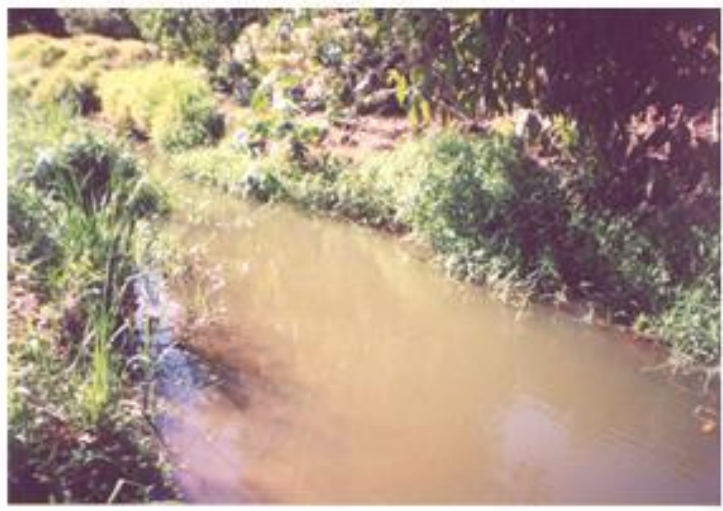

Figura 6. Imagens das estações de coleta - Nascente e Federal. 

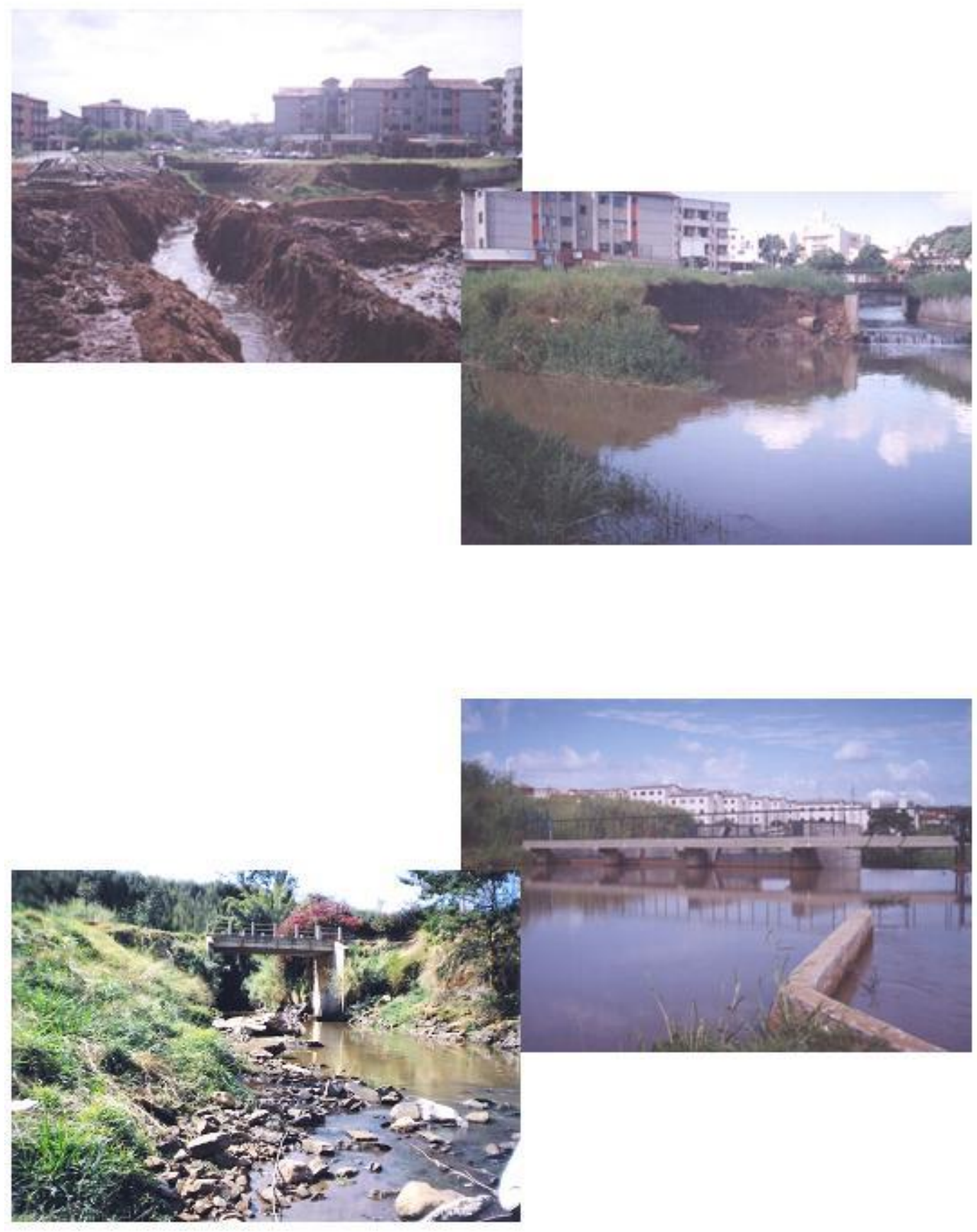

Figura 7. Imagens das estações de coleta - USP e Usina. 

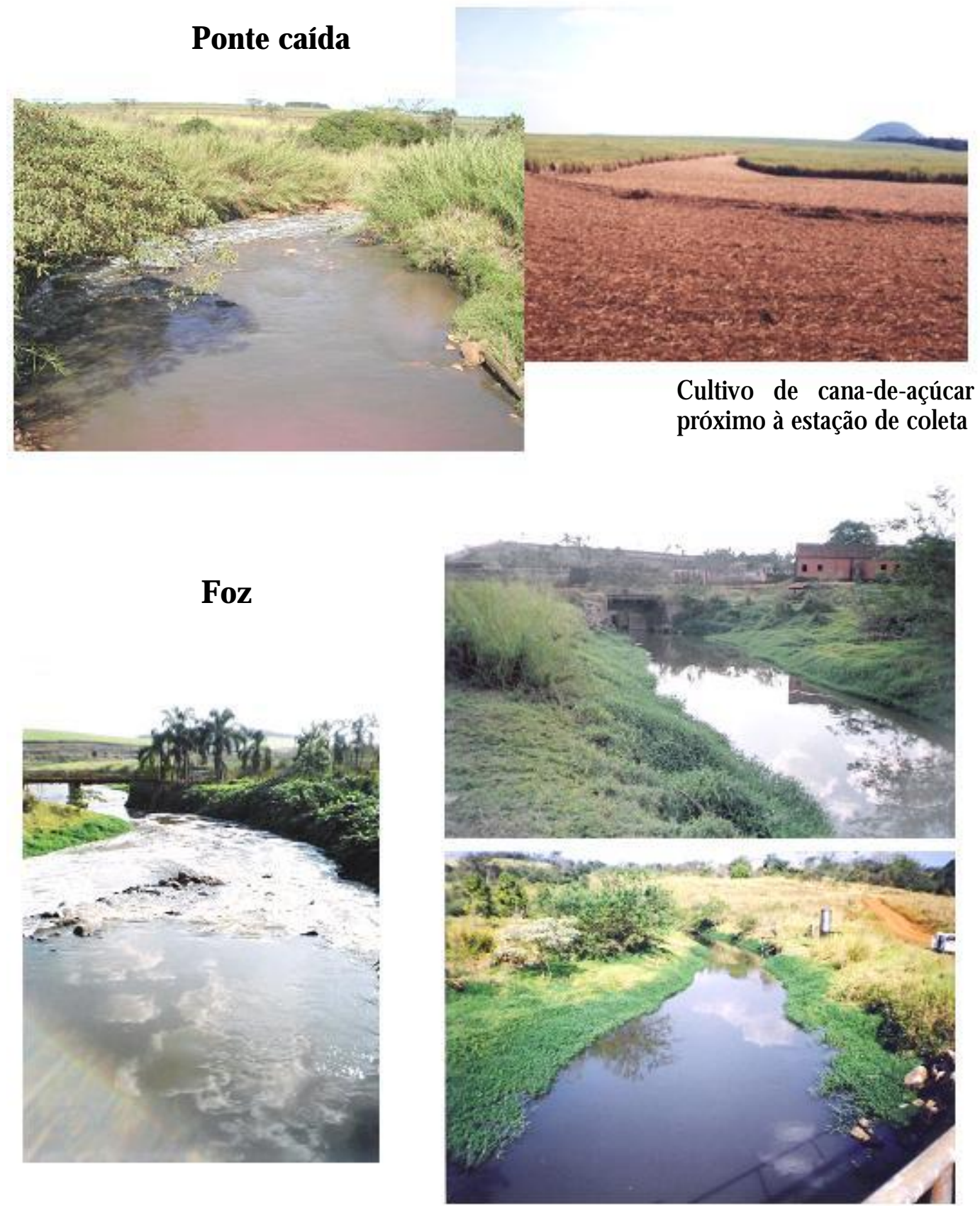

Figura 8. Imagens das estações de coleta - Ponte caída e Foz (Fotos: Sabrina M. Viana, 2004). 

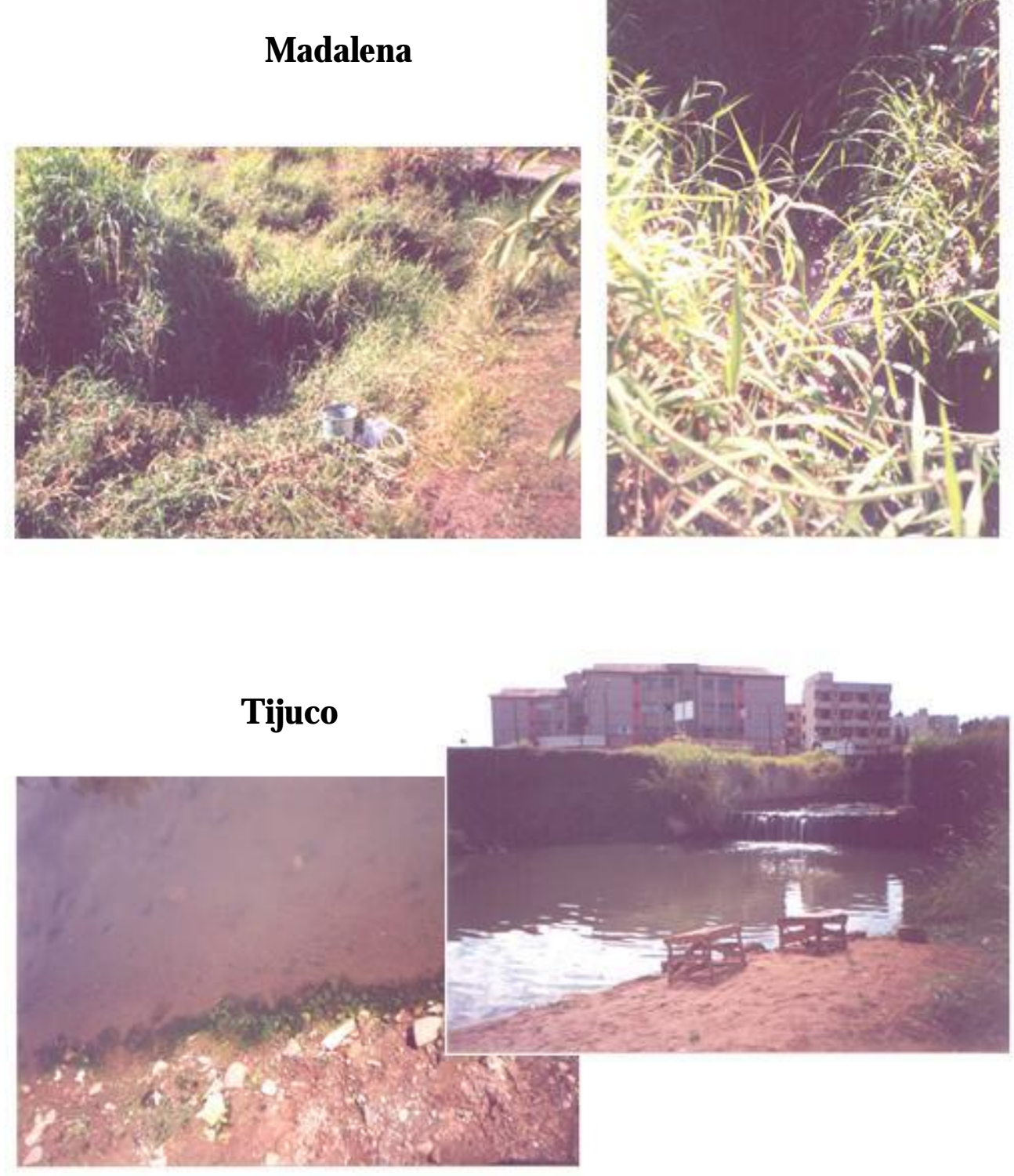

Figura 9. Imagens das estações de coleta Madalena e Tijuco. 


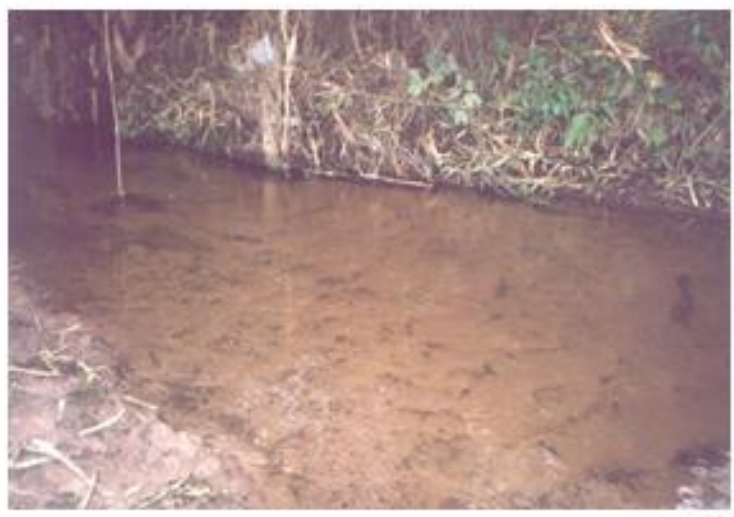

\section{Mineirinho}

\section{Água Quente}

\section{Gregório}
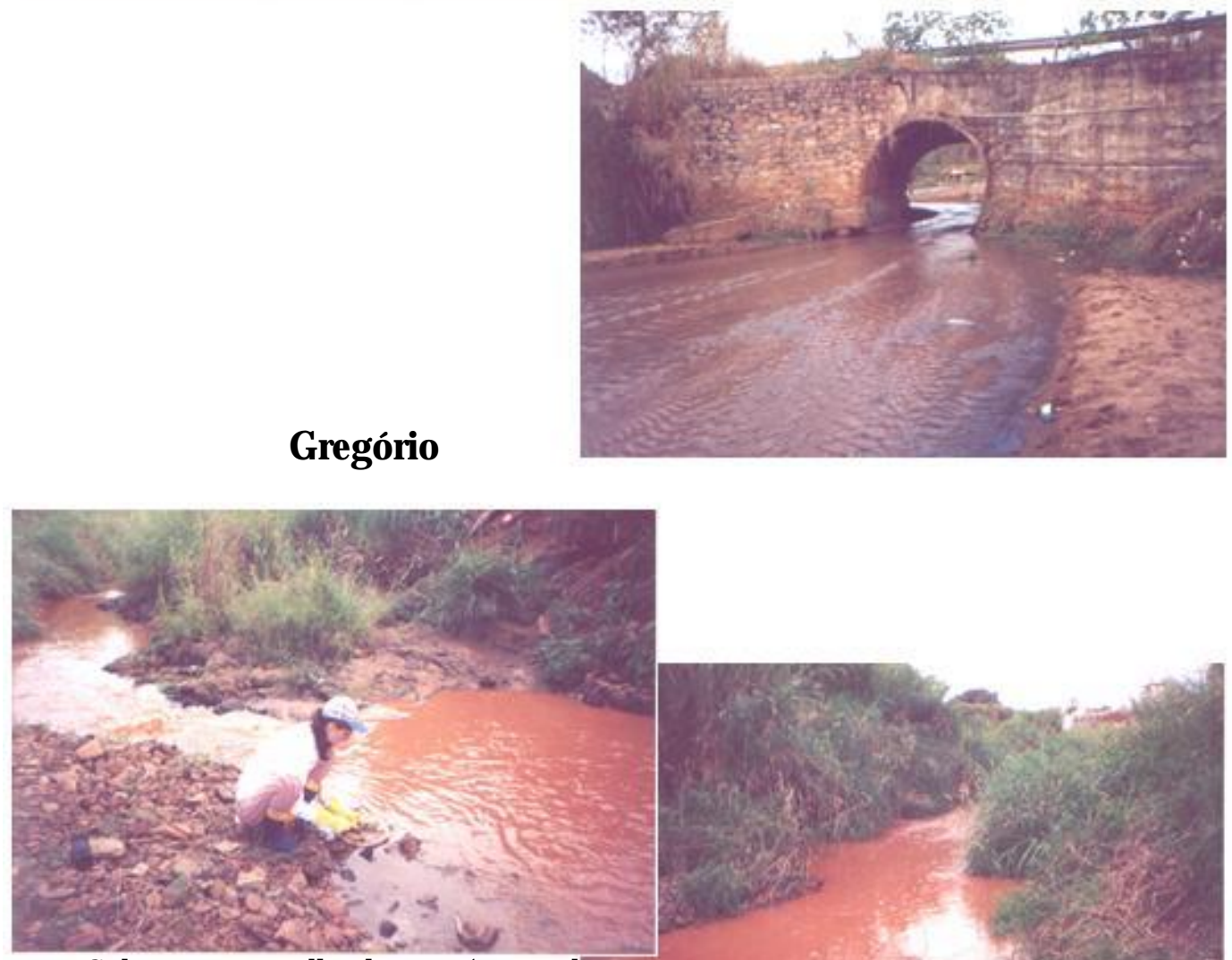

Coloração vermelha da água (material em suspensão) provocada por obras da

Prefeitura Municipal de São Carlos à montante da estacão de coleta

Figura 10. Imagens das estações de coleta - Mineirinho, Água Quente e Gregório. 


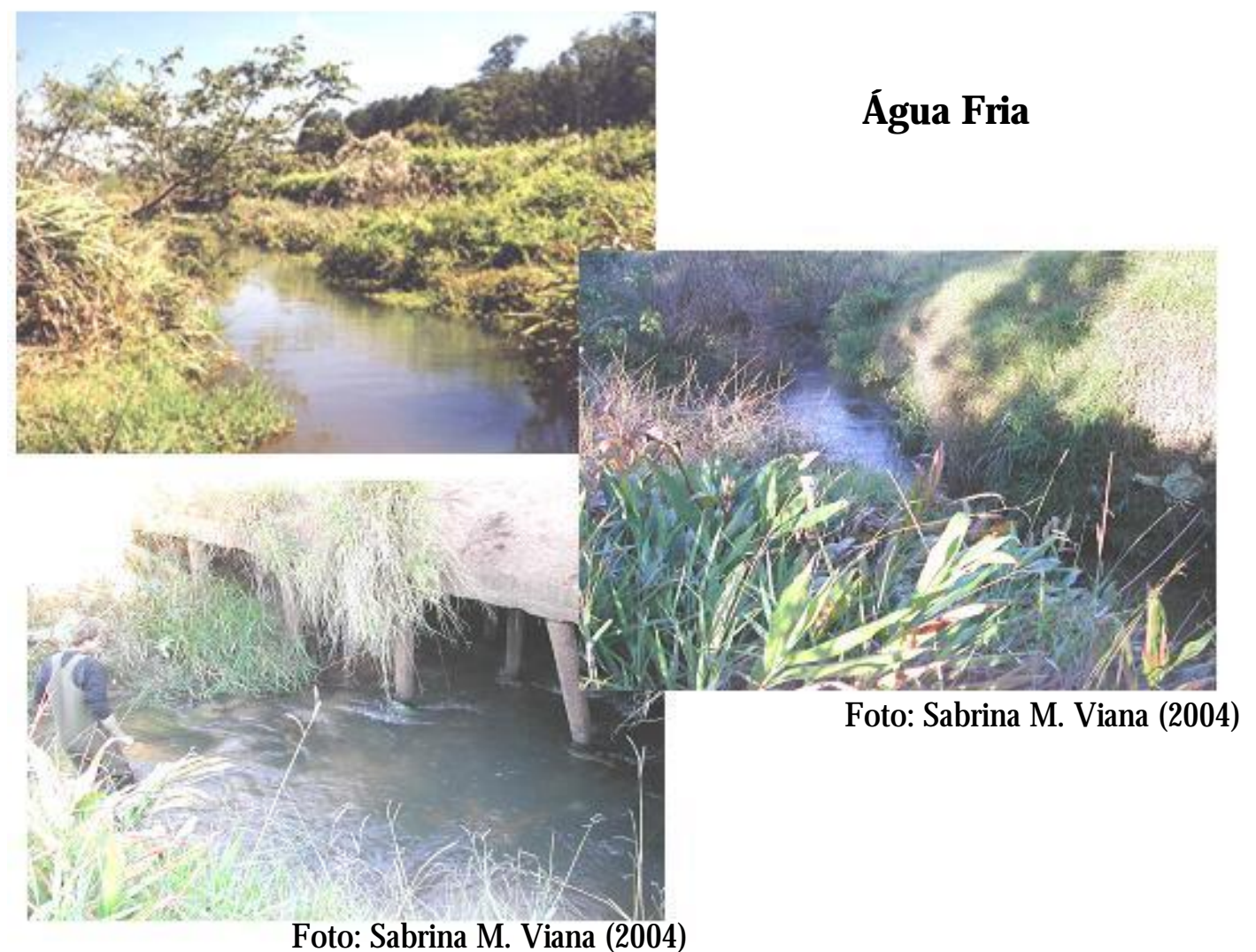

\section{Cancan}
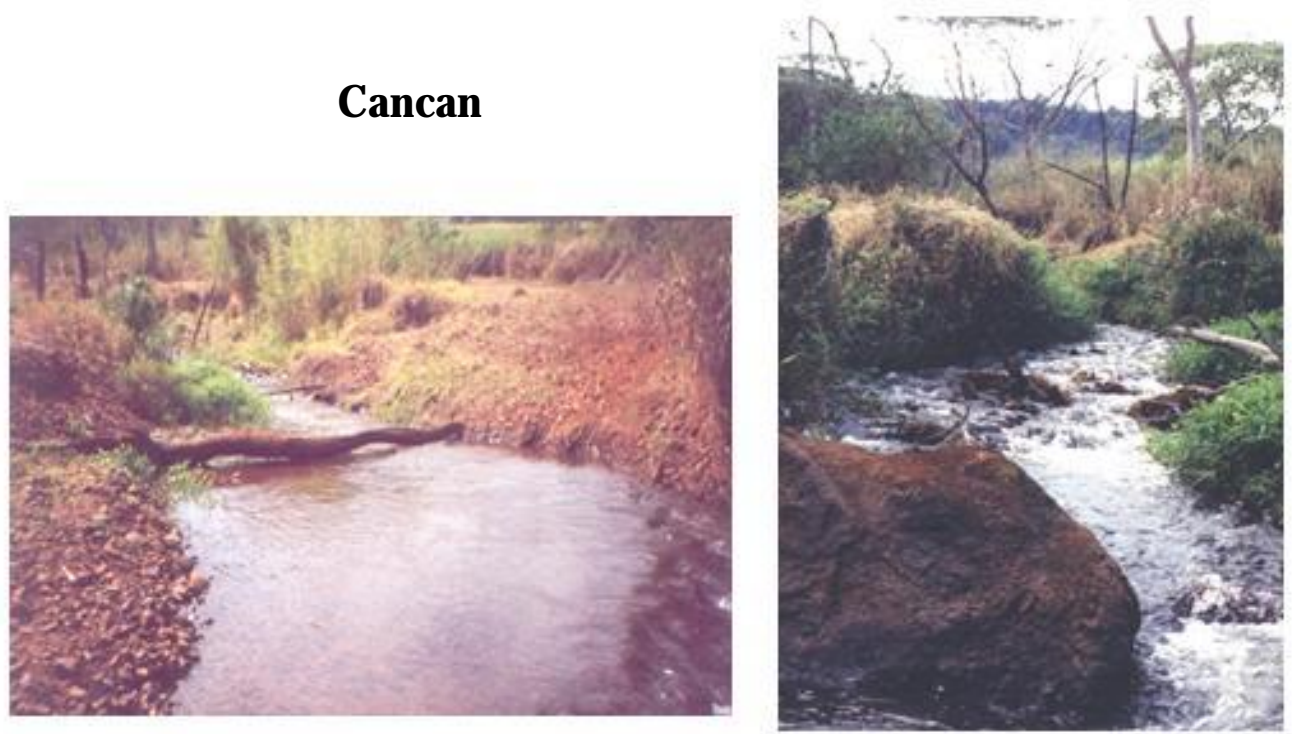

Figura 11. Imagens das estações de coleta - Água Fria e Cancan. 
Apêndice 2

Tabela 3. Pluviosidade diária durante o período de estudo. Em destaque estão os dias em que foram realizadas as coletas de campo.

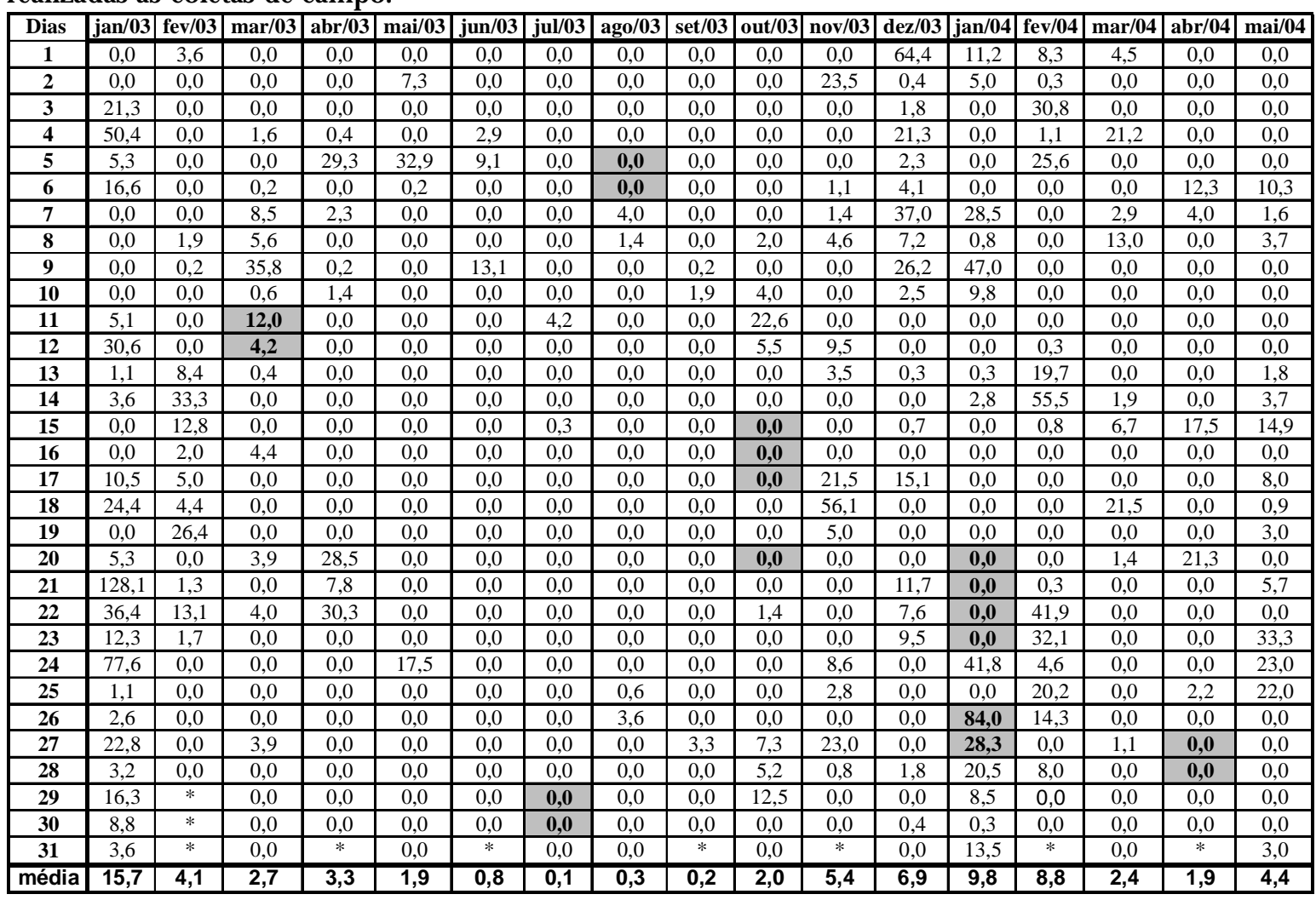

Tabela 4. Valores de vazão $\left(\mathrm{m}^{3} \cdot \mathrm{s}^{-1}\right)$ durante o período de estudo.

\begin{tabular}{lcccc}
\hline & Julho/ $\mathbf{~ O 3}$ & $\mathbf{0 u t u b r o / ~} \mathbf{~ 3}$ & Janeiro/ $\mathbf{~ 0 4}$ & Abril/ 04 \\
\hline Nascente & 0,017 & 0,026 & 0,012 & 0,013 \\
Federal & 0,093 & 0,039 & 0,049 & 0 \\
Madalena & 0,690 & $\mathrm{nc}$ & 1,638 & $\mathrm{nc}$ \\
Tijuco & 0,043 & $\mathrm{nc}$ & 0,060 & $\mathrm{nc}$ \\
USP & 0,339 & 0,230 & 0,342 & 0,724 \\
Mineininho & 0,054 & $\mathrm{nc}$ & 0,068 & $\mathrm{nc}$ \\
Gregónio & 0,128 & $\mathrm{nc}$ & 0,145 & $\mathrm{nc}$ \\
Usina & 2,280 & 0,409 & 1,780 & represada \\
Á. Quente & 0,193 & $\mathrm{nc}$ & 0,223 & $\mathrm{nc}$ \\
Á. Fria & 0,461 & $\mathrm{nc}$ & 0,441 & $\mathrm{nc}$ \\
P. caída & 1,441 & 0,877 & 2,850 & 2,460 \\
Cancan & 0,169 & $\mathrm{nc}$ & 0,508 & $\mathrm{nc}$ \\
Serra & 0,095 & $\mathrm{nc}$ & 0,126 & $\mathrm{nc}$ \\
Foz & 3,360 & 3,020 & 3,190 & 1,277 \\
\hline
\end{tabular}

nc = estação não coletada 
Tabela 5. Material em suspensão (total, inorgânico e orgânico) em mg.L-1, durante o período de estudo.

\begin{tabular}{|c|c|c|c|c|c|c|}
\hline \multirow{2}{*}{$\begin{array}{l}\text { Material em } \\
\text { suspensão }\end{array}$} & \multicolumn{3}{|c|}{ Julho/ 03} & \multicolumn{3}{|c|}{ Outubro/ 03} \\
\hline & total & inorgânico & orgânico & total & inorgânico & orgânico \\
\hline Nascente & 2,350 & 1,340 & 1,010 & 2,467 & 0,817 & 1,650 \\
\hline Federal & 13,800 & 10,200 & 3,600 & 6,533 & 3,167 & 3,367 \\
\hline USP & 6,630 & 2,670 & 3,960 & 4,633 & 1,300 & 5,217 \\
\hline Usina & 23,750 & 16,970 & 6,770 & 8,750 & 3,450 & 5,300 \\
\hline P.Caída & 46,950 & 23,600 & 23,350 & 12,900 & 15,967 & 11,600 \\
\hline Foz & 12,460 & 5,340 & 7,120 & 39,800 & 26,267 & 13,533 \\
\hline \multirow{2}{*}{$\begin{array}{l}\text { Material em } \\
\text { suspensão }\end{array}$} & \multicolumn{3}{|c|}{ Janeiro/ 04} & \multicolumn{3}{|c|}{ Abril/ 04} \\
\hline & total & inorgânico & orgânico & total & inorgânico & orgânico \\
\hline Nascente & 3,567 & 2,083 & 1,483 & 2,367 & 0,533 & 1,833 \\
\hline Federal & 9,133 & 5,600 & 3,533 & 5,483 & 1,583 & 3,900 \\
\hline Madalena & 4,583 & 2,900 & 1,683 & nc & $\mathrm{nc}$ & $\mathrm{nc}$ \\
\hline Tijuco & 5,333 & 1,183 & 4,150 & nc & nc & $\mathrm{nc}$ \\
\hline USP & 17,167 & 12,050 & 5,117 & 3,700 & 0,900 & 2,800 \\
\hline Mineininho & 33,233 & 23,967 & 9,267 & $\mathrm{nc}$ & nc & $\mathrm{nc}$ \\
\hline Gregónio & 3,967 & 1,200 & 2,767 & nc & nc & nc \\
\hline Usina & 22,250 & 12,100 & 10,150 & 29,417 & 21,133 & 8,283 \\
\hline Á. Quente & 130,067 & 105,000 & 25,067 & $\mathrm{nc}$ & $\mathrm{nc}$ & $\mathrm{nc}$ \\
\hline Á. Fria & 33,100 & 26,833 & 6,267 & $\mathrm{nc}$ & $\mathrm{nc}$ & nc \\
\hline P. Caída & 60,460 & 34,020 & 26,440 & 11,983 & 6,650 & 5,333 \\
\hline Cancan & 21,100 & 15,883 & 5,217 & $\mathrm{nc}$ & $\mathrm{nc}$ & $\mathrm{nc}$ \\
\hline Serma & 5,867 & 3,500 & 2,367 & nc & nc & nc \\
\hline Foz & 31,917 & 23,033 & 8,883 & 13,050 & 8,100 & 4,950 \\
\hline
\end{tabular}

nc = estação não coletada

Legenda das Tabelas 6 a 10: PTD = Fósforo total dissolvido; PI = fosfato inorgânico; $\mathbf{P T}=$ fosfato total; $\mathbf{N O}_{3}=$ nitrato; $\mathbf{N H}_{4}=$ ín amônio; $\mathbf{N O}_{2}=$ nitrito e $\mathbf{N T}=$ nitrogênio orgânico total. Todos os valores em $\mu g . \mathrm{L}^{-1}$, exceto NT, em mg. $\mathrm{L}^{-1}$.

Tabela 6. Concentrações de nutrientes na água obtidos em março/ 03.

\begin{tabular}{lccccccc}
\hline Março/ 03 & PT D & PI & PT & $\mathbf{N O}_{3}$ & $\mathbf{N H}_{\mathbf{4}}$ & $\mathbf{N O}_{\mathbf{2}}$ & $\mathbf{N T}$ \\
\hline Nascente & 10,91 & 9,66 & 30,27 & 350,00 & 64,00 & 3,64 & 0,02 \\
Federal & 17,96 & 10,87 & 108,96 & 110,43 & 153,77 & 9,68 & 0,26 \\
Madalena & 13,27 & 9,24 & 81,47 & 75,94 & 55,50 & 3,74 & 0,56 \\
Tijuco & 289,06 & 282,79 & 476,67 & 2701,40 & 2682,25 & 261,51 & 0,48 \\
USP & 20,12 & 16,25 & 71,19 & 197,72 & 155,43 & 6,26 & 15,18 \\
Mineininho & 23,07 & 17,51 & 68,98 & 158,51 & 102,73 & 7,92 & 0,45 \\
Gregónio & 130,49 & 103,41 & 173,43 & 2351,90 & 1280,00 & 141,78 & 15,18 \\
Usina & 61,05 & 46,71 & 134,14 & 533,93 & 570,57 & 41,40 & 10,57 \\
A. quente & 52,40 & 35,08 & 364,65 & 419,20 & 2700,30 & 83,75 & 1,81 \\
A. fria & 33,06 & 26,30 & 74,57 & 270,42 & 39,04 & 3,31 & 2,97 \\
P. cá́da & 107,28 & 94,21 & 329,23 & 260,30 & 2016,50 & 29,58 & 2,00 \\
Cancan & 16,17 & 11,32 & 32,13 & 74,98 & 39,44 & 1,93 & 0,21 \\
Serra & 20,73 & 12,08 & 54,78 & 107,64 & 66,24 & 4,09 & 0,49 \\
Foz & 64,94 & 45,99 & 123,19 & 275,80 & 734,55 & 92,07 & 0,33 \\
\hline
\end{tabular}


Tabela 7. Concentrações de nutrientes na água obtidos em julho/ 03.

\begin{tabular}{lccccccc} 
Julho/ 03 & PTD & PI & $\mathbf{P T}$ & $\mathbf{N O}_{3}$ & $\mathbf{N H}_{\mathbf{4}}$ & $\mathbf{N O}_{\mathbf{2}}$ & $\mathbf{N T}$ \\
\hline Nascente & 6,12 & 5,22 & 18,00 & 164,98 & 31,89 & 2,19 & 0,23 \\
Federal & 14,98 & 10,16 & 97,61 & 166,93 & 151,29 & 2,55 & 0,61 \\
Madalena & 12,34 & 10,74 & 36,13 & 189,68 & 137,33 & 3,14 & 0,42 \\
Tijuco & 218,11 & 202,95 & 444,34 & 3979,10 & 1006,70 & 528,22 & 0,61 \\
USP & 167,98 & 150,45 & 284,11 & 317,47 & 1496,70 & 32,23 & 0,84 \\
Mineininho & 50,61 & 42,47 & 108,37 & 442,51 & 457,27 & 48,94 & 0,70 \\
Gregónio & 211,46 & 179,11 & 390,18 & 3755,80 & 1923,50 & 519,80 & 1,96 \\
Usina & 92,36 & 74,69 & 271,40 & 810,08 & 1110,80 & 125,89 & 1,26 \\
A. quente & 9,63 & 407,97 & 982,85 & 158,77 & 2220,30 & 25,08 & 4,34 \\
A. fria & 22,58 & 19,50 & 61,11 & 269,83 & 119,73 & 6,53 & 0,42 \\
P. cá́da & 241,25 & 233,99 & 682,56 & 180,07 & 1819,20 & 31,05 & 3,50 \\
Cancan & 9,91 & 8,71 & 53,26 & 142,10 & 29,08 & 3,24 & 0,37 \\
Serra & 9,63 & 8,42 & 54,08 & 276,94 & 187,71 & 20,59 & 0,19 \\
Foz & 357,96 & 355,10 & 615,27 & 110,91 & 2218,60 & 38,32 & 4,01 \\
\hline
\end{tabular}

Tabela 8. Concentrações de nutrientes na água obtidos em outubro/ 03.

\begin{tabular}{lccccccc}
\hline Outubro/ 03 & PT D & PI & PT & $\mathbf{N O}_{\mathbf{3}}$ & $\mathbf{N H}_{\mathbf{4}}$ & $\mathbf{N O}_{\mathbf{2}}$ & NT \\
\hline Nascente & 13,56 & 7,50 & 46,52 & 131 & 278,52 & 2,29 & 0,70 \\
Federal & 22,79 & 13,47 & 67,79 & 164 & 313,15 & 4,52 & 0,37 \\
USP & 124,78 & 98,97 & 197,65 & 467 & 1226,90 & 29,80 & 1,73 \\
Usina & 326,05 & 249,70 & 480,58 & 2291 & 1446,20 & 174,50 & 2,38 \\
P. caída & 387,58 & 341,77 & 787,37 & 348 & 2389,60 & 82,76 & 4,43 \\
Foz & 250,60 & 176,31 & 747,52 & 212 & 2668,00 & 61,94 & 4,57 \\
\hline
\end{tabular}

Tabela 9. Concentrações de nutrientes na água obtidos em janeiro/ 04.

\begin{tabular}{lccccccc}
\hline Janeiro/ 04 & PTD & PI & PT & $\mathbf{N O}_{3}$ & $\mathbf{N H}_{\mathbf{4}}$ & $\mathbf{N O}_{\mathbf{2}}$ & $\mathbf{N T}$ \\
\hline Nascente & 15,80 & 12,00 & 61,38 & 104,30 & 1815,40 & 2,30 & 0,02 \\
Federal & 33,32 & 20,53 & 87,40 & 282,57 & 432,98 & 20,47 & 0,26 \\
Madalena & 24,59 & 15,17 & 42,10 & 45,57 & 121,02 & 1,82 & 0,56 \\
Tijuco & 46,21 & 31,89 & 136,77 & 4084,00 & 1933,10 & 386,49 & 15,18 \\
Usp & 48,69 & 32,89 & 116,95 & 1146,60 & 1970,30 & 100,47 & 0,48 \\
Mineininho & 51,35 & 39,63 & 166,32 & 342,34 & 333,89 & 60,00 & 0,45 \\
Gregónio & 675,97 & 418,77 & 917,29 & 3599,80 & 1009,30 & 27,70 & 15,18 \\
Usina & 187,26 & 121,94 & 288,47 & 1823,00 & 88,14 & 246,94 & 10,57 \\
A. quente & 197,18 & 156,24 & 481,95 & 490,98 & 307,00 & 43,96 & 1,81 \\
A. fria & 25,56 & 16,63 & 74,14 & 206,69 & 702,62 & 1,82 & 2,97 \\
P. caída & 250,18 & 180,14 & 632,88 & 64,02 & 29,80 & 11,92 & 2,00 \\
Cancan & 25,82 & 12,49 & 73,81 & 64,28 & 48,50 & 1,57 & 0,21 \\
Serra & 35,61 & 23,09 & 58,44 & 93,12 & 103,36 & 4,48 & 0,49 \\
Foz & 399,93 & 343,44 & 603,63 & 214,74 & 217,06 & 105,69 & 0,34 \\
\hline
\end{tabular}

Tabela 10. Concentrações de nutrientes na água obtidos em abril/ 04.

\begin{tabular}{lccccccc}
\hline Abril/ 04 & PTD & PI & PT & $\mathbf{N O}_{\mathbf{3}}$ & $\mathbf{N H}_{\mathbf{4}}$ & $\mathbf{N O}_{\mathbf{2}}$ & $\mathbf{N T}$ \\
\hline Nascente & 19,02 & 16,27 & 58,38 & 86,89 & 24,17 & 3,92 & 0,28 \\
Federal & 19,23 & 11,01 & 108,47 & 121,06 & 103,68 & 11,47 & 0,79 \\
USP & 21,61 & 15,67 & 116,77 & 196,03 & 133,76 & 12,95 & 0,42 \\
Usina & 62,10 & 47,50 & 235,60 & 641,97 & 469,41 & 53,24 & 1,03 \\
P. Caída & 405,41 & 353,28 & 644,09 & 207,99 & 1597,80 & 46,27 & 2,94 \\
Foz & 273,76 & 22,70 & 464,95 & 197,23 & 2453,80 & 78,78 & 3,55 \\
\hline
\end{tabular}


D ornfeld, C.B. (2006). U tilização de Chironomus sp (D iptera, Chironomidae)...

Tabela 11. Concentrações (mg. $\left.\mathrm{L}^{-1}\right)$ de Cloretos na água durante o período de estudo.

\begin{tabular}{lccccc}
\hline Estaç̃os & Março/ 03 & Julho/ 03 & Outubro/ 03 & Janeiro/ 04 & Abril/ 04 \\
\hline Nascente & 1,400 & 0,040 & 0,500 & 0,100 & 0,400 \\
Federal & 4,300 & 4,500 & 5,200 & 6,500 & 2,700 \\
Madalena & 6,000 & 0,080 & $\mathrm{nc}$ & 0,200 & $\mathrm{nc}$ \\
Tijuco & 15,400 & 10,700 & $\mathrm{nc}$ & 6,300 & $\mathrm{nc}$ \\
USP & 2,500 & 5,300 & 4,000 & 2,700 & 2,200 \\
Mineirinho & 4,500 & 3,800 & $\mathrm{nc}$ & 1,500 & $\mathrm{nc}$ \\
Gregónio & 7,700 & 20,400 & $\mathrm{nc}$ & 11,600 & $\mathrm{nc}$ \\
Usina & 4,200 & 11,600 & 6,400 & 5,600 & 6,800 \\
A. Quente & 24,500 & 19,700 & $\mathrm{nc}$ & 16,400 & $\mathrm{nc}$ \\
A. Fria & 1,800 & 2,100 & $\mathrm{nc}$ & 1,800 & $\mathrm{nc}$ \\
P. caída & 9,700 & 14,900 & 15,500 & 15,200 & 10,900 \\
Cancan & 4,900 & 3,000 & $\mathrm{nc}$ & 3,700 & $\mathrm{nc}$ \\
Sema & 3,000 & 2,400 & $\mathrm{nc}$ & 1,800 & $\mathrm{nc}$ \\
Foz & 9,100 & 12,100 & 16,900 & 16,600 & 10,300 \\
\hline
\end{tabular}

nc = estação não coletada

Tabela 12. Concentrações (mg.L-1) de Sulfatos na água durante o período de estudo.

\begin{tabular}{lccccc}
\hline E staç̃oes & Março/ 03 & Julho/ 03 & Outubro/ 03 & Janeiro/ 04 & Abril/ 04 \\
\hline Nascente & 7,0 & 2,0 & 6,0 & 5,0 & 5,0 \\
Federal & 12,0 & 7,0 & 5,0 & 7,0 & 5,0 \\
Madalena & 27,0 & 4,0 & $\mathrm{nc}$ & 5,0 & $\mathrm{nc}$ \\
Tijuco & 11,0 & 8,0 & $\mathrm{nc}$ & 2,0 & $\mathrm{nc}$ \\
USP & 30,0 & 6,0 & 4,0 & 9,0 & 4,0 \\
Mineininho & 14,0 & 0,0 & $\mathrm{nc}$ & 0,0 & $\mathrm{nc}$ \\
Gregónio & 10,0 & 59,0 & $\mathrm{nc}$ & 27,0 & $\mathrm{nc}$ \\
Usina & 7,0 & 12,0 & 6,0 & 9,0 & 15,0 \\
A. Quente & 33,0 & 15,0 & $\mathrm{nc}$ & 24,0 & $\mathrm{nc}$ \\
A. Fria & 8,0 & 0,0 & $\mathrm{nc}$ & 8,0 & $\mathrm{nc}$ \\
P. caída & 16,0 & 17,0 & 23,0 & 32,0 & 15,0 \\
Cancan & 7,0 & 0,0 & $\mathrm{nc}$ & 7,0 & $\mathrm{nc}$ \\
Serra & 13,0 & 0,0 & $\mathrm{nc}$ & 6,0 & $\mathrm{nc}$ \\
Foz & 18,0 & 16,0 & 23,0 & 18,0 & 14,0 \\
\hline
\end{tabular}

nc = estação não coletada

Tabela 13. Concentrações (mg.L-1) de Sulfetos na água durante o período de estudo.

\begin{tabular}{lccccc}
\hline E stações & Março/ 03 & Julho/ 03 & Outubro/ 03 & Janeiro/ 04 & Abril/ 04 \\
\hline Nascente & 0,012 & 0,006 & 0,003 & 0,008 & 0,008 \\
Federal & 0,104 & 0,010 & 0,004 & 0,005 & 0,006 \\
Madalena & 0,039 & 0,007 & $\mathrm{nc}$ & 0,003 & $\mathrm{nc}$ \\
Tijuco & 0,014 & 0,017 & $\mathrm{nc}$ & 0,005 & $\mathrm{nc}$ \\
USP & 0,019 & 0,010 & 0,004 & 0,003 & 0,006 \\
Mineirinho & 0,043 & 0,005 & $\mathrm{nc}$ & 0,014 & $\mathrm{nc}$ \\
Gregónio & 0,013 & 0,151 & $\mathrm{nc}$ & 0,010 & $\mathrm{nc}$ \\
Usina & 0,026 & 0,037 & 0,006 & 0,006 & 0,046 \\
A. Quente & 0,094 & 0,043 & $\mathrm{nc}$ & 0,066 & $\mathrm{nc}$ \\
A. Fria & 0,018 & 0,006 & $\mathrm{nc}$ & 0,012 & $\mathrm{nc}$ \\
P. caída & 0,037 & 0,036 & 0,024 & 0,027 & 0,021 \\
Cancan & 0,011 & 0,033 & $\mathrm{nc}$ & 0,010 & $\mathrm{nc}$ \\
Serra & 0,042 & 0,026 & $\mathrm{nc}$ & 0,001 & $\mathrm{nc}$ \\
Foz & 0,053 & 0,032 & 0,019 & 0,019 & 0,019 \\
\hline
\end{tabular}

nc = estação não coletada 
Tabela 14. Demanda Química de Oxigênio (mg.L-1) durante o período de estudo.

\begin{tabular}{lccccc}
\hline Estaç̃os & Março/ 03 & Julho/ 03 & Outubro/ 03 & Janeiro/ 04 & Abril/ 04 \\
\hline Nascente & 0,00 & 0,00 & 9,00 & 0,00 & 1,00 \\
Federal & 40,00 & 0,00 & 8,00 & 55,00 & 6,00 \\
Madalena & 16,00 & 3,00 & $\mathrm{nc}$ & 34,00 & $\mathrm{nc}$ \\
Tijuco & 17,00 & 29,00 & $\mathrm{nc}$ & 41,00 & $\mathrm{nc}$ \\
USP & 6,00 & 2,00 & 15,00 & 42,00 & 4,00 \\
Mineirinho & 6,00 & 4,00 & $\mathrm{nc}$ & 34,00 & $\mathrm{nc}$ \\
Gregónio & 18,00 & 31,00 & $\mathrm{nc}$ & 39,00 & $\mathrm{nc}$ \\
Usina & 6,00 & 12,00 & 18,00 & 20,00 & 22,00 \\
A. Quente & 28,00 & 53,00 & $\mathrm{nc}$ & 17,00 & $\mathrm{nc}$ \\
A. Fria & 29,00 & 0,00 & $\mathrm{nc}$ & 35,00 & $\mathrm{nc}$ \\
P. caída & 27,00 & 45,00 & 33,00 & 34,00 & 15,00 \\
Cancan & 1,00 & 18,00 & $\mathrm{nc}$ & 17,00 & $\mathrm{nc}$ \\
Sema & 12,00 & 17,00 & $\mathrm{nc}$ & 7,00 & $\mathrm{nc}$ \\
Foz & 11,00 & 45,00 & 30,00 & 35,00 & 28,00 \\
\hline
\end{tabular}

nc = estação não coletada

Tabela 15. Demanda Bioquímica de Oxigênio (mg.L-1) durante o período de estudo.

\begin{tabular}{lcccc}
\hline E stações & Julho/ 03 & Outubro/ 03 & Janeiro/ 04 & Abril/ 04 \\
\hline Nascente & 18,556 & 14,321 & 0,316 & 7,589 \\
Federal & 19,727 & 16,792 & 2,656 & 8,125 \\
Madalena & 17,899 & $\mathrm{nc}$ & 2,624 & $\mathrm{nc}$ \\
Tijuco & 22,152 & $\mathrm{nc}$ & 2,764 & $\mathrm{nc}$ \\
USP & 22,019 & 20,33 & 2,745 & 1,989 \\
Mineirinho & 24,592 & $\mathrm{nc}$ & 3,31 & $\mathrm{nc}$ \\
Gregónio & 18,061 & $\mathrm{nc}$ & 2,694 & $\mathrm{nc}$ \\
Usina & 22,424 & 21,425 & 9,231 & 10,256 \\
A. Quente & 26,419 & $\mathrm{nc}$ & 16,357 & $\mathrm{nc}$ \\
A. Fria & 12,517 & $\mathrm{nc}$ & 2,023 & $\mathrm{nc}$ \\
P. caída & 28,194 & 24,541 & 13,586 & 12,998 \\
Cancan & 18,298 & $\mathrm{nc}$ & 0,531 & $\mathrm{nc}$ \\
Sera & 16,287 & $\mathrm{nc}$ & 0,218 & $\mathrm{nc}$ \\
Foz & 21,634 & 19,213 & 7,153 & 9,261 \\
\hline
\end{tabular}

nc = estação não coletada

Tabela 16. Concentrações de metais na água do rio Monjolinho e tributários em março/ 03.

\begin{tabular}{|c|c|c|c|c|c|}
\hline Março/ 03 & $\mathrm{Cr}$ & $\mathrm{Cu}$ & pg. $\mathrm{L}^{-1} \quad \mathrm{Zn}$ & Mn & $\begin{array}{c}\text { Fe } \\
\text { mg.L-1 }\end{array}$ \\
\hline Nascente & 22,400 & 8,800 & 29,400 & 45,000 & 1,226 \\
\hline Federal & 8,000 & 22,800 & 33,600 & 80,800 & 1,653 \\
\hline Madalena & 58,000 & 26,800 & 26,000 & 38,800 & 5,157 \\
\hline Tijuco & 24,800 & 17,600 & 28,000 & 98,200 & 0,662 \\
\hline USP & 10,000 & 9,600 & 15,600 & 1,800 & 0,000 \\
\hline Mineininho & 0,400 & 17,200 & 30,200 & 32,800 & 1,085 \\
\hline Gregónio & 2,400 & 9,600 & 43,600 & 17,400 & 0,001 \\
\hline Usina & 9,600 & 14,000 & 28,200 & 42,800 & 0,826 \\
\hline Á. Quente & & & não foi realizada & & \\
\hline Á. Fria & nd & 10,400 & 13,000 & 5,200 & 0,001 \\
\hline Ponte caída & nd & 16,400 & 31,200 & 133,600 & 1,724 \\
\hline Cancan & 1,600 & 19,200 & 25,000 & 140,000 & 3,407 \\
\hline Serra & 6,800 & 20,400 & 25,600 & 67,400 & 1,234 \\
\hline Foz & nd & 17,600 & 35,200 & 122,800 & 2,180 \\
\hline
\end{tabular}


D ornfeld, C.B. (2006). U tilização de Chironomus sp (D iptera, Chironomidae)...

Tabela 17. Concentrações de metais na água do rio Monjolinho e tributários em julho/ 03.

\begin{tabular}{|c|c|c|c|c|c|c|}
\hline Julho/ 03 & $\mathrm{Cr}$ & Cd & $\begin{array}{c}\mathrm{Cu} \\
\text { Hg. } \mathrm{L}^{-1}\end{array}$ & $\mathrm{Zn}$ & Mn & $\begin{array}{c}\mathbf{F e} \\
\mathbf{m g} \cdot \mathrm{L}^{-1}\end{array}$ \\
\hline Nascente & & 0,400 & 19,200 & 27,667 & 24,333 & 0,581 \\
\hline Federal & 4,400 & 1,200 & 13,600 & 17,000 & 70,333 & 1,772 \\
\hline Madalena & 6,400 & 1,200 & 19,600 & 47,667 & 78,333 & 1,638 \\
\hline Tijuco & 3,600 & 0 & 16,800 & 16,667 & 40,333 & 2,197 \\
\hline USP & 3,600 & 1,200 & 18,400 & 26,667 & 71,667 & 2,134 \\
\hline Mineininho & 4,000 & 0,800 & 12,800 & 34,667 & 21,667 & 1,189 \\
\hline Gregónio & 4,000 & 1,200 & 32,000 & 36,000 & 195,000 & 3,216 \\
\hline Usina & 6,400 & 2,000 & 22,000 & 38,333 & 167,667 & 4,018 \\
\hline Á. Quente & 5,200 & 0,800 & 25,600 & 51,000 & 400,000 & 8,469 \\
\hline Á. Fria & 3,600 & 0 & 12,000 & 34,000 & 65,667 & 1,790 \\
\hline Ponte caída & 8,400 & 0 & 21,200 & 64,000 & 200,667 & 5,089 \\
\hline Cancan & 2,400 & 4,000 & 18,400 & 28,000 & 80,000 & 1,823 \\
\hline Senra & 1,600 & 1,200 & 22,400 & 31,667 & 232,333 & 3,468 \\
\hline Foz & 8,400 & 4,000 & 29,600 & 63,667 & 339,000 & 6,997 \\
\hline
\end{tabular}

nd $=$ não detectado

Tabela 18. Concentrações de metais na água do rio Monjolinho em outubro/ 03.

\begin{tabular}{lcccccc}
\hline Outubm.03 & $\mathbf{C r}$ & $\mathbf{C d}$ & $\begin{array}{c}\mathbf{C u} \\
\mathbf{p g . L} \cdot \mathbf{- 1}\end{array}$ & $\mathbf{Z n}$ & $\mathbf{M n}$ & $\begin{array}{c}\mathbf{F e} \\
\mathbf{m g . L ^ { - 1 }}\end{array}$ \\
\hline Nascente & 5,042 & nd & 3,364 & 22,000 & 29,000 & 5,451 \\
Federal & 1,242 & nd & 0,712 & 23,800 & 98,600 & 2,058 \\
USP & 0,702 & 0,017 & 5,718 & 17,600 & 49,400 & 2,446 \\
Usina & 1,688 & 0,262 & 12,570 & 34,000 & 98,000 & 3,742 \\
P.caída & 2,828 & 0,146 & 8,732 & 14,000 & 171,800 & 8,127 \\
Foz & 4,896 & 0,874 & 19,092 & 38,600 & 227,600 & 13,814 \\
\hline
\end{tabular}

nd = não detectado

Tabela 19. Concentrações de metais na água do rio Monjolinho e tributários em janeiro/ 04.

\begin{tabular}{lcccccc}
\multicolumn{1}{c}{ Janeiro.04 } & $\mathbf{C r}$ & $\mathbf{C d}$ & $\begin{array}{c}\mathbf{C u} \\
\mathbf{p g . L} \mathbf{L}^{-\mathbf{1}}\end{array}$ & $\mathbf{Z n}$ & $\mathbf{M n}$ & $\begin{array}{c}\mathbf{F e} \\
\mathbf{m g . L ^ { - 1 }}\end{array}$ \\
\hline Nascente & 1,390 & 0,309 & 0,508 & nd & 28,400 & 0,348 \\
Federal & 1,504 & 0,272 & nd & nd & 84,200 & 1,063 \\
Madalena & 0,392 & 0,080 & 1,240 & nd & 33,400 & 0,983 \\
Tijuco & nd & 0,156 & 2,462 & nd & 39,200 & 1,318 \\
USP & 0,834 & 0,397 & nd & 24,800 & 47,800 & 1,280 \\
Mineirinho & 1,092 & 0,188 & nd & 19,000 & 21,200 & 0,714 \\
Gregónio & 0,636 & 0,351 & 9,758 & 97,800 & 47,000 & 1,930 \\
Usina & 0,518 & 0,118 & nd & 34,800 & 63,800 & 2,411 \\
Á. Quente & 5,310 & 1,967 & 17,482 & 15,600 & 233,400 & 5,081 \\
Á. Fria & 0,808 & 1,842 & nd & 7,400 & 97,600 & 1,074 \\
Ponte caída & 6,320 & 2,213 & 9,372 & 5,400 & 188,800 & 3,053 \\
Cancan & 1,640 & 4,250 & nd & 9,600 & 132,400 & 1,094 \\
Serra & 0,742 & 0,341 & 11,766 & 3,400 & 133,400 & 2,081 \\
Foz & 1,926 & 1,213 & 8,646 & 19,200 & 208,000 & 4,198 \\
\hline
\end{tabular}


Tabela 20. Concentrações de metais na água do rio Monjolinho em abril/ 04 .

\begin{tabular}{|c|c|c|c|c|c|c|}
\hline Outubro.03 & $\mathrm{Cr}$ & Cd & $\begin{array}{c}\mathrm{Cu} \\
\text { pg.L. }\end{array}$ & $\mathrm{Zn}$ & Mn & $\begin{array}{c}\text { Fe } \\
\text { mg. } \text { L }^{-1}\end{array}$ \\
\hline Nascente & 2,100 & nd & nd & 3,000 & 8,600 & 0,124 \\
\hline Federal & 0,454 & 0,179 & nd & 2,400 & 7,200 & 0,112 \\
\hline USP & 1,052 & nd & nd & 2,200 & 7,000 & 0,170 \\
\hline Usina & 9,097 & 0,417 & 4,916 & 4,400 & 8,400 & 0,342 \\
\hline P.caída & 5,970 & 0,337 & 2,216 & 4,800 & 12,400 & 0,310 \\
\hline Foz & 4,448 & 0,355 & 1,744 & 4,600 & 22,200 & 0,415 \\
\hline
\end{tabular}

nd = não detectado

Tabela 23. Concentrações de clorofila a ( $\left.\mu g . L^{-1}\right)$ na água durante o período de estudo.

\begin{tabular}{lccccc}
\hline Estações & Março/ 03 & Julho/ 03 & Outubro/ 03 & Janeiro/ 04 & Abril/ 04 \\
\hline Nascente & 3,14 & 0,00 & 2,79 & 3,25 & 0,93 \\
Federal & 10,11 & 85,09 & 39,99 & 25,11 & 29,76 \\
Madalena & 34,88 & 1,12 & $\mathrm{nc}$ & 3,72 & $\mathrm{nc}$ \\
Tijuco & 4,38 & 38,01 & $\mathrm{nc}$ & 65,56 & $\mathrm{nc}$ \\
USP & 4,78 & 19,18 & 17,67 & 0,00 & 11,16 \\
Mineirinho & 2,79 & 0,28 & $\mathrm{nc}$ & 9,30 & $\mathrm{nc}$ \\
Gregónio & 3,07 & 7,67 & $\mathrm{nc}$ & 42,32 & $\mathrm{nc}$ \\
Usina & 3,72 & 11,16 & 7,44 & 10,23 & 39,99 \\
A. Quente & 5,58 & 18,83 & $\mathrm{nc}$ & 16,04 & $\mathrm{nc}$ \\
A. Fria & 2,79 & 1,12 & $\mathrm{nc}$ & 3,72 & $\mathrm{nc}$ \\
P. caída & 9,07 & 6,28 & 4,65 & 16,74 & 9,30 \\
Cancan & 1,74 & 7,47 & $\mathrm{nc}$ & 7,44 & $\mathrm{nc}$ \\
Serra & 3,84 & 6,20 & $\mathrm{nc}$ & 7,44 & $\mathrm{nc}$ \\
Foz & 4,65 & 6,70 & 3,26 & 13,49 & 10,70 \\
\hline
\end{tabular}

nc = estação não coletada

Tabela 25. Variação do pH no rio Monjolinho e tributários durante o período de estudo.

\begin{tabular}{lccccc}
\hline Estações & Março/ 03 & Julho/ 03 & 0 utubro/ 03 & Janeiro/ 04 & Abril/ 04 \\
\hline Nascente & 4,64 & 5,65 & 6,13 & 4,77 & 5,29 \\
Federal & 4,61 & 5,76 & 6,63 & 5,54 & 5,93 \\
Madalena & 4,17 & 5,69 & $\mathrm{nc}$ & 5,06 & $\mathrm{nc}$ \\
Tijuco & 6,61 & 6,98 & $\mathrm{nc}$ & 7,70 & $\mathrm{nc}$ \\
USP & 4,41 & 6,97 & 6,69 & 6,56 & 6,15 \\
Mineirinho & 5,23 & 7,04 & $\mathrm{nc}$ & 6,78 & $\mathrm{nc}$ \\
Gregónio & 6,10 & 7,27 & $\mathrm{nc}$ & 7,06 & $\mathrm{nc}$ \\
Usina & 5,78 & 7,42 & 6,95 & 6,92 & 6,48 \\
A. Quente & 5,62 & 7,47 & $\mathrm{nc}$ & 6,99 & $\mathrm{nc}$ \\
A. Fria & 7,10 & 7,47 & $\mathrm{nc}$ & 6,07 & $\mathrm{nc}$ \\
P. caída & 5,10 & 7,12 & 6,65 & 6,82 & 6,49 \\
Cancan & 5,90 & 7,35 & $\mathrm{nc}$ & 6,46 & $\mathrm{nc}$ \\
Serra & 5,26 & 7,27 & $\mathrm{nc}$ & 6,45 & $\mathrm{nc}$ \\
Foz & 5,56 & 7,14 & 6,70 & 7,35 & 6,20 \\
\hline
\end{tabular}

nc = estação não coletada 
D ornfeld, C.B. (2006). U tilização de Chironomus sp (D iptera, Chironomidae)...

Tabela 26. Variação da condutividade $\left(\mu \mathrm{S} . \mathrm{cm}^{-1}\right)$ no rio Monjolinho e tributários durante o peńodo de estudo.

\begin{tabular}{lccccc}
\hline Estaçóes & Março/ 03 & Julho/ 03 & Outubro/ 03 & Janeiro/ 04 & Abril/ 04 \\
\hline Nascente & 19 & 10 & 8 & 8 & 8 \\
Federal & 32 & 47 & 58 & 57 & 34 \\
Madalena & 18 & 23 & $\mathrm{nc}$ & 22 & $\mathrm{nc}$ \\
Tijuco & 244 & 193 & $\mathrm{nc}$ & 158 & $\mathrm{nc}$ \\
USP & 29 & 77 & 66 & 71 & 33 \\
Mineirinho & 29 & 53 & $\mathrm{nc}$ & 39 & $\mathrm{nc}$ \\
Gregónio & 126 & 290 & $\mathrm{nc}$ & 229 & $\mathrm{nc}$ \\
Usina & 66 & 138 & 111 & 106 & 68 \\
A. Quente & 182 & 212 & $\mathrm{nc}$ & 164 & $\mathrm{nc}$ \\
A. Fria & 32 & 20 & $\mathrm{nc}$ & 17 & $\mathrm{nc}$ \\
P. caída & 392 & 165 & 159 & 185 & 115 \\
Cancan & 34 & 32 & $\mathrm{nc}$ & 28 & $\mathrm{nc}$ \\
Serra & 29 & 59 & $\mathrm{nc}$ & 43 & $\mathrm{nc}$ \\
Foz & 97 & 179 & 168 & 156 & 116 \\
\hline
\end{tabular}

nc = estação não coletada

Tabela 27. Variação da temperatura da água $\left({ }^{\circ} \mathrm{C}\right)$ no rio Monjolinho e tributários durante o peńodo de estudo.

\begin{tabular}{lccccc}
\hline Estaç̃oes & Março/ 03 & Julho/ 03 & Outubro/ 03 & Janeiro/ 04 & Abril/ 04 \\
\hline Nascente & 20,9 & 18,6 & 21,7 & 20,4 & 21,0 \\
Federal & 22,7 & 21,3 & 22 & 25,2 & 23,0 \\
Madalena & 21,6 & 17,5 & $\mathrm{nc}$ & 21,2 & $\mathrm{nc}$ \\
Tijuco & 23,6 & 21,1 & $\mathrm{nc}$ & 22,1 & $\mathrm{nc}$ \\
USP & 22,3 & 20,9 & 21,2 & 22,4 & 22,3 \\
Mineirinho & 21,9 & 19,7 & $\mathrm{nc}$ & 21,2 & $\mathrm{nc}$ \\
Gregónio & 23,1 & 22,4 & $\mathrm{nc}$ & 24,1 & $\mathrm{nc}$ \\
Usina & 22,9 & 21,8 & 20,6 & 22,8 & 21,7 \\
A. Quente & 22,7 & 23,8 & $\mathrm{nc}$ & 22,0 & $\mathrm{nc}$ \\
A. Fria & 22,6 & 19,9 & $\mathrm{nc}$ & 22,3 & $\mathrm{nc}$ \\
P. caída & 23,1 & 19,1 & 19,5 & 22,9 & 21,1 \\
Cancan & 24,1 & 19,6 & $\mathrm{nc}$ & 22,4 & $\mathrm{nc}$ \\
Serra & 24,3 & 19,6 & $\mathrm{nc}$ & 22,7 & $\mathrm{nc}$ \\
Foz & 24,1 & 20,4 & 18,4 & 24,0 & 20,6 \\
\hline
\end{tabular}

$\mathrm{nc}=$ estação não coletada

Tabela 28. Variação da concentração de oxigênio dissolvido na água (mg.L-1) do rio Monjolinho e tributánios durante 0 período de estudo.

\begin{tabular}{lccccc}
\hline Estaçóes & Março/ 03 & Julho/ 03 & Outubro/ 03 & Janeiro/ 04 & Abril/ 04 \\
\hline Nascente & 6,72 & 7,87 & 6,48 & 8,07 & 8,83 \\
Federal & 6,65 & 6,31 & 2,70 & 3,29 & 7,52 \\
Madalena & 6,77 & 7,71 & $\mathrm{nc}$ & 6,41 & $\mathrm{nc}$ \\
Tijuco & 7,42 & 8,26 & $\mathrm{nc}$ & 8,41 & $\mathrm{nc}$ \\
USP & 7,22 & 4,38 & 4,66 & 6,54 & 7,48 \\
Mineininho & 8,09 & 8,66 & $\mathrm{nc}$ & 8,38 & $\mathrm{nc}$ \\
Gregónio & 5,08 & 3,70 & $\mathrm{nc}$ & 7,15 & $\mathrm{nc}$ \\
Usina & 7,19 & 6,15 & 6,70 & 6,46 & 4,07 \\
A. Quente & 4,38 & 5,27 & $\mathrm{nc}$ & 6,97 & $\mathrm{nc}$ \\
A. Fria & 7,48 & 7,92 & $\mathrm{nc}$ & 6,94 & $\mathrm{nc}$ \\
P. caída & 3,82 & 3,59 & 3,66 & 1,56 & 4,29 \\
Cancan & 8,10 & 11,87 & $\mathrm{nc}$ & 8,71 & $\mathrm{nc}$ \\
Serra & 5,73 & 17,18 & $\mathrm{nc}$ & 6,16 & $\mathrm{nc}$ \\
Foz & 6,13 & 7,03 & 7,08 & 7,11 & 8,03 \\
\hline
\end{tabular}

nc = estação não coletada 
Tabela 29. Porcentagem de matéria orgânica no sedimento durante o período de estudo.

\begin{tabular}{lccccc}
\hline Estações & Março/ 03 & Julho/ 03 & Outubro/ 03 & Janeiro/ 04 & Abril/ 04 \\
\hline Nascente & 8,07 & 0,40 & 0,39 & 0,19 & 0,21 \\
Federal & 3,50 & 2,15 & 2,62 & 0,63 & 3,53 \\
Madalena & 3,49 & 1,57 & $\mathrm{nc}$ & & $\mathrm{nc}$ \\
Tijuco & 0,00 & 1,97 & $\mathrm{nc}$ & 0,32 & $\mathrm{nc}$ \\
USP & 0,90 & 0,31 & 0,06 & 0,18 & 1,65 \\
Mineirinho & 1,08 & 0,12 & $\mathrm{nc}$ & 0,34 & $\mathrm{nc}$ \\
Usina & 0,10 & 5,50 & 0,17 & 0,35 & $\mathrm{nc}$ \\
A. Q uente & 0,10 & 0,40 & $\mathrm{nc}$ & 0,20 & $\mathrm{nc}$ \\
A. Fria & 0,20 & 0,05 & $\mathrm{nc}$ & 0,18 & $\mathrm{nc}$ \\
P. caída & 10,75 & 1,04 & 0,13 & 0,14 & 0,34 \\
Foz & 0,13 & 4,95 & 3,49 & 0,61 & 0,64 \\
\hline
\end{tabular}

nc = estação não coletada

Tabela 30. Concentração de fósforo total $\left(\mu \mathrm{g} \cdot \mathrm{g}^{-1}\right)$ no sedimento durante o período de estudo.

\begin{tabular}{lccccc}
\hline Estações & Março/ 03 & Julho/ 03 & Outubro/ 03 & Janeiro/ 04 & Abril/ 04 \\
\hline Nascente & 287,39 & 58,78 & 17,53 & 35,92 & 16,85 \\
Federal & 332,11 & 198,76 & 396,75 & 174,17 & 478,81 \\
Madalena & 261,71 & 169,77 & $\mathrm{nc}$ & 0,00 & $\mathrm{nc}$ \\
Tijuco & 0,00 & 487,83 & $\mathrm{nc}$ & 51,86 & $\mathrm{nc}$ \\
USP & 164,80 & 124,22 & 74,56 & 64,66 & 243,66 \\
Mineirinho & 82,80 & 51,33 & $\mathrm{nc}$ & 46,28 & $\mathrm{nc}$ \\
Usina & 108,48 & 168,94 & 33,92 & 97,00 & $\mathrm{nc}$ \\
A. Quente & 60,44 & 53,82 & $\mathrm{nc}$ & 22,88 & $\mathrm{nc}$ \\
A. Fria & 23,17 & 19,03 & $\mathrm{nc}$ & 18,98 & $\mathrm{nc}$ \\
P. caída & 130,84 & 349,51 & 21,62 & 52,68 & 162,68 \\
Foz & 86,12 & 649,35 & 794,60 & 294,29 & 469,29 \\
\hline
\end{tabular}

nc = estação não coletada

Tabela 31. Porcentagem de nitrogênio orgânico total no sedimento durante o peńodo de estudo.

\begin{tabular}{lccccc}
\hline Estações & Março/ $\mathbf{~ 0 3}$ & Julho/ $\mathbf{~ 0 3}$ & $\mathbf{0 u t u b r o / ~ 0 3}$ & Janeiro/ 04 & Abril/ 04 \\
\hline Nascente & 0,22 & 0,04 & 0,01 & 0,00 & 0,01 \\
Federal & 0,11 & 0,08 & 0,06 & 0,03 & 0,17 \\
Madalena & 0,05 & 0,06 & $\mathrm{nc}$ & 0,00 & $\mathrm{nc}$ \\
Tijuco & 0,00 & 0,06 & $\mathrm{nc}$ & 0,02 & $\mathrm{nc}$ \\
USP & 0,01 & 0,02 & 0,01 & 0,01 & 0,06 \\
Mineininho & 0,02 & 0,02 & $\mathrm{nc}$ & 0,02 & $\mathrm{nc}$ \\
Usina & 0,01 & 0,02 & 0,01 & 0,03 & $\mathrm{nc}$ \\
A. Quente & 0,01 & 0,01 & $\mathrm{nc}$ & 0,01 & $\mathrm{nc}$ \\
A. Fria & 0,01 & 0,02 & $\mathrm{nc}$ & 0,01 & $\mathrm{nc}$ \\
P. caída & 0,01 & 0,04 & 0,01 & 0,01 & 0,03 \\
Foz & 0,01 & 0,13 & 0,26 & 0,04 & 0,04 \\
\hline
\end{tabular}

nc = estação não coletada

Tabela 32. Valores do potencial redox $(\mathrm{mV})$ do sedimento durante o período de estudo.

\begin{tabular}{lcccc}
\hline Estações & Julho/ 03 & Outubro/ 03 & Janeiro/ 04 & Abril/ 04 \\
\hline Nascente & 269,00 & 130,00 & 22,00 & 270,00 \\
Federal & $-201,00$ & $-177,00$ & $-1,00$ & $-194,00$ \\
Madalena & 57,00 & $\mathrm{nc}$ & 0,00 & $\mathrm{nc}$ \\
Tijuco & $-210,00$ & $\mathrm{nc}$ & $-34,00$ & $\mathrm{nc}$ \\
USP & $-45,00$ & $-77,00$ & $-1,00$ & 16,00 \\
Mineirinho & 26,00 & $\mathrm{nc}$ & $-24,00$ & $\mathrm{nc}$ \\
Usina & $-164,00$ & $-150,00$ & 9,00 & $\mathrm{nc}$ \\
A. Quente & $-92,00$ & $\mathrm{nc}$ & $-7,00$ & $\mathrm{nc}$ \\
A. Fria & 133,00 & $\mathrm{nc}$ & 29,00 & $\mathrm{nc}$ \\
P. caída & $-143,00$ & 26,00 & 31,00 & $-150,00$ \\
Foz & $-189,00$ & $-192,00$ & 5,00 & $-169,00$ \\
\hline
\end{tabular}

nc = estação não coletada 
Legenda das Tabelas 33 a 37: $\mathbf{P M F}=$ pedregulho muito fino; $\mathbf{A G}=$ areia grossa; $\mathbf{A M}=$ areia média; $\mathbf{A F}=$ areia fina e $\mathbf{S}+\mathbf{A}=$ silte mais argila.

Tabela 33. Porcentagens das frações granulométricas em março/ 03.

\begin{tabular}{lccccc}
\hline Estações & PMF & AG & AM & AF & S+A \\
\hline Nascente & 0,00 & 25,00 & 13,60 & 6,50 & 55,80 \\
Federal & 0,00 & 16,30 & 56,70 & 2,80 & 24,20 \\
Madalena & 0,00 & 33,10 & 24,90 & 7,50 & 32,30 \\
USP & 0,72 & 26,93 & 24,89 & 43,84 & 3,62 \\
Mineininho & 1,85 & 73,93 & 12,74 & 10,90 & 0,58 \\
Usina & 0,00 & 60,90 & 24,90 & 13,66 & 0,54 \\
A. Quente & 2,50 & 51,09 & 19,25 & 26,90 & 0,26 \\
A. Fria & 0,50 & 23,64 & 19,90 & 53,71 & 2,25 \\
P. caída & 0,00 & 6,05 & 16,97 & 72,62 & 4,36 \\
Foz & 0,00 & 12,02 & 29,22 & 58,33 & 0,43 \\
\hline
\end{tabular}

Tabela 34. Porcentagens das frações granulométricas em julho/ 03.

\begin{tabular}{lccccc}
\hline Estaçóes & PMF & AG & AM & AF & S+A \\
\hline Nascente & 3,03 & 22,13 & 42,00 & 32,71 & 0,13 \\
Federal & 0,00 & 22,30 & 56,70 & 4,10 & 17,50 \\
Madalena & 0,00 & 38,60 & 36,00 & 3,80 & 21,60 \\
Tijuco & 62,86 & 20,39 & 11,72 & 4,77 & 0,26 \\
USP & 20,77 & 32,94 & 33,62 & 12,52 & 0,15 \\
Mineininho & 6,74 & 41,32 & 37,68 & 14,21 & 0,02 \\
Usina & 2,65 & 46,32 & 38,03 & 12,10 & 0,90 \\
A. Quente & 10,31 & 8,55 & 33,62 & 47,22 & 0,30 \\
A. Fria & 0,00 & 6,19 & 27,44 & 64,73 & 1,63 \\
P. caída & 0,00 & 1,80 & 73,20 & 7,40 & 16,80 \\
Foz & 0,00 & 1,00 & 5,20 & 64,10 & 29,70 \\
\hline
\end{tabular}

Tabela 35. Porcentagens das frações granulométricas em outubro/ 03.

\begin{tabular}{lccccc}
\hline Estações & PMF & AG & AM & AF & S+A \\
\hline Nascente & 1,93 & 14,75 & 37,63 & 45,27 & 0,42 \\
Federal & 0,00 & 3,60 & 26,40 & 50,30 & 18,90 \\
USP & 1,42 & 72,23 & 25,84 & 0,47 & 0,04 \\
Usina & 0,33 & 18,23 & 57,53 & 23,71 & 0,20 \\
P. caída & 0,04 & 8,72 & 42,56 & 48,40 & 0,28 \\
Foz & 0,00 & 11,00 & 24,70 & 48,00 & 16,30 \\
\hline
\end{tabular}

Tabela 36. Porcentagens das frações granulométricas em janeiro/ 04.

\begin{tabular}{lccccc}
\hline Estações & PMF & AG & AM & AF & S+A \\
\hline Nascente & 0,29 & 18,26 & 50,25 & 30,97 & 0,21 \\
Federal & 0,00 & 2,50 & 51,00 & 36,20 & 10,30 \\
Tijuco & 1,11 & 16,36 & 48,46 & 33,12 & 0,93 \\
USP & 16,80 & 35,53 & 39,48 & 8,05 & 0,05 \\
Mineininho & 0,00 & 25,00 & 58,00 & 8,00 & 9,00 \\
Usina & 5,24 & 32,08 & 45,91 & 16,27 & 0,46 \\
Á. Quente & 0,41 & 16,95 & 45,84 & 36,69 & 0,12 \\
Á. Fria & 0,26 & 4,40 & 48,36 & 46,22 & 0,74 \\
P. caída & 3,11 & 10,48 & 37,37 & 48,97 & 0,04 \\
Foz & 0,00 & 0,00 & 35,00 & 58,50 & 5,30 \\
\hline
\end{tabular}

Tabela 37. Porcentagens das frações granulométricas em abril/ 04.

\begin{tabular}{lccccc}
\hline Estações & PMF & AG & AM & AF & S+A \\
\hline Nascente & 0,06 & 5,06 & 47,74 & 46,75 & 0,20 \\
Federal & 1,90 & 16,80 & 51,30 & 9,00 & 21,00 \\
USP & 9,00 & 41,00 & 32,70 & 3,60 & 13,80 \\
P. caída & 0,00 & 0,45 & 19,69 & 79,33 & 0,47 \\
Foz & 0,00 & 3,30 & 89,80 & 4,10 & 2,80
\end{tabular}


Tabela 1. Teste de Sensibilidade de Chironomus x anthus ao Cloreto de Potássio em 11/ 04/ 03.

DATE $11 / 04 / 03 \quad$ TEST NUMBER $1 \quad$ DURATION $96 \mathrm{~h}$

CHEMICAL Cloreto de potássio SPECIES Chironomus xanthus

RAW DATA

CO NCENTRATIO N(g/L) $\quad 1.50 \quad 2.25 \quad 3.50 \quad 5.00 \quad 7.50$

$\begin{array}{llllll}\text { NUMBER EXPOSED } & 18 & 18 & 18 & 18 & 18\end{array}$

$\begin{array}{llllll}\text { MORTALITIES } & 1 & 6 & 5 & 8 & 18\end{array}$

SPEARMAN-KARBER TRIM $\quad 5.56$

SPEARMAN-KARBER ESTIMATE S LC $50 \quad \underline{\mathbf{4 . 0 6 5 7 8 5 9}}$

95\% LOWER CO NFIDE NCE $\quad 3.41$

95\% UPPER CONFIDENCE $\quad 4.85$

Note: Mortality proportions were not monotonically increasing adjustments were made prior to Spearmankarber estimation.

Tabela 2. Teste de Sensibilidade de Chironomus x anthus ao Cloreto de Potássio em 06/ 06/ 03.

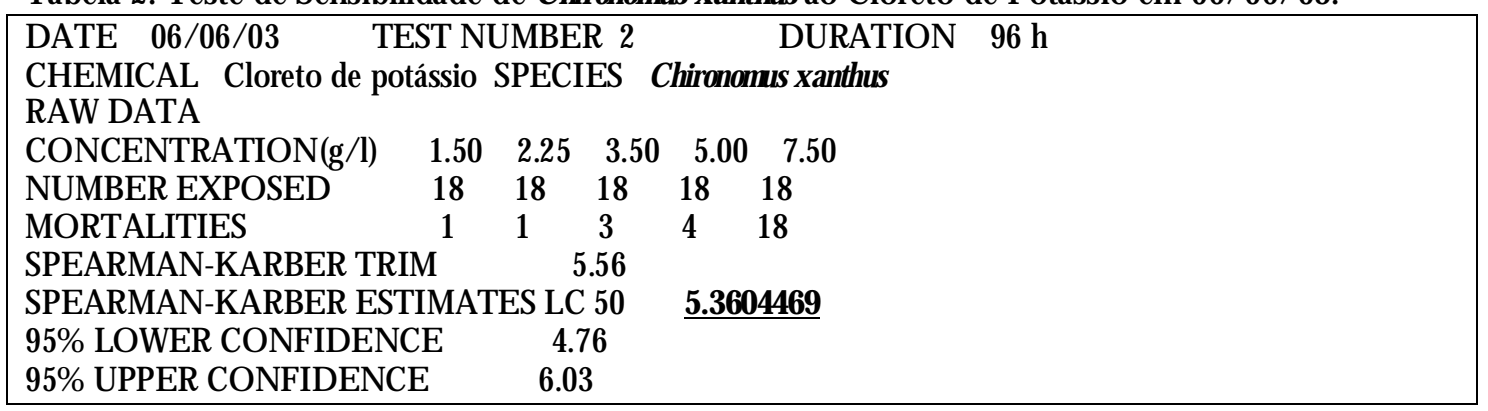

Tabela 3. Teste de Sensibilidade de Chironomus x anthus ao Cloreto de Potássio em 21/ 08/ 03.

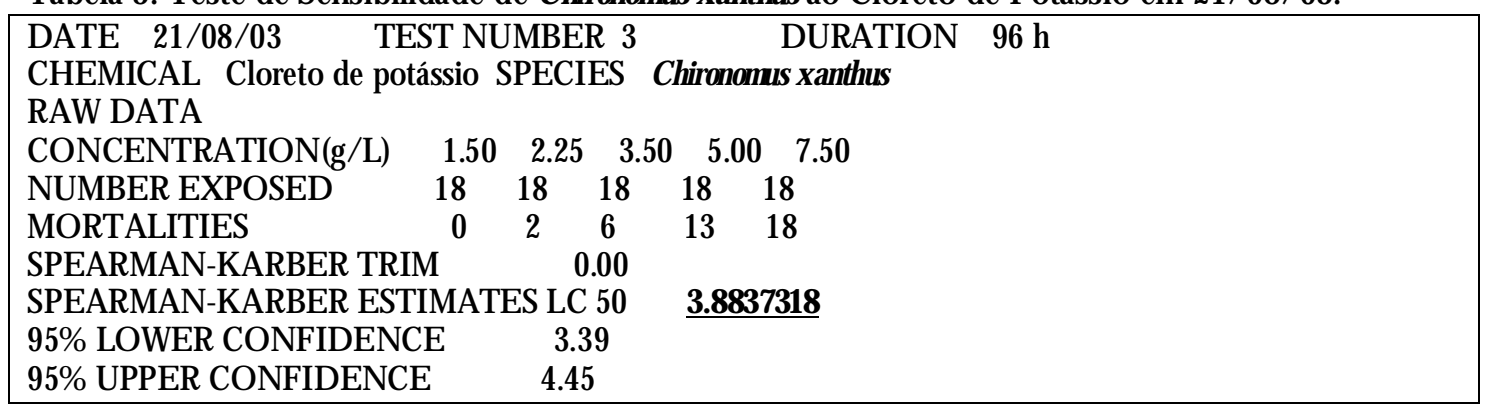

Tabela 4. Teste de Sensibilidade de Chironomus xanthus ao Cloreto de Potássio em 12/ 10/ 03.

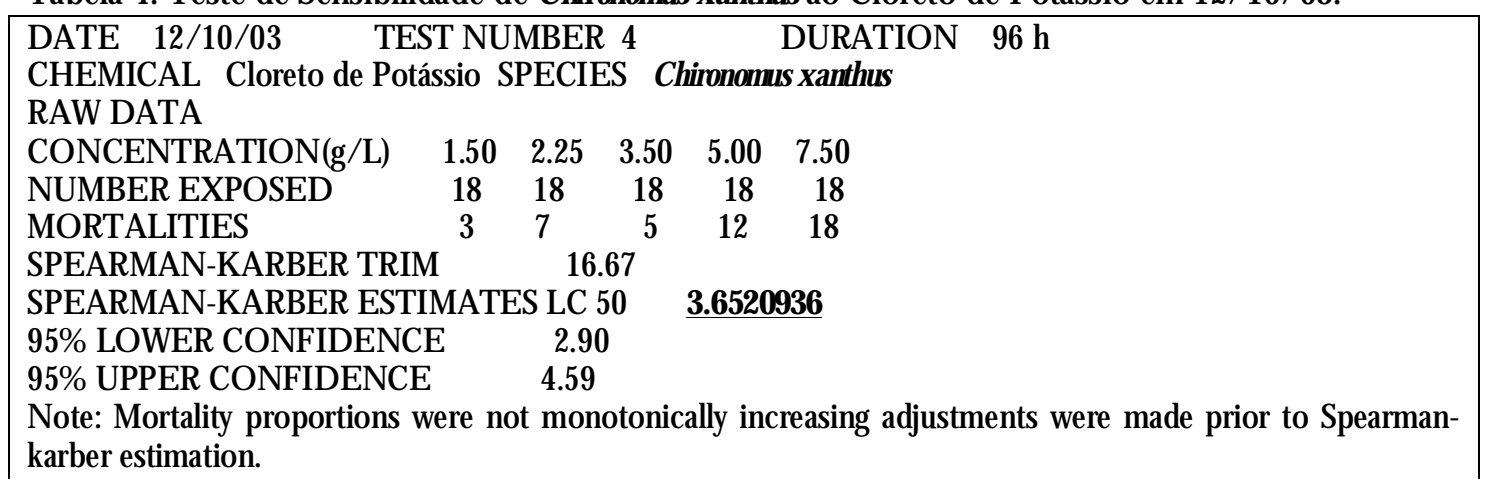


Tabela 5. Teste de Sensibilidade de Chironomus x anthus ao Cloreto de Potássio em 23/ 01/ 04.

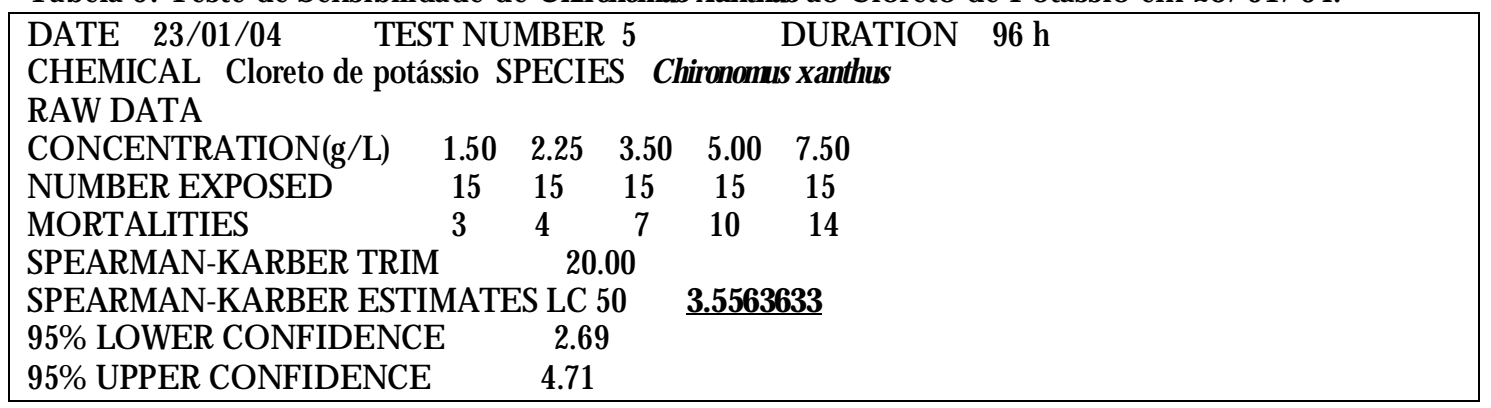

Tabela 6. Teste de Sensibilidade de Chironomus x anthus ao Cloreto de Potássio em 14/ 05/ 04.

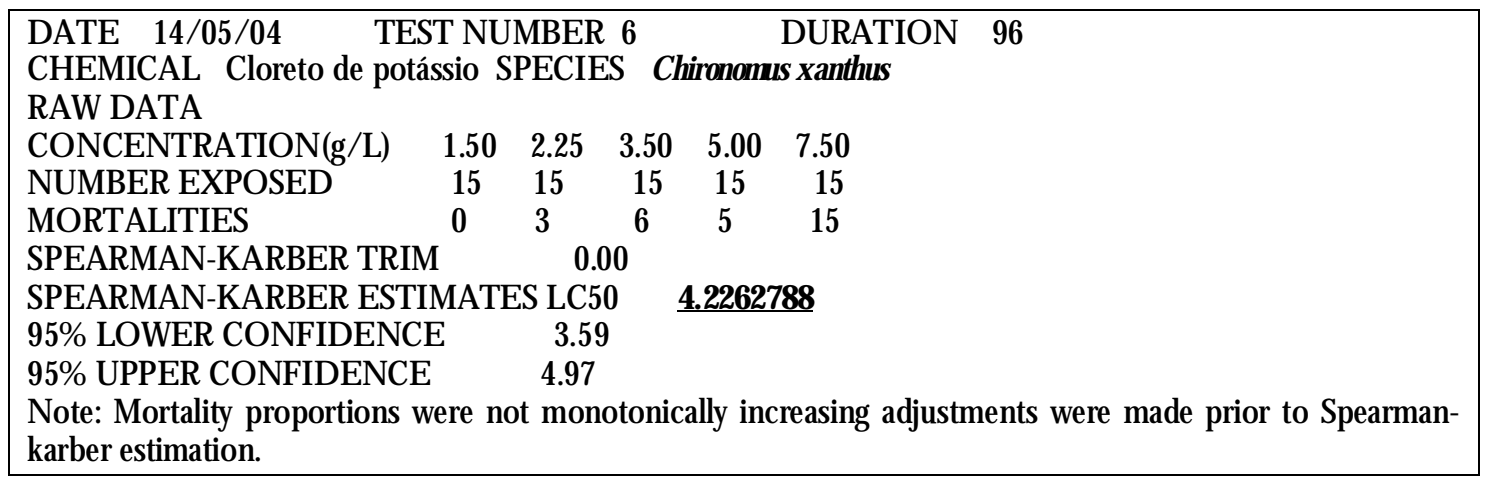

Tabela 7. Teste de Sensibilidade de Chironomus x anthus ao Cloreto de Potássio em 25/ 11/ 04.

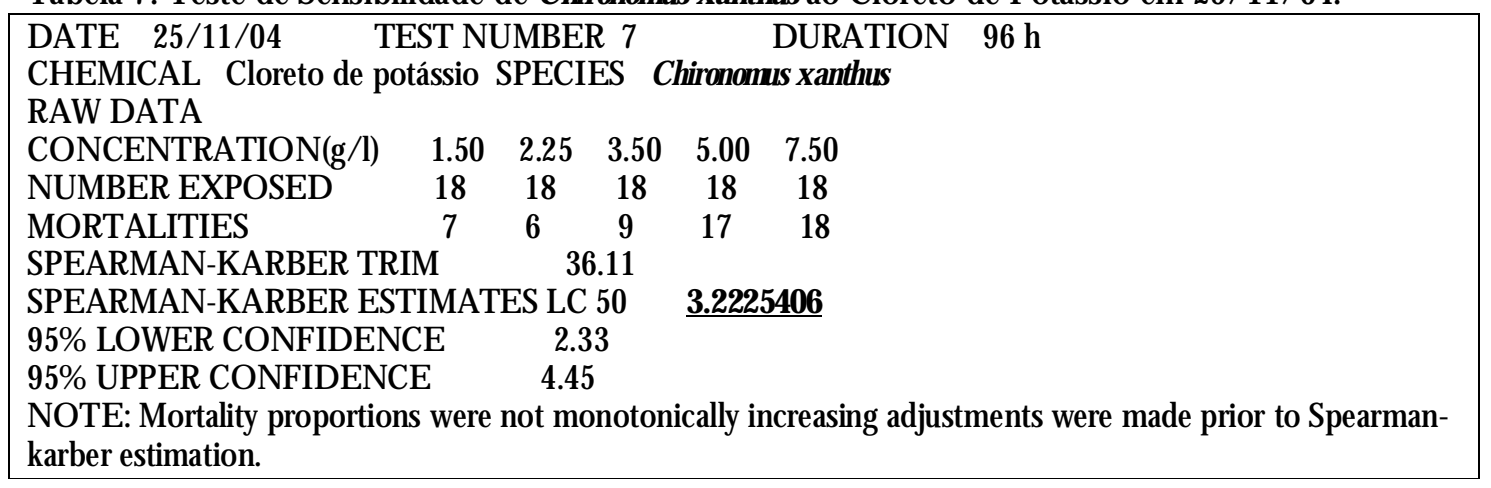

Tabela 8. Resultados dos testes de sensibilidade ao Cloreto de Potássio $(\mathrm{KCl})$ realizados com C. $\mathrm{x}$ anthus, expresso em g.L-1 de $\mathrm{KCl}$.

\begin{tabular}{ccccc}
\hline No do Teste & Data & CL $_{\mathbf{5 0}}$ & Lim. Inferior & Lim. Superior \\
\hline 1 & $11 / 04 / 03$ & 4,06 & 3,41 & 4,85 \\
2 & $06 / 06 / 03$ & 5,36 & 4,76 & 6,03 \\
3 & $21 / 08 / 03$ & 3,85 & 3,39 & 4,45 \\
4 & $12 / 10 / 03$ & 3,65 & 2,9 & 4,59 \\
5 & $23 / 01 / 04$ & 3,55 & 2,69 & 4,71 \\
6 & $14 / 05 / 04$ & 4,22 & 3,59 & 4,97 \\
7 & $25 / 11 / 04$ & 3,22 & 2,33 & 4,55 \\
\hline \multicolumn{7}{r}{} & Média & $\mathbf{4 , 3 5}$ & $\mathbf{3 , 7 0}$ & $\mathbf{5 , 1 6}$ \\
\hline
\end{tabular}


Tabela 10. Porcentagem de mortalidade de $C$. xanthus durante o período estudado.

\begin{tabular}{|c|c|c|c|c|c|}
\hline$\%$ Mortalidade & mar/ 03 & jul/ 03 & out/ 03 & jan/ 04 & abr/ 04 \\
\hline Controle & 0 & 5,5 & 5,5 & 11 & 11 \\
\hline Nascente & 16,6 & 5,5 & 5,5 & 5,5 & 0 \\
\hline Federal & 16,6 & 5,5 & $100^{*}$ & 0 & 5,5 \\
\hline Madalena & 5,5 & 11,1 & - & - & 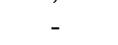 \\
\hline Tijuco & - & 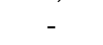 & 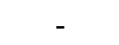 & $27,7^{*}$ & - \\
\hline USP & 11,1 & $38,8^{*}$ & 16,6 & 16,6 & 5,5 \\
\hline Mineininho & 5,5 & 0 & - & 0 & - \\
\hline Usina & 11,1 & $50^{*}$ & 5,5 & 0 & - \\
\hline Á. Quente & 5,5 & 5,5 & - & 11,1 & - \\
\hline Á. Fria & 5,5 & 5,5 & - & $27,7^{*}$ & - \\
\hline P. caída & 5,5 & 11,1 & $33,3^{*}$ & 0 & 5,5 \\
\hline Serra & $33,3^{*}$ & 5,5 & - & 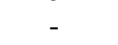 & - \\
\hline Foz & 5,5 & 5,5 & ? & $22,2^{*}$ & 0 \\
\hline
\end{tabular}

- sedimento não coletado; ? sedimento com muitos quironomídeos e, portanto, o bioensaio não foi realizado;

* - indícios de toxicidade (10-40\%) ou toxicidade aguda (> 40\%).

Tabela 11. Análise estatística de Fisher (TOXSTAT 3.4) do bioensaio de toxicidade aguda do sedimento do rio Monjolinho e tributários em março/ 03.

\begin{tabular}{|l|l|c|c|c|}
\hline \multicolumn{5}{|l|}{ SUMMARY OF FISHER'S EXACT TEST S } \\
\hline Number Group & Number Identification & SIG Exposed & Dead & $\mathrm{p}=0,05$ \\
\hline & Controle & 18 & 0 & \\
\hline 1 & Nascente & 18 & 3 & \\
\hline 2 & Federal & 18 & 3 & \\
\hline 3 & Madalena & 18 & 1 & \\
\hline 4 & USP & 18 & 2 & \\
\hline 5 & Mineirinho & 18 & 1 & \\
\hline 6 & Usina & 18 & 2 & \\
\hline 7 & A.Quente & 18 & 1 & \\
\hline 8 & A.Fria & 18 & 1 & \\
\hline 9 & Ponte Caída & 18 & 1 & \\
\hline 10 & Serra & 18 & 6 & $*$ \\
\hline 11 & Foz & 18 & 1 & \\
\hline$*$ diferença significativa em comparação com o Controle & & \\
\hline
\end{tabular}

Tabela 12. Análise estatística de Fisher (TOXSTAT 3.4) do bioensaio de toxicidade aguda do sedimento do rio Monjolinho e tributários em julho/ 03.

\begin{tabular}{|l|l|c|c|c|}
\hline \multicolumn{5}{|l|}{ SUMMARY OF FISHER'S EXACT TEST S } \\
\hline Number Group & Number Identification & SIG Exposed & Dead & $\mathrm{p}=0,05$ \\
\hline & Controle & 18 & 0 & \\
\hline 1 & Nascente & 18 & 1 & \\
\hline 2 & Federal & 18 & 1 & \\
\hline 3 & Tijuco & 18 & 2 & \\
\hline 4 & Madalena & 18 & 2 & \\
\hline 5 & USP & 18 & 7 & $*$ \\
\hline 6 & Mineirinho & 18 & 0 & $*$ \\
\hline 7 & Usina & 18 & 9 & $*$ \\
\hline 8 & A.Quente & 18 & 1 & \\
\hline 9 & A.Fria & 18 & 1 & \\
\hline 10 & Ponte Caída & 18 & 2 & \\
\hline 11 & Cancan & 18 & 0 & \\
\hline 12 & Serra & 18 & 1 & \\
\hline 13 & Foz & 18 & \\
\hline$*$ diferença significativa em comparação com o Controle & & \\
\hline
\end{tabular}


Tabela 13. Análise estatística de Fisher (TOXSTAT 3.4) do bioensaio de toxicidade aguda do sedimento do rio Monjolinho e tributários em outubro/ 03.

\begin{tabular}{|l|l|c|c|c|}
\hline \multicolumn{5}{|l|}{ SUMMARY OF FISHER'S EXACT TEST S } \\
\hline Number G roup & Number Identification & SIG Exposed & Dead & $\mathrm{p}=0,05$ \\
\hline & Controle & 18 & 1 & \\
\hline 1 & Nascente & 18 & 1 & $*$ \\
\hline 2 & Federal & 18 & 18 & $*$ \\
\hline 3 & USP & 18 & 3 & \\
\hline 4 & Usina & 18 & 1 & $*$ \\
\hline 5 & Ponte Caída & 18 & 6 & \\
\hline * diferença significativa em comparação com o Controle \\
\hline
\end{tabular}

Tabela 14. Análise estatística de Fisher (TOXSTAT 3.4) do bioensaio de toxicidade aguda do sedimento do rio Monjolinho e tributários em janeiro/ 04.

\begin{tabular}{|l|l|c|c|c|}
\hline \multicolumn{5}{|l|}{ SUMMARY OF FISHER'S EXACT TEST S } \\
\hline Number Group & Number Identification & SIG Exposed & Dead & $\mathrm{p}=0,05$ \\
\hline & Controle & 18 & 2 & \\
\hline 1 & Nascente & 18 & 1 & \\
\hline 2 & Federal & 18 & 0 & \\
\hline 3 & Tijuco & 18 & 5 & \\
\hline 4 & USP & 18 & 3 & \\
\hline 5 & Mineininho & 18 & 0 & \\
\hline 6 & Usina & 18 & 0 & \\
\hline 7 & A.Quente & 18 & 2 & \\
\hline 8 & A.Fria & 18 & 5 & \\
\hline 9 & Ponte Caída & 18 & 0 & \\
\hline 10 & Foz & 18 & 4 & \\
\hline
\end{tabular}

Tabela 15. Análise estatística de Fisher (TOXSTAT 3.4) do bioensaio de toxicidade aguda do sedimento do rio Monjolinho e tributários em abril/ 04.

\begin{tabular}{|l|l|c|c|c|}
\hline \multicolumn{5}{|l|}{ SUMMARY OF FISHER'S EXACT TEST S } \\
\hline Number Group & Number Identification & SIG Exposed & Dead & $\mathrm{p}=0,05$ \\
\hline & Controle & 18 & 2 & \\
\hline 1 & Nascente & 18 & 0 & \\
\hline 2 & Federal & 18 & 1 & \\
\hline 3 & USP & 18 & 1 & \\
\hline 4 & Ponte Caída & 18 & 1 & \\
\hline 5 & Foz & 18 & 0 & \\
\hline
\end{tabular}


Tabela 16. Correlação de Pearson em março de 2003.

\begin{tabular}{|c|c|c|c|c|c|c|c|c|c|c|c|c|c|c|}
\hline \multirow{3}{*}{ Cloreto } & água & & sedimento & & & & & & & & \multicolumn{3}{|c|}{ Jágua } & mortalidade \\
\hline & Cloreto & Sulfeto & $\mathrm{Cr}$ & $\mathrm{Cd}$ & $\mathrm{Cu}$ & $\overline{Z n}$ & $\overline{M n}$ & $\overline{\mathrm{Fe}}$ & PT & NOT & $\mathrm{MO}$ & $\overline{\mathrm{PT}}$ & $\overline{\mathrm{NH} 4}$ & \%C.lab \\
\hline & & & & & & & & & & & & & & \\
\hline $\begin{array}{l}\text { Sulfeto } \\
\mathrm{Cr}\end{array}$ & $\begin{array}{r}\mathbf{0 , 6 1 5 7 0 8} \\
-0,280593\end{array}$ & $\begin{array}{r}1 \\
0343629\end{array}$ & & & & & & & & & & & & \\
\hline $\begin{array}{l}\mathrm{Cr} \\
\mathrm{Cd}\end{array}$ & $\begin{array}{l}-0,280593 \\
-0,243183\end{array}$ & $\begin{array}{r}0,343629 \\
-0,010355\end{array}$ & -0.065502 & 1 & & & & & & & & & & \\
\hline $\mathrm{Cu}$ & $\begin{array}{l}-0,243183 \\
-0,319416\end{array}$ & 0,369249 & 0,93736 & 0,238068 & 1 & & & & & & & & & \\
\hline$Z n$ & $-0,208734$ & 0,558429 & 0,874896 & 0,181177 & 0,934002 & 1 & & & & & & & & \\
\hline $\mathrm{Mn}$ & $-0,217584$ & $-0,000934$ & $-0,138308$ & 0,836523 & 0,178214 & 0,152077 & 1 & & & & & & & \\
\hline $\mathrm{Fe}$ & $-0,374626$ & 0,080759 & 0,511266 & 0,76324 & 0,690644 & 0,545296 & 0,55868 & 1 & & & & & & \\
\hline PT & $-0,37527$ & 0,108298 & 0,406254 & 0,829354 & 0,670608 & 0,566507 & 0,799169 & 0,9109 & 1 & & & & & \\
\hline NOT & $-0,321846$ & $-0,053737$ & 0,619143 & 0,269864 & 0,597168 & 0,373786 & 0,031436 & 0,780214 & 0,526247 & 1 & & & & \\
\hline MO & $-0,121013$ & $-0,168014$ & 0,225716 & 0,208501 & 0,314107 & 0,151023 & 0,076319 & 0,453701 & 0,35626 & 0,519287 & 1 & & & \\
\hline PT & 0,862224 & 0,467187 & $-0,217334$ & $-0,374547$ & $-0,25364$ & $-0,133028$ & $-0,296386$ & $-0,452094$ & $-0,406808$ & $-0,36279$ & 0,193614 & 1 & & \\
\hline $\mathrm{NH} 4$ & 0,904478 & 0,431919 & $-0,261722$ & $-0,383168$ & $-0,31126$ & $-0,226348$ & $-0,281175$ & $-0,447998$ & $-0,41717$ & $-0,318943$ & 0,157887 & 0,981057 & 1 & \\
\hline$\%$ C.lab & $-0,372634$ & $-0,000891$ & 0,233679 & 0,600171 & 0,456811 & 0,377196 & 0,850057 & 0,625138 & 0,836985 & 0,313091 & 0,104432 & $-0,397318$ & $-0,366921$ & 1 \\
\hline
\end{tabular}

Tabela 17. Correlação de Pearson em julho de 2003.

\begin{tabular}{|c|c|c|c|c|c|c|c|c|c|c|c|c|c|c|}
\hline & água & & sedimento & & & & & & & & & água & & mortalidade \\
\hline & Cloreto & Sulfeto & $\mathrm{Cr}$ & $\mathrm{Cd}$ & $\mathrm{Cu}$ & $Z n$ & $\mathrm{Mn}$ & $\overline{\mathrm{Fe}}$ & $\mathrm{pt}$ & NOT & $\mathrm{MO}$ & PT & $\mathrm{NH} 4$ & \%C.lab. \\
\hline Cloreto & & & & & & & & & & & & & & \\
\hline Sulfeto & 0,891079 & 1 & & & & & & & & & & & & \\
\hline & 0,054621 & $-0,018983$ & 1 & & & & & & & & & & & \\
\hline $\mathrm{Cd}$ & 0,426179 & 0,430996 & 0,686041 & 1 & & & & & & & & & & \\
\hline $\mathrm{Cu}$ & 0,380595 & 0,485429 & 0,65363 & 0,942456 & 1 & & & & & & & & & \\
\hline $\mathrm{Zn}$ & $-0,041896$ & 0,024069 & 0,495062 & 0,23978 & 0,289561 & 1 & & & & & & & & \\
\hline $\mathrm{Mn}$ & $-0,342492$ & $-0,070924$ & $-0,115679$ & $-0,202017$ & $-0,135861$ & 0,16644 & 1 & & & & & & & \\
\hline $\mathrm{Fe}$ & $-0,2897$ & $-0,128007$ & 0,57868 & 0,236055 & 0,325732 & 0,84938 & 0,374712 & 1 & & & & & & \\
\hline pt & 0,244415 & 0,452122 & 0,324587 & 0,529076 & 0,723375 & 0,050994 & 0,102462 & 0,05823 & 1 & & & & & \\
\hline NOT & $-0,083537$ & 0,07888 & 0,592578 & 0,525289 & 0,675215 & 0,1678 & 0,094615 & 0,256716 & 0,859087 & 1 & & & & \\
\hline MO & 0,30528 & 0,481016 & 0,38013 & 0,797351 & 0,889228 & 0,125408 & $-0,161609$ & 0,252993 & 0,590772 & 0,520998 & 1 & & & \\
\hline PT & 0,955238 & 0,81012 & $-0,012798$ & 0,28341 & 0,240324 & $-0,143556$ & $-0,379212$ & $-0,442258$ & 0,262384 & $-0,034294$ & 0,142428 & 1 & & \\
\hline $\mathrm{NH} 4$ & 0,895603 & 0,7604 & $-0,026156$ & 0,35555 & 0,353003 & $-0,239311$ & $-0,448856$ & $-0,475047$ & 0,391002 & 0,053357 & 0,298267 & 0,931636 & 1 & \\
\hline \%C.lab. & 0,166674 & 0,225194 & $-0,149389$ & 0,190528 & 0,218895 & 0,127075 & $-0,182136$ & 0,184009 & $-0,094832$ & $-0,302313$ & 0,439416 & 0,011344 & 0,226277 & \\
\hline
\end{tabular}

PDF created with pdfFactory trial version www.pdffactory.com 
Tabela 18. Correlação de Pearson em outubro de 2003.

\begin{tabular}{|c|c|c|c|c|c|c|c|c|c|c|c|c|c|c|}
\hline \multirow[b]{3}{*}{ Cloreto } & \multirow{2}{*}{$\begin{array}{c}\text { água } \\
\text { Cloreto } \\
\end{array}$} & & \multicolumn{2}{|l|}{ sedimento } & \multirow[b]{2}{*}{$\mathrm{Cu}$} & \multirow[b]{2}{*}{$\mathrm{Zn}$} & \multirow[b]{2}{*}{$\mathrm{Mn}$} & \multirow[b]{2}{*}{$\mathrm{Fe}$} & \multirow[b]{2}{*}{$\mathrm{pt}$} & \multirow[b]{2}{*}{ NOT } & \multicolumn{2}{|r|}{ Tágua } & \multicolumn{2}{|r|}{ mortalidade } \\
\hline & & Sulfeto & $\mathrm{Cr}$ & $\mathrm{Cd}$ & & & & & & & $\mathrm{MO}$ & $\mathrm{PT}$ & $\mathrm{NH} 4$ & \%C.lab. \\
\hline & $\begin{array}{r}1 \\
0,953484\end{array}$ & 1 & & & & & & & & & & & & \\
\hline $\mathrm{Cr}$ & $-0,096928$ & $-0,256077$ & 1 & & & & & & & & & & & \\
\hline $\mathrm{Cd}$ & $-0,113438$ & $-0,280649$ & 0,996255 & 1 & & & & & & & & & & \\
\hline $\mathrm{Cu}$ & $-0,064716$ & $-0,271054$ & 0,981079 & 0,98434167 & 1 & & & & & & & & & \\
\hline $\mathrm{Zn}$ & $-0,010697$ & $-0,19719$ & 0,990563 & 0,99296018 & 0,992301 & 1 & & & & & & & & \\
\hline $\mathrm{Mn}$ & $-0,077163$ & $-0,292051$ & 0,972083 & 0,97740397 & 0,998952 & 0,986332 & 1 & & & & & & & \\
\hline $\mathrm{Fe}$ & $-0,104378$ & $-0,26121$ & 0,999942 & 0,99622543 & 0,979403 & 0,989311 & 0,970201 & 1 & & & & & & \\
\hline pt & $-0,142714$ & $-0,311793$ & 0,993436 & 0,98590301 & 0,983593 & 0,98049 & 0,977453 & 0,993114 & 1 & & & & & \\
\hline NOT & $-0,112844$ & $-0,272192$ & 0,998746 & 0,99904925 & 0,980483 & 0,990936 & 0,972046 & 0,998882 & 0,989064 & 1 & & & & \\
\hline mo & $-0,169108$ & $-0,297744$ & 0,988985 & 0,98932061 & 0,949847 & 0,96895 & 0,938011 & 0,990383 & 0,97306 & 0,992431 & 1 & & & \\
\hline PT & 0,917398 & 0,893468 & $-0,426257$ & $-0,42272785$ & $-0,36313$ & $-0,325327$ & $-0,364509$ & $-0,433538$ & $-0,469673$ & $-0,432101$ & $-0,487631$ & 1 & & \\
\hline $\mathrm{NH} 4$ & 0,877906 & 0,852262 & $-0,500403$ & $-0,51225518$ & $-0,425218$ & $-0,409961$ & $-0,423023$ & $-0,508405$ & $-0,51529$ & $-0,516844$ & $-0,585212$ & 0,962585 & 1 & \\
\hline$\%$ C.lab. & 0,139778 & $-0,003037$ & 0,961646 & 0,94244632 & 0,931686 & 0,958023 & 0,915492 & 0,960303 & 0,948258 & 0,95123 & 0,934318 & $-0,233669$ & $-0,296265$ & . \\
\hline
\end{tabular}

Tabela 19. Correlação de Pearson em janeiro de 2004.

\begin{tabular}{|c|c|c|c|c|c|c|c|c|c|c|c|c|c|c|}
\hline & água & & sedimento & & & & & & & & & Tágua & & mortalidade \\
\hline & Cloreto & Sulfeto & $\mathrm{Cr}$ & $\overline{C d}$ & $\overline{\mathrm{Cu}}$ & $\overline{Z n}$ & $\overline{M n}$ & $\mathrm{Fe}$ & $\overline{p t}$ & NOT & $\mathrm{MO}$ & $\overline{\mathrm{PT}}$ & $\mathrm{NH} 4$ & \%C.lab. \\
\hline Cloreto & $\overline{1}$ & & & & & & & & & & & & & \\
\hline Sulfeto & 0,691042 & 1 & & & & & & & & & & & & \\
\hline $\mathrm{Cr}$ & 0,079775 & $-0,291926$ & 1 & & & & & & & & & & & \\
\hline $\mathrm{Cd}$ & $-0,303179$ & 0,029011 & $-0,245891$ & 1 & & & & & & & & & & \\
\hline $\mathrm{Cu}$ & 0,204924 & $-0,357733$ & 0,80783 & $-0,391445$ & 1 & & & & & & & & & \\
\hline $\mathrm{Zn}$ & 0,317824 & $-0,300618$ & 0,795049 & $-0,414435$ & 0,972721 & 1 & & & & & & & & \\
\hline $\mathrm{Mn}$ & 0,483779 & $-0,057417$ & 0,211121 & $-0,32875$ & 0,615737 & 0,677515 & 1 & & & & & & & \\
\hline $\mathrm{Fe}$ & $-0,234179$ & $-0,481128$ & 0,510317 & $-0,406822$ & 0,497831 & 0,513607 & $-0,097949$ & 1 & & & & & & \\
\hline pt & 0,421747 & $-0,175874$ & 0,626273 & $-0,293776$ & 0,787651 & 0,833042 & 0,829254 & 0,029075 & 1 & & & & & \\
\hline NOT & 0,255679 & $-0,221099$ & 0,586684 & $-0,489362$ & 0,878622 & 0,857891 & 0,82143 & 0,231816 & 0,842004 & 1 & & & & \\
\hline mo & 0,205562 & $-0,244924$ & 0,815906 & $-0,297991$ & 0,912679 & 0,880932 & 0,654637 & 0,23445 & 0,870612 & 0,918384 & 1 & & & \\
\hline PT & 0,923076 & 0,615018 & $-0,170089$ & $-0,275388$ & 0,040751 & 0,14513 & 0,49467 & $-0,388696$ & 0,3655 & 0,176633 & 0,065477 & 1 & & \\
\hline $\mathrm{NH} 4$ & $-0,54264$ & $-0,427789$ & $-0,078036$ & 0,461894 & $-0,221187$ & $-0,150971$ & $-0,247313$ & 0,285346 & $-0,314741$ & $-0,364257$ & $-0,312819$ & $-0,619413$ & 1 & \\
\hline$\%$ C.lab & 0,021834 & $-0,054827$ & $-0,113284$ & $-0,128628$ & $-0,00357$ & 0,058424 & 0,319416 & $-0,07896$ & 0,055916 & 0,084094 & $-0,061353$ & $-0,105265$ & 0,443107 & \\
\hline
\end{tabular}

PDF created with pdfFactory trial version www.pdffactory.com 
Tabela 20. Correlação de Pearson em abril de 2004.

\begin{tabular}{|c|c|c|c|c|c|c|c|c|c|c|c|c|c|c|}
\hline & água & & sedimento & & & & & & & & & água & & mortalidade \\
\hline & Cloreto & Sulfeto & $\mathrm{Cr}$ & $\mathrm{Cd}$ & $\overline{\mathrm{Cu}}$ & $\mathrm{Zn}$ & $\overline{M n}$ & $\mathrm{Fe}$ & $\mathrm{pt}$ & NOT & $\mathrm{MO}$ & PT & $\mathrm{NH} 4$ & \%C.lab. \\
\hline Cloreto & & & & & & & & & & & & & & \\
\hline Sulfeto & 0,958535 & 1 & & & & & & & & & & & & \\
\hline $\mathrm{Cr}$ & $-0,357364$ & $-0,562595$ & 1 & & & & & & & & & & & \\
\hline $\mathrm{Cd}$ & $-0,158336$ & $-0,332095$ & 0,150711 & 1 & & & & & & & & & & \\
\hline $\mathrm{Cu}$ & 0,002459 & $-0,221249$ & 0,328326 & 0,925493 & 1 & & & & & & & & & \\
\hline$Z n$ & $-0,307105$ & $-0,461926$ & 0,174371 & 0,966367 & 0,817006 & 1 & & & & & & & & \\
\hline$M n$ & $-0,303494$ & $-0,459564$ & 0,176939 & 0,966911 & 0,818947 & 0,999984 & 1 & & & & & & & \\
\hline $\mathrm{Fe}$ & $-0,300055$ & $-0,457307$ & 0,179374 & 0,967399 & 0,820767 & 0,999941 & 0,999986 & 1 & & & & & & \\
\hline pt & 0,299023 & 0,058842 & 0,349155 & 0,732563 & 0,927313 & 0,561874 & 0,565249 & 0,56844 & 1 & & & & & \\
\hline not & $-0,266201$ & $-0,477831$ & 0,404611 & 0,948602 & 0,882076 & 0,963559 & 0,964724 & 0,965802 & 0,684462 & 1 & 1 & & & \\
\hline mo & $-0,375917$ & $-0,597496$ & 0,567817 & 0,875955 & 0,833184 & 0,908825 & 0,910067 & 0,911221 & 0,63817 & 0,979627 & 1 & & & \\
\hline PT & 0,975143 & 0,969736 & $-0,427788$ & $-0,273382$ & $-0,169206$ & $-0,374913$ & $-0,371698$ & $-0,368634$ & 0,107559 & $-0,358387$ & $7-0,464817$ & 1 & & \\
\hline $\mathrm{NH} 4$ & 0,939294 & 0,920624 & $-0,370261$ & $-0,18819$ & 0,035142 & $-0,393527$ & $-0,390561$ & $-0,387732$ & 0,35261 & $-0,352681$ & $-0,456818$ & 0,865177 & 1 & 1 \\
\hline$\%$ C.lab & $-0,009281$ & $-0,185482$ & 0,516775 & 0,262316 & 0,19532 & 0,398796 & 0,401771 & 0,404585 & 0,14256 & 0,508913 & 0,560889 & 0,059049 & 310956 & \\
\hline
\end{tabular}


Tabela 5. Teste de Sensibilidade de Chironomus xanthus ao Cádmio em 15/ 06/ 04.

\begin{tabular}{|c|c|c|c|c|c|}
\hline $\begin{array}{llr}\text { DATE } & 15 / 06 / 04 & \text { TES } \\
\text { CHEMICAL Cádmio SPEC } \\
\text { RAW DATA }\end{array}$ & $\begin{array}{l}\text { NUn } \\
\text { S C hi }\end{array}$ & $\begin{array}{l}\text { BER } \\
\text { nomu }\end{array}$ & $\begin{array}{c}5 \\
\text { Is } x \text { an }\end{array}$ & & $\mathrm{U}$ \\
\hline CO NCENTRATION $(\mathrm{mg} / \mathrm{l})$ & 0.25 & 0.50 & 0.75 & 1.50 & 3.00 \\
\hline & 18 & 18 & 18 & 18 & \\
\hline IES & 4 & 7 & 13 & 10 & \\
\hline RIN & & 2. & & & \\
\hline STI & & & & & \\
\hline & & 0.40 & & & \\
\hline 95 & & & & & \\
\hline
\end{tabular}

Tabela 6. Teste de Sensibilidade de Chironomus xanthus ao Cádmio em 15/ 07/ 04.

\begin{tabular}{|c|c|c|c|c|c|}
\hline \multirow{2}{*}{\multicolumn{6}{|c|}{$\begin{array}{ll}\text { DATE } 15 / 07 / 04 & \text { TEST NUMBER } 6 \\
\text { CHEMICAL Cádmio } & \text { SPECIES Chironomus } x \text { anthus } \\
\text { RAW DATA } & \end{array}$}} \\
\hline & & & & & \\
\hline CONCFNTRATION $(\mathrm{mg} / \mathrm{ll})$ & 0.25 & 0.50 & 0.75 & 1. & \\
\hline & & & & & \\
\hline MO RI ALITIES & & & & & \\
\hline \multicolumn{6}{|l|}{ SPEARMAN-KARBER TRIM } \\
\hline \multicolumn{6}{|c|}{ SPEARMAN-KARBER ESTIMATES S LC50 } \\
\hline \multicolumn{6}{|c|}{ 95\% LOWER CO NFIDE NCE $\quad 0.18$} \\
\hline & & & & & \\
\hline
\end{tabular}

Tabela 7. Teste de Sensibilidade de Chironomus x anthus ao Cádmio em 28/ 06/ 04.

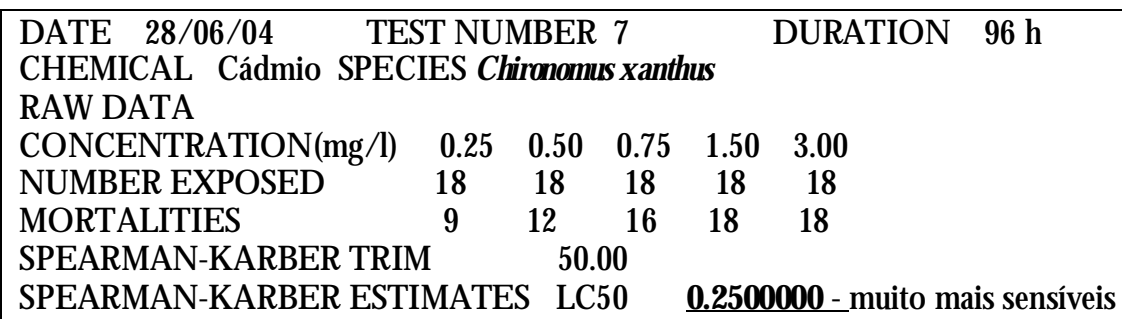

95\% Confidence limits are not reliable

Tabela 8. Teste de Sensibilidade de Chironomus xanthus ao Cádmio em 26/ 07/ 04.

\begin{tabular}{|lllllll|}
\hline DATE & $26 / 07 / 04$ & TEST NUMBER 8 & & DURATION & $96 \mathrm{~h}$ \\
CHEMICAL Cádmio SPECIE S Chironomus x anthus & & & \\
RAW DATA & & & & & & \\
CONCENTRATION(mg/l) & 0.25 & 0.50 & 0.75 & 1.50 & 3.00 & \\
NUMBER EXPOSED & 18 & 18 & 18 & 18 & 18 & \\
MORTALITIES & 1 & 2 & 10 & 13 & 18 & \\
SPEARMAN-KARBER TRIM & 5.56 & & & \\
SPEARMAN-KARBER ESTIMATES & LC50 & $\mathbf{0 . 8 7 9 4 4 2 8}$ & \\
95\% LOWER CONFIDENCE & 0.69 & & & \\
95\% UPPER CONFIDENCE & 1.12 & & & \\
\hline
\end{tabular}


Tabela 9. Teste de Sensibilidade de Chironomus xanthus ao Cádmio em 18/ 07/ 04.

\begin{tabular}{|c|c|c|c|c|c|}
\hline $\begin{array}{llr}\text { DATE } & 28 / 07 / 04 & \text { TES } \\
\text { CHEMICAL Cádmio SPEC } \\
\text { RAW DATA }\end{array}$ & $\begin{array}{l}\text { NUn } \\
\text { SChi }\end{array}$ & $\begin{array}{l}\mathrm{ER} \\
\mathrm{tom}\end{array}$ & 9 & & \\
\hline CO NCENTRATION $(\mathrm{mg} / \mathrm{l})$ & 0.25 & 0.50 & 0.75 & 1.50 & 3.00 \\
\hline & 18 & 18 & 18 & 18 & \\
\hline 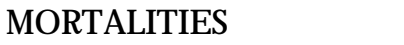 & 5 & 7 & 9 & 13 & \\
\hline RIN & & & & & \\
\hline STI & M & S LC & & .70 & \\
\hline תח & & 0.44 & & & \\
\hline תFIDF & & 11 & & & \\
\hline
\end{tabular}

Tabela 10. Teste de Sensibilidade de C hironomus xanthus ao Cádmio em 13/08/ 04.

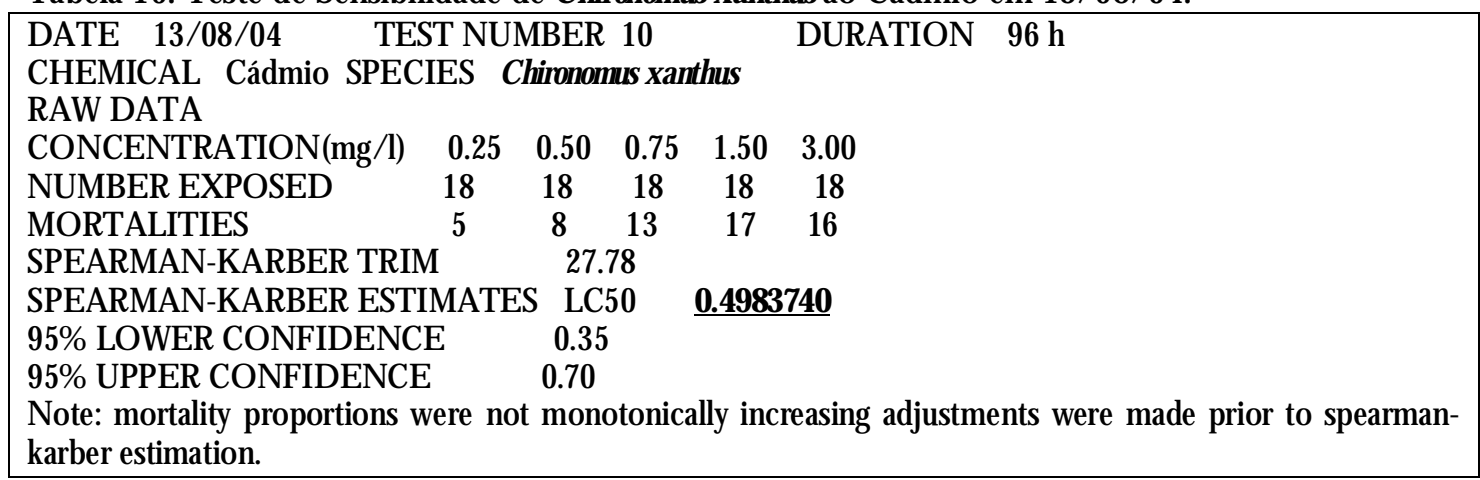

Tabela 13. Teste de Sensibilidade de C hironomus x anthus ao Cobre em 17/ 05/ 04.

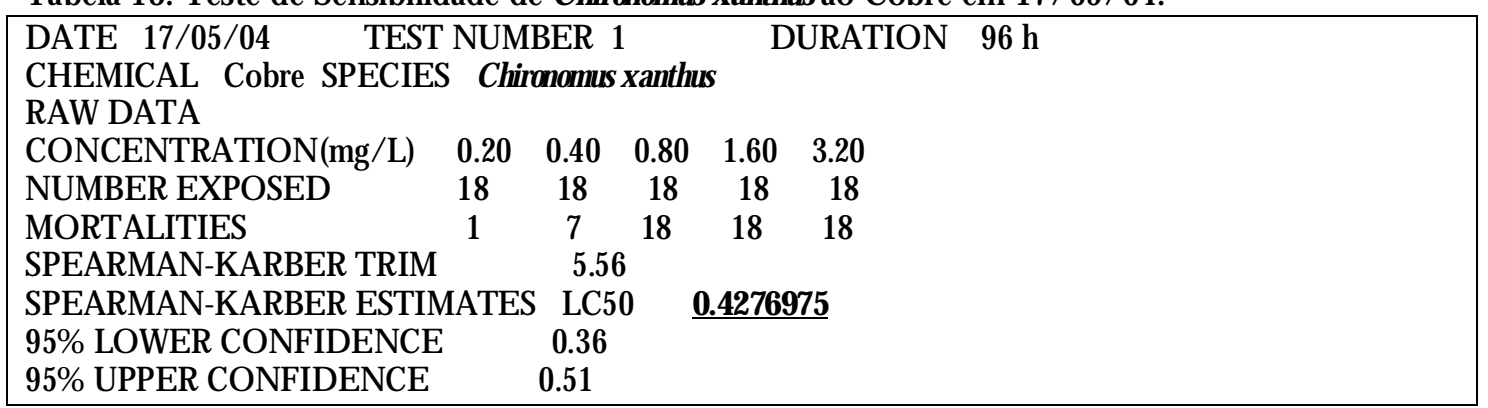

Tabela 14. Teste de Sensibilidade de C hironomus x anthus ao Cobre em 18/ 05/ 04.

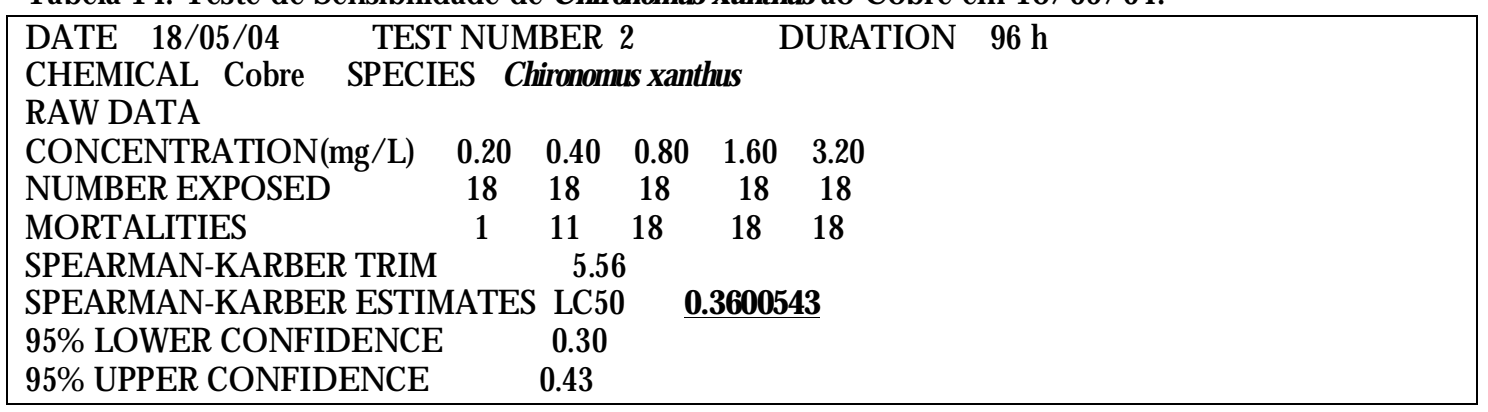


Tabela 15. Teste de Sensibilidade de C hironomus x anthus ao Cobre em 24/ 05/ 04.

\begin{tabular}{|lllllll}
\hline DATE & 24/05/04 & TEST NUMBER & & DURATION & $96 \mathrm{~h}$ \\
CHEMICAL Cobre & SPECIE S Chironomus x anthus & & \\
RAW DATA & & & & & \\
CONCENTRATION(mg/l) & 0.10 & 0.20 & 0.40 & 0.80 & 1.60 & \\
NUMBER EXPOSED & 18 & 18 & 18 & 18 & 18 & \\
MORTALITIES & 2 & 3 & 14 & 18 & 18 & \\
SPEARMAN-KARBER TRIM & 11.11 & & & \\
SPEARMAN-KARBER ESTIMATES & LC50 & $\mathbf{0 . 2 8 9 9 3 2 0}$ \\
95\% LOWER CONFIDENCE & 0.23 & &
\end{tabular}

Tabela 16. Teste de Sensibilidade de C hironomus x anthus ao Cobre em 14/ 06/ 04.

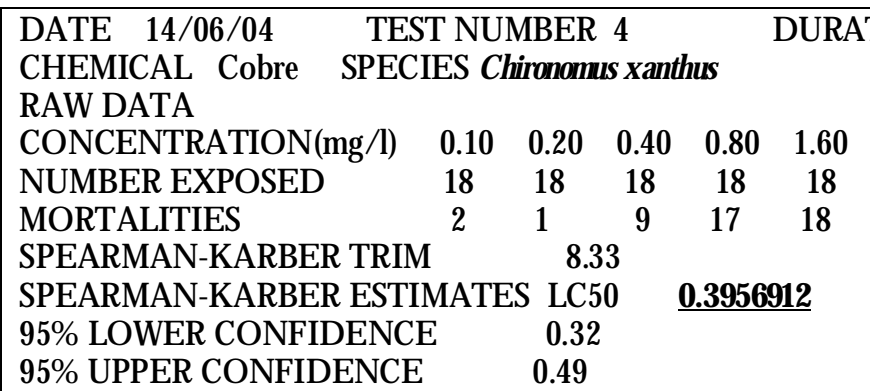

Note: mortality proportions were not monotonically increasing adjustments were made prior to spearmankarber estimation.

Tabela 17. Teste de Sensibilidade de C hironomus x anthus ao Cobre em 14/ 06/ 04.

\begin{tabular}{|lllllll|}
\hline DATE & $14 / 06 / 04$ & TEST NUMBER & 5 & & DURATION & $96 \mathrm{~h}$ \\
CHEMICAL Cobre SPECIES Chironomus xanthus & & & \\
RAW DATA & & & & & & \\
CONCENTRATION(mg/l) & 0.10 & 0.20 & 0.40 & 0.80 & 1.60 & \\
NUMBER EXPOSED & 18 & 18 & 18 & 18 & 18 & \\
MORTALITIES & 5 & 7 & 10 & 15 & 17 & \\
SPEARMAN-KARBER TRIM & 27.78 & & & \\
SPEARMAN-KARBER ESTIMATES S & LC50 & $\mathbf{0 . 2 9 2 8 1 7 2}$ & \\
95\% LOWER CONFIDENCE & 0.17 & & & \\
95\% UPPER CONFIDENCE & 0.49 & & & \\
\hline
\end{tabular}

Tabela 18. Teste de Sensibilidade de C hironomus x anthus ao Cobre em 28/ 06/ 04.

\begin{tabular}{|lllllll|l|}
\hline DATE 28/06/04 & TEST NUMBER & 6 & & DURATION & $96 \mathrm{~h}$ \\
CHEMICAL Cobre SPECIES Chironomus xanthus & & & \\
RAW DATA & & & & & & \\
CONCENTRATION(mg/l) & 0.25 & 0.50 & 0.75 & 1.50 & 3.00 & \\
NUMBER EXPOSED & 18 & 18 & 18 & 18 & 18 & \\
MORTALITIES & 8 & 17 & 18 & 18 & 18 & \\
SPEARMAN-KARBER TRIM & 44.44 & & & \\
SPEARMAN-KARBER ESTIMATES SC50 & $\mathbf{0 . 2 7 0 0 1 4 9}$ & \\
95\% LOWER CONFIDENCE & 0.17 & & & \\
95\% UPPER CONFIDENCE & 0.44 & & & \\
\hline
\end{tabular}


Tabela 19. Teste de Sensibilidade de C hironomus xanthus ao Cobre em 15/ 07/ 04.

\begin{tabular}{|llllll|}
\hline DATE & $15 / 07 / 04$ & TEST NUMBER & & DURA \\
CHEMICAL Cobre SPECIE S Chironomus xanthus & & \\
RAW DATA & & & & & \\
CONCENTRATIO N(mg/l) & 0.10 & 0.20 & 0.40 & 0.80 & 1.60 \\
NUMBER EXPO SED & 18 & 18 & 18 & 18 & 18 \\
MORTALITIES & 7 & 10 & 18 & 18 & 18 \\
SPEARMAN-KARBER TRIM & 38.89 & & \\
SPEARMAN-KARBER ESTIMATES S LC50 & $\mathbf{0 . 1 5 5 9 0 0 4}$ \\
95\% LOWER CONFIDENCE & 0.09 & & \\
95\% UPPER CONFIDENCE & 0.28 & & \\
\hline
\end{tabular}

Tabela 20. Teste de Sensibilidade de C hironomus x anthus ao Cobre em 26/ 07/ 04.

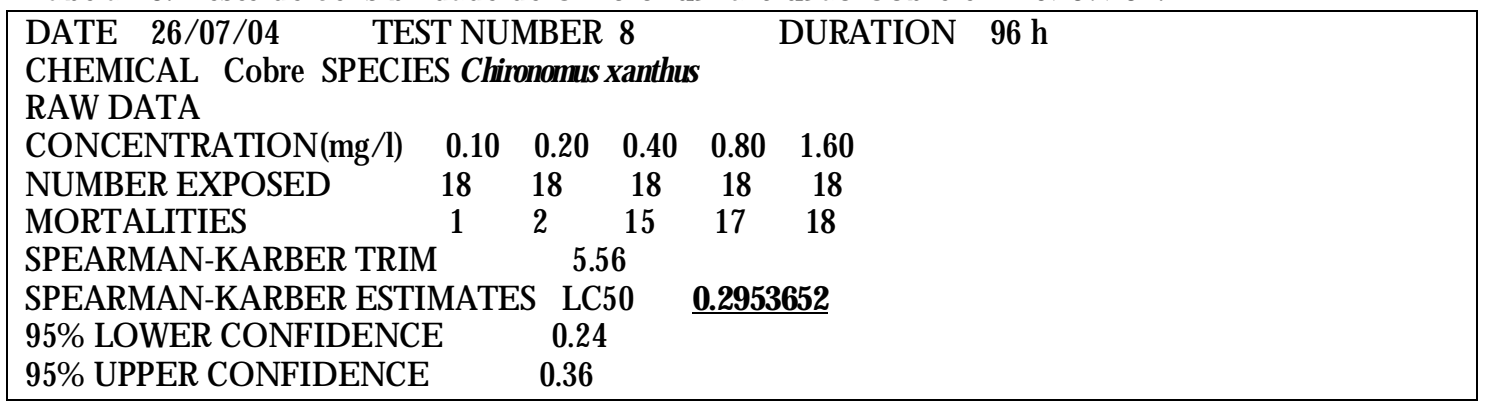

Tabela 21. Teste de Sensibilidade de C hironomus x anthus ao Cobre em 28/ 07/ 04.

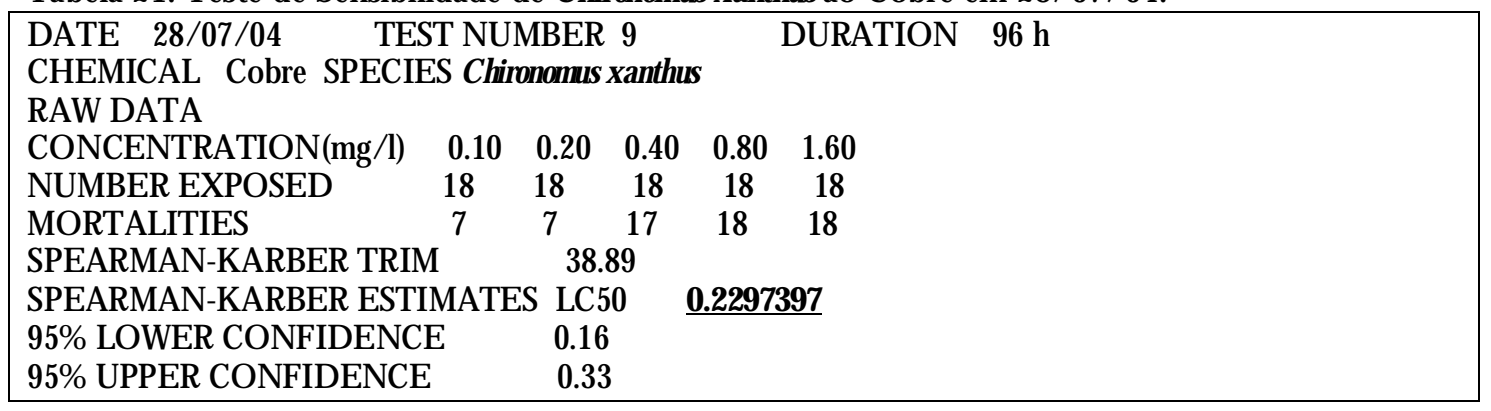

Tabela 22. Teste de Sensibilidade de C hironomus x anthus ao Cobre em 13/ 08/ 04.

\begin{tabular}{|lllllll|}
\hline DATE & $13 / 08 / 04$ & TEST NUMBER & 10 & & DURATION & $96 \mathrm{~h}$ \\
CHEMICAL Cobre SPECIE S Chironomus xanthus & & & \\
RAW DATA & & & & & & \\
CONCENTRATION(mg/l) & 0.10 & 0.20 & 0.40 & 0.80 & 1.60 & \\
NUMBER EXPOSED & 18 & 18 & 18 & 18 & 18 & \\
MORTALITIES & 2 & 2 & 14 & 18 & 18 & \\
SPEARMAN-KARBER TRIM & 11.11 & & & \\
SPEARMAN-KARBER ESTIMATES S & LCC50 & $\mathbf{0 . 3 0 4 6 4 8 0}$ & \\
95\% LOWER CONFIDENCE & 0.26 & & & \\
95\% UPPER CONFIDENCE & 0.36 & & & \\
\hline
\end{tabular}




\section{Legenda das Tabelas de 25 a 30: Cd Co (Cd CONAMA = 1,0 19.L-1); Cd Ce (Cd CENO = 70,0 $\left.\mu g . L^{-1}\right)$ e CuCoCe (Cu CONAMA/ CENO = 20,0 $\left.\mu g . L^{-1}\right)$}

Tabela 25. Resultados dos Testes Crônicos 1, 2 e 3 demonstrando a \% de sobrevivência e 0 peso seco individual (mg) de Chironomus x anthus após 10 dias de exposição.

\begin{tabular}{|c|c|c|c|c|}
\hline Tratamentos/ Parâmetros & no inicial & no final & \% sobrevivência & peso seco (mg) \\
\hline & \multicolumn{4}{|c|}{ Teste 1} \\
\hline Controle 1 & 80 & 64 & 80,0 & 0,438 \\
\hline Controle 2 & 80 & 46 & 57,5 & 0,349 \\
\hline CdCo1 & 80 & 56 & 70,0 & 0,355 \\
\hline CdCo2 & 80 & 62 & 77,5 & 0,344 \\
\hline CuCoCe1 & 80 & 62 & 77,5 & 0,315 \\
\hline \multirow[t]{2}{*}{ CuCoCe2 } & 80 & 40 & 50,0 & 0,667 \\
\hline & \multicolumn{4}{|c|}{ Teste 2} \\
\hline Controle 1 & 80 & 23 & 28,7 & 0,435 \\
\hline Controle 2 & 80 & 15 & 18,7 & 0,253 \\
\hline CdCo1 & 80 & 75 & 93,7 & 0,366 \\
\hline CdCo2 & 80 & 80 & 100,0 & 0,323 \\
\hline CdCe1 & 80 & 16 & 20,0 & 0,053 \\
\hline CdCe2 & 80 & 16 & 20,0 & 0,033 \\
\hline CuCoCe1 & 80 & 18 & 22,5 & 0,398 \\
\hline \multirow[t]{2}{*}{ CuCoCe2 } & 80 & 16 & 20,0 & 0,407 \\
\hline & \multicolumn{4}{|c|}{ Teste 3} \\
\hline Controle 1 & 100 & 93 & 93,0 & 0,235 \\
\hline Controle 2 & 100 & 66 & 66,0 & 0,221 \\
\hline CdCo1 & 100 & 85 & 85,0 & 0,144 \\
\hline CdCo2 & 100 & 79 & 79,0 & 0,225 \\
\hline CdCe1 & 100 & 52 & 52,0 & 0,196 \\
\hline CdCe2 & 100 & 32 & 32,0 & 0,198 \\
\hline CuCoCe1 & 100 & 55 & 55,0 & 0,196 \\
\hline CuCoCe2 & 100 & 58 & 58,0 & 0,132 \\
\hline
\end{tabular}

Tabela 26. Resultados dos Testes Crônicos 1, 2 e 3 demonstrando a emergência de Chironomus xanthus.

\begin{tabular}{|c|c|c|c|c|c|c|}
\hline Tratamentos/Dia & $1^{\circ}$ dia & $2^{\circ}$ dia & $3^{\circ}$ dia & $4^{\circ}$ dia & $5^{\circ}$ dia & $6^{\circ}$ dia \\
\hline & \multicolumn{6}{|c|}{ Teste 1} \\
\hline Controle 1 & & & & & & - \\
\hline Controle 2 & 9 & 11 & 4 & 5 & 6 & - \\
\hline CdCo1 & 3 & 7 & 12 & 4 & 2 & - \\
\hline CdCo2 & 3 & 10 & 11 & 5 & 2 & - \\
\hline CuCoCe1 & 3 & 5 & 1 & 2 & 5 & - \\
\hline \multirow[t]{2}{*}{ CuCoCe2 } & 0 & 3 & 4 & 1 & 2 & - \\
\hline & \multicolumn{6}{|c|}{ Teste 2} \\
\hline Controle 1 & 3 & 15 & - & - & - & - \\
\hline Controle 2 & 3 & 21 & - & - & - & - \\
\hline CdCo1 & 10 & 8 & - & - & - & . \\
\hline CdCo2 & 6 & 23 & - & - & - & - \\
\hline CdCe1 & 0 & 0 & - & - & - & - \\
\hline CdCe2 & 0 & 0 & - & - & - & - \\
\hline CuCoCe1 & 0 & 4 & - & 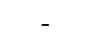 & - & . \\
\hline \multirow[t]{2}{*}{ CuCoCe2 } & 1 & 1 & - & - & - & - \\
\hline & \multicolumn{6}{|c|}{ Teste 3} \\
\hline Controle 1 & 1 & 1 & 2 & 2 & 4 & 12 \\
\hline Controle 2 & 6 & 5 & 9 & 3 & 5 & 15 \\
\hline CdCo1 & 4 & 2 & 3 & 3 & 4 & 14 \\
\hline CdCo2 & 7 & 8 & 4 & 2 & 4 & 11 \\
\hline CdCe1 & 0 & 0 & 0 & 1 & 6 & 7 \\
\hline CdCe2 & 0 & 0 & 0 & 3 & 2 & 6 \\
\hline CuCoCe1 & 9 & 9 & 4 & 1 & 2 & 15 \\
\hline CuCoCe2 & 6 & 4 & 0 & 2 & 3 & 7 \\
\hline
\end{tabular}


Tabela 27. Resultados dos Testes Crônicos 1, 2 e 3 demonstrando a emergência de fêmeas e machos de Chironomus xanthus.

\begin{tabular}{|c|c|c|c|c|c|c|c|c|c|c|c|c|}
\hline \multirow{2}{*}{ Tratamento/ adultos } & \multicolumn{2}{|c|}{$1^{\circ}$ dia } & \multicolumn{2}{|c|}{$2^{\circ}$ dia } & \multicolumn{2}{|c|}{$3^{\circ}$ dia } & \multicolumn{2}{|c|}{$4^{\circ}$ dia } & \multicolumn{2}{|c|}{$5^{\circ}$ dia } & \multicolumn{2}{|c|}{$6^{\circ}$ dia } \\
\hline & 웅 & $0^{1}$ & 우 & $0^{\pi}$ & 우 & 0 & q & $0^{\pi}$ & q & 0 & o & $0^{\pi}$ \\
\hline & \multicolumn{12}{|c|}{ Teste 1} \\
\hline Controle 1 & - & - & - & - & - & - & - & - & - & - & - & - \\
\hline Controle 2 & 0 & 9 & 1 & 9 & 3 & 1 & 3 & 2 & 3 & 3 & - & - \\
\hline CdCo1 & 1 & 2 & 2 & 2 & 5 & 7 & 2 & 2 & 1 & 1 & - & - \\
\hline CdCo2 & 0 & 3 & 1 & 3 & 6 & 5 & 2 & 3 & 2 & 0 & - & - \\
\hline CuCoCe1 & 1 & 2 & 0 & 2 & 0 & 1 & 2 & 0 & 2 & 3 & - & - \\
\hline \multirow[t]{2}{*}{ CuCoCe2 } & 0 & 0 & 1 & 0 & 3 & 1 & 0 & 1 & 1 & 1 & - & - \\
\hline & \multicolumn{12}{|c|}{ Teste 2} \\
\hline Controle 1 & 3 & 0 & 7 & 8 & - & - & - & - & - & - & - & - \\
\hline Controle 2 & 0 & 3 & 16 & 5 & - & - & - & - & - & - & - & - \\
\hline CdCo1 & 8 & 2 & 4 & 4 & - & - & - & - & - & - & - & - \\
\hline CdCo2 & 0 & 6 & 11 & 12 & - & - & - & - & - & - & - & - \\
\hline CdCe1 & 0 & 0 & 0 & 0 & - & - & - & - & - & - & - & - \\
\hline CdCe2 & 0 & 0 & 0 & 0 & - & - & - & - & - & - & - & - \\
\hline CuCoCe1 & 0 & 0 & 2 & 2 & - & - & - & - & - & - & - & - \\
\hline \multirow[t]{2}{*}{ CuCoCe2 } & 1 & 0 & 1 & 0 & - & - & - & - & - & - & - & - \\
\hline & \multicolumn{12}{|c|}{ Teste 3} \\
\hline Controle 1 & 0 & 1 & 0 & 1 & 0 & 2 & 0 & 2 & 0 & 4 & 4 & 8 \\
\hline Controle 2 & 0 & 6 & 0 & 5 & 5 & 4 & 2 & 1 & 3 & 2 & 10 & 5 \\
\hline CdCo1 & 0 & 4 & 0 & 2 & 1 & 2 & 2 & 1 & 1 & 3 & 9 & 5 \\
\hline CdCo2 & 1 & 6 & 0 & 8 & 2 & 2 & 1 & 1 & 3 & 1 & 8 & 3 \\
\hline CdCe1 & 0 & 0 & 0 & 0 & 0 & 0 & 0 & 1 & 1 & 5 & 1 & 6 \\
\hline CdCe2 & 0 & 0 & 0 & 0 & 0 & 0 & 0 & 3 & 0 & 2 & 1 & 5 \\
\hline CuCoCe1 & 1 & 8 & 5 & 4 & 3 & 1 & 0 & 1 & 2 & 0 & 3 & 12 \\
\hline CuCoCe2 & 0 & 6 & 1 & 3 & 0 & 0 & 0 & 2 & 1 & 3 & 2 & 5 \\
\hline
\end{tabular}


Tabela 28 - Medidas do comprimento $(\mu \mathrm{m})$ e largura $(\mu \mathrm{m})$ da cápsula cefálica de C hironomus x anthus expostos aos tratamentos do Teste Crônico 1.

\begin{tabular}{|c|c|c|c|c|c|c|}
\hline \multirow{2}{*}{$\begin{array}{c}\mathrm{n}^{\circ} \mathrm{de} \\
\text { organismos }\end{array}$} & \multicolumn{2}{|l|}{ Controle } & \multicolumn{2}{|l|}{ CdCo } & \multicolumn{2}{|l|}{ CuCoCe } \\
\hline & comprimento & largura & comprimento & largura & comprimento & largura \\
\hline 1 & 685.10 & 518.90 & 782.14 & 589.21 & 722.27 & 580.92 \\
\hline 2 & 753.56 & 573.07 & 669.58 & 496.24 & 656.35 & 551.44 \\
\hline 3 & 757.44 & 529.23 & 688.43 & 500.76 & 725.33 & 533.69 \\
\hline 4 & 669.98 & 556.76 & 733.18 & 627.23 & 700.36 & 535.72 \\
\hline 5 & 785.09 & 590.65 & 736.00 & 576.83 & 758.81 & 567.14 \\
\hline 6 & 686.16 & 546.05 & 869.41 & 658.44 & 698.36 & 522.53 \\
\hline 7 & 702.62 & 614.06 & 682.44 & 525.71 & 655.29 & 561.46 \\
\hline 8 & 759.95 & 557.59 & 766.09 & 592.39 & 816.40 & 623.27 \\
\hline 9 & 684.86 & 533.40 & 638.16 & 522.76 & 733.59 & 550.58 \\
\hline 10 & 643.64 & 385.73 & 722.38 & 598.23 & 685.29 & 483.78 \\
\hline 11 & 783.29 & 583.25 & 709.33 & 533.70 & 786.11 & 586.40 \\
\hline 12 & 688.05 & 571.08 & 758.19 & 598.18 & 701.49 & 565.63 \\
\hline 13 & 771.30 & 662.11 & 674.72 & 533.68 & 658.61 & 563.94 \\
\hline 14 & 681.35 & 515.59 & 728.79 & 557.96 & 791.08 & 604.23 \\
\hline 15 & 727.62 & 574.31 & 664.52 & 510.26 & 725.75 & 556.65 \\
\hline 16 & 743.68 & 594.65 & 749.64 & 581.79 & 763.93 & 566.67 \\
\hline 17 & 731.50 & 566.57 & 761.32 & 573.43 & 727.53 & 562.67 \\
\hline 18 & 720.89 & 520.95 & 735.69 & 576.91 & 745.72 & 593.86 \\
\hline 19 & 762.43 & 574.12 & 763.35 & 591.32 & 694.58 & 508.53 \\
\hline 20 & 731.31 & 564.88 & 785.52 & 597.29 & 691.30 & 529.70 \\
\hline 21 & 742.78 & 542.55 & 832.96 & 562.18 & 651.23 & 543.81 \\
\hline 22 & 695.49 & 551.77 & 759.36 & 578.88 & 724.03 & 566.85 \\
\hline 23 & 724.43 & 579.93 & 774.56 & 623.98 & 654.23 & 513.82 \\
\hline 24 & 759.34 & 617.33 & 679.33 & 588.57 & 743.83 & 555.30 \\
\hline 25 & 714.01 & 561.12 & 710.44 & 568.93 & 745.15 & 570.38 \\
\hline 26 & 768.12 & 645.29 & 756.04 & 600.06 & 638.97 & 488.60 \\
\hline 27 & 746.43 & 648.41 & 760.10 & 672.93 & 648.01 & 504.84 \\
\hline 28 & 741.26 & 618.57 & 726.76 & 573.71 & 686.15 & 534.96 \\
\hline 29 & 766.48 & 623.59 & 705.56 & 520.85 & 705.97 & 559.93 \\
\hline 30 & 741.26 & 590.67 & 666.15 & 506.67 & 759.48 & 586.07 \\
\hline 31 & 769.32 & 584.61 & 741.85 & 571.27 & 763.15 & 557.79 \\
\hline 32 & 658.97 & 492.13 & 798.17 & 599.19 & 754.34 & 564.22 \\
\hline 33 & 656.31 & 485.84 & 771.39 & 566.39 & 705.90 & 509.28 \\
\hline 34 & 704.28 & 628.10 & 758.57 & 608.46 & 664.79 & 539.99 \\
\hline 35 & 736.72 & 599.72 & 752.65 & 563.78 & 743.32 & 583.35 \\
\hline 36 & 863.03 & 658.47 & 730.00 & 524.75 & 745.14 & 614.79 \\
\hline 37 & & & 723.44 & 538.03 & 683.65 & 557.17 \\
\hline 38 & & & 718.17 & 538.08 & 759.49 & 611.42 \\
\hline 39 & & & 697.12 & 515.59 & 685.95 & 625.07 \\
\hline 40 & & & 664.43 & 485.77 & 710.13 & 526.03 \\
\hline 41 & & & 736.04 & 576.54 & 762.67 & 566.64 \\
\hline 42 & & & 730.82 & 585.96 & 711.29 & 581.73 \\
\hline 43 & & & 705.86 & 554.09 & 707.82 & 562.81 \\
\hline 44 & & & 739.93 & 620.25 & 751.95 & 551.96 \\
\hline 45 & & & 666.27 & 508.57 & 715.12 & 574.79 \\
\hline 46 & & & 696.88 & 543.39 & 748.14 & 618.65 \\
\hline 47 & & & 679.46 & 518.31 & 738.73 & 541.85 \\
\hline 48 & & & 715.72 & 591.71 & 710.48 & 507.56 \\
\hline 49 & & & 709.18 & 566.83 & 722.85 & 534.51 \\
\hline 50 & & & 811.53 & 642.73 & 762.74 & 568.77 \\
\hline 51 & & & 729.85 & 577.21 & 747.15 & 513.56 \\
\hline 52 & & & 719.02 & 556.85 & & \\
\hline 53 & & & 784.35 & 641.43 & & \\
\hline 54 & & & 666.61 & 536.68 & & \\
\hline 55 & & & 756.42 & 612.07 & & \\
\hline 56 & & & 686.97 & 505.02 & & \\
\hline 57 & & & 748.92 & 586.15 & & \\
\hline 58 & & & 702.29 & 539.56 & & \\
\hline 59 & & & 755.45 & 579.68 & & \\
\hline 60 & & & 752.82 & 589.85 & & \\
\hline 61 & & & 704.96 & 579.61 & & \\
\hline 62 & & & 723.75 & 552.66 & & \\
\hline 63 & & & 698.64 & 563.49 & & \\
\hline 64 & & & 710.14 & 547.30 & & \\
\hline
\end{tabular}


Tabela 29 - Medidas do comprimento ( $\mu \mathrm{m})$ e largura ( $\mu \mathrm{m})$ da cápsula cefálica de C hironomus x anthus expostos aos tratamentos do Teste Crônico 3.

\begin{tabular}{|c|c|c|c|c|c|c|c|c|}
\hline \multirow{2}{*}{\begin{tabular}{|c|}
$\mathrm{n}^{\circ} \mathrm{de}$ \\
organismos
\end{tabular}} & \multicolumn{2}{|l|}{ Controle } & \multicolumn{2}{|l|}{ CdCo } & \multicolumn{2}{|l|}{$\mathrm{CdCe}$} & \multicolumn{2}{|l|}{ CuCoCe } \\
\hline & comprimento & largura & comprimento & largura & comprimento & largura & comprimento & largura \\
\hline 1 & 675.81 & 530.72 & 716.51 & 599.87 & 740.67 & 568.00 & \begin{tabular}{r|}
707.94 \\
\end{tabular} & 581.73 \\
\hline 2 & 658.56 & 518.24 & 758.97 & 614.17 & 690.50 & 560.23 & 726.64 & 587.15 \\
\hline 3 & 660.02 & 511.81 & 692.77 & 554.80 & 642.21 & 516.84 & 725.78 & 605.03 \\
\hline 4 & 685.18 & 525.50 & 714.67 & 582.08 & 677.31 & 556.01 & 726.56 & 594.28 \\
\hline 5 & 726.64 & 563.88 & 722.42 & 604.57 & 664.13 & 542.70 & 765.45 & 601.03 \\
\hline 6 & 695.48 & 574.45 & 654.23 & 532.72 & 640.77 & 534.08 & 727.31 & 571.24 \\
\hline 7 & 717.70 & 550.05 & 712.68 & 602.14 & 711.13 & 545.94 & 785.21 & 623.70 \\
\hline 8 & 659.77 & 491.14 & 697.56 & 536.80 & 673.72 & 521.05 & 699.06 & 536.66 \\
\hline 9 & 669.79 & 536.56 & 703.39 & 549.67 & 669.63 & 511.84 & 719.50 & 570.24 \\
\hline 10 & 709.03 & 571.22 & 696.44 & 590.45 & 626.97 & 523.71 & 767.59 & 588.41 \\
\hline 11 & 655.71 & 481.81 & 654.18 & 537.09 & 687.50 & 541.03 & 688.92 & 524.78 \\
\hline 12 & 685.76 & 524.23 & 679.28 & 550.02 & 647.85 & 497.27 & 634.65 & 522.85 \\
\hline 13 & 713.74 & 565.34 & 736.73 & 563.20 & 721.33 & 595.01 & 649.63 & 492.64 \\
\hline 14 & 646.48 & 519.22 & 699.24 & 554.56 & 649.50 & 549.21 & 667.07 & 529.18 \\
\hline 15 & 669.11 & 529.22 & 700.55 & 546.71 & 635.13 & 549.75 & 654.97 & 541.95 \\
\hline 16 & 726.95 & 616.45 & 712.97 & 613.92 & 645.24 & 566.98 & 655.43 & 537.93 \\
\hline 17 & 728.74 & 593.99 & 676.91 & 576.91 & 386.68 & 322.19 & 820.90 & 686.13 \\
\hline 18 & 704.57 & 569.13 & 695.49 & 549.69 & 400.98 & 340.86 & 694.79 & 599.87 \\
\hline 19 & 730.00 & 559.16 & 640.29 & 520.13 & 601.41 & 513.61 & 733.54 & 608.42 \\
\hline 20 & 723.30 & 542.24 & 689.23 & 524.41 & 670.58 & 556.62 & 706.88 & 562.18 \\
\hline 21 & 760.87 & 598.78 & 603.49 & 508.58 & 613.40 & 494.53 & 705.37 & 543.09 \\
\hline 22 & 626.10 & 589.24 & 610.76 & 517.78 & 635.25 & 517.61 & 724.45 & 616.97 \\
\hline 23 & 646.92 & 538.42 & 672.56 & 534.90 & 410.77 & 339.04 & 686.08 & 536.85 \\
\hline 24 & 736.49 & 608.48 & 694.06 & 608.06 & 596.38 & 523.80 & $\begin{array}{l}677.55 \\
\end{array}$ & 528.98 \\
\hline 25 & 697.43 & 586.07 & 714.43 & 566.10 & 682.71 & 578.88 & 710.28 & 608.61 \\
\hline 26 & 669.75 & 571.63 & 632.22 & 489.87 & 632.58 & 533.87 & 740.30 & 599.76 \\
\hline 27 & 672.20 & 547.24 & 692.81 & 508.86 & 394.85 & 321.03 & 684.17 & 555.68 \\
\hline 28 & 704.58 & 596.77 & 639.83 & 510.06 & 611.04 & 525.15 & 781.92 & 613.21 \\
\hline 29 & 681.08 & 556.09 & 695.72 & 532.57 & 746.24 & 630.86 & 713.51 & 604.40 \\
\hline 30 & 725.84 & 563.25 & 643.28 & 483.69 & 413.03 & 329.32 & 645.69 & 506.81 \\
\hline 31 & 702.77 & 547.65 & 743.54 & 621.53 & 627.44 & 523.22 & 728.31 & 608.17 \\
\hline 32 & 689.20 & 548.83 & 690.02 & 544.31 & 689.34 & 363.34 & 731.94 & 605.79 \\
\hline 33 & 666.61 & 526.76 & 628.39 & 480.54 & 381.19 & 335.90 & 721.39 & 613.08 \\
\hline 34 & 698.26 & 542.19 & 747.41 & 612.26 & 623.27 & 522.17 & 677.55 & 559.20 \\
\hline 35 & 695.86 & 572.19 & 684.39 & 562.46 & 667.63 & 566.93 & 755.93 & 617.12 \\
\hline 36 & 688.13 & 570.74 & 708.21 & 554.52 & 372.32 & 326.97 & 761.49 & 518.39 \\
\hline 37 & & & & & 635.88 & 519.80 & & \\
\hline 38 & & & & & 697.50 & 553.34 & & \\
\hline 39 & & & & & 363.88 & 333.35 & & \\
\hline 40 & & & & & 618.75 & 525.12 & & \\
\hline 41 & & & & & 386.32 & 302.11 & & \\
\hline 42 & & & & & 349.32 & 311.85 & & \\
\hline 43 & & & & & 738.61 & 578.42 & & \\
\hline
\end{tabular}


Tabela 30. Comprimento do corpo (cm) de Chironomus x anthus referentes aos Testes Crônicos 1 e 3.

\begin{tabular}{|c|c|c|c|c|c|c|c|}
\hline no de & \multicolumn{3}{|c|}{ Teste Crônico 1} & \multicolumn{4}{|c|}{ Teste Crônico 3} \\
\hline organismos & Controle & Cd Co & $\mathrm{Cu} \mathrm{Co/Ce}$ & Controle & Cd Co & $\mathrm{CdCe}$ & $\mathrm{Cu} \mathrm{Co/Ce}$ \\
\hline 1 & 1,00 & 1,20 & 1,30 & 1,10 & 0,95 & 0,90 & 1,25 \\
\hline 2 & 1,30 & 1,20 & 1,10 & 1,20 & 1,00 & 1,10 & 1,10 \\
\hline 3 & 1,20 & 1,05 & 1,10 & 1,10 & 1,00 & 0,95 & 1,00 \\
\hline 4 & 0,90 & 1,20 & 1,20 & 1,35 & 1,10 & 0,80 & 1,10 \\
\hline 5 & 1,20 & 1,30 & 1,30 & 1,40 & 1,20 & 0,90 & 1,35 \\
\hline 6 & 0,90 & 1,30 & 1,20 & 1,35 & 1,00 & 1,15 & 1,05 \\
\hline 7 & 1,10 & 1,20 & 1,20 & 1,30 & 0,95 & 0,90 & 1,05 \\
\hline 8 & 1,20 & 1,40 & 1,40 & 1,15 & 1,10 & 0,80 & 1,00 \\
\hline 9 & 1,10 & 1,10 & 1,10 & 1,15 & 1,20 & 1,00 & 1,20 \\
\hline 10 & 1,10 & 1,40 & 1,20 & 1,40 & 1,00 & 1,10 & 1,15 \\
\hline 11 & 1,25 & 1,25 & 1,40 & 1,25 & 1,10 & 0,85 & 0,90 \\
\hline 12 & 1,15 & 1,40 & 1,20 & 1,25 & 1,00 & 0,75 & 0,90 \\
\hline 13 & 1,40 & 1,10 & 1,10 & 1,30 & 0,95 & 0,95 & 0,90 \\
\hline 14 & 1,10 & 1,30 & 1,40 & 1,20 & 1,05 & 1,20 & 1,00 \\
\hline 15 & 1,15 & 1,05 & 1,25 & 1,10 & 1,15 & 0,80 & 0,90 \\
\hline 16 & 1,35 & 1,25 & 1,25 & 1,10 & 0,90 & 0,80 & 0,90 \\
\hline 17 & 1,30 & 1,20 & 1,10 & 1,30 & 1,00 & 0,60 & 1,15 \\
\hline 18 & 1,20 & 1,40 & 1,35 & 1,25 & 1,00 & 0,60 & 1,25 \\
\hline 19 & 1,35 & 1,10 & 1,20 & 1,00 & 1,00 & 1,00 & 1,10 \\
\hline 20 & 1,15 & 1,30 & 1,10 & 1,25 & 1,10 & 1,15 & 1,10 \\
\hline 21 & 1,40 & 1,40 & 1,00 & 1,10 & 1,15 & 0,90 & 1,15 \\
\hline 22 & 1,30 & 1,30 & 1,35 & 1,10 & 1,05 & 0,80 & 1,15 \\
\hline 23 & 1,30 & 1,20 & 1,10 & 1,00 & 1,20 & 0,65 & 1,10 \\
\hline 24 & 1,35 & 1,25 & 1,35 & 1,30 & 1,10 & 0,80 & 0,95 \\
\hline 25 & 1,25 & 1,30 & 1,15 & 1,10 & 1,10 & 1,00 & 1,20 \\
\hline 26 & 1,25 & 1,30 & 1,15 & 1,05 & 1,10 & 0,85 & 1,30 \\
\hline 27 & 1,25 & 1,30 & 1,15 & 1,10 & 1,00 & 0,60 & 1,10 \\
\hline 28 & 1,30 & 1,25 & 1,20 & 1,20 & 1,10 & 0,85 & 1,20 \\
\hline 29 & 1,40 & 1,10 & 1,20 & 1,25 & 1,25 & 1,00 & 1,10 \\
\hline 30 & 1,25 & 1,10 & 1,35 & 1,30 & 0,90 & 0,60 & 0,95 \\
\hline 31 & 1,20 & 1,40 & 1,40 & 1,20 & 1,05 & 0,85 & 1,10 \\
\hline 32 & 1,35 & 1,15 & 1,15 & 1,20 & 0,85 & 0,70 & 0,95 \\
\hline 33 & 1,30 & 1,30 & 1,10 & 1,10 & 1,15 & 0,60 & 1,10 \\
\hline 34 & 1,05 & 1,40 & 1,10 & 1,10 & 1,20 & 1,00 & 1,00 \\
\hline 35 & 1,30 & 1,30 & 1,30 & 1,20 & 1,20 & 0,75 & 1,10 \\
\hline 36 & 1,20 & 1,20 & 1,35 & 1,25 & 1,10 & 0,55 & 1,30 \\
\hline 37 & & 1,10 & 1,25 & & & 0,85 & \\
\hline 38 & & 1,20 & 1,30 & & & 0,95 & \\
\hline 39 & & 1,10 & 1,40 & & & 0,40 & \\
\hline 40 & & 1,20 & 1,25 & & & 0,50 & \\
\hline 41 & & 1,30 & 1,40 & & & 0,60 & \\
\hline 42 & & 1,20 & 1,35 & & & 0,40 & \\
\hline 43 & & 1,15 & 1,20 & & & 1,10 & \\
\hline 44 & & 1,35 & 1,25 & & & & \\
\hline 45 & & 1,00 & 1,30 & & & & \\
\hline 46 & & 1,20 & 1,30 & & & & \\
\hline 47 & & 1,10 & 1,30 & & & & \\
\hline 48 & & 1,30 & 1,20 & & & & \\
\hline 49 & & 1,15 & 1,25 & & & & \\
\hline 50 & & 1,25 & 1,20 & & & & \\
\hline 51 & & 1,25 & 1,25 & & & & \\
\hline 52 & & 1,00 & & & & & \\
\hline 53 & & 1,10 & & & & & \\
\hline 54 & & 1,20 & & & & & \\
\hline 55 & & 1,35 & & & & & \\
\hline 56 & & 0,95 & & & & & \\
\hline 57 & & 1,20 & & & & & \\
\hline 58 & & 1,10 & & & & & \\
\hline 59 & & 1,25 & & & & & \\
\hline 60 & & 1,35 & & & & & \\
\hline 61 & & 1,20 & & & & & \\
\hline 62 & & 1,20 & & & & & \\
\hline 63 & & 1,20 & & & & & \\
\hline 64 & & 1,00 & & & & & \\
\hline
\end{tabular}




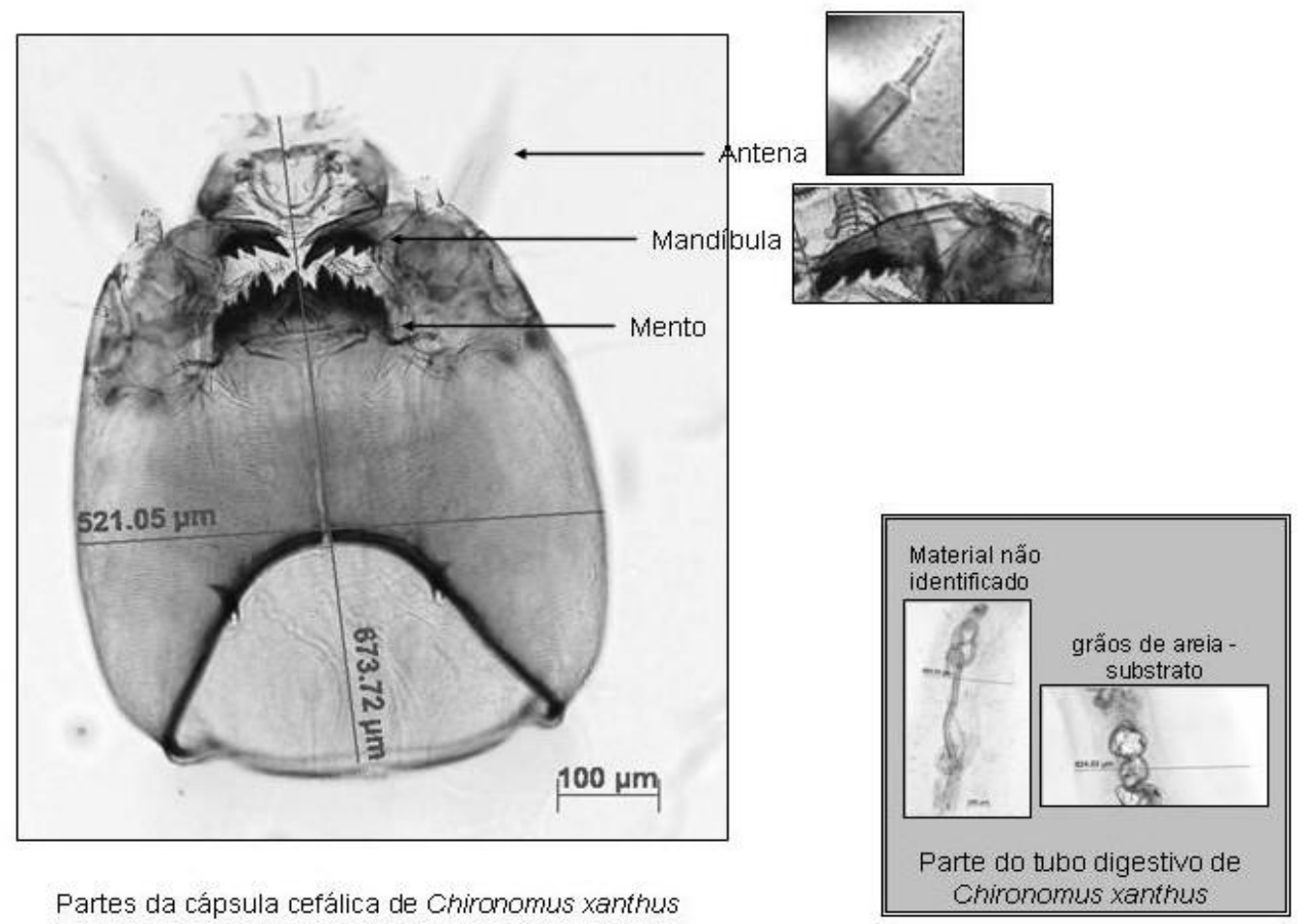

Figura 11. Cápsula cefálica de Chironomus x anthus (aumento de 10x), com detalhe de parte do tubo digestivo.

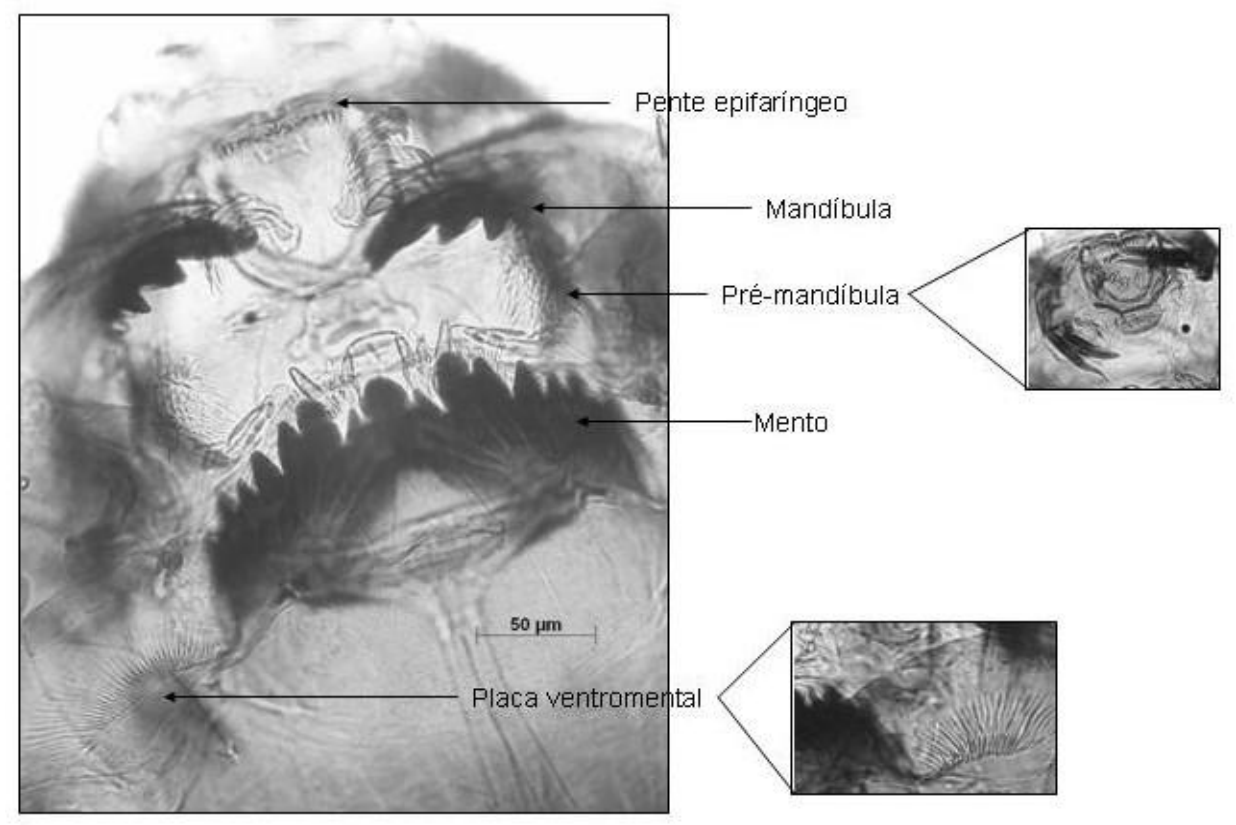

Partes do aparato bucal de Chironomus xanthus

Figura 12. D etalhe do aparato bucal de Chironomus x anthus (aumento de 40x). 
Controle - Teste 1
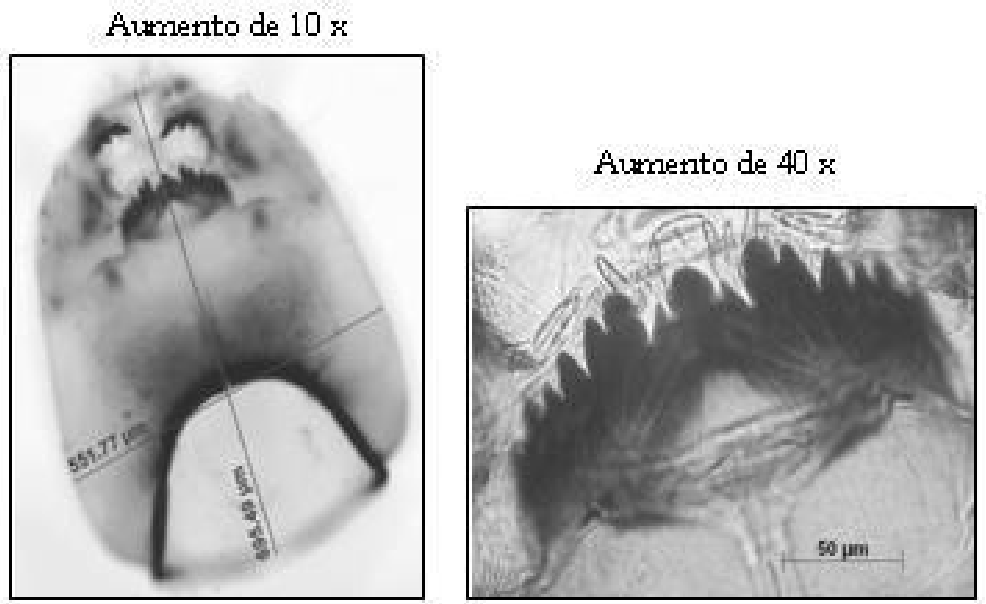

Controle - Teste 3
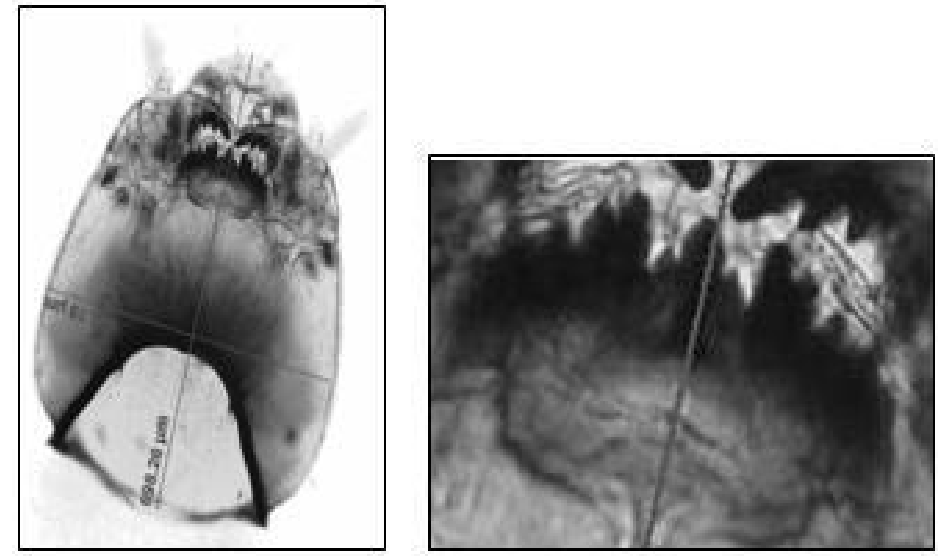

\section{Cd CENO - Teste 3}
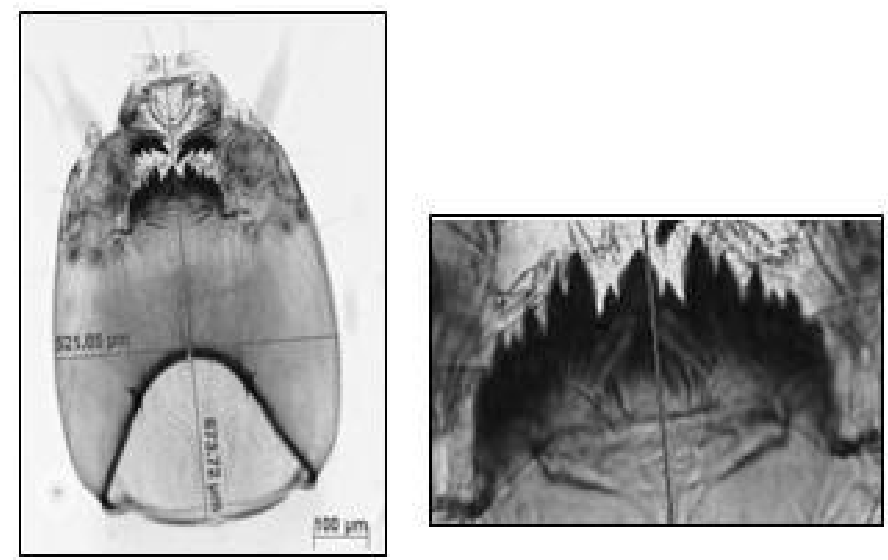

Figura 14. Exemplos de mentos de $C$ hironomus x anthus sem deformidades. 


\section{Deformidades do Mento de Chíronom ws santiors \\ Controle-Teste 1}

Exemplos de deformidade no Controle do

Teste 1

Aumento de $10 \mathrm{x}$

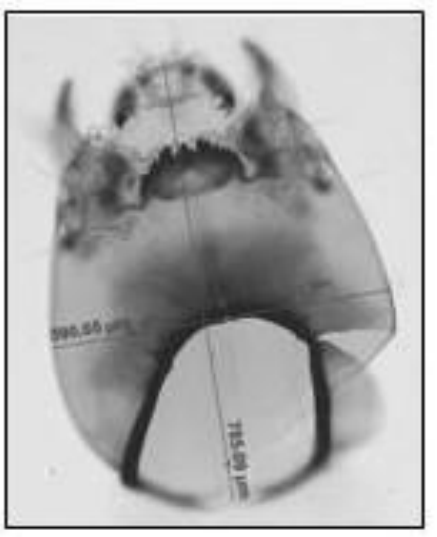

Aumento de $40 x$

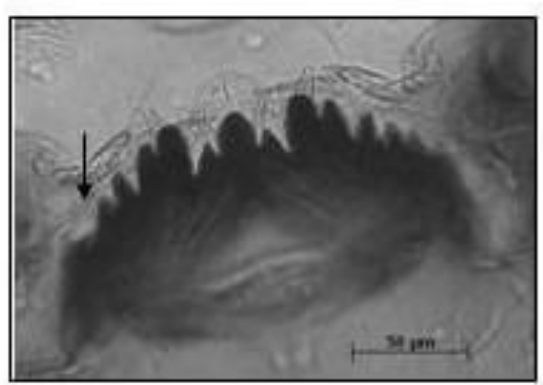

Faltando dente conta como deformidade
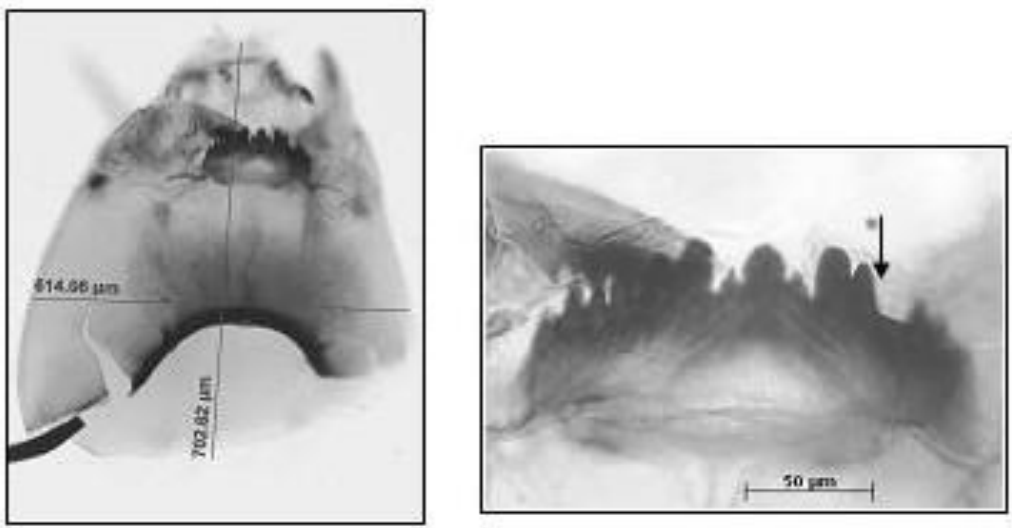

Faltando dente conta como deformidade
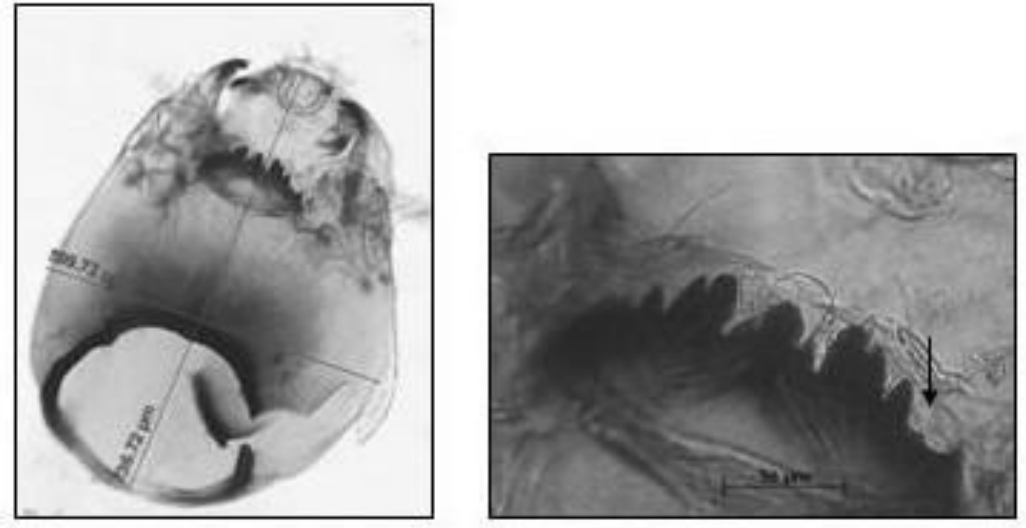

Faltando dente conta como deformidade

Figura 15. Exemplos de mentos de $\mathrm{C}$ hironomus x anthus com deformidades presentes no Controle do Teste Crônico 1. 
Deformidade do Mento de Chronom was sanow

Cd CONAMA - Teste 1

Aumento de $10 \mathrm{x}$

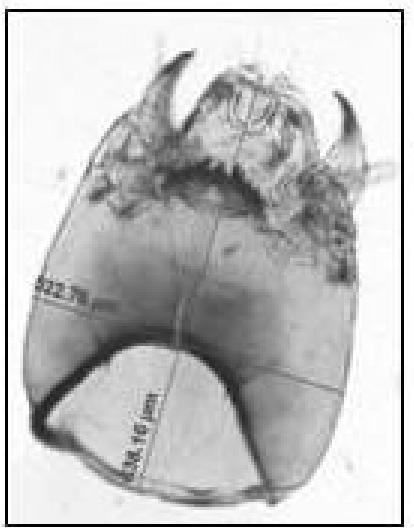

Aumento de $40 \mathrm{x}$

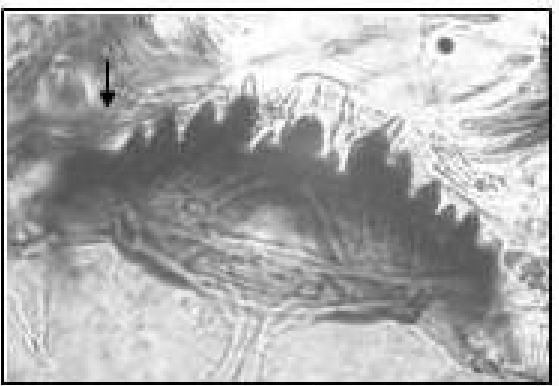

Faltando dente - conta como deformidade
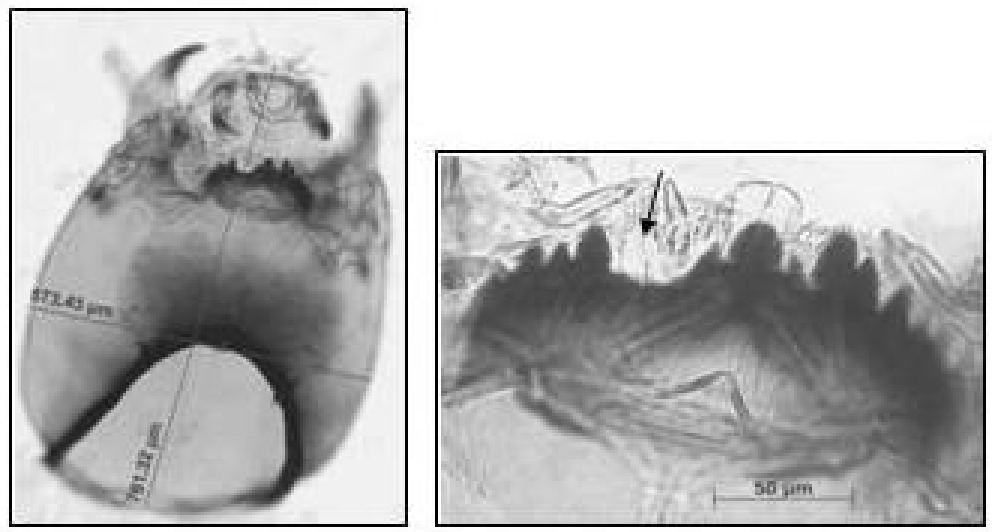

Faltando dente - GAP - conta como deformidade
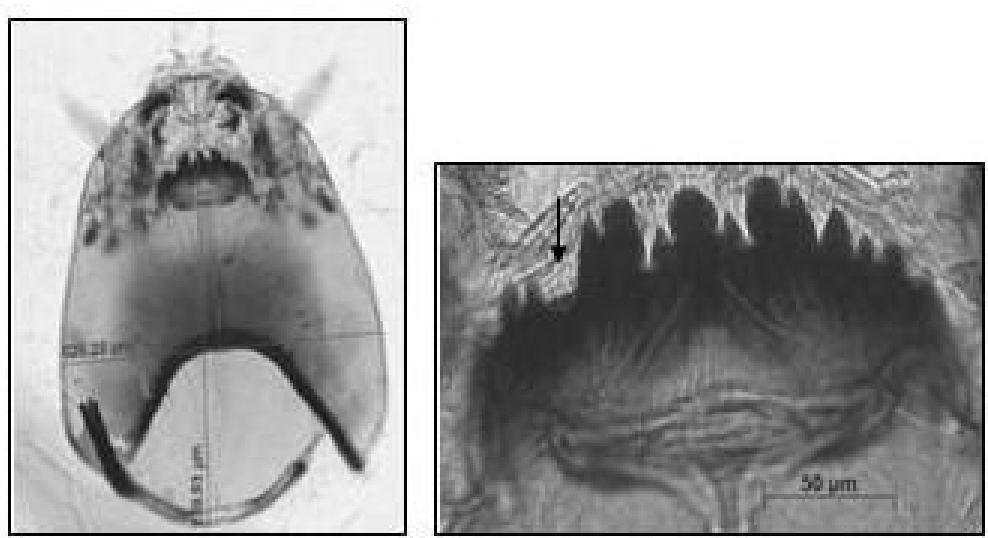

Faltando dente - conta como deformidade

Figura 16. Exemplos de mentos de Chironomus x anthus com deformidades presentes nos organismos expostos ao Cd CONAMA (CdCo) do Teste Crônico 1. 
Deformidade do Mento de Chronom uss santhers Cu CONAMA - Teste 1
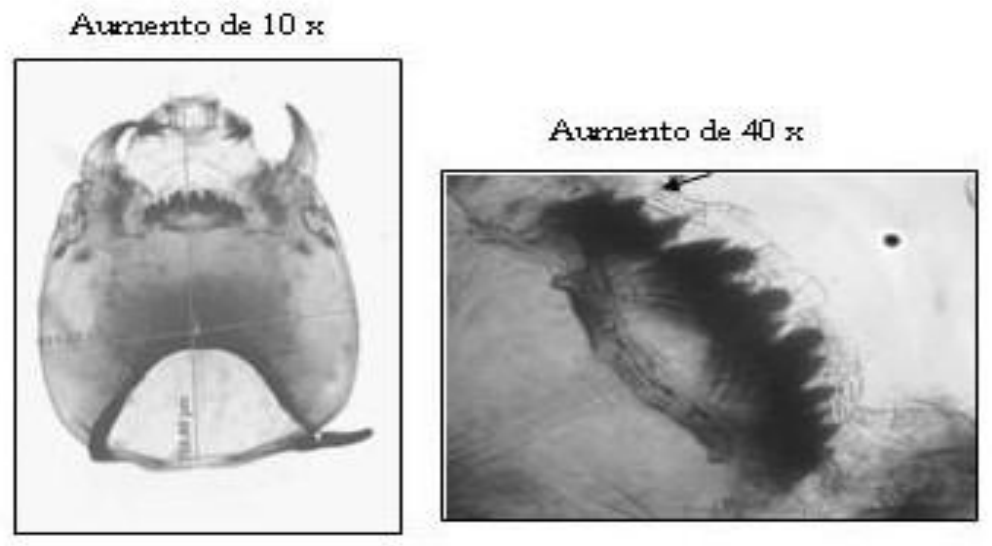

Dente quebrado - não conta como deformidade
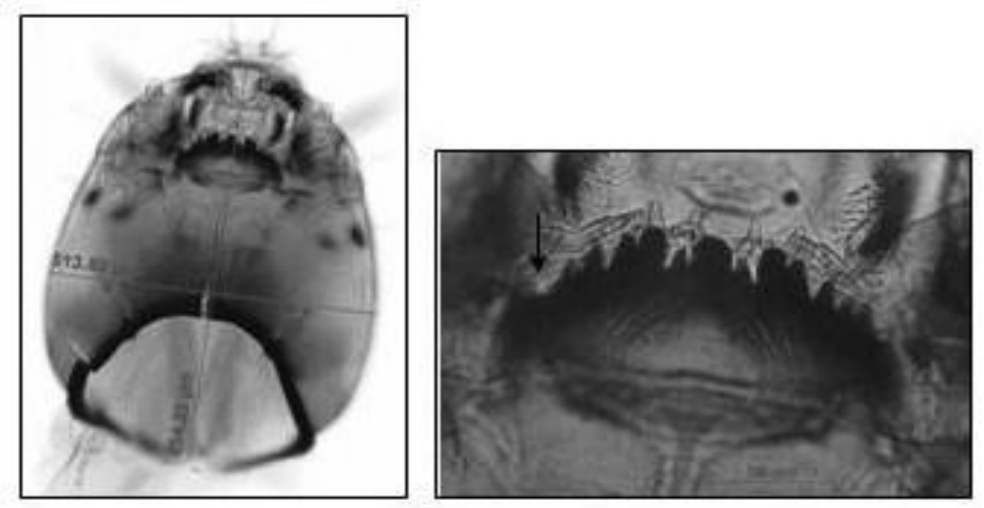

Faltando dente - conta como deformidade
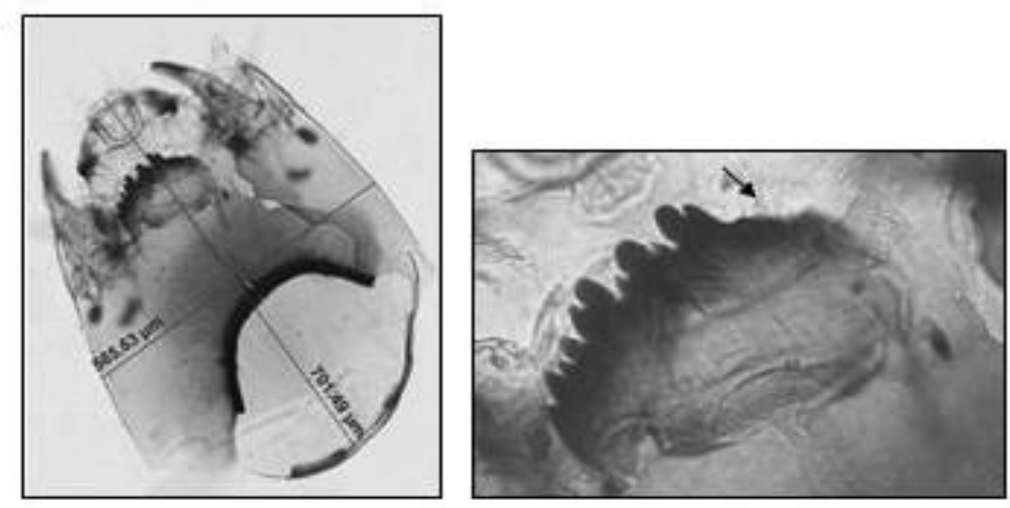

Quebra da cápsula cefálica no preparo da lầmina

Figura 17. Exemplos de mentos de Chironomus $x$ anthus com deformidades presentes nos organismos expostos ao Cu CONAMA/ CENO (CuCo/ Ce) do Teste Crônico 1. 


\section{Deformidade do Mento de Chironomus xanthus}

Cd CONAMA - Teste 3

Aumento de $10 \mathrm{x}$

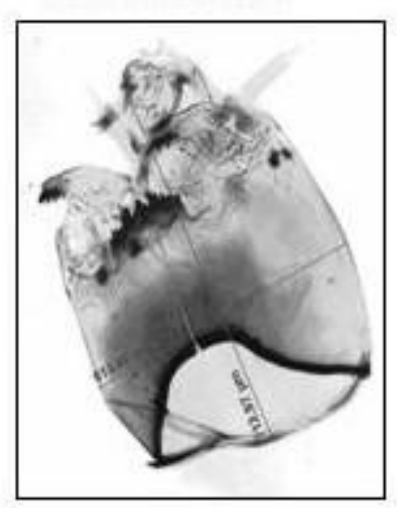

Aumento de $40 \mathrm{x}$

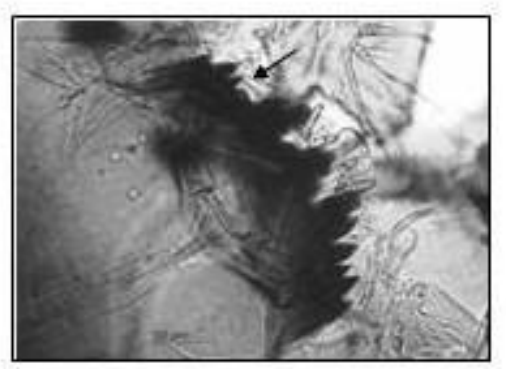

Lâmina mal-feita - dente

quebrado não conta como

deformidade
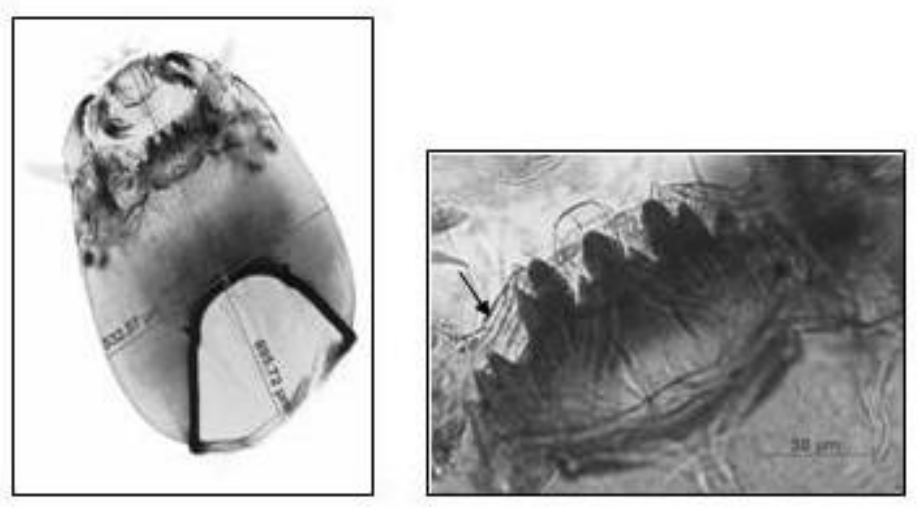

Faltando dente - conta como deformidade

Figura 18. Exemplos de mentos de Chironomus x anthus com deformidades presentes nos organismos expostos ao Cd CONAMA (CdCo) do Teste Crônico 3. 


\section{Deformidade do Mento de Chironomus xanthws}

\section{Cu CONAMA/CENO - Teste 3}

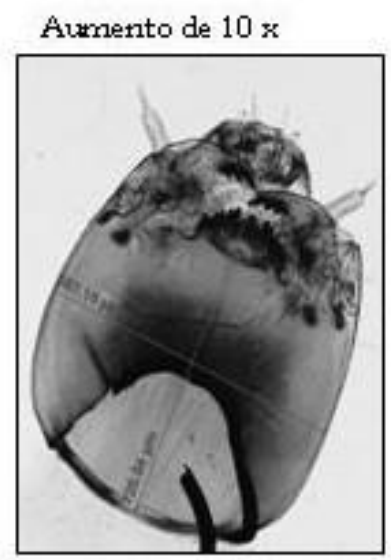

Aumento de $40 \mathrm{x}$

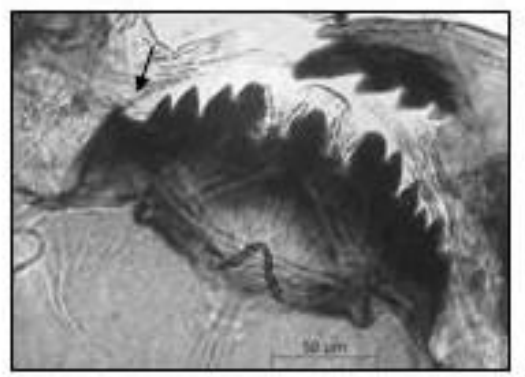

Faltando dente - conta como deformidade
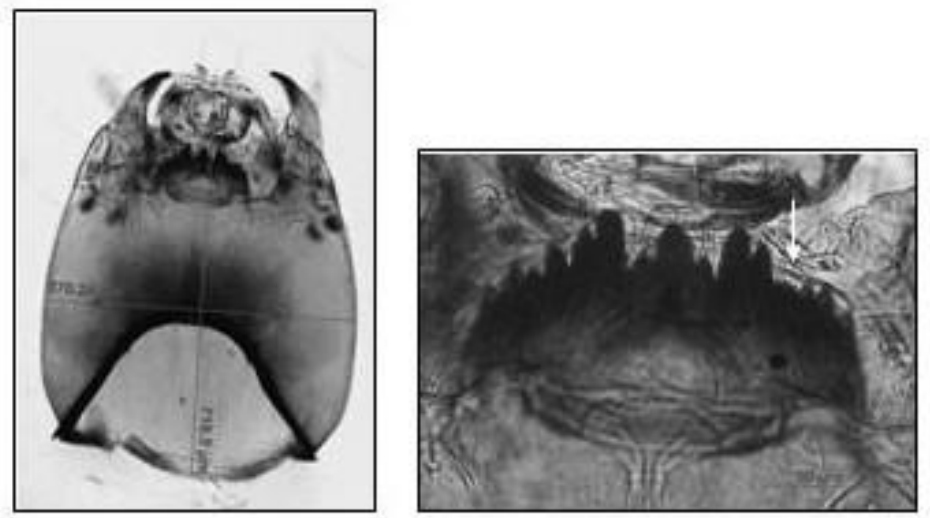

Faltando dente - conta como deformidade
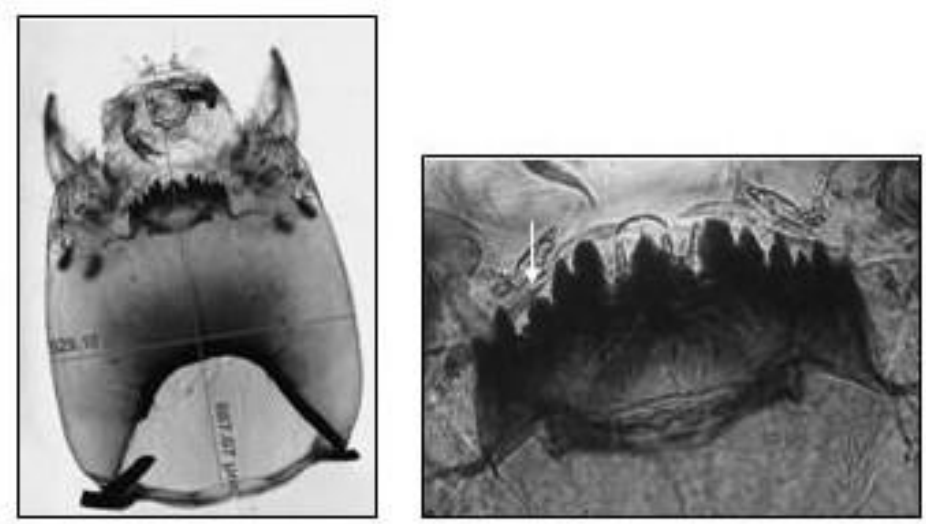

Dentição dife xenciada e faltando dente - conta como deformidade

Figura 19. Exemplos de mentos de $C$ hironomus $x$ anthus com deformidades presentes nos organismos expostos ao Cu CONAMA/ CENO do Teste Crônico 3. 
Tabela 31. Valores das medidas das cápsulas cefálicas (comprimento e largura) e do comprimento do corpo total dos indivíduos de C . xanthus analisados após 10 dias de exposição - Teste 1.

\begin{tabular}{|c|c|c|c|c|c|c|c|c|c|}
\hline \multirow{2}{*}{$\begin{array}{l}\text { Tratamentos } \\
\text { Medidas }\end{array}$} & \multicolumn{3}{|c|}{$\begin{array}{c}\text { Controle } \\
\text { Teste 1 } \\
\mathrm{N}=36\end{array}$} & \multicolumn{3}{|c|}{$\begin{array}{c}\text { Cd CONAMA } \\
\text { Teste 1 } \\
\mathrm{N}=64\end{array}$} & \multicolumn{3}{|c|}{$\begin{array}{c}\text { Cu CONAMA } \\
\text { Teste 1 } \\
\text { N }=51\end{array}$} \\
\hline & $\begin{array}{c}\text { compr. } \\
(\mu \mathrm{m})\end{array}$ & $\begin{array}{l}\text { larg. } \\
(\mu \mathrm{m})\end{array}$ & $\begin{array}{l}\text { como } \\
\text { (cm) }\end{array}$ & $\begin{array}{c}\text { compr. } \\
(\mathbf{p m})\end{array}$ & $\begin{array}{l}\text { larg. } \\
(\boldsymbol{p m})\end{array}$ & $\begin{array}{c}\text { corpo } \\
\text { (cm) }\end{array}$ & $\begin{array}{c}\text { compr. } \\
(\boldsymbol{\mu m})\end{array}$ & $\begin{array}{l}\text { lang. } \\
\text { (pm) }\end{array}$ & $\begin{array}{l}\text { como } \\
\text { (cm) }\end{array}$ \\
\hline & 863,0 & 662,1 & 1,40 & 869,4 & 672,9 & 1,40 & 816,4 & 625,1 & 1,40 \\
\hline Mínimo & 643,6 & 385,7 & 0,90 & 638,2 & 485,8 & 0,95 & 638,9 & 483,8 & 1,00 \\
\hline Média & 729,4 & 571,1 & 1,12 & 729,3 & 567,6 & 1,21 & 719,4 & 556,6 & 1,23 \\
\hline
\end{tabular}

compr.: comprimento da cápsula cefálica; larg.: largura da cápsula cefálica; corpo: comprimento total do corpo, incluindo-se a cápsula cefálica.

Tabela 32. Valores das medidas das cápsulas cefálicas (comprimento e largura) e do comprimento do corpo total dos indivíduos de C . xanthus analisados após 10 dias de exposição - Teste 3.

\begin{tabular}{|c|c|c|c|c|c|c|}
\hline \multirow{2}{*}{$\begin{array}{l}\text { Tratamentos } \\
\text { Medidas }\end{array}$} & \multicolumn{3}{|c|}{$\begin{array}{l}\text { Controle } \\
\text { Teste } 3 \\
\mathrm{~N}=36 \\
\end{array}$} & \multicolumn{3}{|c|}{$\begin{array}{c}\text { Cd CONAMA } \\
\text { Teste } 3 \\
\mathrm{~N}=36 \\
\end{array}$} \\
\hline & $\begin{array}{l}\text { compr. } \\
\text { ( } \mu \mathrm{m})\end{array}$ & $\begin{array}{l}\text { larg. } \\
(\mu \mathrm{m})\end{array}$ & $\begin{array}{l}\text { corpo } \\
\text { (cm) }\end{array}$ & $\begin{array}{l}\text { compr. } \\
(\mu \mathrm{m})\end{array}$ & $\begin{array}{l}\text { larg. } \\
(\mathbf{p m})\end{array}$ & $\begin{array}{l}\text { corpo } \\
\text { (cm) }\end{array}$ \\
\hline Máximo & 760,9 & 616,5 & 1,40 & 758,9 & 621,5 & 1,25 \\
\hline Mínimo & 626,1 & 481,8 & 1,00 & 603,5 & 480,5 & 0,85 \\
\hline Média & 691,9 & 553,9 & 1,19 & 687,7 & 553,9 & 1,06 \\
\hline Tratamentos & \multicolumn{3}{|c|}{$\begin{array}{c}\text { Cd CENO } \\
\text { Teste } 3 \\
\mathrm{~N}=43 \\
\end{array}$} & \multicolumn{3}{|c|}{$\begin{array}{c}\text { Cu CONAMA/ CENO } \\
\text { Teste } 3 \\
\mathrm{~N}=36\end{array}$} \\
\hline Medidas & $\begin{array}{l}\text { compr. } \\
(\mu \mathrm{m})\end{array}$ & $\begin{array}{l}\text { larg. } \\
\text { (pm) }\end{array}$ & $\begin{array}{l}\text { corpo } \\
\text { (cm) }\end{array}$ & $\begin{array}{l}\text { compr. } \\
(\mu \mathrm{m})\end{array}$ & $\begin{array}{l}\text { larg. } \\
(\mathbf{p m})\end{array}$ & $\begin{array}{l}\text { corpo } \\
\text { (cm) }\end{array}$ \\
\hline Máximo & 746,2 & 630,9 & 1,20 & 820,9 & 686,1 & 1,35 \\
\hline Mínimo & 349,3 & 302,1 & 0,40 & 634,7 & 492,6 & 0,90 \\
\hline Média & 596,9 & 487,7 & 0,82 & 713,9 & 575,0 & 1,08 \\
\hline
\end{tabular}

Tabela 33. Concentrações de Cd na água pós-teste, biodisponível no sedimento e organismos.

\begin{tabular}{|c|c|c|c|c|}
\hline Tratamento & & Agua pós-teste ( $\left.\mathrm{\mu g} \cdot \mathrm{L}^{-1}\right)$ & sedimento $\left(\mathbf{p g} . \mathrm{g}^{-1}\right)$ & organismo $\left(\mathbf{\mu g} \cdot \mathbf{g}^{-1}\right)$ \\
\hline \multirow{4}{*}{ Teste 1} & Controle 1 & 0,2870 & 0,0041 & 8,0023 \\
\hline & Controle 2 & 0,2410 & 0,0035 & 7,5215 \\
\hline & Cd Co1 & 0,4570 & 0,0042 & 12,4930 \\
\hline & $\mathrm{Cd} \mathrm{Co2}$ & 0,3225 & 0,0036 & 21,1192 \\
\hline \multirow{6}{*}{ Teste 2} & Controle 1 & 1,1800 & 0,0038 & 13,5215 \\
\hline & Controle 2 & 0,2620 & 0,0021 & 7,2691 \\
\hline & Cd Co1 & 0,2140 & 0,0087 & 12,2621 \\
\hline & Cd Co2 & 0,2640 & 0,0134 & 19,2920 \\
\hline & Cd Ce1 & 4,2410 & 0,0516 & 125,4167 \\
\hline & Cd Ce2 & 4,7960 & 0,0593 & 163,3019 \\
\hline \multirow{6}{*}{ Teste 3} & Controle 1 & 0,2020 & 0,0071 & 5,9425 \\
\hline & Controle 2 & 0,1590 & 0,0233 & 5,4744 \\
\hline & Cd Co1 & 0,2770 & 0,0086 & 12,6738 \\
\hline & Cd Co2 & 0,4080 & 0,0097 & 5,2557 \\
\hline & Cd Ce1 & 5,8950 & 0,0895 & 168,0324 \\
\hline & Cd Ce2 & 8,1000 & 0,1068 & 324,6789 \\
\hline
\end{tabular}


Tabela 35. Fator de Bioacumulação (FB) de Cd relacionando as concentrações na água ( $\mu g . L^{-1}$ ) e as concentrações nos organismos ( $\left.\mu \mathrm{g} . \mathrm{g}^{-1}\right)$.

\begin{tabular}{|c|c|c|c|}
\hline Testes Crônicos - Cd & Organismos ( $\left.\mu \mathrm{g} \mathrm{g}^{-1}\right)$ & Água ( $\left.\mu g . L^{-1}\right)$ & FB \\
\hline \multicolumn{4}{|c|}{ Teste 1} \\
\hline Controle 1 & 8,0023 & 0,2870 & 27,8825 \\
\hline Controle 2 & 7,5215 & 0,2410 & 31,2095 \\
\hline Cd1- conama & 12,4930 & 0,4570 & 27,3369 \\
\hline $\mathrm{Cd} 2$ - conama & 21,1192 & 0,3225 & 65,4858 \\
\hline \multicolumn{4}{|c|}{ Teste 2} \\
\hline Controle 1 & 13,5215 & 1,1800 & 11,4589 \\
\hline Controle 2 & 7,2691 & 0,2620 & 27,7448 \\
\hline Cd1 - conama & 12,2621 & 0,2140 & 57,2995 \\
\hline $\mathrm{Cd} 2$ - conama & 19,2920 & 0,2640 & 73,0759 \\
\hline $\mathrm{Cd} 1$ - ceno & 125,4167 & 4,2410 & 29,5724 \\
\hline $\mathrm{Cd} 2$ - ceno & 163,3019 & 4,7960 & 34,0496 \\
\hline \multicolumn{4}{|c|}{ Teste 3} \\
\hline Controle 1 & 5,9425 & 0,2020 & 29,4183 \\
\hline Controle 2 & 5,4744 & 0,1590 & 34,4302 \\
\hline Cd1- conama & 12,6738 & 0,2770 & 45,7538 \\
\hline $\mathrm{Cd} 2$ - conama & 5,2557 & 0,4080 & 12,8817 \\
\hline Cd1 - ceno & 168,0324 & 5,8950 & 28,5042 \\
\hline $\mathrm{Cd} 2$ - ceno & 324,6789 & 8,1000 & 40,0838 \\
\hline
\end{tabular}

Tabela 36. Concentrações de Cu na água pós-teste, biodisponível no sedimento e organismos.

\begin{tabular}{|c|c|c|c|c|}
\hline Tratament & & Água pós-teste (pg.L-1) & sedimento $\left(\mu \mathrm{g} . \mathrm{g}^{-1}\right)$ & organismo $\left(\mu \mathrm{g} . \mathrm{g}^{-1}\right)$ \\
\hline \multirow{4}{*}{ Teste 1} & Controle 1 & 26,17 & 0,9262 & 218,1507 \\
\hline & Controle 2 & 24,58 & 1,0207 & 172,0630 \\
\hline & $\mathrm{Cu} \mathrm{Co} / \mathrm{Ce} 1$ & 24,31 & 1,0450 & 281,4286 \\
\hline & $\mathrm{Cu} \mathrm{Co} / \mathrm{Ce} 2$ & 25,85 & 1,6922 & 399,5502 \\
\hline \multirow{4}{*}{ Teste 2} & Controle 1 & 13,04 & 1,5180 & 216,2669 \\
\hline & Controle 2 & 24,03 & 2,0587 & 60,5394 \\
\hline & $\mathrm{Cu} \mathrm{Co} / \mathrm{Ce} 1$ & 25,94 & 0,2990 & 269,1074 \\
\hline & $\mathrm{Cu} \mathrm{Co} / \mathrm{Ce} 2$ & 19,77 & 0,3162 & 178,2324 \\
\hline \multirow{4}{*}{ Teste 3} & Controle 1 & 9,755 & 0 & 73,3759 \\
\hline & Controle 2 & 5,585 & 0 & 185,4669 \\
\hline & $\mathrm{Cu} \mathrm{Co} / \mathrm{Ce} 1$ & 24,98 & 0,3890 & 66,6437 \\
\hline & $\mathrm{Cu} \mathrm{Co} / \mathrm{Ce} 2$ & 25,695 & 0 & 920,8889 \\
\hline
\end{tabular}

Tabela 38. Fator de Bioacumulação (FB) de Cu relacionando as concentrações na água ( $\mu g . L^{-1}$ ) e as concentrações nos organismos ( $\left.\mu \mathrm{g} . \mathrm{g}^{-1}\right)$.

\begin{tabular}{|c|c|c|c|}
\hline Testes Crônicos - Cu & Organismos (jg. $\left.\mathrm{g}^{-1}\right)$ & Água (pg.L-1) & FB \\
\hline \multicolumn{4}{|c|}{ Teste 1} \\
\hline Controle 1 & 218,1507 & 26,1750 & 8,3343 \\
\hline Controle 2 & 172,0630 & 24,5850 & 6,9987 \\
\hline $\mathrm{Cu} \mathrm{Co} / \mathrm{Cel}$ & 281,4286 & 24,3150 & 11,5742 \\
\hline $\mathrm{Cu} \mathrm{Co} / \mathrm{Ce} 2$ & 399,5502 & 25,8550 & 15,4535 \\
\hline \multicolumn{4}{|c|}{ Teste 2} \\
\hline Controle 1 & 216,2669 & 13,0400 & 16,5848 \\
\hline Controle 2 & 60,5394 & 24,0300 & 2,5193 \\
\hline Cu Co/Ce1 & 269,1074 & 25,9400 & 10,3742 \\
\hline $\mathrm{Cu} \mathrm{Co} / \mathrm{Ce} 2$ & 178,2324 & 19,7700 & 9,0152 \\
\hline \multicolumn{4}{|c|}{ Teste 3} \\
\hline Controle 1 & 73,3759 & 9,7550 & 7,5218 \\
\hline Controle 2 & 185,4669 & 5,5850 & 33,2080 \\
\hline Cu Co/Ce1 & 66,6437 & 24,9800 & 2,6678 \\
\hline $\mathrm{Cu} \mathrm{Co} / \mathrm{Ce} 2$ & 920,8889 & 25,6950 & 35,8392 \\
\hline
\end{tabular}

